\title{
DOCTRINAS Y PARROQUIAS DEL OBISPADO DE QUITO EN LA SEGUNDA MITAD DEL SIGLO XVI
}

Mons. Augusto E. Albuja Mateus 



\section{DOCTRINAS Y PARROQUIAS DEL OBISPADO DE QUITO EN LA SEGUNDA MITAD DEL SIGLO XVI}

Mons. Augusto E. Albuja Mateus

Ediciones

Abya-Yala

1998 


\section{DOCTRINAS Y PARROQUIAS DEL OBISPADO DE QUITO EN LA SEGUNDA MITAD DEL SIGLO XVI}

Mons. Augusto E. Albuja Mateus

$1^{\text {a Edición }}$

1998

(C) Ediciones Abya-Yala

Av. 12 de Octubre 14-30 y Wilson

Casilla 17-12-719

Télf: 562-633/506-217/506-251

Fax: (593 2) 506255

Quito, Ecuador

E-mail: editorial@abyayala.org

Página electrónica: http://www.abyayala.org

Autoedición: Abya-Yala Editing

Quito, Ecuador

ISBN:

9978-04-321-7

Impresión Digital: Docutech

U.P.S. / XEROX

Quito-Ecuador

Impreso en Quito-Ecuador, 1998 


\section{ÍNDICE}

Principales Abreviaturas ................................................................. 11

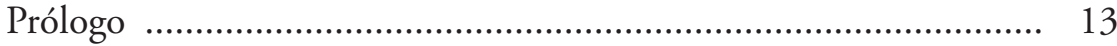

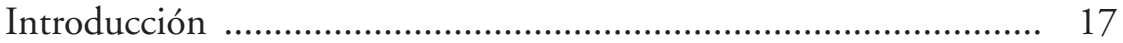

CAPÍTULO I

LA ENCOMIENDA Y LA REAL AUDIENCIA DE QUITO ................... 21

La Encomienda .............................................................................. 21

Naturaleza - historia - vicisitudes - aspecto jurídico - Encomenderos: sus

deberes y derechos.

La Real Audiencia de Quito

Descripción - divisiones civiles - Encomiendas - Encomenderos - tributos

de los indios.

CAPÍTULO II

LA DIÓCESIS DE QUITO Y SUS PRIMEROS OBISPOS

El Obispado como tal: erección - límites - descripción geográfica y ciudades

que comprendía. Primeros Obispos: Ilmos. Garci Díaz Arias - Fr. Pedro de

la Peña - Fr. Antonio de San Miguel y Solier - Fr. Luis López de Solís.

CAPÍTULO III

NATURALEZA Y ORGANIZACIÓN DE LAS DOCTRINAS

Y PARROQUIAS

Naturaleza de las doctrinas y parroquias.

Conceptos - identificación - diferencia - evolución histórica y jurídicocanónica de las Doctrinas de indios.

Organización de las doctrinas y parroquias

Reseña de los cinco Concilios limenses celebrados entre 1551 y 1601 y de los tres Sínodos diocesanos de Quito correspondientes a los años 1570, 1594 y 1596

CAPÍTULO IV

PROVISIÓN DE DOCTRINAS Y PARROQUIAS....................................... 73

Conocimiento del idioma indígena ......................................................... 76

Examen de los candidatos....................................................................... 80 
Elección hecha por el Prelado ................................................................... 84

Presentación del candidato ............................................................................ 88

Institución canónica ......................................................................... 90

Toma de posesión .............................................................................. 95

CAPÍTULO V

NÚMERO DE INDIOS POR DOCTRINA …........................................ 101

Reducciones de indios a pueblos - fijación del número de indios tributarios que debía tener cada Doctrina - resolución tomada en la Junta celebrada en Quito; parecer del Rey - preocupación de los Obispos - cuadro estadístico.

CAPÍTULO VI

RESIDENCIA DE LOS PÁRROCOS

Tiempo mínimo que debía estar el cura o doctrinero en una Doctrina de indios - multas pecuniarias a irresidentes ocasionales - excepción para poder confesarse - regreso a Europa.

CAPÍTULO VII

INSTRUCCIÓN RELIGIOSA Y CUIDADO PASTORAL

Instrucción religiosa

Normas generales - Compendio de la catequesis - Catequistas - Idioma -

Cartillas - Días de catequesis - Enseñanza de la doctrina cristiana en la diócesis de Quito

Cuidado pastoral

Indios "coadjutores" - Visita a los anejos - Labor social

CAPÍTULO VIII

EL CULTO DIVINO

133

Las iglesias ............................................................................................ 133

Cosas necesarias para el culto .............................................................. 136

Misa "pro populo" ............................................................................... 140

Fiestas de precepto y días de ayuno y abstinencia ...................................... 143

CAPÍTULO IX

ADMINISTRACIÓN DE SACRAMENTOS .......................................... 155

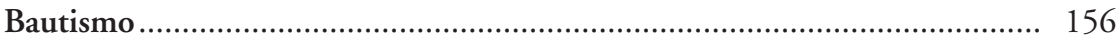

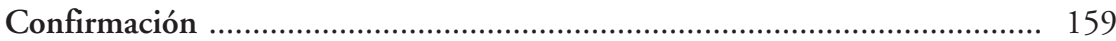

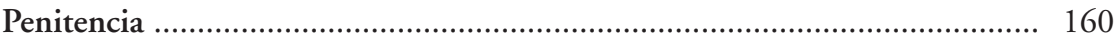

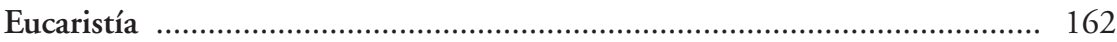

Extremaunción ................................................................................ 164

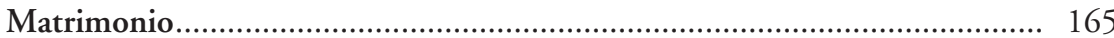


CAPÍTULO X

LIBROS PARROQUIALES ............................................................... 175

Libros parroquiales ............................................................................ 175

Libro de bautizados - libro de matrimonios - libro de difuntos - libro del estado de las almas - libro de los confesados - libro de confirmados - libro de los castigos impuestos a los indios

Libros personales del párroco 180

Imposición de castigos

CAPÍTULO XI

SOSTENIMIENTO DE PARROQUIAS Y MINISTROS ......................... 189

Salarios de curas y doctrineros ............................................................... 189

Aranceles parroquiales .......................................................................... 194

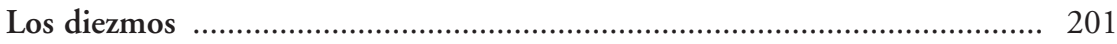

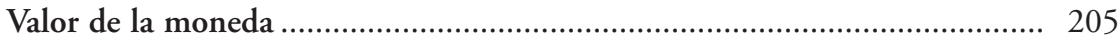

CAPÍTULO XII

REFORMA DEL CLERO Y SACERDOTES BENEMÉRITOS ................. 213

Reforma del clero ............................................................................... 213

Negociación - juego - caza - trato con mujeres - hábito y buenas costumbres

Sacerdotes beneméritos ........................................................................ 221

CAPÍTULO XIII

SEMINARIO Y ORDENACIÓN DE MESTIZOS ................................... 231

Seminario ....................................................................................... 231

Ordenación de mestizos ................................................................... 236

CAPÍTULO XIV

VICARIOS (ARCIPRESTES) ................................................................. 245

Su necesidad - sus facultades - Vicarios Generales

CAPÍTULO XV

EL CLERO REGULAR ......................................................................... 253

Dificultades con los Obispos - sus virtudes y méritos

CAPÍTULO XVI

SITUACIÓN DEL OBISPADO DE QUITO A FINES DEL SIGLO XVI.. 265

Estadística general: nombre del Obispo, Prebendados, Parroquias, Doctrinas, Curas y Doctrineros; salario que percibían y número de indios tributarios en varias Doctrinas 


\section{APÉNDICES}

Apéndice 1

295

Apéndice 2

296

Apéndice 3

300

Apéndice 4

301

Apéndice 5

302

Apéndice 6

307

Apéndice 7

308

Apéndice 8

309

Apéndice 9

311

Apéndice 10

327

Apéndice 11

339

Apéndice 12

Apéndice 13

343

Apéndice 14

344

Apéndice 15

Apéndice 16

353

Apéndice 17

355

Apéndice 18

357

Apéndice 19

Apéndice 20

Apéndice 21

Apéndice 22

Apéndice 23

Apéndice 24

Apéndice 25

Apéndice 26

Apéndice 27

Apéndice 28

Apéndice 29

Apéndice 30

Apéndice 31

Apéndice 32

Apéndice 33

359

360

368

369

373

380

381

382

394

395

398

399

402

404

406

Apéndice 34

409

Apéndice 35

410

Apéndice 36

411

Apéndice 37

415

Apéndice 38

416

Apéndice 39 
Apéndice 40 ..................................................................................... 420

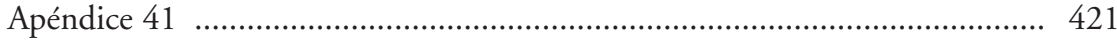

Apéndice 42

424

Apéndice 43

433

Apéndice 44

435

Apéndice 45

439

Apéndice 46

442

Apéndice 47

444

Apéndice 48

445

Apéndice 49 456

Apéndice 50

465

Apéndice 51

466

Apéndice 52

477

Apéndice 53

479

Apéndice 54

480

Apéndice 55

481

Apéndice 56

481

Apéndice 57

487

Apéndice 58

488

Apéndice 59

492

Apéndice 60

493

Bibliografía

495 



\section{PRINCIPALES ABREVIATURAS}

$\begin{array}{ll}\text { AGI } & \text { Archivo General de Indias, Sevilla. } \\ \text { c. } & \text { canon } \\ \text { cc. } & \text { cánones } \\ \text { cap. } & \text { capítulo } \\ \text { CIC } & \text { Código de Derecho Canónico de } 1983 \\ \text { CIC 17 } & \text { Código de Derecho Canónico de } 1917 \\ \text { Conc. Trid. } & \text { Concilio de Trento } \\ \text { Const. } & \text { Constitución } \\ \text { f. } & \text { folio } \\ \text { leg. } & \text { legajo } \\ \text { lib. } & \text { libro } \\ \text { ms. } & \text { manuscrito } \\ \mathrm{n}^{\circ} & \text { número } \\ \text { Ps. } & \text { pesos (unidad monetaria) } \\ \mathrm{R}^{\circ} & \text { Ramo } \\ \text { secc. } & \text { sección } \\ \text { sess. } & \text { sesión } \\ \text { tít. } & \text { título } \\ \text { Trat. } & \text { Tratado } \\ & \end{array}$





\section{PRÓLOGO}

\section{EL PRIMER MEDIO SIGLO}

Desde la erección de la diócesis de Quito en 1545 hasta la despedida de su obispo Luis López de Solís en 1606, corre la mitad de un siglo. Tal acotación temporal merece ser ponderada en su propia densidad, pues no todo tiempo encierra la misma trascendencia histórica. Hay años que marcan alteraciones duraderas, hay siglos que se deslizan por cauces prácticamente anodinos. También en la historia de las colectividades el decurso del tiempo adquiere aquellas relevancias subjetivas, que Bergson puso de relieve frente a la fría cuantificación cartesiana. Mirado de este modo, el medio siglo de tiempo tomado por Augusto Albuja para su estudio reviste una fuerza muy particular.

En efecto, el fin del siglo decimosexto implica, para el ámbito que luego se llamará Ecuador, un momento de cúspide luego de una centuria extraordinariamente activa. En interesante coincidencia, este juicio puede ser compartido en el área política como en la religiosa. La perspectiva que ofrece el tiempo transcurrido conduce, en efecto, a los estudiosos a percibir con toda claridad el inicio de un cambio de sentido, de crecimiento a decadencia, justamente en el gozne del cambio del siglo. Resulta hasta increíble que los contemporáneos no se dieran cuenta de que se hallaban en trance de hacer pasar una página a la historia.

El imperio español se extendió a lo largo de todo el siglo decimosexto como en un siglo de oro, marcando una hegemonía en todos los sentidos respecto de los demás centros europeos de poder. No cabe, desde luego, glorificar los imperios conforme a los cánones de una historiografía que valore simplemente la capacidad de expansión. Sin entrar en un juicio de valor, en que sería preciso analizar los complejos factores que desembocan en un predominio geopolítico, cabe dibujar una parábola creciente desde el solar implantado por los Reyes Católicos hasta el extenso manto imperial tendido por Carlos I y robustecido por Felipe II. En particular, mientras los finales del siglo anterior tenían todavía en la incertidumbre más grande el alcance de los descubrimientos de Colón, las postrimerías de los años quinientos extiende perfectamente una organización política que se extiende por todo el continente americano, bajo la arma- 
zón de dos virreinatos y la conjugación de variadas instituciones políticas, tomadas de la tradición europea y aplicadas a las nuevas tierras con no poca creatividad. Sin embargo, cuando Felipe II muere a dos años del fin de siglo, el imperio español, americano y europeo, atravesaba una de aquellas circunstancias en que impera el lema de renovarse o morir. Y no se renovó el esquema, continuaron más bien los mismos parámetros de orden económico y social, pero ya en un lento plano inclinado de continua decadencia. De la medida de este proceso decadente quedaría levantada acta en los comienzos del siglo dieciocho, con el término de la dinastía austríaca y el paso a la dinastía francesa en el suelo español. Aun faltaría otro siglo para que América lograra su independencia política.

En el plano eclesial, la gigantesca obra de la evangelización de América tomó dirección sobre todo con la llegada a tierra firme, por Centroamérica y México, como luego por todo Sudamérica. Se habla de 'evangelización fundante' cuando se evoca ese tiempo tan generoso y de realizaciones tan amplias. Llegado en nuestros días el Concilio Vaticano II, que ha suscitado un vasto movimiento de renovación en orden a reforzar la fidelidad del trabajo eclesial respecto de su misión propia, la mirada de muchos ha vuelto hacia aquel siglo en que el Evangelio fue recibido en las culturas aborígenes; propiamente, se inculturó. Tomó cuerpo la Iglesia como congregación de creyentes nuevos, habló otros idiomas, nacieron nuevas Iglesias particulares. El ímpetu misional, del que se destaca su fortaleza y capacidad creativa, se plasmó poco a poco en estructuras estables. Hubo concilios en Lima y sínodos en Quito. Pero también hacia el final del siglo, cuando todos los problemas habían recibido aparentemente una respuesta, se entró en un período de estancamiento, en mentalidad cercana a la del dueño o admirador que vive de rentas. Ya nadie echó de menos a los concilios y a los sínodos. Es más, la propia estructura de las relaciones con el imperio o con el reino manifestó cada vez más claramente su carácter sofocante y esterilizador, particularmente en el siglo borbónico.

Para Quito, ese siglo fue el de una Real Audiencia cuyos límites repiten de memoria nuestros estudiantes: Paita, Piura, Cajamarca, Cha- 
chapoyas, Moyobamba y Motilones por el sur, Pasto, Popayán, Cali, Buga, Chapanchica y Guarchicona por el norte; mientras la amazonía se iba hasta donde 'se descubriere'. Dos diócesis comprendía la Real Audiencia, la payanesa y la quiteña. La quiteña conoció cuatro obispos desde su erección hasta el comienzo del diecisiete. El primero, Garci Díaz Arias bregó por espacio de unos quince años en la procura de los aspectos institucionales más básicos. El tercero Antonio de San Miguel y Solier, murió en Riobamba, según llegaba a hacerse cargo del puesto. El segundo y el cuarto fueron unos titanes. Favorecidos por un período relativamente largo de tiempo para gobernar, Pedro de la Peña y Luis López de Solís, dominico y agustino respectivamente, dejaron para el cierre del siglo de oro una diócesis bien organizada y en plena marcha: con catedral y seminario, con normativa ajustada a la realidad, con servicios pastorales que cubrían todo el territorio, mediante 208 parroquias.

El presente trabajo se ha dirigido a describir y documentar ese tiempo fundacional. La división de la población en parroquias y doctrinas en orden a la formación de la comunidad cristiana, los criterios para hacer estas divisiones y la forma observada para proveerla con sus pastores. Como un corte transversal que permite congelar el panorama en el momento del cambio de siglo, Augusto Albuja describe cómo se atendía a la instrucción religiosa, al culto y a la administración de los sacramentos, cómo se regulaba la disciplina, cual era la fuente de mantenimiento. El recuento se detiene con más detalle en referencia al clero, diocesano y religioso. Culmina con un cuadro estadístico de la administración eclesiástica al final del episcopado de López de Solís, cuando se trasladaba la Virgen del Quinche desde Oyacachi hasta el lugar que actualmente ocupa el santuario.

No deja de admirar que, para ese entonces, había en la catedral de Quito un cuerpo de canónigos tan nutrido como el actual. Se encontraban en plena vida las parroquias urbanas de San Sebastián, San Roque, Santa Bárbara, San Marcos, San Blas, Santa Prisca, San Juan de Machángara y Machangarilla, además de las cercanas de Cotocollao y Chillogallo, con todas las poblaciones actuales del Valle de los Chillos, con núcleos 
aun hoy remotos como Mindo, Nanegal y Gualea. En la Sierra, se puede anotar desde Pasto y Tulcán hasta Loja y Zamora incluso hasta Jaén, Túmbez y Piura. No se ha fundado aun Ibarra, pero hay parroquias y doctrinas por Otavalo, Cotacachi, Atuntaqui, Urcuquí y Pimampiro, o sea, por todas las actuales cabeceras cantonales de Imbabura. Mucho más débil aparece la situación en toda la zona de Costa, donde Guayaquil tiene una sola parroquia y el distrito conoce solamente los puntos de Baba, Yaguachi, Daule, Chongón e Isla Portoviejo, Jipijapa, Manta y Picoazá. En realidad, hay que llegar hasta el siglo veinte para ver crecer la organización eclesiástica en la zona costera.

El apéndice documental sale más extenso que el mismo texto. Es a la vez garantía de seriedad y apoyo a la erudición. En suma, la presente monografía elige un importante tiempo y deja una importante investigación.

Ibarra, 1 de noviembre de 1997

+Antonio Arregui Yarza

Obispo de Ibarra

Secretario General

de la Conferencia Episcopal Ecuatoriana 


\section{INTRODUCCIÓN}

Esta obra abarca dos partes. La primera corresponde directamente al tema que nos hemos propuesto; y la segunda, a manera de suplemento, es una colección de sesenta documentos relacionados con el título escogido para este trabajo.

Así pues, al presentar los dieciseis capítulos subsiguientes, conviene advertir que los dos primeros bien podrían constituir el preámbulo, pues aunque se tenga la impresión que no vienen al caso, juzgamos muy conveniente tomarlos en cuenta porque así conoceremos el medio ambiente de la época de nuestro estudio, es decir, la segunda mital del siglo XVI. Después de una breve reseña de lo que fue la Real Audiencia de Quito, sus límites, divisiones civiles, Encomiendas y Ecomenderos, hacemos una pequeña biografía de los primeros Obispos, porque conociendo la relevante personalidad, sobre todo del segundo y del cuarto Obispo, no nos extrañará que en media centuria la incipiente Diócesis haya cobrado vitalidad, tanto por su organización como por el número de Doctrinas y Parroquias erigidas.

Hecha esta referencia por medio de los dos primeros capítulos, pasamos de inmediato al tema propuesto. Exponemos en primer lugar los conceptos de Doctrina y de Parroquia, su identificación y diferencia; luego damos a conocer los cinco Concilios limenses y los tres Sínodos diocesanos de Quito, cuyas constituciones relacionadas con Doctrinas y curas doctrineros, Parroquias y curas párrocos, citamos a lo largo de este trabajo, sin prescindir del Concilio de Trento y del Código de Derecho Canónico. Viene después la manera cómo se hacía la provisión de Doctrinas y Parroquias. En los capítulos siguientes estudiamos algunos puntos jurídicos relacionados con doctrineros y párrocos, a saber: residencia, cuidado pastoral, instrucción religiosa de los fieles, administración de sacramentos, libros parroquiales y misa pro populo. Además tratamos de los aranceles parroquiales, salarios de curas y doctrineros, diezmos diocesanos. Respec- 


\section{8 / Augusto E. Albuja}

to a los fieles, damos a conocer las fiestas de precepto y los días de ayuno y abstinencia. Estudiamos en los capítulos finales las principales reformas del clero, sin omitir exponer una extensa lista de sacerdotes beneméritos, la mayoría de los cuales ejercía el ministerio parroquial en Doctrinas y Parroquias de la Diócesis. Otro punto importante que tratamos es la fundación del Seminario conciliar en Quito; y el referirnos a las Ordenes sagradas de mestizos, exponemos las dificultades que encontraron los primeros Obispos. Si casi todo el trabajo lo hemos dedicado exclusivamente a curas y doctrineros, muy justo tratar en un capítulo aparte de los Arciprestes y Vicarios Generales, quienes ayudaban al Obispo en el buen gobierno de la Diócesis. Hemos reservado otro capítulo para el clero regular, ya que en esta época ejercía el ministerio parroquial, al igual que el clero secular. Y por último, poniemdo punto final a este estudio de Doctrinas y Parroquias, y como una síntesis de todo lo expuesto, gracias al trabajo de investigación, podemos dar a conocer cuál era la situación de la Diócesis a fines del siglo XVI. Juzgamos que este último capítulo despertará algún interés, sobre todo en aquellos que en el futuro se dediquen a profundizar la historia de la iglesia en el Ecuador.

Las fuentes que hemos investigado para este trabajo son en su mayor parte inéditas, sobre todo los Sínodos de Quito, provisiones canónicos de Parroquias y Doctrinas, cartas e informes de Obispos etc. Sin embargo, no hemos dejado de consultar obras impresas, algunas de las cuales nos han prestado enorme ayuda.

Asimismo, ya por la conveniencia de que esta obra resulte más completa, ya también porque algunas personas de prestigio intelectual y amantes de la investigación así nos han insinuado, adjuntamos la colección de sesenta documentos y que son las transcripciones de los manuscritos del Archivo General de Indias, donde personalmente hemos investigado. Tales documentos han sido catalogados en orden cronológico y los presentamos bajo el título de "APÉNDICES"; en su mayoría son inéditos. Conviene advertir que para facilitar su lectura, evitando que resulte cansina, publicamos no con la grafía original de los manuscritos -que desde luego sí tenemos- sino con la ortografía moderna, al igual que lo hacemos 
en las numerosas citas de esta obra, respetando los arcaismos propios de la época, tan hermosos y tan significativos de la lengua española en el siglo XVI.

Aprovechamos de esta ocasión para cumplir con el deber de la gratitud para con todas aquellas personas que de una u otra forma han contribuido, a fin de que podamos llevar a feliz término este trabajo.

EL AUTOR 



\section{CAPÍTULO I \\ LA ENCOMIENDA Y LA REAL AUDIENCIA DE QUITO}

Nuestro intento es hacer un breve estudio de lo que fue, en general, la Encomienda Indiana; y luego, tratar de la Real Audiencia de Quito, en lo que se relacionaba con sus límites, Gobernaciones, Encomiendas y Encomenderos, en la segunda mitad del siglo XVI.

\section{La encomienda}

El sistema de las Encomiendas, empleado en América a raíz de la conquista, fue, sin duda, una de las instituciones más sobresalientes y características del Derecho Indiano.

¿En qué consistía la Encomienda? La respuesta nos da el célebre jurista Solórzano Pereira: "La Encomienda -dice este autor- es un derecho concedido, por merced real, a los beneméritos de las Indias para recibir y cobrar para sí los tributos de los indios que se les encomendaren por su vida y la de un heredero, con cargo de cuidar del bien de los indios en lo espiritual y temporal y defender las provincias donde fueran encomendados" 1 . En cambio, para Ots Capdequi, la Encomienda era "Una institución de origen castellano, que pronto adquirió en las Indias caracteres peculiares. Por la Encomienda un grupo de familiares de indios, mayor o menor, según los casos, con sus propios caciques, quedaba sometido a la autoridad de un español Encomendero. Se obligaba a éste jurídicamente a proteger a los indios que así le habrían sido encomendados y a cuidar de su instrucción religiosa con los auxilios del cura doctrinero. Adquiría el derecho de beneficiarse con los servicios personales de los indios para las 


\section{2 / Augusto E. Albuja}

distintas necesidades del trabajo y de exigir de los mismos el pago de diversas prestaciones económicas. Con el Rey contraía el compromiso, todo español Encomendero, de prestar el servicio militar a caballo cuando para ello fuese requerido. Tuvieron las Encomiendas, en un primer momento, un carácter temporal o vitalicio. Al vencer el plazo requerido por el cual habían sido concedidas, o la muerte del Encomendero, se incorporaban los indios encomendados a la Corona. Pronto surgió la costumbre de consentir, por vía de disimulación, que la viuda y los hijos del Encomendero siguieran disfrutando de los indios a la muerte de su causante. Se sancionó esta costumbre con la Real Provisión del 26 de marzo de 1513, y ya desde entonces se concedieron las Encomiendas por dos vidas: por la del primer poseedor y por la de su sucesor inmediato, el mayor de los hijos varones, en su defecto la hija y en último término la mujer."

Así pues, teniendo presentes estos conceptos, preciso y claro el primero, amplio el segundo, podremos darnos cuenta de la finalidad que se intentaba con esta institución jurídica conocida con el nombre de Encomienda, a saber: la protección del indio, su civilización, su instrucción religiosa y social. Pero, no siempre se logró tal intento. Algunos Encomenderos, en vez de cumplir su sagrado deber, abusaron de los indios a ellos encomendados, razón por la cual se entabló la eterna lucha: múltiples cartas fueron dirigidas por Obispos, sacerdotes, Virreyes y Gobernadores en las que daban a conocer al Rey unas veces la necesidad de modificar esta institución y otras veces pedían la misma muerte de la Encomienda.

Habían transcurrido apenas cuatro años desde el descubrimiento de América, cuando "el sistema de Encomiendas fue implantado por Colón, después del fracaso de su intento para imponer a los indios un tributo determinado. Repartió los indios de la Española entre los españoles, quienes exigían de ellos servicio de preferencia al tributo"3. De manera que, según Lewis Hanke, fue Cristóbal Colón a quien se atribuye la paternidad de las Encomiendas. La Reina Isabel, al saber semejante cosa hecha por Colón, protestó enérgicamente, ordenando la inmediata libertad de los indios por medio de aquella frase tan conocida: “¿Con qué autoridad dispone el Almirante de mis vasallos?..." 
Sin embargo, razones de orden político, social y religioso impulsaron a los Reyes Católicos a despachar el 20 de diciembre de 1503 una Real Orden, por la cual Nicolás de Ovando fue autorizado a entregar indios a los conquistadores, pues "a causa de la mucha libertad que los dichos indios tienen, huyen o se apartan de la conversión y comunicación de los cristianos, por manera que no quieren trabajar e andan vagabundos, ni menos los pueden hacer para doctrinar e atraer a que se conviertan a nuestra fe católica...mandé que compeláis e apremiéis a los dichos indios que traten y conversen con los cristianos y trabajen en sus edificios y coger y sacar oro e otros metales... pagándoles el jornal que por vos fuera tasado; lo cual hagan y cumplan como personas libres como lo son, y no como siervos, y haced que sean bien tratados los indios" 5 La orden había sido dada y por tanto se comenzó a ponerla en práctica.

La fórmula utilizada por Gonzalo Pizarro en el Perú, al hacer los Repartimientos de los indios, rezaba así: "Considerando que vos habéis servido a Su Majestad en estos dichos reinos, e que vos habéis casado con intención de permanecer en ellos... Por la presente, en nombre de Su Majestad, os deposito el pueblo de... con la persona del cacique principal... e con todos sus indios e principales, e que habiendo religiosos en la dicha villa que doctrinen a los hijos de caciques los traigáis ante ellos para que sean instruidos en las cosas de nuestra santa religión ... de los cuales indios os habéis de servir en tanto que seáis obligados a los doctrinar..., e les hacer buen tratamiento, e si así no lo hiciéredes, cargue sobre vuestra conciencia e no sobre la de Su Majestad e mía, que en su real nombre os los deposito"6.

Pronto surgieron varios inconvenientes de los tales Repartimientos, pues los Encomenderos, prescindiendo las más de las veces del bienestar espiritual y temporal de los indios encomendados, se preocupaban primariamente de su provecho personalista y mezquino7. "La teoría de la Encomienda podrá haber sido espléndida; pero en la práctica de aquellos primeros años no sirvió para proteger a los indios y, con el arribo de los dominicos a la Española, la protesta contra el trato que daban los conquistadores a los nativos, comenzó a alcanzar notoriedad. El domingo anterior 
a la Navidad de 1511, un fraile dominico, nombrado Antonio de Montesinos, predicó un sermón revolucionario en la iglesia, techada de guano, de la Isla de la Española. Hablando sobre el texto "Yo soy una voz que clama en el desierto", Montesinos formuló deliberadamente la primera e importante protesta pública contra el tratamiento que daban sus compatriotas a los aborígenes" 8 .

Si Fr. Antonio de Montesinos atacaba a Encomenderos y a la misma institución, Fr. Alonso del Espinar era, en cambio, el defensor de las Encomiendas. A raíz de las discusiones de los dos frailes, discusiones que cada día eran más conocidas, se convocó la famosa Junta de Burgos, de donde surgieron las llamadas "Leyes de Burgos" u "Ordenanzas para el buen tratamiento de los indios", y que fueron redactadas el 27 de diciembre de 1512 .

Cuando Hernán Cortés hizo varios Repartimientos de indios en Nueva España, el Emperador Carlos V, por medio de una Real Cédula del 20 de julio de 1523, condenaba dicha institución. Sin embargo, al poco tiempo tuvo que revocar sus disposiciones.

A partir del 20 de marzo de 1524, la Encomienda fue considerada como una tutoría de orden espiritual, pues Cortés, en sus "Ordenanzas de Buen Gobierno", mandaba: "Primeramente, que cualquier español u otra persona que tuviera indios, sea obligado a les mostrar las cosas de nuestra santa fe"; y a fin de que "todos los naturales de estas partes participen de la palabra de Dios y el sonido de ella mejor con todos se comunique, mando que cualquier persona que tuviera indios de Repartimiento, que sean de dos mil arriba, para que los instruya en las cosas de nuestra santa fe, e les prohiba sus ritos e ceremonias antiguas ... e que si, pudiéndolo haber, no lo tuviere, pierda así mismo los dichos indios" 10 .

Las Encomiendas jurídicamente se asemejaban a los mayorazgos y feudos de España en la Edad Media; pero, sin embargo, había una diferencia notable, a saber: el feudo era perpetuo y el señor feudal gozaba de jurisdicción en lo civil y en lo criminal; la Encomienda, en cambio, se daba por dos vidas, o a lo más para tres; los encomendados tenían obligación de pagar un tributo y el Encomendero debía protegerlos contra las 
incursiones de los enemigos y velar por el bienestar espiritual, procurándoles un sacerdote para que se dedicara a la instrucción religiosa ${ }^{11}$.

Según las Ordenanzas de Zaragoza en 1518, la Encomienda resultaba un verdadero contrato bilateral, pues al Encomendero le correspondía la provisión de la enseñanza de la doctrina cristiana y de las cosas que hiciesen falta a los indios, quienes, como contribución, prestarían servicio a los españoles ${ }^{12}$.

Como, en general, las Encomiendas no eran perpetuas sino temporales, estaban sometidas al vaivén de ciertas circunstancias o causas por las que podían quedar vacantes. Arcila Farias señala trece causas de la vacancia de Encomienda, de las cuales las más corrientes eran: muerte del Encomendero sin sucesor, de acuerdo con la ley de sucesión; muerte del Encomendero en última vida, ésta era la más común; defectos de confirmación; maltratos a los indios; el hecho de poseer una Encomienda era suficiente para que la segunda se declarase vacante; y, "en general, por causa de poseer las Encomiendas contra las Cédulas u Ordenes Reales"13.

Siendo las Encomiendas premios que se concedían en Indias, en nombre del Rey, a los "descubridores, pacificadores y pobladores" 14 , nos preguntamos: ¿Quién era el Encomendero?. Encomendero, según Peña Montenegro, era aquel "bajo cuya tutela estaban aquellos que habían sido asignados por el Rey para que sean instruidos y protegidos". De esta definición se desprenden las dos obligaciones generales de todo Encomendero: instrucción religiosa y enseñanza política o defensa temporal de las personas y de sus bienes. Al principio, en Indias, los llamados Encomenderos desempeñaron un papel muy importante. Después, fueron los $\mathrm{Cu}$ ras Doctrineros, quienes asumieron la obligación de enseñar la doctrina, administrar los sacramentos, etc., pero, no por esto desaparecieron los Encomenderos, sino que, de las dos obligaciones generales, se quedaron con la segunda ${ }^{15}$.

Si analizamos de un modo detenido las obligaciones que pesaban sobre el Encomendero, con relación a su Encomienda y a los indios encomendados, podemos señalar tres clases de obligaciones: materiales, espirituales y morales. 
El Encomendero estaba obligado a defender la integridad del territorio conquistado ${ }^{16}$, para lo cual podía disponer de caballo, lanza, espada y de otras armas ofensivas y defensivas ${ }^{17}$. Asimismo, se pedía que el Encomendero se preocupase de la construcción de "casas de piedra en el lugar, parte, forma y traza, que se dispone en el título de la población de las ciudades... y si en la tierra o comarca no hubiera comodidades de piedra para el edificio, provea que se haga de argamasa, o tapicería u otros materiales, los más durables que se puedan haber, y que estén hechas y acabadas dentro de dos años, contados desde el día que se le diere la Encomienda" 18 .

Hacia el año 1538, Carlos V dispuso que todo Encomendero debía construir en su Encomienda una casa de "piedra o ladrillo en la parte donde quisiera morar" 19 . El plazo dado para edificar esta casa era dentro de los seis primeros meses; si no obedecía, su Encomienda se declaraba vacante. Al principio se había juzgado conveniente que el Encomendero viviera en su propia Encomienda; pero, por los abusos cometidos, se determinó "que ningún Encomendero de indios, ni su mujer, padres, hijos, deudos, criados ni huéspedes, ni mestizos, ni mulatos, ni negros, libres o esclavos, puedan residir, ni entrar en los pueblos de su Encomienda, porque de esta comunicación y asistencia resulta que los naturales son fatigados con servicios personales a que sin causa ni razón los obligan, ocupándoles en traer yerba y frutas que van a buscar por larga distancia, pescar, moler y amasar trigo, en que pasan grandes y excesivos trabajos y molestias, aunque sea con pretexto de utilidad de los indios, o curarlos, o curarse, por gozar de la diferencia de temple, pena de cincuenta pesos. Y mandamos -continúa esta ley- a nuestras Justicias Reales que no lo consientan ni permitan y ejecuten la dicha pena y encargamos a los Prelados Eclesiásticos que castiguen y corrijan los excesos que en esto hicieren los doctrineros" 20 .

Si las obligaciones materiales de los Encomenderos eran graves, más graves aún eran las de orden espiritual, porque, sencillamente, "el motivo y origen de las Encomiendas fue el bien espiritual y temporal de los indios, y su doctrina y enseñanza en los artículos y preceptos de nuestra santa fe católica" 21 . 
Por tanto, cada Encomendero debía edificar "a lo menos una iglesia en lugar conveniente, proveyendo al ministro de lo necesario"22. "Ordenamos y mandamos -decían Doña Juana y el Príncipe Don Carlos, el 9 de diciembre de 1518, dirigiéndose al Licenciado Rodrigo de Figueroa, juez de Residencia de la Isla Española- que el vecino a quien se encomendaren los dichos indios, sea obligado a les tener una casa para iglesia en la cual ponga imágenes de Nuestra Señora y una campanilla para los llamar a rezar... y sea obligado a los llamar en anocheciendo e ir con ellos a la tal iglesia e hacerlos sinar e santiguar, todos juntos, e decir el Ave María y el Pater noster y Credo y Salve Regina, de manera que todos ellos oigan a la dicha persona y la tal oiga a todos, porque sepa cual acierta y cual yerra, porque al que errare lo enmiende;... cada mañana, antes que vayan a labrar, los hagan ir a la dicha iglesia y rezar como lo hacían a las tardes" 23 .

No solamente la construcción de una iglesia corría de cuenta del Encomendero, sino que éste debía sufragar los gastos de culto como ornamentos, vino y cera ${ }^{24}$, y el sostenimiento del sacerdote o laico doctrinero, "porque todos los naturales de estas partes participen de la palabra de Dios y el sonido de ella mejor con todos se comunique, mando que cualquier persona que tuviere indios de Repartimiento, que sean de dos mil arriba, tenga en el pueblo o pueblos de ellos un clérigo o otro religioso para que los instruya en las cosas de nuestra santa fe, e les prohiba sus ritos e ceremonias antiguas... e que si, pudiéndolo haber, no lo tuviere, pierda asimismo los dichos indios". Y en caso de no ser posible conseguir un sacerdote, el Encomendero estaba obligado a proveer de "alguna persona lega, de buena edad y vida y ejemplo para que los instruya y enseñe en la vida y doctrina cristiana, y los haga ir a la iglesia, y aconseje a vivir virtuosamente" 25 .

Y en lo que respecta a los indios encomendados, se pedía a Virreyes y Presidentes de Audiencias que vigilasen a los Encomenderos de sus respectivos distritos para que éstos cumplieran fielmente sus deberes y obligaciones a fin de que los dichos indios "sean instruidos -decía Felipe II- en nuestra santa fe católica, muy bien tratados, amparados, defendidos y mantenidos en justicia y libertad como súbditos y vasallos nuestros, pa- 
ra que, estando con esto la materia dispuesta, puedan los ministros del Evangelio conseguir más copioso fruto en beneficio de los naturales sobre que a todos les encargamos las conciencias" 26 .

De esta forma, la responsabilidad del Rey se descargaba en los Encomenderos, a quienes, además de las obligaciones señaladas, se les pedía que cada uno en su Encomienda pusiera especial diligencia a fin de evitar amancebamientos, supersticiones, hechicerías y la embriaguez, cosas estas muy corrientes entre los indios. Por todos los medios se trataba de implantar la pureza de las buenas costumbres. Terminantemente estaba prohibido que los Encomenderos, bajo ningún pretexto, pudiesen tener en sus casas indias de sus Repartimientos o Encomiendas; y al que violaba esta orden, incurría en una multa de cien pesos. Asimismo, los Encomenderos debían dejar en libertad a los indios para que contrajesen matrimonio cuando ellos quisieren y con quien quisieren, pues de lo contrario se los amenazaba con la pérdida y privación de la Encomienda, y el juez secular procedería a castigar este delito 27.

Respecto a la vida conyugal, los Encomenderos debían ser un ejemplo viviente, razón por la cual el Encomendero soltero debía contraer matrimonio dentro de los tres primeros años que tuviere Encomienda ${ }^{28}$; y si algún Encomendero estaba casado y su esposa se había quedado en España, a pesar de la prohibición estricta de poder ausentarse, con mucha facilidad se le concedía la autorización, dándole el plazo de dos años, para que hiciera el viaje y volviese trayendo a su esposa ${ }^{29}$.

No todos eran llamados a ser Encomenderos. Prelados y clérigos, Virreyes y Gobernadores, monasterios y hospitales, casas de religión, etc., estaban excluidos ${ }^{30}$. Solamente podían desempeñar este cargo aquellos que habían prestado sus servicios a la Corona, que merecían una recompensa y de quienes habían esperanzas fundadas que se portarían bien, cumpliendo fielmente sus obligaciones; pues, para mayor seguridad, se había dispuesto que, antes de tomar posesión de una Encomienda, "los Encomenderos hagan juramento judicial ante el Gobernador, y con fé de Escribano, de que tratarán bien a sus indios, y conforme a lo que está dispuesto y ordenado" 31 . 
Deberes y derechos son correlativos. Si los Encomenderos tenían obligaciones, era natural que también tuviesen derechos, pues, de lo contrario, nadie hubiera querido desempeñar el cargo de Encomendero.

"Tener Encomienda -dice Cuevas- implicaba el derecho de percibir los tributos de quinientos indios de algún pueblo, tributo que no debía de pasar de dos mil pesos al año"32; pues la Encomienda no debía ser considerada como una ocasión propicia para negociar y enriquecerse, sino como un medio de poder subsistir y satisfacer las necesidades del Encomendero con los tributos que le pagaban los indios ${ }^{33}$.

Doloroso es confesarlo, pero la realidad es que en los primeros años que siguieron a la institución de la Encomienda, muchos Encomenderos cobraban demasiado tributo y exigían de los indios aún el servicio personal, no como peones sino como parte de sus derechos, a tal punto que "los Encomenderos, padres de estos miserables -escribe el Obispo Peña Montenegro- los hacen más miserables con su amparo... es culpa grave con exageración, que estos miserables anden desnudos, y con hambre trabajando para pagar su tributo a quién los defienda, y ampare, y cuando con dineros compran padre, encuentran un tirano que los degüella, y no hay en el mundo sentimiento y dolor, como recibir agravios de quién se esperaban beneficios; y experimentar rigores, donde se prometían piedades" 34 .

El Rey, al tener conocimiento de estos abusos de parte de los Encomenderos, abolido el servicio personal, ordenó que se "igualen las tasas -de los tributos-, de forma que no paguen más los unos indios que los otros... ; y por el mismo caso que algún Encomendero contraviniese en algo a lo dispuesto y ordenado, incurra en perdimiento de la Encomienda". Asimismo, para evitar el que se pudiese exigir de los indios el servicio personal, fue dada la siguiente disposición: "Ordenamos -decía el Monarcaque los Encomenderos, Jueces e Comisarios, de las tasas no conmuten, ni hagan que se pague el tributo de los indios en servicio personal, ni los $\mathrm{Vi-}$ rreyes lo concedan, porque de este abuso han resultado tantos agravios y clamores de los indios" 35 . 
Los tributos debían ser tasados por las autoridades civiles; y para que no se cometiesen injusticias, se pedía que "los tasadores asistan a una misa solemne del Espíritu Santo, que alumbre sus entendimientos, para que bien justa y derechamente hagan la tasación, y, acabada la misa, prometan y juren con solemnidad al sacerdote, que hubiese celebrado, que la harán bien y fielmente, sin odio ni afición... Se informarán de lo que antiguamente solían pagar a sus caciques y a los otros que los señoreaban y gobernaban... y de lo que justamente debieren pagar de allí adelante, quedándoles con qué poder pasar, dotar y alimentar sus hijos, reparo y reserva para curarse en sus enfermedades y suplir otras necesidades comunes, de forma que paguen menos que en su infidelidad. Después de bien informados, declaren, tasen y moderen, según Dios y sus conciencias, tributos moderados" 36 . Hermosa disposición, saturada de caridad verdaderamente cristiana, digna de tomarse en cuenta en aquellas regiones donde los obreros, sobre todo del campo, al igual que muchos indios durante la Colonia, son explotados por sus respectivos amos, no porque les exijan un tributo sino porque les pagan jornales insignificantes que no están de acuerdo con los servicios que ellos realizan.

Respecto al tributo que los Encomenderos percibían de los indios, la Junta de 1536 celebrada en la Nueva España llegó a las siguientes conclusiones:

"1) Que las personas que se encargan de la Encomienda, si han cumplido lo que son obligados,... habrán llevado con buena conciencia lo que justamente han llevado.

2) Que los negligentes y los descuidados, además de haber estado y estar en culpa muy grave, sean obligados a restituir todo aquello que justamente se habia de gastar en lo susodicho.

3) Y si ha habido alguno que, con espiritu diabólico, ha procurado que no bubiera ni viniesen ministros a sus pueblos... estos tales, allende de haber ofendido a Dios N.S. gravisimamente, son obligados a mucha más restitución y satisfacción"37.

Después de haber expuesto en términos casi generales las características de la Encomienda, las obligaciones y derechos de los Encomende- 
ros y el fin que se pretendía conseguir con esta institución, a saber: civilización del indio y propagación del reino de Cristo en el Nuevo Mundo, tenemos que afirmar que "vistas así en teoría, las Encomiendas eran la mejor manera, la única por entonces, de sostener el dominio español y la necesaria protección de los mismos ministros del Evangelio"38.

En cambio, Jaramillo Alvarado dice: "en la práctica, esas Encomiendas fueron el origen de la eterna esclavitud del indio... El indio, como personalidad humana, fue literalmente aniquilado... Sobre el vencido pesaron todas las ignominias... Desde el oficio de sirviente perpetuo o yanacón hasta el de acémila y carne de cañón en las guerras civiles entre conquistadores, todo lo soportó el indio" 39 . Estas frases son demasiado fuertes; por eso, juzgamos oportuno salvar la responsabilidad de la Iglesia, ya que a través de sus Obispos y del clero siempre se preocupó del indio como persona humana y las disposiciones conciliares y sinodales le eran muy favorables, como estudiaremos a lo largo de este trabajo. Además, ¿qué culpabilidad tenían los Reyes de España? Las Reales Cédulas nunca aprobaban abusos; antes bien, siempre los condenaban y las disposiciones que se enviaban de la Corona eran lo más cristianas y lo más humanas. Que uno que otro empleado del Rey no haya correspondido a la confianza en él depositada, es cosa muy distinta. Es peligroso generalizar los casos particulares.

Sin dejarnos llevar de prejuicios, debemos concluir diciendo con González Suárez que "a primera vista, la institución de las Encomiendas parece odiosa, pero examinada atentamente, no puede menos de ser aprobada, pues en si mismas las Encomiendas, tales como se organizaron en el Virreinato del Perú, no tienen nada de injusto" 40 .

La Encomienda, al igual que toda otra institución humana, llegó a su fin. No nos interesa averiguar cuál fue la verdadera causa para su supresión. La realidad es que el Rey, por una Cédula del 23 de noviembre de 1718, incorporaba todas las Encomiendas a la Corona, "anulando las segundas vidas", por las que generalmente eran concedidas, y conservando solamente las que tenían el carácter de perpetuas, que probablemente debieron ser muy pocas ${ }^{41}$. 


\section{La Real Audiencia de Quito}

El departamento de Quito, en la segunda mitad del siglo XVI, no era una simple Gobernación dependiente del Virreinato del Perú sino que tenía la categoría de Real Audiencia y estaba bajo la vigilancia y jurisdicción del Virrey de Lima.

La ciudad de San Francisco de Quito, fundada por el español Sebastián de Benalcázar el 6 de diciembre de 1534, era la sede de la Real Audiencia, cuyo Presidente estaba asistido de tres Oidores, un fiscal, dos secretarios, un relator, seis procuradores, un alguacil mayor, un alguacil menor, dos porteros, un alcalde y un capellán.

La Real Audiencia de Quito comprendía cuatro Gobernaciones, a saber: la de Yaguarsongo y Bracamoros, la de los Quijos, la de las Esmeraldas y la de Popayán. Hacia el año 1577 desempeñaban el cargo de Gobernadores: Juan de Salinas Loyola, en la Gobernación de Yaguarsongo y Bracamoros; Melchor Vázquez de Avila, en la de los Quijos; Andrés Cantero, en la de Las Esmeraldas, y un tal Benalcázar, en la de Popayán ${ }^{42}$

Las Gobernaciones se dividían en Corregimientos y éstos, a su vez, en Repartimientos o Encomiendas. "Hay -dice Vázquez de Espinosaen el distrito del Obispado de Quito diez Corregimientos, y un Gobierno, provee su Majestad, por consulta del Supremo Consejo de las Indias, los de Quito, Guayaquil, Loja y Zaruma, Cuenca, el Gobierno de los Quijos; y los cuatro siguientes el Virrey del Perú, que son: Riobamba, Chimbo, Latacunga, Otavalo, y más provee el de Yaguarsongo; y en la ciudad de Pasto provee el Gobernador de Popayán”43.

Antes de exponer una lista de Encomenderos y Encomiendas en la Real Audiencia de Quito, que es lo que más podría interesarnos en nuestro estudio, debemos advertir que el territorio que comprendía dicha Audiencia de Quito era muy extenso y había sido señalado por el Rey Felipe II el 29 de noviembre de 1563. Así pues, en ese entonces la Provincia de Quito, que había sido erigida en Real Audiencia, se extendía: "por la Costa, hacia la parte de la Ciudad de los Reyes, hasta el Puerto de Paita exclusive: y por la tierra adentro hasta Piura, Cajamarca, Chachapoyas, 
Moyobamba y Motilones exclusive, incluyendo hacia la parte susodicha los pueblos de Jaén, Valladolid, Loja, Zamora, Cuenca, la Zarza y Guayaquil, con todos los demás pueblos que estuvieren en sus comarcas y se poblaren; y hacia la parte de los pueblos de la Canela y Quijos, tengan los dichos pueblos, con los demás que se descubrieren; y por la Costa hacia Panamá, hasta el Puerto de la Buenaventura inclusive: y la tierra adentro a Pasto, Popayán, Cali, Buga, Chapanchica y Guarchicona; porque los demás lugares de la Gobernación de Popayán son de la Audiencia del Nuevo Reino de Granada, con lo cual, y con la Tierra Firme para términos por el Septentrión; y con la de los Reyes por el Mediodía, teniendo al Poniente la Mar del Sur, y al Levante provincias aún no pacíficas, ni descubiertas" 44 .

Nuestro deseo hubiera sido poder presentar una estadística completa de cómo estaba la Real Audiencia de Quito, respecto a Encomiendas, Encomenderos, número de indios, etc. en una época determinada del tiempo que comprende nuestro estudio; pues, de esta forma hubiéramos tenido una visión de conjunto del campo eclesiástico y civil, los cuales, durante la Colonia, estaban íntimamente relacionados, ya que del número de Encomiendas y Encomenderos dependían también el de curas y doctrineros como veremos más adelante.

Gracias a una relación hecha por los Oficiales de la Audiencia de Quito el 23 de enero de 1577, y que fuera enviada al Rey para informarle del estado de las Indias, podemos presentar la estadística siguiente:

\section{ENCOMENDEROS}

Rodrigo Nuñez de Bonilla

Diego Montañero y la Real Corona Alonso Flores de Avila

Lorenzo Vargas

Capitán Miguel Fernández de Sandoval y su esposa Ana de Sandoval.

Lucas Poncel

Juan de la Fuente

\section{ENCOMIENDAS}

Pomallacta y Pachamama

Tiquizambe

Tiquizambe (términos).

Pallatanga-Guamarica-Puratico

Chimbo (3100 indios) -Cañares-Sangai-

Angamarca (300 indios)

Sicho (1000 indios) 
Garciponce

Catalina Díaz

Gaspar Ruíz

Francisco de Arellano

Cristóbal Calvachi

Rodrigo de Paz Maldonado y su

esposa doña Isabel de Aguilar

Ruidíaz de Fuenmayor

Juan de Galarza, Alguacil mayor

de la Real Audiencia

Hernando de Paredes

Juan Arias Altamirano y Cristóbal

Moreno Maroto

Alonso de Aguilar y su esposa

María de Salazar.

Juan de Londoño

Capitán Diego de Sandoval

Garciduque de Estrada y otros

Francisco de la Carrera

Capitán Francisco Ruíz

más: 4 en Chillo, 2 en Uyumbicho y

2 en la región de los Yumbos.

Lorenzo de Cepeda

Francisco Atahualpa (inga)

Francisco Hernández

Carlos de Salazar

Diego Arcos

Alonso de Bastidas

Capitán Juan Mosquera

Francisco de Olmos

Martín de Aizaga y su esposa,

doña Leonor

Cristóbal Pérez Concha y su

esposa Juana Muñoz

Mateo de Galárraga

Capitán Rodrigo de Salazar
Siccho (1200 indios)

Uno, en la prov. de los Puruáes

Yaruquí (300 indios)

Guano - Chambo (1000 indios)

Uno en la prov. de Macas y Puruáes

Chambo

Luisa

Azacos (1000 indios)

Uno en Tungurahua

Ambato (4000 indios)

Píllaro-Patate-Cochesquí-Tulcán.

Aláquez - Saquisilí

Mulaló (1500 indios)

Cotocollao (500 indios)

Pansaleo

Sangolquí - Pifo - y ocho pueblos

Píntag

Uno en los términos de la ciudad de Quito.

Guangopolo

Yumbos - Chillogallo (pueblo).

Litaquilca-Caguasquí-Alangasí.

Tumbaco-Tungurahua-Zuña-Guambaló

Laracachi - Cotocollao

Mindo - Yambi

Cayambe-Guayllabamba-Iñaquito y Hoyacachi.

Un pueblo en Pomasqui.

Calacalí

Otavalo con 6 pueblos en dicha prov. (2500 indios); (además 2 pueblos entre los Yumbos y Cumbayá) 
Real Corona (tiene la mitad)

Diego Gutiérrez de Logroño El Convento de Monjas de la ciudad de Quito, por concesión especial del Virrey

Capitán Martín Ruíz de Marchena Diego Méndez
Caranqui (500 indios) - Chapiguaza y Tulcán. Mira (250 indios).

Tulcán - Pomasqui.

Tuza

Caranqui.

"Todos los cuales dichos pueblos y Repartimientos de indios están encomendados-decían los oficiales de la Audiencia-y los poseen las personas de suso declaradas, de la manera que está dicha, conforme a lo que Vuestra Majestad tiene proveido; los cuales viven en esta ciudad y en ella hacen vecindad personalmente, guardando la orden que Vuestra Majestad tiene dada a los feudarios de este reino. Todos los cuales dichos Repartimientos están visitados por mandato de don Francisco de Toledo, Visorrey de estos reinos" 45.

Probablemente las Repartimientos o Encomiendas de la región Sur de la Audiencia de Quito debieron estar a cargo de otras personas, pues, en la ciudad de Guayaquil llegaban a quince los vecinos Encomenderos; Loja tenía "hasta veinte y cinco vecinos de Repartimientos"; en Zamora residían unos "veinte o veinte y cinco vecinos y cada uno con pocos indios"; en cambio, en la parte Norte, solamente en lo que se relacionaba con el Corregimiento de Pasto, eran veintiocho o treinta los Encomende$\operatorname{ros}^{46}$.

Y para completar los datos generales de la Real Audiencia de Quito, digamos algo del llamado tributo.

Con ocasión de la visita general que se realizó a todos los Repartimientos por orden del Virrey del Perú, Don Francisco de Toledo, se pudo constatar que en el año 1576 el número de indios tributarios alcanzaba la cifra de cincuenta mil en todo el distrito de la Real Audiencia de Quito.

Los indios que pagaban el respectivo tributo, según las tasas que de antemano debían hacerse, eran los comprendidos entre los dieciocho y 
los cincuenta años. Los indios ancianos, los enfermos y los tullidos estaban exonerados tanto del pago de tributo como de otros trabajos. La comunidad indígena pasaba de doscientas mil personas, hombres y mujeres, chicos y grandes.

La cantidad del tributo anual, que debían pagar los indios, variaba según las tasas señaladas. Así pues, algunos indios pagaban un peso y medio; otros un peso y ducado, y hasta dos pesos. Además, debían entregar ciertas cosas en especie como una manta de algodón o cierta cantidad de trigo, maíz, etc., según el lugar donde vivían y lo que la tierra producía, cuyo valor total no pasaba de tres pesos anuales por cada indio tributario.

Cada año se recaudaba de los tributos unos cien mil pesos de plata corriente, sin contar mantas de algodón y otras especies que servían para los Encomenderos. El pago del tributo se hacía cada seis meses y los indios de un determinado Repartimiento debían entregarlo a su respectivo Encomendero ${ }^{47}$. 
Doctrinas y Parroquias del Obispado de Quito /37

\section{NOTAS:}

1 SOLÓRZANO PEREIRA, Juan, Politica Indiana, II Madrid 1930,22.

2 OTS CAPDEQUI, José María, El Estado Español en las Indias, México 1941, 28.

3 HANKE, Lewis, La Lucha por la Justicia en la Conquista de América, Buenos Aires $1949,29$.

4 ARCILA FARIAS, Eduardo, El Régimen de la Encomienda en Venezuela, Sevilla 1957, 139.

5 HANKE Lewis, Bartolomé de las Casas, La Habana 1949,18.

6 GÓMEZ HOYOS, Rafael, Las Leyes de Indias y el Derecho Eclesiástico en América Española e Islas Filipinas, Medellín 1945,153.

7 SOLÓRZANO PEREIRA, Politica Indiana II, 23.

8 HANKE, La Lucha por la Justicia, 19.

9 Las siete proposiciones de la Junta de Burgos cita el Dr. Ernesto Schäfer en su obra El Consejo Real y Supremo de las Indias, II,Sevilla 1947, 251. También trae ciertos datos de las 35 leyes de Burgos el P. Fr. José María Vargas, 0.P. en La Conquista Espiritual del Imperio de los Incas, Quito 1948 11-12. Asimismo, Silvio A. Zabala en La Encomienda Indiana, Madrid 1935, cap.1, hace una síntesis de las llamadas Leyes de Burgos.

10 GÓMEZ HOYOS, Las Leyes de Indias, 152.

11 GÓMEZ HOYOS, Las Leyes de Indias, 154. Este autor, citando a Morelli, dice: "Ad hoc feudorum genere proxime distant quas vocant Encomiendas".

12 SERRANO Y SANZ, Manuel, Orígenes de la dominación española en América, Madrid 1868, Apéndice.

13 ARCILA FARIAS, El Régimen de la Encomienda en Venezuela, 138.

14 Recopilación de leyes de Indias, Madrid 1943, lib IV,tít 6,ley 5

15 PENA MONTENEGRO, Alonso de la, Itinerario para párrocos de Indios, Madrid M.DC. LXVIII, lib.2,trat.10,f.247.

16 Recopilación, lib.VI,tít 9, ley 4.

17 Ibidem, ley 8.

18 Ibidem, ley 9.

19 AGI, Indiferente general, Leg. 532, f.lv.

20 Recopilación, lib.VI, tit.9, ley 14.

21 Ibidem, ley 1.

22 Ibidem, ley 3.

23 GÓMEZ HOYOS, Las Leyes de Indias, 150.

24 Recopilación, lib.VI, tit.9, ley 3. 
25 GÓMEZ HOYOS, Las Leyes de Indias, 152-153.

26 Recopilación, lib.VI, tit.10, ley 3.

27 Recopilación, lib.VI, tit. 9, ley 21.

28 Ibidem, ley 36.

29 Ibidem, leyes 27-28.

30 Recopilación, lib.VI, tit.8,ley 12

31 Recopilación, lib. VI, tit.9, ley 37.

32 CUEVAS, Mariano, Historia de la Iglesia en México, II, El Paso -Texas- 1928, 225.

33 Recopilación, lib.VI, tit.8, ley 4.

34 PENA MONTENEGRO, Itinerario, lib.2, trat.10, f.251.

35 Recopilación, lib.VI, tit.12, ley 47.

36 Recopilación, lib.VI, tit.5, ley 21.

37 GÓMEZ HOYOS, Las Leyes de Indias, 159.

38 CUEVAS, Historia, II, 225.

39 JARAMILLO ALVARADO, Pío, El Indio Ecuatoriano, Quito 1954, 27.

40 GONZÁLEZ SUÁREZ, Federico, Historia General de la República del Ecuador, III, Quito 1892, 402.

41 GÓMEZ HOYOS, Las Leyes de Indias, 161.

42 Apéndice \# 22.

43 VÁZQUEZ DE ESPINOSA, Antonio, Compendio y Descripción de las Indias occidentales, transcrito del manuscrito original por Charles Upson Clark. Publicado bajo los auspicios del Comité Interdepartamental de Cooperación científica y cultural de los Estados Unidos, Washington 1948, 359.

44 Recopilación, lib,II, tit.15, ley 10.

45 AGI, Quito, leg.17. El número de indios que se señala a varias Encomiendas de la estadística ha sido extractado del mismo AGI, Patronato, leg.240, Ro. 6, y corresponde al año 1592, de tal manera que son datos aproximados.

46 AGI, Patronato, leg.29, Ro. 31.

47 Apéndice \# 22. 


\section{CAPÍTULO II \\ LA DIÓCESIS DE QUITO Y SUS PRIMEROS OBISPOS}

\section{La Diócesis de Quito}

A principios del siglo XVI, Quito "fue curato o parroquia del Cuzco, el primero y el único Obispado que había entonces en todo el Perú; pues los Obispados, en los principios de la conquista, más bien estaban demarcados por las personas sujetas a la jurisdicción espiritual de los Prelados, que por los límites territoriales de las Diócesis" "; y el primer párroco que tuvo la ciudad de San Francisco de Quito fue el presbítero Juan Rodríguez ${ }^{2}$.

Paulo III, ante la solicitud hecha por el Rey, el 8 de enero de 1545 expedía la Bula Super specula militantis Ecclesiae, por la que erigía la Diócesis de Quito y nombraba como su primer Obispo al presbítero Garci Díaz Arias ${ }^{3}$.

Antes de pasar a la descripción de la nueva Diócesis, advirtamos que la Real Audiencia de Quito comprendía en lo civil cuatro Gobernaciones y en lo eclesiástico, dos Diócesis: la de Quito y la de Popayán; a la primera pertenecían las Gobernaciones de Yaguarsongo y Bracamoros, de los Quijos y la de Las Esmeraldas, a las que se añadía el Repartimiento de Pasto que formaba parte de la Gobernación de Popayán.

Cristóbal Vaca de Castro, el 16 de febrero de 1548, probablemente por orden del Rey, hizo la descripción de los Obispados del Cuzco, de Lima y de Quito. Por el interés que tiene dicha descripción, transcribimos lo concerniente a la Diócesis de Quito. 
"Obispado de la ciudad de San Francisco del Quito, que está al presente encomendado al Muy Reverendo e Muy Magnífico Señor Don García Díaz de Arias, se le señala por límites y términos de su Diócesis: la misma ciudad de San Francisco de Quito, con toda su jurisdicción e términos, e la villa de Pasto, con su jurisdicción e términos que llegan hacia la villa de Popayán hasta el pueblo de las Saliques, de la jurisdicción de Pasto, que parte términos con el pueblo de Patía, que es términos e jurisdicción de la ciudad de Popayán; e la villa de Puerto Viejo, con todos sus términos e jurisdicción, que son hasta la bahía de San Mateos, por luengo de costa; y la villa de Santiago, que por otro nombre se dice la Culata; e isla de la Puná, con todos sus términos e jurisdicción, y la entrada e población de los Bracamoros; e la de las Suabaconas, que caen entre los términos de Piura al Quito. Por la parte de la sierra, la ciudad de San Miguel, con su jurisdicción y términos, que llegan, por la costa hacia Trujillo, hasta Jayanca, con todos sus términos, que confinan e parte términos e limites con Tuayme, cacique que es de la jurisdicción de la ciudad de Trujillo, e consientivamente por parte de la sierra, e hacia la sierra el cacique Penachi, que es de la jurisdicción de la ciudad de San Miguel, e parte términos con el cacique de los Guambos, el cual cacique de los Guambos es de la jurisdicción de Trujillo, e por más encima de la sierra el cacique de Huancabamba, con todos sus términos e limites, que es de la jurisdicción de la ciudad de San Miguel, e parte términos con el cacique de los Guambos, que son de la jurisdicción de Trujillo. En este dicho Obispado e términos aqui señalados entran todos los pueblos que al presente están poblados o se poblarán de aquí adelante en aquel paraje e comarca, que sean sujetos al dicho Obispo e Diócesis" 4 .

La Diócesis de Quito tenía una extensión aproximada de 226 leguas de longitud y 70 de latitud $^{5}$, comprendiendo lo que en nuestros días es la República del Ecuador, más una parte de los vecinos países del Perú y de Colombia.

A fines del siglo XVI pertenecían al Obispado de Quito las siguientes ciudades: Quito, Guayaquil, Puerto Viejo, Pasto, Mocoa, Ecija, Cuenca, Zaruma, Loja, Zamora, Jaén, Piura, Baeza, Avila, Archidona, Valladolid, Cumbinamá (conocida también con el nombre de Loyola), Santiago de las Montañas, Santa María de las Nieves y Sevilla del Oro o Ma- 
Doctrinas y Parroquias del Obispado de Quito /41

cas. La población de Riobamba tenía la categoría de ciudad, pero se la designaba con el título honorífico de "Villa de Riobamba"6.

\section{Los primeros Obispos}

Ya que tratamos de la Diócesis de Quito, muy justo recordar los nombres y hacer una pequeña biografía de aquellos beneméritos Prelados que ocuparon la silla episcopal de la ciudad de San Francisco de Quito hasta principios del siglo XVII.

Bonifacio Gams, ${ }^{7}$ al tratar de la Diócesis de Quito y al exponer la lista de los cuatro primeros obispos, trae estos datos que, a pesar de no ser muy exactos ${ }^{8}$, nos dan una visión de conjunto:

\begin{tabular}{|c|c|c|}
\hline OBISPOS & ELECCIÓN & MURIÓ \\
\hline 1. García Díaz Arias & 1545 & 1562 \\
\hline $2^{\circ}$ Fr. Pedro de la Peña, O.S.D. & 1563-28-II & 1583-7-III \\
\hline $\begin{array}{l}\text { 3. Antonio de S. Miguel y Solier } \\
\text { (no entró) }\end{array}$ & 1590 & 1592-7-IX+1591 \\
\hline $\begin{array}{l}\text { 4. Ludovico López de Solís, 0.S.A. } \\
\text { (se celebraron en su tiempo dos } \\
\text { sínodos diocesanos1593 y 1596). } \\
\text { Trasladado a Charcas. }\end{array}$ & 1593 (del Paraguay) & 1603 \\
\hline
\end{tabular}

Garci Díaz Arias

Los datos biográficos acerca del Bachiller Garci Díaz Arias, primer Obispo de Quito, hemos tomado de nuestro gran historiador González Suárez quien, a pesar de su espíritu de investigador, se ve obligado a confesar que "muy pocas noticias tenemos acerca de la vida del primer Obispo de Quito. Sabemos solamente que fue natural de Consuegra, pero ignoramos el año de su nacimiento"?. 
Garci Díaz Arias era pariente lejano del conquistador Francisco Pizarro. Antes de pasar a las Indias desempeñaba su ministerio sacerdotal en la Diócesis de Toledo. Cuando Paulo III erigió la Diócesis de Quito, probablemente el Bachiller Garci Díaz Arias, a quien se eligió como su primer Obispo, ejercía el cargo de cura párroco de Lima. Al año siguiente de su elección fue consagrado Obispo en la ciudad del Cuzco y tomó enseguida posesión de la Diócesis por medio del presbítero Loaisa ${ }^{10}$.

Para fines del año 1547 o principios de 1548, el Ilmo. Garci Díaz Arias se encontraba ya en la ciudad de Quito, pues en la descripción del Obispado hecha por el licenciado Cristóbal Vaca de Castro, el 16 de febrero de 1548, se dice: "que está al presente encomendada al Muy Reverendo e Muy Magnífico Señor Don García Díaz de Arias..."11, lo cual nos da a entender la presencia del nuevo Obispo en la ciudad de San Francisco de Quito.

Respecto a sus cualidades personales, un religioso dominico nos ha dejado ciertos datos, a saber: "El Obispo primero de aquella ciudad (de Quito) fue el Rmo. Don García Díaz Arias, clérigo, de cuya mano recibí, siendo muchacho, la primera tonsura; varón no muy docto, amicísimo del coro; todos los días no faltaba de misa mayor y vísperas, a cuya causa venían los pocos prebendados, que a la sazón había en la ciudad e iglesia; y le acompañaban a ella y le volvían a su casa,; los sábados jamás faltaba de la misa de Nuestra Señora; gran eclesiástico; su iglesia muy bien servida, con mucha música y muy buena de canto de órgano. En esta sazón el Obispo era muy pobre; ahora han subido los diezmos y tiene bastante renta. Era alto de cuerpo, bien proporcionado, buen rostro, blanco, y respetable autoridad, y lo guardaba con mucha llaneza y humildad, que le adornaba mucho; murió en buena vejez" 12 .

El gobierno de la nueva Diócesis, sobre todo en los primeros años, debió ser muy laborioso y difícil. La primera obra del Ilmo. Garci Díaz Arias fue la erección de la catedral. Suponemos que el primer Obispo de Quito desplegaría todo su celo apostólico por la gloria de Dios y el bien de las almas que el Vicario de Cristo, Paulo III, le había confiado, hasta que en el año 1562, descansaba en la paz del Señor. 
"A la muerte del primer Obispo de Quito, el Ilmo. Señor Don Garci Díaz Arias, no habia en la Catedral más que dos canónigos, que eran Don Pedro Rodríguez Aguayo, Arcediano, y Juan de Ocaña, Canónigo, los cuales, el 4 de mayo de 1562, se reunieron en Cabildo, para elegir Vicario Capitular, que gobernase la Diócesis en su primera Sede-vacante. El elegido fue el mismo Arcediano. Para hacer esta elección nombraron primero dos Vice-canónigos, con quienes formaron Cabildo, compuesto de cuatro individuos"13.

\section{Fr. Pedro de la Peña}

Pedro de la Peña, hijo de Hernán Vázquez y de Isabel de la Peña, nació en Covarrubias, provincia de Burgos. El día 3 de marzo de 1540 el joven Pedro de la Peña vestía el hábito de la Orden Dominicana en el convento de San Pablo de Burgos; y poco tiempo después realizaba sus estudios eclesiásticos en la ciudad de Valladolid, donde tuvo la suerte de tener por maestro al célebre teólogo Fr. Domingo de Soto. Ordenado ya de sacerdote, Fr. Pedro de la Peña dejó su Patria, España, y pasó a Nueva España en las Indias en el año 1550. Desempeñó cargos muy importantes con satisfacción de todos: desde 1553 fue catedrático de Prima de Teología; más tarde, Prior del convento máximo de Santo Domingo en México; desde el año 1558 hasta 1562, Provincial de su Orden. En 1562 viajó a España para resolver ciertos asuntos relacionados con su Orden ${ }^{14}$.

Como el Rey Felipe II tenía ya noticias de la vacante de la Sede de Quito, "nadie le pareció más a propósito que el P. Peña para organizar esta Diócesis recientemente erigida, y así lo presentó al Papa para Obispo de ella: antes había sido presentado para el Obispado de Vera-Paz, en Centro-América"15; y, finalmente, Fr. Pedro de la Peña "fue promovido en 28 de febrero de 1563 al -Obispado- de Quito"16.

Durante el tiempo de casi dos decenios que pasó como Obispo de Quito, el Ilmo. Señor Peña "dedicó preferente atención a los problemas vitales para la Diócesis quitense: la formación del clero, a fin de suplir la escasez de sacerdotes, y la instrucción en la fe de los indios"17. En su propia residencia episcopal fundó una especie de seminario para la formación 
e instrucción de los futuros sacerdotes; y con relación a los nativos, podemos afirmar que el Ilmo. Pedro de la Peña fue el gran apóstol de los indios, pues se preocupó porque éstos se redujeran a pueblos y se facilitase así su instrucción religiosa. En la ciudad de Quito erigió dos Parroquias, la de San Blas y la de San Sebastián, exclusivamente para los naturales ${ }^{18}$.

A este segundo Obispo se deben la fundación del convento de monjas de la Concepción en Quito ${ }^{19}$ y la construcción de la Catedral, que tuvo la satisfacción de verla terminada ${ }^{20}$. Además, dándose cuenta del estado lamentable de ciertas Parroquias y Doctrinas, y de algunos curas y frailes que estaban al frente de ellas, celebró un Sínodo diocesano en 1570. "Fue este Sínodo de Quito -escribe Vargas Ugarte- el primero que se celebró en toda la Arquidiócesis (de Lima) y por esta razón es digno de nuestra atención"21. Cuando tratemos de las Parroquias y Doctrinas, de los curas y doctrineros, tendremos la satisfacción de citar algunas constituciones de este primer Sínodo quitense.

El Ilmo. Señor Peña visitó por dos ocasiones su inmensa Diócesis; la primera en 1569 y principios de 1570, y la segunda, cinco años después. "Causaba admiración -escribe González Suárez- ver a un anciano, de más de sesenta años de edad, con los vestidos empapados por la lluvia, con pobre y escaso alimento, andando, muchas veces a pie, por aquellas montañas, donde no había sendero conocido. En estas laboriosas y verdaderamente santas visitas, el señor Peña administró el Sacramento de la Confirmación, y aún el del Bautismo, a millares de indios"22.

Sus relaciones, sobre todo con la autoridad civil, no fueron nada halagüeñas; pues, el haberse consagrado totalmente al servicio de su querida Diócesis, sin transigir en nada que no fuera en beneficio de ésta, fue causa para considerarlo como el Obispo incomprendido, no solamente por Presidente y oficiales de la Real Audiencia de Quito, sino también, en más de una ocasión, hasta por el mismo Rey. El benemérito Prelado fue vilmente calumniado por personas, de quienes se podía esperar comprensión ante las circunstancias de aquellos tiempos.

En los primeros años de su episcopado, el Ilmo. Señor Peña "luchó infatigable con los escándalos que, en la libre sociedad de la colonia, 
había echado hondas raíces; venció con santa tenacidad cuantos obstáculos se oponían a la reforma de costumbres, a fin de enseñar a vivir cristianamente a los viejos conquistadores, que, habituados a la vida libre y suelta de los campamentos, se manifestaban reacios a las disposiciones del Obispo, y les parecía punto menos que imposible amoldar los envejecidos y malos hábitos a la estrecha turquesa de la moral cristiana"23.

En una carta-relación dirigida al Rey por la Audiencia de Quito el 20 de febrero de 1580, encontramos las siguientes acusaciones contra el Ilmo. Peña: “... El Obispo no quiere dar la cuenta de las rentas eclesiásticas... sea servido Vuestra Majestad mandarnos enviar recaudos para ello y poderes bastantes; porque, cierto, es hombre tan terrible de condición que no se puede tratar con é1. El vive a su arbitrio; ordena mestizos, idiotas y todo género de hombres; no guarda la erección y todo lo trae arriba y abajo, como se le antoja. Y cierto convendría mudarle a otro Obispado y que Vuestra Majestad nos hiciese merced de un pastor clérigo, canonista, manso, sufrido, discreto, que nos diese buen ejemplo y visitase estos clérigos y los pusiese en orden y amase las cosas eclesiásticas y temiese las penas canónicas contra simoníacos, y guardase los Concilios e autoridad debida a los ministros de Vuestra Majestad. El Obispo, por tener más Doctrinas que dar a los clérigos, ha tratado con el Comisario de los frailes franciscos, que vive en Lima, que le dejen ciertas Doctrinas, lo cual es en grave detrimento de la doctrina cristiana que se predica a los naturales y de la pulicía que los muestran. Suplicamos a Vuestra Majestad no permita esto; y si los frailes no han de tener Doctrinas, Vuestra Majestad no gaste más dinero en enviar frailes" 24 .

Felizmente el Monarca no dio crédito a todo lo expuesto en la carta por sus Oficiales. Pidió informes directamente al Prelado, quien, el 28 de octubre de 1581, contestaba al Rey en estos términos: "En lo de los religiosos, Vuestra Majestad me envía a mandar por su Real Cédula le dé aviso de la causa o razón que me ha movido para quitar a los religiosos de S. Francisco treinta y seis Doctrinas; y, porque los desfavorezca en ambas cosas, no han informado a Vuestra Majestad de lo que en esto pasa en verdad, porque ninguna Doctrina les he yo quitado. Sus Prelados han deja- 
do algunas por no tener frailes y no las poder sustentar y la Audiencia las ha dado a otros frailes, sin guardar la orden que Vuestra Majestad, por su Real Cédula del Patronazgo, tiene mandado. Creo yo que no tienen autoridad ni pueden administrar los sacramentos fuera de lo que contiene la Cédula del Patronazgo Real, porque dice el Papa que les da facultad para administrar los sacramentos in locis ordinandis, pues el señalar de los lugares es por la Cédula del Patronazgo y no de otra manera; y no guardando aquel orden, no tienen autoridad ni pueden".

"Ahora dejaron los franciscos las Doctrinas de los Pastos, que habia quitado Valverde a los clérigos que las tenian, lenguas de ellos, y los Oidores les han repartido entre los frailes legos y por ordenar para que las defiendan, habiendo sacerdotes clérigos muy beneméritos' 25 .

Cuando tratemos de las Ordenes Sagradas conferidas a los mestizos, veremos si había o no fundamento para las tales acusaciones contra el Ilmo. Pedro de la Peña.

Y siguiendo adelante con esta pequeña biografía del segundo Obispo de Quito, diremos que en el año 1569, al hacer su primera visita pastoral, pudo constatar personalmente el escaso fruto que se conseguía en Parroquias y Doctrinas, por la poca instrucción del clero y por la falta del idioma indígena, sobre todo entre los frailes doctrineros. Asimismo, advirtió que el salario de los doctrineros no se pagaba a su debido tiempo por descuido y, tal vez, por mala voluntad de los Encomenderos; que "sus indios" eran maltratados, y, a veces, explotados por curas y frailes y por los mismos empleados de la autoridad civil. Para remediar estos males del clero, implantó la cátedra de lengua, exigiendo a sacerdotes y frailes la obligación de asistir a ella durante un año. Para confiar una Doctrina, exigía del candidato un examen previo. Castigaba con bondad y con justicia los escándalos. Exigía puntualidad en el pago del salario que debía recibir cada uno de sus sacerdotes doctrineros. Cuando Presidente y oficiales de la Audiencia se extralimitaban en sus poderes respecto a la provisión de Doctrinas y Beneficios eclesiásticos, el Venerable Prelado protestaba enérgicamente ante las autoridades superiores ${ }^{26}$. Ante las disposiciones adop- 
tadas por el celoso Pastor, en vez de grangearse respeto, simpatía y veneración, el pago que recibió de Oficiales reales, del clero regular y de unos pocos sacerdotes, fue el odio, la incomprensión y hasta la misma calumnia.

El 7 de marzo de 1583, hallándose en la ciudad de Lima, en plena celebración del tercer Concilio Provincial, el Ilmo. Peña fallecía santamente para recibir en breve el premio prometido en el Cielo por haber cumplido en esta tierra su deber como verdadero sacerdote y como abnegado y celoso Obispo de Quito.

Han pasado más de cuatro siglos desde la muerte del Ilmo. Pedro de la Peña y el recuerdo que de él conserva la Iglesia Ecuatoriana es de un Gran Obispo.

Fr. Antonio de San Miguel y Solier

Siete años habían transcurrido desde la muerte del segundo Obispo de Quito, y, por tanto, urgía llenar la vacante de la Diócesis. El llamado a sustituir al Ilmo. Peña era el Ilmo. Fr. Antonio de San Miguel y Solier, quien se hallaba de Obispo de la Imperial de Chile, su primera Diócesis, donde "tantas pruebas de no comunes virtudes había dado en el gobierno"27.

Este nuevo Obispo de Quito no tomó posesión de la Diócesis, pues "murió en la Villa de Riobamba, viniendo de Chile, y al tiempo que falleció -seguramente el 7 de septiembre de 1591- ordenó, por descargo de su conciencia, ciertas cosas"28; de manera que "Quito tuvo para su tercer Obispo solamente honores fúnebres; y el ejemplar y virtuoso Prelado pidió a su nueva Iglesia sólo un sepulcro para descanso de sus restos mortales"29.

Fr. Luis López de Solis

Luis López de Solís nació en la ciudad de Salamanca. Sus padres, don Francisco de los Ríos y doña María López de Solís, eran personas 
muy conocidas por su alta alcurnia. Muy joven aún vestía el hábito de humilde fraile agustino en el convento de su ciudad natal. En el año 1556, siendo todavía estudiante, viajaba al Perú, donde recibió la ordenación sacerdotal. En Lima el Padre Fr. Luis López de Solís era profesor de Filosofía y pocos años después fundaba la Cátedra de Teología en la ciudad de Trujillo 30 .

El 1 de julio de 1571 se celebraba en el Cuzco el Capítulo de la Orden. Fr. Luis López de Solís, como Definidor más antiguo, presidía dicha asamblea, en la que, con el beneplácito de todos los asistentes, fue elegido Provincial, cargo que lo desempeñó por dos ocasiones. Durante su primer período se fundó la Provincia agustiniana en Quito ${ }^{31}$.

Al tiempo que fue preconizado para la Diócesis del Paraguay o Río de la Plata, dictaba la Cátedra de Teología en la Universidad de Lima. La muerte inesperada del Ilmo. Antonio de San Miguel, tercer Obispo de Quito, obligaba al Rey Felipe Il a dirigirle una carta confidencial, el 17 de abril de 1592, en la que decía al Maestro de Teología:

"Venerable y devoto Padre Maestro Fray Luis López, de la Orden de San Agustín, catedrático de Teulogía en la Universidad de la ciudad de los Reyes, de las provincias del Perú, y a quien tenía elegido para Obispo de las provincias del Río de la Plata, porque estando al presente vaca la Iglesia y Obispado de la provincia de Quito, por muerte de Fray Antonio de San Miguel, y entender que, demás de ser en ello servido Nuestro Señor, vuestra persona es más a propósito para el dicho Obispado de Quito, he tenido por bien de volveros a elegir y nombrar para é1. Yo os encargo que, si conformándoos con la voluntad de Nuestro Señor le aceptáredes, os váis luego a gobernarle... y si, habiéndolo encomendado muy de veras a Nuestro Señor, os determináredes a no aceptar, guardaréis secreto, volveréis a enviar este despacho, con toda brevedad, para que se provea aquella Iglesia de Prelado"32.

Fr. Luis López de Solís, más por humildad y obediencia que por otros motivos humanos, aceptó la alta designación que se le proponía. Despachadas las Bulas, recibió la ordenación episcopal en la ciudad de Trujillo de manos del entonces Arzobispo de Lima, Santo Toribio de Mo- 
grovejo; y el 18 de febrero de 1594 tomaba posesión de la Diócesis por medio del Deán Bartolomé Hernández de Soto ${ }^{33}$. Pocos meses después, el 15 de junio de 1594, entraba en la ciudad de Quito "el Maestro Don Fray Luis López, Obispo de este Obispado y fue recibido con contento general de toda esta tierra, porque la larga vacante de Prelado -alrededor de doce años- da mucha pesadumbre y había hecho mucha falta" 34 .

Desde el primer momento de su llegada a Quito, el Ilmo. Señor Solís desempeñó su oficio pastoral con mucha autoridad en su persona, recogimiento en su vida, pero también con mucho celo apostólico en el gobierno de su Diócesis, siendo, por tanto, ejemplo viviente para todos cuantos le conocían y le trataban ${ }^{35}$.

Durante los doce años que pasó como Obispo, se celebraron dos Sínodos: el primero, en Quito, en el año 1594, a los dos meses de la llegada del Ilmo. Señor Solís; y el segundo, en la ciudad de Loja del 15 al 24 de agosto de 1596, pues para esta fecha se hallaba allí de visita pastoral. Estos dos Sínodos fueron muy necesarios para reorganizar la Diócesis, puesto que la prolongada vacante había sido causa de cierto relajamiento en una parte del clero, tanto secular como regular, y de la intromisión de malas costumbres.

El Ilmo. López de Solís tiene la gloria de haber sido el fundador del Seminario "San Luis" para la formación de los futuros párrocos de la Diócesis, pues dicho Prelado no se contentaba únicamente con sacerdotes virtuosos, también deseaba que fuesen instruidos ${ }^{36}$. Fundó, además, las Parroquias de San Marcos y de San Roque, en la ciudad de Quito, y extramuros, también la de Santa Prisca, antigua ermita; "hizo edificar la iglesia de Guápulo, pueblo pequeño de indios, media legua de Quito, a donde está la imagen de la Madre de Dios, con vocación de Guadalupe"37.

Y en lo que respecta a las visitas pastorales, debemos resaltar que, al igual que su predecesor en la Sede de Quito, el Ilmo. Solís recorrió por dos ocasiones el extenso territorio de su Diócesis, visitando ciudades, pueblos y aldeas, atravesando montañas, ríos y llanuras. Por la dificultad de caminos, probablemente grandes trechos los hacía a pie. En cada pueblo 
que visitaba permanecía a lo más tres días y cuando menos, veinte y cuatro horas. Con frecuencia el celoso Prelado administraba personalmente el Bautismo a los indios y les predicaba, ya que era muy diestro en la lengua indígena. Confirmó a millares de los naturales ${ }^{38}$. Al final de su primera visita pastoral, hallándose de regreso en la ciudad de Quito, en una carta dirigida al Rey el 8 de mayo de 1597 le decía: “ Año y medio he gastado en la visita general de este Obispado, confirmando la mayor parte de gente, que había muchos que carecían de este sacramento, por la larga vacante de mi antecesor. He hallado buena doctrina en los beneficios que están a cargo de clérigos, porque tienen y guardan los Concilios y Sinodales, y va en mucho aumento, de que doy gracias a Dios Nuestro Señor; lo cual no va en las doctrinas de religiosos, porque, como exentos, usan de libertad... viven como quieren, no hay quien pueda saber si son suficientes, ni si saben la lengua, y así he hallado grandes yerros en la visita, y a los más ignorantes en lo mejor, porque quien los provee no debe de mirar el bien y salvación de las almas"39.

Durante los años que el Ilmo. Señor Solís fue Obispo de Quito se preocupó porque el clero estuviese bien tratado, porque Encomenderos y Corregidores cumpliesen sus obligaciones respecto al pago del salario de Doctrineros. En la provisión de Parroquias y Doctrinas no tenía preferencia sino por los más dignos; no se dejaba llevar nunca de la acepción de personas. Escribiendo al Rey el 10 de abril de 1600 le decía: "Muchos clérigos viejos tengo fuera de beneficios, con intento de no ocuparlos en ellos, y no se descarga la conciencia porque saben muy poco, como gente que los ocupaban en tiempo que era forzoso; y ahora con la ayuda del Seminario y estudios, tengo tan buenos sujetos, voy entremetiendo los que saben y sacando los ignorantes, porque ya no me contento con que sepan los doctrineros la lengua, sino que han de predicar y declarar el Evangelio $\mathrm{y}$ de esto se quejan los ignorantes bien apriesa" 40 .

Cuando se trataba de informar al Rey acerca de los sacerdotes beneméritos a fin de que recibieran recompensa, este Obispo buscaba los méritos aún en la obscuridad de su modestia, como veremos más adelante al tratar este punto. 


\section{Doctrinas y Parroquias del Obispado de Quito /51}

Era exigente consigo mismo y con los demás en el fiel cumplimiento de las leyes eclesiásticas, de las constituciones de los Concilios provinciales de Lima y de los Sínodos de Quito. En algunas ocasiones, si tenía que corregir a tal o cual sacerdote, lo hacía con paternal solicitud. En el peor de los casos, si no había enmienda de parte de los interesados, el Ilmo. Solís no tenía ningún reparo en acudir a otros medios: "Después que estoy en este Obispado -escribía al Rey el 10 de abril de 1600- he desterrado de él más de treinta clérigos de mala vida y costumbres y tienen tanta ventura que, por allá arriba -se refiere a la Diócesis del Cuzco o de Charcas- los ocupan bien, atribúyolo a falta de clérigos" 41 .

Ante la actitud del Prelado, sobre todo respecto a provisión de Parroquias y Doctrinas, de acuerdo a las constituciones conciliares y sinodales, los religiosos se veían perjudicados; de donde los cuatro delegados de las Ordenes Religiosas existentes en Quito: Fr. Jerónimo de Mendoza, dominicano, Fr. Bartolomé Rubio, franciscano, Fr. Agustín, agustino, y Fr. Antonio de Rueda, mercedario, enviaron un Memorial al Rey en que presentaban quejas y acusaban al benemérito Obispo de pretender quitarles las Doctrinas para dárselas a los clérigos y aumentar así sus rentas episcopales, de conferir la ordenación sacerdotal a "clérigos insuficientes e inhábiles y muchos dellos mestizos"; además, que "Ha puesto pleito a las Religiones el dicho Obispo, pidiendo que le paguen seminario y lo cobra de hecho de los estipendios que a los religiosos se les dan, y para esto ha librado censuras contra los Corregidores de los partidos para que ante todas cosas se le paguen, teniendo las Religiones seminarios en sus conventos adonde crían frailes que prediquen y confiesen y enseñen Artes y Apología a hijos de conquistadores ... Pretende visitar y visita de hecho a los religiosos que están en Doctrinas... Pretende asimismo que los frailes que están en Doctrinas, cuando hubieren de ir a ella sea por su mano, poniéndolos el examinado y aprobado y dado licencia para administrar sacramentos, siendo como es esto directamente contra las Bulas de Su Santidad de Pío Quinto, dado a instancia de Su Majestad del Rey Don Felipe 2, Nuestro Señor, que santa gloria tenga;... y si esto se dejase al exámen y aprobación del dicho Obispo, no habría religioso suficiente y sería eximir 
los súbditos de la obediencia de sus Prelados" 42 . Cuando tratemos estos puntos de una manera más detallada, juzgaremos que el Ilmo. Señor Solís tenía razón y que no hacía otra cosa sino cumplir con su deber pastoral antes que amedrentarse frente a las posibles acusaciones.

Y para terminar esta pequeña biografía del cuarto Obispo de Quito, digamos algo de sus virtudes. El Ilmo. Señor Solís daba muestras de su humildad y obediencia a la voluntad de Dios el día en que aceptaba la elección para el episcopado. Su mortificación y espíritu de sacrificio, en extremo admirables. Las dos visitas pastorales nos hablan del celo apostólico de que estaba revestido. Era caritativo para con todos. Su renta episcopal la distribuía entre los pobres y las Parroquias y Doctrinas más necesitadas de medios económicos.

González Suárez, Arzobispo que fue de Quito a principios de siglo, hablando del Ilmo. Luis López de Solís, nos dice: "Virtudes, como las del insigne Obispo Solís, no han sido comunes en nuestra patria... en el claustro fue modelo de religiosos, en el solio fue ejemplar de Obispos" ${ }^{3}$.

A mediados del año 1605 el Rey, por los magníficos informes que tenía del Obispo de Quito, pedía al Sumo Pontífice el traslado del Ilmo. Señor Solís para llenar la vacante del Arzobispo de Charcas. Muy a pesar suyo tenía que dejar su querida Diócesis de Quito, donde, desde el primer momento, había depositado todo su corazón. Púsose en camino hacia donde se lo llamaba; mas, no tomó posesión de su nueva Diócesis, porque Dios le consideraba ya digno de descansar en el cielo, pues en la ciudad de Lima, de edad muy avanzada, fallecía santamente el 5 de julio de 1606.

Quito contrajo una deuda con el Ilmo. Señor Solís; deuda que ha sabido pagarle con el recuerdo cariñoso de su nombre, puesto que "la memoria de este Venerable Prelado se conserva entre nosotros y se conservará, sin duda, mientras haya en el Ecuador quien ame la virtud y reverencie la santidad" 44 . 
Doctrinas y Parroquias del Obispado de Quito /53

\section{NOTAS:}

1 GONZÁLEZ SUÁREZ. Historia General de la República del Ecuador, II, Quito $1891,231$.

2 GONZÁLEZ SUÁREZ, Historia, II, 230

3 HERNAEZ, Francisco Javier, Colección de bulas, breves y otros documentos relativos a la iglesia de América y Filipinas, II, Bruselas 1879, sección quinta.

4 AGI, Patronato, leg.185, R.39.

5 Apéndice \# 48.

6 Apéndice \# 42.

7 GAMS, Pius Bonifacius, Series Episcoporum Ecclesiae Catholicae, Akademische Druck-U-Verlagsanstalt, Graz 1957,164.

8 La fecha de erección de la Diócesis de Quito y, por tanto, de la elección del primer Obispo, Garci Díaz Arias, fue el 8 de enero de 1545; asimismo, la elección del cuarto Obispo, Fr.Luis López de Solís, no fue en el año 1593, como señala Gams, sino en el año 1592, (cf.Apéndice \# 34) como veremos más adelante. Asimismo el Sínodo realizado en tiempo del Obispo Solís fue del 15 al 25 de agosto de 1594, (AGI, Quito, leg. 76-77); y la muerte del Ilmo. López de Solís no fue el año 1603 sino el 5 de julio de 1606, en Lima.

9 GONZÁLEZ SUÁREZ, Historia, II, 428.

10 GONZÁLEZ SUÁREZ, Historia, II, 429.

11 AGI, Patronato, Leg.185, R. 39.

12 GONZÁLEZ SUÁREZ, Historia, II, 433.

13 GONZÁlEZ SUÁREZ, Historia, II, 438.

14 Cartas de Indias. Publícalas por primera vez el Ministerio de Fomento , Madrid $1877,822$.

15 GONZÁLEZ SUÁREZ, Historia, III, 30.

16 Cartas de Indias, 822. Esta misma fecha, "28 de febrero de 1563", trae Gams en su obra arriba citada, 164. González Suárez, en cambio, señala el 22 de mayo de 1565, lo cual juzgamos un dato inexacto, ya que, en una Real Cédula del 15 de junio de 1563, el Rey Felipe II, dirigiéndose a la Audiencia de Quito, decía: “... por relación que nos ha hecho el Reverendo in Cristo Fray don Pedro de la Peña, Obispo de esa ciudad...” (AGI, Quito, leg.209 lib.I, f.6v) Esto manifiesta que el nuevo Obispo estaba ya en Quito.

17 VARGAS UGARTE, Rubén, Historia de la Iglesia en el Perú, I, Lima 1953, 153.

18 VARGAS UGARTE, Historia, I, 153.

19 Cartas de Indias, 822. 
$\mathbf{5 4}$ / Augusto E. Albuja

20 GONZÁLEZ SUÁREZ, Historia, III, 32.

21 VARGAS UGARTE, Historia, II, Burgos 1959, 148.

22 GONZÁLEZ SUÁREZ, Historia, III, 33-34

23 GONZÁLEZ SUÁREZ, Historia, III, 326; cf. tb. Apéndice \#27.

24 AGI, Quito, leg.8.

25 AGI, Quito, leg.76.

26 AGI, Quito, leg, 80.

27 GONZÁLEZ SUÁREZ, Historia, III, 326; cf.tb . Apéndice \# 31.

28 AGI, Quito, leg.23. A pesar de nuestro interés por encontrar siquiera un documento en el que conste lo que el Ilmo. Señor Antonio de San Miguel, tercer Obispo de Quito, había ordenado momentos antes de su muerte en la Villa de Riobamba, debemos confesar que no hemos tenido la suerte de encontrar algo al respecto. Ya que Gams, refiriéndose a la muerte del Ilmo. Antonio de San Miguel, señala dos fechas: 1591 y 7-IX-1592 (Series Episcoporum Ecclesiae Catholicae, 164), hemos puesto "seguramente el 7 de septiembre de 1591", porque Felipe II, en una Cédula fechada el 17 de abril del año 1592 y que fuera dirigida al Cabildo Eclesiástico de Quito, le pedía que se encargase del gobierno de la Diócesis al mismo tiempo que le anunciaba la elección del nuevo Obispo, Fr.Luis López de Solís, cuyas bulas se despacharían lo más pronto posible. (Apéndices \# 32 y 33).

29 GONZÁLEZ SUÁREZ, Historia, III, 326.

30 GONZÁLEZ SUÁREZ, Historia, III, 266-269.

31 CALANCHA, Antonio de la, Crónica Moralizadora de la orden de San Agustín del Perú, Barcelona 1638, 645 s.

32 Apéndice \# 34.

33 GONZÁLEZ SUÁREZ, Historia, III, 271.

34 AGI, Quito, leg.83.

35 Apéndices \# 37, 44, 53, 54 y 55.

36 Apéndice \# 60.

37 Relaciones geográficas de Indias, III, Madrid, 1897, Apéndice \# 1, p, XII-XIII.

38 Apéndices \# 35 y 36.

39 AGI, Quito, leg. 76.

40 AGI, Quito, Leg.76; cf.tb. Apéndice \# 44.

41 AGI, Quito, leg. 76.

42 Apéndices \# 56, 57 y 59.

43 GONZÁLEZ SUÁREZ, Historia, III, 301-278.

44 GONZÁLEZ SUÁREZ, Historia, III, 277. 


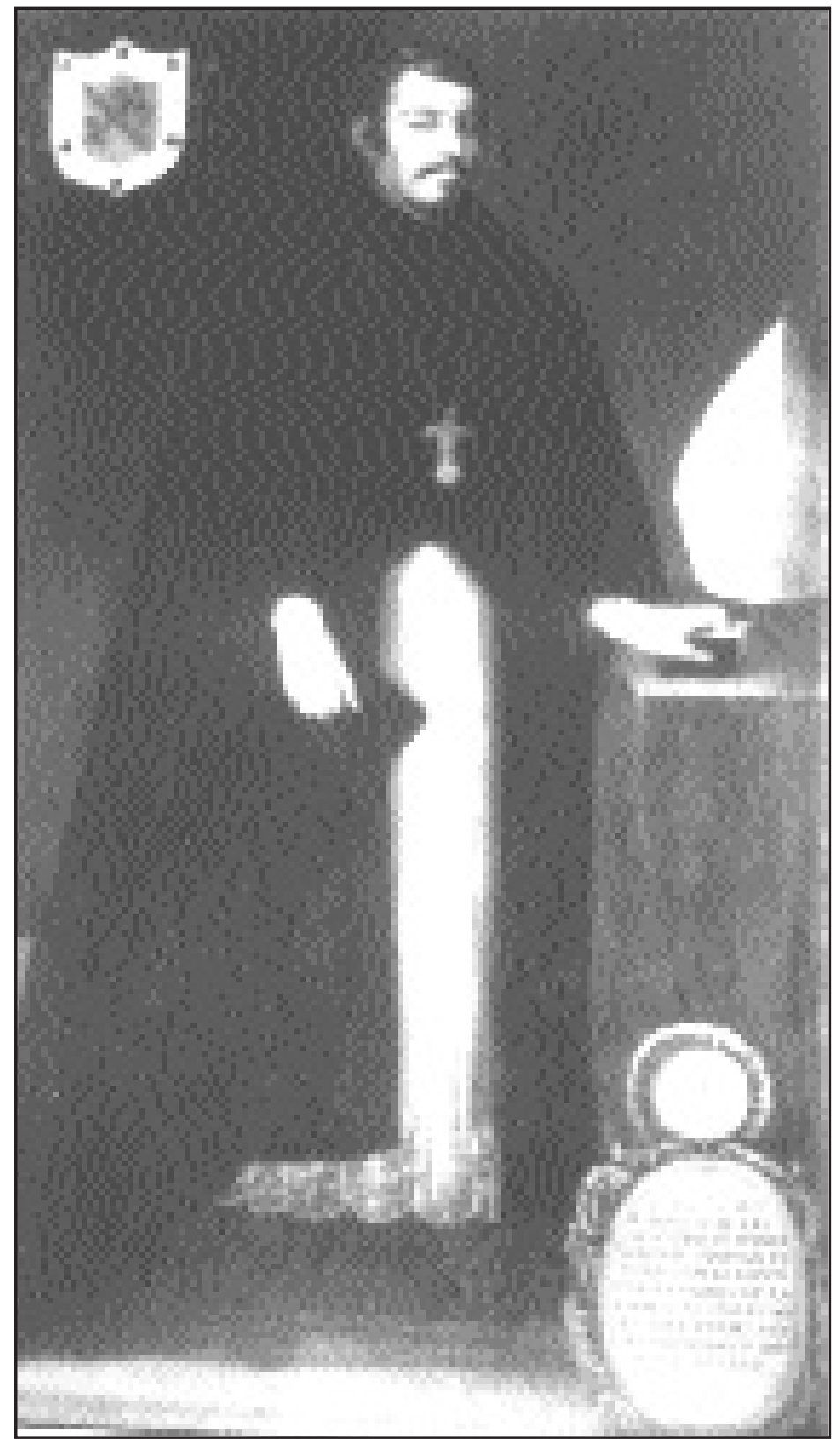

Ilmo. Sr. Dn. Garci Díaz Arias 


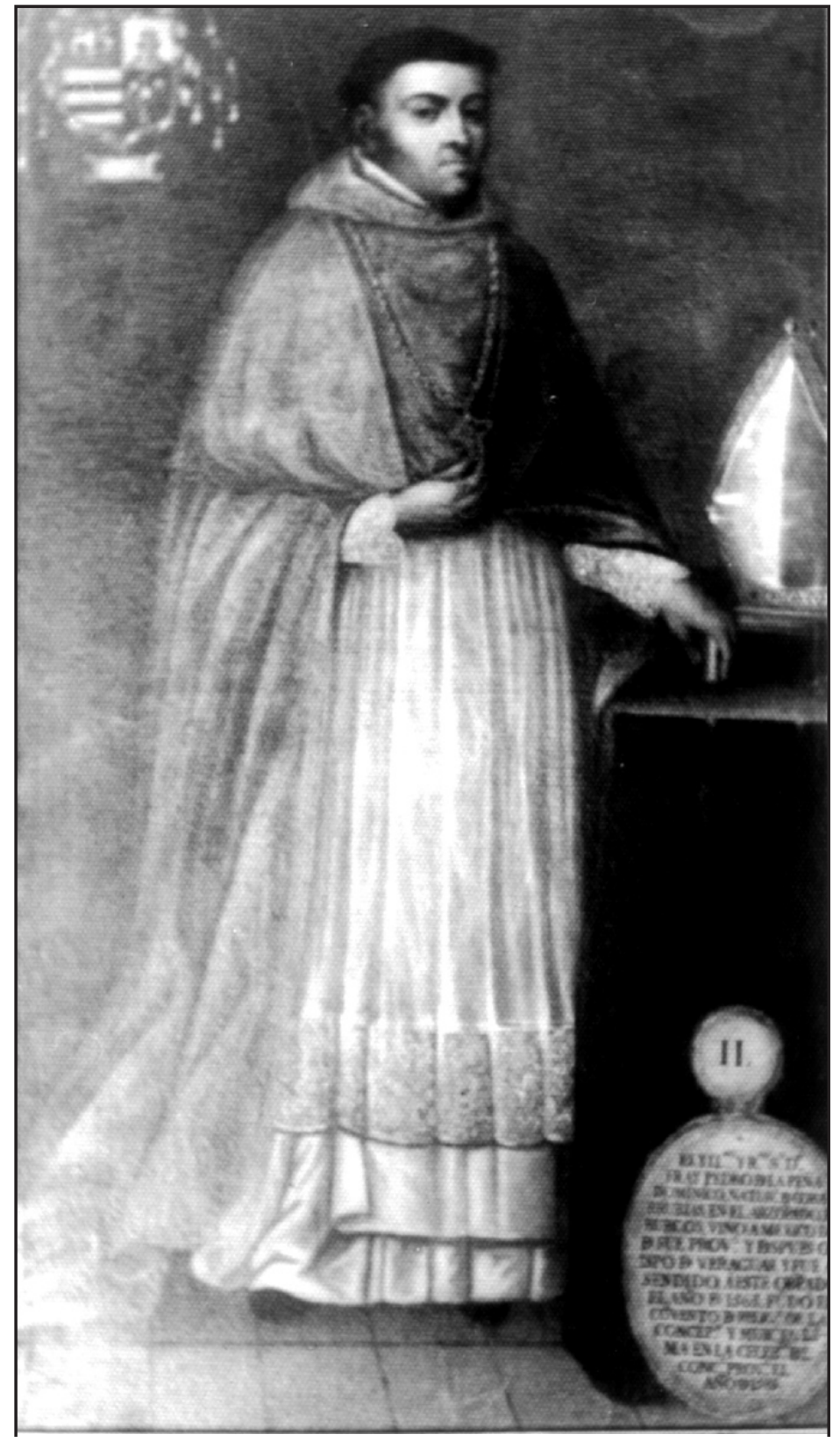

Ilmo. Sr. Dn. Fray Pedro de la Peña

$$
1563-1583
$$




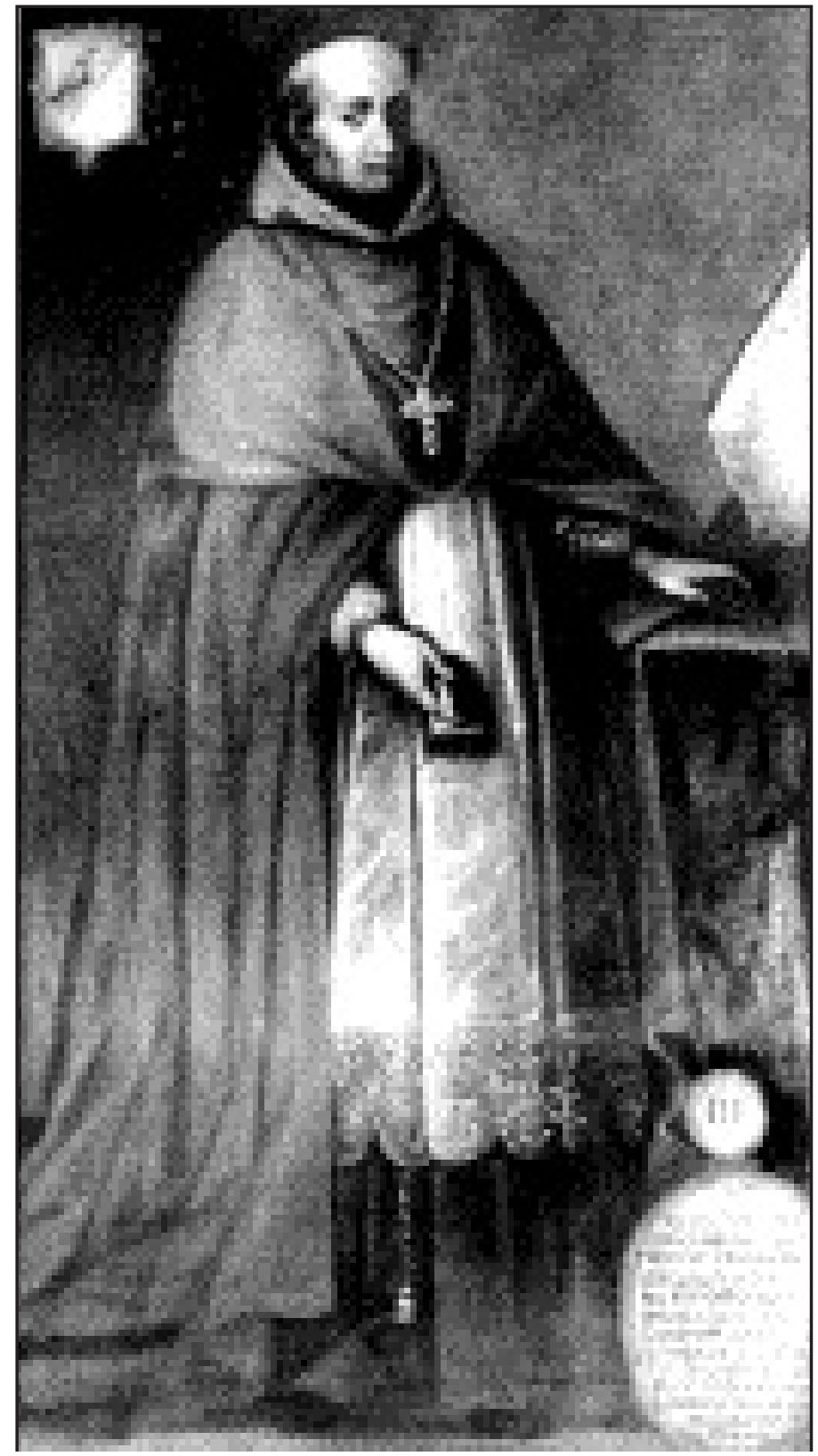

Ilmo. Sr. Dn. Fray Antonio de San Miguel 1590 - No entró. Murió en Riobamba 


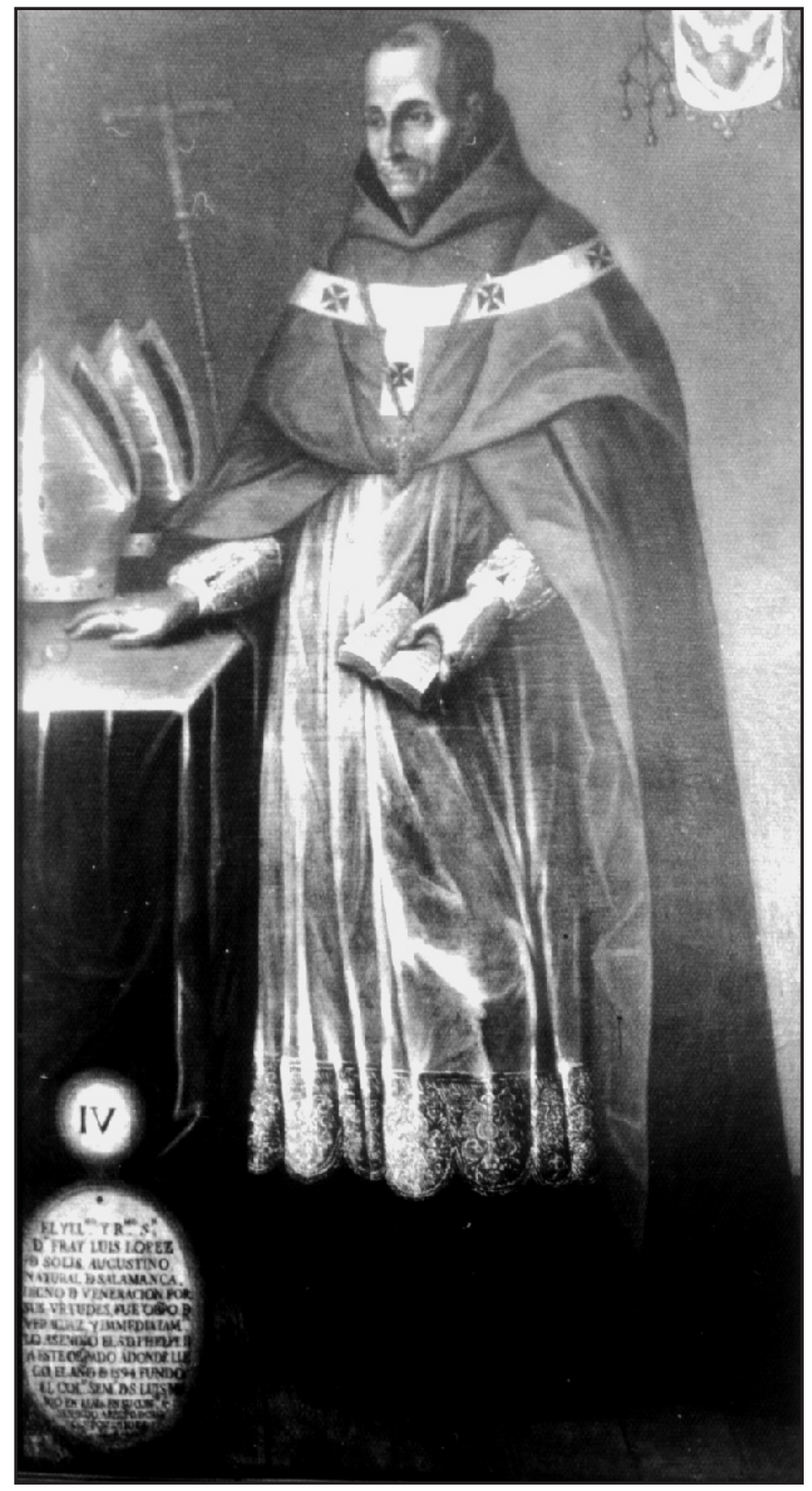

Ilmo. Sr. Dn. Fray Luis López Solis 1594-1606 


\section{CAPÍTULO III \\ NATURALEZA Y ORGANIZACIÓN DE LAS DOCTRINAS Y PARROQUIAS}

Al tratar de la Encomienda anotábamos que ésta tenía doble finalidad: la instrucción religiosa y la civilización del indio. Para conseguir lo primero, cada Encomendero debía preocuparse porque en su Repartimiento de indios hubiese al menos una persona, clérigo o religioso dedicado a la instrucción de la doctrina cristiana. Hasta mediados del siglo $\mathrm{XVI}$, sin duda por la escasez de clero, muchos Encomenderos se vieron obligados a acudir a seglares, pues, en caso de no ser posible conseguir un sacerdote, se podía proveer de "alguna persona lega, de buena edad y vida y ejemplo"1.

Una vez que hemos puesto estos preliminares, pasemos a analizar los dos puntos indicados en este capítulo.

Naturaleza de las doctrinas y parroquias

¿Qué es la Parroquia? La Parroquia, según nos dice el Código de Derecho Canónico, es una de las partes en que se divide una Diócesis ${ }^{2}$. En Indias "las Parroquias, en un principio, se organizaron no por la extensión del territorio ni por el número de feligreses, sino por la clase social, y hubo párrocos para sólo españoles, y curas y doctrineros para indios. En las ciudades las iglesias eran comunes; pero cada clase social tenía propio párroco"3.

La Diócesis de Quito estaba dividida en Parroquias y en Doctrinas. El Repartimiento de indios se llamaba con el nombre típico de "Doctrina”, porque el sacerdote o religioso encargado tenía como principal 
obligación la enseñanza de la doctrina cristiana; de modo que la Parroquia de indios se denominaba, no con el nombre jurídico de Parroquia, sino con el de Doctrina. Lo que variaba entre una y otra era solamente el nombre, pues en lo demás, salvo pequeñas diferencias, era lo mismo Parroquia o Doctrina, como estudiaremos enseguida.

Al sacerdote o religioso encargado de una Doctrina (Parroquia de indios) se le daba el nombre de párroco doctrinero o sencillamente Doctrinero, "porque, al principio, cuando se descubrió este "Nuevo Mundo", así los clérigos como los religiosos, que con los primeros descubridores y conquistadores pasaron de España a estas partes, lo primero que hicieron con los indios, después que tuvieron alguna noticia de su idioma, fue enseñarles y catequizarles en los misterios de nuestra santa fe: pues, sin esta diligencia, no podían administrarles algún sacramento; y luego que hubo Obispos, y se dividieron territorios, y los señalaron a cada iglesia, y los encomendaron a los sacerdotes, se les ordenó que todos los días enseñasen la doctrina a los indios"4.

La Parroquia es un beneficio eclesiástico ${ }^{5}$; y si la Doctrina era lo mismo que Parroquia, debemos afirmar que no solamente había entre ellas identidad de concepto, sino además, identidad de naturaleza jurídica, a saber: que ambas eran beneficios eclesiásticos.

No todos los autores, que han tratado de estas materias en una $\mathrm{u}$ otra forma, están de acuerdo en reconocer que tanto las Doctrinas como las Parroquias en Indias eran verdaderos beneficios eclesiásticos. Así, por ejemplo, Alvarez de Abreu dice: "Con esto no se hará duro de creer... que estas Prebendas y demás que nombramos Beneficios en las Iglesias de las Indias, no lo son eclesiásticos, sino solamente unos meros servicios, porque cuando por los Indultos Apostólicos no se les obligó a sus Majestades a erigir Beneficios algunos Eclesiásticos, sino solamente a que hiciesen servir las Iglesias de aquellos Reinos por las personas que les pareciesen más convenientes, ministrándoles lo necesario, dejando en mano de los Reyes, no solo la elección y nominación de los sujetos, sino también la cuota que habían de gozar en cada un año por vía de cóngrua y recompensa de su empleo y servicio... En consecuencia de esto, estimamos por cosa más 


\section{Doctrinas y Parroquias del Obispado de Quito /61}

conforme a la mente de Su Santidad el que en esta parte quiso dejar en entera libertad la piedad religiosa de los Señores Reyes Católicos: pues tratando la Santidad de Alejandro VI de animar a sus Majestades a la extensión y dilatación del Santo Evangelio en aquellas partes, y de gratificar sus católicas aplicaciones con ver cuanto la devoción de los Reyes se había adelantado, fundando y dotando las Iglesias Parroquiales, Doctrinas, y Misiones que era lo que hasta entonces había"6.

Asimismo, el Arzobispo de Lima, en una contestación dada al Rey para excusarse de no haber ido contra la prohibición de confiar Doctrinas a mestizos, se expresaba así: "... las cuales Encomiendas o Rectorías, verdadera y propiamente no caen debajo del nombre de beneficios..."7.

En cambio, para muchos otros autores, las Parroquias y las Doctrinas eran verdaderos beneficios eclesiásticos. Seguramente la dificultad puede estar con respecto a las Doctrinas de indios; por lo mismo, nuestro propósito es demostrar y poner en claro ciertas dudas del aspecto jurídico en que se hallaban las dichas Doctrinas.

Según Rodríguez Valencia, "las Doctrinas de indios eran beneficios curados en encomienda, amovibles a voluntad (ad nutum) ...; en la Doctrina el sujeto parroquial es muy vario: unos están ya instruidos en la fe, otros no; unos bautizados, otros catecúmenos; y hasta otros, no convertidos aún"8.

Y como para no poner en tela de duda, "Declaramos -decía Felipe II el 26 de mayo de 1573- que todos los beneficios de pueblos de indios, que Nos presentamos, o nuestros Ministros en nuestro nombre, son curados y no simples"'; esto equivalía al reconocimiento por parte del mismo Patrono de las Indias que las Doctrinas o Parroquias de indios eran verdaderos beneficios eclesiásticos. Asimismo, el Gobernador de Popayán, escribiendo al Rey en el año 1587, explícitamente afirmaba esta verdad de la situación jurídica de las Doctrinas, no solo de la Gobernación de Popayán, sino de toda la Real Audiencia de Quito y de todo el Virreinato del Perú, pues, entre otras cosas, le decía "Las Doctrinas de indios de esta provincia y Gobernación estarán muy mejor en los clérigos que en los frailes por algunas razones, ansi porque las Doctrinas se reputan por beneficios 
curados, los cuales son debidos a los clérigos y no los pueden servir los frailes si no fuese a falta de clérigos, como en efecto por ello hasta aquí ha permitido Vuestra Majestad"10.

Peña Montenegro afirma también que las Doctrinas de indios eran verdaderos beneficios ${ }^{11}$; y el gran jurista Solórzano Pereira llegó a identificar a las Doctrinas de indios con las Parroquias de españoles, dándoles el calificativo de beneficios curados ${ }^{12}$.

Finalmente los mismos Concilios Provinciales celebrados en Lima y los Sínodos diocesanos de Quito trataban de las Doctrinas como de verdaderos beneficios, y las normas dadas a los doctrineros eran casi idénticas a las de los curas de Parroquias. De donde, Gómez Hoyos, al tratar de la situación jurídica de las Doctrinas de indios, concluye diciéndonos: "Había, por tanto, fundamento para que las Doctrinas fueran tenidas por beneficios. Así lo creyeron, en efecto, los canonistas americanos, los tratadistas, las leyes reales y los mismos Concilios"13.

Sin embargo, debemos reconocer que existía alguna diferencia entre las Parroquias y las Doctrinas en Indias. Para la provisión canónica de unas y de otras, la presentación real era requisito previo, pues el derecho de Patronato que tenían los Reyes de España, entre las varias concesiones de los Sumos Pontífices ${ }^{14}$, se extendía a "todas las Iglesias, Doctrinas y otros cualesquiera beneficios eclesiásticos de todas las Indias e Islas y Tierra Firme del mar océano"15.

Las Doctrinas se diferenciaban de las Parroquias porque éstas se concedían a título perpetuo, y aquellas, en general, de una manera interina ${ }^{16}$. Además, la diferencia radicaba en la clase social de los feligreses, pues la Doctrina tenía en su totalidad indios ${ }^{17}$.

El hecho de que las Doctrinas, es decir, las Parroquias de indios, fuesen amovibles o ad nutum, lo reconocía y lo afirmaba el mismo Arzobispo de Lima, Santo Toribio de Mogrovejo, cuando en 1589, escribiendo una carta al Rey sobre el constante litigio de religiosos y Prelado, le decía: “... Convendrá ansi mismo proveerse y darse orden, despachándose los recaudos necesarios, que los frailes de las Doctrinas no puedan administrar los santos sacramentos a los indios, ni hacer el oficio de curas sin 
licencia y examen del Obispo o su Provisor, ni poner a ningún religioso sus Prelados para el dicho efecto de hacer oficio de curas, aunque sean ad nutum amovibles como son estas Doctrinas, sin la dicha licencia y examen del Ordinario, conforme al santo Concilio de Trento, en la sesión 25, capítulo 11 , de regularibus" 18 .

Pero, como en la práctica, las Doctrinas, a pesar de su carácter amovible, se conferían, al igual que las Parroquias, por oposición y según las normas del Patronato, Santo Toribio de Mogrovejo, por medio de otra carta, fechada en Lima el 2 de marzo de 1600, pedía al Rey que concediese la inamovilidad a las Doctrinas para que éstas también fuesen consideradas como "beneficios perpetuos colativos"19. Esta transformación se logró nueve años después, cuando Felipe III, por medio de su Real Cédula del 4 de abril de 1609, ordenaba que en adelante todas las Doctrinas de indios tuviesen el carácter de beneficios curados perpetuos ${ }^{20}$.

Para que tengamos una visión de conjunto de la evolución que sufrieron las Doctrinas de indios, nos ha parecido muy conveniente y oportuno presentar un cuadro esquemático, gracias a los datos que sobre esta materia ha escrito Armas Medina ${ }^{21}$. Como este autor señala solamente cuatro épocas, hemos añadido una quinta para que quede más completo este trabajo. 


\section{EVOLUCIÓN HISTÓRICA DE LAS DOCTRINAS DE INDIOS}

\begin{tabular}{|c|c|c|c|c|c|}
\hline Epocas: & $\begin{array}{l}\text { 1 ra. EPOCA } \\
\text { (1524-1552 } \\
\text { Los Encon- } \\
\text { menderos } \\
\text { eran los } \\
\text { directores de } \\
\text { las Doctrinas. }\end{array}$ & $\begin{array}{l}\text { 2da EPOCA } \\
(1552-1567) \\
\text { Los Obispos } \\
\text { como direc- } \\
\text { tores de las } \\
\text { Doctrinas. }\end{array}$ & $\begin{array}{l}\text { 3ra EPOCA } \\
\text { (1567-1574) } \\
\text { Las Doctrinas } \\
\text { bajo el Real } \\
\text { Patronato. }\end{array}$ & $\begin{array}{l}\text { 4ta EPOCA } \\
(1574-1609) \\
\text { Reorganiza- } \\
\text { ción definiti- } \\
\text { va del Real } \\
\text { Patronato. }\end{array}$ & $\begin{array}{c}\text { 5ta EPOCA } \\
(1609-\ldots . .) \\
\text { idem }\end{array}$ \\
\hline Provisión: & $\begin{array}{l}\text { Se efectuaba } \\
\text { por un con- } \\
\text { trato entre el } \\
\text { Encomende- } \\
\text { ro y el doc- } \\
\text { trinero. }\end{array}$ & $\begin{array}{l}\text { Estaba a car- } \\
\text { go de los } \\
\text { Obispos }\end{array}$ & $\begin{array}{l}\text { Como en la } \\
\text { época ante- } \\
\text { rior, previo } \\
\text { examen de los } \\
\text { candidatos y } \\
\text { la presenta- } \\
\text { ción de uno } \\
\text { de ellos hecha } \\
\text { por el Rey o } \\
\text { sus Oficiales. }\end{array}$ & $\begin{array}{l}\text { Se insiste en } \\
\text { el examen } \\
\text { previo, según } \\
\text { lo ordenado } \\
\text { por el Triden- } \\
\text { tino Sess. } \\
\text { XXIV, cap. } \\
18, \text { de re- } \\
\text { form. }\end{array}$ & idem \\
\hline Tiempo: & $\begin{array}{l}\text { Dependía } \\
\text { del contrato } \\
\text { realizado. }\end{array}$ & $\begin{array}{l}\text { Limitado; ad- } \\
\text { nutum Episco- } \\
\text { pi, en tratán- } \\
\text { dose de Doc- } \\
\text { trinas a cargo } \\
\text { de seculares. }\end{array}$ & $\begin{array}{l}\text { Perpetuo, si } \\
\text { la presenta- } \\
\text { ción hizo el } \\
\text { Rey; de lo } \\
\text { contrario li- } \\
\text { mitado. }\end{array}$ & idem & $\begin{array}{l}\text { Por Real } \\
\text { Cédula de } \\
\text { Felipe III el } \\
4 \text { de abril } \\
\text { de } 1609 \text {, } \\
\text { las Doctri- } \\
\text { nas pasaron } \\
\text { a ser ina- } \\
\text { movibles } \\
\text { como las } \\
\text { Parroquias. }\end{array}$ \\
\hline Salario: & $\begin{array}{l}\text { El señalado } \\
\text { en el contra- } \\
\text { to. }\end{array}$ & $\begin{array}{l}\text { El señalado } \\
\text { por el Prela- } \\
\text { do; pero lo } \\
\text { pagaba el En- } \\
\text { comendero. }\end{array}$ & idem & idem & idem \\
\hline
\end{tabular}


Doctrinas y Parroquias del Obispado de Quito /65

\section{Organización de las doctrinas y parroquias}

A mediados del siglo XVI, y más concretamente desde el 8 de enero de 1545, fecha de erección, hasta el 13 de enero de 1848 la Diócesis de Quito dependió de la Metropolitana de Lima, pues en esta última fecha fue erigida la Provincia Eclesiástica en el Ecuador.

Hasta la celebración del primer Concilio limense podemos afirmar que las Doctrinas y Parroquias no estaban organizadas y, por tanto, dependían de la iniciativa y buena voluntad de Encomenderos y Doctrineros. A partir del año 1551, hasta principios del siglo XVII, se celebraron en Lima cinco Concilios Provinciales ${ }^{22}$ : los dos primeros en la época del primer Arzobispo de la ciudad de los Reyes, Ilmo. Fr. Jerónimo de Loaisa, y los tres siguientes, siendo Arzobispo de Lima Santo Toribio de Mogrovejo. A estos Concilios provinciales, y en lo que respecta a la Diócesis de Quito, debemos añadir los tres Sínodos: el primero en la época del Ilmo. Señor Peña; y el segundo y tercero durante el episcopado del Ilmo. Señor Solís.

Así pues, tanto las Doctrinas y Parroquias de la Diócesis de Quito como las demás de toda la América Meridional recibieron una organización definitiva, gracias a los Concilios Provinciales que convocó y presidió el gran Arzobispo de Lima Santo Toribio de Mogrovejo.

He aquí una breve reseña de los cinco Concilios provinciales limenses y de los tres Sínodos diocesanos de Quito:

\section{a) Concilios Provinciales Limenses}

El primer Concilio limense fue convocado por el Ilmo. Señor Jerónimo de Loaisa para el año 1551 y finalizó el 20 de febrero del año siguiente. Comprende dos partes: la primera, que se refiere a los naturales, está compuesta por cuarenta constituciones o decretos; y la segunda, mucho más extensa que la anterior, contiene ochenta y dos constituciones relacionadas con los españoles. 
El segundo principió el 2 de marzo de 1567 y finalizó el 21 de enero de 1568. A este Concilio asistió personalmente el Obispo de Quito, Ilmo. Peña. Al igual que el Concilio anterior, éste fue convocado y presidido por el Ilmo. Loaisa. Su contenido se divide en dos secciones: la primera con 132 constituciones, para los españoles; y la segunda con 122, que se relacionan con los indios y sus sacerdotes.

El tercer Concilio provincial limense, el primero de los celebrados por Santo Toribio de Mogrovejo, fue, sin lugar a dudas, el más importante de todos, pues la trascendencia que ha tenido, y por mucho tiempo, en la organización propiamente dicha de las Diócesis de América Meridional, ha sido muy beneficiosa para la Iglesia. "El Concilio se abrió el 15 de agosto de 1582, con la asistencia del Arzobispo; de Fray Antonio de San Miguel, Obispo de la Imperial; Sebastián de Lartaún, Obispo del Cuzco; Fray Diego de Medellín, Obispo de Santiago de Chile; Fray Alonso Guerra, Obispo del Paraguay; llegando a los tres meses Fray Pedro de la Peña, Obispo de Quito; Fray Francisco de Vitoria, Obispo de Tucumán, y D. Alonso Granero de Avalos, Obispo de Charcas"23. La clausura se tuvo al año siguiente.

Este Concilio tiene cinco acciones o partes: la primera es una breve introducción; la segunda contiene cuarenta y cuatro capítulos o constituciones; la tercera abarca el mismo número de constituciones que la anterior; la cuarta se reduce a veinticinco capítulos y la quinta es muy breve, apenas señala cinco capítulos.

Los temas tratados fueron de suma importancia: Instrucción cristiana, administración de sacramentos, moral pública y por último, vida y costumbres del clero. Los puntos más sobresalientes que determinó este Concilio fueron: la traducción de dos catecismos, uno para adultos y otro para los niños; un sermonario para uso de los curas y doctrineros; la fundación del Seminario en las Diócesis, conforme a lo decretado por el Tridentino, y para sufragar los gastos se obligaba a pagar la contribución del tres por ciento; además, se insistió en el examen del candidato antes de confiarle una Parroquia o Doctrina; y, por último, que todos los sábados del año, en cada Parroquia o Doctrina, hubiese el cántico de la Salve Regina $^{24}$. 
El cuarto Concilio, fue el segundo de los convocados y presididos por Santo Toribio de Mogrovejo, comenzó el 27 de enero de 1591. Al poco tiempo se dio por clausurado. En este Concilio no se hizo otra cosa que renovar las constituciones del celebrado en 1583, salvo algunas modificaciones que vienen en veinte capítulos o decretos.

El quinto fue celebrado en 1601. Lo presidió el mismo Santo Toribio. Duró apenas una semana, del 11 de abril al 18 del mismo mes. Se declararon vigentes las constituciones anteriores, a las que se añadieron solamente ocho decretos.

\section{b) Sinodos diocesanos quitenses}

El primer Sínodo diocesano del Obispado de Quito tuvo lugar en esta misma ciudad, del 17 de marzo de 1570 al 2 de junio del mismo año, y fue convocado y presidido por el Ilmo. Señor Pedro de la Peña 25.

A principios de marzo de 1570, hallándose el Ilmo. Señor Peña de regreso en la ciudad de San Francisco de Quito, después de haber hecho su primera visita pastoral, y como ya había convocado anteriormente el Sínodo diocesano, "citó a su clero para el dicho mes y el 17 se tuvo en la Catedral la sesión de apertura" 26 .

Halláronse presentes en este Sínodo, no solamente los cinco prebendados de la Catedral y los vicarios de las ciudades de Cuenca, Piura, Cajamarca, Pasto, Jaén, Valladolid, Guayaquil y Puerto-Viejo ${ }^{27}$, sino también, "los Superiores de las Ordenes establecidas en Quito, a saber: franciscanos, mercedarios y dominicos, y cuarenta y cinco curas doctrineros, la mayoría de los cuales pertenecía al clero secular".

"Las sesiones se prolongaron hasta el 2 de junio, día en que el Obispo y canónigos suscribieron las constituciones aprobadas. Al domingo siguiente, 4 de junio, se comenzaron a leer desde el púlpito de la Catedral y la lectura se terminó al día siguiente, lunes" 28 .

Este primer Sínodo contiene cuatro partes, con un total de ciento cincuenta y cuatro constituciones distribuidas de la siguiente forma: cuarenta y dos constituciones relacionadas con los Prebendados, con 
asuntos de liturgia y ciertas normas generales; quince constituciones que deberían observar los curas de la Santa Iglesia de la ciudad de Quito; treinta y dos, referentes a los curas que se hallaban en los pueblos de españoles de todo el Obispado; y finalmente, sesenta y cinco constituciones para los curas de las Doctrinas de indios.

Es indudable la importancia de este Sínodo, pues con él se puso en marcha la organización de la Diócesis, sobre todo en relación a las Doctrinas y Parroquias, ya que se dictaron normas para la administración de sacramentos, celebración del culto divino, extirpación de malas costumbres que se habían introducido, y por último se insistió en la enseñanza de la doctrina cristiana a los indios ${ }^{29}$.

El segundo Sínodo tuvo lugar también en la ciudad de Quito desde el día 15 hasta el 31 de agosto de 1594, y fue convocado y presidido por el Ilmo.Señor Luis López de Solís 30 .

Al hacer la biografía del Ilmo. Señor Solís, hemos advertido que este prelado el 15 de junio de 1594 llegaba a Quito para gobernar su Diócesis. Pues bien, a los pocos días de su permanencia convocaba a los Prebendados que habían entonces en la Catedral, a los Superiores de las cuatro comunidades religiosas existentes ya en Quito: franciscanos, dominicos, mercedarios y agustinos, y al clero, en general, para reunirse en Sínodo y tratar de ciertos asuntos para reorganizar la Diócesis, que tanto necesitaba por haber estado vacante alrededor de doce años.

La sesión de apertura se realizó en la Iglesia Catedral el lunes 15 de agosto, festividad de la Asunción de la Santísima Virgen, y el miércoles 31 del mismo mes, se leyeron las ciento quince constituciones o capítulos, dándose así por clausurado este Sínodo.

En general, podemos afirmar que las medidas adoptadas por el Prelado, de acuerdo con los asistentes al Sínodo, fueron muy prudentes y acertadas a fin de restaurar la situación un tanto deficiente en que se encontraban las Parroquias y Doctrinas de la Diócesis; asimismo, se insistió en la instrucción religiosa de los indios y que ésta se hiciese en lengua indígena para obtener mejores resultados; y finalmente, se advirtió que la provisión de Parroquias y de Doctrinas se haría conforme a lo ordenado y 
mandado por el Tridentino, por el Concilio limense de 1583, de acuerdo, desde luego, con las leyes del Patronato.

El tercero tuvo lugar en Loja, desde el 15 al 24 de agosto de 1596, y fue presidido por el mismo Obispo Solís ${ }^{31}$, quien, al finalizar el Sínodo de 1594, había convocado a un nuevo Sínodo para el 15 de agosto de 1596, señalando como sede la misma ciudad de Quito. Sin embargo, razones imprevistas obligaron al benemérito Prelado a llevar a feliz término este tercer Sínodo diocesano, no en la ciudad episcopal, sino en la de Loja; pues, para la fecha señalada, 15 de agosto de 1596, se hallaba en esta última ciudad, haciendo la visita pastoral.

No debió ser muy concurrida la asistencia a este Sínodo por la larga distancia que separaba la ciudad de Loja de las demás ciudades de la Diócesis y por las dificultades de viaje y porque muchas Parroquias y Doctrinas hubieran quedado abandonadas por espacio de dos o tres meses. Sin embargo, no deja de tener especial interés este Sínodo, que se redujo a treinta y cuatro constituciones. Considerando la importancia del Sínodo de 1594, se juzgó muy conveniente y necesario declarar que continuaban en vigencia las anteriores constituciones. "Ante todas cosas, es nuestra voluntad, sancta Synodo approbante, -decía el Obispo Solís- que todas las constituciones sinodales que se hicieron en el Sínodo primero de mil y quinientos y noventa y cuatro, se guarden inviolablemente y queden en su fuerza y vigor, si no fuere las que en este Sínodo y en los de adelante fueren revocadas por convenir así; y declaramos que, aunque alguna constitución o constituciones sinodales, por negligencia, no se guarden, no por eso se entienda ser derogadas; antes, queremos que esté siempre en su fuerza y vigor, aunque no se usen, entre tanto que no se derogan" 32 .

De este modo, el Sínodo de 1594 seguía en vigencia; sin embargo se introdujeron algunas modificaciones, así por ejemplo: "cerca de la constitución 67, en la cual se manda que cada año se publiquen y lean en la Dominica in Albis el Concilio provincial y sumario de 67 -refiriéndose al segundo Concilio provincial limense realizado en 1567- e sinodales al pueblo, se cumpla con leer aquellas constituciones que más hacen al caso para la reformación del pueblo y clero, dejando las que al pueblo no le importan"33. 
$\mathbf{7 0}$ / Augusto E. Albuja

Y para terminar esta reseña referente a los Concilios limenses y Sínodos de Quito, debemos resaltar la labor de los dos Prelados: Ilmos. Peña y Solís, quienes fueron los organizadores inmediatos de la Iglesia ecuatoriana y merecen por tanto nuestra gratitud imperecedera.

A principios del siglo XVII, la Iglesia de Quito había recibido una organización completa, gracias a las leyes canónico-particulares emanadas sobre todo de los Concilios provinciales de 1567 y 1583 y de los Sínodos de 1570 y 1594 celebrados en Quito, y del realizado en Loja en 1596. 
Doctrinas y Parroquias del Obispado de Quito /71

\section{NOTAS}

1 GÓMEZ HOYOS, Las Leyes de Indias, 153.

2 C.I.C.17,c.216,3; C.I.C., c.374,1.

3 GONZÁLEZ SUÁREZ, Historia, III, 419-420

4 PEÑA MONTENEGRO, Itinerario, lib. I, trat.2,f.l.

5 REGATILLO EDUARDUS F., Institutiones luris Canonici, I, Santander 1956, 414, n. 597

6 ALVAREZ DE ABREU, Antonio José, Vacantes de Indias, Madrid, 1769, 338339 .

7 SOLÓRZANO PEREIRA, Politica Indiana, III, 308.

8 RODRÍGUEZ VALENCIA, Vicente, Santo Toribio de Mogrovejo, Organizador y Apóstol de Sur-América, I, Madrid, 1956,387.

9 Recopilación, lib.I. tit.6, ley 41.

10 AGI, Quito, Leg.23

11 PEÑA MONTENEGRO, Itinerario, lib. I, trat.l.f.ll.

12 SOLÓRZANO PEREIRA, Politica Indiana, III, 226.

13 GÓMEZ HOYOS; Las leyes de Indias, 198 ss.

14 Los grandes privilegios, en favor de los Reyes Católicos y de sus sucesores, fueron concedidos, sobre todo, por los Sumos Pontífices Alejandro VI y Julio II, respectivamente. Alejandro VI mediante la Bula "Inter Coetera" del 4 de mayo de 1493, les concedía la posesión del Nuevo Mundo; asimismo, por la Bula "Eximiae Devotionis" , de la misma fecha, se les daba el derecho de Patronato; y por la "Eximiae devotionis sinceritatis" del 16 de noviembre de 1501, los Reyes Católicos podían percibir los diezmos de las Indias. Y por fin el Papa Julio II, por la Bula "Universalis Ecclesiae", fechada el 28 de julio de 1508, concedía a los Reyes de España el derecho de presentación para todas las dignidades y beneficios eclesiásticos en las Indias. (Hernáez, Colección de Bulas, I, Parte Primera, trat.1o.).

15 AGI, Patronato, leg.189, Ro. 41.

16 RICARD ROBERT, La Conquista espiritual de México, México, 1947,228.

17 VARGAS UGARTE, Historia, II, 201.

18 LEVILLIER, Roberto, Organización de la Iglesia y Ordenes Religiosas en el Virreinato del Perú en el siglo XVI, 1, Madrid 1919, 447.

19 LEVILLIER, Organización, 1,662.

20 RODRÍGUEZ VALENCIA, Santo Toribio, I, 391.

21 ARMAS MEDINA, Fernando de, Evolución Histórica de las Doctrinas de Indios, Sevilla, 1952, 8 ss. 
22 Entre las varias obras que ha publicado el P. Vargas Ugarte hay una titulada "Concilios Limenses", en tres volúmenes. Hemos utilizado para este trabajo, de manera preferente, el primero ya que trata exclusivamente de las constituciones de los Concilios limenses, realizados desde 1551 hasta 1772, y que ha sido publicado en Lima en el año 1951. Asimismo, algunas notas hemos tomado del tercer volumen, publicado en Lima en el año 1954, y que trata de la historia de los Concilios limenses. Por tanto, advertimos que, siempre que se citen en este trabajo decretos o constituciones conciliares limenses, nos referimos al primer volumen de dicho autor.

23 LEVILLIER, Organización, I, Introducción, LXXXII.

24 GONZÁlEZ SUÁREZ, Historia, III, Cap. VIII, parte 3o.

25 AGI, Patronato, leg. 189, Ro. 40.

26 VARGAS UGARTE, Historia, II, 147.

27 Apéndice \# 10.

28 VARGAS UGARTE, Historia, II, 147-148.

29 Apéndice \#10.

30 AGI, Quito, leg. 76. También, en la misma sección (Audiencia de Quito, Leg. 77) existe un cuadernillo que contiene una copia de este segundo Sínodo quitense, pero es de fecha posterior, pues corresponde al año 1615; sin embargo, el texto de las constituciones sinodales no varía. De manera que hemos utilizado ambos documentos y las citas posteriores que hagamos, unas veces señalamos el leg. 76 y otras el leg. 77, en el cual se encuentra también el tercer Sínodo de la diócesis de Quito, celebrado en Loja, como advertiremos cuando tratemos de este último.

31 AGI, Quito, leg.77, el cual se reduce a un cuadernillo, forrado en pergamino, 22 por $35 \mathrm{cmts}$. Contiene 78 folios, de los cuales los siete últimos vienen en limpio. Del folio 1 al folio 44v, trata del Sínodo de 1594; del folio $44 \mathrm{v}$ al folio $7 \mathrm{lv}$, en cambio, del Sínodo de 1596. Hacia la mitad del folio 7lv hay una nota en que se advierte que este traslado ha sido corregido y confrontado con el texto original, el cual lo prestó el Ilmo.Señor Fernando Arias Ugarte, séptimo Obispo de Quito, a quien después se le devolvió dicho original, pero lamentablemente no reposa en el archivo de la Curia de Quito. La fecha exacta del traslado es el 20 de marzo de 1615, a pesar de que al cuadernillo se le haya puesto el título: "El Obispo de Quito 1617”. Fueron testigos de la autenticidad de la copia los señores Gabriel de León y Francisco de Rojas.

32 Tercer Sínodo de Quito, Constit. 1, (AGI, Quito, leg.77).

33 Tercer Sínodo de Quito, Constit. 2, (AGI, Quito, leg.77). 


\section{CAPÍTULO IV PROVISIÓN DE DOCTRINAS Y PARROQUIAS}

Cuando una Parroquia o Doctrina quedaba vacante en la Diócesis, se debía poner edicto público, por espacio de un tiempo prudencial, a fin de que los interesados pudieran presentarse a oposición. Una vez admitidos los opositores y hecho el examen acerca de la idoneidad, el Obispo debía presentar los candidatos para que el Patrono o su delegado en Indias eligiese uno de ellos y lo presentase al Prelado para que éste hiciese la provisión canónica propiamente dicha. Durante la segunda mitad del siglo XVI estaba en vigencia una disposición real por la cual se exigían al menos dos candidatos ${ }^{1}$. Pero si la Doctrina pertenecía al clero regular y quedaba vacante, en este caso, el Superior religioso enviaba la nómina de los candidatos, y el Patrono o el que hiciere sus veces escogía uno y lo debía presentar al Obispo para la institución canónica.

A partir del año 1609, se exigía que fuesen siquiera tres los candidatos, "los más dignos y suficientes para cada uno de los dichos Beneficios, prefiriendo siempre los hijos de padre y madre españoles nacidos en aquellas provincias, siendo igualmente dignos a los demás opositores nacidos en estos reinos" 2 .

En el esquema presentado sobre la evolución histórica de las Doctrinas de indios, hemos distinguido cinco épocas. Hasta el primer Concilio limense, los Encomenderos eran los directores de las Doctrinas; de modo que ellos las proveían mediante un contrato con el sacerdote a fin de que tomara a su cuidado pastoral tal o cual Repartimiento de indios. A partir del primer Concilio limense, las Doctrinas dependieron directamente de los Obispos, aunque en teoría el Patronato de los Reyes existía, pero no se lo ejercitaba. Por tanto, los Prelados de las Indias proveían los beneficios eclesiásticos con independencia casi absoluta del Patronato, 
pues Felipe II, por medio de una Real Cédula del 22 de mayo de 1561 y que fue dirigida al Arzobispo de Lima y a los demás Obispos, a cada uno de ellos le decía el Rey: "Os ruego y encargo que de aquí adelante, cuando vacare algún Beneficio, Doctrina, Administración, como Patrón de todas las Iglesias de las dichas mis Indias, le proveáis, haciendo todas las diligencias, advirtiendo que ha de ser entre tanto que nos otra cosa proveyéremos" 3 . Desde 1567, el Rey recabó para sí el derecho de presentación para la provisión de cualquier clase de beneficios. La Real Cédula del 3 de noviembre de 1567, enviada desde El Escorial, ponía de manifiesto la observancia del Patronato. "Por la presente-decía Felipe II- encargamos a todos y cualesquier Prelados de las dichas Indias, a cada uno en su Diócesis, que sin presentación nuestra no hagan colación ni provisión de ninguna Dignidad, ni Beneficio, de cualquier calidad que sea, y en los lugares donde conviniere haber curas puedan los dichos Prelados dar el título de cura al clérigo o beneficiado por nos presentado y darle poder de administrar los santos sacramentos y hacer las otras cosas al oficio de cura pertenecientes". Y para que no fuese demasiado rigurosa esta observancia, por el mucho tiempo que tardaba la correspondencia, se dispuso también en esta misma Cédula Real que “... habiendo en algún pueblo necesidad de clérigo beneficiado, porque no haya dilación en la doctrina cristiana y en la administración de los Sacramentos, confesiones y otras cosas necesarias para la institución de nuestra santa fe católica y provecho de las ánimas, que habiendo la dicha necesidad, los dichos Prelados puedan dar licencia a los dichos clérigos para administrar los dichos beneficios sin hacerles de ellos canónica institución, poniéndoles término de dos años, dentro de los cuales presenten las dichas licencias con aprobación de sus Prelados ante nos, en el nuestro Consejo de las Indias, para que a ellos o a quien más fuéremos servido presentemos a los dichos beneficios, y por virtud de la dicha presentación les hagan los dichos Prelados la colación canónica institución de los tales beneficios; y no trayendo la dicha presentación dentro del dicho término, los dichos Prelados remuevan los tales clérigos y den la dicha licencia a otros clérigos, con la misma obligación de llenar la dicha presentación dentro de los dichos dos años"4. 
Según esto, la presentación de uno de los candidatos a determinado beneficio era competencia exclusiva del Rey. Sin embargo, más tarde, el mismo Rey delegaba su derecho y podían, por tanto, hacer la presentación el Virrey, el Presidente y aún los Gobernadores de la Audiencia, mas no era atribución de los simples Oficiales ni de los Encomenderos ${ }^{5}$.

Como algunas veces los delegados del Rey se dejaban llevar de la acepción de personas o de prejuicios para con los Prelados, "ese derecho de elección molestó considerablemente a los Obispos, que no habrían tenido, en esa forma, clérigos adictos a su persona en la Diócesis, y sí enemigos en los no presentados. Preferían que los cargos fuesen amovibles y a su propia designación para así sujetar con más fuerza a los subalternos".

El no haberse ejercido durante algunos años el derecho de Patronato, en lo que respecta a elección y presentación de uno de los candidatos propuestos por el Prelado, en cierta manera perjudicó a los Obispos, pues sencillamente éstos estaban acostumbrados a proveer los beneficios directamente, a su arbitrio; pero, también debemos señalar que la obediencia al Prelado por parte de sus sacerdotes beneficiados era más asidua y constante. Cuando el Rey exigió que se pusiera en práctica su derecho como Patrono, y sobre todo "cuando el Virrey García de Mendoza quiso aplicarlo con rigor, los Obispos se ingeniaron en eludirlo, presentando solo un candidato, so color de que no encontraban otro digno del cargo, recurso que obligaba al Virrey a aceptar el favorecido sin posibilidad de escoger"6.

Según lo legislado por los Concilios Provinciales de Lima, los Sínodos de la Diócesis de Quito y el Real Patronato de los Reyes de España, podemos distinguir en la provisión de Doctrinas y Parroquias los siguientes requisitos: Conocimiento del idioma indígena; examen de los candidatos; elección hecha por el Prelado; presentación del candidato; institución canónica y toma de posesión.

Examinemos cada uno de estos requisitos: 


\section{Conocimiento del idioma indígena}

La primera y principal dificultad que encontraron los misioneros españoles para la evangelización en Indias, no fue únicamente la falta de medios de comunicación, ni la variedad de clima, ni las malas costumbres tan enraizadas entre los aborígenes, sino sobre todo el desconocimiento del idioma indígena.

"Por experiencia nos consta -decía el Ilmo. Solis- en nuestro Obispado -de Quito- hay diversidad de lengua, que no tienen ni hablan la del Cuzco ni la Aymará"7.

¿Qué lenguas se hablaba en el distrito de la Diócesis de Quito en esta segunda mitad del siglo XVI?. Por los nombramientos hechos por el Prelado para que algunos eclesiásticos se dedicaran a la traducción del Catecismo y del Confesionario, sabemos que se hablaba, a más del idioma del Inga, la lengua llamada de los Llanos y Atallana en los distritos de Piura y Trujillo; la Puruá en la actual provincia del Chimborazo; la Cañari en las provincias del Azuay y Cañar; la de los Pastos, en un sector de la Gobernación de Popayán y la Quillacinga, en la provincia de Imbabura ${ }^{8}$. Pero, la lengua materna, de donde nacieron las demás, era la llamada del Inga.

El primer Arzobispo de Lima, Ilmo. Jerónimo de Loaisa, había sugerido el uso del latín y del castellano para así salvar esta torre de Babel; "pero esto suponía que los indios habían alcanzado el conocimiento de uno y otro idioma... Era, sin embargo, más fácil y más puesto en razón que se utilizara el idioma nativo, pues la dificultad de su aprendizaje no era tanto que no se pudiese vencer y, una vez superado, el camino se allanaba y hasta se volvía grato" 9 .

Como el empleo del latín y del castellano no dio resultado, el aprendizaje del idioma indígena era urgente. Los Obispos en sus Diócesis debían velar porque los curas, sobre todo los encargados de las Doctrinas de indios, aprendiesen la lengua y adoctrinasen en ella a los naturales ${ }^{10}$. Así pues, el Ilmo. Peña exigía de los doctrineros "saber a lo menos la len- 
gua general de los Ingas para que entiendan los indios y los indios se entiendan con los sacerdotes" 11 .

Además, los Obispos debían señalar un tiempo útil, dentro del cual sus sacerdotes debían aprenderla; y para evitar cualquier negligencia, se advertía a todos los curas de indios "que dentro en medio año aprendan la lengua general de los ingas y alguna parte de los naturales de sus parroquianos, por manera que los puedan confesar e dar a entender las cosas de nuestra santa fe católica, y el que no la supiere -advertía una constitución sinodal- pierda el salario del otro medio año y se gaste en obras pías..."12.

Esta medida fue adoptada en la Diócesis de Quito porque, tres años antes, se había ordenado en el segundo Concilio provincial de Lima que podían ser castigados con una multa pecuniaria de la tercera parte de sus rentas aquellos sacerdotes que, pasado un año, todavía ignoraban el idioma indígena; y si pasado el segundo año, la ignorancia del idioma no había desaparecido, la dicha multa podía aumentarse según las circunstancias $^{13}$.

La aplicación de dichas multas estaba reservada al Obispo, quien a su vez descargaba su cometido, nada halagüeño por cierto, en los sacerdotes llamados "Visitadores" y en los vicarios o arciprestes de las ciudades de la Diócesis, pues en caso de que "no hubiera sacerdote que supla la dicha falta -de idioma en el cura o doctrinero- se aplique la multa a la iglesia e indios pobres. Los visitadores y vicarios serán muy vigilantes y estarán muy atentos a esto y que se lleve a debida ejecución -dice una constitución sinodal- sobre que les encargamos la conciencia y que se procederá contra ellos siendo negligentes" 14 .

Era cosa muy natural que al principio el aprendizaje del idioma indígena fuese el caballo de batalla para los sacerdotes, pues no disponían de gramáticas ni diccionarios. Para darles facilidades se pensó en implantar la cátedra de la lengua indígena, y de hecho el Rey Felipe II, por medio de una Cédula suscrita el 19 de septiembre de 1560, creaba esta nueva cátedra en la universidad de Lima ${ }^{15}$. Pero por los múltiples inconvenientes que resultaban para los sacerdotes del Obispado de Quito realizar 
un viaje tan largo hasta Lima, se consiguió en el año 1580 la respectiva autorización real para que dicha enseñanza del idioma se tuviese también en la misma ciudad de Quito ${ }^{16}$. La creación de la cátedra de la lengua en Quito no era suficiente, si se dejaba a los clérigos en libertad de asistir o no a ella; razón por la cual fueron muy oportunas y a la vez necesarias las disposiciones de Felipe II, pues, en su Real Cédula, dirigida a la Audiencia de Quito el 23 de septiembre de 1580, entre otras cosas decía: “... Item, rogamos y encargamos al Obispo de esa provincia y a los demás del distrito de esa Audiencia y a los Cabildos, Sede vacante, y a los Prelados de las Ordenes, que no ordenen de orden sacerdotal, ni den licencia para ello a ninguna persona que no sepa la lengua general de los dichos indios, y sin que lleve fe y certificación del catedrático que leyera la dicha cátedra de que ha cursado en lo que se debe enseñar en ella por lo menos un curso entero, que se entiende desde el día de San Marcos hasta la Cuaresma siguiente, que comienzan las vacaciones, aunque el tal ordenante (sic) tenga habilidad y suficiencia en la facultad que la Iglesia y los Sacros Cánones manda; pues, para el enseñamiento y doctrina de los dichos indios lo más importante es saber la dicha lengua, pues, como está dicho, mediante esta inteligencia se descarga nuestra conciencia y la de los dichos Obispos y Prelados y se sigue el bien espiritual de los dichos indios ... Y también os encargamos que advirtáis a los dichos ministros y sacerdotes de Doctrina, que de aquí adelante los que supieren mejor la lengua serán preferidos en la nominación y presentación a las Doctrinas y beneficios y otros oficios eclesiásticos, a los que no las supieren".

Felipe II no solamente se preocupaba porque los candidatos a Doctrinas u otros beneficios eclesiásticos supiesen la lengua indígena, sino que, además, "ordenamos y mandamos -proseguía en su Real Cédulaque dentro de un año, contado desde el día de la publicación de estas ordenanzas, todos los sacerdotes y ministros de Doctrina que hubiere presentado en las Doctrinas de esa Audiencia, parezcan a ser examinados del dicho catedrático si saben la dicha lengua ... pasado dicho tiempo -esta orden era para el Obispo- daréis por vacas las dichas Doctrinas y se presentarán otros a ellas"17. 
La cátedra de la lengua indígena funcionaba en el convento de Santo Domingo. Años después, el Ilmo. Señor Solís juzgó conveniente que dicha cátedra pasara al Seminario; y manifestando su deseo al Rey, por medio de una carta suscrita el 12 de octubre de 1594, el benemérito Prelado se expresaba en estos términos "Por mandato de Vuestra Majestad se ha leído la cátedra de la lengua general en esta tierra, en el convento de Santo Domingo, por tiempo limitado, y se paga el salario de vuestra real caja. Suplico a Vuestra Majestad dé licencia para que de aquí adelante se lea la cátedra en el colegio-seminario, pues demás de que allí está la práctica de la lengua más afinada, los mismos colegiales han de ser de hoy más proveídos en Doctrinas y beneficios y la han de administrar y se leerá con mucho cuidado; y por este trabajo, sea Vuestra Majestad servido, se le acuda al colegio con el salario que es costumbre y que no se pueda leer en otra parte" 18 .

Ya que la primera condición que se exigía en aquellos que pretendían Doctrinas de indios era saber el idioma, muy natural que se nombraran personas expertas en esta materia a fin de que pudieran examinar y dar el respectivo "visto bueno" a cada uno de los interesados. Fueron designados como examinadores generales de la lengua del Inga en la ciudad de Quito, a más del catedrático, los presbíteros Alonso de Aguilar, en ese entonces cura y rector de la iglesia catedral, y Diego Lobato de Sosa, predicador oficial, a fin de que los tres o por lo menos dos de ellos examinaran a las personas que pretendieren beneficios y Doctrinas y a aquellos que asistían al Sínodo de 1594 y no habían sido examinados todavía ${ }^{19}$.

Si grande fue la preocupación del Ilmo. Señor Peña de que sus sacerdotes supiesen la lengua indígena, mucho mayor fue la del Ilmo. Señor Solís, quien, en su carta del 7 de mayo de 1597, dirigida a Su Majestad el Rey, se expresaba en estos términos: "Las principales letras que procuro en los clérigos que proveo a Doctrinas y beneficios de indios es la lengua de los mismos indios, porque con ella les han de predicar, confesar y administrar los santos sacramentos" 20 . 


\section{Examen de los candidatos}

La mejor manera para que el Obispo se dé cuenta de la idoneidad de aquellos que pretenden beneficios en su Diócesis es sometiéndolos a un examen de doctrina y averiguando, incluso por medio de informes secretos, de las cualidades y virtudes de dichos candidatos ${ }^{21}$.

Siguiendo las disposiciones del Tridentino sobre este punto del examen previo a la provisión de beneficios eclesiásticos, el Concilio provincial limense del año 1567 pedía también a los Prelados que antes de confiar una Doctrina de indios, debían exigir de sus sacerdotes el examen correspondiente $^{22}$. Si esto se pedía para las Doctrinas, es de suponer que con mayor razón se exigiría para las Parroquias, pues, como advertíamos anteriormente, éstas se concedían casi siempre a título perpetuo, es decir, en propiedad.

Sin embargo, la necesidad obligaba en algunas ocasiones a los Prelados a confiar beneficios curados a sacerdotes poco idóneos, pues en los primeros decenios debió existir escasez de clero. En tales casos, para satisfacer la necesidad de instruir al pueblo mediante la predicación de la palabra divina en los días domingos y en los de fiestas de precepto, los sacerdotes encargados de una Parroquia o Doctrina "si no fueren tan suficientes, otras personas doctas a su costa de ellos lo hagan, siguiendo siempre en la exposición de la Escritura el sentido y declaración de los Santos Padres"23.

Pero teniendo en cuenta que en un beneficio curado el ministerio más delicado es el de la confesión a los feligreses, el Tridentino insistía en que los Ordinarios en sus respectivas Diócesis examinasen diligentemente a quienes les iban a conceder facultades para poder confesar ${ }^{24}$. De acuerdo a esta disposición, el tercer Concilio del año 1583, celebrado en la época de Santo Toribio de Mogrovejo, no hizo otra cosa sino urgir su cumplimiento en todas las Diócesis que formaban la Provincia eclesiástica de Lima, recomendando que en dicho examen se guarde la justa medida, a saber: que a los más doctos se les conceda una facultad general para poder confesar a cualquier clase de personas; en cambio, a los menos pe- 
ritos se les podía restringir dicha facultad de confesar, limitándola a ciertas personas hasta que demuestren suficiencia ${ }^{25}$. Anteriormente ya se había puesto en práctica esta disposición en la Diócesis de Quito; pues al sacerdote que se le examinaba ad audiendas, se le exigía también un examen del idioma. Por el interés que pueda despertar en no pocos lectores, transcribimos a continuación el examen que rindieron el Padre Melchor de Alarcón y el presbítero Juan Yáñez; de esta forma sabremos las preguntas que les fueron hechas y la manera cómo respondieron.

Examen del Padre Melchor de Alarcón

"En la ciudad de Quito, a diez y seis de febrero de mil quinientos y sesenta e cuatro".

"Fuele preguntado ¿qué cosas son necesarias para que un sacerdote sea idóneo confesor? Dijo: que tenga jurisdicción ordinaria y eclesiástica y prudencia.

"Preguntado ciertas cosas acerca de estas materias, parece muestra hasta ahora no estar esperto en materia de confesiones. Mándasele tenga las Sumas de conciencia, en especial la Summa que dicen de Navarro para que esperto adelante con la buena habilidad y prudencia que pueda ayudar y en tanto se le da licencia para que pueda confesar la gente menuda de españoles y mestizos y todos los negros y negras. Fr. P. Episcopus Quitensis"

"En lo que toca a los indios y la lengua general del Inga, fue examinado por el Padre Diego Lobato y afirmó, debajo del juramento que tiene hecho, que puede confesar a todos los caciques de este Obispado, alcaldes, oficiales y toda suerte de indios, sin exceptar ninguno y lo firmó de su nombre. Diego Lobato".

Examen del presbitero Juan Yáñez

"Este dicho día, mes y año -11 de febrero de 1574-ante su Señoría Reverendísima -se refiere al Ilmo. Peña-pareció el Padre Juan Yánez, clérigo presbitero, y en cumplimiento del auto por su Señoría Reverendísima proveído acerca del examen que se ha de hacer de los confesores, se presentó an- 
te su Señoría Reverendísima y en presencia de mi, Hernando de Espinar, clérigo subdiácono, notario para el dicho examen, conforme al Motu Proprio de Su Santidad, su Señoría Reverendísima le examinó e haciéndole el dicho examen le hizo las preguntas siguientes:

"Fuele preguntado ¿qué partes ha de tener el confesor para confesar y que sea idóneo confesor?. Dijo que dos: que ha de tener licencia, e buena conciencia,de manera que ha de saber lo que hace y entender bien lo que toca a la conciencia de sus penitentes y ha de tener bondad, de manera que sin pecado mortal confiese".

"Fuele preguntado, si el tal confesor confesaba estando en pecado mortal si verdaderamente absolvía. Dijo que sí, aunque pecaba el tal confesor mortalmente, e que no solamente este sacramento es válido recibido del que está en pecado mortal, pero aun todos los otros sacramentos lo son". "Fuele preguntado del modo que tiene y se debe tener en confesar, acerca de las preguntas que se ha de hacer al penitente al principio de la confesión e cómo se ha de haber acerca del aparejo e disposición. E respondió a todo razonablemente, aunque no tan en consecuencia por no deber estar ejercitado de próximo en leer libros, según él dijo, por lo cual su Señoría Reverendisima, de presente le manda por obra que, pues es buen latino e de tan buenas canas y edad e prudencia, para que en el servicio de Dios haga más fruto, tenga e compre luego, dentro de ocho días, la Suma Silvestrina o la de Navarro, o la de Pedraza o otra que sea Suma de casos de conciencia, que sea de persona docta e aprobada" 26 .

Como hasta el año 1583 el examen de idoneidad debían presentar los sacerdotes en la ciudad de Lima, esto originaba múltiples inconvenientes en no pocas Diócesis. Así pues, los Prelados asistentes al tercer Concilio limense optaron por escribir una carta colectiva al Rey, manifestándole la conveniencia de que en cada Diócesis se pusieran examinadores, ya que esto último era más conforme e incluso lo pedía el Tridentino ${ }^{27}$. Hasta ese entonces una Real Cédula de Felipe II había dispuesto que "ningún sacerdote sea presentado en Doctrina alguna de indios sin que primero sea examinado y aprobado, y en la ciudad de los Reyes, por la persona a cuyo cargo estuviere"; en vista de lo cual, los Prelados deseaban "que por la distancia de que hay de las Doctrinas adonde está el exa- 
minador, que son a 200 y a 300 leguas, conviene que se dé licencia para que cada Prelado, en su Obispado, lo pueda hacer por sí o por la persona que disputaren en cada ciudad de españoles" 28 .

Seguramente la sugerencia hecha por los Prelados fue muy bien acogida por Felipe II, ya que una constitución o decreto del Concilio del año 1583 mandaba que "cada uno de los Obispos dispute y señale en su Diócesis examinadores que examinen a los que han de ser curas de indios y de la suficiencia que tienen, así en letras como en la lengua de los indios, y éstos principalmente residirán en la Matriz, y también habrá otros en otras ciudades en el número y lugar que les pareciere convenir; y para el examen que han de hacer los dichos curas, así en la suficiencia de doctrina como en la lengua, usarán principalmente los examinadores de preguntas por el Catecismo compuesto y aprobado por este Sínodo para que los que han de ser curas le aprendan y entiendan y enseñen por él la lengua de los indios" 29 .

Por tanto, la existencia de examinadores sinodales se hizo urgente en la Diócesis de Quito. Hasta la celebración del segundo Sínodo, no fue posible poner en práctica el deseo del Tridentino. Así pues, en el año 1594, el Ilmo. Señor Solís juntamente con los asistentes al Sínodo, acordaron en determinar "que ningún sacerdote (clérigo o religioso) puede oir confesiones de legos ni eclesiásticos, aunque sean sacerdotes, si no fuere cura de ánimas o expuesto y señalado para confesor, ni por virtud de Bulas, privilegios o costumbre que haya en contrario, aunque sea inmemorial, como lo dispone el Santo Concilio de Trento"30.

Los examinadores sinodales no debían ser menos de tres, sin tomar en cuenta al Obispo o al Vicario General, cuando aquel estuviere impedido $^{31}$, ni tampoco podían pasar de doce, según la anterior legislación canónica ${ }^{32}$.

"En cumplimiento de lo ordenado y mandado por el Santo Concilio de Trento -decía el Ilmo. Solís en el Sínodo quitense de 1594- nombramos por examinadores de los beneficios y Doctrinas y de las personas que pretendieren ordenarse: al Bachiller Cristóbal Loarte Dávila, al Bachiller don Francisco Galavís, Arcediano de nuestra Santa Iglesia, al Canóni- 
go Juan Francisco Talaberano de Mancera y al Guardián de San Francisco y al Prior de San Agustín y al Rector de la Compañía de Jesús. De los cuales se han de hallar, por lo menos tres, a los exámenes, conforme al Concilio de Trento, para los examinar generalmente a las personas que pretendieren beneficios y Doctrinas en todo aquello que les pareciere convenir y ser necesario y ansimismo han de examinar a las personas que pretendieren Ordenes, en todo lo cual les encargamos la conciencia; y los votos y pareceres que sobre esto dieren, han de ser consultivos, diciendo cada uno con secreto lo que entendiere a nuestro secretario, el cual nos dará cuenta y razón de lo que se hiciere para que se provea lo que convenga"33.

\section{Elección hecha por el Prelado}

Transcurrido el tiempo del edicto por el que se convocaba a los opositores a un beneficio vacante y hecho el examen previo, el Obispo debía elegir los más idóneos a fin de presentarlos al Rey o al que hiciere sus veces, para que éste, de acuerdo a las normas del Patronato, señalara uno de la lista, el cual recibiría del Prelado la provisión canónica propiamente dicha.

La nómina de los candidatos era enviada al Rey, cuando se trataba de un beneficio que iba a proveerse en propiedad; pero, si el beneficio era amovible, como generalmente eran las Doctrinas de indios hasta 1609, entonces bastaba con enviársela al Gobernador o al Presidente de la Audiencia, o, en defecto de uno de los dos, se acudía al Rey.

Para que se procediera con imparcialidad en este asunto tan delicado, Felipe II recomendaba a los Prelados y a los Superiores de los religiosos, a Virreyes, Presidentes de Audiencia y Gobernadores, "que en las nominaciones, presentaciones y provisiones que hubieren de hacer ... siempre prefieran y propongan en primer lugar a los que en su vida y ejemplo se hubieren aventajado a los otros, y ocupado en la conversión de los indios, y administración de los santos sacramentos, y a los que mejor supieren la lengua de los indios que han de doctrinar y hubieren tratado 
Doctrinas y Parroquias del Obispado de Quito /85

de la extirpación de la idolatría ... y en segundo lugar a los que fueren hijos de españoles que en aquellas partes -decía el Rey- nos hayan servido"34.

No siempre se observó este trámite legal, sobre todo en la época del Ilmo. Señor Peña, pues este Prelado, a fin de evitar disgustos con el Presidente o Gobernadores de la Audiencia de Quito, prefería usar de las atribuciones que el Rey había concedido por la Cédula del 3 de noviembre de 1567 a todos los Prelados de Indias, a saber: "habiendo en algún pueblo necesidad de clérigo beneficiado, para que no haya dilación en la doctrina cristiana y en la administración de los sacramentos ... los dichos Prelados pueden dar licencia a los dichos clérigos para administrar los dichos beneficios, sin hacerles de ellos canónica institución, poniéndoles término de dos años, dentro de los cuales presenten las dichas licencias con aprobación de sus Prelados ante nos, en el nuestro Consejo de las Indias, para que a ellos o a quien más fuéremos servido presentemos a los dichos beneficios..."35. Cuando tratemos de la institución canónica, daremos a conocer ciertos nombramientos provisionales extendidos por el segundo Obispo de Quito en favor de determinados sacerdotes, quienes generalmente, pasados los dos años, acudían al Rey y eran presentados para recibir de una manera formal la institución canónica. En cambio, en los años posteriores, la nómina de candidatos se enviaba regularmente; pero, de vez en cuando se dejaba pasar mucho tiempo, como podemos advertir respecto a la Parroquia de San Sebastián en la ciudad de Quito. Esta parroquia estaba atendida en 1583 por el presbítero García de Valencia ${ }^{36}$. El 8 de mayo de 1597 el titular de dicho beneficio era Canónigo y en su lugar estaba el presbítero Francisco Durán ${ }^{37}$, quien no debía tener sino un nombramiento provisional como mero ecónomo, pues el 22 de marzo de 1608 se dirigía un oficio al Rey haciéndole saber que, en vista de estar vacante la Parroquia de San Sebastían por haberse concedido una prebenda al presbítero García de Valencia, la nómina de los candidatos propuestos era la siguiente: en primer lugar Alonso Mejía Mosquera, seguido después por Francisco Vélez de Zúñiga, Diego Lobato de Sosa y Alonso de Villanueva ${ }^{38}$. 
$\mathbf{8 6}$ / Augusto E. Albuja

Pero cuando quedó vacante el beneficio de la ciudad de Loja por muerte de su titular el presbítero Juan de Ocampo, inmediatamente se envió la nómina al Rey, a quien le presentaban los siguientes candidatos:

"El bachiller Cristóbal Arias, clérigo presbitero, cura y vicario de la Audiencia -ciudad-de Jaén de los Bracamoros, que ha más de 16 años que pasó al Perú y los siete de ellos se ocupó en estudios y actos de virtud hasta graduarse de Bachiller en Teologia, y ha más de nueve años que sirve en beneficios y Doctrinas de indios, de que ha dado buena cuenta, y por sus dotes y suficiencia el Obispo de Quito le ha encomendado algunas visitas, de que consta por informaciones hechas en la Audiencia".

"Juan Rodríguez Quintero, clérigo presbitero, que por informaciones hechas por la Audiencia de los Reyes, consta que ha servido 22 años en la administración de los santos sacramentos en el Perú, en muchas Doctrinas que ha tenido, y que es muy experto en la lengua general y ha sido examinador general de ella y ha trabajado mucho en la conversión de los indios y sirvió de Capellán de la gente que fue a la conquista del Dorado".

"Luis Lara de Area, clérigo presbitero, que después de haber servido en estos reinos de Capellán del tercio de Infantería del cargo de Marqués de Cerralbo en la jornada de Portugal, pasó al Perú, donde ha servido más de 12 años en el beneficio del puerto de Paita y Colón, con aprobación, sustentando soldados en su casa en las ocasiones que se han ofrecido y gastando en esto de su hacienda, y el Virrey del Perú y Audiencia de Lima le aprueban por virtuoso y de buena vida y ejemplo y que ha dado buena cuenta de lo que ha estado a su cargo" 39 .

El trámite que debía seguirse, respecto a la provisión de beneficios, no siempre fue del agrado de todos los sacerdotes. Algunos se creían perjudicados porque el Obispo no los había tomado en cuenta en la nómina enviada al Rey o a su representante. Así pues, prescindiendo del Prelado y de las autoridades civiles, impulsados por su celo apostólico o por el deseo de comodidades en una Parroquia mejor situada, o por motivos de salud o de lucro, no sabemos ni nos corresponde averiguarlo, la verdad es que dirigían cartas personales al Rey, como Patrono de las Indias, a quien, después de exponerle las virtudes y méritos de los que cada intere- 
sado se hacía un elogio personal, terminaban suplicándole que los tuviese en cuenta a fin de ser presentados para tal o cual beneficio o para alguna Prebenda.

Así tenemos el caso del presbítero Lorenzo Díaz de Ocampo, vecino de Quito, quien manifestaba al Rey "que en su persona concurren las cualidades que se requieren de habilidad, suficiencia, buena vida y costumbres para ser presentado en cualquier Dignidad, canonjía y beneficio, y demás de ello es hijo de Alonso Hernández Cavallón, que ha más de sesenta años que pasó a aquellas partes adonde sirvió en todas las ocasiones que se han ofrecido". Y continuaba: "A vuestra Alteza suplica que, teniendo consideración a todo lo dicho, le haga merced de presentarle a una canonjía de la dicha Iglesia de Quito o en la Doctrina o beneficio de Uyumbicho y sus anejos, o a la Doctrina de Yaruquí, Puembo, o a la de Chillogallo, en que recibirá merced"; y como si los motivos y argumentos a su favor, arriba expuestos, no fuesen suficientes, el dicho presbítero Díaz de Ocampo manifestaba también al Rey que "desde su niñez anduvo ocupado y se ocupó en el servicio y ministerio de la santa Iglesia Catedral de la dicha ciudad de Quito hasta se ordenar de misa"; luego después, "fue proveído por cura de la iglesia parroquial de Santa Bárbara de aquella ciudad de Quito y por su doctrina le promovieron a la Parroquia de San Blas, que ahora sirve" 40 .

Esta solicitud, en parte, merece disculpa, ya que fue enviada el 24 de abril de 1592 y la Sede de Quito, en esta fecha se hallaba vacante por la muerte inesperada del Ilmo. Señor Antonio de San Miguel, y el nuevo Obispo electo del Paraguay, Luis López de Solís, se encontraba en Lima y seguramente no recibiría aun la carta de Felipe II, fechada en Madrid el 17 de abril de aquel mismo año, comunicándole su nueva elección para la Sede de Quito. Pero conviene advertir que si en Quito no había Obispo, estaba el Cabildo de quien el presbítero Lorenzo Díaz de Ocampo debió pedir aprobación, según el trámite legal que en estos casos de solicitudes se había dispuesto, ya que "es nuestra voluntad -decía el Rey- que el que nos suplicare le presentemos a alguna Dignidad, Beneficio u Oficio Eclesiástico, parezca ante el Virrey, Presidente o Audiencia, o ante el 
que tuviere la superior gobernación de la provincia, y declarando su petición, dé información de calidad, letras y costumbres y suficiencia. Y otrosi de oficio la haga el Virrey, Audiencia o Gobernador, y hecha, dé su parecer y la envíe aparte; y asimismo aprobación de su Prelado, con apercibimiento que sin esta diligencia no serán admitidos los que pidieran Dignidad, Beneficio u Oficio Eclesiástico" 41 .

Muy distinta era la solicitud dirigida al Rey en favor de Alonso de Aguilar, diácono, pues, dicha solicitud, suscrita el 1 de diciembre de 1574, estaba recomendada y garantizada por el entonces Obispo de Quito, Ilmo. Pedro de la Peña ${ }^{42}$.

A fin de evitar las recomendaciones orales o escritas en favor de tal o cual clérigo, el segundo Sínodo dispuso que "Las Ordenes y los beneficios no se deben dar sino por méritos y suficiencia y por derecho y motus propios; los que los pretenden por otra vía se hacen indignos. Sancta Synodo approbante, ordenamos y mandamos que cualquiera que trujere carta, presente o intercesor para Ordenes o beneficios sea expulso por aquella vez, aunque sea hábil y suficiente; y lo mismo sea en los que pretendieren prebendas por aquel camino, sobre lo cual encargamos la conciencia a los examinadores que así se guarde" 43 .

\section{Presentación del candidato}

Examinada la nómina de los elegidos o propuestos por el Obispo o el Superior religioso para llenar la vacante de un beneficio, el Rey o su representante en Indias debía elegir uno y presentarlo al Obispo para la institución canónica.

El presentado por el Rey debía comparecer ante el Obispo respectivo dentro del plazo señalado, ya que "si el presentado por Nos -advertía el Rey- dentro del tiempo contenido en la presentación no se presentare ante el Prelado que le ha de hacer la provisión y canónica institución, pasado el dicho tiempo, la presentación sea ninguna y no se puede hacer por virtud de ella la provisión y canónica institución” ${ }^{4}$. De este modo, lo que se pretendía era llenar cuanto antes la vacante del beneficio. Dicho plazo 
variaba según los casos; pero, en general, no debía pasar de los cuatro meses ${ }^{45}$. Además, se pedía "que las presentaciones se despachen con brevedad; y no dando el Prelado la institución dentro de diez días, se recurra al más cercano" 46 .

Por los varios inconvenientes que podían surgir en caso de ser presentado algún pariente o deudo del Encomendero, Felipe II ordenó que los Virreyes, Audiencias y Gobernadores, "para los Beneficios y Doctrinas de indios, no presenten sacerdotes deudos, ni parientes de los Encomenderos", pidiendo a los Prelados de las Indias que si se diese algún caso, no procedieran a la institución canónica en favor del dicho sacerdote ${ }^{47}$.

Cuando los Gobernadores se negaban a presentar a uno de los candidatos propuestos por el Prelado o el Superior religioso, o no presentaban a sacerdotes beneméritos, en este caso correspondía el derecho de presentación a la autoridad superior: Presidente de Audiencia o Virrey ${ }^{48}$.

Asimismo, si el Prelado proponía solamente un candidato, el Gobernador, Presidente de Audiencia o Virrey, según los casos, debían investigar si en realidad no hubo más opositores, y, constándoles de la verdad, debían presentar al que había sido propuesto; en caso contrario, debían exigir del Obispo que enviara la lista de candidatos ${ }^{49}$.

Ya advertíamos anteriormente que la diferencia entre la presentación hecha por el Rey para un beneficio, parroquia o doctrina, con la que hacía el Virrey, Presidente o Gobernador, consistía en que la primera daba derecho a poseer el beneficio a título perpetuo, mientras que la segunda, solamente "ad tempus", es decir, amovible "ad nutum" del Prelado y del Patrón ${ }^{50}$.

Tener al mismo tiempo dos beneficios estaba prohibido; por tanto, el que había sido presentado "para cualquier Prebenda, Dignidad, Canonjía, Beneficio u Oficio, antes de que se le haga colación y provisión, opte y renuncie el que antes tenía, y sirva el otro, o sirva el primero y renuncie el segundo, del cual solamente gazará sin llevar cosa alguna de la Prebenda o Beneficio que renunciare" 51 . Esta disposición del Patronato no hacía otra cosa sino ratificar lo legislado por el Tridentino, es decir: que a cada uno se le confiera sólo un beneficio ${ }^{52}$, ya que ninguno es há- 
bil para aceptar y retener, sea en título, sea en encomienda perpetua, dos beneficios incompatibles ${ }^{53}$.

Y por último, debemos añadir que la presentación del candidato debía hacerse al Ordinario de lugar, porque éste es el único llamado a juzgar de la idoneidad del presentado ${ }^{54}$ y a dar la institución canónica de los beneficios en la Diócesis 55 .

\section{Institución canónica}

Los Prelados de las Indias, antes de hacer la institución o provisión canónica en favor de algún sacerdote, debían cerciorarse de que hubiere sido presentado por el Rey o por el que en su nombre ejercía el derecho del Patronato. Por tanto, "ordenamos -decía el Rey como único Patrón de iglesias y beneficios etc., de todas las Indias y Tierra Firme del mar océano- que ningún Prelado, aunque tenga cierta relación e información de que Nos hemos presentado alguna persona a Dignidad, Canonjía, Ración o otro cualquier Beneficio, no le haga colación ni canónica institución, ni le mande dar posesión, sin que primero ante él sea presentada nuestra provisión original de presentación, ni los Virreyes, ni Audiencias lo hagan recibir en otra forma" 56 .

Pero, si no había ninguna duda del original en la presentación de cada uno de los respectivos candidatos, según las listas enviadas, entonces los Prelados, "sin dilación alguna, hagan a los presentados provisión y canónica institución, excepto teniendo alguna excepción legítima contra ellos y que se les pueda probar; y si no tuvieren excepción legítima, si les dilataren la institución o posesión, sean obligados a les pagar los frutos y rentas e intereses, que por la dilación se les recrecieren" 57 .

Siendo la provisión canónica "la colación de un oficio eclesiástico, hecha por la competente autoridad eclesiástica según las normas de los sagrados cánones" 58 , es lógico pensar que en la Diocesis de Quito dicha autoridad competente era el Obispo. Y para cortar ciertos abusos que se habían presentado, no solamente en esta Diócesis sino también en varias otras de la Provincia Eclesiástica de Lima, se dio un decreto conciliar en 
el año 1583, por el cual se mandaba que "ningún clérigo tome de aquí delante Doctrina o Parroquia de indios, ni la administre sin hacerle colación de ella su Obispo, so pena que si de otra manera la tomare, aunque sea Doctrina que no tenga cura propio, sea excomulgado; lo mismo se guarde por los religiosos" 59 .

Así como el Rey y sus subalternos (Virrey-Presidente-Gobernador) se manifestaban muy celosos en ejercitar el derecho de presentación, así también los Obispos reclamaban sus propios derechos respecto a la institución canónica de curas y doctrineros, sobre todo cuando aquellos, introduciéndose en el campo eclesiástico más allá de lo permitido por el Patronato, se atribuían facultades que eran única y exclusivamente del Prelado. Y, si no, ¿̨porqué el Ilmo. Señor Solís, conocedor de la situación de algunas Doctrinas y Parroquias de la Diócesis de Quito, insistía en la necesidad de la colación hecha por el Obispo para acceder a los beneficios? $^{60}$. Porque sencillamente, debido a la benevolencia del Presidente de la Real Audiencia y de los Gobernadores, algunos doctrineros se hallaban en beneficios sin tener colación, ni aprobación, ni consentimiento del Prelado diocesano, y por tanto en contra de lo dispuesto por el Tridentino, por las Reales Cédulas y particularmente por el tercer Concilio provincial limense ${ }^{61}$.

Para evitar ciertas arbitrariedades que se cometían en el ejercicio del derecho de presentación de uno de los candidatos propuestos por el Prelado, el Ilmo. Señor Peña algunas veces, acogiéndose a la Real Cédula de Felipe II, suscrita en el Escorial el 3 de noviembre de 1567, extendía nombramientos provisionales en favor de tal o cual sacerdote, y así evitaba presentar una nómina de candidatos. No nos parece oportuno y conveniente dar a conocer aquí los varios nombramientos hechos por el segundo Obispo de Quito; bástenos citar el concedido al presbítero Luis de la Peña para el pueblo de Ayabaca. Dice así:

"Nos, el Maestro Don Fray Pedro de la Peña, Obispo del Quito, del Consejo de Su Majestad, por cuanto el pueblo de Ayabaca, término de la ciudad de Paita, está vaco, nombramos a vos, el Rdo. Padre Luis de la Peña, buena lengua de los naturales, por cura y doctrinero de ella hasta que se provea 
conforme a la Cédula del Patronazgo Real de Su Majestad y daréis de ello luego aviso al Excelentísimo Señor Don Francisco de Toledo, Visorrey de estos Reinos, para que vos nombre como a persona suficiente conforme a la dicha Cédula y con su aprobación acudáis a nos para vos demos la canónica institución, supuesta su voluntad; y mandamos a todas e cualesquier personas de cualquier calidad, condición que sean, os tengan por tal cura del dicho pueblo, so pena de excomunión mayor hasta el tiempo dicho -el plazo era de dos años; durante este tiempo el interesado debía acudir al Patrón o Vicepatrón para que le hicieran la presentación oficial-. Y tenemos por bien -continúa este nombramiento- que vos, el dicho Luis de la Peña, gocéis del salario que los demás beneficiados del dicho pueblo han gozado, conforme a lo que su Excelencia tiene determinado y mandado. Fechado en Perucho, cerca de Quito, el 30 de abril 1580. Fr. P. Episcopus Quitensis'62.

Otro nombramiento provisional, semejante al anterior, fue extendido en favor del presbítero Juan Herrera Sarmiento para que se hiciera cargo del beneficio de la ciudad de Jaén. Como habían transcurrido ya los dos años de plazo, dicho presbítero acudió al Rey, por medio de una carta, expresándose en estos términos: "A Vuestra Alteza pide y suplica, sin embargo de haberse pasado el término de los dos años, lo haya por presentado y se le haga merced en mandar se le dé título de Vuestra Alteza del dicho beneficio, sin embargo de que por el dicho Obispo -refiriéndose al Ilmo. Señor Peña - lo hubiere presentado en otro y pide justicia y merced"63. Es de suponer que Felipe II, después de haber recibido los expedientes relacionados con el presbítero Juan de Herrera Sarmiento, habrá hecho su presentación ante el Obispo, quien concedería la provisión canónica definitiva, y así el beneficio de la ciudad de Jaén pasaría a ser atendido "in titulum" por el sacerdote que durante más de dos años lo sirvió provisionalmente.

No nos imaginemos que el Ilmo. Señor Peña, durante sus veinte años como Obispo de Quito y de un modo particular, a partir del año 1567 en que el Rey recabó para sí la presentación a todos los beneficios eclesiásticos, el dicho Prelado haya tratado de eludir las normas del Patronato Indiano; de ninguna manera. En principio las observaba, sobre todo 
Doctrinas y Parroquias del Obispado de Quito /93

cuando las presentaciones de los candidatos eran justas, razonables y beneficiosas para la Diócesis; pero cuando advertía favoritismos y abusos, entonces extendía nombramientos provisionales, de conformidad con las mismas normas dadas por el Rey.

Y ya que tratamos en este acápite de la provisión canónica propiamente dicha, no está por demás que demos a conocer siquiera una, cuyo expediente, al igual que los demás, es bastante extenso, pero no dejará de ser interesante, tanto por la forma como por el contenido.

He aquí el texto de la provisión canónica en favor del presbítero Antonio de Balbuena, quien seguramente fue presentado por el Rey para el beneficio de Gualea y sus anejos:

"Nos, el Maestro Don Fray Pedro de la Peña, por la misericordia divina e de la Santa Sede Apostólica Obispo desta ciudad y Obispado de Quito e del Consejo de Su Majestad, acatando la habilidad, ciencia e suficiencia de vos, el Reverendo Bachiller Antonio de Balbuena de Paz, e confiando de vos que con toda diligencia e cuidado entenderéis en lo que por nos os fuere encomendado y mandado, por la presente, en cuanto nuestra voluntad fuere, os proveemos, nombramos e señalamos por nuestro cura y vicario de la dicha Doctrina y pueblos de Gualea, Alluto e Cuchillata e Vinagre, según que los tenia en Doctrina el Padre Manuel Díaz, para que enseñéis a los naturales de los dichos pueblos la doctrina cristiana y las cosas de nuestra santa fe católica, e como tal cura administréis los santos sacramentos e divinos oficios e oir de confesión a cualesquier personas que en los dichos pueblos e Doctrina residieren, españoles y naturales, y les absolver e absolváis de cualesquier pecados criminales e delitos en que hubieren incurrido e que hubiere cometido, de que la absolución pertenezca a nos, que para ello vos damos poder e cometemos nuestras veces e voces, e como tal Vicario conozcáis de todos los pleitos e causas civiles e criminales que se ofrecieren y los determinar, excepto en los casos de herejía o especie della y matrimonio cuanto a la separación, que en los dichos casos haréis las informaciones, y presos los culpados nos remitiréis las dichas causas para que nos las determinemos y proveamos lo que sea justicia, y en los demás casos pronunciaréis vuestras sentencias, las cuales llevaréis a debida ejecución, si de vos no fuere apelado. E si de vos se apelare, otorgaréis las apelaciones para ante nos en los casos que de derecho 
94 / Augusto E. Albuja

hubiere lugar apelación. $Y$ os encargamos y mandamos que con toda diligencia e cuidado entendáis en la conversión de los dichos naturales y no azotéis ni trasquiléis ninguno dellos, si no fuere procediendo jurídicamente, y entre los dichos naturales procederéis sumaria e brevemente, por evitar las costas. E mandamos a todas e cualesquier personas, de cualquier calidad e condición que sean, que por tal nuestro cura y vicario vos hayan e tengane usen con vos los dichos oficios e vos guarden todas las honras que por razón dellos debéis haber. E por la ocupación e trabajo que en lo susodicho habéis de tener, para ayuda a vuestra sustentación y del gasto de vino y cera que habéis de tener, mandamos que hayáis, llevéis y vos sea dado y pagado trescientos cincuenta pesos de la moneda que los dichos naturales pagan sus tributos a sus Encomenderos, los cuales cobraréis de los Encomenderos de los dichos indios o de los caciques o principales en cada un año, e cobrando de los dichos caciques y principales sus Encomenderos, los tomen y reciban en cuenta de sus tributos, lo cual cumplan so pena de ejecución-excomunión- mayor e de doscientos pesos de oro para la fábrica desta santa Iglesia y nuestra cámara. Dada en Quito, a veinte e ocho dias del mes de septiembre de mil e quinientos y sesenta y ocho años. Y por cuanto os habéis de partir e os partís hoy dicho día para la dicha Doctrina, mandamos que, desde hoy día de la fecha, gocéis del dicho salario de la dicha doctrina. Fecho ut supra. Por mandato de su Señoría Reverendísima, f) Jácome Freile, Notario Apostólico. f). Fr. P. Episcopus Quitensis"64.

De las varias provisiones canónicas que hemos podido encontrar en el Archivo General de Indias de Sevilla, al realizar nuestro trabajo de investigación, debemos decir que, en casi todas, se hacía hincapié en los siguientes puntos:

a) Que el beneficiado sea muy diligente en el cumplimiento de sus obligaciones para descargo de la conciencia del Obispo y del Rey.

b) Que se ponga especial cuidado en la enseñanza de la doctrina cristiana a los feligreses, especialmente a los indios.

c) Que se le conceden amplias facultades para ejercer el ministerio parroquial; y, en tratándose de vicarios o arciprestes, dichas facultades eran aun más amplias, pues podían conocer pleitos civiles y criminales, incluso podían dictar sentencia, excepto en casos de 
Doctrinas y Parroquias del Obispado de Quito /95

herejía y de separación matrimonial, que estaban reservados al Obispo.

d) Que por todos los medios se procure el buen trato de los indios y que no se les infiera castigos sino por causas graves y esto por medio del brazo secular.

e) Que el beneficiado es digno de respeto de parte de todos los feligreses.

f) Que el salario lo debían pagar los Encomenderos y para esto se señalaba la cantidad que dicho beneficiado debería percibir anualmente por sus servicios.

g) Y por último, en algunas provisiones se amenazaba al beneficiado con la pena de excomunión mayor latae sententiae, en caso de abandonar el beneficio antes de rendir cuentas al Prelado o a su delegado. Asimismo, esta pena se impondría a aquellos que impidieren el libre ejercicio del ministerio parroquial ${ }^{65}$.

\section{Toma de posesión}

La provisión canónica consiste substancialmente en la colación o institución del título concedido por el Prelado en favor de algún sacerdote para determinado beneficio eclesiástico. La toma de posesión o institución corporal, ya que es una parte integral de la provisión y está reservada al Ordinario del lugar, el cual puede delegar para eso a otro eclesiásti$\mathrm{co}^{66}$, sin embargo, existiendo una causa justa, puede ser dispensada y en este último caso tal dispensa equivale a la misma toma de posesión ${ }^{67}$.

La toma de posesión se requería solamente para aquellos beneficios que se concedía en propiedad. Por tanto, para las Doctrinas de indios, al menos hasta el año 1609, no era necesaria sino cuando la presentación había sido hecha por el Rey, lo cual sucedía rara vez. En cambio, para las Parroquias la toma de posesión era necesaria, mas no imprescindible; pues muchas veces, de una manera tácita, se concedía la dispensa. Así tenemos, por ejemplo, en la institución canónica del presbítero Antonio de Balbuena como beneficiado de Gualea y sus anejos, expedida en Quito el 28 de 
septiembre de 1568, el Ilmo. Señor Peña decía: "mandamos que, desde hoy día de la fecha, gocéis del dicho salario"68. Con estas palabras, el Prelado dispensaba al presbítero Antonio de Balbuena de la toma de posesión, ya que para gozar de los derechos anejos al beneficio, así espirituales como temporales, el beneficiado debía antes tomar posesión legítima del beneficio $^{69}$.

Así pues, en las Doctrinas conferidas en título y en las Parroquias de la Diócesis de Quito, varias veces no se puso en práctica la toma de posesión, ya que las distancias que separaban a unas de otras y la dificultad de caminos impedían al Obispo enviar al menos un delegado para que hiciera la institución corporal del beneficiado. Lo que interesaba en ese entonces era que, cuanto antes, parroquias y doctrinas estuviesen atendidas. Sin embargo, en aquellos lugares donde el Obispo podía disponer de algún eclesiástico, se hacía la toma de posesión; así sucedió respecto al presbítero Juan de Herrera Sarmiento en el beneficio de la ciudad de Jaén.

Muy pocos han sido los documentos que hemos podido encontrar con relación a este punto de la toma de posesión de los beneficios en la Diócesis de Quito, pero al menos tenemos la satisfacción de poder citar uno, que lo consideramos de gran interés, y se refiere al presbítero Herrera Sarmiento:

"En la ciudad de Jaén, provincias de Chiquimayo de los Reinos, provincia del Perú, a postrero día del mes de julio de mil e quinientos e setenta y cuatro años, estando en la santa Iglesia desta ciudad, por presencia de mí, Juan Pizarro, notario eclesiástico, e de los testigos de yuso escritos, el Muy Reverendo Padre Juan de Herrera Sarmiento, clérigo presbitero, dijo que por cuanto su Señoría Reverendisima del Señor Obispo del Quito -Ilmo.Peñapor Cédula de Su Majestad se le ha proveido por beneficiado desta santa Iglesia, como consta por la provisión de esta otra parte contenida -se refiere a la provisión canónica hecha por dicho Prelado- que usando de ella tomaba y tomó posesión del dicho beneficio desta santa Iglesia. Y en señal de posesión, se paseó por ella y cerró las puertas de la Iglesia y las abrió; y en el coro de la Iglesia, se sentó en él y abrió y cerró un libro de canto. Y pidió a mí, el dicho notario, de cómo tomaba la dicha posesión quieta y pacificamente, sin contradicción de persona alguna. Eyo, el dicho notario, de su pe- 
dimiento doy fe que el dicho Juan de Herrera Sarmiento tomó la dicha posesión, según dicho es que es fecho en el dicho día, mes e año dicho; siendo testigos a la verdad e que se hallaron presentes: el Muy Magnifico Señor Fray Juan Palomino, Visitador deste Obispado, y Alonso García y Hernando Pablos e otras personas vecinos y estantes en esta dicha ciudad; por ende, en testimonio de verdad hice aqui éste, mi signo, que es a tal. f) Juan Pizarro, Notario" 70 .

Al principio de este documento se lee "Derechos: 3 pesos 4 tomines"; esto no significa que haya habido simonía al hacer la institución corporal del presbítero Herrera Sarmiento en el beneficio de la ciudad de Jaén, sino que se los debió cobrar por concepto de gastos de expedientes, ya que el Tridentino ordenaba que tal ceremonia debía hacerse de modo gratuito $^{71}$. 
98 / Augusto E. Albuja

\section{NOTAS:}

1 LEVILLIER, Organización, I, Prólogo, p.LXVI; AGI, Quito, leg.80.

2 Recopilación, lib.I, tit.6, ley 24.

3 AGI, Indiferente General, leg.427, lib.30, f.335v-336.

4 AGI, Indiferente General, leg.427, lib.30, f.188.

5 Recopilación, lib.I, tit.6, leyes 26-27.

6 LEVILLIER, Organización, I, Prólogo, p.LXVI.

7 Segundo Sínodo de Quito, cap. 3, (AGI, Quito, leg.76).

8 Segundo Sínodo de Quito, cap. 3 (AGI, Quito, leg.76); GONZÁLEZ SUÁREZ, Historia, III, 331-332).

9 VARGAS UGARTE, Historia, II, 52.

10 Primer Concilio Limense, Parte Segunda, Constit.33

11 Primer Sínodo.de Quito, Parte Cuarta, Introducción (AGI, Patronato, leg.189 Ro. 40).

12 Primer Sínodo de Quito, Parte Cuarta, C.7 (AGI, Patronato, leg.189 Ro.40)

13 Segundo Concilio Limense, Parte Segunda, Const.3.

14 Segundo Sínodo de Quito, cap.9, (AGI, Quito, leg.77)

15 AGI, Indiferente General., leg. 427, lib.30, f.316-318. La fundación de las universidades de Lima y de México se debió al Emperador Don Carlos y a la Reina de Bohemia, Gobernadora en Valladolid, mediante su Real Cédula del 21 de septiembre de 1551, (Recopilación, lib.I, tit.22,ley l).

16 Recopilación, lib.I, tit.22, ley 46.

17 GARCÉS G.Jorge A, Colección de Cédulas Reales, 352.

18 Apéndice \# 35.

19 Segundo Sínodo de Quito, cap.87 (AGI, Quito, leg.76).

20 AGI, Quito, leg.76.

21 C.I.C..17,c.459; C.I.C. с 524.

22 Segundo Concilio limense, Parte Segunda, Constit.l: “... dioecesani ergo sibi ipsis et commisso gregi attendant, neque indignos praeficiant, neque incapaces admittant, denique neminem ecclesiis proeponant, nisi quem prius diligenter examinatum, cognoverint intelligere quomodo sacramenta administanda sunt, eorumque virtutem et efficaciam".

23 Segundo Concilio limense, Parte Primera, Const.77.

24 Concilio Trid., Sess. XXIII, c. 15.

25 Tercer Concilio Limense Acc. 2o, cap. 14.

26 Apéndice \# 14

27 Conc. Trid., Sess. XXIV, cap. 18 de reform. 


\section{Doctrinas y Parroquias del Obispado de Quito /99}

28 AGI, Lima, leg, 300.

29 Tercer Concilio limense, Acc. 4o, cap.17.

30 Segundo Sínodo de Quito, Cap. 6, (AGI, Quito, leg.76)

31 Conc.Trid., Sess. XXIV, Cap.18 de reform.

32 C.I.C. 17, c.385,2.

33 Segundo Sínodo de Quito, Cap.lll, (AGI., Quito, leg.76)

34 Recopilación, lib.I, tit.6, ley 29. La Real Cédula del 17 de noviembre de 1593, dirigida a la Audiencia de Quito y que trata de esta preferencia en la provisión de beneficios, viene en la obra de Jorge Garcés, Colección de Cédulas Reales, 504505.

35 AGI, Indiferente General, leg. 427, lib.30, f.188.

36 Relación Geográfica de Indias, III, 37.

37 Apéndice \# 42

38 AGI, Quito, leg. 1.

39 AGI, Quito, leg. 1.

40 AGI, Quito, leg. 83; cf. tb. Apéndice\# 28.

41 Recopilación, lib. I, tit.6, ley 19.

42 AGI, Quito, leg. 83.

43 Segundo Sínodo de Quito, Cap.73, (AGI, Quito, leg. 77).

44 Recopilación, lib.I, tit.6, ley 10.

45 Ibidem, ley 35.

46 Ibidem, ley 36.

47 Ibidem, ley 38.

48 Ibidem, ley 27.

49 Ibidem, ley 25.

50 Ibidem, ley 23.

51 Ibidem, ley 20.

52 Conc. Trid., Sess. XXIV, Cap.17 de reform.: “... unum tantum beneficium singulis conferatur".

53 C.I.C. 17, c.156; C.I.C. c.152.

54 Recopilación, lib.I, tit.6, ley 11; C.I.C. 17,c.1464; C.I.C.c 152.

55 C.I.C. 17 , c. 147,1; C.I.C. c. 146.

56 Recopilación, lib.I, tit.6, ley 12.

57 Recopilación, lib.I, tit.6, ley 11.

58 C.I.C. 17, c. 147,2; C.I.C. c. 148.

59 Tercer Concilio Limense. Acc. 4o, Cap. 16.

60 Segundo Sínodo de Quito, cap.97 (AGI, Quito, leg.76). 


\section{0 / Augusto E. Albuja}

61 Conc.Trid.Sess. XXIII, de sacr.Ord.,7: "Si quis dixerit... eos qui nec ad ecclesiastica potestate rite ordinati, nec missi sunt, sed aliunde veniunt, legitimos sesse verbi et sacramentorum ministros, anathema sit”. C.I.C. c 157; el c.152 del C.I.C. 17: "Loci Ordinarius ius habet providendi officiis eclesiasticis in proprio territorio, nisi aliud probetur" Este mismo derecho del Ordinario de lugar se debía poner en práctica, según las normas del Patronato (Recopilación, lib.I,tit.6, leyes 10-11). El tercer Concilio Limense, en la Acc. 4o, Cap. 16 amenazaba incluso con la excomunión a aquel que se atreviera a tomar a su cargo un beneficio, "aunque sea Doctrina que no tenga cura propio", sin preceder la colación y canónica institución hecha por el respectivo Obispo.

62 AGI, Quito, leg.83.

63 Apéndice \# 20.

64 AGI, Quito, leg.81; cf.tb. Apéndices \# 1,3,4,6 y 7.

65 Apéndices \# 7,13,15 y 29.

66 C.I.C. 17 , c. 1443,2 ; C.I.C. c. 157.

67 C.I.C. 17 , c. 1444,1 ; C.I.C. c. $527,2$.

68 AGI, Quito. leg. 81.

69 C.I.C. 17 , c. 1472 ; C.I.C. c. $527,1$.

70 AGI, Quito. leg. 46.

71 Conc. Trid. Sess. XXIV, Cap. 14 de Reform. 


\section{CAPÍTULO $V$ \\ NÚMERO DE INDIOS POR DOCTRINA}

A mediados del siglo XVI la mayor parte de los indios vivía formando apenas pequeños caseríos; de ahí que la labor del sacerdote se hacía difícil y hasta imposible, en cuanto a la enseñanza de la doctrina cristiana. Bien es verdad que sí existían algunos pueblos ya formados y "ciudades" en marcha; pero, la mayor parte de las Doctrinas y Parroquias rurales abarcaban varios caseríos, aldeas, recintos o anejos, muy distantes unos de otros, y que debía atenderlos el párroco o cura doctrinero para cumplir con su misión evangelizadora y su ministerio pastoral.

A pesar de que muchas veces el sacerdote hacía todo lo que podía, el fruto espiritual alcanzado era exiguo, y hasta desconsolador.

Felizmente surgió la idea de agrupar las familias de los indios en pueblos. Felipe II había ordenado que se llevasen a efecto las tales reducciones, obra que al principio no debió ser nada fácil; razón por la cual, el primer Arzobispo de Lima, en carta dirigida al Rey el 2 de agosto de 1564, le exponía las enormes ventajas que se seguirían si los indios estuviesen agrupados formando pueblos. "Vuestra Alteza -escribía el Arzobispo Loaisa- tiene proveído que se tase lo que los indios han de dar a sus caciques y servicio que les han de hacer, y que los indios, que están derramados en poblezuelos, se reduzcan a uno, que ambas son cosas muy importantes, y no se ha hecho. Entre otros provechos que se seguirán, de reducir los indios a menos pueblos, donde cómodamente se pudiese hacer, sería que, donde agora no bastan dos o tres sacerdotes para visitarlos y doctrinarlos, bastaría uno y podríanse poner Alcaldes y Regidores de los mismos y darles orden de vivir en comunidad y policía como Vuestra Alteza también lo tiene mandado, y podríanse excusar los Corregidores españoles, que les son muy perjudiciales y costosos"1. 


\section{2 / Augusto E. Albuja}

Tres años más tarde, el Ilmo. Señor Peña se hallaba en la ciudad de Lima con ocasión del segundo Concilio provincial. En el informe presentado al Presidente Castro, insistiendo en las ventajas de las tales reducciones, el Obispo de Quito suplicaba que "se dé orden para que los indios con mejor voluntad se junten, que es el principio de todo su bien espiritual y temporal"2.

Precisamente para conseguir el bienestar espiritual y temporal de los indios y facilitar la labor pastoral y el ministerio parroquial en la Diócesis, el Ilmo. Señor Peña, en el primer Sínodo de Quito, considerando que "los indios naturales de este nuestro Obispado no están poblados los más de ellos en pueblos formados, sino en caseríos, son tan apartados unos de otros, por lo cual los sacerdotes no pueden estar en todos lugares y los indios juntarse donde está el sacerdote", a fin de poner remedio, ordenaba y mandaba "que los curas de indios, cada uno con su doctrina, con consejo e parecer de sus feligreses, elijan un lugar en la principal comarca de su población, donde sea temple e comodado, para que, cuando Su Majestad mandare poblar los indios, tengan las partes que para pueblos se requieren; y en estos lugares haga nuestro cura una iglesia bien fundada, donde se junten a misa los domingos e fiestas a la doctrina, los naturales que estuviesen poblados en legua y media en la redonda e no más. Esta dicha iglesia haga Parroquia de aquella Doctrina y en los demás pueblos de visita el dicho nuestro cura haga sus iglesias y doctrinas de esta visita, como por nos se lo mandare y por las constituciones, y en todas ponga mayordomos que guarden las iglesias y sus bienes y tenga en ellas imágenes, pilas, puertas, cerraduras y toda buena custodia y limpieza"3.

Asimismo, terminado el Sínodo, el Ilmo. Señor Peña juzgó muy

conveniente exponer ante el Rey los problemas de la Diócesis, ya que "los caseríos y poblados de estos naturales -decía el Prelado refiriéndose a sus queridos indios- están muy apartados y en tierras muy ásperas, montuosas y escondidas, porque cuando en su antigüedad se poblaron, fue a fin de defenderse y esconderse de sus enemigos, lo cual agora es inconveniente, porque conviene que estén poblados en partes donde la justicia los vea e los sacerdotes que los doctrinan, los tengan cerca de sí para que estén 


\section{Doctrinas y Parroquias del Obispado de Quito /103}

aparejados para oír la doctrina cristiana. Vuestra Alteza -continúa la carta del Obispo Peña- sea servido mandar que estos indios se pueblen en lugares cómodos, junto a la iglesia parroquial, y los pueblos se hagan de gente e vecinos, conforme a la disposición de la tierra para la dicha población”. Y para que los indios no tuvieran dificultades, a causa del tributo que debían pagar, el prudente Obispo de Quito pedía al Rey que suspendiese por un año el cobro del dicho tributo; y la causa que presentaba era que "estos indios son pobres, no tienen otra renta sino su trabajo, e del se han de vestir y sustentar sus personas, mujeres y hijos; e habiendo en la población de hacer nuevas casas e iglesia e chácaras, no pueden acudir a la servidumbre de las ciudades y tributos e a la forzosa de su sustentamiento. Vuestra Alteza provea que el año que se poblaren los indios no tributen, sino que se ocupen en hacer la iglesia, casas, chácaras del nuevo pueblo para que con amor y suavidad se ajunten y pueblen con más facilidad" 4 .

Y por último, el Ilmo. Señor Peña no se veía contento con haber legislado en el Sínodo y haber enviado un informe al Rey, sino que él, en persona, "recorrió por dos veces el territorio -de su Diócesis- reduciendo a los indios a poblados, señalándoles propiedades individuales y comunales y fijando la zona que no debían atravesar los elementos españoles.jOjalá se hubiesen cumplido sus sabias providencias!"5.

El fruto que se puede conseguir mediante el ministerio parroquial está en relación directa con el celo desplegado por cada cura y con el número de sus feligreses. Hasta la celebración del segundo Concilio provincial de Lima, no se había legislado nada sobre este punto tan importante del número de feligreses en cada Parroquia o Doctrina. Los Padres conciliares determinaron "que a cada Parroquia no se le den ni señalen más de cuatrocientos indios casados, con los cuales entran los demás que les pertenecen como muchachos, viejos, huérfanos, forasteros"' 6 . Esta resolución tenía una doble finalidad: en primer lugar, combatir la avaricia de algunos Encomenderos, para quienes la instrucción religiosa de los indios encomendados era una cosa secundaria y hasta sin importancia, y por eso no tenían escrúpulo alguno de confiar a un solo sacerdote doctrinero dos y tres Repartimientos de indios con sus respectivos caseríos, llegando a ve- 


\section{4 / Augusto E. Albuja}

ces a prescindir del doctrinero para incrementar sus rentas con el ahorro de los trescientos pesos anuales de salario que hubieran debido pagarle; $y$, en segundo lugar, se deseaba facilitar al cura doctrinero el cumplimiento de su misión y evitar que se dejara llevar de la desidia y del pesimismo frente al mucho trabajo que se presentaba para su apostolado.

Como el Ilmo. Señor Peña había estado presente en el Concilio provincial de 1567, a su regreso a Quito lo primero que hizo fue convocar a una Junta a las principales autoridades eclesiásticas y civiles para darles a conocer lo decretado en Lima, respecto al número de indios jefes de familia que debía tener cada Parroquia o Doctrina. Tres años antes, el Rey Felipe II, en su Real Cédula del 3 de septiembre de 1565, firmada en Segovia, había pedido que se pusieran de acuerdo las dos autoridades, eclesiástica y civil, ya que éstas conocían mejor las circunstancias por las que atravesaba la Diócesis de Quito.

Dicha Junta se reunió en la sala de la Audiencia y Cancillería Real de la ciudad de Quito el 12 de octubre de 1568 y estuvo presidida por el Obispo Pedro de la Peña. Además del Presidente y Oidores de la Real Audiencia, asistieron las siguientes personalidades eclesiásticas: Pedro Rodríguez de Aguayo, Arcediano de la Catedral; Diego de Salas, Chantre y Provisor del Obispado; Fr. Domingo Valdez, Prior del Convento de los dominicos; Fr. Juan Cabezas de los Reyes, Guardián del Convento de San Francisco; Fr. Pedro Martínez, Comendador del Monasterio de la Merced; Fr. Rafael de Segura y Fr. Domingo de Ugalde, dominicos; Fr. Jodoco Rique, franciscano, y Fr. Andrés Gómez, mercedario.

Después de haber examinado las opiniones, en pro y en contra, se llegó a un acuerdo, a saber: que en la Diócesis de Quito, “donde lo tuvieren los naturales tan apartados que no se puedan buenamente juntar, tenga a cargo un sacerdote, clérigo o religioso, hasta número de ochocientos indios tributarios y no más; y donde la tasa no fuere tan gruesa y donde no hubiese el inconveniente de estar apartados, tenga a cargo hasta nuevecientos indios tributarios el tal sacerdote, y a lo más largo hasta mil indios y no más; y deste número no se exceda. E todos los dichos Señores Presidente y Oidores, Obispo, Prelados, Dignidades y Sacerdotes que es- 


\section{Doctrinas y Parroquias del Obispado de Quito /105}

taban presentes dijeron que lo susodicho les parece cosa tan conviniente por el presente y que así se debe cumplir hasta que otra cosa parezca que conviene hacerse; y que, conforme a este número de indios, se guarde, cumpla y ejecute lo contenido con la Cédula de Su Majestad"7.

El celoso Obispo de Quito no quedó muy conforme con lo acordado por la Junta. Para salvar su responsabilidad pastoral y, además, para poner en conocimiento del Rey y acatar la resolución que diere, le decía en una carta: "Item, que Vuestra Alteza sea servido de mandar declarar el número de indios tributarios suficiente para que un ministro pueda doctrinar, porque en el Sínodo que se tuvo en la ciudad de los Reyes el año pasado de sesenta y ocho -aquí se hace referencia al segundo Concilio limense, iniciado el 2 de marzo de 1567 y que fue clausurado el 21 de enero de 1568- pareció a los Prelados que allí se juntaron, que cuatrocientos indios tributarios era número suficiente y aún demasiado, porque en cuatrocientos tributarios por lo menos hay mil doscientas ánimas y tienen más que hacer con ellos los ministros que no los de España. Venido aquí, a este mi Obispado de Quito, se escandalizaron tanto los vecinos que fue necesario que nos juntásemos con esta Real Audiencia y Clerecía y Prelados de las Ordenes, a todos los cuales les pareció por agora, por la dureza de los Encomenderos, que se señalasen para cada sacerdote de ochocientos hasta mil tributarios, y de los tributos que estos tales dan a sus Encomenderos se saque el salario del sacerdote, porque en este número de mil indios tributarios hay más de tres mil ánimas por lo menos. Vea Vuestra Alteza cómo puede bastar el sacerdote para tanto número de gente, y en Dios y en mi conciencia digo, y con ello descargo, que ningún sacerdote, aunque se deshaga, para hacerlo razonablemente, pueda cumplir con seiscientos tributarios o no dende arriba, y menos en la sierra que en los llanos, por estar los indios más derramados y más incultos. Vuestra Alteza mande lo que más convenga a su real servicio y sea con provisión real, porque yo con ello descargo mi conciencia"8.

Probablemente Felipe II ratificó la resolución tomada por la Junta de Quito en 1568, ya que dos años más tarde, el 7 de agosto de 1570, por no haberse puesto en práctica en algunas Doctrinas, o por un mal 


\section{6 / Augusto E. Albuja}

comprendido, el Ilmo. Peña volvía a escribir al Rey: "Item, las Doctrinas que hasta agora habemos encargado a nuestros curas de los indios, ansí por no haberse bien entendido el número de los naturales y también porque los caciques hasta agora con temor del acrecentamiento de los tributos ha crescendido mucha gente y se halla mucha más de la que se pensó en principios. Porque los sacerdotes no pueden cumplir con la administración de los santos sacramentos, Vuestra Alteza sea servido de mandar se visiten las Doctrinas, e por agora sea suficiente número para un curazgo e Doctrina de ochocientos a mil vecinos; y deste número no exceda, porque un sacerdote no puede cumplir con más parroquianos, ni aún con éstos; pero, por agora, le permitimos hasta que haya más ministros"9.

Años más tarde, en el tercer Concilio limense, el primero de los celebrados en la época del Arzobispo Santo Toribio de Mogrovejo, se redujo aún más el número de indios que había señalado el Concilio anterior para cada Parroquia o Doctrina, pues "somos de parecer y acuerdo decían los Padres Conciliares- que en cualquier pueblo de indios que tengan trescientos indios de tasa o doscientos, se debe poner propio cura, y cuando fueren menos que doscientos procure el Prelado con afecto que estén reducidos, de suerte que puedan cómodamente ser doctrinados y regidos" 10 ; y en aquellos pueblos mayores "si pasaran de cuatrocientos indios de tributo, se ponga más de un cura, conforme al número que hubiere"11.

Como no dependía únicamente de los Prelados el determinar el número de indios que debía tener cada Doctrina, pues había necesidad de contar con la voluntad del Rey, se acudió a Felipe II, quien no señaló un número determinado para todas las Diócesis, sino que dejaba al criterio de cada Obispo, ya que dependía también del número de sacerdotes que hubiese en cada una de ellas. Sin embargo, en su Real Cédula, suscrita en San Lorenzo de El Escorial el 25 de julio de 1593, decía: “... por conveniencias particulares de los curas y doctrineros, se quieren encargar y encargan de más indios de los que pueden enseñar, doctrinar y administrar los santos sacramentos: Rogamos y encargamos a los Arzobispos y Obispos que, con especial cuidado, hagan reconocer el número de indios que 
cómodamente pueden ser enseñados y doctrinados por cada doctrinero y cura, atenta la disposición de la tierra y la distancia de unas poblaciones a otras, y en esta conformidad señalen el distrito de cada Doctrina y el número que pareciere conveniente, que nunca ha de exceder de cuatrocientos indios, sino es que la tierra y disposición de los pueblos obligue a aumentar o minorar el número; y sobre esto les encargamos las conciencias"12.

Como, en cierta manera, el Rey dejaba al arbitrio de cada Obispo y, además, parece natural y lógico prestar obediencia a una orden dada por el Soberano, el Ilmo. Señor Solís pensaba reducir a doscientos el número de indios en cada Doctrina, en primer lugar porque disponía en ese tiempo del número suficiente de sacerdotes, y en segundo lugar porque así los indios estarían mejor atendidos por sus doctrineros, sobre todo en aquellas regiones de la Diócesis carentes de medios de comunicación por ser el terreno muy accidentado. Cuando se dio a conocer el deseo del Prelado, fue rechazado de plano por el Presidente y Oidores de la Real Audiencia, porque les parecía que resultaría muy oneroso para los Encomenderos pagar el salario al doctrinero por cada doscientos indios tributarios. A pesar de esta negativa, el Ilmo. Señor Solís confió a algunos sacerdotes Doctrinas con menos de cuatrocientos indios, porque deseaba el bien espiritual de los naturales antes que el bienestar temporal de sus Encomenderos. Pero casi en seguida surgieron las dificultades, porque los Encomenderos se negaron a pagar el salario a estos doctrineros, so pretexto de que no atendían al número de indios que había sido señalado por el Rey el 25 de julio de 1593.13. Seguramente con el transcurso del tiempo, los Encomenderos tuvieron que ceder sus intereses personalistas en bien de la Iglesia y de los pobres indios, pues, hacia el año 1598, existían Doctrinas en la Diócesis de Quito con ciento sesenta, doscientos, trescientos, ochocientos indios; unas pocas, con mil doscientos y hasta mil cuatrocientos indios tributarios. En general, las Doctrinas debían tener cuatrocientos indios, en teoría; pero, en la práctica, como podremos darnos cuenta en la estadística que presentamos, variaba mucho el número de indios de unas Doctrinas a otras. 
Cuando la Diócesis de Quito tenía apenas cincuenta y dos años de vida disponía de un número suficiente de sacerdotes, a tal punto que la Doctrina de Cotocollao era la que más feligreses tenía, pues contaba con ochocientos indios tributarios, es decir, unos tres mil doscientos feligreses para un solo sacerdote. La Parroquia de Otavalo con mil doscientos indios tributarios (alrededor de cuatro mil ochocientos feligreses) estaba atendida por tres doctrineros. Y pensar que habían Parroquias con 200 indios tributarios (unas ochocientas personas) es muy consolador y un motivo más para que España se vanagloríe de haber transformado, en el corto espacio de medio siglo, esta región de las Indias en una Diócesis ya constituida.

Para comprender el siguiente cuadro sobre el número de indios en algunas Doctrinas de la Diócesis de Quito en el año 159814, conviene advertir que no se trata del número total de feligreses, sino de tributarios, es decir, indios comprendidos entre los 18 y los 50 años; y como casi todos ellos eran jefes de familia, habría que multiplicar por cuatro, así tendríamos el número aproximado en cada una de las Doctrinas, respecto a sus feligreses ${ }^{15}$.

La estadística no es completa; apenas constan 46 Doctrinas. Somos los primeros en lamentar no poder presentar, por falta de datos, el número de indios tributarios de todos los beneficios curados de la Diócesis, pues en el año 1597 ascendían a 199 y en 1600 dichos beneficios llegaban a 208 . 
Doctrinas y Parroquias del Obispado de Quito /109

\section{Indios tributarios en algunas doctrinas}

160

$\overline{\text { Aloag- }}$

Cansacoto

200

Pomasqui

(S.Antonio)

Calacalí

Alangasí

Caranqui

(S.Antonio)

Pungalá

S.Miguel
330

Cotacachi

300

Perucho

Urcuquí

Caranqui

Penipe

Paute

Gualaseo

Quimna

Tangua
500

$\overline{\text { Aloasí }}$

Atuntaqui

Ambato

400

Pomasqui

Pintag

Amaguaña

Uyumbicho

Pansaleo

Cibundoy

Lito

Punín

Los Alaquez

Pujilí
700

600

Chambo

700

Ilapo

La Laguna

Mulaló

Tomavela
800

Latacunga 2 doctrineros

Cotocollao

Saquisilí

Ipiales

Pupiales

Yles

San Andrés 2 doctrineros

Guano
1.200

1.400

Otavalo

(3 doctrineros) Hatunquijo

Cosanga

(Estos tres pueblos tenían juntos los 1.400 indios tributarios y estaban atendidos por 3 doctrineros.) 


\section{0 / Augusto E. Albuja}

\section{NOTAS:}

1 AGI, Lima, leg.300.

2 Apéndice \# 5.

3 Primer Sínodo de Quito, Parte Cuarta, c.2, (AGI, Patronato, leg. 189, Ro. 40).

4 Apéndice \# 10.

5 PATTEE, Richard, El Catolicismo contemporáneo en Hispanoamérica, Buenos Aires 1823, 203.

6 Segundo Concilio Limense, Parte Segunda, Const.77.

7 Apéndice \# 8.

8 AGI, Quito, leg. 76.

9 Apéndice \# 10.

10 Tercer Concilio limense, Acc.3a. Cap.11.

11 LEVILLIER, Organización, I, 273. Se trata de una carta colectiva del Arzobispo de Lima y demás Prelados de la Provincia Eclesiástica, dirigida al Rey Felipe II. Está fechada en la ciudad de los Reyes el 30 de septiembre de 1583.

12 Recopilación, lib.I, tit.6, ley 46.

13 Apéndice \# 43.

14 Apéndice \# 48.

15 Decimos que el número de indios tributarios habría que multiplicar por cuatro para saber con cuántos feligreses aproximadamente contaba cada Parroquia o Doctrina, basándonos en las mismas palabras del Ilmo. Señor Peña, quien decía: "porque en cuatrocientos indios tributarios por lo menos hay mil doscientas ánimas"... "porque en este número de mil indios tributarios hay más de tres mil ánimas por lo menos”. Así pues, según las apreciaciones del Obispo de Quito, la relación entre los indios tributarios y el número de feligreses en una Doctrina era como de 3 a 1. Para obtener datos más exactos, hemos pensado en la relación de 4 a l; de donde, la multiplicación por 4 que hemos indicado, no estará exagerada. 


\section{CAPÍTULO VI \\ RESIDENCIA DE LOS PÁRROCOS}

Una de las principales obligaciones de quienes tienen a su cargo un beneficio curado es, sin duda, ésta de la residencia.

La residencia que se exige a los párrocos es de suyo grave, a tal punto que "aún para el tiempo de ausencias más breves -inferior a una semana- debe el párroco proveer a las necesidades de los fieles, sobre todo cuando circunstancias especiales lo exigen"1.

Hasta la celebración del primer Concilio provincial limense, la residencia de los doctrineros dependía principalmente del contrato realizado con los Encomenderos, quienes "tenían tanta mano que, en no satisfaciendo el sacerdote a sus intereses, no paraban hasta quitarle; $y$, lo que peor es, que animaban a los indios tenerles poca obediencia, a lo cual la justicia ponía poco remedio"2.

En general, podemos advertir que para las Doctrinas de indios, según el Concilio de 1551, la residencia obligatoria de los párrocos doctrineros se había fijado en cuatro años; y más tarde, en seis años como mínimum, según el Concilio celebrado en Lima en 1567, "salvo si el Obispo otra cosa mandase" 3 .

"Que el que se encarga de alguna Doctrina de indios -decía una constitución conciliar del año 1567- esté en ella seis años enteros; antes de cumplirse el cual tiempo no sea mudado a otra parte por el Obispo, si no hubiere gran causa para ello o fuere menester remediar algún grave escándalo; acabado el tiempo de seis años, al que quisiere dejar la Doctrina se le dé licencia sin dificultad y hágase la honra que sea razón; mas, si antes del dicho tiempo, quisiere irse, de ninguna manera se le dé licencia, sin que primero dé cuenta de todas las cosas de la iglesia al sucesor y le entre- 
gue los libros de bautizados y casados y el padrón de todos los indios; y, de todo esto y de las licencias del Prelado, lleve testimonio por escrito". Las penas con que se amenazaba a los transgresores de esta constitución conciliar eran: suspensión por un año para el cura; entredicho de un mes para el Obispo que recibía al cura de otra Diócesis que salió de su Doctrina sin rendir cuentas; y si no se trataba de Obispo sino de Vicario, éste incurría en suspensión del oficio por cuatro meses, más una multa de cien pesos $^{4}$.

El Tridentino había dicho: "Cum proecepto divino mandatum sit omnibus, quibus animarum cura commissa est, oves suas dignoscere; pro his sacrificium offerre; verbique divini praedicatione, sacramentorum administratione, ac bonorum omnium operum exemplo pascere'5. Este texto directamente se refiere a los obispos; pero, ¿acaso los párrocos no son también pastores de almas en sus respectivas Parroquias? Y porque son pastores, deben cuidar de sus ovejas, o sea, deben observar la residencia. Sin embargo, cada año el párroco podía ausentarse por el tiempo de dos meses y hasta tres, como máximum ${ }^{6}$; a menos que, existiendo causa grave a juicio del Ordinario, el tiempo de dos meses podía ser más corto; en cambio, la legislación actual permite ausentarse por vacaciones hasta por un mes7.

Esta facultad que concedía el Tridentino a los párrocos para poder ausentarse cada año por un tiempo limitado, a juicio del Ordinario, fue restringida por los Concilios limenses y por los Sínodos diocesanos de Quito, y era una disposición de acuerdo a las necesidades de aquellos tiempos, pues las Diócesis padecían de la escasez de clero.

$\mathrm{Si}$, en principio, la residencia de curas y doctrineros en sus respectivos beneficios se debía observar con mucha escrupulosidad, sin embargo podían ausentarse cuando se trataba de la confesión personal. "Otro si, ordenamos y mandamos -decía el Ilmo. Señor Peña- a nuestros curas de las Doctrinas de los indios que residan todo el año en sus Doctrinas y allí hagan el oficio divino; y no salgan sino fuere a confesarse, y el que saliere a sus negocios no gane el salario de la dicha Doctrina todo el tiempo que hiciere ausencia de ella, el cual aplicamos para ornamentos de la iglesia e 


\section{Doctrinas y Parroquias del Obispado de Quito /113}

para limosnas de indios pobres" 8 . Y en otra constitución sinodal, el benemérito Prelado, refiriéndose a sus curas, se expresaba con estas palabras: “... les exhortamos y, de parte de Dios, les encargamos que se confiesen muchas veces, ansí por lo que les conviene al remedio de su salvación, porque está escrito: siete veces al día cae el justo, como por el ejemplo que se debe dar a los naturales; y el que no tuviere copia de confesor en su compañía e vecindad cercana, lo pueda salir a buscar donde lo tuviere, sin que por ello pierda su salario, con que no ande vagando ni en otras negociaciones. E para dar remedio, el que de nuestra parte se puede, damos licencia a todos los sacerdotes clérigos y religiosos, de este nuestro Obispado, que unos a otros se puedan confesar, sin que para ello tengan licencia especial"'.

Con la nueva disposición dada en el Sínodo de 1570, "el que saliere a sus negocios no gane el salario de la dicha Doctrina todo el tiempo que hiciere ausencia de ella", si bien, es verdad, que la residencia del doctrinero continuaba en estricta vigencia, la multa, en cambio, venía a reducirse, pues el Concilio limense de 1567 había dispuesto que los curas y doctrineros, "por cada día de su ausencia, paguen cuatro pesos"; y, solamente, "el que con licencia -del Prelado- por alguna causa, hiciere ausencia, no cobre el estipendio de aquel tiempo; en lo cual también se advierte y encarga la conciencia a los Superiores de los religiosos"10.

A partir del año 1570, los curas y doctrineros de la Diócesis de Quito estaban facultados por el mismo Sínodo para ausentarse de sus respectivas Parroquias y Doctrinas, siempre que fuera por necesidad de renovarse espiritualmente en el santo tribunal de la Penitencia; pero, no se había determinado cuantos días podían ausentarse, razón por la cual, para cortar ciertos abusos, pues "cuando van a las ciudades y a otros pueblos a buscar quien los confiese -decía el Obispo Solís en el Sínodo de 1594- suelen detenerse en los tales pueblos mucho tiempo, de que se sigue notorio inconveniente, y para que éste cese: ordenamos y mandamos que los dichos sacerdotes no se detengan en los dichos pueblos más tiempo de tres días, en los cuales se pueden prevenir de lo necesario, lo cual guarden y cumplan en virtud de santa obediencia, y que se les haga cargo en la visita; y 


\section{4 / Augusto E. Albuja}

los que estuvieren cerca de las dichas ciudades y pueblos de españoles, no duerman en ellas"11.

Las medidas adoptadas por los Concilios limenses y los Sínodos de Quito como suspensiones, excomuniones y hasta multas, a fin de conseguir de los curas y doctrineros el fiel cumplimiento de su obligación, nos demuestran que la inobservancia de la residencia de no pocos beneficiados era frecuente y constituía una preocupación más para los beneméritos Prelados.

El Presidente de la Real Audiencia de Quito, en una carta dirigida a Felipe II sobre el estado de las Doctrinas, le decía: “... hay Doctrinas que nunca el clérigo entra en los más pueblos sino que, cuando va a cobrar el salario, ni le conocen los indios y otros que quieren tener alguna más curiosidad, se les va el año en andar caminos de unos pueblos a otros, sin reposar en ninguno, ni poder hacer nada. Asimismo, los clérigos que vienen a este Obispado, como a los más no los trae a estas partes otro intento sino codicia, nunca tienen asiento ni hacen nada, porque siempre están de paso y no tienen el ojo sino cuándo podrán haber licencia del Prelado o huirse para subir al Cuzco y Charcas, donde son los salarios más gruesos. Parece que se podría poner en esto algún remedio y atajárseles la codicia con mandar Vuestra Majestad que a los clérigos, que se les da licencia para estas partes, se les señale a cada uno para qué Obispado se le da y que allí sea obligado a residir; y se mande a los Prelados de los demás Obispados que no admitan en ellos, salvo los que fueren consignados para el tal Obispado y les remitan al Obispado para donde trajeron licencia, y evitarse han los inconvenientes dichos y otros muchos y el mal ejemplo que se causa de andar por esos caminos más clérigos fugitivos que negros. A los sacerdotes que están en las Doctrinas, les hago dar todo favor a los que hacen lo que deben, de lo cual había harta necesidad antes, porque los Encomenderos tenían tanta mano que, en no satisfaciendo el sacerdote a sus intereses, no paraba hasta quitarle; $y$, lo que peor es, que animaban a los indios tenerles poca obediencia, a lo cual la justicia ponía poco remedio, y así, gracias a Nuestro Señor, va en mucho aumento y se siente el provecho que se hace"12. 


\section{Doctrinas y Parroquias del Obispado de Quito /115}

No queremos ocultar la verdad, pero tampoco podemos dejar pasar algunas exageraciones de parte del Presidente de la Real Audiencia, ya que estos informes presentados al Rey Felipe II eran demasiado pesimistas y descubrimos en ellos una cierta prevención para con los sacerdotes del clero secular y en parte redundarían también en perjuicio del Ilmo. Señor Peña por la falta de cuidado pastoral. Lo que sí debemos tener muy en cuenta son las palabras del Prelado, en las que se descubre que la residencia de los curas más o menos se observaba, aunque fuese por el temor a la multa; en cambio, por condescendencias del Presidente y Oficiales de la Audiencia para con los religiosos, éstos se preocupaban muy poco de la dicha residencia en las Doctrinas que tenían a su cuidado. He aquí las palabras del Prelado; "Item, la orden que está dada para pagar el estipendio de las Doctrinas -escribía el Obispo Peña al Rey Felipe II- está mandado que el sacerdote que no residiere, se le quite cada día un tanto, porque, por el temor de la pena, los sacerdotes no falten de las Doctrinas; y, aunque esto se ha ejecutado con los clérigos, por el favor que la Audiencia da a los religiosos, hasta hoy no se ha ejecutado con ninguno dellos, y por esta causa los indios naturales padecen mucha falta de doctrina; y para el descargo de la real conciencia conviene que la dicha pena se ejecute, así en los religiosos como en los clérigos, porque desta manera cesen las grandes ausencias que los dichos religiosos hacen de dos o tres meses y así estén siempre doctrinando"13.

Como también fue del parecer del Monarca que los curas que se ausentaren no percibirían el salario correspondiente a los días de ausencia ${ }^{14}$, y el dinero colectado por este concepto debería emplearse en los gastos de iglesia de las respectivas Doctrinas ${ }^{15}$, probablemente a instancias del Ilmo. Señor Peña y del Ilmo. Señor Solís, en el año 1597 se dictó esta ley: "que lo determinado cerca de los sacerdotes que no residieren en las Doctrinas, se ejecute en los religiosos doctrineros, según y cómo se ejecuta en los clérigos" 16 .

Asimismo, el Rey, dirigiéndose a todos los Prelados de Indias, les pedía que no consintieran "en sus Obispados a ningún clérigo que hubiere residido en otro de aquellas provincias, si no llevare licencia, dimisorias 


\section{6 / Augusto E. Albuja}

y aprobación del Prelado de aquella Diócesis, y a los que fueren sin estos despachos los hagan volver a los Obispados de donde hubieren salido, y no los permitan vagar de unos lugares en otros, ni administrar los Santos Sacramentos" 17 .

Todos los sacerdotes que hubieren residido, al menos cuatro meses, en un determinado Obispado, necesitaban licencia de su Prelado para poder ausentarse; y en caso de prescindir de dicha licencia, ningún otro Prelado podía permitirles ni siquiera decir la misa ${ }^{18}$.

Los sacerdotes del clero secular y regular que venían a las Indias a fin de dedicarse a la evangelización y al ministerio parroquial, a veces tenían necesidad de regresar a España, sea para visitar a sus familiares, sea para recobrar su alterada salud por el fatigoso trabajo apostólico, sea también para descansar una temporada y recobrar sus energías. Todo esto estaba previsto por las leyes de Indias. "Ordenamos y mandamos -había dicho Felipe II- que cuando cualesquier clérigos o religiosos, que residieren en nuestras Indias, Islas y Tierra Firme del mar océano, quisieren venir a estos Reinos de las partes donde residieren, sean obligados a pedir licencia a sus Prelados donde hubieren residido, y siendo los tales clérigos o religiosos de los que hubieren ido a título de tratar de predicación, conversión y enseñanza de los indios, los Prelados no les darán licencia si no les constare que han residido diez años, por lo menos, en aquellas provincias para el dicho ministerio. Y asimismo han de tener licencia del Virrey o Gobernador en cuyo distrito hubieren estado; y para sacarla ha de preceder información... y si no trajeren las licencias en esta forma, mandamos a los Generales de las Armadas y Flotas de la Carrera de Indias, Cabos, Capitanes, Maestres y Pilotos de ellas, y de cualesquier otros navíos, que no les consientan embarcar, ni los traigan en ellos, so pena de privación de sus oficios y de cincuenta mil maravedíes para nuestra Cámara a cada uno que lo contrario hiciere, y que mandaremos volver a su costa los clérigos y religiosos que de otra suerte trajeren" 19 .

Asimismo, los clérigos beneméritos, a pesar de que tuviesen licencia de sus Prelados para ausentarse a España, no debían hacer el viaje porque el Rey había juzgado más conveniente que dichos clérigos "sean gra- 


\section{Doctrinas y Parroquias del Obispado de Quito /117}

tificados y consigan desde sus casas el premio de sus servicios, excusando los riesgos, trabajos y costas de viajes" 20 ;y con este fin se pedía a los Arzobispos y Obispos que enviasen, con más o menos frecuencia al Real Consejo de Indias, la nómina de sacerdotes que por sus virtudes y méritos de servicio se hacían dignos de que se los tomara en cuenta para concederles una Prebenda como recompensa ${ }^{21}$. Y porque el Rey confiaba en el criterio recto y desinteresado de los Prelados, ordenaba a los Virreyes "que tengan particular cuidado de no dar licencias a clérigos para venir a estos Reinos a sus pretensiones" 22 .

En general, podemos afirmar que el Rey no era partidario de que los clérigos y religiosos volviesen a España: en primer lugar, por los muchos gastos que los viajes demandaban y, en segundo lugar, porque la ausencia, más o menos prolongada, de los ministros sagrados redundaba en perjuicio de la evangelización en Indias. Por estos motivos el Monarca pedía, y con mucha insistencia, a los Prelados, Virreyes, Presidentes y Gobernadores "que cuando los clérigos o religiosos de cualquier Orden se hallaren empleados en la predicación y enseñanza de la doctrina cristiana y pidieren licencia para volverse a estos Reinos, les persuadan y encarguen mucho que no quieran dejar tan santa obra y oficio apostólico, donde tanto importa. Y si con esto -decía Felipe II- no se quisieren quedar, y perseverando en la resolución de venirse, pidieren licencia para ello, se la darán conforme a lo dispuesto por las leyes" 23 . 


\section{8 / Augusto E. Albuja}

\section{NOTAS:}

1 C.I.C. 17 ,c. 465,6 ; C.I.C. c. 533.

2 AGI, Quito, leg.8.

3 Segundo Concilio limense, Parte Primera, cap.26.

4 Segundo Concilio limense, Parte Segunda, cap.4. También en el primer Sínodo de Quito decía el Obispo Peña: "ordenamos y mandamos, so pena de excomunión en la cual incurran ipso facto, que los curas de indios, que no dejen sus curazgos y Doctrinas, aunque tengan nuestra licencia para ello, sin que primero entreguen al cura que les ha de suceder los bienes de la iglesia, libros padrones de la Doctrina: bautismos, casamientos y difuntos, y dé razón del estado en que está la Doctrina y lo que les pareciere avisarlos, hagan, pues, para ello tienen obligación como cristianos" (AGI, Patronato, leg.189, Ro.40).

5 Conc, Trid., Sess,23, cap.I de reform.

6 Conc. Trid., Sess.23,cap.I de reform.; PEÑA MONTENEGRO, Itinerario, lib.I, tratado 2, f, 47 .

7 C.I.C. 17, c.465,2; C.I.C., c 533,2.

8 Primer Sínodo de Quito Parte Cuarta, c.55. (AGI, Patronato, leg. 189, R 40).

9 Primer Sínodo de Quito, Parte Cuarta, c.39. (AGI, Patronato, leg. 189, Ro.40). Esta licencia para poder confesar que el Ilmo.Señor Peña concedía en general a todos los sacerdotes del Obispado de Quito, era solamente para poder confesar a otros sacerdotes, mas no, a los demás fieles, ya que para esto último se necesitaba licencia expresa del Prelado.

10 Segundo Concilio limense, Parte Segunda, c.11.

11 Segundo Sínodo de Quito, cap.21 (AGI, Quito, leg.76).

12 AGI, Quito, leg.8.

13 AGI, Quito, leg.76.

14 Recopilación, lib. I, tít. 7, ley 16.

15 Recopilación, lib. I, tít.13, ley 18.

16 Recopilación, lib. I, tít. 15, ley 16.

17 Recopilación, lib. I, tít. 7, ley 10.

18 Recopilación, lib. I, tít. 12, ley 15.

19 Recopilación, lib. I, tít. 12, ley 16.

20 Recopilación, lib. I, tít. 12, ley 18.

21 Recopilación, lib. I, tít. 6, ley 19.

22 Recopilación, lib. I, tít. 12, ley 18.

23 Recopilación, lib. I, tít. 12, ley 17. 


\section{CAPÍTULO VII \\ INSTRUCCIÓN RELIGIOSA Y CUIDADO \\ PASTORAL}

La residencia, que tanto se recomendaba y se prescribía a todos los curas y doctrineros, tenía como finalidad principal la instrucción religiosa de los fieles y su cuidado pastoral.

\section{Instrucción religiosa}

La instrucción religiosa que se debe procurar a los fieles encierra una doble obligación, a saber: predicar la palabra divina todos los domingos y los días de precepto ${ }^{1}$ y enseñar la catequesis tanto a los niños ${ }^{2}$ como a los adultos ${ }^{3}$.

En cualquier clase de apostolado y, sobre todo, en el ministerio parroquial, la predicación de la palabra divina ocupa un lugar preeminente, ya que por medio de ella los fieles, conociendo más de cerca a Cristo, se alejan de sus malos hábitos y buscan los medios de imitar al Divino Maestro con la práctica de las virtudes cristianas.

\section{Normas generales}

Siguiendo las normas dadas por el Tridentino, el primer Sínodo de Quito pedía también "que los curas de españoles de este nuestro Obispado prediquen, todos los domingos y fiestas solemnes que son de guardar en sus iglesias, a sus parroquianos, a lo menos tiempo de media hora, en la cual les declaren parte de esta doctrina cristiana y parte del Evangelio del tal domingo y festividad" 4 . Como, probablemente, algunos piadosos 
laicos, no contentos con tener el honor de ser catequistas, querían intervenir activamente en el ministerio de la palabra divina, se ordenó "que los legos no prediquen ni doctrinen en público a los indios"5.

Esta obligación de predicar la palabra divina era tanto de los párrocos como de los doctrineros. Por lo mismo "los curas, -decía el tercer Concilio limense- que siendo examinados se hallaren tener suficiencia, declaren al pueblo, los días de fiesta, el Evangelio; y si no fueren tan suficientes, otras personas doctas, a su costa de ellos, lo hagan, siguiendo siempre en la exposición de la Escritura el sentido y declaración de los Santos Padres" 6 . Y respecto a los fieles, el Sínodo diocesano de 1594 deseaba y pedía que todos acudieran a sus respectivas Parroquias los domingos y días de precepto para oir la misa y escuchar la palabra divina ${ }^{7}$.

Como el tiempo de Adviento y el tiempo de Cuaresma son muy especiales dentro del año litúrgico y el Tridentino pedía que se intensifique la predicación ${ }^{8}$, el Sínodo de 1594 dispuso que "los curas en sus Parroquias, el tiempo de ayunos de Cuaresma y Adviento, predicaran cada día por lo menos tres veces en la semana de Cuaresma y Adviento"?.

Es de suponer que los sacerdotes dedicados al ministerio parroquial en la Diócesis de Quito no se contentarían cumpliendo su obligación los días señalados, sino que harían todo lo posible a fin de poner en práctica el deseo del segundo Concilio limense, a saber: "que la palabra de Dios se predique a menudo al pueblo" 10 , ya que el bien que con ella se podía hacer, tanto a los indios como a los conquistadores, era inmenso.

Fue tal la importancia que tuvo la enseñanza de la doctrina cristiana, sobre todo entre los indios, que a sus párrocos se los llamaba "curas doctrineros" o simplemente "doctrineros", pues, la obligación principal que pesaba sobre ellos era la enseñanza de la doctrina cristiana.

\section{Compendio de la catequesis}

"Ordenamos y mandamos -decía el primer Sínodo de Quito- que los dichos curas de indios, por agora, enseñen e manden aprender de coro las oraciones: el Pater noster, Avemaría, Credo, Salve Regina e los Man- 


\section{Doctrinas y Parroquias del Obispado de Quito /121}

damientos de la ley de Dios, en la lengua de Castilla”. Y luego añadía: “... nuestros curas les dirán por su persona la doctrina general, como está escrita la tabla en la iglesia, para que entiendan los indios que, demás de las oraciones que saben de coro, tienen en la iglesia la dicha doctrina cristiana y son cosas esenciales que conviene todo cristiano las entienda y no las ignore, porque importan a todo buen cristiano para su salvación"11. Y como si esta disposición no fuera suficiente, encontramos una segunda, que es ampliación de la anterior: "Porque el conocimiento de nuestra santa fe católica es necesario a todo fiel cristiano, y los curas de oficio tienen obligación de enseñar los primeros rudimentos de la fe para salud de las ánimas, mandamos que particularmente se enseñe, ansí a los españoles como a los indios naturales de este nuestro Obispado, las cuatro oraciones - Pater noster, Avemaría, Credo, Salve Regina-, Artículos de la fe, los diez Mandamientos de la ley -de Dios-, los siete Sacramentos de la Iglesia, las siete virtudes, de ellas contrarias, las obras de misericordia, así corporales como espirituales, cinco sentidos corporales y potencias del alma. Todo lo cual pongan todos los curas en sus iglesias escrito en una tabla, lo cual esté en lugar público que todos la vean y lean y se aprovechen y corrijan en el saber la doctrina cristiana" 12 .

\section{Catequistas}

En principio, estaba prohibido a los seglares enseñar la doctrina cristiana a los indios. Pero, cuando hay escasez de clero, el elemento seglar presta enorme ayuda; y si un párroco no puede, por sí solo, atender a todas las necesidades de sus feligreses, sobre todo la catequesis de niños y de adultos, entonces deberá buscar colaboradores entre los laicos, porque éstos, después de un período de formación, se convertirán en buenos apóstoles. En el siglo XVI no bastaba la suficiencia para que los seglares pudiesen enseñar la doctrina cristiana; debían ser examinados por el Obispo " $y$ tener licencia suya por escrito". Las mujeres "de ninguna manera se entremetan a doctrinar", había determinado el segundo Concilio limense ${ }^{13}$. 
122 / Augusto E. Albuja

\section{Idioma}

¿En qué idioma se debía enseñar la doctrina cristiana a los naturales?. A mediados del siglo XVI se pensó en el empleo del latín o del castellano, seguramente para facilitar la labor de los doctrineros, sin tener en cuenta las dificultades en los doctrinandos, pues los pobres indios, con mucho esfuerzo, se veían obligados a aprender ciertos párrafos de memoria, sin saber muchas veces el significado. En 1583 se pidió que cada Diócesis tuviese traducciones de la cartilla de la doctrina cristiana, a fin de obtener mejores resultados en la enseñanza ${ }^{14}$; y para poner en práctica lo dispuesto por el tercer Concilio de Lima, en el segundo Sínodo de Quito fueron nombrados algunos sacerdotes muy peritos para que hicieran las respectivas traducciones en los distintos idiomas que se hablaba en todo el Obispado, no tanto para alcanzar uniformidad en la enseñanza de la doctrina cristiana, sino principalmente para facilitar el aprendizaje; por tanto “...ordenamos y mandamos -decía el Ilmo. Obispo Solís en el Sínodo de 1596- que de aquí adelante no se diga ni se enseñe más que en una lengua, y ésa sea la materna, si ser pudiere; y donde no se entendiere la del inga, ni hubiere la materna traducida, se podrá enseñar en la lengua de Castilla" 15 .

Al tratar de la provisión de Parroquias y Doctrinas advertíamos el anhelo de todos los Prelados porque sus sacerdotes, curas y doctrineros, trataran de aprender, en el menor tiempo posible, el idioma indígena; pues, en los primeros años, el desconocimiento del idioma, por una parte, y por otra, la falta de método seguido en la enseñanza de la doctrina cristiana, dieron resultados nada halagüeños. Cada doctrinero enseñaba lo que podía, es verdad; pero, con independencia casi absoluta. De donde era necesario "que se hiciese catecismo uniforme, en la lengua general, y las oraciones, con las mejores lenguas que hubiese en el reino, con quien más sea pura de la propiedad de los vocablos, pues el mayor barbarismo que hay en estos naturales y por cuya causa tantos millares están bautizados sin estar catequizados ni entender, poco ni mucho, lo que toman, y ansí se salen fácilmente apostatando a ser rebeldes y a sus idolatrías, o se vuelven a ellas sin rebeliones" 16 . 


\section{Doctrinas y Parroquias del Obispado de Quito /123}

\section{Cartillas}

Hasta 1545 existían varias cartillas extravagantes, que los doctrineros utilizaban para enseñar la doctrina cristiana; pero, en vista de que los resultados eran más bien perjudiciales, el Ilmo. Señor Jerónimo de Loaisa ordenó que fueran recogidas todas aquellas cartillas y dio una instrucción para unificar el método de la doctrina. Siete años más tarde, en todas las Parroquias de indios se debía seguir la instrucción dada por el primer Arzobispo de Lima. En el Concilio de 1567 se dejaba al criterio de los Obispos la redacción de un breve compendio de la doctrina cristiana para que fuese utilizado en sus respectivas Diócesis. Y, por último, de acuerdo con el Catecismo del Concilio de Trento, que fue muy bien recibido en la provincia eclesiástica de Lima, el tercer Concilio de 1583 ordenó la redacción de un catecismo que tanto bien hizo en las Diócesis, pues así se llegaba a una uniformidad definitiva en la enseñanza de la doctrina cristiana ${ }^{17}$. Asimismo, se pedía a los Prelados y a todos los curas que pusieran mucho cuidado en enseñar la doctrina cristiana a todos los naturales, según la habilidad que tuvieren ${ }^{18}$, y de acuerdo a la capacidad de los oyentes ${ }^{19}$.

En la Diócesis de Quito había la costumbre de enseñar la doctrina cristiana a todos los indios sin hacer distinción de edades, razón por la cual el Ilmo. Señor Solís, a lo largo de su primera visita pastoral, dándose cuenta de las deficiencias, se vio obligado a exigir más trabajo de los curas, pero, en cambio, con más provecho para los indios; pues "el orden y modo que hasta aquí se ha tenido, en general, en el decir toda la doctrina junta a los indios -decía el celoso Obispo- no nos ha parecido conveniente, porque los que no la saben en muchos años no la pueden aprender de aquella manera. Y así, sancta Synodo approbante, ordenamos y mandamos que, de aquí adelante, los curas de indios hagan padrón y memoria de lo que cada indio sabe, y de una en una oración le vayan enseñando lo que le falta, de suerte que hasta que sepa una oración no le enseñen otra; y para esto haga divisiones, poniendo los viejos a una parte y a los que saben toda la doctrina a otra, y a los que saben parte de ella a otra, poniendo quien enseñe a los unos y a los otros, y pidiéndoles cuenta en particular 


\section{4 / Augusto E. Albuja}

cada día, en especial de catecismo, porque éste es la principal doctrina, y faltando éste todo lo demás es relatar oraciones de ciegos. Por lo cual mandamos a todos los curas sepan de coro el catecismo y sepan la doctrina en la lengua, so pena de veinte pesos al que no supiere de coro por lo menos el catecismo y el Credo, y esto por la primera vez; y a la segunda, cuarenta pesos de pena, aplicados para la fábrica de la iglesia; y a la tercera, suspensión del beneficio por un año"20.

\section{Días de Catequesis}

Los días en que se enseñaba el catecismo dependían de la clase de personas: niños, adultos, indios, españoles.

Los niños y niñas debían recibir la instrucción catequística todos los días, hasta la edad de doce años. "Los niños, regularmente, pasaban el día con el sacerdote; bien en la doctrina propiamente dicha, bien en la escuela que el sacerdote debía dar o procurar se diese bajo su control"21. Y para evitar varios inconvenientes que se habían presentado, el Sínodo diocesano de 1594 disponía que "los muchachos y muchachas de la Doctrina, hasta que tengan edad de diez años", debían acudir todos los días a recibir la catequesis; y después de haber cumplido esa edad, quedaban libres para ir con sus padres a ayudarles en el trabajo, siempre que los niños supiesen la doctrina; pues, en caso contrario, el doctrinero podía obligarlos a continuar el aprendizaje, aunque hubiesen cumplido los diez años; mas, a las niñas no se las debía obligar, porque expresamente la constitución sinodal, dirigiéndose a todos los doctrineros de la Diócesis, les decía: “у a las mujeres, aunque no la sepan enteramente -si han cumplido los diez años- las dejen ir" 22 .

La catequesis de adultos se solía tener los miércoles y viernes de todas las semanas, y la hora más oportuna era por la mañana, antes de que salieran los indios a sus trabajos y ocupaciones ${ }^{23}$. Asimismo, en los días de precepto para los naturales, los doctrineros debían enseñarles "los misterios de nuestra fe, mayormente los que se celebran el tal día, y esto se guarde especialmente en las fiestas del Nacimiento y de la Resurrección y Cor- 
pus Christi; y de tal modo se les declare el artículo de fe, que puedan todos percibir bien lo que se les dice; y después de la plática y sermón, pregúntese a los curacas y a los demás lo que se ha tratado; mas, para esta plática y sermón, no obliguen a los indios a juntarse de más lejos de una legua" 24 .

Si los doctrineros estaban obligados a enseñar la doctrina cristiana a los indios adultos, también los curas de españoles de toda la Diócesis, los domingos y días de precepto, debían emplear, al menos media hora, para la explicación del Evangelio y para la respectiva catequesis 25 .

Y para que tengamos una visión de conjunto acerca de la instrucción religiosa, presentamos el siguiente resumen:

Enseñanza de la doctrina cristiana en la Diócesis de Quito

\section{a) Para los niños y niñas}

Hasta el año 1594:

-Todos los días, durante tiempo ilimitado.

-Hasta los 12 años de edad.

\section{A partir del año 1594}

-Todos los días durante tiempo

ilimitado.

-Hasta los 10 años de edad.

\section{b) Para los adultos}

1. Indios

- miércoles y viernes, por la mañana.

- domingos y fiestas de precepto, durante la misa.

\section{Españoles}

- domingos y fiestas de precepto, durante la misa, inmediatamente después de la explicación del Evangelio.

\section{Cuidado pastoral}

Así como el pastor se preocupa de sus ovejas, así el párroco debe cuidar de sus feligreses, particularmente del bienestar espiritual de todos y cada uno de ellos, sin acepción de personas, pues se trata de almas que han sido redimidas con la misma sangre de Cristo. 
Las Parroquias y sobre todo las Doctrinas estaban formadas por varios caseríos más o menos distantes unos de otros. Para que el sacerdote pudiese atender a todos sus feligreses, el primer Sínodo de 1570 prohibía que se estableciera en un lugar determinado, y ordenaba que debía permanecer por una temporada cada año en los respectivos caseríos a fin de que todos los parroquianos pudiesen instruirse en la doctrina cristiana, tanto más cuanto que el doctrinero recibía su salario, no por la Parroquia, sino por el número de indios que en ella había. ${ }^{26}$. Para cumplir esta disposición sinodal se necesitaba tener un espíritu verdaderamente apostólico y auténticamente sacerdotal, pues el ministerio parroquial resultaba mucho más difícil y fatigoso de lo que es en los tiempos actuales.

El Ilmo. Señor Peña, queriendo aliviar un tanto la pesada carga de sus queridos curas, acudió al Virrey de Lima para exponerle la necesidad de escoger uno o dos indios para que ayudasen al sacerdote en la Doctrina, y como remuneración podrían percibir un pequeño salario ${ }^{27}$. Esta insinuación hecha por el Obispo de Quito al representante inmediato del Rey tuvo su aceptación, ya que una constitución conciliar de 1567 decía: "Con precepto, que los curas, cada uno en su Parroquia, señale dos o más indios de confianza, los cuales tengan por oficio avisarle de todo lo necesario que ocurriere, principalmente si está ausente, exempli gratia: de los niños que de nuevo han nacido, para que se bauticen; de los que enferman, para que reciban los sacramentos; de los que andan en borracheras o comunican con los hechiceros, o van a mochar guacas, o hacer otra cosa contra la religión cristiana, para que sean corregidos; y también de los que faltan a la misa o doctrina" 28 .

\section{Indios "Coadjutores"}

Cada doctrinero quedaba autorizado a escoger dos indios, "bien inclinados y bien doctrinados", para que fuesen "sus colaboradores". De preferencia debían ser hijos de caciques, ya que gozarían de cierta autoridad sobre los demás y con su ejemplo y buen comportamiento contribuirían a captar el respeto de todos los naturales ${ }^{29}$. 


\section{Doctrinas y Parroquias del Obispado de Quito /127}

Las principales ocupaciones a las que estaban dedicados estos dos indios "coadjutores", en cada uno de los caseríos que formaban la Doctrina, eran las siguientes:

a) Presidir cada mañana el rezo de las oraciones en la iglesia, antes de que los indios salieran a sus trabajos.

b) Reunirlos para la enseñanza de la doctrina cristiana en los días senalados, a saber: miércoles y viernes de cada semana, y los domingos y fiestas de precepto propias de los indios.

c) Cuidar de la iglesia a fin de que estuviera siempre aseada; además, ellos debían abrirla para los actos religiosos y cerrarla después.

d) Avisar al cura doctrinero: de los indios que no hubieren asistido a la doctrina o a la misa; de los enfermos que hubiesen en el pueblo, para que recibieran los sacramentos; de los niños que hubieren nacido, para que fueran bautizados; de los difuntos, a fin de que se anotara sus nombres en el libro correspondiente ${ }^{30}$; de los indios entregados a borracheras y hechicerías, o que vivían mal, para que fueran amonestados y corregidos ${ }^{31} ; \mathrm{y}$, por último, de los huérfanos y viudas, para que fuesen socorridos ${ }^{32}$.

Según esto, la colaboración de los seglares en la pastoral eclesial, tan recomendada en nuestros tiempos, hace cuatro siglos existió ya en casi todas las Parroquias y Doctrinas de la Diócesis de Quito, y los frutos alcanzados no podían ser mejores, demostrando desde luego que el elemento seglar, de cualquier clase social que sea, siempre que tenga buena voluntad y esté bien formado, podría ser llamado a colaborar en el apostolado.

Los vicios más comunes entre los indios eran la embriaguez, la hechicería y la idolatría, a los que Peña Montenegro dedica tratados especiales $^{33}$. Sobre el vicio de la embriaguez, dicho autor nos dice "que apenas se hallará uno, que teniendo a mano bebida de vino o chicha, que es lo que comúnmente usa, que no se embriaguen" 34 .

Todos los doctrineros debían hacer lo posible a fin de que los vicios de los indios desaparecieran, preferentemente la hechicería y todos aquellos oficios diabólicos, "porque, entretanto los usaren -dice una constitución sinodal- hacemos cuenta que no se ha comenzado el cristianismo entre los indios, por estar tan arraigados y llenos de supersticiones"; y con 
este fin se pedía a los curas "que con tres moniciones públicas exhorten y requieran a los dichos hechiceros se aparten de servir al demonio y de usar los ritos y supersticiones infieles, y que sirvan a Dios; pues, es su Padre Celestial, Criador y Redentor, amenazándoles con la pena perpetua del infierno" 35 .

Asimismo, el Ilmo. Señor Peña recomendaba a los curas de las Doctrinas de indios que "no les consientan ofrecer sobre los muertos si no fuere pan, vino, cera y lo que los cristianos españoles acostumbraban ofrecer, por las muchas supersticiones que los indios hacen en las ofrendas que ofrecen sobre los muertos"; y para esto, lo mejor era explicar a los naturales el valor que tenía la ofrenda hecha a Dios, cuando estaba libre de supersticiones y de idolatrías, ya que éstas en vez de agradarle, más bien constituían una ofensa ${ }^{36}$.

Gracias al cuidado pastoral, la idolatría y la hechicería, aunque no habían desaparecido entre los indios, al menos el número de sus simpatizantes quedaba reducido. El vicio de la embriaguez, en cambio, ofreció mayor resistencia. El segundo Sínodo de Quito deseaba para el futuro "que los indios no hagan borracheras los días de los Santos de sus nombres, ni de los Patrones de la iglesia, ni otros santos algunos, ni cuando bautizan sus hijos, o entierran sus muertos, o les hacen exequias, ni cuando hacen sus casas, o labran sus chácaras". Por tanto, párrocos y doctrineros debían predicar a menudo sobre los graves daños ocasionados por la embriaguez, visitar a caballo todos los días sus pueblos o Parroquias para evitar las reuniones de indios y las borracheras, "y a los indios que hallaren en ellas les podrán castigar y derramarles la chicha y quebrar los cántaros..." y "en virtud de santa obediencia y so pena de excomunión mayor", se prohibía a todo español, mestizo o mulato consentir en su casa borrachera de indios o de negros ${ }^{37}$.

Visita a los anejos

Con relativa frecuencia, al menos siete veces al año, los curas debían visitar los caseríos de indios; y al que se manifestara negligente en este 


\section{Doctrinas y Parroquias del Obispado de Quito /129}

punto, el segundo Concilio de Lima había ordenado que se le impusiera una multa de veinte pesos. Esta obligación debía extenderse también a los religiosos doctrineros, pues las palabras que emplea dicho Concilio son muy explícitas: “... y los religiosos que tienen cargo de indios sepan que están obligados a lo propio" 38 .

La disposición conciliar de 1567, obligando al cura a visitar siete veces al año cada uno de los anejos o caseríos que dependían de su Doctrina, no era exigirle una cosa imposible, pero sí heroica. Tres años más tarde, el primer Sínodo de Quito fue más benigno con los curas de la Diócesis, pues, considerando las distancias que separaban unos caseríos de otros y los malos caminos que el sacerdote tenía que recorrer, se abstuvo de establecer una norma general, sino más bien recomendaba a todos los párrocos de indios que "visiten muchas veces sus parroquianos, porque se les sigue mucho provecho; y los pueblos que estuvieren a cuatro leguas de la iglesia parroquial, los visiten seis veces en un año; y que los que estuvieren a cinco leguas, los visiten cuatro veces; y los que estuvieren más de ocho leguas, los visitarán tres veces e más, si más pudieren"39.

Como estas visitas a los distintos caseríos de la Parroquia eran de carácter apostólico, el Prelado pedía a los naturales "que salieran a la entrada de las poblaciones para recibir al sacerdote; y después que fueran todos a la iglesia, debían rezar la doctrina cristiana; y acabada, vea -el sacerdote- las imágenes, pilas, limpieza de los altares, iglesia y las puertas y cerraduras, e luego se informe -por medio de sus indios coadjutores- de los indios pobres, y sepa si tienen casas, chácaras, mujeres; y las mujeres, maridos; si tienen qué comer o si no tienen de qué vestir, e en todo les procure remedio, persuadiendo a los caciques lo remedien con caridad, porque Dios se los encomienda y de esto hay necesidad, porque los pobres, entre los indios, son pobrísimos" 40 . También en estas ocasiones era muy oportuno visitar a los enfermos para confesarlos; " $y$ traiga consigo el sacerdote -decía el Obispo Peña- algunas medicinas, así como aceite, con que los cure y regale, lo cual haga con mucha caridad, rezando los Evangelios e otras bendiciones, e signándolos con la señal de la Cruz, e dándoles de comer, porque, muchas veces, el hambre es enfermedad grave de los indios" ${ }^{\prime \prime}$. 
130 / Augusto E. Albuja

\section{Labor Social}

Además del ministerio parroquial, los sacerdotes encargados de las Doctrinas de indios debían ejercer una labor social, instruyéndoles "en toda policía, principalmente en que tengan buenas casas de vivienda y en ellas hagan sus apartamentos en que duerman, y usar las casas y otras en que tengan sus bienes ... No consientan ni permitan dormir en el suelo, ni juntos, si no fueren marido y mujer, y les aconsejen y manden tengan limpias sus casas y hagan chácaras y sementeras, previniendo de la obligación que tienen a sustentar sus mujeres y hijos, y que tengan ganados, e que hagan ropa para vestirse, e anden limpios en el ornato de sus personas, y los que pudieren comprar caballos y carneros para que les sirvan de las cargas, e supongan a los indios por las vías posibles, excusen de cargar sus personas, porque se los muele y atormenta y les causa muchas enfermedades, de que mueren muchos; e a que, como vayan pudiendo, procuren de adquirir bueyes e vacas, con que hagan sus sementeras, porque con ellos se les aliviarán de muchos trabajos y serán muy aprovechados; e a los que son casados les amonesten se quieran y amen con amor, diciendo que ansí lo manda Dios, y que cuiden sus hijos con toda limpieza y los traigan a la iglesia para que allí se les enseñen y doctrinen, y las mujeres casadas que se echen un paño en la cabeza cuando fueren a misa" 42 . 


\section{Doctrinas y Parroquias del Obispado de Quito /131}

\section{NOTAS:}

1 Primer Sínodo de Quito, Parte tercera,c.3 (AGI, Patronato.leg.189, Ro. 40); Conc. Trid. Sess.V, cap.2, y Sess.XXIV, cap.4 de Reform; C.I.C.17,c,1344; C.I.C. c.767.

2 C.I.C. 17, cc.1330, 1331; C.I.C. c. 777.

3 C.I.C. 17, c. 1332; C.I.C. c. 776.

4 Primer Sínodo de Quito, Parte tercera, c.3 (AGI, Patronato, leg.189, Ro. 40) .

5 Segundo Concilio limense, Parte Primera, c.80.

6 Segundo Concilio limense, Parte Primera, c.77:-Segundo Sínodo de Quito, c.109 en AGI, Quito, leg.77. Esta constitución sinodal lleva por título "los curas prediquen en sus Parroquias los domingos y fiestas", y, ratificando lo dispuesto por el Segundo Concilio de Lima, dice: "los curas de las Parroquias de todo este obispado han de predicar per se y si estuvieren impedidos o no tuvieren suficiencia para predicar, el Obispo proveerá de personas que prediquen, doctas, idóneas, a costa de los mismos curas".

7 Segundo Sínodo de Quito, cap.54 (AGI, Quito, leg.77).

8 Conc. Trid. Sess. XXIV, cap.4, de reform.

9 Segundo Sínodo de Quito, cap.109 (AGI, Quito, leg.77); C.I.C. 17, c.1346; C.I.C.. c. 767.

10 Segundo Concilio limense, Parte Primera, c. 78.

11 Primer Sínodo de Quito, Parte Cuarta, c.3 (AGI, Patronato, leg.189, Ro. 40).

12 Primer Sínodo de Quito, Parte Tercera, c.1 (AGI, Patronato, leg. 189, Ro. 40).

13 Segundo Concilio limense, Parte Primera, c.80.

14 Tercer Concilio,limense, Acc.2o., cap.3.

15 Segundo Sínodo de Quito, Const.3 (AGI, Quito, leg. 76); Tercer Sínodo de Quito, Const. 21 (AGI, Quito, leg. 77).

16 AGI, Lima, leg.300.

17 VARGAS UGARTE, Historia, I, 225.

18 Tercer Concilio limense, Acc, 2o., cap.4.

19 Segundo Concilio limense, Parte Primera, c.80.

20 Tercer Sínodo de Quito, Const.7 (AGI, Quito, leg.77).

21 RODRÍGUEZ VALENCIA, Santo Toribio de Mogrovejo, I, 429.

22 Segundo Sínodo de Quito, cap.18 (AGI, Quito, leg.76).

23 Segundo Concilio limense, Parte Segunda, c.89; Primer Sínodo de Quito, Parte Cuarta, c.3, en AGI, Patronato, leg. 189, Ro. 40.

24 Segundo Concilio limense, Parte Segunda, c. 92.

25 Primer Sínodo de Quito, Parte Tercera, c.3 (AGI, Patronato, leg. 189, Ro. 40). 
132 / Augusto E. Albuja

26 Primer Sínodo de Quito, Parte Cuarta, c.18 (AGI, Patronato, leg.189. Ro. 40).

27 Apéndice \# 5.

28 Segundo Concilio limense, Parte Segunda, c. 118. Mochar: idolatrar, rendir culto.

29 Primer Sínodo de Quito, Parte Cuarta, c.4 (AGI, Patronato, leg.189, Ro. 40).

30 Ibidem.

31 Segundo Concilio limense, Parte Segunda, c.118.

32 Apéndice \# 10.

33 PEÑA MONTENEGRO, Itinerario, lib.2, tratados 4o., 5o. y 7 o.

34 PENA MONTENEGRO, Itinerario, lib.2, trat. 7o., Secc.12, f.202.

35 Primer Sínodo de Quito, Parte Cuarta, c.22; (AGI, Patronato, leg. 189, Ro. 40).

36 Ibidem, c.26.

37 Segundo Sínodo de Quito, Const.93 (AGI, Quito, leg.77).

38 Segundo Concilio limense, Parte Segunda, cap.13.

39 Primer Sínodo de Quito, Parte Cuarta, c.8 (AGI, Patronato, leg.189, Ro. 40).

40 Ibidem, c.9.

41 Ibidem, c. 10.

42 Ibidem, c.19. 


\section{CAPÍTULO VIII \\ EL CULTO DIVINO}

El culto, siendo un homenaje que se rinde a Dios, debe manifestarse en lugares especiales, donde los fieles se sientan, en cierto modo, abstraídos de las cosas terrenas. Tales lugares son las iglesias. Además, como el culto divino se compone de ritos y ceremonias, hay necesidad de disponer de cosas necesarias y decentes, dignas de Dios, a quien van dirigidas.

Así pues, en este capítulo vamos a tratar de las iglesias, de las cosas de culto, de una de las obligaciones del párroco, la misa pro populo, ya que la misa es el sacrificio por excelencia; y finalmente, de las fiestas de precepto y días de ayuno y abstinencia.

\section{Las iglesias}

La construcción de iglesias en Indias fue necesaria y urgente. Los Reyes Católicos, conscientes de su obligación, "desde el descubrimiento de las Indias Occidentales, ordenaron y mandaron que en aquellas provincias se edificasen iglesias donde ofrecer sacrificio a Dios nuestro Señor y alabar su Santo Nombre"1.

Y considerando que "Misa y Catecismo eran indiscutiblemente el centro de la vida cristiana en las Doctrinas"2, los sucesores en el trono de los Reyes Católicos, dirigiéndose a Virreyes, Presidentes de Audiencia y Gobernadores, les decían: "que nos informen y den cuenta de las Iglesias que están fundadas, y de las que pareciere conveniente fundar, para que los indios que han recibido la santa fe católica, sean enseñados y doctrinados como conviene y los que hoy perseveran en su gentilidad, reducidos y convertidos a Dios nuestro Señor"3. 
Las iglesias debían construirse en lugares convenientes, teniendo en cuenta el número de parroquianos. Para esto se debía pedir el parecer del Prelado, del Encomendero y del cacique principal. Si los indios no estaban agrupados en pueblos, sino que vivían en pequeños caseríos, entonces era lo más conveniente que en estos sitios hubiese también iglesias pequeñas, donde se pudiera administrar el Santo Bautismo a los naturales y enseñarles la doctrina cristiana ${ }^{4}$.

Entre otras disposiciones dadas por Felipe II a Francisco de Toledo, Virrey del Perú, el 28 de diciembre de 1568, le decía: “... es muy necesaria y conveniente en aquellas provincias y que, por lo que está entendido, son pocas las Parroquias que están erigidas, y los curas y ministros que hay, y que así en todo caso se deberá luego esto hacer y ordenar, y que así en los pueblos principales como en todos los demás Repartimientos y lugares, se erigiesen y instituyesen las Parroquias que, conforme a la tierra, lugares y número de personas conviniese, de manera que tengan sus iglesias y curas propios y conocidos, a cuyo cargo sea la administración de los Sacramentos, institución, doctrina y gobierno espiritual de los feligreses; y que esto se debería hacer con toda brevedad, asignando a cada Parroquia los limites que parecieren convenientes, los cuales, por no se poder de acá distinguir, se podrían allá con más facilidad aplicar y asignar. Por Nos haber parecido esto muy conveniente y por lo mucho que importa al servicio de Dios, beneficio de las almas y buen gobierno eclesiástico de aquellas provincias, os encargamos que, habiendo tratado y conferido lo que a esto toca con el dicho Arzobispo y otros Prelados, o haciéndolos para esto juntar o aparte, según que entendiéredes que más conviene, y habiéndose mucho mirado la forma que en esto se debe tener, déis orden que los dichos Prelados lo pongan en efecto, pues, según lo que somos informado, no es necesario para lo susodicho nueva comisión de $\mathrm{Su}$ Santidad, pudiéndose hacer por el derecho común y en virtud de las erecciones de las iglesias y vos daréis de nuestra parte, para ejecución de lo que se ordenare, el favor y ayuda que fuere menester" 5 .

Los gastos que demandaba la construcción de cada una de las iglesias corrían de cuenta del Rey, del Encomendero y de los mismos in- 


\section{Doctrinas y Parroquias del Obispado de Quito /135}

dios; por tanto, "las iglesias parroquiales que se hicieren en pueblos de españoles -ordenaba el Monarca- sean de edificio durable y decente, y la costa que en ellas se hiciere se reparta y pague por tercias partes: la una de nuestra hacienda real; la otra a costa de los vecinos Encomenderos de indios de la parte donde se edificaren; y la otra de los indios que hubieren en ella y su comarca. Y si en los términos de la ciudad, villa o lugar estuvieren incorporados algunos indios en nuestra Real Corona, mandamos que también se contribuya, por nuestra parte, con lo mismo que contribuyen los vecinos Encomenderos respectivamente; y a los vecinos que no tuvieren indios, también se les reparta alguna cantidad para el dicho efecto, conforme a la calidad de sus personas y haciendas, y lo que a éstos se repartiere se descuente de la parte que tocare pagar a los indios"6.

Esta contribución real para la construcción de iglesias, a partir de 1604, se debía dar una sola vez, porque, "después de hechas y fabricadas, y habiéndose acudido con la parte concedida por Nos -decía Felipe III- las derriban los Encomenderos u otras personas para alargarlas o mudarlas, y se vuelve a pedir, no debiéndose dar más que una vez. Declaramos y mandamos que la contribución se ha de entender por la primera vez y no más, si Nos, avisados de ello, no proveyéremos otra cosa"7.

En la Diócesis de Quito hubo mala voluntad y también descuido respecto a la construcción de varias iglesias parroquiales. El Ilmo. Señor Peña, en su primera visita pastoral, pudo constatar que "en los más pueblos, así de españoles como de indios, están por edificar iglesias"; y, escribiendo al Rey, el benemérito Prelado, después de manifestarle la situación lamentable de varias Parroquias de la Diócesis, le decía: "Vuestra Alteza, por su Real Cédula, tiene mandado que a su costa e de los Encomenderos estantes e indios de la comarca se edifiquen; Vuestra Alteza las mande edificar y proveer de dónde se edifiquen, pues dello tanta obstinación hay" 8 .

Con esta nueva disposición real ya no habrían dudas, pues, en adelante, para sufragar los gastos de la construcción de iglesias, ordenaba el Rey que "se aparta de los tributos, que los indios hubieren de dar a Nos y a sus Encomenderos cada año, lo que fuere necesario, hasta que las igle- 


\section{6 / Augusto E. Albuja}

sias estén acabadas, con que no exceda de la cuarta parte de los dichos tributos; y esta cantidad se entregue a personas legas, nombradas por los Obispos, para que la gasten en hacer las iglesias a vista y parecer, y con licencia de los dichos Prelados" 9 . Fue tal la solicitud del Rey, pues pedía a todos los Prelados de las Indias que cada uno en su Diócesis vigilase porque "las iglesias comenzadas se acaben de edificar, levanten y reparen las arruinadas, y hagan de nuevo las que fueren menester, y todo lo demás necesario para su servicio, sin permitir exceso ni desorden, y advirtiendo a los Virreyes y Gobernadores de lo que conviniere y pareciere, para que ayuden por sus partes a lo referido"10. Y para evitar posibles dificultades, en caso de que personas particulares edificasen iglesias, el segundo Concilio limense disponía que se pidiera siempre la respectiva licencia del Obispo 11 "so pena que todos los gastos hechos en tal edificio los torne a pagar de nuevo a la iglesia"12. De modo que, sin la licencia expresa del Prelado diocesano, estaba prohibido tanto el edificar una iglesia como el continuar la obra comenzada; de esta manera se evitaba que construyesen iglesias en lugares nada convenientes, solamente por el gusto y comodidad de unos pocos, en perjuicio de la mayoría de los feligreses; también estaba prohibido construir iglesias demasiado pequeñas, so pretexto de ahorrar dinero, en beneficio de tal o cual encomendero.

Ya que los curas y doctrineros debían prestar especial atención al edificio de la iglesia parroquial, si amenazaba ruina en caso de que la reparación no fuese inmediata, entonces, sin necesidad de pedir licencia al Prelado, pero sí con el parecer del mayordomo, podían dichos curas y doctrineros sufragar los gastos tomando de los fondos parroquiales lo necesario; fuera de este caso, ninguno de ellos podía gastar, sin licencia del Ordinario, "más de cincuenta pesos por año, so pena que lo que más gastare, lo vuelva a la iglesia de su propia hacienda"13.

\section{Cosas necesarias para el culto}

No basta construir el edificio destinado a iglesia, si no se le provee de las cosas necesarias para el culto divino. Siendo la iglesia el lugar 
destinado a la celebración del culto religioso, en cuanto sea posible se debe disponer de ornamentos, vasos sagrados, campanas, etc. dignos del fin que los hombres se proponen, a saber, rendir culto a Dios.

Si los Sumos Pontífices concedieron a los Reyes Católicos y a sus sucesores grandes privilegios, les impusieron también la obligación "de erigir iglesias, dotándolas de todo lo necesario, a fin de que se pudiese atender con ello decorosamente tanto al material como al personal del culto divino" 14 . De donde, para cumplir fielmente con su grave responsabilidad y corresponder a los deseos de los Sumos Pontífices, el Rey disponía diciendo: "Rogamos y encargamos a los Arzobispos y Obispos de nuestras Indias que, informados por sus personas o las de sus Visitadores del estado que tienen las fábricas de Iglesias de sus distritos en los pueblos de españoles e indios, estancias y asientos de minas, y la decencia con que está colocado el Santísimo Sacramento, cálices y ornamentos, y todo lo demás que pertenece al culto divino ... nos avisen de lo que hicieren, y de dónde y cómo se podrá socorrer a la fábrica, ornamentos y servicio de las iglesias" 15 .

Hacia el año 1567, hallándose el Ilmo. Señor Peña en Lima para la celebración del segundo Concilio provincial, expuso al Presidente Castro las necesidades de la Diócesis de Quito, esperando que acatara la solución que por ese entonces parecía más acertada, pues "las más de las iglesias o todas son paupérrimas, les haga vuestra Señoría merced de los dos novenos para el ornato y sustento de las cosas necesarias, tal como $\mathrm{Su}$ Majestad hasta agora lo ha hecho y se tiene cierto lo confirmará"16.Tres años más tarde, con ocasión de la primera visita pastoral, habiendo constatado que la mayor parte de las iglesias de las Doctrinas de indios no estaban bien atendidas como era de suponerse, el Ilmo. Señor Peña se vio obligado a dirigir una carta al Rey, en la que el celoso Obispo se expresaba en estos términos: "en los pueblos de indios, donde hay edificadas iglesias, las más están sin puertas e cerraduras e ornato de altar, sin ornamentos ni campanas ni otras cosas con que se administren los santos sacramentos. Vuestra Alteza mande a los Encomenderos o a quien lo ha de proveer con brevedad que provean" 17 . 
¿Qué debemos pensar frente a esta situación de varias iglesias de la Diócesis de Quito? ¿Atribuir, tal vez, al Rey el descuido de no haberse puesto en práctica las disposiciones relacionadas con el culto divino? Juzgar de esta manera sería un absurdo, porque la culpabilidad no la tenía el Rey sino sus subalternos, especialmente aquellos que eran los primeros llamados a poner el remedio, es decir, los señores Encomenderos. Cuando tratamos de ellos, expusimos cuáles eran sus derechos y cuáles sus obligaciones. Lo que sucedía era que reclamaban lo primero, olvidándose de lo segundo; de ahí tanta penuria en las iglesias de los indios.

En realidad, el Rey descargaba sus responsabilidades en los Encomenderos; por consiguiente, estos debían proveer de todo lo necesario para el culto divino, desde los ornamentos sagrados hasta el vino y la cera, sin excluir el correspondiente salario de los curas doctrineros. Solamente en el caso de que la Encomienda hubiese sido incorporada a la Corona, las obligaciones que correspondían al Encomendero pasaban entonces a los Oficiales Reales ${ }^{18}$. Pero también tengamos en cuenta que en ese tiempo para edificar una iglesia, en cualquier Diócesis de las Indias, los gastos debieron ser ingentes, tanto para los indios como para sus Encomenderos; de ahí que el Rey había ordenado que con el parecer del Gobernador y del Prelado, los oficiales de la Real Hacienda proporcionaran "un ornamento, un cáliz con patena para celebrar el Santo Sacrificio de la Misa, y una campana, por una vez, al tiempo que la iglesia se fundare"19.

Y siguiendo la vida de las Parroquias y Doctrinas con relación a sus respectivas iglesias y objetos de culto, advirtamos que en la época del Ilmo. Señor Solís se consiguió cierto progreso; sin embargo algunas iglesias necesitaban de medios económicos para guardar el decoro y la decencia que les eran debidos. Al igual que su predecesor en la Sede de Quito, el Ilmo. Señor Solís había querido poner en práctica ciertas órdenes dadas por el Rey; pero, como no le fue posible porque encontró serias dificultades, se quejaba ante el Monarca con estas palabras: “...Item, estando tan bien ordenado en la Ses. 3, cap. 87 del dicho Concilio limense de 83 que los Obispos tengan mucho cuidado en hacer proveer las iglesias de los indios a costa de los Encomenderos y como mejor pudieren, como también 


\section{Doctrinas y Parroquias del Obispado de Quito /139}

lo manda el santo Concilio de Trento en la Ses. 21, cap. 7, y Vuestra Majestad me lo tiene mandado por particulares Cédulas, haciendo relación de la grande necesidad que las iglesias tienen, por relación verdadera que de ello se ha dado a Vuestra Majestad, vuestro Presidente y Oidores me lo han estorbado diciendo que no me entremeta en lo dicho, porque es entremeterme en la jurisdicción real; y cuando los sacerdotes curas, viendo que yo no lo puedo remediar, acuden a esta Real Audiencia a pedir remedio, se les responde con dar traslado al Encomendero, haciéndolo pleito ordinario, lo cual es causa que los sacerdotes, por no pleitear y evitar trabajo, lo dejan y así se quedan las iglesias con la misma indecencia y necesidad que Vuestra Majestad le ha informado, que es menos de lo que yo, por vista de ojos, he visto, y debía bastar para remediar esto que, pues, el Obispo lo ve por sus ojos y por sus visitadores, se les diese crédito y se les dejase remediar, pues se ve que los Encomenderos lo han de contradecir" 20 .

Al poco tiempo de haber dirigido desde Quito el pliego de quejas al Rey, el celoso Obispo Solís salió de la ciudad para hacer su primera visita pastoral a la Diócesis. Cuando se hallaba en la ciudad de Loja, donde celebró su segundo Sínodo del 15 al 24 de agosto del año 1596, y como había constatado la situación lamentable de no pocas iglesias de las Doctrinas de indios, por culpa precisamente de los Encomenderos, en la constitución cuarta de dicho Sínodo y que lleva por título "En que se provee a las necesidades de las iglesias de los indios", adoptó medidas rigurosas para restablecer el decoro religioso y proveer de ornamentos y demás cosas necesarias para el culto. "Muchas iglesias de los indios -son palabras del Obispo Solís en Loja, en el tercer Sínodo diocesano- padecen grande necesidad de ornamentos y de todo lo necesario para el culto divino, como lo hemos visto en nuestra visita general que vamos haciendo, de que hemos tenido grande sentimiento; por lo cual, si no se diese alguna traza para remediar esta falta, el culto divino no se podría celebrar sino es con mucha indecencia, y aunque es verdad que los Encomenderos, por los Concilios provinciales y sobre todo el de Trento y por Cédulas de Su Majestad, están obligados a suplir esta falta, muchos Repartimientos hay tan 
pobres que no podrían suplir esta carga. Por tanto, sancta Synodo approbante, nos ha parecido dar este orden y traza para suplir las necesidades presentes, forzosas en todas aquellas iglesias que hubiese necesidad de alguna cosa para el culto divino, se provea a costa del Encomendero y, para que esto no haya dilación ni excusa alguna, damos poder a nuestros Vicarios -arciprestes- para que en sus distritos puedan compeler a los dichos Encomenderos a suplir esta necesidad por cualquiera rigor, aunque sea con censuras de excomunión mayor" 21.

Asimismo, como las iglesias merecen todo respeto y reverencia no sólo de parte de los sacerdotes, sino también de los fieles, el Rey, deseando que los indios, neófitos en la fe, tuviesen este respeto y reverencia en esos lugares destinados a rendir culto a Dios, había legislado diciendo: "Defendemos y prohibimos a todas y cualquier persona de cualquier estado y calidad que sean, asistir en las iglesias ni monasterios: arrimados, ni echados sobre los altares, ni pasearse al tiempo que se dijeren las misas, celebraren los oficios divinos, y predicaren los sermones, ni tratar, ni negociar en las iglesias ni monasterios en cualesquier negocios, ni poner impedimento a que se digan los divinos oficios, ni estorbar, ni retraer de su devoción a las personas que a las iglesias ocurrieren a los oir". Y dirigiéndose a sus oficiales, les pedía que "hagan guardar y guarden con el rigor que convenga la inmunidad eclesiástica en las cosas que conforme a derecho de estos nuestros Reinos de Castilla se debe guardar, y tengan muy particular cuidado con la autoridad de los Prelados y ministros de las iglesias, para que las cosas del servicio de Dios Nuestro Señor y culto divino se hagan con la decencia conveniente, y ocasione a los naturales mayor edificación y para su conversión a nuestra santa fe católica" 22 .

\section{Misa "pro populo"}

Hasta la celebración del Tridentino ninguna ley general prescribía esta obligación de todos los párrocos de decir la misa pro populo los días domingos y fiestas; sin embargo, leyes y costumbres particulares la establecieron en algunas Diócesis ${ }^{23}$. 


\section{Doctrinas y Parroquias del Obispado de Quito /141}

El Concilio de Trento, al dar el siguiente decreto: “Cum proecepto divino mandatum sit omnibus, quibus animarum cura commissa est, oves suas dignoscere, pro iis sacrificium offerrre..." 24 , solamente recordaba la obligación de celebrar por los fieles, pero no trató expresamente de la misa pro populo. Más tarde, Benedicto XIV, por la Constitución "Cum Semper" del 19 de mayo de 1744, imponía la obligación de aplicar la misa pro populo los domingos y fiestas de precepto. Pío IX en la Constitución "Amantissimi" del 1 de mayo de 1858, declaraba que se cumpliese dicha obligación, aún en las fiestas de precepto suprimidas. Y, por último, León XIII, el 10 de junio de 1882, en la Constitución "in suprema" obligaba también a los obispos aplicar la misa pro populo, pues hasta esa fecha había sido exclusiva de los párrocos y vicarios ${ }^{25}$.

Aplicar la misa pro populo significa ofrecer el santo sacrificio de la misa por las necesidades e intenciones de los feligreses, sin poder recibir estipendio alguno. Según la legislación actual, la obligación de aplicar la misa pro populo incumbe a los Obispos Residenciales ${ }^{26}$, a los Vicarios y Prefectos Apostólicos y Prelados territoriales 27 , a los párrocos ${ }^{28}$, a los Administradores diocesanos ${ }^{29}$ y administradores parroquiales ${ }^{30}$. Por tanto, los vicarios parroquiales están exentos de aplicar la misa pro populo ${ }^{31}$.

Esta aplicación de la misa por el pueblo los domingos y días de fiesta ${ }^{32}$ es una obligación personal del párroco, quien debe cumplir por sí mismo, a menos que estuviera legítimamente impedido ${ }^{33}$. Además dicha misa conviene celebrarla en la iglesia parroquial, a no ser que circunstancias especiales obligaren al párroco a decirla en otro lugar ${ }^{34}$.

Para que los feligreses pudiesen oir misa los domingos y fiestas de precepto, el segundo Concilio limense exhortaba a los Obispos que, en sus respectivas Diócesis, concedieran fácilmente a sus párrocos la facultad de decir dos misas, siempre que celebren en dos pueblos distintos ${ }^{35}$. Según esto, el segundo Sínodo diocesano de Quito, "en conformidad de lo proveído por el Concilio provincial del año de setenta y siete", concedía "licencia y facultad, por la vía que más convenga y ha lugar de derecho, a todos los curas, así de españoles como de indios de este Obispado, para que puedan decir dos misas, ofreciéndose necesidades obligatorias a su 


\section{2 / Augusto E. Albuja}

oficio, los domingos y fiestas de guardar de precepto, en dos iglesias, estando tan distantes y apartadas que cómodamente las personas que asistieren en la una iglesia no puedan acudir a oir misa a la otra; y habiendo otro sacerdote que diga misa en las dichas iglesias o pueblo -dice la constitución sinodal -en tal caso no puede el dicho cura decir las dichas dos misas, sino solamente una, pues, con el otro sacerdote se satisface la necesidad; ni pueda el dicho cura, en el mismo pueblo, decir las dichas dos misas aunque no haya otro sacerdote en el dicho pueblo, y las misas que dijeren sea por los naturales"36. De las últimas palabras se desprende claramente que el Ilmo. Señor Solís, al conceder la facultad de binar, imponía a todos los doctrineros de su Diócesis la obligación de aplicar las dos misas por el pueblo. Pero si otro sacerdote decía una de las dos misas, entonces éste no estaba obligado a aplicar por el pueblo, ya que tal obligación es del párroco por razón del beneficio, y, por tanto, en estos casos se debía aplicar por el pueblo solamente la una misa, o sea la que celebraba el cura párroco o doctrinero.

El tercer Sínodo, celebrado en 1596, introdujo una modificación, obligando tan sólo a aplicar pro populo una de las dos misas de binación, y no las dos, como fue ordenado en 1594, pues "cerca de la constitución 32 -del Sínodo anterior- donde se ordena que los curas puedan decir dos misas a los indios donde hubiere necesidad", el Obispo Solís declaraba que "diciendo la una misa de las dos por sus feligreses, el cura tenga cumplido con su obligación, y esto en las fiestas de los indios" 37.

A pesar de que tratemos de la misa "pro populo", no estará por demás añadir algo acerca de la "Oración Imperada".

Según el Tridentino, los párrocos, y, por tanto, en la Diócesis de Quito también los doctrineros, ya que eran verdaderos párrocos como advertíamos al principio de esta obra, al menos los domingos y días de precepto debían celebrar la misa para que los feligreses puedan oirla y también cuando las necesidades espirituales de la parroquia lo exigiesen como en las velaciones, entierros, etc. ${ }^{38}$. Sin embargo suponemos que los sacerdotes encargados de las Parroquias y Doctrinas, no se contentarían con decir la misa, con más o menos frecuencia, principalmente cuando esta- 
ban obligados por su ministerio, sino que procurarían decirla todos los días. Esto supuesto, el segundo Sínodo quitense ordenaba que se dijera diariamente la oración imperada que se usaba en España; y para evitar alteraciones en el texto de dicha oración, se la daba a conocer a todos; y para que también nosotros la conozcamos, he aquí textualmente:

"Et famulos tuos Papam et Philipum Regem nostrum et principem cum prole regia populo sibi commisso et exercitum suum ab omni adversitate custodi; et Antistem -Antistitem-nostrum et Senatum Regalem pacem et salutem nostris concede temporibus et ab Ecclesia tua cunctam repelle nequitiam, et gentes indorum gratia tua illuminentur et in fide catholica confirmentur, et gentes paganorum et hereticorum dexterae tuae potentia conterantur. Per Dominum Nostrum Jesum Christum Filium tuum..."39.

Fiestas de precepto y días de ayuno y abstinencia

a) Fiestas de precepto

Ya en tiempo de los Apóstoles se observaba el domingo como día festivo, a fin de recordar la resurrección del Señor. En los primeros siglos se introdujeron algunas fiestas de precepto como Epifanía, Navidad, Circuncisión, Pascua, Pentecostés y Purificación de la Santísima Virgen. Hacia el siglo VII apareció el primer catálogo de fiestas de precepto, debido a los Concilios particulares y a los Obispos. Después se añadieron las fiestas introducidas por costumbre observada por el pueblo. A mediados del siglo XVII el número de fiestas de precepto fue tan excesivo que el Papa Urbano VIII, en la Constitución "Universa", del 13 de septiembre de 1642, redujo el número y pidió a los Obispos que se abstuvieran de introducir nuevas fiestas. Y, finalmente, el Sumo Pontífice San Pío X, en el Motu Propio "Supremi disciplinae", del 2 de julio de 1911, hizo una última reducción, quedando solamente ocho días de precepto, fuera del domingo, a los que se añadieron después las fiestas de San José y Corpus Christi ${ }^{40}$. De esta forma, según la legislación canónica actual, son días de pre- 
cepto en la Iglesia Universal, a más de los domingos, los diez días siguientes: Navidad, Santa María Madre de Dios, Epifanía, Ascensión y Corpus Christi, Inmaculada Concepción y Asunción de María Santísima, San José, los Santos Apóstoles Pedro y Pablo, y la fiesta de Todos los Santos ${ }^{41}$.

Ya que tratamos de las Doctrinas y Parroquias de la Diócesis de Quito en la segunda mitad del siglo XVI, no dejará de interesarnos saber qué días de fiesta de precepto estaban en vigencia en aquella época. Al señalar los días de precepto, el Ilmo. Señor Peña hacía una distinción entre españoles e indios, pues éstos, gracias a la Bula "Altitudo", del 1 de junio de 1537, gozaban de los privilegios concedidos por Paulo III y, por tanto, sus fiestas de precepto habían quedado reducidas a 13, fuera de los domingos $^{42}$. Asimismo, considerando la gran devoción que tenían los indios a Todos los Santos y a los bienaventurados Santo Domingo y San Francisco, a más de las fiestas de precepto señaladas por el primero y segundo Concilio limense, "les mandamos guardar-decía el Obispo Peña- el día de Todos los Santos y Santo Domingo y San Francisco". Para los españoles, en cambio, el número de fiestas de precepto llegaba a 41, como indicaremos a continuación.

Advertimos que las fiestas que llevan asterisco $(*)$ son las que debían observar tanto los indios como los españoles; por lo demás, la lista que presentamos corresponde a sólo los españoles, según decreto del Sínodo quitense $\mathrm{e}^{43}$. 
Fiestas de precepto en la Diócesis de Quito según el Primer Sínodo de 1570

Enero

Circuncisión*

Epifanía *

San Sebastián

Abril

San Marcos

Julio

La Visitación

Sta.Ma. Magdalena

Santiago

Octubre

San Francisco*

San Lucas

SS.Simón y Judas
Febrero

Purificación*

San Matías
Marzo

La Anunciación*
Mayo

S.Felipe y Santiago

La invención de la

Santa Cruz

Agosto

Santo Domingo*

la Transfiguración

San Lorenzo

Asunción*

San Bartolomé

Noviembre

Todos los Santos*

Sta. Catalina

San Andrés
Junio

San Bernabé

S.Juan Bautista

Stos. Pedro y Pablo*

Septiembre

Natividad de María*

San Mateo

San Miguel
Diciembre

Sto. Tomás

Inmac.Concepción

Navidad * 
Además, los españoles debían guardar las fiestas de la Ascensión, Corpus Christi y los tres días siguientes a la Navidad, Resurrección y Pentecostés. En cambio, los indios estaban obligados a las fiestas de la Ascensión, Corpus Christi (al igual que los españoles) y al primer día que seguía a Navidad, Resurrección y Pentecostés.

Más tarde, al celebrarse el Concilio provincial de 1583, Santo Toribio de Mogrovejo, Arzobispo que fue de Lima, considerando que los días festivos de precepto para los españoles eran muy numerosos, con el parecer de los obispos sufragáneos y de los asistentes al Concilio, redujo a 35 las fiestas que los españoles debían guardar, a más de los domingos, en toda la provincia eclesiástica. Pero, al señalar los días de precepto para los naturales, el Santo Arzobispo de Lima decía: “... mas, los nuevos en la fe, que son los indios, a los cuales la Iglesia, con piedad de Madre, les ha aliviado, en gran parte, de la carga de sus preceptos, los días que serán obligados a guarda, conforme al estatuto del Sínodo provincial pasado -se refería al Concilio limense de 1567- son los siguientes: primeramente, todos los domingos del año, como la Iglesia Universal siempre los guarda”, y luego les señalaba siete fiestas del Señor, cuatro de la Santísima Virgen y una de los Santos. (Estos 12 días de precepto se señala también con asterisco $\left(^{*}\right)$ al dar a conocer la lista general de las fiestas de los españoles). "Si quisieren, empero,-proseguía el Arzobispo de la ciudad de los Reyesalgunos de los indios guardar otros días de fiesta de los que nosotros guardamos -es decir de las fiestas que obligaban a sólo los españoles- y no trabajar ni hacer obra servil, tengan libertad para hacerlo conforme a su devoción; y no sean compelidos por persona alguna a trabajar en los tales días de fiestas que ellos quisieren guardar" 44 . 
Fiestas de precepto en la Arquidiócesis de Lima y en las demás Diócesis sufragáneas, según el concilio provincial de $1583^{45}$ :

Fiestas del Señor.

- para españoles ......................... 11

- para indios ............................ 7

Navidad*

Circuncisión*

Epifanía *

Resurrección (para los españoles los dos días siguientes; para los indios sólo un día)

Ascensión*

\section{Fiestas de la Santísima Virgen:}

Inmaculada Concepción

Natividad de María*

Anunciación*

Fiestas de los Santos.
Pentecostés (para los españoles los dos días siguientes; para los indios sólo un día)

Corpus Christi*

Invención de la Santa Cruz

La Transfiguración

- para españoles

- para indios

4

Purificación*

Asunción*

- para españoles

- para indios
S. Esteban
SS. Pedro y Pablo*
S. Juan, Ap. y Ev.
Santiago Ap.
S. Miguel Arcángel
S. Matías, Ap.
S. Lorenzo
S. Marcos
S. Ma.Magdalena
S. Lucas
SS. Felipe y Santiago
S. Bartolomé
SS. Simón y Judas
S. Bernabé
S. Mateo
Sto. Tomás
S. Andrés
S. Juan Bautista 
"Fuera de éstos- dice la constitución conciliar, refiriéndose a los domingos y los 35 días de precepto correspondientes a españoles- si hubiere algunos otros días de fiestas introducidas por costumbre aprobada o por privilegios legítimos, también se guarden con devoción, en cada tierra los suyos" 46 .

Las fiestas de precepto, señaladas por el tercer Concilio de Lima en 1583, estaban en vigencia en la Diócesis de Quito hasta después de la celebración del segundo Sínodo diocesano de 1594, porque éste, en vez de modificarlas, más bien ratificaba la obligación de seguir observándolas. Además, dicho Sínodo añadía algunas otras más, a saber: las fiestas de San Agustín, San Francisco y Santo Domingo, por ser los Fundadores de las Ordenes Religiosas existentes en Quito; las advocaciones de las Parroquias de la capital: San Sebastián, San Blas y Santa Bárbara; además, las festividades de San Jerónimo, de San Luis Rey de Francia, Patrono del Seminario, de Santa Lucía y la fiesta de la Visitación. La festividad mariana de la Expectación no se señalaba con carácter obligatorio, mas "quien quisiera guardarla por devoción -decía el Ilmo. Señor Solís- le concedemos cincuenta días de perdón”.

Así pues, según este Sínodo, en la Diócesis de Quito los españoles debían guardar un total de 45 días de precepto, fuera de los domingos, a saber: las 35 fiestas ordenadas por el Concilio de 1583, más las 10 señaladas por el Sínodo de 1594. "Y mandamos -añadía el Prelado- que fuera de estas fiestas y las que mande el Santo Concilio, no se guarden otras, y quien tuviere devoción las puede guardar" 47.

El sínodo de 1596 vino a modificar un tanto en lo que respecta a las fiestas que fueron añadidas por el Sínodo anterior de 1594; así tenemos que las fiestas de San Sebastián, San Blas, Santa Bárbara, San Jerónimo, San Luis Rey de Francia y Santa Lucía, se las debía guardar solamente en la ciudad de Quito "y en las ciudades donde hubiere las tales vocaciones y no más, porque para los indios son de grande inconveniente las muchas fiestas" 48 .

Estas últimas palabras empleadas en la constitución sinodal "porque para los indios son de grande inconveniente las muchas fiestas", pueden hacernos pensar que las 10 fiestas añadidas por el Sínodo de 1594 obligaban tanto a españoles como a indios. Creemos que tales fiestas de 
precepto fueron exclusivamete para los españoles y de ninguna manera obligaban a los naturales; porque, en primer lugar, el título que lleva la constitución 13 del segundo Sínodo "De las fiestas que han de guardar los españoles, demás de las que se ordena en el Concilio provincial de 83", es claro y no puede tergiversarse; y, en segundo lugar, porque el Ilmo. Señor Solís no habrá querido agravar a los indios con la observancia religiosa de tantas fiestas, teniendo en cuenta que el mismo Sumo Pontífice Paulo III se había manifestado muy benigno con los naturales de las Indias al concederles grandes privilegios en este sentido. Por tanto, las palabras del Prelado, "porque para los indios son de grande inconveniente las muchas fiestas", tienen su explicación. Ellas constituían una advertencia hecha a los doctrineros para que vigilaran a los indios porque, so pretexto de celebrar sus fiestas y no tener que trabajar, se dedicaban a sus borracheras, a las que eran muy proclives. Asimismo, las muchas fiestas de los españoles constituían un grave inconveniente para los indios, porque como aquellos no trabajaban en esos días, eran considerados como privilegiados, ya que el indio por naturaleza está inclinado a la ociosidad y consideraba el trabajo, no como un medio impuesto por Dios para poder subsistir y hacer méritos para el Cielo, sino como un gran sacrificio del cual no sacaba ningún provecho personal. En el presente cuadro podemos constatar la diferencia numérica de las fiestas de españoles y de los naturales, según los tres Sínodos de Quito y el principal de los Concilios limenses, el celebrado en 1583, que tanta trascendencia tuvo en la Arquidiócesis de Lima y en las demás Diócesis sufragáneas.

\begin{tabular}{|lcccl|}
\hline Año & $\begin{array}{c}\text { 1o. Sínodo } \\
(1570)\end{array}$ & $\begin{array}{c}\text { 3o. Concilio } \\
(1583)\end{array}$ & $\begin{array}{c}\text { 2o. Sínodo } \\
(1594)\end{array}$ & $\begin{array}{l}\text { 3o. Sínodo } \\
(1596)\end{array}$ \\
\hline Españoles & 41 & 35 & 45 & $\begin{array}{l}45 \text { (Quito Ciudad) } \\
\text { (Diócesis en general) } \\
\text { Indios }\end{array}$ \\
\hline DIFERENCIA & 25 & 12 & 12 & 12
\end{tabular}


La finalidad de un día de precepto es doble: rendir culto a Dios mediante la asistencia a la santa misa, y abstenerse de los trabajos para disfrutar de un justo descanso ${ }^{49}$.

En esta segunda mitad del siglo XVI, en las Indias la observancia de los días de precepto fue rigurosa, a tal punto que se imponía castigos a aquellos que no dieran facilidades a los indios para cumplir en dichos días con sus obligaciones de cristianos. "Mandamos -decía el Rey- que ninguno sea osado de impedir a los indios, aunque sean sus criados, el ir a las iglesias y monasterios a oír misa, y aprender la doctrina cristiana los domingos y fiestas de guardar, pena de doscientos mil maravedíes, la mitad para nuestra Cámara y Fisco, la otra mitad para la fábrica de dichas iglesias" 50 . El Monarca deseaba no solamente que los indios oyeran misa los domingos y las fiestas propias para ellos, sino que, además, para evitar abusos por parte de los Encomenderos, dictaba esta otra ley: "que los domingos y fiestas de guardar no trabajen los indios, ni negros, ni mulatos; y que se dé orden que oigan todos Misa y guarden las fiestas, como los otros cristianos son obligados; lo cual se ha de entender y entienda en las fiestas que, según nuestra Santa Madre Iglesia, Concilios Provinciales o Sinodales de cada Provincia, estuvieren señaladas por de precepto para los dichos indios, negros y mulatos" 51 .

También el primer Sínodo de Quito se preocupó de tomar ciertas medidas necesarias para que en todas las Parroquias de la Diócesis se observasen fielmente los días de precepto, y por esto pedía que los curas de españoles "compelan a sus parroquianos a oir misa todos los domingos y fiestas de guardar; e no consientan que los dichos días se abran tiendas de mercaderías, ni los oficiales trabajen en ningún oficio, ni los arrieros ni caminantes caminen en los dichos días, ni permitan que los indios, así mitayos como indios yontales, ni yanaconas, ni ningunos, ni mestizos, se ocupen en traer yerba, leña e otras cargas que sus Encomenderos o señores, a quien sirven, les compelen traer" imponiendo al Encomendero culpable una multa de medio peso la primera vez y la segunda un peso ${ }^{52}$.

En cambio, sobre este punto de la obligación de la misa los días de precepto, el tercer Sínodo de Quito fue demasiado estricto, pues im- 


\section{Doctrinas y Parroquias del Obispado de Quito /151}

ponía como pena veinticuatro azotes para el indio que, sin causa suficiente, dejaba de oirla un domingo o un día de fiesta; y si se trataba de un cacique, se le debía imponer una multa de media libra de cera para la iglesia de su Doctrina ${ }^{53}$.

Hermosa y a la vez edificante era la costumbre que había en beneficio de los indios que servían en casas particulares, pues "los domingos y fiestas los mitayos no traen leña ni yerba; por la mañana se les dice misa a todo el servicio, y a la una, después de mediodía, les enseñan lo que el cristiano está obligado a hacer y creer, y en algunas casas se les enseña de ordinario cada noche, estando de rodillas delante de alguna imagen" 54 .

\section{b) Días de ayuno y abstinencia}

Gracias a la Bula "Altitudo", del 1 de junio de 1537, el Sumo Pontífice Paulo III señalaba para los indios como días de ayuno los siguientes: las vigilias de Navidad y Pascua de Resurrección y todos los viernes de Cuaresma. Respecto a la abstinencia, los naturales, al igual que los españoles, podían usar de los privilegios concedidos en la Bula de la Cruzada o de San Pedro; por tanto, "declaramos -dice una constitución del Concilio de 1551- que pueden comer carne los sábados, por la falta que tienen -dichos indios- de mantenimiento" 55 .

Para los españoles, los días de ayuno que señalaba el segundo Sínodo de Quito eran los siguientes: toda la Cuaresma, excepto los domingos; los miércoles, viernes y sábado de la segunda semana de Cuaresma, del octavario de Pascua del Espíritu Santo; después de la Exaltación de la Santa Cruz, y después de la fiesta de Santa Lucía. Además, las vigilias de Navidad, de Pentecostés, de San Juan Bautista, de San Lorenzo, de la Asunción de la Santísima Virgen al Cielo, de Todos los Santos, y de todos los Apóstoles, excepto de San Juan Evangelista y de San Felipe y Santiago. Si la vigilia caía en domingo, el ayuno se adelantaba al sábado. Fuera de estos días señalados, si alguno quería guardar ayuno en otros días, se le concedía por cada vez cuarenta días de perdón ${ }^{56}$. 
A nadie le era lícito comer carne en los días prohibidos; se necesitaba el parecer tanto del médico como del sacerdote. También estaba prohibido vender o comprar carne en dichos días. En los tres días de Letanías o Rogaciones no era obligatoria, pero se recomendaba "la loable abstinencia de carne" 57 .

Y si alguno quebrantaba esta ley de la abstinencia, no teniendo causa justa, merecía veinticuatro azotes en público, en tratándose de un indio; si era cacique, la pena se le conmutaba por una libra de cera a la primera vez, y, no enmendándose, se podía llegar incluso a la imposición de un mes de prisión ${ }^{58}$. 
Doctrinas y Parroquias del Obispado de Quito /153

\section{NOTAS:}

1 Recopilación, lib. I, tit.2, ley 1.

2 GÓMEZ HOYOS, Las Leyes de Indias, 198.

3 Recopilación, lib.I, tit.2, ley 1.

4 Segundo Concilio Limense, Parte Primera, c.84.

5 AGI, Indiferente General, Leg.2.859, lib.2, f.5v á f.6v.

6 Recopilación, lib.I, tit.2, ley 3.

7 Recopilación, lib.I, tit.2, ley 5.

8 Apéndice \# 10.

9 Recopilación, lib.I, tit.2, ley 6.

10 Recopilación, lib.I, tit.2, ley 16.

11 Segundo Concilio limense, Parte Primera, c.60.

12 Ibidem, c.34.

13 Ibidem, c.60.

14 LEVILLIER, Organización, I, Prólogo, p.XLII.

15 Recopilación, lib.I,tit.2, ley 16.

16 Apéndice \# 5.

17 Apéndice \# 10.

18 Recopilación, lib.I, tit.2, ley 23.

19 Recopilación, lib.I, tit.2, ley 7.

20 Apéndice \# 49.

21 Tercer Sínodo de Quito, Const.4 (AGI, Quito, leg.77).

22 Recopilación, lib. I, tit.5, ley 1.

23 REGATILLO, Institutiones luris Canonici, I,343, \# 499.

24 Conc. Trid., Sess. XXIII, cap. 1 de reform.

25 REGATILLO, Institutiones luris Canonici, I, 343, \# 499.

26 C.I.C. 17, c.339; C.I.C., c.388.

27 C.I.C. 17 , c.306; CIC., c.368.

28 C.I.C. 17 , c.466 \& 1, según el c.339; C.I.C. c.534.

29 C.I.C. 17 , c. 440 ; C.I.C. c. 429.

30 C.I.C. 17, c. $473 \& 1$; C.I.C. c. 540.

31 C.I.C. 17, cc.476 \& 6, $475 \&$ \& 2; C.I.C., c. 549.

32 C.I.C. 17, ,. 466 \&1; C.I.C., c. 534.

33 C.I.C. 17, c.466 \&5; C.I.C. cc.388-534.

34 C.I.C. 17, c.466 \&4; C.I.C., c. 534. 
35 Segundo Concilio limense, Parte Segunda, Const.14.

36 Segundo Sínodo de Quito, Const.32 (AGI, Quito, leg.77).

37 Tercer Sínodo de Quito, Const. 2 (AGI, Quito, leg.77).

38 Conc. Trid., Sess. XXIII, cap.14 de reform.: PENAA MONTENEGRO, Itinerario, lib.I, trat. 3-, Secc. 1-, f.56.

39 Segundo Sínodo de Quito, Const. 12 (AGI, Quito, leg.77).

40 REGATILLO, Institutiones luris Canonici, II, 70, \# 89.

41 C.I.C. $17, c, 1247 \&$ 1; C.I.C. C. $1246 \& 1$.

42 Primer Concilio limense, Parte Primera, Const. 21.

43 Primer Sínodo de Quito, Parte Tercera, c.32 (AGI,Patronato, leg.189, R40).

44 Primer Concilio limense, Acc.4-, cap.9.

45 Ibidem.

46 Ibidem.

47 Segundo Sínodo de Quito, cap.13 (AGI, Quito, leg.76).

48 Tercer Sínodo de Quito, cap. 2, (AGI, Quito, leg.77).

49 C.I.C. 17 , c. 1248 ; C.I.C. c. 1247.

50 Recopilación, lib.I, tit.1, ley 14.

51 Recopilación, lib.I, tit.1, ley 17.

52 Primer Sínodo de Quito, Parte Tercera, c. 10, (AGI, Patronato, leg.189, R40). "Los indios mitayos, que sirven de traer leña y yerba para provisión del pueblo, ganan cada mes peso y dos tomines, de manera que sale por año ca$\mathrm{da}$ indio por quince pesos". "Los indios anaconas -yanaconas- sirven de curar un caballo y llevar una carta cuando se ofrece de un pueblo a otro"... "Un anacona gana dos mantas y dos camisetas y dos pesos en cada un año". (Relaciones Geográficas de Indias, III, 95, \# 175-176).

53 Tercer Sínodo de Quito, Const. 30, (AGI, Quito, leg.77).

54 Relaciones Geográficas de Indias, III, 95, \# 176.

55 Primer Concilio limense, Parte Primera, Const. 21.

56 Segundo Sínodo de Quito, cap. 39, (AGI, Quito, leg. 77).

57 Tercer Concilio limense, Acc. 3-, cap. 41.

58 Tercer Sínodo de Quito, Const.30, (AGI, Quito, leg.77). 


\section{CAPÍTULO IX ADMINISTRACIÓN DE SACRAMENTOS}

La única finalidad por la que sacerdotes y religiosos venían a América era dedicarse a la evangelización para conseguir después la conversión de los naturales a la fe católica. Por tanto, la administración de los sacramentos y el servicio a la iglesia debían constituir su principal preocupación; además, los salarios se los daba por tal cometido. De donde, dedicarse a otros trabajos y negocios, a más de constituir escándalo y causar mal ejemplo a los indios, iba en perjuicio del fin que se trataba de conseguir, a saber, la evangelización del Nuevo Mundo ${ }^{1}$.

La erección de Parroquias en una Diócesis no tiene otro objeto sino las necesidades espirituales de los fieles para conservar e intensificar su vida cristiana mediante la frecuencia de los sacramentos, la catequesis, la predicación de la palabra divina, etc.

Antes de estudiar la legislación conciliar y sinodal respecto a la administración de cada sacramento en particular, en las Doctrinas y Parroquias de la Diócesis de Quito, conviene tener presentes las siguientes advertencias generales hechas por el segundo Concilio provincial de Lima en 1567, en el cual se mandaba:

a) "Que los sacramentos se administren en la Iglesia y antes de comer, si la necesidad no pide otra cosa"2.

b) "Que los sacramentos no se administren sino por el propio cura, o con su licencia, excepto el Bautismo o Penitencia, en caso de necesidad"3.

c) "Con precepto que los sacerdotes no puedan recibir cosa alguna de los indios para administrar cualquier sacramento, ni por darles sepultura, ni por otra cosa sagrada, y si lo recibieren lo vuelvan al 
doble" 4 ; y el tercer Concilio añadía: "Cualquiera conciertos, expreso o tácito, por administrar sacramentos o dar sepultura, los sacros cánones los abominan, como tratos tan feos de simonía pestilencial" 5 .

No debemos creer que desde los primeros años que siguieron a la erección de la Diócesis de Quito se administraban todos los sacramentos, tanto a españoles como a indios. Precisamente, porque los naturales eran neófitos y con poca instrucción, se los excluía de ciertos sacramentos. De ahí que el primer Concilio limense, en la constitución 13, "en que declara qué sacramentos se les han de administrar a los indios", considerando "que esta gente es nueva en la fe, y, conforme al Apóstol, a los nuevos en ella se les ha de dar leche espiritual, y no mantenimiento de que usan los mayores, sancta synodo approbante-decían los Padres Conciliares- mandamos que por el presente, hasta que estén más instruidos y arraigados en la fe y conozcan mejor los misterios y sacramentos, solamente se les administren los sacramentos del Bautismo, Penitencia y Matrimonio. Podrán también los Prelados, si les pareciere y vieren conveniente, comunicarles el sacramento de la Confirmación. Y con sola su licencia, o de su Provisor o Vicario en su ausencia, dar a alguno de los que pareciere que entienden lo que reciben, el Santísimo Sacramento de la Eucaristía"6.

Como del sacramento del Orden se tratará en un capítulo aparte, aquí vamos a exponer la legislación canónico-particular de los demás sacramentos, dedicando una atención especial a las normas dadas para la administración del Bautismo, de la Penitencia y del Matrimonio.

\section{Bautismo}

Siendo el sacramento del Bautismo el primero y principal de todos los demás, se puso especial cuidado para que los indios, infieles aún, lo recibieran dignamente. Y con este propósito, en el primer Concilio limense de 1551 se mandaba que cada indio infiel, antes de ser bautizado, "a lo menos por espacio de treinta días, sea industriado en nuestra fe ca- 


\section{Doctrinas y Parroquias del Obispado de Quito /157}

tólica, dándole a entender, dentro del dicho término, el error y vanidad en que ha vivido, adorando al sol y a las piedras, y a las demás criaturas dejando al Criador"7.

No bastaba que el indio, que iba a recibir el santo Bautismo, asistiera a la instrucción religiosa por el tiempo señalado, había necesidad de que pasara un examen ${ }^{8}$; pero, en tratándose de indios enfermos o de edad muy avanzada, entonces podían "ser bautizados aunque no sepan la doctrina"9.

La norma general que se debía observar en todas las Doctrinas y Parroquias era "que cuando se han de bautizar los indios adultos -decía una constitución conciliar- respondan ellos por sí mismos”, y por esto "sean obligados los curas a tener los catecismos y preguntas hechas en lengua de indios ... so pena de diez pesos"10.

En la Diócesis de Quito, y probablemente en las demás Diócesis del Arzobispado de Lima, surgió un grave inconveniente, pues los Encomenderos exigían de los naturales el pago del tributo, y los curas y doctrineros, cumpliendo las disposiciones conciliares, exigían a su vez la asistencia al curso del catecumenado durante un año. Para evitar dificultades, el Ilmo. Señor Peña, el 15 de febrero de 1569 en la Relación del Obispado enviada al Rey, le exponía: "Item, que en los términos de aquel Obispado hay mucho número de indios por bautizar, por culpa de sus Encomenderos, y conviene a vuestro real servicio que los tales no tributen a sus Encomenderos hasta que los hayan industriado en las cosas de nuestra santa fe católica y bautizado. A Vuestra Majestad suplicamos lo mande proveer ansí, porque será ocasión que los dichos Encomenderos tengan el cuidado que son obligados a los hacer bautizar y industriar en las cosas de san fe (sic) católica"11. El Ilmo. Señor Peña, al dirigir esta solicitud al Monarca, no hacía otra cosa que cumplir con su deber pastoral en favor de los pobres indios. Anteriormente en 1567, el mismo Obispo de Quito había pedido al Presidente Castro en la ciudad de Lima, que exhonerara a los indios del tributo durante el año que lo dedicaban a aprender la doctrina y las demás cosas necesarias para recibir el santo bautismo y ser buenos cristianos $^{12}$. No sabemos si el Presidente Castro consultaría el caso a Felipe II; 
la verdad es que el 12 de abril de 1570 se envió la siguiente Cédula Real: "EL REY.- Presidente y Oidores de Nuestra Audiencia Real que reside en la ciudad de San Francisco de Quito, de las provincias del Perú: por parte de Don Fray Pedro de la Peña, Obispo de esa provincia, se me ha hecho relación que en los términos del dicho Obispado hay mucho número de indios por bautizar por culpa de sus Encomenderos, y para su salvación convenía que no les tributasen hasta que fuesen instruidos en las cosas de la fe y estuviesen bautizados; y me fue suplicado lo mandase hacer proveer, porque sería ocasión que los Encomenderos tengan cuidado que convenía; y, porque Nos deseamos que los dichos indios sean cristianos y tratados e instruidos como tales para que se salven, vos mando que para que el dicho Obispo lo pueda procurar y dar la orden que convenga, como Prelado a cuyo cargo está el remedio de ello, le déis y hagáis dar para ello el favor y ayuda y auxilio del brazo seglar que sea necesario, sin poner en ello impedimento alguno. Fecha en Córdoba, a doce de abril de mil y quinientos y setenta años. YO, EL REY. Por mandato de su Majestad, Francisco de Erazo. Concuerda con el original, Pedro de Robles, escribano público"13.

Esta Real Cédula nos demuestra el espíritu verdaderamente cristiano del Monarca, pues, más le interesaba pagar el tributo a Dios con el mayor número de indios cristianos, que recibir de éstos el tributo monetario. Con esta disposición de Felipe II los indios tuvieron todas las facilidades para dejar su paganismo y recibir la fe de Cristo en las aguas bautismales.

Respecto al Bautismo de los niños, el segundo Concilio limense recomendaba a todos los párrocos y doctrineros que insistiesen "a los indios cristianos que traigan a bautizar a sus hijos o personas que están a su cargo, dentro de ocho días de su nacimiento"14. Pero, como el cura doctrinero no podía estar en todos los caseríos y anejos de su Parroquia, a veces podían darse casos de enfermedad, y, por tanto, peligro de muerte para los niños hijos de cristianos y de infieles, y para que no muriesen sin el bautismo, lo más conveniente era "que en cada pueblo de indios haya alguna persona bien instruida que pueda bautizar, en ausencia del sacerdote, por caso de necesidad". Esta persona debía ser nombrada por el respec- 


\section{Doctrinas y Parroquias del Obispado de Quito /159}

tivo cura, con aprobación del Obispo o del Vicario general o también del Visitador diocesano ${ }^{15}$.

Como el Bautismo de adultos era muy frecuente, se juzgó como una cosa muy corriente y a la vez muy útil y necesaria, señalar en cada pueblo de indios un mismo padrino y una misma madrina para todos los bautizandos; de esta manera se evitaba el impedimento de parentesco espiritual en aquellos que después hubieren de contraer matrimonio ${ }^{16}$.

En cuanto a la administración misma del sacramento del Bautismo, todos los curas debían observar las rúbricas y ceremonias contenidas en el manual pequeño de la Iglesia Romana ${ }^{17}$. Posteriormente entró en vigencia también el manual mexicano en todas las Diócesis de Indias. Y para que los curas supiesen cuál debían seguir, una constitución sinodal del año 1594, sobre el "orden que han de guardar los beneficiados y curas en el administrar los sacramentos", decía: "El número de españoles y naturales es mucho para que los sacerdotes puedan con más brevedad administrar los santos sacramentos, en especial el del Bautismo y de la Extremaunción y otras partes. Por tanto, ordenamos y mandamos que en la administración del santo sacramento del bautismo y extremaunción, puedan usar los sacerdotes el orden del manual mexicano pequeño y del romano pequeño; y si no hubiere copia de los dichos manuales, lo puedan hacer con sus traslados aprobados por nuestro Provisor y autorizados de nuestro escribano, y no en otra manera" 18 .

\section{Confirmación}

Ya que el ministro ordinario del sacramento de la Confirmación es el Obispo ${ }^{19}$, los Prelados de la Diócesis de Quito, en sus visitas pastorales, no se contentaban con visitar las Doctrinas y Parroquias y darse cuenta de cómo cumplían los sacerdotes el ministerio parroquial, sino que, además, ellos personalmente administraban la Confirmación a millares de los naturales. Sin embargo, suponemos que en caso de necesidad, es decir, en peligro de muerte, los mismos párrocos habrán sido diligentes en administrar a los bautizados también el sacramento de la Confirmación para fortalecer su fe. 
160 / Augusto E. Albuja

\section{Penitencia}

El ministro del sacramento de la Penitencia es el sacerdote ${ }^{20}$; pero, para absolver válidamente de los pecados se requiere que el ministro, además de la potestad de orden, tenga facultad de ejercerla sobre los fieles a quienes da la absolución ${ }^{21}$. Los Ordinarios de lugar no deben conceder la facultad o licencia para que un presbítero pueda oir confesiones sino después de un examen previo, a fin de darse cuenta de su idoneidad, a menos que les conste de otro modo 22 .

En la Diócesis de Quito los Ilmos. Peña y Solís fueron muy estrictos en este punto, exigiendo a los sacerdotes un examen previo antes de confiarles una Parroquia o Doctrina; y al sacerdote que encontraban idóneo, le concedían facultades generales; en caso contrario, o le limitaban la jurisdicción para ciertas personas o sencillamente se la negaban ${ }^{23}$.

Como los fieles están obligados a cumplir con el precepto pascual, y por tanto, con la confesión anual, ${ }^{24}$ el segundo Concilio limense prescribía "que los curas, por la Cuaresma, oigan las confesiones de los indios" 25 ; y "si algún cura no supiera la lengua bastantemente -advertía el mismo Concilio en otra constitución- el Diocesano le dé ayuda de otro para el efecto, con parte de su estipendio" 26 .

No porque un párroco o doctrinero tuviese jurisdicción dentro de los límites de su Parroquia o Doctrina, podía, fuera del caso de necesidad, confesar a toda clase de personas. Le estaba prohibido atender las confesiones de los que no fueran sus feligreses, pues cada beneficiado tenía la obligación de enviar al Provisor la lista de los que se habían confesado y de los que no habían cumplido con el precepto pascual. De este modo se quería evitar dificultades, pues esta disposición, nada prudente ni pastoral, contrarrestaba la negligencia de algún doctrinero, ya que los indios se hubieran visto obligados a acudir a otro sacerdote para evitar los castigos si no se confesaban ${ }^{27}$.

La facultad para confesar que tenían párrocos y doctrineros no solamente se limitaba a sus feligreses, sino además no podían absolver de ciertos pecados que estaban reservados. Si hasta 1983 disponía la legisla- 


\section{Doctrinas y Parroquias del Obispado de Quito /161}

ción canónica diciendo: "los que por derecho ordinario pueden conceder la potestad de oir confesiones o pueden decretar censuras, pueden también, excepto el Vicario Capitular y el Vicario General, sin mandato especial, avocar a sí algunos casos, para juzgarlos ellos, limitando la potestad de absolver de los inferiores"28, no deberá extrañar que el Ilmo. Señor Solís, después de haber pedido el parecer de los asistentes al segundo Sínodo diocesano, haya reservado la absolución de algunos pecados cometidos por aquellos que no fuesen indios.

La legislación canónica anterior pedía que los casos reservados sean "muy pocos, a saber, tres o a lo más cuatro, de entre los crímenes externos más graves y atroces, específicamente determinados"; $y$, recomendaba que "no debe mantenerse en vigor la reservación más tiempo del que sea necesario para extirpar un vicio público arraigado o para restaurar la disciplina cristiana tal vez quebrantada" 29 . Como esta reservación dependía del criterio de cada Obispo, no nos extrañe que en la diócesis de Quito, a fines del siglo XVI, los casos reservados llegaban a siete, lo cual demuestra que la moral cristiana estaba muy descuidada.

¿Cuáles eran estos casos reservados? Antes de responder a esta pregunta, advirtamos que los indios, por ser nuevos en la fe, gozaban de grandes privilegios concedidos por Paulo III, y los Prelados también fueron muy benignos con ellos, de ahí que la constitución sinodal, al señalar los casos reservados, dice: "Los casos que en este Obispado reservamos, de todas las personas que no son indios, son los siguientes:

"Lo primero: los incendiarios".

"Lo segundo: los que maliciosamente levantan falso testimonio a algunas personas en algún tribunal, si se hubiere seguido o comenzare a seguir el efecto o se teme se seguirá".

"Lo tercero: los que hurtan algo de las iglesias o monasterios".

"Lo cuarto: los que retienen los diezmos, si no es que hayan enteramente satisfecho".

"Lo quinto: los que conocieren carnalmente algún pariente o parienta suya espiritual".

"Lo sexto: los incestuosos dentro del primero y segundo grado de consanguinidad o afinidad". 
"Lo séptimo: los que hurtan papeles de algún tribunal o procesos de visitas eclesiásticas en los archivos y en otra cualquiera manera; todo lo cual se entiende ultra de los casos que por derecho nos convienen y a nos están reservados"30.

Según esto, los pecados reservados por el Sínodo quitense estaban comprendidos en estos versos que fueron compuestos en aquella época:

"El perjurio judicial,

si daño con él causare;

el que a monasterio hurtare,

a iglesia o a tribunal

algún papel procesal:

quien pagar diezmos rehusa;

el que de pariente abusa, ahora fuere en grado espiritual,

o hasta el segundo carnal;

y el que de incendiar se acusa" 31

La absolución de estos pecados estaba reservada al Ordinario de lugar, es decir, al Obispo y es de suponer que delegaría esta facultad a los vicarios o arciprestes de toda la Diócesis, pues si a éstos, como veremos más adelante, les concedía facultades muy amplias, inclusive la de imponer censuras, con mayor razón, les debió delegar la facultad de absolver de los pecados reservados al Ordinario.

\section{Eucaristía}

Hasta mediados del siglo XVI, los misioneros fueron tal vez demasiado exigentes, respecto a la administración de la Eucaristía a los indios. "En México, en la primera Junta apostólica convocada por Fr. Martín de Valencia, O.F.M., se puso de manifiesto que se les había negado, por neófitos y rudos, pero se dejó a la discreción de los confesores el administrarla. Más adelante, en 1546, en la Junta convocada por el Visitador Tello de Sandoval, los Obispos asistentes fueron de parecer que no se debía negar sino a los poco instruidos en la fe". En cambio, en lo que se refería a la 


\section{Doctrinas y Parroquias del Obispado de Quito /163}

provincia eclesiástica de Lima, "el Arzobispo Loaisa, en su instrucción del año 1545, nada dice acerca de dar la comunión a los indígenas, y este silencio es ya revelador" 32 porque seis años más tarde, en el primer Concilio limense de 1551, se suprime la tal prohibición; sin embargo se necesitaba licencia del Prelado o del Provisor para "dar a alguno de los que pareciere que entienden lo que reciben, el Santísimo Sacramento de la Eucaristía"33. Con el transcurso del tiempo, los Padres Conciliares, reunidos en la ciudad de Lima en el año 1567, considerando que los naturales estaban un tanto más instruidos en la doctrina cristiana, recomendaban a todos los curas y doctrineros que "no dejen de dar el Santísimo Sacramento, en los tiempos determinados por la Iglesia, a los indios que, habiéndoles examinado, hallaren tener noticia y deseo de la comunión" 34 . Y finalmente, el primer Concilio convocado por Santo Toribio de Mogrovejo, deseaba que todos los indios, "a los que su cura hallare bien instruidos y asaz enmendados en sus costumbres, no deje de darles el Sacramento, a lo menos por Pascua de Resurrección"35.

Alonso de la Peña Montenegro, Obispo de Quito a mediados del siglo XVII, refiriéndose a su Diócesis, afirma que muchos curas negaban la Eucaristía a la mayor parte de los indios ${ }^{36}$; y Vargas Ugarte advierte: "En la práctica, este alejamiento del indígena de la sagrada mesa subsistió hasta los tiempos cercanos a nosotros, especialmente en las provincias interiores del Ecuador, Perú y Bolivia y sólo se ha ido desterrando poco a poco, gracias al celo de los misioneros y de algunos párrocos y a la difusión de la enseñanza religiosa" 37 .

¿A qué se debió este alejamiento del indígena de la Eucaristía? Tal vez a la falta de preparación, porque la ignorancia religiosa en que vivió y vive todavía la mayor parte de la población indígena, no tiene como causa principal su capacidad intelectual; se debe sobre todo a la escasez de clero dedicado especialmente a su evangelización. Además, pensamos que probablemente habría otro motivo, pues tal alejamiento de la Eucaristía no sólo existió en las Diócesis de la provincia eclesiástica de Lima sino también en las de México. Si muchos sacerdotes no eran partidarios de admitir a los indios a la Comunión fue, sin duda, por el temor de que se 


\section{4 / Augusto E. Albuja}

cometieran sacrilegios, mas no porque pensaran que el indio, por el hecho de serlo, estuviera excluido de la sagrada eucaristía.

\section{Extremaunción}

No porque los indios estuviesen, en cierto modo, excluidos de la Eucaristía, había razón suficiente para privarles de los últimos sacramentos, especialmente del sacramento de la Extremaunción; antes bien, todos los curas debían administrarlo "a los que estuvieren con peligro de enfermedad mortal, aunque sean indios o negros", decía el segundo Concilio limense 38 ; y en otra constitución mandaba "que a los indios que están en lo último de la vida se les dé el sacramento de la Extremaunción, del cual tienen en aquel trance extrema necesidad para defenderse de las asechanzas del demonio y de los engaños de hechiceros, ministros del diablo"39.

Los curas y doctrineros de la Diócesis de Quito no debían considerarse obligados solamente a administrar este sacramento a los enfermos, sino que, además, debían ayudarlos "a bien morir y les den a entender ordenaba el Sínodo de 1570- que el bien morir sea en gozar los cristianos del descanso y gloria que Dios tiene aparejado a los buenos cristianos que han vivido bien y han hecho buenas obras y confesado sus pecados, y ansi mesmo les den a entender cómo, por virtud de los sacramentos, alcanzamos de Dios remisión y perdón de los pecados, y les aclaren el artículo de fe y resurrección de los muertos, de modo que entiendan que, aunque la muerte vean apartar el cuerpo del ánima, el ánima de los buenos va a gozar de Dios y de la bienaventuranza, e la de los malos va a las penas del infierno. E que otra vez se han de juntar los cuerpos y las ánimas para venir al juicio final" 40 .

Fue tal la solicitud de los Prelados porque los indios no murieran sin recibir el sacramento de la Extremaunción, que en el tercer Concilio provincial de Lima del año 1583 se insistió en esta obligación de todos los curas y doctrineros, ya que algunos se habían manifestado negligentes; y hasta se les amenazaba castigar si no cumplían con su deber, pues, no había ninguna razón para negar a los enfermos de gravedad la administra- 


\section{Doctrinas y Parroquias del Obispado de Quito /165}

ción de este último sacramento. Por lo mismo, "para que de aquí adelante -ordenaba el Concilio- la tibieza de algunos curas no ponga en esto frívola escusa, se dé, conforme al decreto del Concilio pasado, a todos los fieles indios y morenos que tuvieren muestras de penitencia, a su tiempo, este sacramento, y que los Visitadores, entre los demás capítulos, hagan particular inquisición de éste, y que a los negligentes se les pongan las debidas penas, a arbitrio de su Ordinario" 41 .

\section{Matrimonio}

Antiguamente la poligamia era una costumbre muy corriente entre los indios, principalmente entre los caciques, quienes vivían con varias mujeres y con mucha facilidad dejaban unas y tomaban otras ${ }^{42}$.

Los primeros misioneros que llegaron a tierras americanas para evangelizar y civilizar a los naturales, debieron encontrarse con este problema muy difícil de resolver, pues, si algún indio infiel recibía el bautismo y había estado casado, ¿cómo quedaba resuelta su situación moral?. Fue urgente, por tanto, consultar a las Autoridades Eclesiásticas qué se debía hacer en tales casos, ya que no podía permitirse que continuara el indio en un estado de desmoralización.

Examinemos brevemente la legislación pontificia y las principales disposiciones conciliares y sinodales que se pusieron en práctica para resolver de un modo canónico la situación conyugal del indio.

\section{a) Legislación pontificia}

Paulo III, San Pío V y Gregorio XIII fueron muy condescendientes y generosos con los naturales de las Indias.

Ante todo, la Iglesia reconoció el matrimonio natural, siempre que se hubiesen cumplido las condiciones necesarias para que fuera legítimo, a saber: consentimiento mutuo y la intención de unirse toda la vida. 
Paulo III, en la Constitución "Altitudo" del 1 de junio de 1537, con respecto a los matrimonios de los indios, en caso de que alguno se convirtiera a la fe católica, "mandamos -decía el Pontífice- que se observe lo siguiente: los que antes de su conversión tenían varias esposas y no recuerdan cuál fue la primera que tomaron, una vez convertidos a la fe, tomarán una de ellas, la que quisieran, para contraer con la misma matrimonio por palabras de presente, como se acostumbra; $y$ los que recuerdan cuál tomaron primero, deben conservar ésta, separándose de las otras" ${ }^{\$ 3}$.

Después de varios años de haberse puesto en práctica la resolución dada por el Sumo Pontífice, surgieron ciertas dudas porque uno que otro indio, después de convertirse a la fe católica, había contraído matrimonio con aquella que no fue su primera esposa. Entonces San Pío V, en la Constitución Romani Pontificis del 2 de agosto de 1571, no sólo ratificó lo dispuesto por Paulo III, sino que lo amplió aún más, pues, decía: "...Como a los indios que permanecen en la infidelidad se les permite, según hemos sabido, tener varias esposas, a las cuales repudian ellos por causas levísimas, se les ha concedido que, al recibir el bautismo, permanezcan con aquella que juntamente con el marido está bautizada; y como ocurre muchas veces que ésa no es la primera esposa, de donde resulta que tanto los ministros como los Obispos, juzgando que aquel no es verdadero matrimonio, se ven atormentados por escrúpulos gravísimos; y como, por otra parte, sería muy duro separar a los indios de las esposas en unión de las cuales ellos mismos recibieron el bautismo, sobre todo porque les sería muy difícil encontrar a la primera esposa: por tanto, Nos... a tenor de las presentes letras, declaramos con autoridad apostólica que los indios ya bautizados según se ha dicho, y los que en adelante se bauticen pueden permanecer, como con esposa legítima, separándose de las otras, con aquella de sus esposas que se haya bautizado o se bautice con ellos, y que tal matrimonio entre ellos es matrimonio firme y legítimo" 44 .

Y finalmente, por la Constitución Populis del 25 de enero de 1585 , considerando que muchos infieles eran apresados y llevados a tierras lejanas, con frecuencia fuera de su país, y por tanto estaban separados de sus cónyuges respectivos, si uno de ellos se convertía a la fe, por la di- 


\section{Doctrinas y Parroquias del Obispado de Quito /167}

ficultad de llenar los requisitos previos para la aplicación del privilegio paulino, "Nos -decía Gregorio XIII-, teniendo en cuenta que dichos matrimonios celebrados entre infieles son ciertamente verdaderos, pero no firmes hasta tal punto que, aconsejándolo la necesidad, no puedan disolverse, y compadeciéndonos con misericordia de padre de la flaqueza de esas gentes, con autoridad apostólica, y a tenor de las presentes letras, concedemos a todos y cada uno de los Ordinarios y párrocos de dichos lugares y a los sacerdotes de la Compañía de Jesús aprobados por sus Superiores para oír confesiones y a la sazón enviados a dichas regiones o admitidos en ellas, plena facultad de dispensar a los fieles de uno y otro sexo que habitando en las expresadas regiones contrajeron matrimonio antes de recibir el bautismo y más tarde se convirtieron a la fe, para que cualquiera de ellos, viviendo el cónyuge infiel, y sin pedir su consentimiento o sin esperar su respuesta, pueda contraer matrimonio con cualquier fiel, aunque sea de otro rito, solemnizarlo en la faz de la Iglesia y permanecer lícitamente en él mientras vivan, consumándolo después por medio de la cópula carnal: siempre que conste, aunque sea sumaria y extrajudicialmente, que el cónyuge ausente, como se ha dicho, no puede ser legítimamente interpelado o que, habiéndolo sido, no manifestó su voluntad dentro del plazo fijado en la misma interpelación; decretamos que estos matrimonios jamás deben rescindirse, sino que serán siempre válidos y firmes, y legítima la prole que de ellos se tenga, aunque después se averigüe que los primeros cónyuges infieles no pudieron manifestar su voluntad por justo impedimento y que también se habían convertido ya cuando se celebró el segundo matrimonio" 45 .

Según las tres Constituciones, los Sumos Pontífices, en cierto modo, venían a disolver el matrimonio contraído en la infidelidad, no exclusivamente en virtud de la aplicación del privilegio paulino, sino, "de la potestad que tiene el Romano Pontífice de disolver los matrimonios no consumados de los cristianos" 46 .

Bien es verdad que el matrimonio válido rato y consumado no puede ser disuelto por ninguna potestad humana ni por ninguna causa, fuera de la muerte ${ }^{47}$; pero, también es verdad que el matrimonio no con- 


\section{8 / Augusto E. Albuja}

sumado entre bautizados, o entre una parte bautizada y otra que no lo está, puede ser disuelto por el Romano Pontífice, con causa justa, a petición de ambas partes o de una de ellas, aunque la otra se oponga ${ }^{48}$. Este era el caso de algunos matrimonios que fueron contraídos en la infidelidad de ambos cónyuges, y, sin embargo, S.Pío V y Gregorio XIII, respectivamente, los disolvían, no mientras los cónyuges permanecían paganos, pues no eran súbditos de la Iglesia y además el matrimonio era legítimo, sino cuando alguno de ellos o ambos se habían convertido y el matrimonio no había sido consumado después del bautismo. Por tanto, no nos extrañe esta manera de proceder de los Sumos Pontífices, pues, aquellas mismas disposiciones de hace cuatro siglos y que fueron dadas para determinados lugares como Angola, Etiopía e Indias, pueden aplicarse también a las demás regiones en las mismas circunstancias ${ }^{49}$.

\section{b) Disposiciones conciliares y sinodales}

Siguiendo las Constituciones Pontificias respecto a los matrimonios de los indios infieles que se convertían a la fe católica, el primer Concilio limense pedía que el sacerdote párroco o doctrinero, antes de administrar el bautismo a algun indio que vivía con varias esposas, "examine cuál fue la primera mujer que tomó, de manera que no entienda el tal indio para qué fin se hace, porque no lo niegue; y averiguado, sea compelido estar y casar con ella, aunque según sus costumbres lo haya dejado. Y si no se pudiere averiguar cuál fue la primera, podrase casar con la que quisiera de aquellas, o con otra, tornándose primero cristiana" 50 .

Sin embargo, "si requiriendo el fiel al infiel tres veces, por espacio de seis días, de manera que lo entienda que esté con él o que se desista de la tal persuasión, no lo quisiere hacer" 51 , entonces, en virtud del privilegio paulino ${ }^{52}$, quedaba el fiel "libre para poderse casar con otra persona"53.

Si los infieles estaban casados y recibían juntos el bautismo, debían ratificar "luego el matrimonio en faz de la Santa Iglesia; y si el uno de ellos no se quiere convertir -advertía una constitución conciliar de 


\section{Doctrinas y Parroquias del Obispado de Quito /169}

1567- sea amonestado con notario y testigos que de seis meses se haga cristiano, y la misma amonestación se le torne a hacer muchas veces, por lo menos seis en el dicho espacio de tiempo, y si todavía no quisieren convertirse, el cura consulte al Obispo, si el otro compañero que está bautizado deba apartarse del infiel" 54 .

Asimismo, presentándose el caso de dos personas indias que estuvieren bautizadas y deseaban contraer matrimonio, estando ligadas por parentesco de consanguinidad o afinidad en tercero o cuarto grado, los párrocos y doctrineros, en virtud de la Constitución Altitudo de Paulo III, no debían impedir tal matrimonio ya que los indios estaban dispensados de tales impedimentos 55 .

Además, debemos advertir las siguientes normas dadas para los matrimonios entre indios: todos los curas y doctrineros, antes de proceder a las celebraciones de matrimonios de sus respectivos feligreses, debían interrogar a los contrayentes si libremente daban su consentimiento ${ }^{56}$.

Después de las informaciones prematrimoniales, "ningún cura ni clérigo despose a persona alguna, sin que primero procedan las tres amonestaciones del derecho, en tres días, de los cuales el uno al menos sea domingo o fiesta de guardar" 57 . Era muy conveniente también que se les exhortara a que antes de contraer matrimonio, los interesados se confesaran y comulgaran ${ }^{58}$; y si los contrayentes no sabían "signarse e santiguarse y las oraciones de la Iglesia" (Credo, Pater Noster, Avemaría, artículos de la fe y mandamientos de la ley de Dios), ningún cura podía desposarlos "so pena de 20 pesos" 59 .

Respecto a las velaciones, el segundo Concilio limense ordenaba que "se hagan en su propia Parroquia y esto siendo ya bien de día"60. Y para que "ningún cura sea osado a casar indios de otra Doctrina”, el Ilmo. Señor Peña, en el Sínodo de 1570, advertía: "y el que lo contrario hiciere sea suspenso de administración de sacramentos ipso facto, hasta que por nos o por nuestro Provisor sean absueltos, conforme al Tridentino"61.

$Y$ finalmente, para que los indios no contrajeran matrimonio obligados por sus Encomenderos, el Segundo Concilio limense amenazaba con la excomunión a aquellos que "estorban a los esclavos o criados y 
a yanaconas que se casen con quienes es su voluntad"62. Aún más, para que se respetara la libertad de los indios y para salvaguardar su vida conyugal, Santo Toribio de Mogrovejo en el Concilio de 1583, manifestando su buen deseo en favor de esclavos, indios, morenos, exhortaba: "que no sean impedidos de sus amos de contraer, ni usar de matrimonio, ni los esclavos ya casados se envíen o lleven o vendan en partes donde por fuerza han de estar ausentes de sus maridos o mujeres perpetuamente o muy largo tiempo, que no es justo que la ley del matrimonio, que es natural, se deroge por la ley de servidumbre, que es humana"63. 


\section{Doctrinas y Parroquias del Obispado de Quito /171}

\section{NOTAS:}

1 Primer Concilio limense, Parte Primera, c.31.

2 Segundo Concilio limense, Parte Primera, c.2.

3 Ibidem c.29.

4 Ibidem c.26.

5 Tercer Concilio limense, Acc. 2-, cap. 38.

6 Primer Concilio limense, Parte primera, c. 14.

7 Ibidem, c.4.

8 Ibidem, c.6.

9 Ibidem, c.5.

10 Segundo Concilio limense, Parte Segunda, c. 35.

11 Apéndice \# 9.

12 Apéndice \# 5.

13 GARCÉS, Colección de Cédulas Reales, 202-203.

14 Segundo Concilio limense, Parte Segunda, c. 28.

15 Ibidem, c. 45.

16 Ibidem, c. 44.

17 Primer Sínodo de Quito, Parte Cuarta, C.27 (AGI, Patronato, leg. 189, R40).

18 Segundo Sínodo de Quito, cap.11 (AGI, Quito, leg.76).

19 Conc. Trid. Sess. VII, c.3 de Confirmatione; cf.tb. C.I.C. c. 882.

20 C.I.C. 17 , c. 871 ; C.I.C. c. 965.

21 C.I.C. 17, c.872c; C.I.C. c. 966.

22 C.I.C. 17 , c. 877 ; C.I.C. c. 970.

23 Apéndice \# 14.

24 C.I.C. 17,c. 906; C.I.C. c. 989.

25 Segundo Concilio limense, Parte Segunda, c.52.

26 Ibidem, c. 53.

27 Tercer Sínodo de Quito, Const. 30 (AGI, Quito, leg.77).

28 Código de Derecho Canónico, 6- Edición c.893.

29 Ibidem, c.897.

30 Segundo Sínodo de Quito, cap. 114 (AGI, Quito, leg. 77).

31 GONZÁLEZ SUÁREZ, Historia, III, 19.

32 VARGAS UGARTE, Concilios limenses, I, 15.

33 Primer Concilio limense, Parte Primera, c. 14. 
34 Segundo Concilio limense, Parte Segunda, c. 58.

35 Tercer Concilio limense, Acc. 2- cap. 20.

36 PEÑA MONTENEGRO, Itinerario, lib. 3- trat. Unico, Secc. 1-.

37 VARGAS UGARTE, Concilios Limenses, III, 16.

38 Segundo Concilio limense, Parte Primera, c. 28.

39 Segundo Concilio limense, Parte Segunda, c. 75.

40 Primer Sínodo de Quito, Parte Cuarta, c. 17 (AGI, Patronato, leg. 189, R- 40).

41 Tercer Concilio limense, Acc. 1-, cap. 28.

42 Primer Concilio limense, Parte Primera, c. 16.

43 Código de Derecho Canónico, 6- Edición, Documento IV, p.896.

44 Código de Derecho Canónico, 6- Edición, Documento V, p. 897.

45 Código de Derecho Canónico, 6- Edición, Documento VI, p.897.

46 Código de Derecho Canónico, 6- Edición, Comentario al c. 1125, como aplicación del c. 1119 del C.I.C. 17; correspondiente al C.I.C., cc. 11471148 y 1149 .

47 C.I.C. 17,c. 1118; C.I.C. c. 1141.

48 C.I.C. 17 ,c. 1119 ; C.I.C. c. 1142.

49 C.I.C. 17 ,c. 1125 ; C.I.C. cc. $1147-1149$.

50 Primer Concilio limense, Parte Primera, c. 16; Primer Sínodo de Quito, Parte Cuarta, c. 49 (AGI, Patronato, leg. 189, R- 40).

51 Primer Concilio limense, Parte Primera, c. 15.

52 C.I.C. 17,c. 1120; C.I.C. c. 1143.

53 Primer Concilio limense, Parte Primera, c. 15.

54 Segundo Concilio limense, Parte Segunda, c.36.

55 Primer Concilio limense, Parte Primera, c. 18. Paulo III, en la Constitución Altitudo, del 1 de junio de 1537, se expresaba en estos términos: "Les concedemos asimismo que si son parientes aún en tercer grado de consanguinidad o de afinidad, no les impida contraer matrimonio, en tanto esta Santa Sede no tuviere a bien disponer lo contrario" (Código de Derecho Canónico. Documento IV, p. 896).

56 Segundo Concilio limense, Parte Primera, c. 18; Primer Sínodo de Quito, Parte Tercera, c, 29 (AGI, Patronato, leg. 189 R-40).

57 Primer Concilio limense, Parte Primera, c. 63; cf. tb. C.I.C. 17, cc. 10221024; C.I.C. c. 1067 deja a criterio de cada Conferencia Episcopal.

58 Segundo Concilio limense, Parte Primera, c. 14; C.I.C. 17, c.1033; C.I.C. c. $1065 \& 2$. 


\section{Doctrinas y Parroquias del Obispado de Quito /173}

59 Primer Concilio limense, Parte Primera, cc. 63-67; el Segundo Concilio limense, Parte Primera, c. 16 adoptó también la misma disposición, pero suprimió la multa de 20 pesos.

60 Segundo Concilio limense, Parte Primera, c. 16.

61 Primer Sínodo de Quito, Parte Cuarta, c.45 (AGI, Patronato, leg. 189 R40); Segundo Concilio limense, Parte Primera, c.17.

62 Segundo Concilio limense, Parte Primera, c. 19.

63 Tercer Concilio limense, Acc. 2-, cap.36; Conc. Trid. Sess. 24, cap. 9. 



\section{CAPÍTULO X \\ LIBROS PARROQUIALES}

Como al tratar de los libros parroquiales, advertiremos luego la exigencia de que en todas las Parroquias y Doctrinas de la Diócesis de Quito sus respectivos curas y doctrineros llevaran también un libro de los castigos impuestos a los indios, hemos dividido este capítulo en dos párrafos, a saber: libros parroquiales e imposición de castigos.

\section{Libros parroquiales}

Los libros parroquiales, prescritos por el Concilio de Trento $^{1} \mathrm{y}$ que están en vigencia actualmente, son los siguientes: el de bautizados, de confirmados, de matrimonios, de difuntos, y, de ser posible, también el que se relaciona con el estado de las almas 2 .

Examinemos qué libros se exigían en las Parroquias y Doctrinas de la Diócesis de Quito en esta segunda mitad del siglo XVI. Según los tres Sínodos $^{3}$, los libros parroquiales obligatorios eran:

1. Libro de bautizados

2. Libro de matrimonios

3. Libro de difuntos

4. Libro de estado de almas

5. Libro de "confesados"

6. Libro de confirmados

7. Libro de los castigos impuestos a los indios

Nota Bene. Libros personales del párroco
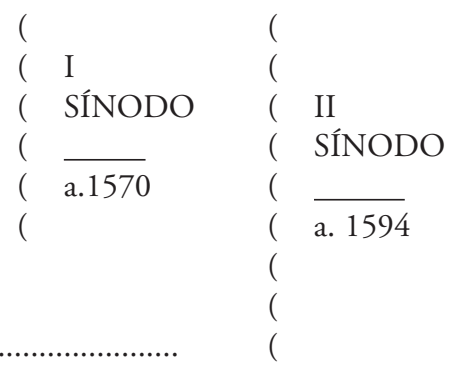

III SÍNODO

a. 1596 
Antes de conocer lo que se debía anotar en cada uno de estos libros parroquiales, juzgamos conveniente advertir que al informar del estado de las almas, muy bien se podía incluir también la nómina o al menos indicar el número de feligreses que habían cumplido con el precepto pascual, como se exigió en la época del Ilmo. Señor Solís; pero al Ilmo. Señor Peña le pareció más conveniente que se llevara en cada Parroquia o Doctrina un libro especial de los confesados, a más del libro que trataba del estado de las almas. Asimismo, el libro de los confirmados ocupa el sexto lugar en la lista porque se hizo obligatorio a partir del segundo Sínodo en el año de 1594, ya que se había prescindido de é1, no por falta de importancia sino por las dificultades que llevaba consigo, pues, cuando el Obispo salía de visita pastoral el número de confirmados ascendía a algunos miles de indios.

\section{Libro de bautizados}

El párroco o doctrinero debía anotar en este libro el nombre de cada bautizado, si era o no legítimo, la fecha, año, mes y día; además, los nombres del padre y de la madre, de los padrinos, del ministro que bautizó, y del cacique, si se trataba de algún indio; y, por último, a qué parcialidad o pueblo pertenecía y en qué iglesia se administró el Bautismo.

En caso de haberse omitido la inscripción de algunos datos el día en que se administró este sacramento, entonces el doctrinero, cuando iba de visita por los distintos caseríos de su jurisdicción, tenía la obligación de preguntar al mismo interesado o a sus padres o padrinos o al mismo cacique, los datos que faltaban para anotarlos luego en el libro de bautizados 4 .

\section{Libro de matrimonios}

Los datos referentes al bautismo, nombres, apellidos, fecha, lugar, etc. se debían inscribir en tratándose del matrimonio 5 . En cuanto al número de testigos no se dio una norma general, pues el Sínodo de 1570 se contentó con recomendar a los párrocos y doctrineros "que asienten los 


\section{Doctrinas y Parroquias del Obispado de Quito /177}

que se casan, poniendo día, mes y año, y cuatro o seis personas que se hallaren presentes..." 6 . Por tanto, en todo matrimonio se debía exigir siquiera cuatro testigos, mientras que la legislación actual pide que se hallen presentes al menos dos testigos para la validez del matrimonio ${ }^{7}$.

\section{Libro de difuntos}

El Ilmo. señor Peña, por medio del Sínodo diocesano, con mucha insistencia recomendaba y pedía a todos sus curas que tuvieran especial cuidado a fin de que en este libro "se asienten los difuntos, chicos y grandes, los que testaron o murieron ab intestato, las misas que mandaron decir y las obras pías, con día, mes y año, y albaceas y herederos, y ante qué escribano pasó; todo lo cual será firmado del tal nuestro cura".

Pero, como el párroco no siempre se hallaba presente a la muerte de algún feligrés, ni podía tener conocimiento de los que hubieren fallecido en los términos de su extensa Parroquia, no por el número de feligreses, pero sí por el territorio que comprendía, al menos debía informarse de quienes tuvieran conocimiento de los indios fallecidos para inscribirlos "en el libro de los difuntos con el apellido, cuyos son mujeres e hijos que dejaron, si murieron ab intestato o si hicieron testamento, dónde están enterrados, e se informen de los indios coadjutores si los vieron amortajar"8. Por tanto, el Sínodo quería no sólo que se siguiese un control exacto de los feligreses, sino además, de esta forma, tomaba ciertas precauciones para evitar posibles homicidios.

\section{Libro del estado de las almas}

Este libro parroquial, recomendado por el Derecho Canónico9, en la Diócesis de Quito era obligatorio porque sólo así los curas podían tener un conocimiento de sus respectivas Parroquias, de la vida moral que llevaban sus feligreses, de sus trabajos, ocupaciones y necesidades; además, dicho libro facilitaba enormemente, sea al Prelado, sea también a sus delegados, en la visita pastoral de la Diócesis. Teniendo en cuenta todos es- 
tos beneficios, el Ilmo. Señor Peña, en una constitución sinodal, decía: "ordenamos y mandamos que los dichos curas hagan un padrón, cada uno en su Doctrina, en que, por los pueblos y casas, asienten todos sus feligreses como se entienda cuántos son y de qué edad, los que son cristianos, casados y solteros y los que son infieles" 10 . Y para que la labor de un sacerdote no fuera destruida por el sucesor, se debía anotar también en este libro los vicios más predominantes entre los feligreses, el método seguido en la catequesis de niños y de adultos, qué partes de la doctrina cristiana han sido explicadas, en qué pueblos están más propagadas las supersticiones y hechicerías, qué medios han sido empleados para tratar de extirparlas y qué resultados se han obtenido. De esta forma, si un doctrinero era trasladado a otra Doctrina o Parroquia no por eso la obra realizada quedaba deshecha o paralizada, pues se suponía que continuaría, gracias al espíritu apostólico del doctrinero sucesor ${ }^{11}$.

\section{Libro de los confesados}

En la época que estudiamos, segunda mitad del siglo XVI, los párrocos y doctrineros no debían contentarse con llevar el libro del estado de las almas; era preciso también que inscribieran "en un libro todos los nombres de los que se han de confesar" 12 para cumplir con el precepto pascual. De manera que cada párroco o doctrinero "en cada un año, haga padrón de los que se confiesan, y pasada la octava de Corpus Christi -decía el Obispo Peña- lo envíen a nuestros vicarios para que nos dé relación de la gente que se confesó y de la que no se hubiere confesado"13.

En el segundo Sínodo diocesano, el Ilmo. Señor Solís señaló un plazo más breve, pues, a partir del día siguiente a la fiesta de la Ascensión, todos los beneficiados de la Diócesis debían enviar, no a los Arciprestes como había sido costumbre, sino al Provisor o Vicario General, la lista de las personas que se hubieren confesado en las respectivas Parroquias o Doctrinas $^{14}$. Al poco tiempo de haberse dado esta nueva disposición de enviar todos los padrones de los confesados directamente al Provisor de la Diócesis, fue preciso modificarla porque el tercer Sínodo, en cambio, dis- 
puso "que se cumpla con enviarlos a los Vicarios - Arciprestes- de sus distritos, con cargo de dar cuenta al tiempo de la visita ${ }^{15}$.

¿Qué finalidad tenía en aquellos tiempos esta información de los que habían cumplido con el precepto pascual?. Juzgamos que aquella nómina de los confesados se exigía a todos los párrocos y doctrineros por un doble motivo: primero, para que el Prelado pudiera darse cuenta de la diligencia que había tenido cada uno de sus curas en el ministerio de la confesión; y segundo, para aplicar las sanciones respectivas a aquellos que no hubieran cumplido con el precepto pascual, pues, su descuido no solamente era un pecado sino caso de excomunión para indios y españoles; y, en tratándose de mulatos, negros y zambos, los curas estaban facultados por el mismo Sínodo para imponerles castigos saludables ${ }^{16}$.

\section{Libro de confirmados}

A pesar de las dificultades de obtener los datos necesarios para anotarlos en el libro de los confirmados, y teniendo en cuenta que hasta 1594 no había sido obligatorio en ninguna Parroquia ni Doctrina, el Ilmo. señor Solís, por medio de una constitución sinodal, ordenaba que, "de los que hasta aquí se han confirmado, los curas y beneficiados, así de españoles como de indios, cuando hicieren padrón para las confesiones, lo hagan también de los confirmados, con la mayor claridad que se pueda, asentando el nombre y sobrenombre del confirmado y el padrino y el padre y madre y el Obispo que lo confirmó y dónde y en qué iglesia”. Y para facilitar el trabajo de inscribir tales datos, "avisaremos, pero con tiempo -decía el Prelado- dónde hubiéramos de ir a administrar este santo sacramento para que el sacerdote tenga escritos, con mucha claridad, los que se hubieren de confirmar" 17 . Esta era una medida muy prudente del Obispo, pues solamente en su viaje de Lima a Quito, después de la ordenación episcopal que recibió en la ciudad de Trujillo de manos del Arzobispo Santo Toribio de Mogrovejo, había administrado la confirmación a más de diez mil almas, quedando otras cincuenta mil por recibir este sacramento ${ }^{18}$, y en una carta, del 1 de abril de 1595 , dirigida al Rey, el celoso 
Obispo le informaba: “...que los naturales son muchos, gente doméstica y aficionada a las cosas de Dios, con cuyo auxilio he comenzado a confirmar, que por la larga vacante de Obispo había mucha necesidad, y en el poco tiempo -escasos diez meses- he confirmado veinte mil ánimas y hecho Sínodo diocesano y visitado mi Iglesia y fundado el Colegio -seminario. Ahora salgo a hacer lo mismo en el Obispado, que es distrito de trescientas leguas de latitud, y donde hay doscientas mil que confirmar" 19 .

\section{Libro de los castigos impuestos}

El tercer Sínodo de 1596 dedicó la constitución trigésima para señalar los diversos castigos que se podía imponer a los indios, si descuidaban sus deberes como cristianos. Al final de dicha constitución sinodal, "para que los curas sepan mejor lo que han de hacer en esto, se ordena y manda que tengan un libro blanco, el cual comprarán a costa de la comunidad, y en é1 asentarán con día, mes y año y testigos, los delitos graves que acontecieren y la pena con que han sido castigados, y de las amonestaciones que hubieren fecho a los amancebados, advirtiendo que los casos de idolatría, hechicerías, incestos y divorcios, se guarde lo ordenado en el Concilio provincial de 83, donde se ordena y manda a los curas hacer las informaciones y, como casos graves, remitirlas a los Superiores" 20.

\section{Libros personales del párroco}

Hace cuatro siglos, el amor al estudio y a los libros no era una cosa muy corriente en la mayoría de los sacerdotes dedicados al ministerio parroquial. El Ilmo. Señor Solís teniendo en cuenta que todo párroco o doctrinero debía predicar el Evangelio los domingos y fiestas de precepto, convenía saber al menos lo indispensable, para ejercer debidamente el ministerio parroquial y de manera particular para resolver ciertos casos que se les podían presentar en el santo tribunal de la Penitencia o al hacer las informaciones prematrimoniales, y como era muy difícil que todo supie- 


\section{Doctrinas y Parroquias del Obispado de Quito /181}

sen de memoria o por ciencia infusa, "sancta Synodo approbante, -decía el Obispo de Quito en el Sínodo de 1596- mandamos a todos los curas que, fuera de tener algunos libros devotos para ocupar el tiempo, tengan algunas Summas de casos de conciencia y en particular el Directorum curatorum, pudiéndolo haber, so pena de cuatro meses de suspensión al que no tuviere los libros necesarios para este ministerio"21. El gran Maestro de Teología de la Universidad de Lima, Ilmo. Señor Solís, sabía perfectamente que los estudios hechos en Seminarios o en Universidades, con el transcurso de los años fácilmente pasan al olvido si no se vuelve sobre ellos, por esto deseaba que los párrocos de su Diócesis, al menos por el temor a la suspensión, se preocuparan por adquirir los libros más indispensables para el ministerio parroquial.

\section{Imposición de castigos}

La conquista de las almas se consigue más fácilmente con la caridad y el amor cristiano, antes que con el rigor y los castigos.

Sin duda que parecerá extraño tener que tratar de imposición de castigos y que precisamente dependiesen de sacerdotes, quienes más bien son los llamados a predicar el Evangelio de Cristo, cuyo principal mandamiento es la caridad. En los tiempos actuales deberán llamar nuestra atención aquellas medidas adoptadas por los asistentes al tercer Sínodo, y muchos, incluso, hasta podrán escandalizarse de la actitud de la Iglesia frente a los neófitos indios de la Diócesis de Quito a fines del siglo XVI.

Antes de dar a conocer los diversos castigos que se podía imponer a los indios negligentes en sus prácticas religiosas y que continuaran reacios en abandonar sus malos hábitos, si pensamos con la mentalidad del siglo XVI, juzgaremos que en ese entonces la Iglesia ejercía su "derecho connatural y propio, independiente de toda autoridad, a castigar a los delincuentes súbditos suyos con penas tanto espirituales como también temporales"22. La Iglesia, como sociedad perfecta, puede imponer toda clase de penas y castigos, siempre que sean necesarios para conseguir su fin y para salvaguardar el orden social. Porque la Iglesia de hecho no ejecuta 
ciertas penas temporales, no por eso podemos pensar que carezca del derecho a imponerlas y, por tanto, que los castigos señalados por la constitución sinodal de 1596 eran arbitrariedades cometidas por la Iglesia.

La psicología del indio exigía que se diera a conocer la gravedad de ciertos pecados, mediante los consiguientes castigos que habían para ellos. Además, los indios eran neófitos; no tenían una conciencia ya formada como para cumplir motu proprio sus obligaciones y deberes. Pero por más considerandos que hagamos, siempre descubriremos que la mayoría de los castigos señalados eran muy drásticos y exagerados, sin duda porque no se tomó en cuenta toda la advertencia hecha por el Concilio de Trento: "Acuérdense los Obispos y los demás Ordinarios de que son pastores, y no verdugos, y que conviene rijan a sus súbditos de tal forma que no se enseñoreen de ellos, sino que los amen como a hijos y hermanos, y se esfuercen con exhortaciones y avisos en apartarlos del mal, para no verse en la precisión de castigarlos con penas justas, si llegan a delinquir, y si ocurriere que, por la fragilidad humana, llegaren éstos a delinquir en algo, deben observar aquel precepto del Apóstol de razonar con ellos, de rogarles encarecidamente, de reprenderlos con bondad y paciencia, pues en muchas ocasiones puede más, para con los que hay que corregir, la benevolencia que la austeridad, la exhortación más que las amenazas, y la caridad más que el poder; mas, si por la gravedad del delito, es necesario el castigo, es entonces cuando deben hacer uso del rigor con mansedumbre, de la justicia con misericordia, y de la severidad con blandura, para que, sin asperezas, se conserve la disciplina, saludable y necesaria a los pueblos, y los que han sido corregidos se enmienden o, si éstos no quieren volver sobre si mismos, para que el castigo sirva a los demás de ejemplo saludable y se aparten de los vicios"23.

Si el fin que perseguía el tercer Sínodo de la Diócesis de Quito, con la lista de castigos para ciertos pecados y vicios, era atemorizar al indio, somos los primeros en reconocer que aquellas medidas eran magnificas en teoría; pero, en la práctica, por ser demasiado exageradas, dejaban de ser cristianas, pues no solamente eran imposición de castigos, sino imposición del Evangelio por el miedo a la imposición del castigo. 


\section{Doctrinas y Parroquias del Obispado de Quito /183}

¿Debemos ver, acaso, prejuicios para con los indios de parte del Ilmo. señor Solís y de los asistentes al tercer Sínodo celebrado en la ciudad de Loja?. Creemos que el benemérito Obispo de Quito jamás obró con prejuicios, sino que su celo apostólico le impulsó a adoptar tales medidas, porque amaba entrañablemente a los indios y deseaba que fuesen felices eternamente, siendo buenos cristianos en este mundo.

Como la constitución sinodal que trata de la imposición de castigos es muy explícita, bástenos transcribirla como viene en el manuscrito del Archivo General de Indias de la ciudad de Sevilla.

"Constitución 30: sobre el castigo que han de hacer los curas en los indios, sobre algunos pecados y excesos": "Aunque, por los Concilios provinciales de 67 y 83, les está prohibido a los curas beneficiados de indios el castigar a sus feligreses por sus propias personas, por convenir así a su autoridad, pues, no es justo, como dice el santo Concilio de Trento, que los que han de ser Pastores y Padres sean verdugos en los que han de atraer más con amor que con temor; con todo eso, se les permite, por los mismos Concilios, castigar los indios de los delitos que cometieren, por algún ministro fiscal o alguacil, porque si no hubiese temor y castigo, con mucha dificultad serían cristianos. Pero, porque no todos los curas tienen prudencia y discreción en el modo de castigar; antes, como se ha visto, han excedido muchas veces en esto, ordenando los dichos Concilios que los Obispos, en sus Diócesis, declaren y señalen las penas y castigos en particular que se puedan dar a los indios por los delitos que cometieren tocante al foro eclesiástico; y así, conformándonos con este santo decreto, sancta Synodo approbante, nos ha parecido se guarde el orden siguiente en el castigo que los curas podrán mandar ejecutar en sus feligreses":

- "Al indio común que no se confesare en el tiempo que le está señalado cada año, se le dará por pena: por la primera vez, veinte y cuatro azotes; y por la segunda, trasquilado y seis días de prisión. Y si fuere cacique, primera o segunda persona: por la primera vez, ocho dais de prisión y un pa- 
tacón para la fábrica; y por la segunda, la pena doblada. Y si el tal cacique fuere rico y ladino, los beneficiados agraven la pena como viere que conviene".

- "El indio que estuviere amancebado sea amonestado a que se aparte, quitándole la manceba como reprensión; y si después de amonestado, reiterare, azotarlo han en público, haciéndole dar cincuenta azotes; $y$ a la tercera vez, será azotado y trasquilado, y si perseverare en su pecado, írsele aumentándole la pena con destierro o con servicio en algún hospital o iglesia y con estos indios comunes no se ha de proceder por papel y tinta, sino por el conocimiento de la verdad por no les hacer costas. Pero, si fueren caciques, primera o segunda persona, se procederá contra ellos por escrito, sumariamente; y la primera vez se le perdonará con reprensión y amonestación y prohibición de juntarse; y por la segunda, los prendan y tengan cuatro días en la cárcel, que no beba ni chicha ni vino; y a la tercera, serán penados en cuatro pesos de plata para la iglesia y quince días de destierro, y si perseverare en su pecado y reincidiere, sea desterrado por un año de su Repartimiento".

- "Cuando algún indio se apartare de su mujer, o alguna mujer de su marido, siendo casados, y lo hicieren sin autoridad de la iglesia: por la primera vez, al que tuviere culpa, se le den cincuenta azotes en público con voz de pregonero, que declare su delito; y por la segunda vez, sobre los cincuenta azotes, serán trasquilados los cabellos; y por la tercera, si perseveraren, demás de la pena dicha, serán condenados a servir a algún hospital, iglesia o monasterio, como al cura le pareciere, por tiempo de un año. Y si fuere cacique principal o segunda persona, hecha la información: por la primera vez, se le declare un mes de cárcel y seis pesos de pena para la iglesia; y por la segunda, doblado -es decir, dos meses de cárcel y doce pesos de multa-; y por la tercera, destierro de un año de su Repartimiento; y si perseverare y no se enmendare, se dará aviso al Ordinario para que provea". 


\section{Doctrinas y Parroquias del Obispado de Quito /185}

"Que no vienen a la doctrina" - "Al indio que no viniere a la doctrina en los días que tiene obligación, no habiendo tenido impedimento justo, le den: por la primera vez, doce azotes; $y$, si no se enmendare, se le vaya aumentando la pena".

"Para los que no oyen misa" - "Al indio que dejare de oír misa los días que tiene de obligación oírla, si no hubiere justo impedimento y bastante descargo que le excuse, se le dará: veinte y cuatro azotes, por la primera vez; y si acostumbrare a no oírla, le quitarán el cabello en público y le darán cuatro días de prisión. Y si fuere cacique principal o segunda persona: por la primera vez, pagará media libra de cera para la iglesia; y por la segunda, una libra; y si no se enmendare, se le irá agravando la pena. Y lo mismo se entenderá con los alcaldes".

"Borracheras" - "En lo que toca a las borracheras se regirán los curas por la sinodal 93 del año de 94". Dicha constitución 93 del segundo Sínodo diocesano de Quito, celebrado en 1594, decía : "Cualquiera persona que topare algún indio borracho y le presentare así ante cualquier juez de $\mathrm{Su}$ Majestad, o diere información de que se emborrachó, se le entregue trasquilado y azotado para que le sirva medio año o uno, y no sea obligado a darle más que de comer".

"Contra los que comieren carne"- "A los que comieren carne en días prohibidos, sin necesidad: por la primera vez, veinte y cuatro azotes en público; y por la segunda, que sirvan dos meses en el hospital o iglesia que les fuera señalado. Y si fueran caciques, primera o segunda persona: por la primera vez, una libra de cera; y por la segunda, dos libras para la iglesia; y la tercera, más de la dicha pena, un mes de prisión".

"Fiscales"-"A los fiscales que disimularen delitos y no dieren aviso al cura para que lo remedie o fueren negligentes en hacer su oficio, se les dará: por la primera vez, veinte y cuatro azotes en público; y por la segunda, doblado, -es decir, cuarenta y ocho azotes-; y a la tercera, se le quitará el oficio y se le darán ocho días de prisión". 
Cuando tratábamos de los libros parroquiales, advertíamos que a partir del año 1596 se exigía también que en todas las Parroquias y Doctrinas hubiese un libro especial, en el cual se debía inscribir los delitos graves y las penas con que hubieren sido castigados los infractores.

Generalmente el que ejecutaba las penas era el doctrinero; pero, "en las ciudades de españoles, donde hubiere beneficiados de indios, por haber en ellas jueces, vicarios -arciprestes- ésos ejecuten las dichas penas de naturales y no los beneficiados".

"Y para que a los indios les conste de estas penas -las enumeradas arriba- y vivan apercibidos y con más recato que hasta aquí y no puedan alegar ignorancia", el Ilmo. señor Solís decía: "mandamos a todos los curas de indios que primero que estas penas se ejecuten, se las publiquen y declaren en público muchas veces en lengua que todos lo entiendan, de suerte que venga a noticia de todos" 24 .

Antes de finalizar este párrafo, nada agradable por su contenido, conviene advertir que, a pesar de haber investigado muchos legajos de la sección Audiencia de Quito, tanto del ramo eclesiástico como del civil, en el Archivo General de Indias de la ciudad de Sevilla, no hemos encontrado ni un solo documento que trate exclusivamente de los castigos impuestos por los sacerdotes a los indios, señalando sus nombres, qué pecados o delitos fueron cometidos, qué castigos fueron impuestos y en qué día, mes y año, según las disposiciones dadas por el tercer Sínodo de Quito. No tratamos de ocultar la verdad, pero tampoco queremos escribir una novela. La falta de documentos nos hace pensar que, probablemente, la imposición de castigos no debió ser nada frecuente, o que los indios, por obediencia a las leyes o por temor al castigo, no dieron ocasión para que la constitución trigésima del Sínodo diocesano de 1596 pasara de la teoría a la práctica. 


\section{Doctrinas y Parroquias del Obispado de Quito /187}

\section{NOTAS:}

1 Conc. Trid., Sess. XX, cap.1 y 2.

2 C.I.C. 17,c.470; C.I.C. 535.

3 Primer Sínodo de Quito, Parte Tercera, c.6, y Parte Cuarta cc.19 y 37, en AGI, Patronato, leg. 189, R-40; Segundo Sínodo de Quito, cap. 15, en AGI, Quito, leg. 76; y Tercer Sínodo de Quito, celebrado en la ciudad de Loja, Const. 12 y 30, en AGI, Quito, leg.77.

4 Primer Sínodo de Quito, Parte Tercera, c.6 (AGI, Patronato, leg.189, R-40); Primer Concilio limense, Parte Segunda, Const.65; Segundo Concilio limense, Parte Segunda, cap.16.

5 Segundo Concilio limense, Parte Segunda, cap. 16.

6 Primer Sínodo de Quito, Parte Tercera, c.6 (AGI, Patronato, leg. 189, R-40).

7 C.I.C. 17, c. 1094; C.I.C. c. 1108.

8 Primer Sínodo de Quito, Parte Cuarta, c.19 (AGI, Patronato, leg. 189, R40).

9 C.I.C. 117 , c. $470 \& 1$; C.I.C. c. 535.

10 Primer Sínodo de Quito, Parte Cuarta, c.57 (AGI, Patronato, leg.189, R40). El libro de bautizados lo prescribió el Primer Concilio limense, Parte Segunda, Const. 65: "Otrosí, mandamos a los dichos curas de todo nuestro Arzobispado e Provincia que tengan libro donde asienten los que bautizaren...”.

11 Primer Sínodo de Quito, Parte Cuarta, c.57 (AGI, Patronato, leg. 189, R40).

12 Segundo Concilio limense, Parte Segunda, c.55.

13 Primer Sínodo de Quito, Parte Cuarta, c.37 (AGI, Patronato, leg. 189, R-40).

14 Segundo Sínodo de Quito, cap. 10 (AGI, Quito, leg.77).

15 Tercer Sínodo de Quito, Const. 2 (AGI, Quito, leg.77).

16 Segundo Sínodo de Quito, cap. 7 (AGI, Quito, leg.76).

17 Segundo Sínodo de Quito, cap. 15 (AGI, Quito, leg.76).

18 Apéndice \# 35.

19 AGI, Quito, leg. 76.

20 Tercer Sínodo de Quito, Const. 30 (AGI, Quito, leg.77).

21 Tercer Sínodo de Quito, Const. 12 (AGI, Quito, leg.77).

22 C.I.C. 17, c. 2214 \& 1; C.I.C. c. 1311.

23 Conc. Trid. Sess. XIII, de refor. cap. I y que lo transcribe el c. $2214 \& 2$ del C.I.C. 17; cf.tb. C.I.C. c. 1317.

24 Tercer Sínodo de Quito, Const. 30 (AGI, Quito, leg.77 



\section{CAPÍTULO XI \\ SOSTENIMIENTO DE PARROQUIAS Y MINISTROS}

Es muy natural que "el que sirve al altar, viva del altar". Los sacerdotes que se dedican al apostolado, y estando entregados por su misma vocación al bien de las almas, necesitan de medios económicos para poder subsistir y sufragar sus gastos personales. Con este fin, todos los curas y doctrineros percibían cada año su salario y podían, además, exigir de sus respectivos feligreses ciertos derechos con ocasión de algunos servicios parroquiales; a esto se añadía una parte que les correspondía de los diezmos, ya que, como estudiaremos más adelante, éstos servían para el sostenimiento del Prelado, Cabildo, Iglesia Catedral, iglesias parroquiales y hospitales.

\section{Salario de curas y doctrineros}

Hasta la celebración del primer Concilio provincial limense, el salario de los sacerdotes que se ocupaban del ministerio parroquial no estaba determinado, sino que "era estipulado libremente entre las partes contratantes", a saber: entre el Encomendero y el sacerdote doctrinero, quien recibía cierta cantidad de dinero "a cambio de unos servicios apostóli$\cos ^{\prime \prime} 1$.

No debió ser conveniente, bajo ningún aspecto, que la fijación del salario dependiese de los Encomenderos sino más bien de los respectivos Prelados. Por eso, una constitución conciliar decía: "Mandamos y encargamos a los Prelados y a sus Provisores y Vicarios de este nuestro Arzobispado e Obispados a él sufragáneos que, atentos el valor y precios de las cosas necesarias para la sustentación de los tales clérigos, moderen y tasen lo 


\section{0 / Augusto E. Albuja}

que buenamente les pareciere que se debe dar a cada clérigo, cada año, y lo que moderaren lo firmen de sus nombres". Y, en tratándose de los religiosos doctrineros, para que éstos "no tengan cuidado de buscar lo necesario para su sustentación y servicio del altar, mandamos que para cada religioso que estuviere ocupado en la dicha Doctrina, el Comendero o Comenderos, en cuyos indios estuviere, le dé para cada un año seis arrobas de vino, y media arroba de jabón, y una de conserva , y otra de aceite, otra de cera, y otra de vinagre, cada año, y un vestuario y ornamento para que diga misa" 2 .

En el año de 1567, el segundo Concilio provincial también pedía a los Prelados que hicieran lo posible a fin de que cada Parroquia estuviese atendida por su respectivo cura, "al cual pague el Encomendero el salario señalado por el Obispo, siendo, si fuere menester, compelido con censuras a ello"; y aquellos Encomenderos "que no quisieren pagar el estipendio señalado, de ninguna manera sean admitidos al sacramento de la Penitencia"3.

La costumbre observada en la Diócesis de Quito, y seguramente en las demás Diócesis de Indias, era que el Encomendero, después de cobrar los tributos de los indios, pagaba el salario al doctrinero. Este sistema originó serias dificultades porque, o no se le pagaba puntualmente, o si se lo pagaba, el doctrinero recibía su salario por dividendos, razón por la cual, en 1567 el Ilmo. Señor Peña pedía al Presidente Castro, en la ciudad de Lima, que diera una orden "para que los sacerdotes que doctrinan a indios reciban el salario o vestuario de los indios, antes que entreguen el tributo a sus Encomenderos,... para que en el cobrar no tengan diferencias con los Encomenderos" ${ }^{4}$. Y la mejor manera para que se pusiera en práctica la sugerencia hecha por el Obispo de Quito, era sin duda que "una persona de buena conciencia e abonado para que, de los tributos que los naturales dan, de sus Encomenderos recoja el salario que a los sacerdotes está señalado por los Obispos y lo retengan en sí, para que de allí se pague a los sacerdotes la limosna que les estuviere señalada con libramiento del Obispo y que no tengan que ver los clérigos con los Encomenderos, porque muchas veces los traen inquietos y desasosegados y les hacen gas- 
tar más en pleitos que el salario vale y se quedan los Encomenderos con la limosna que son obligados a dar al sacerdote, sin restituirlo a los indios, ni procurar de satisfacer a lo que son obligados para el descargo de la conciencia real" 5 .

Esta idea de nombrar una persona encargada de reclamar el salario del doctrinero, para evitar así dificultades con los Encomenderos, fue muy bien acogida por el Rey, quien dictó una ley al respecto ${ }^{6}$.

Para cumplir con lo dispuesto por los Concilios provinciales, el Ilmo. Señor Peña, sin dejarse llevar de prejuicios para con los Encomenderos y sin querer favorecer demasiado a sus sacerdotes, después de haber consultado seriamente, decidió fijar el salario de cada doctrinero en la cantidad de 350 pesos de oro al año. Si relacionamos esta tasación con los salarios que habían sido señalados en las Diócesis del Cuzco, Charcas, Lima, Nueva Granada y Guamanga, constatamos que no era exagerada, sino más bien exigua, según indicamos en el siguiente esquema:

\begin{tabular}{|l|l|l|}
\hline \multicolumn{2}{|c|}{$\begin{array}{c}\text { Fijación del salario de doctrineros } \\
\text { correspondiente a las siguientes Diócesis }\end{array}$} \\
\hline Diócesis & \multicolumn{2}{|c|}{ Años } \\
\hline \multirow{4}{*}{ Quito } & \multicolumn{1}{|c|}{1569} & 1595 \\
Cuzco & 350 Ps.oro & 350 Ps. \\
Lima & 500 o 600 Ps. & $550 \%$ \\
Charcas & 350 Ps. & $450 "$ \\
Nueva Granada & 500 o 600 Ps. & $750 "$ \\
Guamanga & 400 Ps. & $?$ \\
& $?$ & $500 ”$ \\
\hline
\end{tabular}

De los 350 pesos de oro, señalados para cada doctrinero en la Diócesis de Quito, 300 pesos eran por concepto del salario anual, y los 50 restantes para los gastos de cera, vino y aceite. Así pues, "no hay Estanciero, Corregidor o Teniente -decía el Ilmo. Señor Peña- a quien menos se dé, 


\section{2 / Augusto E. Albuja}

que especialmente agora que en el Sínodo provincial, que se tuvo en la ciudad de Lima, se mandó, y con rigor se ejecutó, que ningún otro aprovechamiento, ni género de grangerías tengan los sacerdotes"7.

La tasación del salario hecha por el Prelado no agradó en nada a los Encomenderos, pues enseguida acudieron al Presidente de la Real Audiencia para protestar pidiendo que los salarios de los doctrineros fuesen solamente de "trescientos pesos de plata marcada, demás de la comida que los indios les dan muy abundante". Como resultado de este desacuerdo fue la carta-relación dirigida por la Audiencia de Quito al Rey Felipe II, el 23 de diciembre de 1574, en la que encontramos estas frases relacionadas con el salario de los doctrineros: "como quiera que sea -decían los Oficiales de la Audiencia - por lo que acá vemos, en lo que toca a este negocio, nos parece que no conviene que el Obispo tenga este poder, por ser interesado en ello, y de condición que es, y la Audiencia lo proveerá con más libertad, mirando solamente lo que será mejor para todos" 8 .

No había razón suficiente para prescindir del Prelado, pues "Presidente y Oidores -escribía al Rey el Arcediano de Quito en 1577, a nombre del Cabildo- se entremeten en tasar los salarios de las Doctrinas, perteneciendo al Prelado, y por odio y enemistad que le tienen, estando tasada cada Doctrina en trescientos y cincuenta pesos de oro de a cuatrocientos y cincuenta maravedíes, que son las más pobres de todos estos reinos del Perú, las tasan a trescientos pesos de plata corriente; y como no se pueden sustentar con lo susodicho, se van muchos -clérigos- del Obispado... Conviene que se remedie y se envíe Cédula Real para que los salarios sean de trescientos y cincuenta pesos"9.

Es de suponer que así como el Rey dejaba al criterio del Prelado determinar el número de indios tributarios que debía tener cada Parroquia o Doctrina, así también procedería respecto al salario correspondiente a cada doctrinero. Además, en el año 1580, Felipe II pedía que no hubiese ninguna distinción de clérigo o fraile doctrinero, en cuanto al pago de dicho salario ${ }^{10}$. Esta disposición real nos parece muy acertada, pues si al fraile doctrinero se le pedía que cumpliese sus obligaciones al igual que cualquier otro clérigo, ¿por qué se le podía negar lo que en justicia le correspondía?. No porque pertenezca a una Orden Religiosa es causa sufi- 
ciente para que un religioso preste sus servicios gratuitamente; sobre todo cuando otro clérigo, por los mismos servicios, tendría que percibir una contribución económica.

Al igual que el número de indios tributarios, así también el salario de los doctrineros variaba según la clase de Doctrina, dificultades de clima, medios de comunicación, etc. Así pues, en el año 1583, refiriéndose a la Diócesis de Quito, se dice que "el estipendio de las Doctrinas de clérigos y frailes de todo este Obispado vale cada una de ellas, al sacerdote que la tiene, trescientos pesos, y a trescientos y cincuenta y algunas cuatrocientos, según la calidad y disposición de la tierra donde están, porque las que llegan a cuatrocientos pesos, no les dan camarico; y las de trescientos y cincuenta, ponen vino y cera de su casa; de suerte que se padece entre los sacerdotes necesidad por los muchos gastos extraordinarios y carestía de la tierra y por las muchas novedades que cerca de esto cada día hay de parte de las personas a cuyo cargo está vuestro real gobierno"11.

Como advertíamos al principio de este capítulo, en esta segunda mitad del siglo XVI, algunas veces había descuido en pagar a tiempo el salario de los sacerdotes. Para que no resulte cansado, bástenos citar dos ejemplos: el 14 de octubre de 1591 se pagó la suma 214 pesos, 5 tomines y medio al bachiller Diego Mejía, cura de la ciudad de Avila, por su salario de año y medio, desde el 20 de julio de 1586 hasta el 20 de enero de 1588, a razón de 50.000 maravedíes al año; asimismo, "en trece del mes de abril de mil y quinientos y noventa e un años, dio en descargo el dicho tesorero, Bernardino de Vega, noventa y cinco pesos de plata corriente, marcada, por tantos que este día se le pusieron por cargo de la mitad de la doctrina de trescientos y cincuenta y seis indios que hay en el pueblo de Lita, del medio año postrero del pasado de noventa. U-XCV P-s -1-"12.

Además, para evitar tantos abusos, así en el pago como en la cantidad del salario, el cuarto Concilio limense mandaba que los jueces, ministros seglares y Gobernadores no se molestaran en "señalar los salarios a los curas de españoles ni de indios, dejándolo hacer a los Ordinarios eclesiásticos, a quien está reservado y compete"13. Asimismo se prohibía que, bajo ningún pretexto, dichos ministros seglares disminuyeran el salario de 
las Doctrinas ${ }^{14}$, ni tampoco que trataran de averiguar si los clérigos se hubieren o no ausentado de sus Parroquias para rebajar su salario, pues estas cosas no eran de su competencia ${ }^{15}$.

Gracias a un documento del año 1598, en que el Ilmo. Señor Solís enviaba al Real Consejo de Indias la relación de los prebendados y beneficiados de todo el Obispado de Quito, hemos podido constatar que, en general, el salario de Parroquias y Doctrinas ascendía a 350 pesos de plata corriente; sin embargo, habían algunas que reportaban al beneficiado 180, 250, 400, 600 pesos, respectivamente. La parroquia de la ciudad de Pasto era una excepción, pues su titular percibía 1.000 pesos de renta al año. En cambio, la Parroquia de la ciudad de Archidona era tan pobre que el Rey había ordenado dar de la real caja la cantidad de 50.000 maravedíes como salario anual al clérigo que prestaba allí sus servicios ${ }^{16}$.

Y por último, son dignas de citarse las palabras del Ilmo. Señor Solís, quien, en el año 1600, escribiendo al Rey, le decía: "El salario y estipendio de los beneficios de indios es de trescientos y cincuenta pesos de plata en cada año, en general; y en algunas partes más y menos, excepto en alguna de las ciudades de españoles, que en seis o siete partes son buenos beneficios; pero, el mejor, nunca ahorra el clérigo quinientos pesos por año"17.

\section{Aranceles parroquiales}

Los sacerdotes, ya fuesen párrrocos, ya curas doctrineros, a más de percibir el salario señalado por cada Obispo en su Diócesis y que lo hacía efectivo cada Encomendero, podían exigir de los fieles una determinada tasa por ciertos servicios parroquiales. Sin embargo, en general, debemos advertir que "en las Doctrinas de Indias estaban prohibidos los derechos parroquiales; no podían -los doctrineros- percibir retribución alguna por la administración de los sacramentos de Bautismo, Matrimonio, etc..."18.

Para no agravar tanto a los pobres indios, también el Rey dictó una ley prohibiendo que los curas y doctrineros exigieran alguna cosa de 
los naturales, "aunque digan que lo dan por su voluntad"; de manera que no se debía pedir "derechos a los indios, ni otra ninguna cosa, por pequeña que sea, por los casamientos, entierros, administración de sacramentos, ni otros ministerios eclesiásticos", pues ya había sido "señalada -decía el Rey-a los curas y doctrineros congrua y suficiente porción para su sustento, y vivir con la decencia que conviene" 19 .

Esta prohibición de exigir a los indios los derechos parroquiales se debía observar en la Diócesis de Quito "so pena de doce pesos" de multa, que el doctrinero culpable debería pagar; "pero permitimos -continúa la constitución sinodal- que de curaca y principales e yanaconas, en todo se guarde la loable costumbre de esta santa Iglesia" 20 . Por tanto creemos que en la Diócesis estaban en vigencia los aranceles parroquiales, excepto cuando se trataba de los feligreses indios.

Con el fin de conseguir uniformidad en los derechos parroquiales de todas las Diócesis, el tercer Concilio provincial de Lima fijó el arancel para que "se guarde inviolablemente por los Obispos y sus oficiales en sus Diócesis y Obispados"; fuera del Perú, se debía guardar el arancel que hubiere sido señalado ${ }^{21}$.

Ya que solamente en el tercer Sínodo, celebrado en la ciudad de Loja en el año 1596, se estableció el arancel que regiría en todas las Parroquias y Doctrinas del Obispado de Quito, es de suponer que hasta esta fecha se debió observar el señalado en Lima. 
196 / Augusto E. Albuja

He aquí el arancel diocesano elaborado en la ciudad de los Reyes (Lima) el 15 de septiembre de 1583:

1. De un español

\section{Entierros}

(- en la Iglesia Catedral 14 pesos

(- en un Monasterio

21 pesos

(- hijo de españoles

6 pesos

2. De un niño menor de 10 años

(- hijo de español o mestizo

7 pesos

3. De un negro o yanacona

4 pesos

2 pesos

\section{Misas}

1. Misa rezada

(- con vigilia de 3 lecciones

1 peso

2. Misa cantada $(-$

(- de Santos o de Requiem 6 pesos

Nota. Si se pedía con vísperas o vigilia, se añadía

3 pesos

\section{Velaciones}

1. De españoles (siempre debía decirse la misa)

10 pesos

2. De negros, indios, mulatos

1 peso 
De los derechos parroquiales, al sacristán le correspondía la cuarta parte, más los derechos de tañer las campanas, incensar etc. ${ }^{22}$. Y ya que hemos nombrado al sacristán, no estará por demás indicar que el primer Sínodo de Quito había dispuesto que, en todas las Parroquias y Doctrinas, los sacristanes tuviesen "mucho cuidado en tañer las campanas al rayar el alba, a medio día y al anochecer, so pena de medio peso cada vez que lo dejaren de hacer; por lo mismo, que los curas tengan mucho cuidado al toque de campanas, que los parroquianos recen el Avemaría de rodillas, porque muestren la devoción interior y para dar buen ejemplo a los naturales"23.

Decíamos que solamente en el tercer Sínodo diocesano de Quito se señaló un arancel propio, y esto se explica porque el Ilmo. Señor Solís celebró el segundo Sínodo a los dos meses de haber llegado a la sede episcopal, y, por tanto, como no tenía todavía un conocimiento exacto de la Diócesis, juzgaría más conveniente no tratar de este asunto y dejarlo más bien para después de dos años, es decir, para el Sínodo diocesano realizado en Loja en 1596. 
198 / Augusto E. Albuja

Según el tercer Sínodo diocesano, el arancel que debía observarse en todo el obispado de Quito era el siguiente:

a) Derechos del párroco o doctrinero

1. De un español

\section{Entierros}

$$
\text { (- con misa y vigilia }
$$

21 pesos

(- en un Monasterio

27 pesos

$(-\sin$ misa

9 pesos

2. De un niño menor de (- hijo de españoles 10 años

(-con misa cantada 10 pesos

(- hijo de español o mestizo

6 pesos

$(-\sin$ misa

3 pesos

3. De un negro o yanacona

4. De un indio, si se pedía con misa cantada

4 pesos

\section{Misas}

(- ordinaria

1 peso

1. Misa rezada

2. Misa cantada 


\section{Doctrinas y Parroquias del Obispado de Quito /199}

\section{Velaciones}

1. De españoles (incluida la intención de la misa)

12 pesos

2. De montañeses (incluida la intención de la misa)

6 pesos

(-sin la intención de la misa 3 pesos

3. De negros, mulatos, yanaconas

(-con la intención de la misa 4 pesos

\section{Otros actos de piedad}

1. De cada posa hecha en algún entierro

4 pesos

(- rezado, con sus responsos

12 pesos

2. De un novenario

(- entre misas cantadas, con su vigilia

12 pesos

(- sin la vigilia acostumbrada

9 pesos

b) Derechos de otras personas eclesiásticas

(- en un funeral

3 pesos

1. Si un sacerdote se hallaba presente (

$$
\text { (- en la misa y funeral }
$$

4 pesos

2. Los clérigos y religiosos que no eran sacerdotes y sin embargo se hallaban presentes, como invitados, en algún entierro o funeral de "cuerpo presente", c/u

3. Si el Deán y Cabildo de la Catedral eran invitados a asistir a la misa solemne de fin de año en alguna Parroquia 70 pesos Asimismo, por la asistencia y el acompañamiento en algún funeral, sea en la iglesia mayor o en cualquier Monasterio 
200 / Augusto E. Albuja

\section{c) Derechos del sacristán \\ I. Entierros}

1. "Por doblar un entierro" (

\section{Velaciones}

"De las velaciones le pertenecen las arras y la cuarta parte de las ofrendas y candelas, excepto entre indios que no se les ha de pedir arras; $y$ en lo que toca a candelas y ofrendas, ha de ser a voluntad de los naturales".

\section{Otros ingresos}

(- "la primera carta de excomunión" 1/2 peso

1. Por la lectura de (- "la segunda -carta- y de la tercera", por $\mathrm{c} / \mathrm{u} \quad 1$ peso
(- "una paulina”
2 pesos

2. "De las primicias, la octava parte".

3. "De la Extremaunción, los platos". 


\section{Doctrinas y Parroquias del Obispado de Quito /201}

Una vez que se había determinado el arancel diocesano, el Ilmo. Señor Solís pedía que se lo pusiera en práctica "en todas las iglesias, Catedral, Parroquias de este Obispado, y por los vicarios y beneficiados de españoles y naturales, porque, desde luego -decía el Prelado- se revoca y anula otro cualquier arancel de curas -seguramente se refería al determinado en Lima el 15 de septiembre de 1583- y para que sea notorio se ponga en las sinodales de esta sancta Synodo, y ansí le proveyó, mandó y firmó. Fray Ludovicus, Epíscopus Quitensis. Por mandato de su Señoría Iltma. Melchior de Castro Macedo, secretario"24.

\section{Los diezmos}

Diezmos, como su nombre mismo lo indica, eran las contribuciones de los fieles, mediante la décima parte de los frutos que pagaban a la Iglesia o al Rey y servían sobre todo para el sostenimiento del culto divino.

Nueve años después del descubrimiento de América, el Sumo Pontífice Alejandro VI, por la Bula "Eximiae Devotionis", expedida en Roma el 16 de noviembre de 1501, concedía los "diezmos de las partes adquiridas, y que en lo sucesivo adquirieren, a los reyes peticionarios y a sus legítimos sucesores, pero con la condición de que, ante todo, señalaren real y efectivamente rentas suficientes, a juicio de los Obispos respectivos, sobre lo cual les gravaba las conciencias, para que los rectores de las iglesias fundadas, y que en lo sucesivo fueran fundando, se mantuvieran cómodamente y sufragaran los gastos del culto divino".

"De la lectura atenta de la Bula-escribe García Gutiérrez- se desprende: 1) Que la concesión de los diezmos fue hecha a petición de los Reyes de España; 2) Que fue hecha como una compensación por los grandes gastos y trabajos de la conquista; 3) Que fue hecha en atención a que la conquista temporal no era sino la precursora de la espiritual; 4) Que a los Reyes no se concedía sino el sobrante de los diezmos, después de hecha la dotación de las iglesias a juicio de sus Pastores"25.

Así pues, Alejandro VI concedía a los Reyes Católicos no todos los diezmos sino el sobrante, pues tal repartición se debía hacer de la si- 
guiente manera: todos los diezmos de una Diócesis se dividían en cuatro partes; las dos primeras correspondían al Prelado y al Cabildo, respectivamente; las otras dos se subdividían en nueve: los dos novenos correspondían al Rey, los cuatro novenos para los curas, y el resto, es decir, los tres novenos para la fábrica de las iglesias y para hospitales ${ }^{26}$.

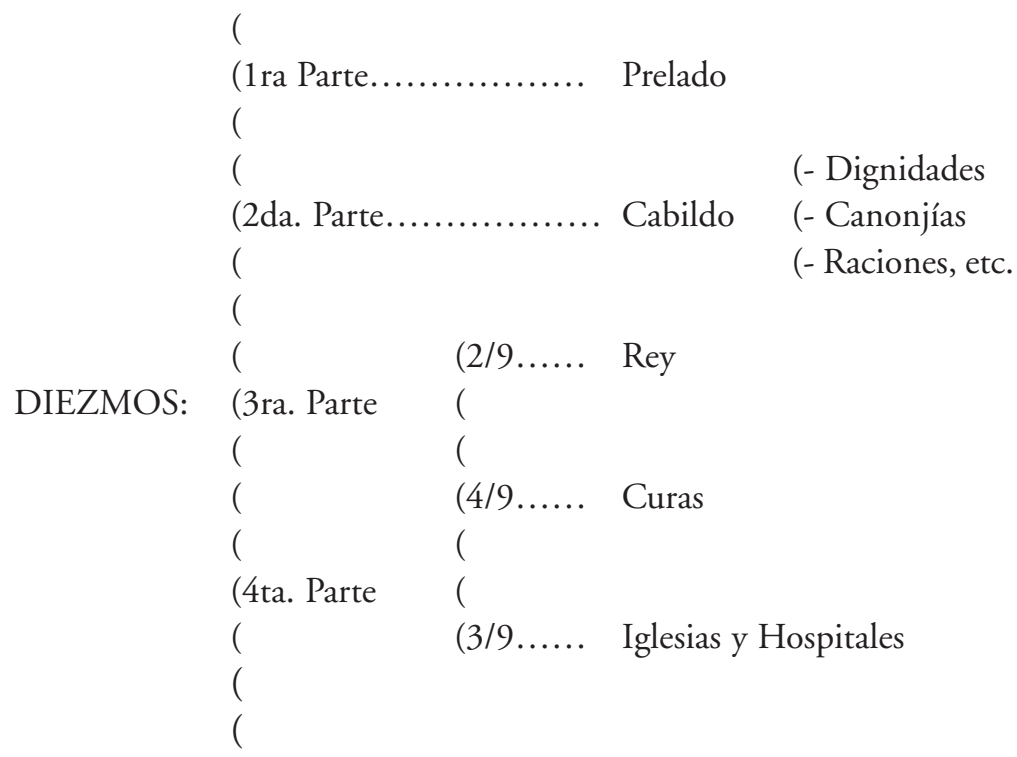

Si los diezmos de las Diócesis eran suficientes para sufragar los gastos, entonces administraban los mismos Prelados y Cabildos; pero, "donde los diezmos no fueren suficientes -decía el Rey Carlos V- para que de ellos se pague la dotación de la iglesia, conforme a su erección, o a la que ahora tuviere, los Oficiales de nuestra real hacienda cobren todos los diezmos y los metan en nuestras cajas reales por cuenta aparte, y de ésta y la demás hacienda nuestra, que en las dichas cajas hubiere, se sustente el Prelado y clero" 27.

¿De qué se debía pagar los diezmos?. Para responder a esta pregunta que nos hemos formulado, acudimos a la respectiva ley vigente en 
Doctrinas y Parroquias del Obispado de Quito / 203

Indias, en donde encontramos que el pago de los diezmos se debía hacer del trigo, cebada, maíz, avena, garbanzos, lenteja, yerbas, legumbres, semillas, arroz, cacao, corderos, cabritos, lechones, pollos, palominos, becerros, potros, muletos, borricos, cochinos, aves, frutos de cualquier árbol, excepto de la piña y bellotas; asimismo, se debía pagar los diezmos de la uva y de aceitunas, de la miel, cera y enjambres, incluso de la seda se pagaba de diez capullos uno ${ }^{28}$. Hasta los mismos Encomenderos estaban obligados a entregar en la Real Caja la décima parte de los tributos que percibían de los indios encomendados ${ }^{29}$.

Respecto a las personas que debían pagar los diezmos y a la manera cómo se los recaudaba, nos parece suficiente transcribir las disposiciones dadas por Felipe II, el 28 de diciembre de 1568, a Francisco de Toledo, Virrey del Perú. "Como en las provincias del Perú y otras partes de las Indias -decía el Monarca- los indios convertidos a nuestra santa fe católica no han pagado ni pagan diezmos, y los españoles, que en ellas residen, le pagan de pocas cosas, de lo cual resulta que en las dichas provincias falta el verdadero y principal fundamento que es éste de los diezmos para la dote y sostenimiento de las iglesias y ministros eclesiásticos; y así, no hay ni puede haber los ministros en el número y calidad que serían necesarios, ni puede lo de la institución, doctrina y conversión de los indios... habiendo nos mandado juntar y platicar a personas graves, doctas y religiosas, celosas del servicio de Nuestro Señor y beneficio público, y habiéndoseles hecho particular relación de todo lo que en esto de los diezmos hasta agora ha pasado... se tomó resolución que los dichos diezmos se debían cobrar y pagar en las dichas provincias y otras partes de las Indias en la forma y manera siguiente:

-"que los dichos diezmos se lleven y cojan en titulo y nombre de diezmos, sin mezclarlo con otros tributos ni derechos, ni debajo de otro color"-

-"que se lleven de todas personas, sin distinción de indios ni españoles, ni otro género de personas algunas y sin diferencia de sexo, ni edad, aunque aquella la haya en lo que toca a los tributos"-

-"que se lleven y paguen de todos los frutos de la tierra y ganados y crianza, pero que por agora no se lleven de artificios ni negociaciones ni tratos" 30. 
En principio, no estaba prohibido arrendar los diezmos, probablemente por las dificultades que debieron presentarse al tiempo de cobrarlos; sin embargo, el Rey pedía a todas las Audiencias Reales que "no consientan ni den lugar a que los Prelados, Prebendados, clérigos, ni personas interesadas en ellos, por sí ni por interposición de otros, hagan posturas ni se les rematen" 31 .

En la época del Ilmo. Señor Solís, y más concretamente en el año 1597, los diezmos de la Diócesis de Quito ascendían a la cantidad de 18.538 pesos de plata corriente, según testimonio de García de Valencia, Canónigo de la Iglesia Catedral y juez colector de las rentas decimales de la Diócesis ${ }^{32}$. Si a la cantidad indicada se añade los 300 pesos correspondientes a los diezmos de las minas del cerro de Zaruma ${ }^{33}$, tendríamos que la suma total de los diezmos en el año 1597 era de 18.838 pesos de plata corriente. Y refiriéndose al año 1598, nos dice: "Este año presente se arrendaron los diezmos en 18 mil pesos de plata corriente, y los años pasados en lo mismo, poco más o menos; lleva el Obispo de esto la cuarta parte, y el Cabildo otra cuarta parte, y las otras dos restantes se hacen nueve novenos, de los cuales lleva dos Su Majestad, y lo demás la fábrica y hospital, curas-rectores y otros ministros de la Iglesia" 34 .

Según esto, los diezmos correspondientes al año 1598 en la Diócesis de Quito estarían distribuidos así:

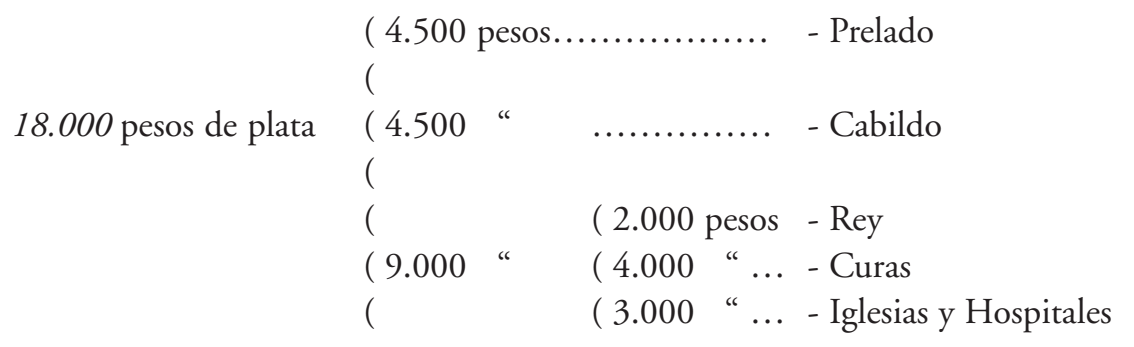

Como hemos tratado en los párrafos anteriores sobre el salario de curas y doctrineros, aranceles parroquiales y diezmos, no estará por demás añadir un cuarto párrafo acerca del valor de la moneda para que tengamos 


\section{Doctrinas y Parroquias del Obispado de Quito /205}

una idea menos abstracta de los ingresos destinados para el sostenimiento de las Parroquias y de sus ministros.

\section{Valor de la moneda}

No es nuestro intento dejar zanjada esta cuestión monetaria del siglo XVI; primero porque cae fuera de nuestro fin propuesto y luego, porque otros autores más competentes, como el Doctor Manuel Luengo Muñoz, han realizado varios estudios para dilucidar este problema, al parecer sencillo, pero, que, en realidad, es origen de múltiples confusiones, pues entran en juego los pesos oro y de plata corriente, los maravedíes, los reales y los tomines.

Seguramente el lector se preguntará: ¿Por qué tratar acerca del valor de la moneda en un trabajo sobre las Doctrinas y Parroquias del Obispado de Quito en la segunda mitad del siglo XVI?. Pues, sencillamente, porque también la moneda, aunque de una manera secundaria, entra en el campo eclesiástico como en los aranceles diocesanos, en los diezmos y en los salarios o estipendios de los sacerdotes.

Cuando los Oficiales de la Audiencia de Quito, a instancias de los Encomenderos, trataban de que fuesen los salarios de los curas y doctrineros solamente de 300 pesos de plata corriente y no de 350 pesos oro, como había fijado el Ilmo. Señor Peña, es porque había una gran diferencia, como constataremos en seguida.

Al principio se había señalado un salario único para cada Parroquia y Doctrina; incluso, durante unos pocos años, se lo puso en práctica. Pero varios fueron los motivos para que dicho salario dependiese de la clase de Doctrina o Parroquia, del número de indios tributarios que en ella había, de los caseríos, si eran o no distantes unos de otros, etc. y así encontramos datos muy distintos, pues mientras una Doctrina valía 400 pesos oro, otra no llegaba sino a 250 pesos de plata corriente.

A continuación señalamos unas cuantas Parroquias y Doctrinas con los nombres de sus beneficiados y el respectivo salario que percibían cada año. Estos datos corresponden al año $1598^{35}$. 
206 / Augusto E. Albuja

\section{Parroquias:}

S.Sebastián

Sta.Bárbara

S. Marcos

Pasto (ciudad)

Pbro. Francisco Durán

" Antonio Borja

" Martín de Gaviria

" Diego de Bracamontes
500 Pesos plata

250 ” "

$200 "$,

$1.000 "$

\section{Doctrinas:}

La Laguna

Cibundoy

Carlosama
Fr. Pedro de Montoya

Domingo de Cevallos

Pedro de Quiroga
90 Pesos oro

$400 " ”$

$300 "$

Generalmente, las cosas se vendía en Indias, no en pesos sino en maravedíes. He aquí algunos precios que cita Luengo Muñoz ${ }^{36}$ :

\section{Cantidad En Castilla En Indias}

$\begin{array}{llrr}\text { Aceite } & \text { arroba } & 100 & 375 \\ \text { Arroz } & \text { arroba } & 250 & 400 \\ \text { Azúcar } & \text { arroba } & 853 & 238 \\ \text { Caballo } & ------ & 30.000 & 50.000 \\ \text { Cabrito } & \text { arroba } & 315 & 204 \\ \text { Gallina } & ------ & 34 & 8 \\ \text { Huevo } & ------ & 2 & 1 \\ \text { Pollo } & ------ & 4 & 2 \\ \text { Ternera } & \text { arroba } & ? & 408 \\ \text { Vino blanco } & \text { arroba } & 100 & 1.632 \\ \text { Vino tinto } & \text { arroba } & 130 & 1.900\end{array}$

Durante el siglo XVI, "en el Perú -escribe el citado autor- como calidad característica figura el oro ensayado de tributo, valorado en 425 maravedíes $-12,1 / 2$ reales $=$ el peso. Este se valoraría en 1590 por 13,1/4 
Doctrinas y Parroquias del Obispado de Quito / 207

reales, pudiendo haber inducido a error a los autores que valoran el peso de oro de minas, según hemos dicho en 13,1/4 reales, en lugar de los 450 maravedíes" 37 .

En la Diócesis de Quito, en cambio, el peso de oro, no el de los tributos, sino el de los salarios de los curas y doctrineros, estaba valorado en 450 maravedíes, pues, en un oficio dirigido a Felipe II, encontramos estas palabras:..." estando tasada cada Doctrina en trescientos y cincuenta pesos de oro de a cuatrocientos y cincuenta maravedies" 38 .

El peso de plata corriente equivalía a 9 reales, antes y después del año 1590, y nos apoyamos en un documento de 1598 en que el Ilmo. Señor Solís, después de exponer la lista de todos los beneficiados existentes en la Diócesis y sus respectivos salarios, la mayoría de los cuales era en pesos de plata corriente, nos dice que "también se ha de advertir que donde va declarado, que los pesos son de plata de a nueve reales el peso" 39 .

Nuestro deseo es establecer una relación, aunque sea aproximada, entre el peso de oro y el peso de plata corriente. En otro documento, que trata de las rentas de los diezmos de todo el Obispado de Quito, encontramos estos datos bastante concretos: "Iten, los diezmos de la ciudad de Pasto, en mil y cuatrocientos pesos de oro de veinte quilates, como corre en la dicha ciudad, que valen de plata dos mil y cien pesos corrientes. 2 U. 100 ps." ${ }^{40}$. Por tanto, la relación que podríamos establecer sería de 2 a 3; es decir, dos pesos oro equivaldrían a tres pesos de plata corriente. De modo que, según el último texto citado, tendríamos:

$\begin{array}{rrr}1.400 \text { ps. oro } & = & 2.100 \text { ps. plata } \\ 200 " ” & = & 300 " \\ 2 " » " & = & 3 "\end{array}$

Advertimos que esta relación de 2 a 3 sería a partir del año 1590, en que probablemente el peso de plata corriente sufrió una devaluación, pues continuaba con su equivalente a 9 reales, mientras que el peso oro, que hasta esa fecha se cotizaba en 12,1/2 reales, se valoró a 13,1/4 reales. De donde, entre el salario de 350 pesos oro, fijado por el Ilmo. Señor Pe- 
208 / Augusto E. Albuja

ña para las Parroquias y Doctrinas de la Diócesis, y el propuesto por los Encomenderos de sólo 300 pesos de plata corriente, la diferencia era enorme, pues:

350 ps. oro c/peso $12,1 / 2$ reales

300 ps. plata corriente c/ peso 9 reales

$$
\text { Diferencia }
$$

$=\quad 4.375$ reales
$=\quad \frac{2.700 "}{1.675 "}$

Esta diferencia de 1.675 reales equivalía a 186 ps. de plata o lo que era lo mismo 134 ps. oro.

Ya que el peso oro hasta el año 1590 se cotizaba en 12,1/2 reales y como un peso oro equivalía a 450 maravedíes, tenemos que un real valdría 36 maravedíes. Luego, si el peso oro correspondía a 450 maravedíes, el peso de plata corriente venía a resultar por 324. A partir del año 1590 si el peso oro subió a 13,1/4 reales, cada real valía apenas 34 maravedíes.

De donde, la lista de Parroquias y Doctrinas con sus respectivos beneficiados y salarios, como exponíamos anteriormente, quedaría de la siguiente forma:

Parroquias:

Maravedies:

S.Sebastián

Pbro. Francisco Durán

500

Sta. Bárbara

" Antonio Borja

S. Marcos

Martín de Gabiria

250

Pasto (ciudad)

Diego de Bracamontes

200

1000

Ps. Plata

" "

"

”,

,
153.000

76.000

61.200

306.000

\section{Doctrinas:}

La Laguna

Cibundoy

Carlosama
Fr. Pedro de Montoya

" Domingo de Cevallos

" Pedro de Quiroga
90

400

300
40.500

180.000

135.000 
El siguiente esquema viene a ser como una síntesis de todo este embrollo acerca del valor de la moneda en la segunda mitad del siglo XVI, y esperamos que servirá de guión para apreciar las diversas cantidades relacionadas con el tributo que pagaban los indios y los salarios que recibían anualmente los curas y doctrineros, los diezmos que recaudaban y los derechos arancelarios que estaban en vigencia en todas las Parroquias y Doctrinas de la Diócesis de Quito:

\begin{tabular}{|c|c|c|c|}
\hline \multicolumn{2}{|c|}{ Antes del año 1590} & \multicolumn{2}{|c|}{ A partir del año 1590} \\
\hline Peso Oro & Peso Plata & Peso Plata & Peso Oro \\
\hline 12,1/2 Reales & 9 Reales & 9 Reales & 13,1/4 Reales \\
\hline 450 maravedíes & 324 maravedíes & 306 maravedíes & 450 maravedíes \\
\hline \multirow{3}{*}{\multicolumn{2}{|c|}{ UN REAL = 36 maravedíes }} & \multicolumn{2}{|c|}{ UN REAL = 34 maravedíes } \\
\hline & & \multicolumn{2}{|c|}{$\begin{array}{l}\text { RELACIÓN } \\
\text { APROXIMADA }\end{array}$} \\
\hline & & 3 & 2 \\
\hline
\end{tabular}


210 / Augusto E. Albuja

\section{NOTAS:}

1 ARMAS MEDINA, Evolución Histórica de las Doctrinas de indios, 8-9

2 Primer Concilio limense, Parte Primera, Const. 28.

3 Segundo Concilio limense, Parte Segunda, c. 78.

4 Apéndice \# 5.

5 AGI, Quito, leg.76; cf.tb. Apéndices \# 9 y \# 10.

6 Recopilación, lib.I, tit.13, ley 15.

7 AGI, Quito, leg.76. Y para confirmar que el salario estaba fijado en 350 pesos citamos dos ejemplos: En la provisión canónica de la Doctrina de Gualea, hecha por el Ilmo. Señor Peña en favor del presbítero Antonio de Balbuena, el 28 de septiembre de 1568, decía el Prelado de Quito: “...por la ocupación e trabajo que en lo susodicho habéis de tener, para ayuda a vuestra sustentación y del gasto de vino y cera que habéis de tener, mandamos que hayáis, llevéis y vos sea dado y pagado trescientos cincuenta pesos de la moneda que los dichos naturales pagan sus tributos a sus Encomenderos, los cuales cobraréis de los Encomenderos..." (AGI,Quito,leg.81). Asimismo, en la provisión canónica del presbítero Gaspar de Ulloa como beneficiario de Tiquizambe-Sibambe y Pomallacta, fechada el 21 de octubre de 1572, consta lo siguiente: "...y por la ocupación y trabajo que en la dicha Doctrina habéis de tener, para ayuda a vuestra sustentación, mandamos sea dado y pagado trescientos y cincuenta pesos de oro". (Apéndice \# 13).

8 AGI, Quito, leg.8.

9 Apéndice \# 25.

10 Recopilación, lib. I, tít. 13, ley 15.

11 Relaciones Geográficas de Indias, III, Madrid 1897,48, camarico era la comida que los indios daban al cura doctrinero. El camarico estaba estipulado en 100 pesos anuales; cf.tb. Apéndice \# 48.

12 AGI, Contaduría, leg. 1583.

13 Cuarto Concilio limense, cap.4.

14 Ibidem, cap. 5.

15 Ibidem, cap. 6.

16 Apéndice \# 48.

17 Apéndice \# 51.

18 RODRÍGUEZ VALENCIA, Santo Toribio de Mogrovejo, I, 408.

19 Recopilación, lib. I, tit. 18, ley 10. 


\section{Doctrinas y Parroquias del Obispado de Quito /211}

20 Primer Sínodo de Quito, Parte Primera, c.4; (AGI, Patronato, leg.189.R.40)

21 Tercer Concilio limense, Acc. 4-, cap.15.

22 LEVELLIER, Organización, I, 250-251.

23 Primer Sínodo de Quito, Parte Tercera c.18; Parte Segunda c,12. (AGI, Patronato, leg. 189, R-40).

24 Tercer Sínodo de Quito, Const. 32; (AGI, Quito, leg.77).

25 GARCÍA GUTIÉRREZ, Jesús, Apuntes para la historia del origen y desenvolvimiento del Regio Patronato Indiano hasta 1857, México 1941, 62 - 63.

26 Apéndice \# 43; cf.tb. Apéndice \# 9.

27 Recopilación, lib.I, tit.16,ley 23.

28 Ibidem, ley 2.

29 Ibidem, ley 12.

30 AGI, Indiferente General, leg.2.859, lib. 2, f.21v.22v.

31 Recopilación, lib.I, tit. 16, ley 31.

32 Apéndice \# 46.

33 Apéndice \# 46.

34 Apéndice \# 48; cf.tb. Apéndice \# 43.

35 Apéndice \# 48.

36 Anuario de Estudios Americanos, VIII, Sevilla 1951, 44. El artículo titulado "Sumaria noción de poder adquisitivo de la moneda en Indias durante el siglo $X V I$ ” es escrito por el doctor Manuel Luengo Muñoz, y comprende desde la pág. 35 hasta la pág. 57.

37 Anuario de Estudios Americanos, VII, Sevilla 1590, 347.

38 Apéndice \# 25.

39 Apéndice \# 48.

40 Apéndice \# 46. 



\section{CAPÍTULO XII \\ REFORMA DEL CLERO $Y$ SACERDOTES BENEMÉRITOS}

\section{Reforma del clero}

A raíz del descubrimiento de América el 12 de octubre de 1492,"muy pronto -escribe Gómez Hoyos, citando a García Icazbalcetacomenzaron a afluir clérigos que más tenían de aventureros que de evangelizadores. Sin previa elección, ignorantes y viciosos, perseguidos muchas veces por sus Prelados, ex-religiosos, venían al Nuevo Mundo en busca de libertad, de fortuna o de adelantos en su carrera"1.

¿Qué se podía esperar de ciertos clérigos que tenían muy poco espíritu apostólico, por no decir que lo habían perdido?. Sus ocupaciones favoritas eran el juego y la negociación. Sus correrías apostólicas se reducían a cacerías y al ir y venir de un Obispado para otro en busca del Encomendero que resultara el mejor postor, y en este caso se establecían en un determinado Repartimiento para enseñar a su manera la doctrina cristiana a los pobres indios, sedientos de la verdad del Evangelio y necesitados de robustecer la fe recibida en el santo bautismo. Además, no se preocupaban de aprender el idioma indígena; pensaban que era más que suficiente que los humildes indios, sus feligreses, recitaran de memoria y en latín, o en romance, ciertas preguntas y respuestas de alguna cartilla, más o menos piadosa, que tuviera relación con la doctrina cristiana.

Los Prelados de las distintas Diócesis erigidas en la primera mitad del siglo XVI, casi en seguida advirtieron las deficiencias del clero; $y$, a partir del año 1551, se trató de conseguir la reforma de párrocos y doctrineros, pues, de lo contrario, la magna obra de la conquista y de la evangelización de América hubiese caminado al fracaso. 
De la reforma del clero se preocuparon los Concilios provinciales de Lima, los Sínodos diocesanos de Quito y las Reales Cédulas enviadas desde España por el Monarca.

Examinemos las principales reformas para restablecer las buenas costumbres clericales en la Diócesis de Quito, aunque, en general, se podía aplicarlas en toda la Provincia eclesiástica de Lima en la segunda mitad del siglo XVI.

\section{Negociación}

Ya que la negociación desdice del estado clerical, pues, los sacerdotes en vez de dedicarse a la evangelización propiamente dicha, más les preocupaba los bienes materiales y por el mal ejemplo que se daba a los indios, el primer Concilio limense dispuso que los clérigos "no tengan con los indios ningunas granjerías, ni rescates, ni tengan ganados, si no fuera una o dos yeguas y hasta quince o veinte cabras y no más, so pena de cincuenta pesos; y la mitad del ganado que así tuviere, aplicado la mitad para la iglesia del pueblo donde el tal clérigo doctrina, y la otra mitad para indios pobres de tal Repartimiento"2.

Como a partir de 1551, el salario de los párrocos y doctrineros debía ser señalado por los respectivos Prelados para evitar abusos de parte de los Encomenderos, el Concilio de 1567 fue más estricto en este punto de la negociación en los clérigos, "aunque digan que lo hacen para sustentarse", porque en esta época tenían ya "su estipendio cómodo señalado"3. Y si, a pesar de esto, hubiese algún transgresor de esta constitución conciliar, el Rey pedía a todos los Obispos que procediesen "castigando con mucho rigor y demostración", pues "que para ello -decía el Monarca- darán el favor y ayuda necesaria nuestras Reales Audiencias"4.

En la época de Santo Toribio de Mogrovejo, probablemente, en algunas Diócesis, la negociación en el clero no había desaparecido, porque, sin duda, la amenaza de multas pecuniarias o de pérdida de los bienes adquiridos por este medio era incapaz de curar esta enfermedad de muchos clérigos. Por eso, en el tercer Concilio provincial de 1583, el San- 


\section{Doctrinas y Parroquias del Obispado de Quito /215}

to Arzobispo de Lima y los Obispos sufragáneos adoptaron una medida drástica, pero que debió dar magnífico resultado, pues, “...cualquiera que hiciera alguna cosa de las dichas -negociación o granjería- entienda que, por el mismo caso, incurre en excomunión mayor latae sententiae". Lo que se trataba de conseguir por todos los medios posibles, incluso con esta amenaza de excomunión, era que los doctrineros no abusaran de los indios, sus feligreses, pues no podía darse una cosa más absurda y contradictoria que ocuparlos "en sus ganancias temporales los que debían procurar las ganancias espirituales de sus almas"5.

¿En qué se basaban los Padres del Concilio para imponer una pena tan grave, como es la excomunión mayor latae sententiae, contra los clérigos comerciantes?. Las razones fueron las mismas que motivaron a la Sagrada Congregación del Concilio en Roma para ratificar la legislación del año 1583 , a saber:

“1. Porque el comercio de los párrocos es muy escandaloso a los indios, haciéndoles juzgar es venal la religión de Jesucristo;

2. porque eran ocupados y maltratados los indios con sumo exceso en aquellos tráficos;

3. porque con ese pretexto habían de disimular los vicios de los caciques y principales;

4. porque los clérigos, embebidos en sus granjerías, descuidaban la administración de los sacramentos;

5. porque de aquí se ocasionaba el fraude, porque los indios, a fin de ganarse la voluntad del cura, conmutaban sus mercancías al precio que a él le placía.

Y finalmente, porque cada negociación, en sí, es sórdida; indigna del sagrado ministerio y contraria a la propagación del Evangelio". Esta pena de la excomunión fue abrogada por Paulo V mediante un Motu Propio el 7 de marzo de 1607, "pero fue renovada más tarde por Clemente IX, el 17 de julio de 1669"6.

La prohibición rigurosa de la negociación en los clérigos estuvo vigente en la Diócesis de Quito hasta 1596, pues el Ilmo. Señor Solís que 
conocía muy de cerca la situación económica de muchos de sus curas, especialmente de los que se hallaban encargados de las Doctrinas de indios, permitió "que los dichos curas puedan tener cincuenta carneros y veinte y cuatro cabras, con sus padres, y tres puercos para su sustento cada año"7.

Si hace cuatro siglos la negociación en los clérigos era algo que desdecía de su estado, a pesar del transcurso del tiempo sigue en vigencia dicha prohibición, y el Código de Derecho Canónico dispone que los castigos para los transgresores tengan relación directa con la gravedad del delito ${ }^{8}$.

\section{Juego}

El juego en sí no es malo; es indiferente. Se hace malo por las circunstancias y por el tiempo que se le dedique, ya que, muchas veces, se prescinde de las obligaciones de estado para dedicarse a un mero pasatiempo?.

Es muy aconsejable cambiar de ocupación para distraerse un poco; y, de vez en cuando, aprovechando de los momentos libres, alguno podría distraerse en el juego, siempre que éste no vaya en perjuicio ni de su salud, ni de la moral, ni de los deberes propios de cada individuo.

A mediados del siglo XVI, el juego de dados, naipes y otros semejantes se extendió mucho entre los doctrineros, quienes descuidaban el cumplimiento del ministerio parroquial, porque más les importaba ganar una partida de naipes en la que habían apostado unos cuantos pesos de plata. Este exceso no podía durar mucho tiempo. En el primer Sínodo diocesano, al ordenar el Ilmo. Señor Peña que los curas "no sean jugadores de naipes, ni de otros juegos, en que los sacerdotes dan mal ejemplo, y el que fuere jugador sea multado y penado en otro tanto como perdió o ganó en el juego"10, no hacía otra cosa sino llevar a la práctica la disposición del segundo Concilio limense, a saber: "que los Obispos y Visitadores castiguen con rigor a los sacerdotes que juegan dados, naipes o juegos semejantes"11.

Más tarde, en la celebración del tercer Concilio provincial limense, el primero de los celebrados en la época del Arzobispo Santo Toribio 
de Mogrovejo, se volvió a insistir en la dicha prohibición del juego a los clérigos, amenazándoles incluso con la excomunión, al igual que la negociación ${ }^{12}$. Pero esta medida fue considerada por la Sagrada Congregación del Concilio como demasiado exagerada; de ahí que fue necesaria esta aclaración: se incurriría en la excomunión si la cantidad que se jugare excediera de cincuenta escudos de oro, o sea unos ochenta pesos, como estima Vargas Ugarte ${ }^{13}$; manteniéndose, sin embargo, la prohibición. A esto se añadía la recomendación hecha por el Rey a todos los Prelados, a fin de que en sus respectivas Diócesis a sus clérigos "no permitan que jueguen en ninguna cantidad"14.

\section{Caza}

Como muchos sacerdotes se dedicaban a este deporte de la cacería, dejando abandonadas sus Parroquias o Doctrinas por varios días y sirviendo de escándalo a los indios, los Concilios limenses y los Sínodos quitenses no se contentaron con hacer hincapié en la residencia de los beneficiados, sino, además, se ordenó a todos los clérigos que "no se ocupen en cazas o monterías, y si lo hicieren sean penados"15. Además se recomendó a los Prelados y Visitadores que "al clérigo que hallaren dado a semejantes impertinencias, no dejen de darle la corrección que convenga" 16 , ya que estaba terminantemente prohibido a los clérigos el uso "de armas seglares como arcabuz, montante, partesana o semejante, so pena de perder las dichas armas y más treinta pesos"17.

\section{Trato con mujeres}

Por el peligro que encierra el trato con mujeres y para que los sacerdotes anduvieran siempre vigilantes, si querían ser fieles a su voto de castidad prometido a Dios, se exhortaba "que ningún sacerdote, que estuviere en Doctrina de indios, tenga en su compañía, ni para su servicio, india ni mujer alguna, sino que le guisen de comer indios; y si alguna in- 
dia tuviere para esto, que sea casada y que esté con su marido, apartada de donde estuviere el dicho sacerdote" 18 .

Teniendo en cuenta que en muchas ocasiones la falta de prudencia en el sacerdote es causa de escándalo en los fieles, el tercer Concilio de Lima prescribía que "ningún clérigo de orden sacro sirva de escudero a ninguna mujer, o acompañándola, aunque sea su hermana o madre, so pena que, así el clérigo como la mujer que lo contrario hicieren, sean por el mismo caso descomulgados". Esta pena de excomunión seguramente fue suprimida, pues, al margen del manuscrito original, como advierte Vargas Ugarte, se dice: "sean castigados al arbitrio del Obispo"19. Asimismo, se pedía a todos los sacerdotes que procuren evitar la compañía de mujeres "para no perder la castidad que han prometido a Dios, o a lo menos no menoscabar su honor, y poner nota en el estado eclesiástico, de suerte que venga a ser despreciado", amenazando castigar con penas graves a los clérigos concubinarios. Estas penas podían ser: privación de la tercera parte de los frutos del beneficio, si el culpable no se enmendare después de la primera monición hecha por el Obispo; y si no obedeciere, habiéndosele amonestado dos veces, entonces le vendría la suspensión del beneficio; y se llegaría a la privación de todo beneficio y oficio en la Iglesia, declarando la inhabilidad del clérigo para cualquier cargo, si no se hubiere enmendado después de haber sido amonestado tres veces por su Obispo ${ }^{20}$.

Si muy estrictos fueron sobre este asunto, tanto el Tridentino como los Concilios limenses, no lo fue menos el segundo Sínodo de Quito, ya que el Obispo Solís advertía "que ningún clérigo de orden sacro trate ni comunique con monjas, si no tuviere nuestra licencia especial y no de otra persona, lo cual cumplan en virtud de santa obediencia y en ninguna manera las hablen sin licencia nuestra, so pena de excomunión"21.

\section{Hábito y buenas costumbres}

Hermoso y a la vez paternal es el consejo que el Ilmo. Señor Peña daba a todos sus sacerdotes en el primer Sínodo de Quito. 


\section{Doctrinas y Parroquias del Obispado de Quito /219}

"Encargamos -decía el celoso Obispo- a los curas de los indios que sean muy ejemplares y que no se descuiden, porque el demonio, con las malas obras de los ministros de la ley de Dios, arguye el contrario a la doctrina cristiana. Traigan siempre su hábito y vestido decente y no laical; abierta la corona y barba cortada. Recen sus horas y digan misa; y ordinariamente ocupen el tiempo en obras virtuosas con frecuente predicación, consolando los tristes, dando remedio a los pobres y amparando los huérfanos, administrando los santos sacramentos con mucha diligencia y cuidado, enseñando a los niños en la escuela y Doctrina. Consideren el santo oficio de su sacerdocio y a lo que están obligados en el beneficio de esta viña de Dios"22.

El Concilio que fue más explícito en dar normas para reformar abusos en la manera de vestir de los clérigos y restablecer las buenas costumbres, fue, sin duda, el celebrado por Santo Toribio en 1583. Todos los sacerdotes, por su misma condición de personas consagradas a Dios y al servicio de las almas, debían llevar un vestido y hábito decente "sin muestra de profanidad y ambición; el vestido no ha de ser de color ni de seda, ni demasiado corto y pulido, ni más largo e hinchado, sino como conviene a la gravedad eclesiástica, que llegue a los pies y del todo se quiten del uso clerical unas nuevas invenciones de trajes y galas que más son de soldados que no de clérigos, como son lechuguillas, polainas, puñetes, guarniciones de seda, fajas en los manteos, alamares, monteras, pantuflos, zapatos de seda, follajes en las calzas o muslos, aunque sean de paño, y cualquier otro aderezos semejantes; y lo que por ninguna vía se ha de sufrir es que anden clérigos de noche con armas y traje corto como soldados; no siendo razón que ni aún en su hábito clerical anden de noche. Si alguno, teniendo en poco lo dicho, usare de vestidos profanos o trajera armas, pierda luego todos los vestidos profanos ya dichos y las armas para que el Prelado las aplique como le pareciere, y con otras penas más graves le castigue, según mereciere su culpa”.

El ministerio parroquial no tiene que regirse por un horario señalado de antemano, sobre todo en tratándose de feligreses enfermos, en este caso el párroco está obligado a atenderlos a cualquier hora del día o de la 
noche, por eso "si algún negocio -advertía la constitución conciliar de 1583- obligare a salir de noche de su casa, es bien que lleven luz adelante, o compañía honesta, que muestre que anden buenos pasos".

A más de llevar hábito decente, se recomendaba a todos los sacerdotes que "la corona y la barba, por lo menos, cada mes se la hagan" 23 . Los sacerdotes fumadores fueron también tomados en cuenta por el tercer Concilio, ya que para ellos se dio el siguiente decreto: "Con precepto estrecho se prohibe a los sacerdotes que, antes de celebrar, no tomen por la boca ni por las narices el humo o polvo del tabaco, aunque sea so color de medicina" 24 .

Asimismo para que la buena costumbre del estudio se mantenga entre los sacerdotes, se les recomendaba "tener especialmente autores que traten bien de casos de conciencia, en que es necesario sean versados, y si en ello fueren negligentes sean reprendidos" 25 .

Y para terminar este estudio de la reforma del clero, conviene dar a conocer las principales penas impuestas por la legislación en ese entonces vigente para castigar los delitos de los eclesiásticos. Tales penas las hemos tomado de la obra de Peña Montenegro ${ }^{26}$, y son las siguientes:

-Excomunión, cuando un sacerdote, sin tener potestad, por malicia o por ignorancia crasa, absolvía de los casos y censuras reservados al Papa.

- Pena del talión, si un clérigo acusaba a otra persona de algún delito y no lo probaba.

-Privación del oficio y beneficio: cuando un párroco se negaba a bautizar y, por su culpa, moría una persona sin bautismo alguno. Esta misma pena se debía aplicar para aquél que, fuera del peligro de muerte, administraba el sacramento del bautismo con óleo y crisma antiguos.

-Irregularidad contraía quien, maliciosamente, reiteraba el bautismo; asimismo, el que celebraba misa estando excomulgado, entredicho o suspenso de oficio.

-Suspensión ipso facto del oficio y beneficio para el clérigo que fuese claramente concubinario.

- Privación del beneficio, cuando un sacerdote decía misa sin estar en ayunas; y si alguno se atrevía a decir misa sin agua, sin luz o con cáliz 


\section{Doctrinas y Parroquias del Obispado de Quito / 221}

de madera, entonces se le castigaba con la privación tanto del oficio como del beneficio.

- Pena arbitraria para el que decía misa sin ara consagrada; y si la decía sin casulla ni otras vestiduras sagradas, podía ser suspendido ad tempus.

- Pena de no comulgar todo el año, si un sacerdote decía misa y no comulgaba el Cuerpo y la Sangre de Cristo.

\section{Sacerdotes beneméritos}

Al estudiar la reforma del clero en la segunda mitad del siglo XVI, no fue nuestro intento sembrar un desconcierto y hasta pesimismo para con los sacerdotes que vinieron a América a raíz del descubrimiento en 1492 y para con los que debieron llegar en los años posteriores.

Es triste pensar que muchos no fueron lo que debían ser; pero, también es verdad y tenemos una enorme satisfacción en reconocer que a las Diócesis de Indias, y particularmente a la de Quito, llegaban sacerdotes pletóricos de entusiasmo y de verdadero celo apostólico que se desvivieron por el bienestar espiritual, moral y social de los pobres indios.

Los dos Obispos, Ilmos. Fr. Pedro de la Peña y Fr. Luis López de Solís, cuando se trataba de corregir abusos y faltas de sus sacerdotes, antes de imponerles castigos, hacían todo lo posible para conseguir la enmienda por medio de sus consejos verdaderamente paternales; y, cuando había necesidad de premiarles o de influir ante el Rey para conseguirles un mejor beneficio, imparcialmente sacaban a relucir virtudes y méritos que hasta entonces habían permanecido ocultos y, seguramente, muchos de aquellos sacerdotes hubieran preferido pasar desapercibidos, antes que haber sido tomados en cuenta. Pero los Obispos no hacían otra cosa sino cumplir un deber de justicia y acatar la Ordenanza Real de enviar de vez en cuando una nómina "de los sacerdotes beneméritos que hubiere en sus distritos, que más hayan servido en la doctrina y conversión de los indios, y de sus calidades, edad, habilidad, suficiencia, vida y costumbres y en quien concurren las otras partes necesarias para servir las Prebendas y Beneficios" 27 . 
Enumerar aquí a todos los sacerdotes beneméritos que trabajaron en la Diócesis de Quito haciendo el bien, sembrando la semilla del Evangelio, a fin de que el Reino de Cristo llegara hasta el corazón mismo de los indios, sería una labor muy difícil y extensa, y temeríamos olvidar varios nombres. Sin embargo, nos permitimos sacar a relucir a los siguientes sacerdotes:

Pedro Rodríguez de Aguayo, sacerdote que desempeñó importantes cargos. En la época del Ilmo. Señor Garci Díaz Arias, el Cabildo estaba compuesto por dos miembros: Pedro Rodríguez de Aguayo, como Arcediano, y Juan de Ocaña, como canónigo. En 1562, una vez que quedaba la Sede vacante por muerte del primer Obispo, Pedro Rodríguez de Aguayo era elegido Vicario Capitular ${ }^{28}$; y durante el episcopado del Ilmo. Señor Peña, continuó de Arcediano de la Catedral.

Diego de Salas, por sus méritos y virtudes y por su experiencia en el ministerio parroquial, colaboró con el Ilmo. Señor Peña en calidad de Vicario General y de Provisor de la Diócesis; y en el Cabildo de la Catedral ocupó la Dignidad de Chantre ${ }^{29}$.

Gómez de Moscoso, de quien el Ilmo. Señor Peña, al nombrarle cura del beneficio de Zamora el 27 de diciembre de 1572, hacía el siguiente elogio: “...acatando la habilidad y suficiencia que vos, el Reverendo Padre Gómez de Moscoso, clérigo presbítero, e que sois hijo deste obispado y benemérito en él, y que habéis dado buena cuenta de lo que por nos ha sido encargado y mandado; por la presente, en nombre de Su Majestad, conforme a la dicha Real Cédula, vos damos licencia para que seáis beneficiado en la dicha iglesia e ciudad de Zamora" 30 .

Pedro Arias Dávila, sacerdote que se hallaba ejerciendo el ministerio parroquial en la Doctrina de Pacaybamba, cuando el Prelado enviaba al Rey, el 13 de octubre de 1579, el siguiente informe: “...es sacerdote honrado -escribía el Ilmo. Señor Peña- de buena fama y vida y costumbres, y ha vivido en ésta-refiriéndose a la Diócesis de Quito- recogidamente y con buen ejemplo; y en la dicha doctrina de Pacaybamba ha hecho mucho fruto a los naturales y ellos, por ser asi, le tienen mucho amor. El cual tiene habilidad y suficiencia para servir cualquiera beneficio curado de espa- 


\section{Doctrinas y Parroquias del Obispado de Quito /223}

ñoles y de Doctrinas de indios, por lo cual...cabe en el dicho Pedro Arias Dávila la merced que Su Majestad fuere servido de le hacer y será bien empleado"31.

Bachiller Antonio de Balbuena, sacerdote de letras y con un verdadero espíritu apostólico; era muy hábil y hablaba perfectamente el idioma indígena. Desempeñó cargos muy importantes como cura y Vicario de la ciudad de Cuenca. En el año 1568 pasó a la Doctrina de Pallatanga, donde ejerció el ministerio parroquial escasos seis meses, pues recibió la provisión canónica como cura y Vicario de la Doctrina y pueblos de Gualea, Vinagre, en reemplazo del Padre Manuel Díaz. Cuando Diego Flores, siendo Vicario y Visitador de la ciudad de San Juan de Guamanga, el 27 de enero de 1567, concedía la respectiva autorización para que el presbítero Bachiller Antonio de Balbuena pudiera pasar a la provincia del Perú a prestar allí sus servicios, se expresaba en estos términos: “...hago cierto que el dicho Bachiller Antonio de Balbuena ha dado y dio muy buena cuenta de los curazgos que ha tenido a su cargo en este distrito de los naturales de ella, dando muy buen ejemplo y vida y fama...: 32 .

Juan de Olmos Bolaños, sacerdote de suma confianza para el Ilmo. Señor Peña; mereció ser nombrado Vicario General de la Gobernación de Juan de Salinas Loyola; pues “...por haber muchos días que la dicha Gobernación no se visita, como por ser tierra áspera y nuevamente descubierta, -escribía el Obispo el 12 de octubre de 1575- conviene en ella tengamos Juez que mantenga en paz y justicia nuestra jurisdicción. Confiando de vos, el Reverendo Padre Juan de Bolaños, nuestro cura y vicario de la ciudad de Loyola, que sois persona cual conviene para lo de yuso escrito, por la presente vos nombramos por nuestro Vicario General en toda la dicha Gobernación de Juan de Salinas, ciudades, villas y lugares e de los pueblos de indios della y de todos los clérigos y vecinos estantes y habitantes... y vos damos facultad para que, faltando en alguna parte de la dicha Gobernación alguno de los curas y vicarios de las ciudades y lugares de españoles o de pueblos y Doctrina de indios, podáis, en nuestro nombre, ponerlo y señalarlo el que vos pareciere..."33. 
Pedro Hernández de Narváez, quien, por sus méritos y virtudes, llegó a ocupar en 1583 la Dignidad de Deán del Cabildo de Quito ${ }^{34}$; pero, fue muy lamentable que el 20 de marzo de 1577, al enviar una carta a Felipe II, se quejara injustamente del benemérito Prelado, poniendo así una nota obscura en su vida preclara y diáfana ${ }^{35}$.

Francisco Galavís, en el año 1576 era el Arcediano de la santa Iglesia Catedral de Quito; más tarde, en 1597, ocupaba la alta Dignidad de Deán del Cabildo ${ }^{36}$.

Alonso de Aguilar, nació en la ciudad de Quito hacia el año 1551; sus padres, don Rodrigo de Paz Maldonado y doña Isabel de Aguilar, eran personas principales y muy distinguidas. A la edad de 23 años recibió el Diaconado y probablemente en 1576 fue ordenado sacerdote por el Ilmo. Señor Peña y en 1577 estaba de Párroco en la Doctrina de Sigchos. Era "hábil de la Latinidad y Retórica... diestro del canto llano y de órgano, y en todas las ceremonias de la Iglesia muy hábil, y en su vida y costumbres muy virtuoso". Al igual que el presbítero Diego Lobato de Sosa, Alonso de Aguilar hablaba correctamente el idioma indígena y con la predicación hacía excelente apostolado entre los naturales ${ }^{37}$. En el año 1585, los presbíteros Jácome Freile de Andrade y Alonso de Aguilar eran rectores de la Catedral ${ }^{38}$. Años más tarde, en el segundo Sínodo diocesano eran nombrados examinadores del idioma indígena los presbíteros Diego Lobato de Sosa y Alonso de Aguilar, quien, en 1597, por sus méritos y virtudes, formaba parte del Cabildo de la Catedral de Quito ${ }^{39}$.

Jorge Ramírez de Arellano, Chantre de la Iglesia Catedral desde 1595; "muy virtuoso, de buena vida y ejemplo".

Benito Hernández Ortega, "Maestro en Artes y Licenciado en Teología”, desempeñó el ministerio parroquial como cura y Vicario de la ciudad de Cuenca; desde el año 1594 fue el colaborador inmediato del Ilmo. Señor Solís ya que le nombró Vicario General y Provisor de la Diócesis. Informando al Rey acerca del Maestro Benito Hernández Ortega, el Obispo Solís se expresaba en estos términos: “...es uno de los más virtuosos ... es sujeto para servir una Dignidad de Deán, Arcediano o Maestrescuela en cualquiera de las Catedrales del Perú". 
Doctrinas y Parroquias del Obispado de Quito / 225

Andrés de Sepúlveda, sacerdote "de buena vida y costumbres" y uno de los más antiguos en la Diócesis. Ejerció el ministerio sacerdotal en Parroquias de españoles y de indios con beneplácito de todos; por su gran experiencia parroquial, en el año 1594 fue nombrado "Visitador General del Obispado" y en 1600, "cura y Vicario de Olmos de los Llanos".

Juan Antonio de Rueda, natural de la Diócesis de Quito, "hombre virtuoso, buen eclesiástico y predicador de naturales". En el año 1598 era "beneficiado y Vicario de Cumbayá"; y en 1600, "beneficiado de la Parroquia de San Blas de Quito".

Alonso de Cirues, "graduado en Teología, predicador"; en 1598 era "cura y Vicario de Manta”, y por sus virtudes y la labor desempeñada por este sacerdote, "merece una Dignidad", decía el Ilmo. Señor Solís.

Hernando Martín de Cáceres, "presbítero beneficiado y Vicario de la ciudad de Loja" en 1598; "muy buen eclesiástico,... Visitador General de este Obispado".

Luis Suárez Ponce de León, "beneficiado y Vicario de Yaruquí" en 1598. Por largo tiempo prestó sus servicios en la Diócesis "con mucha aprobación".

Pedro Núnez de los Reyes,"antiguo y muy buen eclesiástico". En 1594 cuando el Ilmo. Señor Solís tomaba posesión de la Diócesis, este sacerdote era "beneficiado y Vicario de Pasto".

Miguel León y Almonte, a los pocos años de haber llegado a la Diócesis, fue nombrado Maestrescuela de la Catedral; y estas palabras del Ilmo. Señor Solís son el mejor elogio de este sacerdote: “... hombre docto y virtuoso, buen eclesiástico".

Miguel Sánchez Solmerón, rector de la Catedral de Quito en el año 1597, "Uno de los mayores eclesiásticos deste reino -decía el Obispo Solís-, gran voz y muy diestro en el canto de órgano, es Sochantre de esta santa Iglesia y de los eclesiásticos de más virtud y ejemplo que hay en ella".

Gabriel de Peralta y de la Cueva, cuyo elogio lo encontramos en estas palabras del Obispo Solís cuando, el 10 de marzo de 1600, refiriéndose al presbítero Peralta, "beneficiado de Alausî”, decía al Rey: “... Es hombre virtuoso, de buena vida y costumbres, buen eclesiástico, merece más de lo que tiene" 40 . 
Diego Lobato de Sosa, sacerdote meritísimo, "hijo del español Diego Lobato y de Isabel Yarupalla, que había sido una de las mujeres de Atahualpa". Múltiples motivos existen para considerarlo como "El doctrinero más celoso del siglo XVP'41. Recibió la ordenación sacerdotal de manos del Ilmo. Señor Peña hacia el año 1566.

Sus cualidades excepcionales para la predicación redundaron en beneficio de los naturales. En 1583 desempeñaba el cargo de maestro de capilla en la Catedral de Quito, percibiendo como renta anual apenas 130 pesos. Fue examinador y a la vez profesor del difícil idioma indígena, pues era uno de los pocos sacerdotes o tal vez el único que lo hablaba de maravilla. A pesar de las solicitudes y recomendaciones hechas en favor del presbítero Diego Lobato de Sosa para que el Rey le concediera una canonjía, en el año 1597 continuaba como simple maestro de capilla, pero ya jubilado.

El 10 de marzo de 1600, cumpliendo un deber de estricta justicia, el Ilmo. Señor Solís incluyó el nombre de Diego Lobato de Sosa en la lista de los beneméritos sacerdotes de la Diócesis, pues "es el más antiguo clérigo de este Obispado -decía el Prelado- y que ha treinta años que se ocupa en la predicación a los naturales con notable fruto, porque es el que más ha trabajado en este ministerio y el que ha enseñado a otros a predicarles, con lo cual se ha descargado la real conciencia. Merece premio en una canonjía en esta santa Iglesia” 42 .

También encontramos palabras muy elogiosas en favor del presbítero Diego Lobato de Sosa en el testimonio del Capitán Juan Mosquera, Visitador de la provincia de Quito, el cual conocía muy de cerca al dicho presbítero y entre otras cosas, bajo juramento, decía: "Que el Padre Diego Lobato es mestizo e hijo de conquistador, desta ciudad y deste reino... es muy buena lengua y muy virtuoso; y ha visto este testigo hacer sermones a los naturales y en ellos convertir número dellos que se baptizasen y a los baptizados, en moverlos a contrición que se vengan a confesar con él y esto ha visto... en la plaza pública desta ciudad y en la Parroquia de San Blas y en los indios de su Encomienda y de otros; y sabe este testigo que el dicho Diego Lobato es de muy buena vida y costumbres, 
porque ha tratado con él mucho tiempo y estado juntos, y es clérigo de muy mucha habilidad en la Latinidad y en el canto y tecla y en todas las cosas tocantes al culto divino, que muy aventajados clérigos que vienen de Castilla no le exceden" ${ }^{43}$.

Hemos dado a conocer algunos nombres de sacerdotes beneméritos por la labor desempeñada en la Diócesis de Quito a través de su media centuria de existencia. Estamos seguros que, bajo el polvo de los manuscritos, yacen en el olvido otros nombres de sacerdotes que, al igual que los citados, merecen toda nuestra sincera gratitud y especial admiración porque fueron verdaderos ejemplos para los clérigos que vendrían después a trabajar en la viña del Señor. 
228 / Augusto E. Albuja

\section{NOTAS:}

1 GÓMEZ HOYOS, Las Leyes de Indias, 222.

2 Primer Concilio limense, Parte Primera, c.33.

3 Segundo Concilio limense, Parte Segunda, c.17.

4 Recopilación, lib. I, tit.12, ley 2.

5 Tercer Concilio limense, Acc. 3a. cap. 5

6 VARGAS UGARTE, Concilios limenses, III, 108

7 Tercer Sínodo de Quito, Const. 3 (AGI, Quito, leg.77).

8 C.I.C. 17,cc. 142 y 2380; C.I.C. cc.286 y 1392.

9 PEÑA MONTENEGRO, Itinerario, lib. lro., trat.12, f.132.

10 Primer Sínodo de Quito, Parte Cuarta, c.56 (AGI,Patronato, leg.189 R.40).

11 Segundo Concilio limense, Parte Segunda, c.22.

12 Tercer Concilio limense, Acc.3a, cap.17.

13 VARGAS UGARTE, Concilios Limenses, III, 107.

14 Recopilación, lib. I, tit.12, ley 20.

15 Segundo Concilio limense, Parte Segunda,c. 18;C.I.C. 17, c.138; C.I.C. c. 285.

16 Tercer Concilio limense, Acc. 3a, cap. 23.

17 Segundo Concilio limense, Parte Segunda, c.21.

18 Primer Concilio limense, Parte Primera, c.33.

19 Tercer Concilio limense, Acc. 3a, cap. 18.

20 Tercer Concilio limense, Acc. 3a, cap. 19; Conc.Trid., Sess. XXV, cap.14; Segundo Concilio limense, Sess. 2, c.82 y Sess. 3, c.7.

21 Segundo Sínodo de Quito, cap. 78 (AGI, Quito. leg. 77).

22 Primer Sínodo de Quito, Parte Cuarta, (AGI, Patronato, leg.189, R.40).

23 Tercer Concilio limense, Ac. 3a. cap. 16; Conc. Trid. Sess. XIV, cap.16; Segundo Concilio limense, Sess e, c. 87; y Sess. 3, c.30 y c. 21.

24 Tercer Concilio limense, Acc. 3a. cap. 24.

25 Tercer Concilio limense, Acc. 3a. cap. 22; Conc. Trid. Sess. XXI, cap.18.

26 PEÑA MONTENEGRO, Itinerario, lib.19, trat. 13, Secc. 1a.,fol.133.

27 Recopilación, lib. I, tit.6, ley 19.

28 GONZÁLEZ SUÁREZ, Historia, II, 438.

29 Apéndice \# 8.

30 Apéndice \# 29.

31 Apéndice \# 28. 


\section{Doctrinas y Parroquias del Obispado de Quito /229}

32 Apéndice \# 4; cf.tb. Apéndices \# 1,3,6 y 7.

33 Apéndice \# 17.

34 Relaciones Geográficas de Indias, III, 37.

35 Apéndice \# 23.

36 Apéndices \# 19 y 42.

37 AGI, Quito, legajos 83 y 80.

38 Apéndice \# 30

39 Segundo Sínodo de Quito, Const. 87; cf.tb. Apéndice \# 42.

40 Apéndice \# 58.

41 VARGAS, José María, La Conquista espiritual del Imperio de los Incas, Quito, 1948,183 .

42 Apéndice \# 52.

43 Apéndice \# 19. 



\section{CAPÍTULO XIII \\ SEMINARIO Y ORDENACIÓN DE MESTIZOS}

\section{Seminario}

Hasta mediados del siglo XVI, la formación e instrucción de los candidatos al Sacerdocio eran muy deficientes. Gracias al Concilio de Trento celebrado en 1563, se estableció que hubiese Seminarios en todas las Diócesis, para lo cual los respectivos Prelados deberían poner especial solicitud $^{1}$.

Cuatro años después, para llevar a la práctica el decreto del Tridentino respecto a los Seminarios, el segundo Concilio limense pedía a todos los Obispos de la Provincia Eclesiástica que fundaran, cuanto antes, el Seminario en cada una de las Diócesis para procurar la conveniente formación e instrucción de los futuros sacerdotes. Asimismo, dicho Concilio de 1567, para ayuda del Seminario, establecía una contribución del tres por ciento de todas las rentas: de beneficios, capellanías, hospitales, cofradías, sin exceptuar las Doctrinas de indios que estuvieren a cargo de religiosos ${ }^{2}$, dejando la fundación y administración a iniciativa de cada Prela$\mathrm{do}^{3}$.

Según esto, el Obispo Pedro de la Peña, al regresar a la ciudad de Quito, después de haber asistido al Segundo Concilio de Lima, y convencido, como estaba, "de que la buena intención y la piedad, sin la ciencia, no pueden bastar al sacerdote para desempeñar como conviene el importantísimo ministerio de maestro y director de los pueblos", no tuvo ningún inconveniente de establecer "en su misma casa uno como bosquejo o ensayo de Seminario, abriendo dos clases, una de Gramática latina y otra de Teología moral, cuya dirección encargó a dos sacerdotes competentes". Fue tal el interés que se despertó con estos estudios, que "hasta los religio- 
sos de los tres conventos que había entonces en Quito acudieron a la clase de Teología, en la cual se presentaba muy a menudo el Obispo, para estimular con su presencia a los estudiantes" ${ }^{\prime \prime}$.

La preocupación porque hubiese Seminarios en las Diócesis no era únicamente de los Obispos, sino que también el mismo Rey los juzgaba necesarios y urgentes para cumplir la delicada y grave responsabilidad como Patrono de Indias; y por eso, entre las disposiciones dadas al Virrey del Perú, Francisco de Toledo, el Monarca ordenaba: "que en los lugares principales haya Colegios y Seminarios, y que también se mire en lo de los estudios...y por qué orden esto se podrá asentar, y cómo y de qué se podrán sostener..." 5 .

La muerte del Ilmo. Señor Peña y la prolongada vacante que sufrió la Diócesis de Quito fueron causa para que la fundación propiamente dicha del Seminario permaneciera en suspenso. Sin embargo, tan pronto como fue provista la Diócesis de Prelado, en la persona del Ilmo. Fr. Antonio de San Miguel, Felipe II, el 22 de septiembre de 1590, dirigía al Obispo de Quito una Real Cédula, en que manifiesta claramente su interés y preocupación por el Seminario: "Reverendo in Christo Padre, Obispo de Quito, de mi Consejo: Yo he sido informado que el Colegio-seminario no se ha hecho por no haber habido Prelado en ese Obispado, y porque los religiosos que tienen Doctrinas no quieren pagar la parte que les cabe y que convendría se hiciese el colegio de niños y Universidad, y que cada beneficiado, desde el Obispo hasta el sacristán, pagase a razón de tres por ciento por el dicho efecto; y, como podréis considerar, ésta es cosa muy importante y como tal se consideró y determinó en el Santo Concilio de Trento. Os ruego y encargo, hagáis ejecutar lo dispuesto en el que se celebró en la ciudad de los Reyes, en lo que toca a lo sobredicho, o me enviéis relación de la causa por qué no se cumple"6.

Esta Real Cédula no tuvo contestación inmediata, pues el Obispo electo, Ilmo. Antonio de San Miguel, había fallecido en 1591 en la ciudad de Riobamba, cuando se hallaba de camino para tomar posesión de la Sede de Quito. Por tanto, el Obispo que tuvo que informar al Rey acerca del Seminario fue el Ilmo. Señor López de Solís, quien llegó a Quito el 


\section{Doctrinas y Parroquias del Obispado de Quito /233}

15 de junio de 1594, y a los dos meses de su llegada fundó el Seminario Conciliar, a pesar de los múltiples obstáculos que le salieron al paso.

Una vez fundado el Seminario, el Obispo Solís, escribiendo una carta al Rey el 12 de Octubre de 1594 para informarle y al mismo tiempo para dar contestación a la Real Cédula del 22 de septiembre de 1590, se expresaba en estos términos: "Hallé Cédula de Vuestra Majestad, en que manda funde Colegio-seminario y que se cobre la renta para sustento en la conformidad que el Concilio de Trento y el provincial de Lima de 83 disponen, lo cual puse en ejecución y he tenido la mayor contradicción del mundo con las Ordenes-Religiosas-diciendo no habían de pagar la renta. Y como es cosa tan cierta deberla los religiosos que tienen beneficios y Doctrinas, por razón del salario y estipendio que se les paga, de lo cual ha declarado Vuestra Majestad y los Cardenales que se debe a tres por ciento, tratóse pleito y como estaba tan cierto de la justificación del caso, sin aguardar a la determinación, fundé el Colegio en una muy buena casa, donde metí cuarenta colegiales, con hábito pardo y beca de grana, hijos de conquistadores y de la gente más principal de esta tierra, y tan buenos estudiantes que pueden competir con los buenos Seminarios de España. Los pobres entran como tales, y los ricos pagan un tanto al Seminario para ayuda a su costa".

"Determinóse la causa en esta Real Audiencia y declaróse que los religiosos que tuviesen Doctrinas y beneficios debían pagar el seminario a tres por ciento, en la conformidad que el Concilio ordena".

"Este Colegio he encargado a los religiosos de la Compañía de Jesús por ser,como es, su Instituto inclinado a estas cosas de virtud y del servicio de Dios Nuestro Señor; los cuales han puesto Rector en el dicho Colegio y religiosos, y tienen maestros que los enseñan, y van tan adelante en letras y virtud, que de hoy más se proveerán del seminario los clérigos que fueren menester en el Obispado, porque los voy ordenando y preparando con este intento".

"Suplica a Vuestra Majestad sea servido hacer merced a este Colegio-seminario de cuatro mil pesos de renta en los primeros indios que vacaren en esta ciudad, para que prosiga en el aumento de toda esta tie- 
rra, acrecentándose en él otros muchos que no se reciben por la pobreza y poca renta que tienen, la cual será una de las limosnas más aceptas y bien empleadas de todo este reino, por ser el primer Colegio-seminario del, y comunicarse esta buena obra a tantos conquistadores y pobres que aquí meten sus hijos, y ellos mismos darán la recompensa con el fruto que han de hacer, con el favor divino, siendo Vuestra Majestad servido que el cumplimiento y ejecución venga a esta Real Audiencia, prefiriendo otra cualquiera Cédula" 7 .

Para fundar y, sobre todo, para sostener un Seminario en la Diócesis no es suficiente la buena voluntad del Obispo; hay necesidad también de disponer de medios económicos. De donde, para solucionar, en gran parte, este problema común de las Diócesis, los Concilios limenses de 1567 y 1583 señalaron una contribución del 3\% "desde el Obispo hasta el sacristán”.

Respecto a esta contribución, los religiosos que atendían las Doctrinas en la Diócesis de Quito pusieron resistencia; de aquí surgieron desavenencias con los Obispos, especialmente con el Ilmo. Señor Solís, quien se vio obligado a ejercer su autoridad con todo rigor, pues, "por estar la renta del Seminario dividida y cobrarse -el impuesto- con tanta dificultad -decía el Prelado en una constitución sinodal de 1596- nos ha parecido remedio conveniente proveer el que todos los Vicarios -Arciprestesde nuestra Diócesis en sus distritos, con mucha diligencia y cuidado, procuren de cobrar y cobren lo que se debiere al Seminario, para lo cual les damos toda facultad, que de derecho les podemos dar, para que en este caso procedan en la ejecución, como nuestra persona podrá, y proceder con censuras y los demás remedios que fueren necesarios para la cobranza contra cualesquier personas que estuvieren obligadas a pagar el dicho seminario" 8 . Con este decreto el Obispo Solís no exigía una cosa extraordinaria; quería solamente que las leyes tuvieran su cumplimiento, sin prejuicios para con nadie, tanto más cuanto que el mismo Rey Felipe II, ratificando las disposiciones dadas por los Concilios limenses en favor del Seminario, había pedido a sus Oficiales reales que, de los estipendios correspondientes a los religiosos doctrineros de la Orden de San Francisco, rebajaran 
Doctrinas y Parroquias del Obispado de Quito / 235

"los tres por ciento que han de haber los Seminarios, en dinero y no en especie, y con la restante cantidad acudan a los religiosos"'.

Tres Cédulas Reales fueron dirigidas a la Audiencia de Quito, en las que se insistía en el pago del 3\% para el sostenimiento del Seminario. Como algunos doctrineros se manifestaban reacios a las órdenes del Obispo Solís, éste pidió ayuda a los Oficiales reales para que rebajaran de los salarios de dichos doctrineros el 3\%, pues "sin esto -decía el Prelado en una carta dirigida al Rey el 8 de mayo de 1597- no se puede conservar el Colegio que fundé en esta ciudad de Quito"; y luego añadía: "por estas causas soy odiado de religiosos, pero yo hago mi oficio y, aunque me cueste más trabajo, le tengo de hacer"10.

La gran obra del Seminario Conciliar de la Diócesis de Quito fue para el Ilmo. Señor Solís causa de sufrimientos e incomprensiones, de desvelos y hasta de lágrimas. Sin embargo, a los pocos años tuvo también la satisfacción de ver los primeros frutos, pues, escribiendo al Rey el 10 de abril de 1600, le decía: “... y agora con la ayuda del Seminario y estudios, tengo buenos sujetos; voy entremetiendo -en Parroquias y Doctrinas- los que saben y sacando los ignorantes, porque ya no me contento con que sepan los doctrineros la lengua, sino que han de predicar y declarar el Evangelio, y de esto se quejan los ignorantes bien apriesa" 11 .

Si en la segunda mitad del siglo XVI la principal preocupación de los primeros Obispos de Quito era la escasez de clero, el Seminario venía a solucionar este problema. Así tenemos que el octavo Obispo de la Diócesis, Ilmo. Fr. Alfonso de Santillana, refiriéndose al Seminario, con gran satisfacción suya, en carta dirigida al Rey el 29 de abril de 1621, se expresaba en estos términos: "Una de las cosas de más importancia en estas partes para el estado eclesiástico y educación de los mozos es el Seminario donde se les enseña la virtud y letras, de que salen para curas y vicarios del Obispado personas doctas y predicadores, como se ha experimentado...y el Seminario que hay en esta ciudad es de los más bien fundados del Perú. Hay, de ordinario, ochenta -seminaristas-, los veinte y tres de ellos a nuestra costa y del Obispado; los demás a las de sus padres... Se fundó siendo Obispo el santo don fray Luis López, con mucho trabajo suyo, y el fruto ha sido como de 
236 / Augusto E. Albuja

tan buen principio, pues todos los buenos sujetos que tiene el Obispado se han criado en él. De mi parte, el tiempo que aquí estoy he hecho lo posible por su acrecentamiento" 12 .

\section{Ordenación de mestizos}

El decreto del Tridentino, pidiendo a los Prelados que fundaran Seminarios en sus respectivas Diócesis, tenía como finalidad la formación del clero nativo.

En la época del Ilmo. Señor Peña no fue posible la fundación del Seminario en Quito; sin embargo el celoso Obispo convirtió su casa en una especie de Seminario a fin de poder atender a unos cuantos jóvenes que se sentían atraídos por la vocación al Sacerdocio. Entre estos jóvenes debieron estar hijos de españoles y unos cuantos mestizos. Para que no se forjaran ilusiones, pensando que el acceso al Sacerdocio era como cualquier profesión humana, o tal vez más fácil, el Ilmo. Señor Peña, en el Sínodo diocesano de 1570 , señalaba las cualidades necesarias y las condiciones que deberían cumplirse en los candidatos, ya que "Una de las cosas en que hay más necesidad de remedio -advertía el Prelado en una constitución sinodal- es el no ordenar sacerdotes indignos. Por lo cual, ordenamos que en este nuestro Obispado tendremos examinador letrado, hombre de conciencia y juramento, para que examine los que se han de ordenar, porque nos estamos ocupados en otros negocios; e los que han de recibir Ordenes han de ser por lo menos buenos gramáticos, e han de saber cantar, e han de entender el canto, e han de probar la edad, si son legítimos e domiciliarios de este Obispado, o si tienen otro impedimento de los que el Derecho dispone; y en todo se guarde lo dispuesto por el Santo Concilio Tridentino cerca de esto"13.

Por la falta de medios económicos en los candidatos a las Ordenes sagradas, el segundo Concilio de 1567 facultaba a los Obispos de la provincia eclesiástica de Lima, sustituir el título canónico de "patrimonio" por el "título de indios", siempre que al clérigo se le asignara alguna Doctrina, "en la cual sea obligado a permanecer seis años continuos, salvo si el Obispo otra cosa mandase" 14 . 


\section{Doctrinas y Parroquias del Obispado de Quito / 237}

El tercer Concilio limense de 1583 suprimió la condición puesta por el celebrado en 1567 y consideró como título canónico competente el de doctrinero de indios, "Ad titulum indorum", es decir, en los candidatos al Sacerdocio era suficiente el deseo de ejercer el ministerio pastoral en las Doctrinas de indios, "aunque no se les señale, desde luego, alguna Doctrina particular" 15 .

Advirtamos también que Gregorio XIII, para que hubiese en las Diócesis de Indias clero nativo por las múltiples ventajas en favor de los mismos indios: conocimiento del idioma y mejor adaptación a sus costumbres, etc., por medio del Breve "Nuper" del 25 de enero de 1576, concedió a los Ordinarios la facultad de poder ordenar a mestizos y criollos, con tal que fuesen idóneos; inclusive, podían dispensarlos de la ilegitimidad y de cualquier otro impedimento, menos el homicidio voluntario o bigamia ${ }^{16}$.

El Ilmo. Señor Peña, siguiendo fielmente las disposiciones conciliares y sinodales, confirió las Ordenes sagradas a algunos mestizos, a los cuales consideró idóneos para el Sacerdocio. Pero este hecho escandalizó a muchos frailes y hasta a algunos miembros del Cabildo, porque la manera de pensar en aquella época era que los mestizos, indios y negros, por su origen humilde, no debían ser admitidos fácilmente al Sacerdocio. He aquí dos cartas que fueron dirigidas al Rey Felipe II, a raíz de la Ordenación sacerdotal de algunos mestizos; la primera fue escrita por Fray Diego de Ugalde y la segunda por el presbítero Pedro Hernández de Narváez, este último en representación del Cabildo.

"Una de las cosas que conviene mucho para el bien de aquellas tierras, espiritual y aún temporal, -decía Fray Diego de Ugalde- es que mande Su Majestad, con todo rigor, a todos los Obispos y Arzobispos de todas Indias que en ninguna manera ordenen a ningun mestizo, aunque mal hijo de conquistador, sea por estos veinte años, aunque lleven y tengan habilitación de Su Santidad ya (para) ello; y que, a los que hasta agora han ordenado, en ninguna manera les pongan en Doctrinas de indios, porque son perjudicialísimos a causa de ser gente viciosísima y sin verdad, ni vergüenza ninguna, ni ninguno género de respeto de hombres y de 
bien; y esto atestiguo como persona de vida y veinte años de experiencia; y no solamente a los mestizos, pero aún a los nacidos en la tierra importaba harto que en aquella Iglesia nueva no se permitiesen ordenarse hijo de los españoles a causa de lo mal que aprueban, que aún en las Ordenes con hallarlos con tanto rigor y con tener tantos Prelados, no se pueden valer con ellos, cuanto más estando cincuenta y aún cien leguas del Obispo que se separa de ellos"17.

Y el presbítero Pedro Hernández de Narváez, en nombre del Cabildo, en su carta del 20 de marzo de 1577, decía al Monarca: "Vuestra Real Cédula ha sido intimada al Obispo Don Fray Pedro de la Peña sobre que no ordene mestizos, ansí porque conforme a Derecho son inhábiles, como porque por experiencia se ve son escandalosos y de mal vivir. El dicho Obispo ha ordenado después acá nueve de los dichos mestizos, los cuales y otros muchos tiene ocupados en los mejores beneficios de aquel Obispado, de que, ansí los españoles como los propios indios naturales, se sienten por agraviados; y habiendo acudido a vuestro Presidente y Oidores de aquella Audiencia ha sido encomendado y encargado a los Obispos guarde y cumpla la dicha vuestra Cédula Real y se abstenga de ordenar los dichos mestizos, y los ya ordenados y ocupados en los dichos beneficios, los recoja y ocupe en otros ministerios y no lo ha querido hacer.... A Vuestra Alteza pido y suplico sea servido de mandar... se recojan los dichos mestizos y se ocupen en capellanía o sacristías o otros ministerios y se provean en sus lugares otras personas beneméritas y capaces y que se espere dellos se servirá Dios Nuestro Señor y Vuestra Alteza"18.

¿Qué delito había cometido el Ilmo. Señor Peña confiriendo las Ordenes Sagradas a unos pocos mestizos?. ¿Acaso el Obispo no se daba cuenta de su responsabilidad ante Dios y ante la Iglesia? Si delito se puede llamar la violación de una orden, nada conforme con el espíritu de la Iglesia Católica, y que, por tanto, carece de fundamento, Felipe II, en calidad de Patrón de las Indias, debió acudir al Sumo Pontífice y no reprochar al celoso Obispo de Quito con palabras respetuosas, es verdad, pero que en el fondo se descubre una actitud extremadamente rigorista, a causa de las cartas que recibió. 
Doctrinas y Parroquias del Obispado de Quito /239

Cuando el Ilmo. Señor Peña, en los primeros años de su episcopado, confirió la ordenación sacerdotal a unos seis u ocho mestizos, Felipe II envió esta Real Cédula que textualmente dice así:

"EL REY. Reverendo en Cristo Padre, Obispo de la Iglesia Catedral de la ciudad de San Francisco de la provincia del Quito, del nuestro Concejo: Nos somos informados que habéis dado Ordenes a mestizos y a otras personas que no tienen suficiencia para ello, lo cual, como podéis considerar, es de gran inconveniencia por muchas razones y la principal por lo que podía suceder, por no ser las personas a quien se han de dar las dichas Ordenes, recogidas, virtuosas y suficientes y de las calidades que se requieren para el estado del Sacerdocio; y, pues es cosa que toca tanto al servicio de Dios Nuestro Señor y bien de las almas de esos naturales, os ruego y encargo que miréis mucho en ello y tengáis en el dar las dichas Ordenes el cuidado que de vuestro buen celo y cristiandad se confía, dándolas sólo a personas en quien concurren las partes y calidades necesarias, y por agora no las daréis a los dichos mestizos de ninguna manera hasta que, habiéndose mirado en ello, se os avise de lo que ha de hacer. Fecha en el Pardo, a dos de diciembre de mil y quinientos y sesenta y ocho. Yo, el Rey. Por mandato de Su Majestad, Antonio de Erazo"19.

Después de enviar esta Real Cédula, probablemente Felipe II pidió informes a sus Oficiales de la Audiencia de Quito acerca de los mestizos ordenados sacerdotes por el Ilmo. Señor Peña. En la carta de los mismos Oficiales del Rey encontramos unas frases que constituyen una alabanza para el clero nativo y, al mismo tiempo, salvan la responsabilidad del Prelado, pues "A persuasión y parecer que para ello dieron vuestro Presidente y Oidores de esta Real Audiencia -informaban al Rey- el Obispo acabó de ordenar a uno o dos que estaban comenzados; y hasta entonces eran muy pocos y de buena vida y ejemplo y aprovechamiento entre los naturales por su buena lengua, que todos los mestizos ordenados por el Obispo de este Obispado, Maestro Don Fray Pedro de la Peña, son seis u ocho y no más..."20. Debemos advertir que entre estos sacerdotes mestizos se hallaba el presbítero Diego Lobato de Sosa, a quien hemos mencionado al tratar de los sacerdotes beneméritos, pues, por múltiples razones, es considerado como "el doctrinero más celoso del siglo XVI"21. 
Pero, como el Monarca quería guardar el principio de autoridad y además no estaba en condiciones de saber toda la realidad que había en la Diócesis de Quito, mantuvo la orden dada al Ilmo. Señor Peña: “...y por agora no las daréis -las Ordenes sagradas- a los dichos mestizos de ninguna manera hasta que, habiéndose mirado en ello, se os avise de lo que se ha de hacer". Años después, cuando supo nuevamente, por cartas de personas interesadas, que el Obispo de Quito había conferido las Ordenes Sagradas a otros mestizos, Felipe II, extrañado de este proceder del Prelado, despachó otra Cédula Real reprochándole.

El Ilmo. Señor Peña pensó guardar silencio; pero como esta actitud hubiera sido mal interpretada por el Rey, el 20 de enero de 1577 escribía una carta a Felipe II, diciéndole: "En lo de los mestizos, me parece bien lo que Vuestra Majestad por ella tiene proveído, y la razón me dictaba que así se había de mandar, y con esto he tenido siempre la mano abreviada, como Vuestra Real Majestad mandará ver por la descripción deste Obispado que envío, y así por todo el discurso del tiempo que Vuestra Real Majestad me hizo merced de presentarme a este Obispado, que anda en doce años, sólo dellos hay cuatro sacerdotes en todo este Obispado, que ningún español de buena vida les hace ventaja" 22 .

Las medidas adoptadas en los primeros años que siguieron a la Conquista fueron en parte muy prudentes, pues se había "ordenado que ninguno de la raza india se admita al Sacerdocio y a las Ordenes mayores ...por ser nuevos en la fe y de bajo linaje"23.

La primera razón que señala Acosta, "por ser nuevos en la fe", nos parece muy acertada; pero, la segunda, " $y$ de bajo linaje", no era una causa suficiente para retraer del Sacerdocio a indios y mestizos, porque el alto y bajo linaje son distintivos humanos y en las cosas divinas, como es el Sacerdocio, se debe pensar con criterios más elevados y espirituales, pues la vocación viene de Dios y, por tanto, no debe ser considerada como patrimonio de un pueblo o de una raza.

Razón tenía el célebre jurista Solórzano Pereira, cuando, al manifestar su criterio sano e imparcial, decía: "Si a éstos -refiriéndose a los indios y negros- los hallara yo idóneos, de entera capacidad y decencia, no 


\section{Doctrinas y Parroquias del Obispado de Quito / 241}

dudara de admitirlos al Sacerdocio; porque, aunque hay muchas Cédulas que prohiben el ordenarlo, y no sólo a ellos, sino a los mestizos... eso se pudo y debió practicar recién descubiertos y convertidos, cuando el ser bárbaros y neófitos les pudo ser para esto algun embarazo"24. Así lo interpretó el Ilmo. Señor Pedro de la Peña; para él la prohibición real no debía durar mucho tiempo, teniendo en cuenta que los indios y negros, y los que por su padre o su madre descendían de estas razas, de ninguna manera estaban separados de las Ordenes sagradas cuando se cumplían en ellos los requisitos señalados por los sagrados cánones 25 .

La prohibición de conferir Ordenes sagradas a mestizos no fue dada únicamente al Obispo de Quito. Felipe II también ordenó al Arzobispo de Lima, Santo Toribio de Mogrovejo, en 1578, que no admitiese "al Sacerdocio a ningún mestizo hasta tanto que se dispusiere otra cosa”. Tal disposición, nada conforme con el espíritu de la Iglesia, duró poco tiempo, pues hasta "los mismos indios se sintieron ofendidos, por lo cual dirigieron una carta a Gregorio XIII, datada en el Cuzco el 12 de febrero de 1583. Gregorio XIII, a cuyas manos llegó la carta, no se hizo sordo a estos clamores, antes bien ordenó que se escribiese al Nuncio en Madrid, Mons. de Lodi, para que se averiguase lo que había de cierto en el caso, advirtiendo que no parecería bien que el Rey se ingiriese en esta materia, ajena a su potestad" 26 .

Felipe II, quien se había dejado influenciar de ciertas cartas de algunos clérigos y frailes, revocó la prohibición de ordenar a mestizos, pues en una Real Cédula del año 1588 y que ha pasado a la Recopilación, decía: "Encargamos a los Arzobispos y Obispos de Indias que ordenen de sacerdotes a los mestizos de sus distritos, si concurrieren en ellos la suficiencia y calidades necesarias para el Orden sacerdotal" 27.

"La necesidad, por una parte, y, por otra, la buena conducta que dieron de sí algunos mestizos e indios ordenados in sacris" 28 , fueron causa para que se revocase semejante disposición real, ya que la manera de pensar de hace cuatro siglos respecto al Sacerdocio de indios y mestizos era muy equivocada, pues, "teniendo con ellos el cuidado que debe tenerse con todos los candidatos al Sacerdocio, se podía obtener -como de he- 
242 / Augusto E. Albuja

cho se obtuvo- elementos útiles y de provecho" 29 . No vayamos a pensar que los Prelados de Indias admitían al Sacerdocio a cualquier mestizo, so pretexto de la escasez de clero; antes por el contrario, siempre tuvieron en cuenta aquella máxima del tercer Concilio limense: "es mucho mejor y más provechoso para la salvación haber pocos sacerdotes y ésos buenos, que muchos y ruines" 30 . 
Doctrinas y Parroquias del Obispado de Quito / 243

\section{NOTAS:}

1 Con. Trid., Sess. XXIII, cap. 18 de reform.; C.I.C. 17, c. 1354; C.I.C. cc. 234-237.

2 Segundo Concilio limense, Parte Primera, c. 72.

3 Tercer Concilio limense, Acc. 2a, cap. 44; C.I.C. 17, c. 1357; C.I.C. c. 259.

4 GONZÁLEZ SUÁREZ, Historia, III, 38.

5 AGI, Indiferente General, leg. 2.859, lib. 2o, f. 14v.

6 AGI, Quito, leg. 209, lib. lo., f. $84 v$.

7 Apéndice \# 35.

8 Tercer Sínodo de Quito, Const. 31 (AGI, Quito, leg. 77).

9 Recopilación lib. I, tit. 23, ley 7.

10 Apéndice \# 40.

11 AGI, Quito, leg. 76.

12 AGI, Quito, leg. 77.

13 Primer Sínodo de Quito, Parte Tercera c.23 (AGI, Patronato, leg.189, R40); Conc. Trid., Sess. XXIII, cap. 11 y 7.

14 Segundo Concilio limense, Parte Primera, cap. 26.

15 Tercer Concilio limense, Acc. 2a, cap. 31.

16 VARGAS UGARTE, Historia,II, 217; PEÑA MONTENEGRO, Itinerario, lib. 5-, trat. 1, secc. 1-.

17 AGI, Patronato,leg. 189, R- 34.

18 Apéndice \# 23.

19 GARCÉS, Colección de Cédulas Reales, 168.

20 Relaciones Geográficas de Indias, III, 50.

21 VARGAS, La Conquista espiritual del Imperio de los incas. Quito 1948, 183.

22 Apéndice \# 21.

23 ACOSTA, José de, De promulgando Evangelio apud bárbaros seu de procuranda indorum salute, Salamanca 1589, lib.6-cap.19.

24 SOLÓRZANO PEREIRA, Politica Indiana, I, 436.

25 HERNAEZ, Colección de Bulas, I, 95.

26 VARGAS UGARTE, Historia, II, 216.

27 Recopilación, lib. I, tit. 7, ley 7.

28 VARGAS UGARTE, Historia, II, 214.

29 VARGAS UGARTE, Concilios Limenses, III, 45.

30 Tercer Concilio limense, Acc. 2-., cap. 33. 



\section{CAPÍTULO XIV \\ VICARIOS (ARCIPRESTES)}

La descripción de la Diócesis que hemos presentado al comienzo de esta obra, debió darnos una idea del inmenso territorio que comprendía, pues en la actualidad, lo que es la República del Ecuador, más una parte del Perú y de Colombia, constituían el Obispado de Quito en la segunda mitad del siglo XVI.

La extensión de la Diócesis era una verdadera preocupación para el Ilmo. Señor Peña. Resultaba materialmente imposible que el celoso Pastor pudiese atender debidamente a su grey. Las grandes distancias, pues la Diócesis podía alcanzar aproximadamente 226 leguas de longitud y 70 de latitud $^{1}$, y la falta de caminos obligaron al Ilmo. Señor Peña a dirigir una carta al Rey, como Patrono de las Indias, para que se interesara y acudiera al Sumo Pontífice porque era urgente "proveer más Obispos en aquella tierra, atento a que los Obispados son muy grandes y los naturales nuevos en muchas cosas de nuestra santa fe católica, y por su rarísima capacidad tienen necesidad de muchos ministros y que el Prelado ande siempre sobrellos y sobre los ministros que tienen cargo dellos para que sean bien instruidos en las cosas de nuestra santa fe católica, lo cual no se puede en ninguna manera hacer-decía con mucha tristeza el Obispo Pedro de la Peña- siendo los Obispados tan grandes como son y las tierras tan trabajosas y los caminos tan peligrosos, porque hay Obispados que tienen doscientas leguas de largo y poco menos de ancho, como el que donde yo estoy" 2 .

Esta Instrucción extensa y detallada fue para Felipe II causa de grandes desvelos, ya que se le daba a conocer la realidad de la Diócesis de Quito, y además era la primera vez que recibía un informe semejante. Los demás Prelados habían permanecido en silencio frente a estos serios problemas, pues, como se advierte al margen del manuscrito, "ninguno de- 
llos -debió decir el Rey- más me ha hablado ni preguntado nada". En aquellos tiempos no se podía dar una solución inmediata; de ahí que la respuesta fue muy sobria y viene al margen del mismo manuscrito: "que se proveerá lo que conviene"3.

Para facilitar el gobierno de la Diócesis, a todos los párrocos de las ciudades se les dio el título de Vicarios (Arciprestes) y, para descargar un tanto la responsabilidad que pesaba sobre el Prelado, éste juzgó conveniente, en el primer Sínodo diocesano de 1570, concederles facultades muy amplias, pues hasta entonces solamente había estado al cuidado de dichos Vicarios la vigilancia de doctrineros y curas de sus respectivos distritos, en lo relacionado con la residencia, decoro en las iglesias e instrucción de los indios.

"Por cuanto este nuestro Obispado, -advertía el Ilmo. Señor Peña en una constitución sinodal- es tan grande y de tanta parte y de muchos pueblos de españoles y estar tan desviados de esta ciudad -de Quito- no puede ser regido ni gobernado por nos solo ni por nuestro Provisor sin ayuda de nuestros ministros, ordenamos y mandamos que los Vicarios de las ciudades tengan jurisdicción, cada uno en la comarca y términos de la ciudad de su Vicaría, a los cuales encargamos la jurisdicción eclesiástica y tengan sus Oficiales, como Derecho y costumbre, para la ejecución de la justicia en todos los casos que se ofrezcan en la dicha ciudad y jurisdicción, cuyo reconocimiento a nos pertenecía, excepto las cosas tocantes a la separación del matrimonio, las cuales nos reservamos, en los cuales casos dichas informaciones nos las envíen con la persona o personas que parecieren ser culpados conforme a Derecho, teniendo, en las cosas de la fe, se hagan con todo secreto y se quite todo escándalo; e de la sentencia o sentencias que dieren, si las partes apelaren, les otorguen la apelación para ante nos" 4 . Para evitar la molestia que causaba a los Arciprestes tener que trasladarse a Doctrinas y Parroquias para solucionar ciertos problemas de carácter espiritual, se concedía asimismo especial facultad a todos los curas y doctrineros para que "puedan hacer y hagan -decía el Prelado- todas las informaciones de todas las cosas tocantes a nuestra jurisdicción que se ofrecieren en sus curazgos, ansí de españoles como de indios, e, hechas, las 
envien a los Vicarios de las ciudades en cuya jurisdicción tienen sus curatos para que los tales Vicarios procedan en la causa conforme a Derecho" 5 .

Como la colaboración que prestaban los Vicarios o Arciprestes era muy beneficiosa, ya que sustituían en parte al Obispo, quien no podía atender todos los asuntos relacionados con el buen gobierno de la Diócesis, el segundo Sínodo de Quito dedicó una constitución para especificar las facultades que cada uno debía tener en su respectivo arciprestazgo. Aunque dicha constitución sinodal es bastante extensa, no estará por demás que la transcribamos a continuación.

"Nuestros Vicarios conozcan en las causas que aquí irán declaradas":

-"Las matrimoniales de nulidad de matrimonio, separación quoad torum y mutua cohabitación, nos las ha de remitir; y ofreciéndose caso que dos se quieran casar y alegaren impedimento legítimo, conocerán hasta la definitiva y nos lo remitirán; y en las personas que manifiestamente se supiere que no tienen impedimento, por haber nacido en aquel pueblo o distrito, hechas las amonestaciones conforme al santo Concilio de Trento, el cura los despose y vele".

-"Todas las veces que una mujer pidiere divorcio, recibirá la información el Vicario y, depositando la mujer, remitirá la causa; y en los demás casos que requiera dispensación para contraer matrimonio, tomada la dificultad del caso por las partes que la pusieren, remitirá la determinación y dispensación".

-"Cuando los diezmeros pidan censuras contra los que no pagan las rentas decimales, siendo requeridos conforme a Derecho, se la podrán dar y excomulgar; y cuando dieren censuras ha de ser expresada la causa, justificándola la primera con prudencia”.

- "En los negocios que se ofrecieren criminales contra los clérigos beneficiados o mercenarios o viandantes, harán sus informaciones y prenderán a los culpados de él, restando los bienes y haciendo depósito en persona abonada, remitirán las causas; si las criminales fueren leves y que se pueden por allá componer, lo hagan de consentimiento de las partes y proceder en ellas y sentenciarlas". 
-"Y en las causas criminales, matrimoniales, beneficiales y decimales, donde interviene alguna persona secular, pueda remitir y mandar parecer ante nos a las tales personas en prosecución y seguimiento de sus causas y compelerles a ello por censuras".

-"En los negocios civiles se les da plena jurisdicción para que puedan conocer de ellos y sentenciarlos hasta cantidad de quinientos pesos; y si fuera negocio ejecutivo, hará pago a la parte con la fianza de la ley de Toledo. Y si de los demás y en éstos apelaren, otorgará las apelaciones conforme a Derecho; y si las causas fueren de más de quinientos pesos, substanciarlas han y remitirán a nuestro Provisor y Vicario General. Y ofreciéndose otros negocios leves, entre españoles y naturales, civiles y criminales, que no sean contrarios a los de arriba, harán en el caso justicia como hallaran por Derecho".

En general, los Vicarios o Arciprestes gozaban de las amplias facultades concedidas por el Obispo en el Sínodo, y desde el primer momento en que tomaban posesión del beneficio parroquial, salvo que en la provisión canónica dichas facultades hubieran sido ampliadas o restringidas, pues, al Ilmo. Señor Solís le pareció muy conveniente añadir, al final de la constitución sinodal, la siguiente cláusula: "y reservamos en nos el acrecentar o disminuir lo que nos pareciera a los Vicarios que proveyéremos, según sus partes y suficiencia; y los demás guardarán lo aquí contenido"6, es decir, las facultades arriba señaladas. Según esto, el Prelado debió tener especial cuidado en elegir para el cargo de Arciprestes a sacerdotes dignos y de experiencia en la vida parroquial, pues no se trataba de concederles un título meramente honorífico, sino de confiarles un oficio de mucha responsabilidad ante Dios, ante la Diócesis y ante el Rey.

Así como un Arcipreste tenía facultades cuasi episcopales porque las circunstancias de aquellos tiempos lo exigían, así también sus obligaciones eran múltiples: al igual que los demás curas y doctrineros, debía atender el ministerio parroquial en su respectivo beneficio; y como Arcipreste, en cambio, vigilaría las Parroquias y Doctrinas de su Arciprestazgo, visitándolas al menos una vez al año, cuidando que los Encomenderos pagasen cumplidamente el salario a los beneficiados, que los diezmos 
Doctrinas y Parroquias del Obispado de Quito / 249

fuesen recaudados sin dificultad, que los curas y doctrineros cumplieran lo dispuesto y ordenado por los Concilios y Sínodos acerca de la residencia, libros parroquiales, derechos arancelarios, enseñanza de la doctrina cristiana, predicación de la palabra divina, ornato y decencia en la iglesia, etc. $^{7}$.

Probablemente podemos formularnos la pregunta siguiente: ¿Cuántas Vicarías foráneas o Arciprestazgos habían en la Diócesis de Quito en esta segunda mitad del siglo XVI?. No tenemos datos concretos; sin embargo, como en el primer Sínodo de 1570 se dice: "ordenamos y mandamos que los Vicarios de las ciudades tengan jurisdicción, cada uno en la comarca y términos de la ciudad de su Vicaría" ${ }^{8}$, y, además, en un documento del año 1598 consta que la Diócesis de Quito comprendía veinte ciudades y una Villa ${ }^{9}$, es de suponer que al menos llegarían a un total de veintiún Arciprestazgos, aunque nos inclinamos a pensar que pasarían de este número, porque en Gualea, sin ser ciudad sino un pueblo grande del cual dependían varios otros, estaba en 1568 el Bachiller Antonio de Balbuena con el título, no de doctrinero, sino de Vicario, ya que en la provisión canónica el Ilmo. Señor Peña se expresaba así: “...por la presente, en cuanto nuestra voluntad fuere, os proveemos, nombramos e señalamos por nuestro cura y Vicario de la dicha Doctrina y pueblos de Gualea... e como tal Vicario conozcais de todos los pleitos e causas civiles e criminales que se ofrecieren y los determinar, excepto en los casos de herejía o especie della y matrimonio, cuanto a la separación, que en los dichos casos haréis las informaciones y, presos los culpados, nos remitiréis las dichas causas para que nos las determinemos y proveamos lo que sea justicia, y en los demás casos pronunciaréis vuestras sentencias, las cuales llevaréis a debida ejecución... E mandamos a todas e cualesquier personas, de cualquier calidad e condición que sean, que por tal nuestro cura y Vicario vos hayan e tengan e usen con vos los dichos oficios e vos guarden todas las honras que por razón dellos debéis haber..."10.

Siendo el Obispado de Quito tan extenso, proporcionalmente, también los Arciprestazgos, en que se dividía, comprendían extensiones de territorio que en la actualidad se han convertido en una o dos Dióce- 
sis. Tenemos, por ejemplo, que la Vicaría o Arciprestazgo de la Villa de Riobamba, provista el 6 de febrero de 1584 en la persona del presbítero Juan Sánchez Mino como cura y Vicario de dicha Villa, dependían como sufragáneos los siguientes beneficios curados: Pallatanga, Quero, Pelileo, Angamarca, Tomavela, Ambato, Latacunga y las regiones de Chambo y Guano, con sus respectivos anejos ${ }^{11}$. Según esto, el territorio que en la segunda mitad del siglo XVI constituía la Vicaría o Arciprestazgo de la Villa de Riobamba, con el transcurso de cuatro siglos, se ha convertido en las actuales Diócesis de Riobamba y de Ambato, más una parte de la Diócesis de Latacunga.

$\mathrm{Y}$ ya que hemos tratado de los Vicarios o Arciprestes, conviene añadir algo acerca de los Vicarios Generales de los primeros Obispos de la Diócesis de Quito. Conviene advertir que en cada Diócesis el Obispo tiene obligación y tan pronto como toma posesión, debe nombrar un Vicario General, que dotado de potestad ordinaria ha de ayudarle en el gobierno de toda la Diócesis ${ }^{12}$. Desde luego, su designación y nombramiento lo realiza libremente el Obispo y cuando éste se ausenta, entonces el Vicario General lo reemplaza. En la segunda mitad del siglo XVI las ausencias de los Obispos, Ilmos. Peña y López de Solís, cuando asistían a los Concilios limenses o salían de visita pastoral a su diócesis, eran muy prolongadas, llegando a varios meses y hasta pasaban de un año y medio, como hemos expuesto anteriormente.

El primer Obispo de Quito, Ilmo. Garci Díaz Arias, ante la escasez de clero en los años que siguieron a la erección de la Diócesis, se vería obligado a prescindir de Vicario General. En cambio, el Ilmo. Señor Peña encontró un buen colaborador inmediato para el gobierno eclesiástico en la persona del presbítero Diego de Salas, quien desempeñó a la vez dos cargos, el de Vicario General y el de Provisor de la Diócesis ${ }^{13}$. Es de suponer que el Ilmo. Señor Peña, si a los Arciprestes les daba facultades muy amplias, a su Vicario General no le habrá restringido ninguna, sino solamente aquellas que por derecho exigían mandato especial del Obispo ${ }^{14}$.

Hacia el año 1575 el Obispo Peña se hallaba de visita pastoral en la ciudad de Loja. Considerando que su edad muy avanzada no le permi- 


\section{Doctrinas y Parroquias del Obispado de Quito /251}

tía ya acudir al cumplimiento de sus deberes pastorales en la Gobernación del Capitán Juan de Salinas Loyola, no tuvo ningún reparo en nombrar el 12 de octubre de aquel año al presbítero Juan de Olmos Volaños como segundo Vicario General para que hiciera sus veces en toda aquella región ${ }^{15}$. Medida más prudente y acertada no podía adoptarse. Cuando el Ilmo. Señor Peña se sentía con fuerzas para cumplir fielmente su deber pastoral, él en persona lo desempeñaba ayudado solamente de un Vicario General; pero, cuando le fue materialmente imposible, a pesar del "non recuso laborem" -no rehuyo el trabajo- solicitó ayuda de un segundo Vicario General, porque al Obispo Peña no le gustaba centralizar en su persona toda la autoridad, ya que esta manera de obrar hubiera redundado en perjuicio de su querida Diócesis de Quito, descuidando las visitas pastorales, permaneciendo por mucho tiempo Doctrinas vacantes y los doctrineros y curas sin poder recibir una palabra de aliento de su Prelado y Pastor.

El cuarto Obispo, Ilmo. Señor Solís, tan pronto como llegó a la ciudad de Quito, nombró como su Vicario General y Provisor de la Diócesis al benemérito sacerdote Benito Hernández de Ortega, quien desempeñó los dos cargos a satisfacción de todos ${ }^{16}$. Si el episcopado del Ilmo. Señor Solís fue brillante, honrando así a la Sede de Quito, no debemos olvidar que se debió en gran parte a la colaboración eficaz, sincera, constante y leal de su Vicario General, en quien había depositado toda su confianza desde el primer momento en que tomó posesión de sus querida Diócesis de Quito. 
252 / Augusto E. Albuja

\section{NOTAS:}

1 Apéndice \# 48.

2 Apéndice \# 9.

3 Apéndice \# 9.

4 Primer Sínodo de Quito, Parte Tercera c.28 (AGI, Patronato leg. 189, R40).

5 Ibidem.

6 Segundo Sínodo de Quito, Const. 104 (AGI, Quito, leg.77).

7 Segundo Sínodo de Quito, Const. 50; Tercer Sínodo, cap. 30,31,34,88, 104 (AGI, Quito, leg.77).

8 Primer Sínodo de Quito, Parte Tercera, c. 28 (AGI, Patronato, leg.189, R40).

9 Apéndice \# 48.

10 AGI, Quito, leg.81.

11 AGI, Quito, leg.83.

12 C.I.C. 17 , c. 366 ; C.I.C. c. 475.

13 Apéndice \# 8.

14 C.I.C. 17 , c. 368 ; C.I.C. c. 479.

15 Apéndice \# 17.

16 Apéndice \# 52. 


\section{CAPÍTULO XV \\ EL CLERO REGULAR}

"Fue otra providencia de Dios -escribe Gómez Hoyos- que la conquista de América tocara en suerte a España, por disponer de un número de religiosos tan abundante y selecto como ninguna otra nación católica"1.

Para que los religiosos pudiesen viajar a las Indias con el fin de dedicarse a la evangelización, se les exigía dos requisitos : obediencia a su respectivo Prelado y licencia del Rey o del Consejo Supremo de Indias ${ }^{2}$ Y para que no pasen a las Indias "religiosos que no sean cuales conviene, ordenamos -decía el Emperador Carlos V-que no se dé licencia por nuestro Consejo, ni consienta por los Jueces Oficiales de la Casa de Contratación pasar a las Indias algunos religiosos, sin tener primero noticia de quién son, y de qué parte, y de su vida y doctrina, y que sean celosos de nuestra santa Religión, y que darán tan buen ejemplo, que Dios nuestro Señor sea servido"3; asimismo, los Prelados de las Ordenes religiosas debían informar al Consejo de Indias de la calidad de sus súbditos "y si conviene que los dichos religiosos pasen a aquellas provincias" 4 .

La labor de los primeros religiosos misioneros en Indias debió ser en extremo heroica por los múltiples obstáculos que encontrarían: inclemencia del tiempo, falta de medios de comunicación, diversidad de lenguas, $\mathrm{y}$, principalmente, las costumbres depravadas y vicios que estaban muy enraizados entre los indios. A pesar de todo, con las bendiciones del Cielo y la buena voluntad desplegada por todos los religiosos, a fines del siglo XVI la evangelización, sin duda, presentaba otro aspecto, pues los grandes privilegios concedidos por los Sumos Pontífices y la ayuda económica y moral prestada por los Reyes de España, sembraron optimismo en el corazón de los misioneros, quienes, de día en día, ganaban almas para 
Cristo e implantaban a su paso por estas vastas regiones la cultura y civilización del indio.

La erección de las primeras Diócesis, la fundación de Doctrinas y Parroquias demuestran el fruto obtenido por los beneméritos misioneros. Aun más, por la escasez de clero secular, los religiosos tomaban a su cargo sobre todo las Doctrinas de indios en cada una de las Diócesis. Los privilegios de que gozaban los religiosos para poder administrar los santos sacramentos en cualquier parte de las Indias, si bien fueron de mucho provecho en los primeros decenios, luego se convirtieron en ocasión de largas y continuas controversias con los primeros Obispos, ya que éstos, como era natural, a los sacerdotes del clero secular les exigían el fiel cumplimiento de las constituciones conciliares y sinodales y esperaban también que los religiosos doctrineros se someterían a las leyes canónico-particulares.

Cuando los Obispos, cumpliendo con su deber pastoral, visitaban las Parroquias y Doctrinas de su Diócesis, encontraban serias dificultades en aquellas que eran atendidas por los religiosos, de modo que no podían darse cuenta, muchas veces, si cumplían o no con el ministerio parroquial. Los religiosos doctrineros llegaron a afirmar que ellos estaban exentos de la jurisdicción del Obispo y que desempeñaban el ministerio parroquial solamente por caridad; mas, en justicia, que no estaban obligados como los demás clérigos. Era una cosa absurda pensar de esta manera porque tales privilegios les habían sido concedidos en cuanto religiosos, mas no en cuanto religiosos doctrineros. Además, quien tiene derechos, debe tener también obligaciones. A los religiosos se les atendía en la medida de las posibilidades. El Rey les daba todo; hasta las medicinas corrían de cuenta de la Real Hacienda. Al examinar un documento en que consta la cantidad de dinero que había dado la Real Hacienda de la Audiencia de Quito para los conventos de las Ordenes de Santo Domingo, San Francisco y San Agustín, por concepto de medicinas y dietas de los frailes enfermos, desde el año 1563 hasta 1587, la cifra llegaba nada menos que a 18.631 pesos 7 tomines $^{5}$. Los mismos indios contribuían al sostenimiento del religioso doctrinero; prestaban sus servicios para construir el convento, etc. Con todo esto, decir que no estaban obligados "ex justitia" pa- 
Doctrinas y Parroquias del Obispado de Quito / 255

rece difícil creerlo, hasta que en el año 1586 una orden del Rey Felipe II dilucidó este asunto, pues decía: "Encargamos que los religiosos tengan y sirvan las Doctrinas, como hasta ahora... Y por lo mucho que importa que la doctrina, administración y enseñanza de los indios, tan nuevos en la fe, no quede a voluntad de los religiosos, todos los que sirvieren las Doctrinas, curatos y beneficios han de entender en el ministerio y oficio de curas non ex voto charitatis, como dicen, sino de justicia y obligacion, administrando los sacramentos a españoles e indios, sus feligreses, por los indultos apostólicos y comisión de los Obispos,para lo cual se la han de dar, y a Nos muy particular relación de cómo cumplen de su parte los religiosos esto que les toca, y han de hacer precisamente y de obligación"6.

Las leyes del Patronato y las Constituciones conciliares y sinodales no hacían distinción alguna respecto a provisión de beneficios, visitas del Obispo, salarios, residencia, administración de Sacramentos, etc. entre clérigos y religiosos, pues los unos y los otros eran considerados como beneficiados.

Durante esta segunda mitad del siglo XVI surgieron múltiples dificultades entre los religiosos y los Obispos Peña y Solís, respectivamente, ya que "pertenecía a la Iglesia y sus representantes -escribe Roberto Levillier- el derecho de controlar y la obligación de vigilar aquellas Ordenes que, por favores especialmente concedidos por los Papas, tuviesen a su cargo casas de Doctrinas. Esto implicaba -continúa diciéndonos dicho autor- la intervención de los Prelados en el examen, nombramiento, castigo, remoción de los religiosos provistos de algún beneficio de indios, y la sujeción consecuente de las Ordenes a la Iglesia. Además, celosos de los fueros eclesiásticos, negaban los Obispos a los religiosos de las Ordenes el derecho de hacer de curas y administrar sacramentos, sino en casos excepcionales, y con licencia del Ordinario. Las Ordenes replicaban, exhibiendo un Breve de S. Pío V, por el cual gozaban del privilegio de poder servir y administrar sacramentos, a lo cual contestaban el Arzobispo y los Obispos que el tal privilegio había sido derogado por un Motu Proprio de Gregorio XIII, del año 1572, por cuyos términos quedaba estipulado que sólo podían actuar en esa forma con licencia del Ordinario"7. 
Es lógico pensar que quien tiene privilegios concedidos por la autoridad máxima en la Iglesia, como es el Sumo Pontífice, está en su derecho de usarlos; tal fue el caso de los religiosos. En este punto, los Obispos debían respetar dichos privilegios; y para que tuvieran conocimiento de los grandes favores concedidos por S.Pío $\mathrm{V}$ a los religiosos de Indias, por medio de un Breve, el 24 de marzo de 1567, Felipe II dirigió al año siguiente una Real Cédula a los Presidentes y Oidores de las Audiencias de Lima, de La Plata y de San Francisco de Quito, diciéndoles: "Bien sabéis o debéis saber cómo Su Santidad, a nuestra suplicación, concedió un Breve para que los religiosos de las Ordenes Mendicantes de las nuestras Indias puedan administrar los santos Sacramentos en todos los pueblos de Indias, según y de la manera que lo hacían antes del santo Concilio Tridentino; e porque al servicio de Dios Nuestro Señor y nuestro conviene y que para evitar discusiones y discordias entre las dichas Ordenes y los clérigos que en esas partes residen...conviene que el dicho Breve se publique en todas esas partes, vos mando, a todos y a cada uno de vos, que luego esta nuestra Cédula os sea notificada por parte de algunos dichos religiosos de las dichas Ordenes, hagáis publicar e publiquéis, de manera que convenga a noticias de todos, que en ello seré servido" 8 .

El problema quedaba resuelto; los religiosos gozaban de amplias facultades. Pero en la Diócesis de Quito algunas veces se extralimitaban, y por esta razón el 4 de mayo de 1571 el Ilmo. Señor Peña, informando al Virrey del Perú, Francisco de Toledo, le decía: “...sin haber consentimiento del Prelado e sin asignarles las Doctrinas, -los religiosos- administran los Sacramentos e demás desto, so color de la dicha Bula, piden y toman otras de nuevo donde están puestos clérigos curas en nombre de $\mathrm{Su}$ Majestad; y en esta ciudad -de Quito-, por la dicha razón han deshecho dos Parroquias, la una de San Blas y la otra de San Sebastián”. Y citando otro caso concreto, el Obispo pone en conocimiento del Rey que los religiosos franciscanos de la ciudad de Quito, "no teniendo sobre los yanaconas, que en ella sirven a españoles, jurisdicción ni facultad para administrarles los Sacramentos, se entremeten a se los administrar, casar y velar contra lo que está ordenado por Derecho". 


\section{Doctrinas y Parroquias del Obispado de Quito / 257}

"Ansi mesmo -prosigue el Ilmo. Señor Peña en dicho informehay otro inconveniente, porque la dicha Bula se concede por causa de que había falta de sacerdotes que doctrinasen los naturales, y en este Obispado hay muchos clérigos, hijos de conquistadores y pobladores, muy buenas lenguas y de mucho recogimiento y hábiles; y demás de cesar la causa por qué se concedió la dicha Bula, éstos han de ser preferidos por los méritos e servicios de sus personas, pues muchos dellos son pobres y es justo que los dichos frailes no adquieran posesión para apropiar así las dichas Doctrinas, ni administrar Sacramentos habiendo clérigos. Y suplica a Vuestra Excelencia la mande remediar para que la dicha Bula se guarde en esta limitación"'.

La respuesta que dio Felipe II, a este informe presentado, fue favorable al Prelado;y, además, como en ella no se habla de ningun Breve especial de S.Pío V, esto demostraba que fue revocado por Gregorio XIII en 1572.

"Por relación que nos ha hecho el Reverendo en Cristo Padre, Don Fray Pedro de la Peña, Obispo de esa ciudad -decía Felipe II en su Real Cédula del 15 de junio de 1573, dirigida al Presidente y Oidores de la Audiencia de Quito-, hemos entendido que los frailes del Monasterio de San Francisco de ella, no teniendo jurisdicción sobre los yanaconas que sirven a españoles... se entremeten a administrar los Sacramentos y casarlos, contra lo que por Derecho está ordenado; que han suplicado lo mandásemos proveer como más conviniese, lo cual, visto por los de nuestro Consejo de las Indias, fue acordado que debía mandar dar esta mi Cédula, y yo hélo tenido por bien. Por ende, yo vos mando que hagáis guardar su derecho al dicho Obispo, y no consintáis que los frailes de ninguna de las Ordenes que residieren en esa provincia se lo inquieten ni perturben, ni se entremetan en lo que no les pertenece, que así es nuestra voluntad" 10 .

¿Qué podemos pensar ante esta Real Cédula?. Pues que los privilegios de los religiosos habían sido restringidos y que como doctrineros debían someterse a la autoridad del Obispo. Y para que las leyes del Patronato sean puestas en práctica también por los religiosos, "rogamos y en- 
cargamos a los Arzobispos y Obispos de nuestras Indias -decía el Monarca- que a ningún religioso permitan entrar a ejercer oficio de cura ni doctrinero, sin ser primero examinado y aprobado por los Prelados diocesanos o las personas que para este efecto nombraren, así en cuanto a la suficiencia, como en la lengua de los indios, a que han de doctrinar y administrar los santos Sacramentos, y a los españoles que allí hubiere, lo cual se guarde inviolablemente, aunque los religiosos doctrineros sean Superiores de las casas o conventos donde habitan; y no se les admita excusa alguna por eminencia del sujeto o dignidad en su Religión, porque nuestra voluntad es que, para ejercer y administrar, concurran en todas las calidades referidas...; y si en la visita que los Prelados hicieren los hallaren sin la suficiencia necesaria y pericia en la lengua de los indios que doctrinaren, los remuevan, como está prevenido, y avisen a sus Superiores para que nombren otros en que concurran las dichas partes y calidades". Y para evitar posibles desavenencias entre los religiosos y el Obispo diocesano, "mandamos -prosigue la orden real- a nuestros Virreyes, Presidentes y Audiencias Reales que den el favor y ayuda necesarios a los Arzobispos y Obispos para que todo lo referido tenga cumplido efecto; y si los religiosos presentaren algunos indultos o Bulas de exención, hagan su oficio, y no permitan ni den lugar a que de otra forma sean admitidos a las Doctrinas, y nuestros Fiscales pidan lo que convenga"11.

Si el Ilmo. Señor Peña encontró serias dificultades tratando de conseguir que los religiosos doctrineros observaran las leyes conciliares y sinodales, el Ilmo. Señor Solís tuvo también que soportar no pocas contrariedades y hasta se acudió a los tribunales para resolver este pleito en que ambas partes, Obispo y religiosos, decían tener la razón. El fallo fue favorable al Prelado porque obraba en conformidad con el Tridentino, con las constituciones conciliares de Lima y sinodales de Quito, y además, de acuerdo con las leyes del Patronato y las disposiciones del Rey. ${ }^{12}$.

La actitud y proceder del Obispo Solís fueron mal interpretados por los religiosos doctrineros, quienes pensaban que iban contra el voto de obediencia a sus respectivos Superiores si se sometían al Obispo: permitiéndole que hiciera en las Doctrinas la visita pastoral, pagando la con- 


\section{Doctrinas y Parroquias del Obispado de Quito /259}

tribución del 3\% para el Seminario, rindiendo examen para que les concediera facultades de poder confesar, etc. De donde, no nos extrañen las cartas que los religiosos dirigieron al Rey para presentarle un sinnúmero de quejas de toda índole, algunas con fundamento pero la mayoría de ellas sin razón y hasta llegando a la calumnia porque su situación no era como en años anteriores, y porque pretendían a todo trance desprestigiar al Obispo $^{13}$. Pero el Ilmo. Señor Solís no podía ni debía transigir porque en conciencia, deseaba, sobre todo, cumplir sus deberes pastorales, manteniendo, desde luego, el principio de autoridad ${ }^{14}$.

El Obispo de Quito y los Obispos de las demás diócesis que formaban la provincia eclesiástica de Lima, "como era natural, se inclinaron a favorecer a los clérigos, tanto porque el orden natural y la ley canónica así lo exigía, como porque los clérigos se les sometían más fácilmente, en tanto que los religiosos, con sus exenciones y privilegios, no se mostraban tan dóciles y aún llegaban a resistir a los Ordinarios"15.

Sin embargo prescinciendo de estas dificultades surgidas entre religiosos y Prelados diocesanos, debemos reconocer el mérito que tuvieron todas y cada una de las Ordenes religiosas que se fundaron en Quito hasta principios del siglo XVII, pues, "habían llegado en la hora primera", y, por consiguiente, "tomaron a su cargo la evangelización del indígena, y en este sentido nadie puede regatearles el elogio" 16 .

Los dos Obispos que en esta segunda mitad del siglo XVI organizaron la incipiente Diócesis de Quito y la pusieron en marcha hacia un futuro mejor, eran precisamente dos ilustres y beneméritos frailes, Pedro de la Peña, dominico, y Luis López de Solís, agustino, quienes "no sólo desempeñaban con celo ininterrumpido el patrocinio del indio, sino que fueron los civilizadores del Ecuador" 17.

"Los frailes -escribe Richard Pattee, - ejercían la policía del amor y el apostolado de la paz en pueblos carentes de toda otra energía ordenadora. La religión atemperaba la violencia de los conquistadores, dignificaba la obediencia de los súbditos, ponía coto al individualismo de la raza y al genio levantisco de la audaz colonia". 
"Apenas establecidos en Quito, los jesuitas tomaron a su cargo el Seminario de San Luis, a petición de otro santo Obispo y estupendo promotor del adelanto moral y material de su grey, Fray Luis López Solís. A la par que procuraron la mejor instrucción del Clero, para que atendiese debidamente a las ingentes labores de la transformación espiritual de un pueblo incipiente, implantaron sus admirables tradiciones humanísticas, y en ellas educaron a dos centurias".

"Los agustinos fundaron el Colegio San Nicolás para los indios; y en 1603, la primera facultad de Teología o Universidad de San Fulgencio".

"Los dominicos no quisieron irse a la zaga y establecieron el Colegio San Fernando, donde sostuvieron afamadas cátedras de cánones y jurisprudencia y más tarde de Medicina"18. El aprendizaje del idioma indígena, tan necesario para poder ser doctrinero, fue solucionado con la cátedra que estuvo a cargo de los Padres Dominicos hasta 1594, en que pasó a funcionar en el Seminario Conciliar. El religioso que tanto bien hizo con la enseñanza del difícil idioma fue el dominico Fr. Hilario Pacheco ${ }^{19}$.

$\mathrm{Y}$ respecto a los franciscanos, debemos decir que el 13 de enero de 1552, el Padre Guardián del Convento de Quito, Fr. Francisco Morales, dirigiendo una carta al Presidente y Oidores del Consejo de las Indias, les manifestaba que: "en esta provincia de Quito habrá bien 50.000 indios y los religiosos que en su conversión entendemos somos solos veinte. Tenemos 8 casas de Doctrinas entre los indios, a dos frailes cada una; y en Quito hemos comenzado un colegio a la forma de Nueva España..."20. Este colegio, al que se hace referencia, es el Colegio San Andrés, donde antiguamente los franciscanos "enseñaban a leer, escribir,doctrina cristiana, gramática latina y música, siendo frecuentado este estudio principalmente por los hijos de los caciques, indios nobles e hijos de españoles pobres" 21 . Por tanto los religiosos franciscanos tienen la gloria de haber fundado en la ciudad de Quito el primer establecimiento dedicado a la enseñanza y que aún en nuestros días es conocido con el nombre de Colegio San Andrés. 
La labor apostólica de las Comunidades religiosas no sólo se reducía a fundar colegios y dedicarse a la enseñanza de la niñez y juventud de aquellos tiempos, sino que, mientras hubo escasez de clero secular, "en una gesta incesante de gloria, se distribuían la evangelización del antiguo Reino de Quito, adoctrinando al indio en sus propias lenguas y enseñándoles los rudimentos de la civilización" 22 y cuando hubo necesidad de ejercer el ministerio parroquial, los Prelados de las Religiones existentes en Quito siempre pusieron en práctica aquel deseo de Felipe II cuando decía: "Y rogamos y encargamos a los Prelados de las Religiones, que cuando los Arzobispos u Obispos les pidieren religiosos para ocupar en algunas Doctrinas, se los den y hagan dar los que convinieren y fueren necesarios, sin poner excusa, ni impedimento" 23 . Y para ratificar lo expuesto, damos a conocer la lista de las Doctrinas, es decir, de los beneficios curados atendidos por los religiosos franciscanos, dominicos, mercedarios y agustinos entre 1597 y 1600 . Pero antes tengamos en cuenta el siguiente esquema ${ }^{24}$ :

\begin{tabular}{|crrrrr|}
\hline \multicolumn{2}{|c}{ D I O C E S I S D E } & Q U I T O & & \\
\hline & Años .... & 1574 & 1583 & 1597 & 1600 \\
\hline - CLERO SECULAR & 44 & $57 ?$ & 114 & 120 \\
- CLERO REGULAR a) Franciscanos & 11 & 21 & 37 & 37 \\
b) Dominicos & 7 & 17 & 26 & 29 \\
c) Mercedarios & 5 & 10 & 15 & 15 \\
d) Agustinos & $\ldots$ & 4 & 7 & 7 \\
\hline TOTAL DE BENEFICIOS CURADOS & 67 & $109 ?$ & 199 & 208 \\
\hline
\end{tabular}


262 / Augusto E. Albuja

\section{LISTA DE LAS DOCTRINAS ATENDIDAS POR LOS RELIGIOSOS EN LOS AÑOS 1597 - 1598 Y 1600}

\section{Franciscanos}

$\begin{array}{lll}\text { 1. Cotocollao } & \text { 13. S.Antonio de Caranqui } & \text { 25. Calahote } \\ \text { 2. Pomasqui } & \text { 14. Salinas } & \text { 26. Tungurahua } \\ \text { 3. Calacalí } & \text { 15. Mulaló } & \text { 27. Quimña } \\ \text { 4. San Antonio } & \text { 16. Latacunga } & \text { 28. Penipe } \\ \text { 5. Perucho } & \text { 17. Los Aláquez } & \text { 29. Tangua } \\ \text { 6. Malchinguí } & \text { 18. San Miguel } & \text { 30. Chapagua } \\ \text { 7. Otavalo } & \text { 19. Pujilí } & \text { 31. Valle Angonsí } \\ \text { 8. La Laguna } & \text { 20. Saquisilí } & \text { 32. Yaconque } \\ \text { 9. Cotacachi } & \text { 21. San Andrés } & \text { 33. Paute } \\ \text { 10.Atuntaqui } & \text { 22. Guano } & \text { 34. Gualaceo } \\ \text { 11.Urcuquí } & \text { 23. Punín } & \text { 35. Molleturo } \\ \text { 12.Caranqui } & \text { 24. Chambo } & \text { 36. Ilapo } \\ & & \text { 37. Pungalá }\end{array}$

\section{Dominicos}

$\begin{array}{lll}\text { 1. Alangasí } & \text { 11. Ipiales } & \text { 21. Daule } \\ \text { 2. Píntag } & \text { 12. Cibundoy } & \text { 22. Chongón } \\ \text { 3. Uyumbicho } & \text { 13. Laguna } & \text { 23. Cosanga } \\ \text { 4. Amaguaña } & \text { 14. Ingenios } & \text { 24. Hatunquijo } \\ \text { 5. Pansaleo(Aloasí) } & \text { 15. El Valle de Baeza } & \text { 25. Pachamama (Yles) } \\ \text { 6. Alóag y Cansacoto } & \text { 16. Paccha } & \text { 26. Maspa } \\ \text { 7. Ambato } & \text { 17. Garruchamba } & \text { 27. Pansaleo de arriba } \\ \text { 8. Píllaro } & \text { 18. Pozol } & \text { 28. Cansacoto } \\ \text { 9. Tomavela } & \text { 19. Calva } & \text { 29. Guarnahama } \\ \text { 10. Pupiales } & \text { 20. Cariamanga } & \end{array}$


Doctrinas y Parroquias del Obispado de Quito /263

\section{Mercedarios}

1. Caguasquí

2. Túcar

3. Puntal

4. Guaca

5. Tulcán
6. Gualea

7. Camoqui (Nanegal)

8. Males

9. Mallana

10. Carlosama
11. El Valle

12. Túmbez

13. Frías (Quilca)

14. Capuna (Isla Puná)

15. Picoaza

\section{Agustinos}

1. Hatunsicho

3. Ingenio (Isinliví)

5. Túqueres

2. Cañares

4. Los Calientes de Sigchos

6. Capuil

7. Malacatos

Nota Bene: $\quad$ Estas Doctrinas corresponden al año 1597 y también al año 1600, a excepción de las Doctrinas de los dominicos, quienes atendían 26 en la primera fecha indicada; y después, 29 en 1600. Por tanto, las Doctrinas que después se les asignaron fueron: Pansaleo de arriba, Guarnahama porque la Doctrina de Garruchamba se dividió en dos en el año 1598, y Cansacoto se fundó en 1600, separándola de la Doctrina de Alóag 25 . 
264 / Augusto E. Albuja

NOTAS:

1 GÓMEZ HOYOS, Las Leyes de Indias, 218.

2 Recopilación, Lib.I, tít.14, ley 13.

3 Ibidem, ley 15.

4 Ibidem, ley 17.

5 AGI, Quito, leg.8.

6 Recopilación, lib. I, tit.15, ley 30.

7 LEVELLIER, Organización, I, Prólogo, pp.LXXIII y LXXIV.

8 GARCÉS, Colección de Cédulas Reales, 157 - 158

9 Apéndice \# 11.

10 GARCÉS, Colección de Cédulas Reales, 251 - 252.

11 Recopilación, lib.I, tit.15, ley 6.

12 Apéndices \# 41 y 44.

13 Apéndices \# 38, 40, 56, 57 y 59.

14 Apéndices \# 35, 41 y 43.

15 VARGAS UGARTE, Historia, II, 205 y 206.

16 VARGAS UGARTE, Historia, II, 205.

17 PATTEE, Richard, El Catolicismo contemporáneo en HispanoamËrica, Buenos Aires, 1823,203.

18 PATTEE, El Catolicismo, 203-204.

19 AGI, Quito, leg. 83.

20 AGI, Quito, leg. 81; LISSON CHAVES, Emilio, La Iglesia de España en el Perú, I, Sevilla 1943. 218.

21 BANDIN HERMO, Manuel, El Obispo de Quito, D.Alonso de La Peña, (15971687), Madrid 1951, 130. Sobre este Colegio puede leerse el interesante estudio del P.Benjamín Gento Sanz O.F.M., "San Andrés, primer Colegio Politécnico en Sudamérica” en: España Misionera, V, Madrid 1948, 142-61, 23-47.

22 PATTEE, El Catolicismo, 203.

23 Recopilación, lib. I, tit.15, ley 15.

24 Los datos correspondientes al año 1574, hemos extractado de la obra de Juan López de Velasco. (Geografia y Descripción Universal de las Indias, Madrid 1894, 430) Para la estadística correspondiente al año 1583, hemos utilizado las Relaciones Geográficas de Indias, III, 37-53. Los beneficios de clérigos probablemente no son exactos, por eso indicamos con un signo de interrogación; de donde el total de 109 sería aproximado.Los otros datos hemos extractado de dos listas enviadas al Consejo de Indias por el Obispo de Quito; la primera el año 1597 y la segunda de 1600. (Apéndices \# 42 y 51).

25 Apéndices \# 48 y 5. 


\section{CAPÍTULO XVI \\ SITUACIÓN DEL OBISPADO DE QUITO A \\ FINES DEL SIGLO XVI}

Nuestro deseo es presentar en este capítulo una estadística general de la situación de la Diócesis de Quito a fines del siglo XVI.

Con la ayuda de tres documentos del Archivo General de Indias de la ciudad de Sevilla, el primero correspondiente al año $1597^{1}$, el segundo a $1598^{2}$ y el tercero a $1600^{3}$, hemos logrado conseguir nuestro propósito, a pesar del mucho trabajo que nos ha exigido porque ninguno de los tres manuscritos nos dan datos completos. Además, no hemos tenido la suerte de conseguir un mapa geográfico de aquella época, lo cual hubiera facilitado enormemente nuestro trabajo.

En la estadística, que a continuación presentamos, damos a conocer los nombres de Parroquias y Doctrinas, de los beneficiados, tanto seculares como regulares, salario anual que percibían, número de indios tributarios que tenían en sus respectivas Doctrinas o Parroquias, y finalmente señalamos con la palabra "lengua" cuando el sacerdote sabía el idioma indígena.

A fin de apreciar mejor dicha estadística, conviene que hagamos las siguientes advertencias:

1. Los nombres de los religiosos doctrineros van subrayados y corresponden a aquellos que atendían tal o cual Doctrina en el año 1598. Algunos de ellos percibían su salario y los indios les daban el llamado camarico (c), o sea la comida durante el año, y estaba valorado dicho camarico en 100 pesos de plata corriente.

2. Las Parroquias y Doctrinas atendidas por el clero secular llevan, en cambio, tres nombres de los beneficiados porque se trataba de los 
266 / Augusto E. Albuja

años 1597-1598 y 1600. El nombre que corresponde al beneficiado que atendía la Parroquia en el año 1598 también va subrayado.

3. Cuando señalamos tres nombres, el primero corresponde al año 1597, el segundo al año 1598 y el tercero al año 1600 .

4. El número de indios tributarios habría que multiplicar por cuatro para saber con cuantos feligreses aproximadamente contaba cada Doctrina o Parroquia, como advertimos oportunamente al tratar de este asunto.

\section{Obispado de Quito}

Longitud....................................

Latitud.

226 leguas

Diezmos (año 1598)

18.000 Pesos

Ciudades

20

Villa (Riobamba)

1

\begin{tabular}{rrrrr} 
Beneficios curados Años & 1597 & 1598 & 1600 \\
\hline 1.. Clero secular................ & 114 & 114 & 120 \\
2o. Clero regular............... & 85 & 87 & 88 \\
\cline { 2 - 4 } TOTAL...... & 199 & 201 & 208
\end{tabular}

He aquí las ciudades que dependían del Obispado de Quito a fines del siglo XVI y que las distribuimos según las Gobernaciones que formaban la Real Audiencia. 
Doctrinas y Parroquias del Obispado de Quito /267

\section{GOBERNACIONES}

\section{Las Esmeraldas}

1. Quito

2. Puerto Viejo

3. Riobamba (Villa)

4. Cuenca

5. Santiago de

Guayaquil

6. Loja

7. Zamora

8. Zaruma

9. Ecija

10. Mocoa

11. Jaén

12. San Miguel de Piura

\section{Bracamoros y III. Quijos (La Canela) Yaguarsongo}

13. Loyola

18. Baeza

(Cumbinamá)

19. Avila

14. Valladolid

15.Santiago de las Montañas

16. Santa Marìa de

20. Archidona

(De la Gob. de

Popayán)

17. Sevilla del Oro

(Macas)

OBISPO

Ilmo.Luis López de Solis.

6.000 pesos

CABILDO:

Deán

Lic. Francisco Galavís.

850

Arcediano

Juan de Ovando

730

Chantre

Jorge Ramírez de Arellano

730

Maestrescuela

Miguel León de Almonte.

(Maestrescuela y Tesorero, vacantes en 1598 - 1600)

Canónigos:

Juan Fco. Talaverano Mancera........ 550

Andrés López de Albarrán .............. 550

Gaspar de Zamora......................... 550

Diego de Agüero Maldonado...... 550

Alonso de Aguilar.................. 550

García de Valencia. . 
268 / Augusto E. Albuja

VICARIO GENERAL Y

PROVISOR DE LA

DIOCESIS ....................... Benito Hernández de Ortega............ ?

Maestro de Capilla

(Jubilado)

Diego Lobato de Sosa

130 pesos

VISITADORES GENERALES

DE LA DIOCESIS

en el año 1600

Lic. Diego de Bracamonte.............. ?

Francisco Suárez Salgado ................. ?

\section{I.- GOBERNACIÓN DE “LAS ESMERALDAS”}

\section{1) QUITO}

\section{a) Quito (ciudad)}

CATEDRAL (2 rectores) - Jácome Freile de Andrade ............. 400 pesos

(Desde 1600

- Miguel Sánchez Solmerón. 400 pesos

3 rectores)

- Antonio Borja, lengua

400

-Sacristán Mayor

- Francisco de Santiago $350 "$

-Sacristán Menor ........ - Juan de Olmedo.

-Maestro de Capilla.... - Hernando de la Parra Cisneros.....

SAN SEBASTIÁN

- Francisco Durán (músico)

- Francisco Durán (músico).

500 pesos

- Francisco Durán (músico).

SAN BLAS

- Francisco Suárez Salgado, lengua .

- Francisco Suárez Salgado, lengua...

- Juan Antonio de Rueda, lengua y pred.

SANTA BÁRBARA ...... - Antonio Borja, lengua

250 pesos

- Antonio Borja, lengua

- Diego Ortuño de Larrea ................

SAN MARCOS

- Martín de Gaviria, lengua.

200 pesos

- Martín de Gaviria, lengua.............

- Pedro de Rojas 
SANTA PRISCA........... - Andrés de Mansilla, lengua .......... 300 pesos

- Andrés de Mansilla, lengua

- Hernando de Zamora

SAN JUAN DE

MACHÁNGARA ......... - Francisco del Castillo Figueroa, lengua ........................................ 250 pesos

- Alonso Mosquera.

- Luis Suárez Ponce, lengua .............

MACHANGARILLA ... - Gonzalo de Saavedra, lengua........ 200 pesos

- Gonzalo de Saavedra, lengua..........

- Gonzalo de Saavedra, lengua.........

SAN ROQUE

(desde 1600) .................. - Melchor de la Puente................... ?

VICARIA Y CAPELLANIA

DE LAS MONJAS DE LA

CONCEPCION.

(Desde 1600)

- Juan Cortés, lengua...

b) Quito (distrito)

COTOCOLLAO.......... - Fr. Juan Ramos (franciscano) 800 indios..................................... 300 pesos-c

POMASQUI................ - Fr. Juan de Paz (franciscano) 400 indios.................................. $200 \quad "$ - c

SAN ANTONIO DE

POMASQUI................. - Fr.Gabriel Martín (franciscano) 200 indios.................................. 80 " - c

CALACALI................... - Fr. Jerónimo Picón (franciscano) 200 indios.................................. 100 " - c

PERUCHO .................. - Fr. ... Palomo (franciscano)

300 indios .................................... 150 pesos-c

MALCHINGUI ........... - N ....... N ....... (franciscano)

? indios....................................... ? 
GUAYLLABAMBA.......

Y EL QUINCHE......... - Francisco Sancho de la Carrera, lengua ....................................... 350 pesos

- Francisco Sancho de la Carrera, lengua

- Francisco Sancho de la Carrera, lengua .....

CAYAMBE

- Juan Cortés, lengua.....

450 pesos

- Juan Cortés, lengua.......................

- Gregorio de Loza .........................

PINTAG

- Fr. Jerónimo de Londoño (dominico) 400 indios.

350 Ps.-c.

ALANGASI ................. - Fr.Tomás de Porras,(dominico) 200 indios 250 Ps.

AMAGUAÑA

- Fr.Gaspar de Lara (dominico) 400 indios.

UYUMBICHO (Priorato). - Fr. Domingo de Sta. María (dominico) 400 indios

300 Ps.-c.

PANSALEO DE ARRIBA - Fr. .................. (dominico) 400 indios................................ 350 Ps.-c

ALOASI

- Fr.Diego de Mediavilla (dominico) 500 indios

350 Ps.-c.

ALOAG Y

CANSACOTO

- Fr. Felipe de Ortega (dominico) 160 indios. 130 Ps.-c

CONOCOTO

- Gabriel de Peralta, lengua .... 300 pesos

- Juan de Paredes?

- Juan de Paredes

SANGOLQUI (CHILLO) - Cosme de Robles, lengua

- Cosme de Robles, lengua....

- Jerónimo de la Plaza, bachiller.....

CHILLOGALLO

- Gabriel de Jaramillo, lengua. 450 ”

- Diego Alonso de Bastidas, lengua...

- Diego Alonso de Bastidas, lengua 
GUALEA NANEGAL

MINDO (1598) CUMBAYA.

TUMBACO

PIFO Y PUEMBO . .. -

$$
\text { - Hernán García, bachiller.. }
$$$$
\text { - Hernán García, bachiller. }
$$

YARUQUI.

- Luis Suárez Ponce, lengua

- Luis Suárez Ponce, lengua

- Francisco Suárez Salgado, lengua .

TABACUNDO (1600). - Alonso de Mendoza, lengua .......... ZAMBIZA ................... - Hernando de Suárez Vinueza, lengua

- Hernando de Suárez Vinueza, lengua ............................................

- Lorenzo Díaz de Ocampo, lengua

GUAPULO (1600) ........ - N Serrano

350 pesos

350 pesos

450 pesos

300 pesos

(Provincia de Otavalo)

OTAVALO (Guardián) . - Fr. Cristóbal Martínez (franciscano),

1.200 indios (ayudado por dos frailes) 400 pesos $2 \mathrm{c}$

LA LAGUNA - Fr. Juan Jiménez (franciscano), .... 700 indios................................... 200 pesos-c

COTACACHI .............. - Fr. Antonio Martínez (franciscano), 330 indios 200 
ATUNTAQUI .............. - Fr. Miguel de Romero (franciscano), 500 indios.

200 pesos-c

URCUQUI.................. - Fr. Alonso Rodríguez (franciscano), 300 indios................................... 200

GARANQUI (Guardián) - Fr. Alonso Díaz (franciscano), 300 indios.

SAN ANTONIO

DE CARANQUI

- Fr. N.

$\mathrm{N}$.

(franciscano), 200 indios.

$150 "$

SALINAS

- Fr. N. N. (franciscano). ?

PIMAMPIRO

- Francisco Ordóñez, lengua. 450 pesos

- Pedro Ordónez, lengua....................

- Francisco Ordóńez, lengua.............

MIRA

- Francisco Rodríguez Yañez, lengua 450

- Francisco Rodríguez Yañez, lengua.

- Francisco Rodríguez Yañez, lengua

TUCAR

- Fr. Alonso López (mercedario)........

350 pesos-c

PUNTAL

- Fr. Juan de Molina (mercedario)...

300

GUACA

- Fr. Hernando del Espada

(mercedario)

300

TULCAN

- Fr. Jerónimo de Aguilar(mercedario) 300

CAGUASAQUI

- Fr. Juan de Meneses (mercedario)..

300

QUILCA (FRIAS)

- Fr. Hernando Saldaña (mercedario) 250

\section{2) PUERTO VIEJO}

PUERTO VIEJO

- Gabriel de Zuñiga, lengua

250 pesos

- Gabriel de Zuñiga,? lengua ............

- Roque Maldonado, licenciado .....

JIPIJAPA

- Rodrigo Maldonado?

- Rodrigo Maldonado

- Rodrigo Maldonado 
MANTA

- Hernando de Alarcón, lengua ...... 300 pesos

- Alonso de Cirues, doctor en Teología

- Francisco Basurto, lengua

PICOAZA.

- Fr. Pedro de Malagata (mercedario) 700 "

\section{3) RIOBAMBA (VILLA)}

a) Riobamba (centro)

RIOBAMBA................ - Bernardino de Cantos, lengua...... 600 pesos

- Bernardino de Cantos, lengua .......

- Bernardino de Cantos, lengua......

SAN SEBASTIÁN

(YANACONAS) ........... - Francisco Canceco, lengua ........... 400 pesos

- Francisco Canceco, lengua ..............

- Miguel Muñiz.

b) (Provincia de Latacunga)

LATACUNGA

(Guardián)

- Fr. Antonio Maldonado

(franciscano), 800 indios

(ayudado por otro fraile) .............. 400 Ps.2c.

MULALO..................... - Fr. Juan de la Concepción (franciscano), 700 indios.............. 200 Ps.-c.

LOS ALAQUEZ ........... - Fr. Martín de Nava (franciscano), 400 indios................................... 150

SAQUISILI................... - Fr. Alonso de Saavedra (franciscano), 800 indio.

PUJILI ......................... - Fr. Pablo de Hinojosa (franciscano), 400 indios................................... 100 Ps.1/2c.

SAN MIGUEL ……..... - Fr. Juan Farfán (franciscano), 200 indios................................... 100 Ps.1/2c. 
(Priorato de Sigchos).

HATUNSICHO

- Fr. N...... N..... (agustino) ........

350 pesos

ISINLIVI

- Fr. N...... N..... (agustino).....

350 ”

LOS CALIENTES.

- Fr. N

N...... (agustino)

350 ”

ANGAMARCA.

- Juan Andrés Campino, lengua ..

400 ”

- Juan Andrés Campino, lengua.......

- Juan Andrés Campino, lengua .....

TOMAVELA

- Fr.Manuel Rodríguez, (dominico), 700 indios.

350 Ps.-c.

TUNGURAHUA

- N.

(franciscano)

AMBATO

- Fr.Miguel de Sta.María (dominico), 500 indios.

350 Ps.-c.

PILLARO

- Fr.Pedro de Torres (dominico)

350 ”

GUANUJO

- Diego del Castillo, lengua.

200 pesos

- Diego del Castillo, lengua...............

- Francisco de Buendía.

PELILEO

- Antonio de Urbina, lengua

450 pesos

- Antonio de Urbina, lengua.

- Antonio de Urbina, lengua

QUERO

- Cristóbal Núñez, lengua

450 pesos

- Cristóbal Nuñez, lengua

- Rodrigo de Araujo

TISALEO

- Gregorio Vázquez, lengua

- Gregorio Vázquez, lengua.

- Gil Guerrero de Luna

PATATE.

- Gaspar de Chávez, lengua

- Gaspar de Chávez, lengua

- Gaspar de Chávez, lengua 
Doctrinas y Parroquias del Obispado de Quito /275

c) Provincia de los Puruáes

GUANO (Guardián) .... - Fr.Juan Gallegos (franciscano),
800 indios

(ayudado por otro fraile).

ILAPO

- Fr. Pedro Machado (franciscano

700 indios

PENIPE

- Fr.Juan de Estrada (franciscano)

300 indios

QUIMNA................... - Fr.Francisco Rabelo (franciscano), 300 indios.....

CHAPAGUA.

- Fr.N.....N....(franciscano) indios

CHAMBO (Guardián) . - Fr. Juan Muñoz (franciscano) 600 indios

(ayudado por otro fraile)....

SAN ANDRÉS

- Fr. Francisco de Torres y Fr. Juan de Castro (franciscanos), 800 indios..

LITO (CALAHOTE)... - Fr.Antonio de Villasancta (franciscano), 400 indios.

PUNGALA

- (Atiende el Guardián de Chambo), 200 indios.

PUNIN

- Fr.Lucas Hernández (franciscano), 400 indios.

LICAN.

- Francisco de Basurto, lengua

- Lorenzo Yánez, lengua

- Lorenzo Yánez, lengua

CALPI

- Juan Alvarez, lengua..

- Juan Alvarez, lengua.

- Juan Alvarez, lengua.

YALOQUIZ

- Alvaro Guerrrero Zalamea, lengua y predicador

- Alvaro Guerrero Zalamea, lengua y predicador.

- Francisco Peñafiel
250 Ps. 2 c.

400 Ps. 2 c.

100 Ps. $1 / 2$ c.

150 Ps. c. $100 "$

400 Ps. 2 c. 200 Ps. c.

Sin salario 200 pesos 450 " 450 ” 450 ” 
276 / Augusto E. Albuja

d) Provincia de Chimbo

CHIMBO

- Diego Gutiérrez.

500 pesos

- Juan Luis Pérez de Ayala, lengua...

- Juan Luis Pérez de Ayala, lengua..

SAN MIGUEL DE

CHIMBO

- Lorenzo Yánez, lengua

$450 \cdots$

- Francisco de Basurto, lengua...........

- Alonso López Mejorada

SAN LORENZO DE

GUAMARICA.

- Diego Alonso Bastidas

$450 "$

- Gabriel Jaramillo, lengua ................

- Gabriel Jaramillo, lengua ...............

AZANCOTO

- Lorenzo Díaz de Ocampo, lengua

450 ”

- Lorenzo Díaz de Ocampo, lengua..

- Alvaro Guerrero Zalamea, lengua

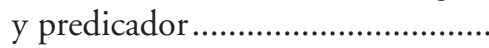

PALLATANGA

- Melchor Pérez Quivira, lengua ...

350

- Melchor Pérez Quivira, lengua......

- Melchor Pérez Quivira, lengua ....

\section{4) CUENCA}

a) Cuenca (centro)

CUENCA.

- Antonio Morán, bachiller en Teología

750 pesos

- Antonio Morán, bachiller en Teología ......................

- Antonio Morán, bachiller en Teología

YANACONAS

- Juan Sánchez Mejía, lengua y predicador

- Juan Sánchez Mejía?, lengua y predicador. idem? (Rodrigo Mejía?) 
SAN BLAS DE CUENCA

(San Sebastián)

- Rodrigo Márquez, lengua

- Rodrigo Márquez, lengua .....

- Rodrigo Márquez, lengua

b) Cuenca (distrito)

ALAUSI

- Diego de Mendieta, lengua

450 pesos

- Gabriel de Peralta, lengua.............

- Gabriel de Peralta, lengua

CHUNCHI (Sibambe). - Diego Melchor de Rojas, lengua ..
- Diego Melchor de Rojas, lengua....

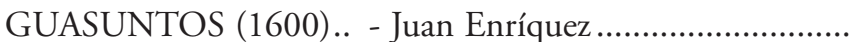

PAUTE ……................ - Fr. Juan García, (franciscano) 300 indios.

200 Ps. c

GUALASEO ................. - Fr. Juan Márquez, (franciscano) 300 indios.

200 Ps. c

VALLE ANGONSI....... - Fr. N...... N........ (franciscano) ...........indios ...........................

YACONQUE .............. - Fr. N...... N........ (franciscano) .indios ............................ ?

MOLLETURO............. - Fr. N....... N........ (franciscano) indios ............................ ?

CAÑARES ................... - Fr. N........ N......... (agustino) indios

MALACATOS ............. - Fr. N........ N......... (agustino) .indios ............................. ?

PACAYBAMBA GIRON - Pedro Arias de Avila, lengua......... 450 pesos

- Pedro Arias de Avila, lengua..........

- Andrés de Villoslada

EL AZOGUE

- Gaspar de Vega, lengua y predicador

- Gaspar de Gallegos.

- Gaspar de Gallegos 
278 / Augusto E. Albuja PACCHA..................... - Fr. Juan de Arce (dominico) ........ 280 Ps.-c.

CAÑARIBAMBA ......... - Pedro Juan de Cárdenas, lengua y predicador..................................... 450 pesos

OÑA Y NABÓN

(Caragaro 1600)............ - Juan de Campos, lengua ...............

- Juan de Campos? lengua ............... idem? (vacante?)

GUATAGSI

- Pedro Juan de Cárdenas, lengua y predicador.

- Juan Sánchez Mejía, lengua ..........

- Fernando de Villalobos, lengua.... ?

- Fernando de Villalobos, lengua......

- Fernando de Villalobos, lengua....

5) SANTIAGO DE GUAYAQUIL

a) Guayaquil (centro)

GUAYAQUIL ............... - Diego Ugarte de Velasco, lengua.. 700 pesos

- Juan de Copete, lengua y licenciado

- Juan Pérez de Herrera

b) Guayaquil (distrito)

BABA Y PIMOCHA

(Amay 1598)

- Juan Luis Pérez de Ayala, lengua..

450 pesos

- N............. N .............

- Pedro de Cárdenas, lengua y predicador

YAGUACHI ................. - Juan de Copete, lengua y licenciado 450 ”

- Luis de la Peña, lengua

- Luis de la Peña, lengua

DAULE - Fr. Vicente de Mendoza (dominico) - Fr. Juan de Zamora (dominico) .... 400 pesos - Fr.Juan de Camudio (mercedario). 400 ” 250 
Doctrinas y Parroquias del Obispado de Quito /279

\section{6) LOJA}

a) Loja (centro)

LOJA

- Hernando Martín de Cáceres.

800 pesos

- Pedro Martín.

- N..... Zurita, lengua y bachiller..

YANACONAS. - Juan de Lozada Castro, lengua.....

- Juan de Lozada Castro, lengua......

- Juan de Lozada Castro, lengua.....

CAPELLANÍA DE

MONJAS.

- Diego Pérez, lengua ...

- Diego Pérez?, lengua

- Gaspar de Vega, lengua y

predicador....

b) Loja (distrito)

SAN JUAN DEL VALLE - Luis García de Jerez, lengua

450 pesos

- Luis García de Jerez, lengua

- Luis de Jerez (idem?)

AMBOCA

- Cristóbal de Ortega, lengua.....

- Cristóbal de Ortega, lengua............

- Rafael de Alarcón, lengua y predicador.

CALBA

- Fr. Alonso Pérez (dominico)

CARIAMANGA ........... - Fr.Alonso de Saavedra (dominico).

CARRUCHAMBA ....... - Fr. Manuel Quero (dominico) ..... 400 "

GUARNAHAMA ......... - Fr. Francisco Correa (dominico).... 400 "

POZOL ....................... - Fr. Gabriel Felipe (dominico) ...... 400 "

OTUANA..................... - Fr. Diego de Guzmán (dominico). 400 " 
$\mathbf{2 8 0}$ / Augusto E. Albuja

\section{7) ZAMORA}

ZAMORA

- Francisco Castellanos, bachiller en Cánones

400 pesos

- Juan Gómez de Talavera, lengua ...

- Juan Gómez de Talavera, lengua ..

NAMBIZA

- Juan de Flandes Grimaldo,lengua

450 ”

- Juan de León, lengua ......................

- Juan de Flandes (idem?) lengua....

PURINANGA

- Zebrián de la Roca, lengua

$600 "$

- Zebrián de la Roca, lengua.............

- Alonso de Peralta

\section{8) ZARUMA}

ZARUMA.

- Pedro de Coronado

800 pesos

- Pedro de Coronado.

- Pedro de Coronado

YANACONAS

- Diego de Chávez, lengua

- Diego de Chávez, lengua

- Diego de Chávez, lengua

CANUCHAMBA (Yauna) - Juan Gómez, lengua $400 "$

- Juan Gómez, lengua

- Juan Gómez, lengua.

\section{9) ECIJA}

ECIJA (Sucumbíos)....... - Francisco de Torres, lengua

- Francisco de Torres, lengua Lo que diere

- Juan de Corvera el pueblo 


\section{0) MOCOA}

MOCOA ……............... - Rodrigo Alvarez López, bachiller . 600 pesos

- Francisco Vélez de Zuñiga, lengua .

- Rodrigo Alvarez López, bachiller .

VALLE (CUCOY) ....... - Alonso de Mendoza, lengua......... 500 pesos

- Alonso de Mendoza, lengua

- Gaspar Ribera Pacheco

\section{1) JAEN}

a) Jaén (centro)

JAEN

- Cristóbal Arias, bachiller en Teología

750 pesos

- Cristóbal Arias, bachiller en Teología ......................

- Cristóbal Arias, bachiller en Teología

b) Jaén (distrito)

CHERINOS

- Pedro Juan Quintero, lengua y predicador..................................... 450 pesos

- Pedro Juan Quintero, lengua y predicador.

- Pedro Juan Quintero, lengua y predicador.

RIO DE JAEN

- Bartolomé Rodríguez Hidalgo, lengua

- Rafael de Alarcón, lengua y predicador.

- Antonio Rodríguez Hidalgo, lengua

MOLLUPA

$-\mathrm{N}$

- N........... Thenorio

450 pesos

- N. 
GUAMBOS (Calleque y

Guartoca)

- Bartolomé Rodríguez Hidalgo, lengua...

- Bartolomé Rodríguez Hidalgo, lengua .............................................

OTRA DE LOS

GUAMBOS

- Alonso Núñez de Saavedra, lengua ?

- Alonso Núnez de Saavedra, lengua..

- Alonso Núñez de Saavedra, lengua

ACOPIÑA

- N............Milena, lengua y canonista?

- Diego de Mora?, lengua

- Diego de Mora, lengua

EL VALLE

- Fr. N...... N...... (mercedario)

450 pesos

\section{2) SAN MIGUEL DE PIURA}

a) Piura (centro)

PIURA.

- Francisco de Alvear.....

450 pesos

- Francisco de Alvear.

- Francisco de Alvear

YANACONAS

- Gabriel Pérez

- Gabriel Pérez

- Antonio Gómez

b) Piura (distrito)

CATACOAS

- Juan González Castro

800 pesos

- Juan González Castro......................

- Juan González Castro

OLMOS

- Andrés de Sepúlveda, lengua........ ?

- Andrés de Sepúlveda, lengua...........

- Andrés de Sepúlveda, lengua......... 
MOSCALAQUE ......... - Alonso Ruiz Calderón, lengua ..... ?

- Alonso Ruiz Calderón, lengua

- Alonso Ruiz Calderón, lengua .....

VALLE DE PIURA....... - Diego López Morales?.................. ?

(desde 1598 este beneficio fue suprimido)

SECHURA

- Melchor de Morales

400 pesos

- Melchor de Morales (con coadjutor)

- Melchor de Morales

MOTUPE

- Gaspar de Cáceres, lengua

600 pesos

- Andrés Gómez.

- Gaspar de Cáceres, lengua

ZAYANGA

- Alonso Nuñez de Sampedro, lengua y predicador.

700 pesos

- Alonso Nuñez de Sampedro, lengua y predicador

- Alonso Núñez de Sampedro, lengua y predicador.

PACORA

- Juan Rodríguez Ramos, lengua ....

- N............Peinado.

400 pesos

- Juan Rodríguez Ramos, lengua ....

AYABACA

- Diego de Ribera, lengua

500 pesos

- Diego de Ribera, lengua

- Diego de Ribera, lengua ...

GUANCABAMBA ....... - Miguel Fernández de Córdoba, lengua

700 pesos

- Hernando de Alarcón, lengua........

- Hernando de Alarcón, lengua......

HALAO Y PENACHI

- Alonso de Carvajal, lengua 400 pesos

- Diego López Morales....

- Alonso de Carvajal, lengua

LOMAO Y CAPALCEN - Rafael de Alarcón, lengua y predicador. 500 pesos

- Andrés González?

- Andrés González 
$\mathbf{2 8 4}$ / Augusto E. Albuja

PAITA Y COLÁN ........ - Juan de Llerena............................. 400 pesos

- Juan de Llerena..............................

- Juan de Llerena..............................

TÚMBEZ ..................... - Fr. Diego de Avila (mercedario) .... 250 pesos

\section{II.- GOBERNACIÓN DE BRACAMOROS Y YAGUARSONGO}

(Ciudades de esta Gobernación: Loyola, Santiago de las Montañas, Valladolid,Santa María de las Nieves y Sevilla del Oro (Macas)

\section{3) LOYOLA (Cumbinamá)}

LOYOLA

(CUMBINAMA) .......... - Pedro Pacheco de Centenares....... 500 pesos

- Esteban Riberos

- Pedro Pacheco de Centenares.......

LAS CABALLERIZAS.. - Diego Espínola Malatesta ............ 450 pesos

- Pedro de Orellana?.........................

- Pedro de Orellana

\section{4) SANTIAGO DE LAS MONTAÑAS}

SANTIAGO DE LAS

MONTAÑAS

- Bernabé de Ferraguto

600 pesos

- Bernabé de Ferraguto

- N.......... Ayala (con coadjutor),

CANGASSA bachiller

- Juan de Cáceres Patiño

450 pesos

- Juan de Cáceres Patiño.

- Juan de Cáceres Patiño

VUINACA (Yranaca).... - Juan Bautista Zuleta,bachiller en Cánones

450 pesos

- Diego de Morales

- Juan Bautista Zuleta, bachiller en

Cánones. 


\section{5) VALLADOLID}

VALLADOLID.

- Esteban Riberos

400 pesos

- Pedro Pacheco de Centenares

- Esteban Riberos

YAGUARSONGO

(El Valle)

- Juan de León, lengua

400 pesos

- Diego Espinola Malatesta

- Diego Espínola Malatesta

\section{6) SANTA MARÍA DE LAS NIEVES}

SANTA MARÍA DE

LAS NIEVES

- Marcos Rodríguez Lozano

400 pesos

- Marcos Rodríguez Lozano.

- Marcos Rodríguez Lozano

DOCTRINA ANEJA

DE INDIOS

- Diego de Mora, lengua

- Juan Perdomo

- Juan Perdomo?

\section{7) SEVILLA DEL ORO (MACAS)}

SEVILLA DEL ORO

(MACAS)

- Gabriel Alvaro de Minaya, lengua y predicador...................... 500 pesos

- Gabriel Alvaro de Minaya, lengua y predicador

- Gabriel Alvaro de Minaya, lengua y predicador

400 pesos

- N............. Zurita, bachiller y lengua

450 pesos

- N.............. Zurita, bachiller y lengua

- N.............. Zurita, bachiller y lengua 
$\mathbf{2 8 6}$ / Augusto E. Albuja

OTRA DOCTRINA

COMARCANA ............ - Manuel Rodríguez de Castro, lengua ....................................... ?

- Manuel Rodríguez de Castro, lengua ..........................................

- Manuel Rodríguez de Castro, lengua ..........................................

\section{III.- GOBERNACIÓN DE LOS QUIJOS (LA CANELA)}

(Ciudades de esta Gobernación: Baeza, Avila, Archidona)

\section{8) BAEZA}

BAEZA

- Pedro de Rojas

450 pesos

- Pedro de Rojas.

- Gonzalo Hernández, lengua..........

VALLE DE BAEZA

Priorato) ........................ - Fr. Francisco de Arcos (dominico).. 1.400 indios

HATUNGUIJO

- Fr. Francisco de Hinojosa (dominico)

COSANGA

- Fr. Joseph García (dominico)

LA COCA

- Alvaro (Alonso) Núnez, lengua....

- Alvaro (Alonso) Núñez, lengua......

- Alvaro (Alonso) Núnez, lengua....

HOYACACHI

- Cristóbal Marmolejo, lengua

200 pesos

- Alonso Suárez?

- Alonso Suárez

19) AVILA

AVILA

- Gonzalo Hernández, lengua.

- Gonzalo Hernández, lengua

- Lucas Cerrato de Godoy bachiller

Vale tan poco que el Rey da 50.000 maravedíes 
Doctrinas y Parroquias del Obispado de Quito / 287

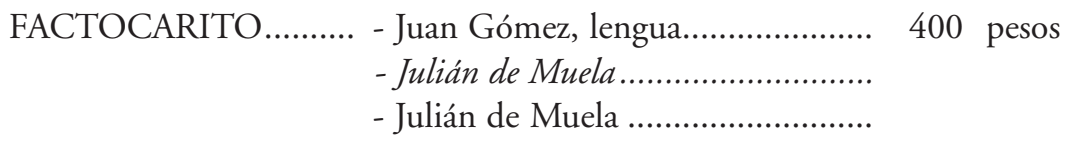

\section{0) ARCHIDONA}

ARCHIDONA

- Benito Velázquez

Vale tan poco

- Cristóbal Marmolejo, lengua ......... que el Rey da

- Cristóbal Marmolejo, lengua ....... 50.000maravedíes.

\section{IV.- GOBERNACIÓN DE POPAYÁN}

(Ciudades de esta Gobernación: Cali, Puerto de Buenaventura, Antioquia, Caramanga y Pasto; esta última pertenecía a la Diócesis de Quito)

\section{1) PASTO}

a) Pasto (centro)

PASTO

- Diego de Bracamonte,licenciado.. 1.000 pesos

- Pedro de los Reyes (sustituto)

- Diego de Bracamonte, licenciado.

SANTIAGO - N. 200 pesos

- N.............. (vacante?)

- Antonio de Benavides?, lengua.....

SAN SEBASTIÁN

- Diego Bermúdez, lengua 300 pesos

- Antonio de Benavides, lengua ........

- Pedro de los Reyes

VICARÍA Y CAPELLANÍA

DE MONJAS

- Salvador Lucero

- Salvador Lucero

- Salvador Lucero 
$\mathbf{2 8 8}$ / Augusto E. Albuja

b) Pasto (distrito)

VALLE DE PASTO ...... - Antonio de Benavides, lengua...... 300 pesos

- Diego Bermúdez, lengua ................

- Antonio de Benavides ?, lengua ...

JOANAMBU

- Francisco Vélez de Zuñiga, lengua 400 pesos

- Pedro Quiróz

- Francisco Vélez de Zuñiga, lengua

QUINA

- Blas Rosero, lengua.

400 pesos

- N........... Peñafiel.

- Jerónimo de Cepeda

CIBUNDOY

- Fr. Domingo de Cevallos,

(dominico) 400 indios

400 ps.oro c.

LOS INGENIOS.......... - Fr.Jacinto (dominico) ................... $250 "$ c.

IPIALES (Priorato) ....... - Fr.Juan de Meza, ayudado por otro fraile (dominico).

800 indios $\mathrm{y}$

PUPIALES ................... - Fr.Diego de Aguirre (dominico) ....

YLES

- Fr. Francisco García (dominico)....

750 ps.oro c.

LA LAGUNA ................ - Fr. Pedro de Montoya (dominico).. 90 ps.oro c. OTRA DOCTRINA

- Atiende el Prior de Pasto

Sin estipendio

MALES

- Fr.Gaspar Velásquez (mercedario)..

280 ps.oro

CARLOSAMA.

- Fr.Pedro de Quiroga (mercedario).

MALLANA

- Fr.Juan del Castillo (mercedario) ..

300 ps.oro

TANGUA

- Fr. Juan Guerrero (franciscano)

300 indios

200 ps.oro c.

TUQUERES

(Priorato)

- Fr. N............... (agustino) ......

500 ps.oro

CAPUIL

- Fr. N. (agustino) 
YASCUAL ………….... - Francisco González Calderón, (Mangalapún) lengua ........................................ 400 pesos

- Francisco González Calderón, lengua .........................................

- Blas Rosero, lengua .........................

LOS ABADES .............. - Andrés Moreno de Zúñiga, lengua 450 pesos

- Andrés Moreno de Zúniza, lengua.

- Andrés Moreno de Zúñiga, lengua

MADRIGAL................. - Juan de la Roca, lengua.................

- Juan de la Roca, lengua .................

- Diego Bermúdez, lengua................ 


\section{0 / Augusto E. Albuja}

\section{NOTAS:}

1 Apéndice \# 42

2 Apéndice \# 48

3 Apéndice \# 51 


\section{CONCLUSIONES}

Después de haber expuesto la evolución de la antigua Diócesis de Quito y por el trabajo que hemos realizado sobre las Doctrinas y Parroquias en la segunda mitad del siglo XVI, llegamos a las siguientes conclusiones:

$1^{a}$ Que la Diócesis de Quito, cuando apenas tenía cincuenta y cinco años de vida, no podía haber alcanzado una mejor organización, ni sus Parroquias y Doctrinas podían haber estado mejor servidas por sus sacerdotes.

$2^{a}$ Que es indudable la importancia que tuvo la Institución jurídica de las Encomiendas, principalmente en el aspecto religioso, ya que dichas encomiendas fueron el origen de las doctrinas (parroquias de indios), las cuales no sólo dejaron de depender exclusivamente de los señores encomenderos, pasando a la estricta vigilancia de los Prelados, sino que además perdieron su carácter de amovilidad y se situaron al igual que las parroquias propiamente dichas, es decir, se las consideró como beneficios perpetuos, a partir del 4 de abril de 1609, merced a la Real Cédula de Felipe III.

$3^{\text {a }}$ Que la Iglesia, mediante los Concilios provinciales de Lima y los Sínodos de Quito, adoptó las mejores medidas para organizar doctrinas y parroquias, exigiendo muchas veces a curas y doctrineros no una labor apostólica imposible, pero sí heroica, en favor del bienestar espiritual, moral, social y humano del indio.

$4^{a}$ Y finalmente, que la labor de los primeros obispos que honraron la Sede de Quito fue en extremo admirable, pues, en colaboración de todos los sacerdotes, tanto del clero secular como regular, pusieron la Diócesis en marcha hacia un futuro mejor. 
APÉNDICES 



\section{Doctrinas y Parroquias del Obispado de Quito /295}

\section{APÉNDICE \# 1}

\section{Delegación del Obispo de Panamá en favor del presbítero Antonio de Balbuena, para que se informe de los agravios cometidos por el cacique Juan Caldera contra los indios de su Repartimiento.}

\section{AGI, Quito, leg. $81 \quad$ Panamá, 14 de diciembre de 1562}

De nos, Don Fray Juan de Vaca, por la gracia de Dios y de la santa Iglesia de Roma Obispo de Panamá y reino de Tierra Firme, nombrado Castilla del Oro e Ducado de Veragua del Consejo de Su Majestad etc., por la presente cometemos a vos, el Reverendo Padre Antonio de Balbuena, nuestro cura e vicario en la ciudad de Nata, e a vos, Luis de Rojas, Corregidor de los pueblos y estancias de los indios del término e juredición de Nata, que, luego que con esta nuestra provisión fuéredes requeridos e la veáis, hagáis información e sepáis los agravios que ha hecho en los pueblos de Ola y Caldera Juan Caldera, cacique vecino e cacique del dicho pueblo de Caldera, a los dichos indios y naturales dellos, por cuanto hemos sido informados que después que por nos le fue dada cierta provisión, ha hecho agravios e cometido delitos contra los dichos indios y contra los dichos pueblos y han dizque antes que la fuese dada la nuestra provisión los había agraviado y maltratado a la hora.

Habiendo visto y sabido lo susodicho, por la presente os cometemos este dicho negocio e que hagáis las dichas informaciones, y si por ellas pareciere culpado, le castiguéis conforme a justicia, porque ahora es nuestra voluntad de revocar y revocamos la dicha provisión que ansí dimos al dicho Juan Caldera, cacique, y la anulamos y damos por ninguna dende ahora para siempre; y si viéredes que el susodicho no hace ni ha hecho su oficio de tal cacique, en servicio de Dios y de Su Majestad y provecho y utilidad de los dichos indios e pueblos, le quitaréis e nombraréis y pondréis otro cacique, tal cual convenga al servicio de Dios y de Su Majestad e provecho de los dichos pueblos, poniendo al dicho Juan Caldera, cacique, en otro pueblo donde sirva a Dios nuestro Señor, porque en eso dichos pueblos no ha hecho ni hace lo que es obligado, según servicio de Dios y de Su Majestad, para lo cual, por la presente os damos poder cumplido, tal cual en tal caso se requiere, e nos le habemos e tenemos, lo cual haréis y cumpliréis, según dicho es, so pena de descomunión mayor late sentencie, trina canónica monicione premisa, y de cincuenta pesos para la nuestra Cámara. 
En testimonio de lo cual mandamos dar e dimos la presente, firmada de nuestro nombre y sellada con nuestro sello acostumbrado e firmada del notario de nuestra Audiencia. Fecha en Panamá, a catorce días del mes de diciembre, año de mil e quinientos y sesenta e dos años.

\author{
Joannes, Episcopus \\ Castille Aurree /rubricado/ \\ Por mandato de su Señoría Reverendísima, \\ A.N- de Segovia, \\ notario apostólico.
}

\title{
APÉNDICE \# 2
}

El Presidente de la Real Audiencia de Quito, Hernando de Santillán, reparte Doctrinas a los franciscanos y señala lo que cada Encomendero deberá pagar anualmente al fraile doctrinero.
AGI, Quito, leg. 82
Quito, 22 de julio de 1565

El Licenciado Hernando de Santillán, Presidente de la Audiencia y Cancillería Real de Su Majestad, que reside en esta ciudad de San Francisco del Quito, etc. a vos, los Alcaldes ordinarios desta ciudad y Oficiales de la vuestra real hacienda y a los vecinos que tiene indios en Encomienda en términos desta dicha ciudad que de yuso irán declarados y ahora cualquier persona a quien es de yuso contenido, toca y atañe, de cualquier manera, ya sabéis cómo de la Orden de Señor San Francisco entienden en la doctrina de los naturales que de yuso irán declarados, por lo cual se les ha de dar en cada un año la limosna que por el santo Sínodo se manda dar de vistuario, vino y cera y otras cosas a los religiosos que entienden en la dicha doctrina, lo cual se ha tasado y moderado en lo que de yuso se contiene; y visto lo mucho que importa al servicio de Dios Nuestro Señor y de Su Majestad y descargo de su real conciencia y de los dichos Encomenderos y bien y conversión de los dichos naturales en que sean enseñados e industriados en las cosas de nuestra santa fe católica, para que tengan lumbre espiritual de cristianos, ha parecido que en cada pueblo y partido de los que irán declarados es- 


\section{Doctrinas y Parroquias del Obispado de Quito /297}

tén religiosos de la dicha Orden, como hasta aquí han estado, para que los doctrine y se repartió lo que cabe a pagar de limosna a Su Majestad por los indios que están en su Real Corona y a los dichos Encomenderos por la doctrina de los dichos indios conforme al tributo que por las tasas tienen al presente, en la forma y manera siguiente:

\section{LA DOCTRINA DE CARANGUE Y SU PARTIDO}

El Repartimiento del dicho pueblo de Carangue que está encomendado en Diego Méndez y Antonio de Ribera, ciento y noventa pesos

El Repartimiento de Mira que está encomendado en el menor Diego Gutiérrez, sesenta pesos

\section{LA DOCTRINA DEL PUEBLO DE OTAVALO}

CXC ps.

\begin{tabular}{cc} 
LX & ps. \\
\hline CCL & ps.
\end{tabular}

El mismo Repartimiento de Otavalo, encomendado en el Capitán Rodrigo de Salazar, doscientos y cincuenta pesos

CCL ps.

\section{LA DOCTRINA DE LATACUNGA Y SU PARTIDO}

El Repartimiento de don Sancho, encomendado en el menor Rodrigo Núnez de Bonilla, ochenta y cinco pesos El Repartimiento de Mulahaló, encomendado en Diego de Sandoval, cuarenta pesos Los Repartimientos de don Joan de Londoño, el uno de los mitimas, sesenta pesos Y el otro pueblo que se dice los Alaquez, otros sesenta y cinco pesos

LXXXV ps.

XL ps. LX ps. $\frac{\text { LXV ps. }}{\text { CCL ps. }}$

\section{LA DOCTRINA DE LOS SIGCHOS}

Los dos Repartimientos de Francisco Ponce y de Joan de la Puente, doscientos y cincuenta pesos; son de Sicho

CCL ps. 
298 / Augusto E. Albuja

LA DOCTRINA DE LOS PURUAES DE GUANO Y SU PARTIDO

El Repartimiento de Martín de la Calle, de Luisa, cien pesos C ps.

El Repartimiento de Martín de Mondragón, de los puruáes, cien pesos C ps.

El Repartimiento de Hernando de la Parra, en los puruáes,

cincuenta pesos

$\frac{\mathrm{L} \text { ps. }}{\text { CCL ps. }}$

\section{POR LA DOCTRINA DE CHAMBO Y SU PARTIDO}

El Repartimiento de Achambo, encomendado en Rodrigo de Paz, ciento y treinta pesos

El Repartimiento del Rey, que era de Joan de Padilla, en los

puruáes, ochenta pesos

CXXX ps.

El Repartimiento de Joan de Lanes, en los puruáes, cuarenta pesos

LA DOCTRINA QUE VIENE AL MONASTERIO DE

LXXX ps.

$\frac{\mathrm{XL} \text { ps. }}{\text { CCL ps. }}$ SEÑOR SAN FRANCISCO DE QUITO

Machángara, de Diego Méndez, veinte pesos

Chillogallo, de Carlos Salazar, diez pesos

Yllugua y los demás indios del Capitán Salazar de los Collaguazos, ocho pesos

Pillajo de Quito, del Capitán Salazar, veinte pesos

Unos anaconas de Añequito, de Joan de Larrea, cinco pesos

Cotocollao, del menor Pedro Martín Montanero,quince pesos

Cotocollao, de Juan Mosquera, quince pesos

Cotocollao, de Sancho de Paz Ponce, veinte y un pesos

Zámbiza, de Francisco de Jerez, diez y siete pesos

El pueblo de Conocoto, de don Francisco Atabalipa, cinco pesos

El pueblo de Guangopolo, de Francisco Hernández, seis pesos

Ambaya, del Rey, que se dice de Tanta, seis pesos

XX ps.

$\mathrm{X}$ ps.

Cotocollao, de Pedro Muñoz, veinte y dos pesos

VIII ps.

XX ps.

$\mathrm{V}$ ps.

$\mathrm{XV}$ ps.

$\mathrm{XV}$ ps.

XXI ps.

XVII ps.

$\mathrm{V}$ ps.

VI ps.

VI ps.

$\frac{\text { XX II ps. }}{\text { CLXXXI ps. }}$ 


\section{LA DOCTRINA DEL VALLE DE POMASQUE}

Nivei, que es de Francisco de Jerez, ocho pesos

VIII ps.

Calacalí, que es del menor de Machín, y Pululagua,

veinte y ocho pesos

XXVIII ps.

Pomasque de Aguilar, nueve pesos

Pomasque del Capitán Sandoval, ocho pesos

Pomasque de Antonio de Rivero, ocho pesos

Pomasque de Hernando de Villanueva, once pesos

Pomasque de Diego Gutiérrez, siete pesos

Pomasque de Antón de Sevilla, dos pesos

Pomasque del menor Rodrigo Núñez de Bonilla,diez pesos

Pomasque de Collaguazos, del Capitán Salazar, veinte y

ocho pesos

Pomasque los Cañares, de Ponce, veinte y VII pesos

Del menor de Pedro Martín Montanero, junto de Nibli, cinco pesos

Pomasque de Sancho de Paz, cinco pesos

Pomasque de doña Ana de Valverde, tres pesos

IX ps.

VIII ps.

VIII ps.

XI ps.

VII ps.

II ps.

$\mathrm{X}$ ps.

XXVIII ps.

XXVII ps.

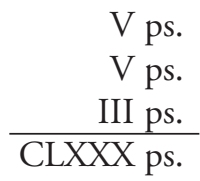

Los cuales dichos partidos, en la forma arriba declarados, se han de doctrinar por los religiosos de la dicha Orden del Señor San Francisco y las contías (sic) de pesos de oro que van repartidas se les han de dar en cada un año de los que estuvieren ocupados en la dicha doctrina para el vistuario, vino y cera, y lo demás que por el santo Sínodo se manda; y conforme a él y los dichos pesos de oro se han de entregar al Síndico del Monasterio desta dicha ciudad o a quien su poder hobiere, y porque conviene que la paga - limosna de las dichas Doctrinas se haga sin haber inconveniente ni dilación, para que vaya adelante e por la falta dello no se deje de hacer, dí el presente por el cual, en el entretanto que otra cosa se provee, mando que el dicho Síndico o a quien su poder hobiere pueda cobrar y cobre los dichos pesos de oro que arriba van declarados de la Doctrina de cada partido de los Oficiales de la real hacienda, por lo que toca a los indios que está en cabeza de Su Majestad y de los dichos Encomenderos lo que allardes le pertenece, lo cual se ha de cobrar de seis en seis meses la mitad, y si luego no lo dieren e pagaren, lo pueda cobrar y cobre de los pesos de oro que por las tasas son obligados a pagar los dichos naturales, con lo cual les acudan los principales 
e indios de los dichos pueblos, e con este mi mandamiento e su traslado e carta de pago del dicho Síndico e de quien su poder hobiere, los dichos Oficiales reales y Encomenderos pasen en cuenta del tributo a los dichos indios lo que ansí en la dicha razón dieren e pagaren; todo lo cual ansí se haga y cumpla, so pena de doscientos pesos de oro, la mitad para la Cámara de Su Majestad y la otra mitad para retablos y ornamentos de los dichos pueblos, de la cual dicha pena mando que las dichas justicias lo hagan guardar y cumplir como arriba va declarado. Fecho en Quito, a veinte e dos días del mes de julio de mil y quinientos y sesenta y cinco años.

\section{El Licenciado Hernando de Santillán/rúbrica/ \\ Por mandato de su Señoría, \\ Antonio de León /rúbrica/.}

\section{APÉNDICE \# 3}

\section{Licencia para que el presbítero Antonio de Balbuena pueda confesar en todo el Obispado de Guamanga.}

\section{AGI, Quito, leg. $81 \quad$ Guamanga, 25 de marzo de 1566}

El Bachiller Baltazar Sánchez, Juez, Visitador General y examinador en esta ciudad de Guamanga y su distrito, por el Muy Magnífico y Muy Reverendo Señor, el Canónigo Esteban Villalón, Provisor y Vicario General en este Obispado etc., habiendo examinado, conforme a lo mandado por el santo Concilio, al Reverendo Padre, el Bachiller Antonio de Balbuena, clérigo presbítero, y hallándole hábil e suficiente, le mandó dar e dio licencia para que pueda confesar todas e cualesquier personas que con él se quisieren confesar, y lo firmó de su nombre. Que es fecha en la ciudad de Guamanga, a veinte e cinco días del mes de marzo de mil e quinientos e sesenta e seis años.

El Bachiller Baltazar Sánchez.

Por mandato del Juez Visitador,

Joan de Herrera, notario. derechos IX pesos. 


\title{
Doctrinas y Parroquias del Obispado de Quito /301
}

\section{APÉNDICE \# 4}

Licencia que el Visitador de la ciudad de San Juan de la Frontera de Guamanga concedió al presbítero Antonio de Balbuena para que pudiera ausentarse de la Diócesis y radicarse en el Arzobispado de Lima .

\author{
AGI, Quito, leg. $81 \quad$ Guamanga, 27 de enero de 1567
}

Don Diego Flores de Loazes, Juez, Vicario y Visitador desta ciudad de San Juan de la Frontera de Guamanga y su jurisdicción etc, hago saber a todos los señores que la presente vieren cómo el Muy Reverendo Padre Bachiller Antonio de Balbuena, clérigo presbítero, me hizo relación diciendo que él se quiere ir de esta ciudad e Obispado al Arzobispado de la ciudad de los Reyes e a otras partes porque se le ofrecían negocios.

Me pidió le mandase dar mi licencia, y visto por mí ser justo, por la presente doy licencia al dicho Bachiller Antonio de Balbuena para que pueda salir e irse desta dicha ciudad y su Obispado al dicho Arzobispado de los Reyes y a donde a él le pareciere. Y por ésta hago cierto a los dichos señores que el dicho Bachiller Antonio de Balbuena ha dado y dio muy buena cuenta de los curazgos que ha tenido a cargo en este distrito, de los naturales de ella, dando muy buen ejemplo y vida y fama y buen ejemplo; y a mí no me consta que el susodicho vaya suspenso, ni excomulgado, ni irregular, ni lleva otro ninguno impedimento que le estorbe a hacer el oficio sacerdotal. En testimonio de lo cual di la presente, firmada de mi nombre y refrendada del infrascripto notario. Dada en la ciudad de Guamanga, a veinte e siete días del mes de enero de mil quinientos e sesenta e siete años.

Por mandato del Señor Juez y Vicario e Visitador, Bartolomé Berrocal, notario apostólico /rubricado/ Diego Flores /rúbrica/. 
302 / Augusto E. Albuja

\title{
APÉNDICE \# 5
}

Informe que el Ilmo. Pedro de la Peña presentó al Presidente Castro en la ciudad de los Reyes (Lima) acerca de la situación de la Diócesis de Quito.

\author{
AGI, Patronato, leg. 189, Ramo 34
}

Año 1567

Muy Ilustre Señor:

La obligación que al servicio de Su Majestad y al descargo de su real conciencia tenemos y el amor que Vuestra Señoría muestra tener a en todo acertar como se ve y nos obliga a dar esta breve memoria de las cosas que nos parece convernían al servicio de Dios Nuestro Señor y de Su Majestad y al descargo de su real conciencia y bien y pro de la tierra y naturales della, de los cuales hemos sido avisados o de la mayor parte dellas por peticiones y memoriales que en este santo Concilio se han dado, deseando, como deseamos, que en todo Vuestra Señoría acierte.

Lo primero, que Vuestra Señoría mande y procure se guarden las Cédulas de Su Majestad acerca de que no vengan indios de tierras frías a tierras calientes, ni, por el contrario, a ninguna cosa de trabajo, ni que vengan a las ciudades de tan lejos a servir, ni que, contra su voluntad, los hagan ir a la coca, pues para todo ello hay Cédulas de Su Majestad que tanto lo encargan.

Iten, Vuestra Señoría mande dar orden que los indios que se alquilaren cobre ellos la plata que les dan por su trabajo y no los caciques ni alguaciles, y el trabajo y carga que se les diere sea moderada.

Iten, para la paga de los indios y para otros muchos bienes que dello se seguiría, convernía se cumpliese la Cédula de Su Majestad, en que manda se haga moneda en estos reinos.

Iten, porque en muchas partes de los Obispados destos reinos hay indios alzados y otros por conquistar y Su Majestad ha proveído cristianísimamente que a los tales se les persuada que vengan de paz a la obediencia de la santa madre Iglesia y de la suya, dando a los tales libertad que por diez años no tributen ni sirva a nadie; Vuestra Señoría le mande ejecutar en estos reinos, dándola a los Obispos para que con los religiosos y clérigos lo intenten y ponga por ejecución una tan santa obra.

Iten, que, cuando está la mayor parte, que de los indios que tributan, por bautizar, Vuestra Señoría mande dar orden en que a estos tales, por un año, 


\section{Doctrinas y Parroquias del Obispado de Quito /303}

que se ocupen en aprender la doctrina y lo necesario para se bautizar y ser cristianos, no tributen porque haciendo esto aprovecharán muchos medios que en este santo Concilio se han dado para que los dichos indios sean cristianos.

Iten, se provee en el correr de los toros que, ya que no se puede quitar, no se haga con tanto daño de los indios, ansí en el hacer de los cosos como en las muertes que en el lidiar de los toros se les siguen.

Iten, se pide que en los pueblos de los indios, ni en sus términos, no entren otras justicias con varas ni alguacil si no fuere el Oidor que los visitare o su Corregidor, porque reciben de los tales grandes agravios.

Iten, en algunas partes en los caminos reales hay indios que llaman chaquis, a legua y media, para llevar cartas sin ser pagados, y están con mucha vejación de los pueblos que los sustentan.

Iten, conviene mucho Vuestra Señoría provea que un indio o dos o más, según el pueblo fuere, de cada pueblo se le dé vara y con qué se sustente para que son muy necesarias para andar en busca de los enfermos y de los que nacen, para dar aviso a los sacerdotes porque no mueran los tristes indios como mueren muchos sin sacramentos.

Iten, porque las más de las iglesias o todas son paupérrimas, les haga Vuestra Señoría merced de los dos novenos para el ornato y sustento de las cosas necesarias, tal como Su Majestad hasta agora lo ha hecho y se tiene cierto lo confirmará y terná por bien y ansí se le suplica por este santo Concilio.

Y Vuestra Señoría mande advertir a los señores Oidores que visitan y tasan los indios, que supuesto que Su Majestad quiere que el tributo de los indios sea personal y no real, que nos parece excesivo tributo, de sólo el sudor y trabajo de indios, tres y cuatro pesos y en partes cinco que les echan; y nos parece sería moderado que en los llanos tributasen cada indio valor de dos pesos y en la sierra, donde ordinariamente son más pobres, a peso y medio.

Iten, se pide que se guarde la Cédula de Su Majestad en que los indios tributen de lo que en su tierra cogen; y para ello, les repartan y den suficientes tierras, y esto no se conmute en oro ni plata, a lo menos la mayor parte, porque haya provisión bastante para ellos y para la república.

Iten, que en las visitas no hagan tributarios a los caciques y a sus hijos y sucesores de legítimo matrimonio. Que no se permita que a los caciques y señores se les quiten los indios y las tierras que tienen del señorío para su sustento y el gobierno del pueblo, y era entre ellos y es como de iure gentium dado por las repúblicas y están en la posesión dello y lo estuvieron sus pasados. Que los 


\section{4 / Augusto E. Albuja}

caciques y señores sean amparados en sus señoríos; y donde no los hay propios, se busquen y sean restituidos en el señorío con todo lo que les pertenece.

Iten, Vuestra Señoría mande dar orden que los caciques y señores no se sirvan de mujeres mozas porque ordinariamente las tienen por mancebas y son mal casados con sus mujeres por ellas.

Iten, a causa de quitarles los propios indios, se sirven los dichos caciques y principales de indios por fuerza como yanaconas, sin pagarles nada ellos ni la comunidad.

Iten, conviene se provea que ningún cacique ni indio principal, en perjuicio de los indios, tenga compañías en tratos ni en rescates, ni en otras compras ni ventas, con ningún español por los grandes daños y vejaciones que a los indios particulares se siguen.

Iten, convendría proveer que los caciques ni principales no sean llamados tan fácilmente de las justicias, Corregidores y Alcaldes ordinarios a los pueblos de españoles porque, allende del daño que se les sigue en sus haciendas, causan grandes vejaciones y daños en los indios e indias que con ellos traen para su servicio.

Iten, Vuestra Señoría mande dar orden cómo los indios curacas y principales, cuando hubieren de ir con algún pleito al Audiencia, trayan carta del Corregidor o del clérigo o religioso que los tiene a su cargo, de los cuales la Audiencia primero se informe y ellos examinen si conviene se intente el tal pleito, porque los tales no inventen pleitos como lo suelen hacer en daño de las comunidades.

Iten, se procure, conforme a la Cédula de Su Majestad que para ello hay, que los que tienen indios encomendados tomen estado porque, allende de que conviene al servicio de Su Majestad, sería muy gran servicio de Dios Nuestro Señor y sería evitar grandes males de amancebamientos y malos estados que en los tales ordinariamente están y mueren, como cada día se ve.

Iten, Vuestra Señoría mande poner remedio con todo rigor en lo de los amancebamientos, en lo que es de parte de la justicia real, porque, cierto, es lástima ver la perdición que en esto hay en las repúblicas y todos claman y nadie los remedia.

Iten, Vuestra Señoría y la Real Audiencia manden con todo rigor que los casados en España o en otros reinos o provincias se vayan a sus mujeres o las vayan ellos a traer porque engañan con el tiempo que piden y fianzas que dan con lo que se entretiene como parece. 


\section{Doctrinas y Parroquias del Obispado de Quito /305}

Iten, conforme a la Cédula de Su Majestad, Vuestra Señoría sea servido dar provisión general para que los sacerdotes que doctrinan a indios reciban el salario o vestuario de los indios antes que entreguen el tributo a sus Encomenderos, teniendo cédula del Prelado que el tal sacerdote ha residido el tiempo que en la cédula dijere, para que en el cobrar no tengan diferencias con los Encomenderos y en pagar se tenga cuenta con los días que el sacerdote ha faltado de la Doctrina para quitárselos.

Iten, conviene como cosa muy importante, Vuestra Señoría dé una provisión para que la parte que cabe el sacerdote que está en la Doctrina, aunque el sacerdote no resida o haya faltado algún tiempo, no se saque ni quite de la comunidad ni lo lleve el Encomendero, sino que esté allí guardado o haya un depositario dello abonado, para que acuda a quien el Obispo le dijere con ello para el bien y utilidad de los ministros de la Doctrina o ornato de la iglesia.

Vuestra Señoría mande proveer que en los pueblos despañoles que se van poblando entre los indios, que hay muchos que por su pobreza agora al principio no tienen de qué mantener a los curas y vicarios que allí se han de poner, ni los diezmos de las principales iglesias alcanzan para ellos, se les dé a los dichos curas de la hacienda real suficiente salario con que se sustenten, porque de ninguna otra parte hay donde, y ansí están los más de los dichos pueblos sin ministros.

A Vuestra Señoría le consta el mal que de la coca se sigue, ansí en el beneficio della, que parecen tantos que no tienen número como el fin y uso para que la tienen, que es para sacrificar y para sus supersticiones y hechicerías; Vuestra Señoría, por amor de Dios lo mande remediar por los grandes males que con el remedio se evitarían.

Con grande instancia piden a Vuestra Señoría mande guardar las Cédulas de Su Majestad en que los Encomenderos no estén en sus pueblos ellos, ni sus hijos, ni criados, mestizos, ni mulatos, ni negros, por los grandes daños que a los indios se les siguen y ofensas que a Dios Nuestro Señor se hacen, como cada día se ve y por espirencia.

Iten, que los dichos Encomenderos no tengan estancias de ganados ni granjerías ni contrataciones en sus pueblos.

Iten, que ningún Encomendero pueda pedir ni llevar tributo adelantado a sus indios.

Iten, se dé orden para que los indios con mejor voluntad se junten, que es el principio de todo su bien espiritual y temporal; que una legua del pueblo 
donde se juntaren no haya sitios destancias ni corrales de ganados menores despañoles y a dos leguas de ganados mayores, y los que hubiere en esta distancia los trayan sus dueños con guardas propias, porque les quede a los tristes indios algún consuelo para poder sembrar y coger sus semillas.

Iten, se debe proveer que ningún Alcalde mayor, ni Corregidor, ni ministro de justicia que estuviere entre los indios, no tenga el tal granjería alguna de crianza ni labranza ni trato alguno entre los indios ni con los indios donde tuviere el tal cargo o ministerio.

Iten, se nos ha pedido se proponga que en ninguna ciudad, ni otros pueblos, ni provincia, haya Corregidor ni Alcalde; mejor que sea vecino de aquel pueblo, ni tenga allí su habitación ni asiento, ni sea Encomendero de los tales indios, ni sean de algún pariente suyo, por los grandes daños que dicen desto se sigue.

Iten, de las cosas que en este nuevo orbe tienen falta es de que hay pocos que miren por ellos para les hacer bien y a todos los miramos para nos aprovechar dellos; y si los Corregidores, que Vuestra Señoría pone, hicieren su oficio mirando por los indios sin hecerles nuevas vejaciones, sería santo y bueno y ansí los dejamos a que Vuestra Señoría lo vea, pero el añadir a los indios el salario y comida para los Corregidores, nos parece que es gran vejación de los indios.

También se nos quejan muchos celosos del servicio de Dios de la perdición que hay en esta república acerca de los negros y negras que traen sus amos agaña; Vuestra Señoría, por amor de Dios, lo mande remediar, que no sea con tantas ofensas de Dios Nuestro Señor.

Vuestra Señoría sea servido mandar que los intérpretes del Audiencia sean pagados de la caja real de Su Majestad con buen salario y no puedan llevar cosa alguna de indio particular, ni de comunidad, so graves penas que se ejecuten por los inconvenientes grandes que dello se siguen.

El Obispo de Quito/rubricado/. 
Doctrinas y Parroquias del Obispado de Quito /307

\section{APÉNDICE \# 6}

Autorización dada al presbítero Antonio de Balbuena, en ese entonces párroco de la ciudad de Cuenca, para que conozca la causa e imponga saludable castigo al alguacil mayor por haber injuriado de obra a algunos religiosos mercedarios.

AGI, Quito, leg. $81 . \quad$ Loja, 17 de febrero de 1568

Fray Mateo de la Cuadra, presentado en santa Teología, Comendador del monasterio que la Orden de Nuestra Señora de las Mercedes tiene en la ciudad de Trujillo, por la presente doy todo mi poder cumplido e bastante, según que de derecho le debo e puedo dar, e cometo todas mis veces para que el Muy Reverendo Señor, el Bachiller Balbuena de Paz, cura e vicario de la ciudad de Cuenca, conozca de la causa e culpa que contra el alguacil mayor de la ciudad de Cuenca resulta por la información hecha por el Muy Reverendo Padre Fray Domingo de Ugalde, Visitador de la dicha ciudad, por haber puesto el dicho alguacil mayor manos violentas en religiosos de la dicha Orden perteneciente a mi jurisdición, e le cometemos, asimismo, todas mis veces para que, habiéndole dado pertenencia (sic) saludable, le pueda absolver e absuelva de cualquiera descomunión e gravamen en que el dicho haya incurrido, con tal condición que, habiendo sido la culpa pública, la penitencia sea pública y in fatie populi; y de otra manera, y no lo haciendo ansí, niego y anulo y doy por ninguna esta dicha comisión, que es fecho en esta ciudad de Loja, a 17 de febrero. Va firmada de mi firma y sellada con el sello de la Orden. En testimonio de verdad,

Fr. Matheo Laquadra/rubricado/. 


\title{
APÉNDICE \# 7
}

\section{Provisión del beneficio curado de Pallatanga y sus anejos en favor del presbítero Antonio de Balbuena.}

\author{
AGI, Quito, leg. 81 \\ Quito, 23 de marzo de 1568
}

Yo, el Chantre don Diego de Salas, Provisor e Vicario General en esta ciudad y Obispado de Quito por el Muy Ilustre e Reverendísimo Señor, el Maestro Don Fray Pedro de la Peña, Obispo de esta dicha ciudad y Obispado, inquisidor ordinario y del Consejo de Su Majestad, mi Señor, acatando la habilidad y suficiencia de vos, el Muy Reverendo Bachiller Antonio de Balbuena, por la presente, en cuanto la voluntad de su Señoría Reverendísima del Obispo, mi Señor, e mía, en su nombre, fuere, vos proveo y nombro por cura e vicario del pueblo de Pallatanga y Dotrina dél e de los demás pueblos de la dicha Dotrina, según que la tuvo Diego Pérez, clérigo, para que, como tal cura, entendáis en la conversión y dotrina de los naturales de los dichos pueblos y les enseñéis las cosas de nuestra santa fe católica y administréis los santos sacramentos e divinos oficios, de cualquier calidad que sean, e oir de confesión a cualesquier personas de cualquier condición y estado que sean, ansi españoles como naturales, que estuvieren y residieren en la dicha Dotrina, y los absolver y absolváis de cualesquier pecados, crímenes e delitos que hobieren cometido, cuanto de derecho podáis y debáis, que para ello vos cometo los casos ordinarios de su Señoría Reverendísima e vos doy por cumplido.

E, como tal vicario, podáis conocer e conozcáis de cualesquier pleitos ceviles e criminales que se ofrecieren e ante vos ocurrieren, y los sentenciar y llevar vuestras sentencias a efecto si de vos no fuere apelado, excepto los casos de herejía o especie della o matrimonios, cuanto a la separación, que en los dichos casos haréis las informaciones y procesos; e con los culpados, y secuestados sus bienes, presos los remitiréis a su Señoría Reverendísima o a mí, en su nombre. E si de vos fuere apelado, otorgaréis las apelaciones en los casos que de derecho hobiere lugar apelación para ante su Señoría Reverendísima, que para lo que dicho es y lo a ello tocante, anejo y dependiente vos doy poder e comisión en forma cual de derecho se requiere.

Y os encargo que con toda deligencia e cuidado entendáis en la instrución e conversión de los dichos naturales y los tratéis con benignidad y no azotaréis ni trasquiléis ninguno si no fuere procediendo contra ellos conforme a derecho. 


\section{Doctrinas y Parroquias del Obispado de Quito /309}

E mando a cualesquier personas, de cualquier calidad y condición que sean, que por tal cura e vicario vos hayan y tengan, e vos guarden todas las honras y preheminencias que por razón de los dichos oficios debéis haber y gozar; e mando que hayáis e llevéis de salario, en cada un año que estuviéredes en la dicha Dotrina, lo que se suele dar y que lleva el dicho Diego Pérez, clérigo, lo cual cobraréis de los dichos Encomenderos o de los dichos naturales, e con vuestra carta de pago se les reciban e pasen en cuenta; e más, llevaréis el camarico y comida que los dichos naturales suelen dar. En testimonio de lo cual, mandé dar e di la presente, que es fecha en la ciudad de Quito, a veinte y tres días del mes de marzo de mil e quinientos y sesenta y ocho años.

$$
\begin{gathered}
\text { El Chantre de Quito /rubricado/ } \\
\text { Por mandato del Señor Provisor, } \\
\text { Jácome Freile, } \\
\text { notario apostólico /rúbrica/. }
\end{gathered}
$$

\section{APÉNDICE \# 8}

\section{Auto de los Señores de la Real Audiencia de Quito sobre las Doctrinas.}

\section{AGI, Patronato, leg. 189, Ramo 34 Quito, 12 de octubre de 1568}

En la ciudad de San Francisco de Quito, doce días del mes de octubre de mil e quinientos e sesenta y ocho años, en la sala del Audiencia e Cancillería Real de Su Majestad que en esta ciudad reside, se juntaron los Señores: Presidente e Oidores desta Real Audiencia y el Reverendísimo Señor Don Fray Cristóbal de la Peña, Obispo deste Obispado, y fray Domingo Valdés, Prior del monasterio de Señor Santo Domingo desta ciudad, que dijo tener poder y facultad para las cosas tocantes a las Doctrinas que en esta provincia están a cargo de la dicha Orden, y fray Juan Cabezas de los Reyes, Guardián del convento de Señor San Francisco desta ciudad, que dijo ser Comisario desta custodia y tener facultad para lo tocante a las Doctrinas que en ella hay a cargo de los religiosos de su Orden, y fray Pedro Martínez, Comendador del monasterio de Nuestra Señora de la Merced desta ciudad, que dijo tener poder e facultad para lo tocante a las Doctrinas que están a cargo de los religiosos de su Orden, y, asimesmo, don Pedro 
Rodríguez de Aguayo, Arcediano de la santa Iglesia desta ciudad, y don Diego de Salas, Chantre y Provisor deste Obispado, y fray Rafael de Sigura y fray Domingo de Ugaldes, frailes de la Orden de Santo Domingo, y fray Jodoco Rique, de la Orden de San Francisco, y fray Andrés Gómez, de la Orden de la Merced, los cuales se juntaron con los dichos Señores Presidente e Oidores, Obispo y Prelados, porque, aunque conforme a la Cédula Real de Su Majestad de que yuso se hará relación, no son llamados sino los Prelados de las Ordenes para se hacer con más deliberación y consejo, los llamaron y, estando así juntos por los dichos Señores, Presidente e Oidores, se propuso y dijo cómo Su Majestad, por una su Real Cédula cuya data es en el bosque de Segovia, a tres de septiembre de mil e quinientos y sesenta y cinco años, manda que se trate y dé orden en la que han de tener los religiosos y curas en la administración de los santos sacramentos a los naturales y en poner los curas, y que para ello se habían juntado, conforme a la dicha Cédula Real que allí se leyó, y aunque no entraban personas, los Prelados Provinciales de las Ordenes, parecía que bastaba los dichos por Guardián y Comendador que allí estaban para tratar lo tocante a esta provincia e que por decir ellos que tenían facultad para tratar todo lo tocante a lo desta provincia, y, asimesmo, el dicho Señor Obispo y Dignidades decían que se tratase en general todo lo tocante a todas las Doctrinas, asi de religiosos como de clérigos, les encargaban y encargaron que traten sobre ello lo que les parezca que conviene para que, vistos sus pareceres, se dé orden y asiento por los dichos Señores, Presidente y Oidores, Obispo y los demás Prelados, en lo que se deba hacer.

Y los dichos Prelados, Dignidades y sacerdotes de suso nombrados hablaron y platicaron en ello y dieron sus pareceres, conforme a lo que dijeron entender en Dios y en sus conciencias, y después de conferido y platicado sobre lo susodicho, se vinieron a resolver de un acuerdo que parece en que por agora y hasta que otra cosa parezca convenir proveerse, conforme a la comodidad de los tiempos y sucesos en lo que toca a los naturales que han de tener a cargo y dotrinar un sacerdote, clérigo o religioso, se guarde esta orden, que porque en algunas provincias y partes desta tierra los naturales están poblados en pueblos y viven juntos y otros tienen sus tierras fértiles y gruesas, y conforme a esto tienen hechas tasas de lo que han de dar a sus Encomenderos, de suerte que el Encomendero tiene y lleva dellos buen tributo, y en otras partes los dichos naturales no tienen tan buenas tierras y otros están divisos y apartados y en otros no hay tanta grosedad en las tasas: que en las partes y lugares donde fuere la tasa tan gruesa que se pueda cómodamente hacer lo que de yuso se declara, donde lo tu- 


\section{Doctrinas y Parroquias del Obispado de Quito /311}

vieren los naturales tan apartados que no se puedan buenamente juntar, tenga a cargo un sacerdote, clérigo o religioso , hasta número de ochocientos indios tributarios y no más; y donde la tasa no fuere tan gruesa y donde no hobiese el inconveniente de estar apartados, tenga a cargo hasta nuevecientos indios tributarios el tal sacerdote, y a lo más largo hasta mil indios y no más; y deste número no se exceda. E todos los dichos Señores, Presidente y Oidores, Obispo, Prelados, Dignidades y sacerdotes que estaban presentes, dijeron que lo susodicho les parece cosa tan conviniente por el presente y que así se debe cumplir hasta que otra cosa parezca que conviene hacerse, y que, conforme a este número de indios, se guarde, cumpla y ejecute lo contenido en la Cédula de Su Majestad y, si para ello fuere necesario, se libren en esta Real Audiencia las provisiones que convinieren y se pidieren. El Doctor Loarte-F.P.Epíscopus Quitensis- El Licenciado Pedro Rodríguez Aguayo- El Chantre de Quito -Fray Domingo de Valdés, Priory Fray Rafael de Sigura- Fray Juan de los Reyes, Guardián y Comisario- Fray Pedro Martínez, Comendador- Fray Domingo de Ugalde- Fray Jodoco RiquezFray Andrés Gómez.

Yo, Diego Suárez, escribano de Cámara de Su Majestad Real en su Audiencia e Cancillería de San Francisco de Quito, fui presente a lo que dicho es y lo fice escribir aquí mi signo en testimonio de verdad.

Diego Suárez /rubricado/.

\section{APÉNDICE \# 9}

Instrucción presentada al Rey Felipe II para darle a conocer las múltiples necesidades de la Diócesis de Quito, al mismo tiempo que se le sugería varias soluciones en el buen gobierno de las Indias.

AGI, Patronato, leg. 189, Ramo 34 Quito, 15 de febrero de 1569

$$
\text { C. R. M. }
$$

Alonso de Herrera y Fray Domingo de Ugalde, en nombre del Maestro Don Fray Pedro de la Peña, Obispo de la ciudad de Quito, digo que al servicio de Dios nuestro Señor y de Vuestra Majestad y bien general de las repúblicas de 


\section{2 / Augusto E. Albuja}

la provincia del Quito y naturales della, conviene mandar proveer lo contenido en los capítulos desta instrucción. A Vuestra Majestad, en el dicho nombre, suplicamos provea en cada uno dellos lo cual convenga al servicio de Dios nuestro Señor y a Vuestra Majestad, vecinos y naturales de la provincia de Quito.

1.- Primeramente, que los Sínodos provinciales se celebren de ocho en ocho años, atento que los Obispados están muy lejos de Lima, cabeza del Arzobispado, y los caminos muy malos y peligrosos, y que para que esto haya efecto, se saque Bula de Su Santidad y se mande confirmar y guardar y ejecutar con todo rigor el Sínodo provincial que se celebró en la ciudad de los Reyes; y para la ejecución y cumplimiento della, se despachen las proviciones necesarias. (En nota: Tráigase lo proveído en el Sínodo).

2.- Iten, que los tales Sínodos provinciales que se tuvieren, no se prolonguen de tres meses arriba y que mande que los Prelados que se hallaren en el Concilio provincial se junten de ordinario mañana y tarde, como se hace en las Reales Audiencias, y los Prelados que se hallaren en los lugares diputados en el dicho Sínodo provincial desinen, consulten y determinen, aunque falte algunos, como si estuviese presente, porque en los tales Concilios no se trata ninguna cosa ni determinación de la fe y las cosas de costumbres; todos los Prelados las traen tendidas y averiguadas de sus Obispados. (En nota: No hay necesidad, con ser cosa que importa mucho, porque el Sínodo pasado duró año y medio y aún más).

3.- Otro sí, que Vuestra Majestad sea servido de haber de Su Santidad Bula y declaración para que los Sínodos provinciales deshagan los agravios y fuerzas que los Prelados hacen, ansí Obispos como Arzobispos, por estar tan lejos el Sumo Pontífice; y el remedio de las dichas fuerzas y agravios a cuya causa zueldan muchos agravios sin haber quien los desagravie, entiendo en no castigar a la persona ni tratar de culpas personales cuanto a los Prelados, como el Concilio tridentino lo dispone. (En nota: Que por agora no conviene tratar desto, que antes importa muy mucho por estar el remedio de los agravios muy lejos cuando el $\mathrm{Pa}$ pa y el Rey).

4.- Iten, que Vuestra Majestad sea servido de mandar no de eche derrama para las cosas de oficiales y ministros de las costas necesarias al Concilio provincial sino que el Arzobispo, atento que será en su casa y no hace costas extraordinarias como los Obispos, sean obligados a poner oficiales y letrados necesarios para el dicho Concilio provincial a su costa, para lo cual bastarán dos mil pesos, dándosele orden referida de que no dure más de tres meses o proveer Vuestra Ma- 


\section{Doctrinas y Parroquias del Obispado de Quito /313}

jestad de la orden que se ha de tener para los dichos gastos de manera que las iglesias y clerecía no queden con tal susidio. (En nota: El Arzobispo y Obispo provean en esto lo que convenga).

5.- Iten, Vuestra Majestad sea servido de proveer dos Obispados que en aquellas partes vacaren, con la brevedad posible, porque de la delación se han siguido y siguen grandes inconvenientes y daños y necesarios de remedio, como se ha entendido y entiende por el Obispado del Cuzco y Panamá cuanto tiempo han estado vacos. (En nota: Que se tendrá todo quitado desto).

6.- Iten, que por cuanto las iglesias de aquellas partes tienen necesidad grande de servicio por no residir en ellas más que solos los prebendados, de los cuales, de ordinario, de vacante, enfermedad o ausencia, falte la tercia parte y conviene muy mucho a vuestro real servicio para descargo de la real conciencia haya suficiente servicio, mande expresamente que los prebendados que de nuevo se proveyeren, se presenten dentro de dos años en el Cabildo de la Iglesia donde fueren proveído, y pasado el término, sea ninguna la tal provisión, porque, proveyendo así, habrá servicio y los proveídos tendrán cuidado de se presentar en tiempo y no estarse cuatro y seis y ocho y diez años y más tiempo sin ir a tomar la posesión, entendiendo que en todo tiempo han de ser admitidos a ella, como el Deán desta Iglesia que ha casi cinco años que está proveído. (En nota: Que está proveído lo que conviene. No parece estar nada proveído acerca desto).

7.- Iten, que Vuestra Majestad provea con todo rigor que los prebendados no puedan salir de los obispados con licencia de la sede vacante, sino que, iso fato cesare, haya perdido la tal prebenda o Dinidad; y si para dentro del Obispado le dieren licencia que esté en alguna Dotrina, no pueda estar más de ocho años, porque los prebendados, sede vacante, con intento de gozar dellos sólo de los diezmos, echan de sí cuantos tienen y las iglesias quedan defraudadas. (En nota: Cédula con la relación desto para los Cabildos que, sede vacante, tengan cuenta con tener la mano en dar estas licencias, que esto es no dar nada).

8.- Iten, que Vuestra Majestad sea servido de mandar fundar universidades en todas las cabeceras de Obispados, con especial en la ciudad de los Reyes que es cabeza destos reinos y en las demás ciudades metropolitanas; que por comisión haya lición de gramática, en especial en la de Quito, y que Vuestra Majestad ayude con su limosna por la gran pobreza de los diezmos y vecinos, mandando poner algún Repartimiento en vuestra Real Corona y que de los tributos se dé la cantidad que Vuestra Majestad fuere servido con la cantidad que se da al colegio de San Francisco de la dicha ciudad, que de ninguna cosa sirve más de 


\section{4 / Augusto E. Albuja}

nombre de colegio, e mande confirmar y aprobar el concierto que entre los religiosos y mí hubo acerca de pagar al Bachiller que lea la gramática que es en provecho de todos, así de los religiosos como de los clérigos. (En nota: Que está proveído lo que conviene. Nunca me han querido dar lo que está proveído.)

9.- Iten, que Vuestra Majestad mande guardar con todo rigor las inmunidades eclesiásticas e por ser aquella tierra nueva y los naturales tengan el respeto, que es razón a las cosas de Dios nuestro Señor, viendo que los ministros de Vuestra Majestad, que son a quien ellos tienen por espejo, tienen respeto en todas las cosas, y que tengan respeto a los Obispos, pues están en lugar de los Apóstoles de Cristo, porque ha habido y hay muy grandes desvergüenzas y descomedimiento contra los dichos Prelados y ningún castigo de la parte de los ministros de la justicia, sino antes todo calor y favor a sus desvergüenzas y atrevimientos. (En nota: Que se den las Cédulas acordadas acerca desto. No parecieron ningunas ni me han querido dar nada en esto).

10.- Iten, que Vuestra Majestad no permita ni dé lugar que vayan a aquella tierra indulgencias ni jubileos que piden de cuya limosna para sacar de aquel reino, sino que si alguno dellos fueren, la tal limosna se reparta en aquel reino en obras pías, por la gran necesidad que dellas hay y de cada día habrá mayor. (En nota: idem, y no parece nada estar proveído que haga al caso).

11.- Iten, que Vuestra Majestad sea servido de proveer más Obispos en aquella tierra, atento a que los Obispados son muy grandes y los naturales nuevos en las cosas de nuestra fe católica; y por su bajísima capacidad, tienen necesidad de muchos ministros y que el Prelado ande siempre sobre ellos y sobre los ministros que tienen cargo dellos, para que sean bien instruidos en las cosas de nuestra santa fe católica, lo cual no se puede en ninguna manera hacer, siendo los Obispados tan grandes como son y las tierras tan trabajosas y los caminos tan peligrosos, porque hay Obispado que tiene doscientas leguas de largo y poco menos de ancho, como el que dondo yo estoy. (En nota: Que proveerá lo que conviene. Esta es la hora que nunca más se les ha acordado dello, porque ninguno dellos más me ha hablado ni preguntado nada).

12.- Iten, que Vuestra Majestad mande proveer de religiosos de letras y suficiencia de las Ordenes de Santo Domingo y San Francisco y algunos teatinos para las ciudades metropolitanas y cabeza de Obispado porque han comenzado hacer fruto y aprobado bien. (En nota: Que se tendrá cuenta con esto y se proveerá lo que conviene. En esto hay muy gran descuido; muy mal en Sevilla porque los proveen). 


\section{Doctrinas y Parroquias del Obispado de Quito /315}

13.- Iten, que por cuanto la costa que se hace con cada religioso que aquellas partes va es muy grande, se las mande expresamente; y por el consiguiente, a los clérigos que asimismo fueren, que no puedan volver dentro de los dichos años porque tengan lugar de hacer en la tierra y naturales della algun fruto y descargar en alguna parte vuestra real conciencia; o si pasados los ocho años se quisieren venir a estas partes, no les puedan negar la ciencia (sic), ni el Obispo ni Prelados de las Ordenes les pongan impedimento en su venida, porque así conviene a vuestro real servicio y descargo de la real conciencia a causa que de lo contrario se siguen grandes inconvenientes y notables escándalos. (En nota: Que se den las Cédulas proveídas acerca desto. Ninguna hay que haga al caso en esta materia ni la quieren dar).

14.- Iten, que Vuestra Majestad mande que ningún clérigo, ni aún religioso de ninguna Orden, de los que en aquellas partes hubieren estado, se le conceda prebenda ninguna en aquellas partes, ni se le dé licencia para volver a ella si no fuere proveído por la persona del Prelado y pedido vuelva a ella, por haber casi todos de los que allá vuelven aprobado y aprobar mal en aquellas partes y pretender volver a ella por vivir con más libertad, y con esto conviene mucho haya muy gran rigor. (En nota: Que así se ha hecho y se hará. Ni así se hace ni se hará si no ponen más rigor que hasta agora; antes, en esto hay muy gran descuido y en la tierra redunda mucho daño).

15.- Iten, que Vuestra Majestad sea servido de remediar que no pasen aquellos reinos clérigos ni frailes sin licencia, examen e aprobación deste Real Consejo o de la persona o personas a quien lo remitieren, porque pasan muchos faltos de habilidad y capacidad, que son de ningún fruto; allende de lo dicho, lo mandó ansí Alejandro Sexto en la Bula de la concesión, y los que de otra manera pasan, los declara por excomulgados, y sobrello hay gran confusión y escrúpulo, y no sólo para los ministros del evangelio, pero para todos los demás seglares de otras naciones. Y conviene que sobrello haya declaración, y ansimismo se declare por suspensos todos los ministros que aquella tierra fueren sin la dicha licencia y examen; y al Prelado que los recibiere, la misma suspensión. (En nota: Que está proveído lo que conviene. A lo menos ello no se guarda y hay en esto un gran escrúpulo, y no lo han querido aclarar ni tratar dello).

16.- Iten, que lo que llaman residuo en las iglesias catedrales, que cierta parte de los diezmos, los cuales se reparten en esta manera: la mitad de todos los diezmos lleva el Obispo y prebendados, por iguales partes; y de la otra mitad que queda, se sacan los dos novenos de Vuestra Majestad; las siete partes que que- 


\section{6 / Augusto E. Albuja}

dan se reparten: las tres en la iglesia y hospital, por iguales partes; de las otras cuatro partes que quedan, pagado el cura y sacristán, lo que resta, que es lo que llaman residuos, reparten entre el Prelado y Prebendados. Ansí se ha hecho y acostumbrado, aunque después que yo tomé la posesión del Obispado de Quito, no he remitido tal, sino antes mandado que se gaste en las fábricas de las iglesias el tal residuo. Y conviene al servicio de Dios nuestro Señor y de Vuestra Majestad que los residuos de todas las Indias se repartan en que haya más número de ministros en las iglesias para aumento del culto divino y no lo lleven los prebendados ni se haga costumbre dello. Vuestra Majestad, en dicho nombre, lo mande proveer ansí. (En nota: Que se guarde la erección y se den Cédulas para ello. En el Obispado de Quito no hay erección ni en otros Obispados de las Indias).

17.- Iten, Vuestra Majestad sea servido de mandar hacer una ereción que sea común para todas las iglesias para que señale y aumente el número de prebendados y canónigos, atento a que las rentas han crecido en algunos de los Obispados con muy gran cantidad, y que esto se cometa a una persona que entienda y tenga noticia de toda la tierra, porque desta manera, con la costumbre que se ha tomado, los Obispos y Cabildos lleven perpetuamente de cuantía parte las tres. (En nota: Que se proveerá lo que convenga; el cuándo, Dios sabe).

18.- Iten, que Vuestra Majestad provea en que los Obispos visiten a los religiosos que tienen curazgos a su cargo, asi de seglares como de naturales, y saber de cómo administran los santos sacramentos y hacen la doctrina, conforme a lo que santo Concilio tridentino manda en la sesión veinte y cinco, capítulo once, y deshacer y castigar los agravios y vejámenes que a los indios hicieren, haciéndoles volver lo que demasiado y contra su voluntad les hubieren llevado. (En nota: Se le dé lo que está proveído acerca desto).

19.- Iten, que Vuestra Majestad mande con todo rigor que los religiosos en sus Doctrinas no tengan granjerías ningunas ni haciendas, como se manda para la Nueva España, por ser cosa muy perjudicial para los indios de las tales Doctrinas porque las cultivan y labran con los dichos indios sin pagalles su trabajo, debajo de título dotrina, y hacen sus haciendas con gran molestia y vejación de los indios; y que lo mismo hagan y guarden los Obispos y Arzobispos, por seguirse los mismos inconvenientes, sino que se ocupen en lo espiritual que es su oficio. (En nota: Que las Cédulas que están dadas para la Nueva España se den para el Pirú).

20.- Iten, que Vuestra Majestad sea servido de que por algunos capítulos disimule y aún mande que todos los Repartimientos que vacaren de indios, 


\section{Doctrinas y Parroquias del Obispado de Quito /317}

poniéndolos en vuestra Real Corona, se reparta la renta dellos entre las personas que más hubieren servido, mandando sean preferidos, y no como se ha hecho y hace hasta agora que se da de comer y los oficios públicos a los amigos, parientes y paniaguados de los Gobernadores y Oidores que mandan la tierra, a cuya causa los que han trabajado en la tierra se quejan tanto y aún hay tantos motines que desta manera, con la renta que tenía uno, con contar a cuatro y a cinco y se salgan los pechos mal intencionados. (En nota: Que está proveído lo que conviene).

21.- Iten, que Vuestra Majestad provea con todo rigor a sus Gobernadores que desmiembren todas las Encomiendad gruesas porque no haya gruesos Encomenderos, que es causa de mucho mal en la tierra; y en vacando, no los tornen a encomendar hasta que los dividan. (En nota: Que se proveerá lo que conviene).

22.- Iten, que Vuestra Majestad provea con todo rigor se cumpla y ejecute que cada tres años o cuatro, de todos los pueblos de las Indias se envíen mestizos a estos reinos para que en ellos sirvan a Vuestra Majestad en fronteras o donde más fuere servido para evitar muy grandes inconvenientes que de aquí adelante se podrán seguir por la gran multitud que dellos hay y de cada día multiplican señalando persona especial de cada Audiencia en su distrito para que lo ejecute, sin que se entienda que depende de la voluntad de Vuestra Majestad; y que lo mismo se ejecute en los mulatos horros, por lo mucho que conviene a vuestra Corona Real, servicio y seguridad de aquella tierra, aumento y conservación della y bien de los naturales.

23.- Iten, que Vuestra Majestad sea servido que los Obispos y canonjías, prebendas y Dignidades que aquellas partes se hubieren de proveer, se provean en teólogos, de que hay muy gran necesidad por estar las...(en blanco) enredadas y enmarañadas más que en parte ninguna de la cristiandad; e importa mucho se provean los dichos oficios y Dignidades en los dichos teólogos para el descargo de la real conciencia, por la gran falta que hay de teólogos en aquellas partes. (En nota: Que se tendrá cuenta que se haga así).

24.- Iten, que conforme lo dispuesto por el santo Concilio tridentino en que mandó que la primera Dignidad o canonjía que vacare sea para un teólogo que sea persona suficiente para leer la santa Teología, y que mientras no hubiere clérigo suficiente, cual convenga para el efecto, que el Prelado ponga religioso para que lea en el entretanto y se le pague su trabajo de lo que ansí rentare la dicha Dinidad o canonjía por ser cosa tan importante y necesaria y los Prelados no te- 


\section{8 / Augusto E. Albuja}

ner posibilidad para pagar al que hubiere de leer la dicha lición de Teología. (En nota: Que se proveerá lo que convenga; el cuándo, Dios lo sabe).

25.- Iten, que no se permita que se hagan entradas ni descubrimientos de indios en ninguna manera, y que conviniendo que se haga, sea con limitación que el Capitán que la tal entrada hubiere de hacer, lleve consigo dos religiosos de santa y buena vida, con autoridad y examen del Obispo en cuyo distrito cae de la dicha entrada, y que no yendo los dichos religiosos, no se permita hacer por evitar innumerables daños y muertes, robos y desafueros hechos en los naturales. (En nota: Que está proveído lo que conviene. Nunca jamás se ha guardado esta orden, ni han castigado a ninguno que lo haya quebrantado; y así, cada día se hace peor).

26.- Iten, que porque hay en aquellas partes infinidad de leyes y Cédulas proveídas por este Real Consejo, muy justas, necesarias, de las cuales muy pocas o no ninguna, por los ministros de la justicia, se ponen en ejecución por ser en favor de los naturales, que ya que Vuestra Majestad no es servido que los Obispos sean protectores de los indios, que era una cosa muy necesaria, porque tuvieran quien volviera por ellos defendiéndolas de tanto número de gente como hay, que los persiguen y procuran de beberle su sangre y sudor, mande que todas las Cédulas, mercedes que Vuestra Majestad hiciere a los dichos naturales, y al presente tiene hechas, se den y entreguen y envíen encaminadas a los dichos Obispos para que den cuenta a Vuestra Majestad de cómo se cumplen y ejecutan, porque de otra manera todas se encubren y son de ningún efecto y los indios dejar de conseguir la merced que por ellos se les hace. (En nota: Que se traiga lo proveído en esto al Consejo. Nunca se halló nada ni yo llevo nada que importe en esto).

27.- Iten, que porque se ha privado y cada día se privan los señores naturales de sus señoríos, los ministros de vuestra real justicia, y aún los que comen de otros, ponen y quitan los señores que les parece, lo cual no se puede hacer sin grandísimo escrúpulo, y, ansi mismo, hacen tributarios a los hijos y nietos de los señores caciques y caballeros, pues de jure gentium hay libertad y la habido siempre en los caballeros hijosdalgo de todas las naciones, y hay más razón que, aún obligación, se guarde ésta en los naturales, lo uno y lo otro Vuestra Majestad sea servido de lo proveer y remediar. (En nota: Que se dé la Cédula que está proveída acerca desto; es bien corta la que habla en esto).

28.- Iten, que porque hay mucha cantidad de indios en aquel Obispado, por conquistar, y por los malos tratamientos y vejaciones que en sus vecinos 


\section{Doctrinas y Parroquias del Obispado de Quito /319}

han visto y ven los tributos excesivos que los llevan, no quieren venir a conocimiento de Dios nuestro Señor y sujetarse a vuestro real dominio; conviene a vuestro real servicio se les den provisión para que, queriendo venir de paz, ni tributen ni sirvan a ningún español, por término de diez años, con lo cual se entiende vendrán a conocimiento de nuestra santa fe católica, que es conforme a la Cédula sobre el mismo caso proveída para la Nueva España. (En nota: Que dé todo lo que hay proveído en favor de los que vienen a sujetarse de paz).

29.- Iten, que en los términos de aquel Obispado hay mucho número de indios por bautizar, por culpa de sus Encomenderos, y conviene a vuestro real servicio que los tales no tributen a sus Encomenderos hasta que los hayan industriado en las cosas de nuestra santa fe católica y bautizado. A Vuestra Majestad suplicamos lo mande proveer ansí porque será ocasión a que los dichos Encomenderos tengan el cuidado que son obligados a los hacer bautizar y industriar en las cosas de santa fe católica. (En nota: Que el Obispo haga sus diligencias acerca desto y que la Audiencia le dé favor para ello y se dé Cédula sobre esto).

30.- Iten, que Vuestra Majestad mande que ningún Encomendero se sirva de ningún indio ni india en su Repartimiento y Encomienda por evitar grandísimas vejaciones y molestias que los indios reciben de los Encomendereos y los tienen como a esclavos; $y$, ansi mismo, que no tengan estancias ni otras granjerías en los tales pueblos de su Encomienda porque los indios son muy vejados y molestados y reciben muy notables daños, los cuales Vuestra Majestad es obligado a quitar y remediar, demás que se descargue vuestra real conciencia. (En nota: Que se den las Cédulas que disponen acerca desto. No pareció ninguna que trate desto sino solamente del servicio personal y no hay remedio que den ninguna cosa).

31.- Iten, que Vuestra Majestad provea y mande, que en casándose cualquier indio o indias, los dejen libres de servicio de cualquier español en cuyo servicio estuviere, para que libremente se puedan ir a sus pueblos o a donde quisieren, con toda libertad, pues lo son, por pasar, como pasa, en ellas muy grande tiranía; y los que peor lo hacen son los ministros de vuestra real justicia porque los tienen peores que esclavos, y por ser gente tímida y medrosa, lo sufren todo sin osar hablar, porque, hablando, son gravemente castigados, que en ello a Vuestra Majestad descargará su real conciencia.

32.- Iten, que Vuestra Majestad mande proveer que cuando se hubiere de visitar las Audiencias de aquel reino, se tome particular cuenta a los Oidores dellas si han guardado y cumplido lo que Vuestra Majestad tiene proveído por 
Cédula y provisiones en favor de los naturales, y se vea el libro de acuerdo y visitas que hubieren hecho, y se castiguen con todo rigor los que en esto fueron remisos. (En nota: Que así está proveído y se hace. Nunca tal se ha visto hasta agora en Indias, aunque es cosa que importa mucho al descargo de la conciencia real).

33.- Iten, que Vuestra Majestad sea servido de proveer que los oficiales reales, secretarios de las Audiencias, alguaciles mayores, relatores, intérpretes de indios, no tengan granjerías, chácaras, si sustancias (sic), conforme a como está proveído a los Oidores, porque se siguen los mismos inconvinientes y aún mayores por ser los indios tan miserables que cualquiera que tiene oficio en el Audiencia o vara de justicia, hace dellos lo que quiere; y conviene poner remedio en ello, pues no tiene otro amparo sino el de Vuestra Majestad. (En nota: Que está proveído lo que conviene).

34.- Iten, que porque los naturales de aquel Obispado es gente miserable y están demasiadamente cargados de tributos, se manda moderar la tasa que agora comienzan y que paguen conforme a la cantidad que pagan los naturales de Nueva España, o muy poco más, pues la tierra es más pobre que de la Nueva España y hay la mesma causa y razón para moderar lo del dicho tributo, y que a la sazón que se hace la tal tasa, el Prelado tenga voto en ella porque, como tiene entendido la miseria y trabajo de los naturales, tratarán con descargo de vuestra real conciencia lo que conviene a los dichos naturales con más libertad. (En nota: Acudan a la Audiencia cuando se hiciere agravio. Muy buen remedio para los tristes indios que los agravia la Audiencia).

35.- Iten, que por lo mucho que conviene al descargo de vuestra real conciencia y bien y conservación de los naturales de aquel reino, se señala una persona de ciencia y conciencia y espiriencia, de los más contiguos que han estado en aquellas tierras, que resida en esta Corte para que informe, como persona de vista, la manera del vevir de los españoles, clérigos y religiosos, y dé aviso de las cosas que en aquellos reinos conviene proveer. (En nota: Que no hay necesidad. En lo que más importa y conviene al servicio de Dios y de su Majestad y conservación de los naturales dicen que no hay necesidad).

36.- Iten, que Vuestra Majestad mande que los hospitales que están debajo de la inmediata protección de Vuestra Majestad, que son los que se han fundado y dotado a costa de la real hacienda, que los visiten los Obispos con un señor y ministro de justicia, porque así conviene para la conservación de los dichos hospitales. (En nota: Que se traiga lo que está proveído. No parece haberse proveído nada, y así no lo llevo nada). 


\section{Doctrinas y Parroquias del Obispado de Quito /321}

37.- Iten, que porque al presente hay gran necesidad de que en aquellos reinos se plante la fe en los naturales como en plantas nuevas, y para que esto haya efecto, los indios tienen necesidad a su modo de gobierno como todas las demás cosas tienen de muchos dellos, y no más dé para esto eseto (sic) de que los recojan y traigan a la dotrina y a misa. Por tanto que a Vuestra Majestad suplico mande proveer de que para esto se den suficientes alguaciles de los mismos indios y que los Obispos y Prelados puedan poner todos los alguaciles que fueren necesarios entre los naturales, en su real nombre, porque quitándolos y poniendo los ministros de Vuestra Majestad, demás de que les llevan muchos derechos por los mandamientos que les dan, se siguen grandes inconvenientes porque les ponen y quitan ad libitum, de lo cual se siguen muchos inconvenientes, porque los tales alguaciles no tienen ningún provecho ni salarios, ni pueden prender ni castigar a nadie más de solamente llamar y traer a los indios a la dotrina y a misa, en lo cual antes padecen gran trabajo, y si no hay gran número de alguaciles en los pueblos grandes y al respeto en los pequeños, así para juntar la dotrina como para dar noticias y cuenta a los sacerdotes que están entendiendo en la conversión de los dichos indios, así de los indios enfermos como de los que no vienen a misa y de los que no están bautizados y viven en mal estado, morían muchos sin sacramento ni vernían a misa todos. Los cuales inconvenientes cesarán, dando Vuestra Majestad provisión real para en su real nombre los expertos de aquellas partes pongan los alguaciles que sean necesarios para la dotrina de los dichos naturales, cada Obispo en su Obispado. A Vuestra Majestad suplicamos, en el dicho nombre, lo mande proveer ansí por ser cosa tan necesaria para el bien espiritual de aquellos naturales. (En nota: Tráigase lo proveído. No se halló nada proveído y respondieron que no había lugar. Suplico a Vuestra Majestad se informe de todos cuantos de Indias han venido y vienen, si se puede hacer doctrina ni ninguna cosa entre los naturales sin estos alguaciles, y que de concederlos, ningún inconveniente hay; y de negarlo, se siguen grandísimos daños espirituales y temporales).

38.- Iten, que los Sínodos provinciales que en aquellas partes se celebraren, les parecieren a los Prelados que en él se hallare que conviene venga alguno dellos a estos reinos a informar a Su Santidad o a Vuestra Majestad de las cosas que en aquellas partes conviene remediar, pueda venir libremente sin que se le estorbe al que fuere eligido para ello. (En nota: Que cuando el caso se ofreciere, avisen a Su Majestad en este Consejo de la persona que quieren inviar, ya que para que se provea lo que convenga. Si las Indias estuvieran en Sevilla, tienen razón). 
39.- Iten, que porque en aquel Obispado de Quito hay muchos pueblos despañoles nuevamente poblados y de cada día se van poblando con la esperanza de minas de oro que comienzan a descubrir y son pobrísimos los pobladores para poder sustentar curas en cada pueblo y estar muy lejos en gran distancia los tales pueblos unos de otra y el Marqués de Cañete, Visorrey que fue de Vuestra Majestad en aquellas partes, entendiendo ser así, señaló cincuenta mil maravedís a cada un cura que en los tales pueblos residían, de vuestra real hacienda, para que con ellos y los diezmos que en los tales pueblos hubiere, que es muy poco o casi no nada, y con otro poco que los vecinos le ayudasen, tuviesen una cómoda satisfacción. A Vuestra Majestad suplicamos que teniendo consideración a lo dicho y a que todas las cosas valen a muy excesivos precios en las Indias, y en especial en los tales pueblos nuevos que por su pobreza no acuden las cosas de España para comer y vestir en tanta abundancia, como a los demás pueblos que están ya asentados y más cerca de los puertos; y de no haber sacerdote en los tales pueblos se siguen muy grandes daños espirituales y temporales, les hagan merced que a cada uno de los tales curas vicarios de los tales pueblos nuevos se les den de vuestra real hacienda doscientos pesos para ayuda a su sustentación. (En nota: Que se proveerá lo que convenga. Yo no sé cuando, pues estoy aquí ocho meses ha pidiéndoselo cada día y no lo proveen).

40.- Iten, que porque todos los pueblos despañoles de aquel Obispado de Quito en sus Iglesias son paupérrimas por no tener fábrica ni otros réditos ningunos, Vuestra Majestad les haga merced de los novenos a Vuestra Majestad pertenecientes de los diezmos de aquel Obispado para vino y cera y aceite, principalmente a la Catedral por tener aún mayor necesidad, y así suplicamos a Vuestra Majestad. (En nota: Que se vea por los libros si se les ha hecho alguna merced en esto).

41.- Iten, pedimos y suplicamos a Vuestra Majestad mande proveer de remedio para que los Obispos y Arzobispos puedan poner y señalar en cada un pueblo despañoles una persona de buena vida y conciencia llana y abonada para que de los tributos que los indios de aquel distrito dieren a sus Encomenderos, pueda recoger y cobrar el salario que a los sacerdotes que están en las tales Doctrinas les están señalados por los Obispos, y los tengan en sí en depósito para que de allí se pague a los tales sacerdotes la limosna y salario que así les está señalado con libramiento del Obispo o de su Provisor, y que los tales Encomenderos no tengan que ver con los sacerdotes, ni los sacerdotes con ellos, acerca del cobrar de su salario, porque les hacen tantas vejaciones y molestias por no pagarles su 


\section{Doctrinas y Parroquias del Obispado de Quito /323}

salario que a veces les hacen gastar en pleitos más de lo que el salario vale. Y habiendo una persona señalada en cada pueblo, como dicho tengo, que de los tributos que los dichos naturales dan a sus Encomenderos cobre el salario de los sacerdotes, se evitarán todos estos inconvenientes, porque en la Nueva España tiene caja de comunidad los indios donde guardan las sobras de los tributos y en el Pirú todo lo que tributan llevan sus Encomenderos y después que los han recogido en sí, háceseles muy de mal de pagar el salario a los sacerdotes y sacar el dinero de su bolsa; porque pocos Repartimientos hay, a lo menos desde el Obispado de Quito para bajo, que tengan sólo a un sacerdote, sino que se juntan tres y cuatro Repartimientos, los más cercanos, para tener un sacerdote, y de las obras que alguna vez podría haber en los reales depósitos se podrían proveer las iglesias de los tales naturales de retablos, campanas, ornamentos, para decir misa, porque ningunas o muy pocas hay que tengan ningún recaudo y el Obispo no pide más a causa de que los ministros de Vuestra Majestad en ninguna cosa les favorecen, estorbarles sí en muchas cosas,suplicamos a Vuestra Majestad mande dar su provisión real para esto por lo mucho que importa para el descargo de la conciencia de los Encomenderos de aquellas partes, con quien Vuestra Majestad descarga su real conciencia, y para que los naturales tengan doctrina y los sacerdotes no sean defraudados de su trabajo. (En nota: Tráigase lo proveído con esto. No pareció estar proveído nada por ser una cosa de que se seguirían artos provechos; no hay remedio y no haber inconveniente de concederse).

42.- Iten, que Vuestra Majestad provea que de la cuarta parte del valor de los tributos se saque para que haya dotrina suficiente, de la cual hay grandísima falta para el sacerdote. (En nota: Que se provea lo que convenga. Hay grandísima necesidad que haya en esto alguna claridad).

43.- Iten, que se dé Cédula para que el salario que a los clérigos y religiosos fueren señalado por los Prelados nadie le ande variando. En aquel Obispado de Quito se dan trescientos pesos de oro que corre del salario y cincuenta para cera, vino y aceite, que se de en todo el Perú, porque en la gobernación y nuevo reino se dan cuatrocientos pesos y en el Cuzco y Charcas a quinientos y seiscientos, y de allí arriba, y en Lima trescientos y cincuenta, que no hay estanciero, Corregidor o teniente a quien menos se de; que especialmente agora que en el Sínodo provincial que se tuvo en la ciudad de Lima se mandó, y con rigor, se ejecute que ningún otro aprovechamiento y género de granjería tengan los sacerdotes. (En nota: Que cuando el caso sucediere, invíe información dello al Consejo. Están las Indias muy a la mano para ir y venir cada día acá). 
44.- Iten, que por cuanto Vuestra Majestad tiene proveído en sus causas y negocios de los indios se concluya sumariamente por su pobreza, se dé comisión a los Obispos y sus jueces eclesiásticos para que los puedan prender sin que tengan necesidad de refrendar mandamiento por ser gente tan desventurada y casi como niños; porque haciéndose por vuestra Real Cédula, no habrá que dejar si usurpan ni usurparán la juresdición real, pues aquéllas, si es espiritual y temporal, todo es de Vuestra Majestad, sino solamente por evitar causas de desabrimientos y desasosiegos entre los Prelados y ministros achaconas de la justicia real, entendiéndose en casos que pertenecieren a fuero eclesiástico solamente. (En nota: que está proveído lo que conviene. Pedí lo proveído y no hay remedio dello, ni parece haberse proveído cosa que importe).

45.- Iten, que porque las iglesias que están en los pueblos de los indios no tienen ninguna posibilidad y tienen necesidad de cantores, así, para dotrinar a los pueblos, que los tales cantores se han reservado de pagar tributo ninguno; ni en las visitas que se hicieren se visiten por tributarios, con tal que el número de cantores no exceda, en los pueblos donde están de asiento los sacerdotes, de diez medios, y que todo se entienda mientras sirven habitualmente a la iglesia. (En nota: No ha lugar. La cosa que con más facilidad en las Indias las Audiencias y Gobernaciones conceden es ésta que acá dicen que no ha lugar).

46.- Iten, que por cuanto las Audiencias conocen, so color de fuerza, de todas cuantas cosas ante los jueces eclesiásticos penden, mandando que se anulen y repongan todos los que se determinan por los dichos jueces eclesiásticos, retiniendo en el Audiencia todos los pleitos eclesiásticos; y las causas mixtas, y aún eclesiástica decláranse mere profana, las detienen en su Audiencia, y como es por vía de Audiencia, se cumplen todas, de lo cual se sigue y quedan los vicios sin castigo y es gravísimamente nuestro Señor ofendido en ello y los delincuentes quedan escarneciendo de los Prelados, de las iglesias de Dios y de su poca autoridad, porque, como está referido, con ninguna cosa van a la Audiencia y no lo mandan exhibir a los jueces eclesiásticos donde se echa el carnero, y se quedan los vicios en su lugar y fuerza. A Vuestra Majestad suplico declare los casos que el Audiencia ha de conocer por vía de fuerza y mande que en sólo ellos, y no otro alguno, la dicha Audiencia se entremeta. (En nota: Que está proveído lo que conviene, que cuando no se guarde, traigan testimonio al Consejo que nunca ha podido haber lo que cerca desto está proveído y mal se puede guardar desta manera). 


\section{Doctrinas y Parroquias del Obispado de Quito /325}

47.- Iten, que Vuestra Majestad sea servido de alcanzar Bula de Su Santidad para que el Obispo y Arzobispo solos tengan más autoridad que la ordinaria en casos de inquisición para con los españoles, frailes y clérigos, porque hay extrema necesidad della en aquella tierra por la gran corución de costumbres que acerca desto hay y de cada día se teme que habrá más por la gran libertad que la tierra consigo tiene; y no se remediando con rigor al principio, se podrán seguir dello muy grandes daños. (En nota: Que se provea lo que convenga. Esto importa mucho porque, cierto, la gente española en aquellas partes es viciosísima y puede ir cada día de mal en peor, como lo vemos por experiencia).

48.- Iten, que por cuanto los oficiales de las Audiencias llevan los derechos tres doblados a la Iglesia y Obispo, siendo tan pobres, como a Vuestra Majestad consta, en lo cual reciben daño, a Vuestra Majestad suplico se dé Cédula para que no se les lleven más derechos que a los demás. (En nota: Cédula para la Audiencia para que no consienta se les haga agravio. ¡Muy buen remedio!).

49.- Iten, que Vuestra Majestad sea servido de proveer los oficios de que estuviere vacos o vacaren, con toda brevedad, porque los que se ponen en el entretanto son muy perjudiciales a la república por ser mercenarios. (En nota: Que se terná cuenta con ello).

50.- Iten, que Vuestra Majestad mande guardar con todo rigor la Cédula y provisión real que está dada para que los indios se junten y vivan en congregación juntos, porque mientras esto no hubiere, no puede haber pulicía y cristiandad entrellos, como no la hay agora ni se espera que la habrá hasta que se junten y vivan en congregación poblando junto. (En nota: Que así se hace. No en las Indias don lo vemos).

51.- Iten, que por cuanto hay gran desorden en dar multitud de provisiones a los indios y los llevan más por ellas que ellos tienen de hacienda, se probarán, pues tienen Corregidores y alcaldes les remiten los negocios de los dichos indios tocantes a sus pleitos e no en grado de apelación. (En nota: Que está proveído lo que conviene. Ninguna cosa aprovecha proveer si allá no hay ejecución dello, como no lo hay).

52.- Iten, Vuestra Majestad sea servido de les dar facultad a los Prelados para que puedan poner en todos los pueblos un alguacil eclesiástico para que ejecute la justicia eclesiástica, porque la premática no dice más de que el Obispo tenga un alguacil y la Audiencia no permite que haya tal del Obispo tiene a donde está su persona; y aunque la tierra según es mucha la libertad que los hombres tienen en emplear tan desenfrenadamente en todo género de vicios, es necesario 
para cada español: un mestizo o negro, un alcalde y su Obispo. (En nota: Idem. No hay tal idem, a lo menos yo no lo hallo en los libros). Fray Domingo de Ugalde (rubricado).

Otro sí, convenía que se mandase con rigor que ninguno que haya sido esclavo ni esclava pueda tener indios en encomienda, porque en las tierras nuevas dan y encomiendan indios a los tales; y entenderá Su Majestad cómo han de ser tratados los indios en poder de las tales personas y la gran desorden que acerca destas cosas hay, ni hay ningún extranjero, convenía que los tuviese porque son crudelísimos con ellos, y aunque creo está mandado esto por Su Majestad, ninguna cosa en lo que toca al bien de los naturales se pone en ejecución a causa de no tener los indios en las Audiencias quien vuelva por ellos, aunque Su Majestad les hace cada día muchas mercedes y no gozan dellos. (En nota: Cédula con relación desto dirigida al Virrey para que convenga de manera que cesen estos inconvenientes).

Iten, otro sí, que ningún esclavo de los Encomenderos se permita estar entre los indios porque son perjudicialísimos, y aunque está mandado esto por Su Majestad y mandado que ningún calpisque pongan entre los naturales si no fuere dando fianza si algún mal hicieren, muy cristianamente mandado; pero allá no se guarda nada desto, porque los mismos gobernadores y justicias son los que lo hacen primero, y, como digo, los naturales no tienen quien por ella vuelva $y$ por esto pasan muchas vejaciones y molestias a causa de tener quien en las Audiencias Reales vuelvan por ellos y les favorecen. (En nota: Que se dé lo proveído acerca desto y Cédula en relación desto para que se guarde).

Iten, que Vuestra Majestad sea servido de mandar declarar el número de indios tributarios suficiente para que un ministro pueda dotrinar, porque en el Sínodo que se tuvo en la ciudad de los Reyes, el año pasado de sesenta y ocho, pareció a los Prelados que allí se juntaron que cuatrocientos indios tributarios era número tributario y suficiente y aún demasiado, porque cuatrocientos indios tributarios por lo menos hay mil y doscientas ánimas, y tienen más que hacer con ellas los ministros que no los de España. Venido aquí, a este mi Obispado de Quito, se escandalizaron tanto los vecinos, que fue necesario que nos juntásemos con esta Real Audiencia y clerecía y Prelados de las Ordenes, a todos los cuales pareció, por agora, por la dureza de los Encomenderos, que se señalasen para cada sacerdote de ochocientos hasta mil tributarios, y de los tributos que estos tales dan a sus Encomenderos, se saque el salario del sacerdote, porque en este número de mil hombres indios tributarios hay más de tres mil ánimas, por lo me- 


\title{
Doctrinas y Parroquias del Obispado de Quito /327
}

nos. Vea Vuestra Alteza cómo puede bastar el sacerdote solo para tanto número de gente, y en Indias; y a mi conciencia digo, y con ello descargo, que ningún sacerdote, aunque se haga pedazos para hacerlo razonablemente, puede cumplir con seiscientos indios tributarios, y no dende arriba, y menos en la sierra que en los llanos, por estar los indios más ramados y más incultos. Vuestra Alteza mande lo que más convenga a su real servicio y sea con provisión real, porque yo con ello descargo mi conciencia. (En nota: Que está proveído lo que conviene. Y está proveído que cada sacerdote tenga mil indios tributarios a cargo, donde y por lo menos tres mil ánimas, ¿cómo podrá un sacerdote tener cuenta con ellos?).

Fray Domingo de Ugalde/rubricado/.

\section{APÉNDICE \# 10}

Memorial que el Obispo de Quito, Ilmo. Señor Pedro de la Peña, envió al Rey, a raíz del primer Sínodo diocesano, exponiéndole la situación moral, social y religiosa de la Diócesis a fin de que se suprimieran muchos abusos.

\author{
AGI, Quito, leg. 46 \\ Quito, 2 de mayo de 1571
}

Muy poderoso Señor: el Maestro Don Fray Pedro de la Peña, Obispo deste Obispado, digo que, con celo de servir a vuestra real persona e hacer lo que incumbe a mi oficio pastoral, he procurado con cuidado de recopilar estos capítulos que hago presentación e platicado en el Sínodo que al presente hice para que vuestra real persona e Señoría sea avisado que conviene proveer a vuestro real servicio e doctrina de los indios e pulicía de ellos. Pido y suplico a Vuestra Alteza mande a vuestro Presidente e Oidores lo vean e den su parecer sobre ello para que, con su parecer, vuestra real persona e Señoría provea sobre todos los dichos capítulos e cada uno dellos lo que conviene a la doctrina, conversión e buenas costumbres y población de los dichos naturales; y para el dicho efecto se me dé para que yo lo envíe a vuestra real persona, y pido justicia, etc. El Obispo de Quito.

En la ciudad de Quito, a siete días del mes de agosto de mil e quinientos y setenta años, ante los Señores Presidentes y Oidores estando en acuerdo de justicia, se metió esta petición y capítulos en ella contenidos y los dichos Señores mandaron que el relator lo traiga para ver. Antonio de León. 


\section{8 / Augusto E. Albuja}

Muy poderoso Señor: el Maestro, Don Fray Pedro de la Peña, Obispo de Quito, etc., por nos y por el santo Sínodo diocesano, congregación en él fecha, conviene, a saber: el Deán e Cabildo desta santa Iglesia e los Prelados de las Ordenes de Santo Domingo, San Francisco y la Merced, los vicarios de las ciudades: Cuenca, Peura, Cajamarca, Pasto, Jaén, Valladolid, Guayaquil, Puerto Viejo, los religiosos y curas de las Doctrinas de naturales que en este santo Sínodo con nos se han congregado, decimos que habiéndonos definido e acabado santa constituciones para la administración de los sacramentos e celebración de el culto divino, corrección de costumbres, principalmente de las personas eclesiásticas, en que se les ha dado reglas para que vivan con toda honestidad y buen ejemplo, como está dispuesto por derechos antiguos y en este santo Sínodo lo ha renovado con favor del Espíritu Santo, añadiendo constituciones necesarias para la doctrina de los indios, demás de lo cual esta santa congregación, vistos los memoriales de las ciudades y personas particulares, ha platicado algunas cosas convenientes al aprovechamiento, conversión e pulicía destos naturales, que también son concernientes a la doctrina e conversión de los dichos naturales, para cuyo remedio es necesario auxilio de vuestra real persona en la cual, por estos indios miserables personas nuevamente convertidos, este santo Sínodo desea sean favorecidos con vuestro real favor; e ansí, usando de la autoridad evangélica que manda se de a Dios lo que es de Dios e al César lo que es del César, suplico a Vuestra Alteza provea justicia en las cosas siguientes:

Primeramente, en los confines de los pueblos e provincias de indios que sirven a las ciudades deste Obispado, hay otras provincias de indios de guerra, los cuales si entendiesen que Vuestra Alteza los recibiría a vuestra real obediencia de paz e con alivio de tributo, vendrían a vuestro real servicio y los que así vinieren de paz, no siendo conquistados, no tributen por tiempo de diez años conforme a vuestra Real Provisión. (Al margen: Que esto se guarde así conforme a las Cédulas que para ello están dadas y la Audiencia las haga guardar).

2.- Las caserías y poblaciones destos naturales están muy apartadas y en tierras muy ásperas, montuosas y escondidas, porque, cuando en su antigüedad se poblaron, fue a fin de defenderse y esconderse sus enemigos, lo cual agora es inconveniente, porque conviene que estén poblados en partes donde la justicia los vea e los sacerdotes que los doctrinan los tengan cerca de sí para que estén aparejados para oir la doctrina cristiana. Vuestra Alteza sea servido mandar que estos indios se pueblen en lugares cómodos, junto a la iglesia parroquial, y los pueblos se hagan de gente e vecinos, conforme a la dispusición de la tierra para 


\section{Doctrinas y Parroquias del Obispado de Quito /329}

la dicha población. (Al margen: Que él lo predique ansí y haga que los curas lo prediquen y por vía de dotrina los persuadan a ello y se dé Cédula a la Audiencia que entienda en.../roto/ la población, conforme a la orden que está dada).

3.- Iten, estos indios son pobres, no tienen otra renta sino su trabajo e dél se han de vestir y sustentar sus personas, mujeres y hijos; e habiendo en la población de hacer nuevas casas e iglesia e chácaras, no pueden acudir a la servidumbre de las ciudades y tributos e la forzosa de su sustentamiento, Vuestra Alteza provea que en el año que se poblaren los indios no tributen, sino que se ocupen en hacer la iglesia, casas, chácaras del nuevo pueblo para que con amor y suavidad se ajunten y pueblen con más facilidad. (Al margen: En esto está dada orden; que aquella se guarde).

4.- Iten, que a los pueblos de los indios se les señalen ejidos para sus ganados, demás de las tierras vastas que se les debe dar para sus sementeras, las cuales han de ser dobladas para año y vez. (Al margen: Ya está dada orden y que el Presidente la haga guardar).

5.- Iten, se debe proveer que españoles ni clérigos ni frailes no puedan poner estancias de ganado menor a menos de una legua de las chácaras que están junto a los pueblos de los indios e no puedan poner ni tener estancias de ganado mayor dentro de dos leguas de las dichas chácaras, ni se puedan dar tierras para sementeras ni labranzas, viñas ni huertas, a los españoles dentro de la dicha legua, porque los dichos indios tengan sus tierras conocidas para sus sementeras e crías de ganados.

6.- Iten, que ningun Encomendero tenga estancias de ganados ni sementeras en todos los términos de los pueblos de su Encomienda ni tenga heredades ni ningún género de granjerías con los indios de su Encomienda por los grandes daños que dello se les sigue.

7.- Iten, que ningún Encomendero tenga en los pueblos de su Encomienda, para ninguna granjería ni aprovechamiento, calpisque español, mestizo, negro, mulato e yanacona ladino, porque éstos son pestilencia en los pueblos haciendo grandes agravios a los indios.

8.- Iten, que ningún criado ni paniaguado ni yanacona de Encomendero, que es o haya sido, puede tener vara de justicia ni comisión particular en los pueblos del tal Encomendero, ni con la dicha vara de justicia puedan enviar los dichos Encomenderos a los tales a recoger los tributos, como los hacen, en que se sigue grandes agravios que se hacen a los naturales. 
9.- Iten, ha de proveer Vuestra Alteza que ningún Encomendero pueda tener en su casa, ni en su servicio, indio ni india de su Encomienda, ni traiga ni tenga los caciques ni principales de sus tierras, ni los saque dellas para ninguna cosa, porque, allende de los males y gastos e daños que se siguen a todos los naturales, los pueblos están casi todo el año sin sus caciques e sin ellos la dotrina no se puede hacer la dotrina a derechas, porque tras ellos se va la mayor parte del pueblo, demás que los naturales se desasosiegan de sus tierras y sementeras y se pierden mucho por las ausencias de sus caciques que son los que los congregan e ayuntan en su natura.

10.- Iten, porque los caciques e principales e otros indios ladinos, sin ser negros, se vienen de sus tierras a esta Corte, dejando la dotrina y se están en esta ciudad siguiendo sus vicios con mal ejemplo con sus mancebas, ocupándose en juegos, borracheras y otros embustes de ociosos, acompañándose de mestizos, mulatos y negros, que les enseñan a vivir mal e algunas veces exigen los tales negocios para engañarlos, los cuales para gastarles lo que tienen, Vuestra Alteza debe proveer que ningún indio cacique, ni principal ni particular, pueda venir a esta Corte a ningún negocio sin que primero dé cuenta a su cura del negocio que tiene y el dicho cura dé cuenta a esta Vuestra Real Audiencia, si hobiere que remediar e si no se atajan los dichos males e gastos; y el indio que así viniere a negocios de su pueblo, lleve firmado de letrado, procurador,secretario, relator, lo que hobiere gastado y dello dé cuenta delante la justicia y, en su ausencia, al cura, y sepan las deramas que para esto echaron.

11.- Iten, asimismo, para quitar muchas vejaciones o inconvenientes que se hacen a los indios, se provea que en ningún pueblo de indios no entren otras justicias con varas si no fuere el Oidor que visitare a sus oficiales, el Contador y Alcalde mayor, porque cualquiera otro que la trae hace muchos agravios so color de la vara e los indios es gente llana y tímida e no pueden restituir ni aún osan, en especial cuando están lejos del Audiencia. (Al margen: Que el Presidente provea lo que convenga).

12.- Iten, que Vuestra Alteza mande señalar letrado y procurador para los indios en esta Real Audiencia e un Relator en esta ciudad y en las demás deste Obispado, cada uno el suyo, los cuales sean temerosos de Dios e de buena conciencia, salariados y pagados de Vuestra Real Hacienda para que no tengan ocasión de llevar a los indios sus miserias ni servirse dellos, como lo hacen, y los Contadores las lleven dineros, aves ni otras cosas. 


\section{Doctrinas y Parroquias del Obispado de Quito /331}

13.- Iten, que los tales protectores tengan los traslados de las tasas de los indios de su comarca e vean si se cumple con todo lo demás que Vuestra Alteza tiene proveída en favor de los indios, y los defienda y ampare e dé aviso a Vuestra Real Audiencia de los excesos.

14.- Iten, Vuestra Alteza haga merced de los indios de estancias y heredades como a los españoles se les da y les suele repartir en este reino.

15.- Iten, en esta tierra se entiende hay muchos tesoros escondidos y enterrados y trazas donde hay gran riqueza de oro y plata, esmeraldas e otras cosas preciosas, lo cual no osan descubrir los indios e se pierden grandes riquezas porque ni en los indios que los descubrieron no han de haber nada dello e han de ser castigados, Vuestra Alteza mande declarar que los indios que descubrieren trazas, sacrificios, enterramientos e otro cualquier género de tesoro, abran libremente lo que sacaren, pagando a Vuestra Alteza su real quinto. (Al margen: Que esto está proveído que se guarde con los indios lo mismo que con los españoles, y el Presidente lo haga ansí guardar).

16.- Iten, porque en esta tierra hay ricos mineros de oro y plata y esmeraldas, las cuales labraban los indios y las tienen encubiertas y se pierden grandes riquezas, Vuestra Alteza mande declarar que los indios que descubrieren o hallaron minas puedan tener sus minas y labrallas, como los españoles vasallos de $\mathrm{Su}$ Majestad, pagando vuestro real quinto.

17.- Iten, en los tambos de los caminos e de los pueblos están alguaciles para bien e provecho e para la servidumbre de toda la república; para proveer los españoles e los indios que pasan por los caminos, vuestra real justicia les da mandamiento; e para ello, en cada un año, que se provea que, pues ellos sirven de gracia a la república, que se les dé de gracia los dichos mandamientos y no se les lleve por ello cosa alguna. (Al margen: Que ansí se haga.)

18.- Iten, que se provea que con gran rigor se guarden las Cédulas Reales en que Vuestra Alteza manda que no vengan los indios a servir las ciudades de estos términos ni traigan cargas de maiz ni trigo ni frutas, en especial cuando vienen o van a diversos temples de tierra fría a tierra caliente o de tierra caliente a tierra fría, porque estas diversidades de temples y servidumbres causan muchos daños en los naturales. (Al margen: Que está proveído y aquello se guarde.)

19.- Iten, Vuestra Alteza mande que los indios no vayan a minas a sacar oro ni plata, ni a proveer los mineros en las dichas distancias, ni en la diversidad de los temples, sus naturales, porque en todo perecen muchos indios e para ello tiene Vuestra Alteza proveído remedio, el cual no se guarda. 
20.- Iten, que lo que toca a cargarse los indios serviles en la dicha distancia e para la dicha diversidad de temples, que no saquen cargas de sus naturales, en especial que los serranos no bajen cargas ni las traigan a los embarcaderos ni puertos, porque el ordinario son tierras calidísimas e así mueren muchos indios serranos en los caminos y se les recrecen graves enfermedades.

21.- Iten, entre estos indios acuden de cuando en cuando enfermedades pestilenciales e cuando empiezan a morir, mueren gran multitud; e aunque tenemos mandado que nuestros curas de los indios de ordinario traigan medicinas y en los tales casos ejerciesen la caridad cristiana, no bastan a remediarlo todo, en especial estando privados del principal remedio que es la sangría; Vuestra Alteza provea de personas y medicinas para cada provincia, en semejantes tiempos, a vuestra real costa o de los Encomenderos o de los indios o de todos, como vuestra real voluntad fuere.

22.- Iten, que se provea que en los asientos de indios e indias, que la vuestra real justicia hace para el servicio de los españoles, sea sin vejación de los pueblos; en especial, en la de las indias, no se permita se den indias mozas sospechosas a hombres sospechosos, de ninguna edad e calidad que sean, porque debajo de título de servicio se hacen muchas ofensas a Dios y se causa escándalo.

23.- Iten, Vuestra Alteza ha proveído que se dé libertad a los indios que cuando se casen. Acontece casarse indios de un pueblo con indios de otro e indios yanaconas con personas de pueblos e indios de pueblos con indias que están asentadas en el servicio de los españoles; no obstante el dicho matrimonio, les compelen a las mujeres a las servidumbres que antes que se casasen tenían. Vuestra Alteza sea servido mandar que las tales indias que se casaren, sigan la condición de los varones e consigan por reverencia del matrimonio toda libertad para la cohabitación matrimonial.

\section{IGLESIAS}

24.- Iten, en los más pueblos, así de españoles como de indios, están por edificar iglesias. Vuestra Alteza, por su Real Cédula, tiene mandado que a su costa e de los Encomenderos estantes e indios de la comarca se edifiquen; Vuestra Alteza las mande edificar y proveer de dónde se edifiquen, pues dello tanta obtinación hay.

25.- Iten, en los pueblos de indios, donde hay edificadas iglesias, las más están sin puertas e cerraduras e ornato de altar, sin ornamentos ni campanas, ni otras cosas con que se administren los santos sacramentos. Vuestra Alteza mande a los Encomenderos o a quien lo ha de proveer con brevedad se provean. 


\section{Doctrinas y Parroquias del Obispado de Quito /333}

\section{DOCTRINAS}

26.- Iten, que en muchas partes los Encomenderos no han tenido dotrina y el estipendio que se había de dar al sacerdote por congregaciones de personas doctas, teólogos y juristas, que se han fecho en México y Lima en otras personas, se ha determinado no ser el dicho estipendio de los Encomenderos que están obligados a restituir para aumento de la doctrina e culto divino; Vuestra Alteza mande que todo esto que así se ha dejado de dar, los que lo deben dar para el dicho aumento de la doctrina, si fuere necesario, más de la que en el tal pueblo hay; dello se provean las necesidades del servicio.

\section{DEL CULTO DIVINO}

27.- Iten, porque ordinariamente los sacerdotes cobran mal los salarios de las Dotrinas de mano de los Encomenderos, a cuya causa Vuestra Alteza fue servido proveer que los caciques pagasen al clérigo su salario antes que entrase el tributo en poder de los Encomenderos, Vuestra Alteza sea servido mandar que, con certificación del Prelado, los caciques paguen el salario al cura e dotrinero por sus tercios primero, que entren los tributos en poder del Encomendero, y, proveyéndose esto, pedimos e suplicamos no haya cogedor de los dichos salarios porque dello se sigue nuevos inconvenientes, porque los cobran en oro e plata e lo gastan e le pagan a los curas en ropa e otras cosas que valen menos que el oro e plata que cobraron, e los dichos curas los reciben por no podello cobrar en otra manera.

28.- Iten, porque esta Iglesia nueva no puede ir adelante sin ministros e los tales conviene de sitios instructos e impuestos en los rudimentos cristianos e católicos, y esperar que vengan de España los tales ministros, es a gran costa de Vuestra Real Hacienda; y en estas partes se van criando mozos que vienen de España e otros que acá nacen y esta Iglesia, por ser pobre, no tiene para hacer seminario ni el Prelado puede ayudar e los beneficiados e Dotrinas son asimismo pobres, Vuestra Alteza sea servido proveer de ayuda para sustentar un letor -sicde Gramática o otro de Teología para la administración de los sacramentos e casos de conciencia, los cuales al presente tienen entretenimientos por mucho trabajo y con ayuda de nuestros ministros para que este ejercicio santo vaya adelante e con él se puedan habilitar personas para poderse ordenar.

29.- Iten, las Dotrinas que hasta agora habemos encargado a nuestros curas de los indios, ansí por no haberse bien entendido el número de los naturales y también porque los caciques hasta agora con temor del acrecentamiento de los tributos ha crescendido mucha gente y se halla mucha más de la que se pen- 
só en principios. Porque los sacerdotes no pueden cumplir con la administración de los santos sacramentos, Vuestra Alteza sea servido de mandar se visiten las Doctrinas, e por agora sea suficiente número para un curazgo e Doctrina de ochocientos a mil vecinos; y deste número no se exceda, porque un sacerdote no puede cumplir con más parroquianos, ni aún con éstos; pero, por agora, lo permitimos hasta que haya más ministros. (En nota: Que los haga empadronar para que se sepa las ánimas que cada uno tiene a cargo y avise al Presidente donde fuere necesario presentar más de un ministro de doctrina).

30.- Iten, los sacerdotes que andan en las Doctrinas han menester algunos indios coadjutores para que junten a la dotrina e les den aviso de los que enfermaren y de los que hicieren pecados públicos, e los huérfanos e de otras obras de piedad que por nuestras constituciones tenemos mandando hagan nuestros curas, Vuestra Alteza lo mande proveer e que el tiempo que en esto se ocuparen, no paguen tributo; antes, los naturales lo ayuden con algunas cosas para que se sustenten. (En nota: Que acuda al Presidente que provea lo que convenga.)

31.- Iten, porque la orden que han dado los santos Concilios para la dotrina destos naturales el que se críen los ministros en las iglesias y les enseñen la dotrina e otras policías y los adictos se catequicen en la dicha dotrina, a el menos tiempo de dos meses, para poderse bautizar; e de la dicha Dotrina algunos Encomenderos, justicias e otras personas, para su servicio han sacado indios e por haberse causado escándalo en la Dotrina hemos puesto con censura en nuestras constituciones; Vuestra Alteza sea servido mandar que ninguna persona saque indios ni indias de la dicha dotrina, con graves penas, las cuales se ejecuten con rigor para que los indios no escondan sus hijos ni hijas de la dicha dotrina, lo cual hacen entendiendo los dichos españoles los sacan de la dotrina.

32.- Iten, porque los hechiceros, omo e condevicis (sic), fueron ministros del demonio e, aunque algunos están bautizados,todavía el diablo les tienta para tornarlos a usar sus oficios, a lo cual conviene haya remedio e por nuestras constituciones lo tenemos proveído; Vuestra Alteza sea servido mandar que los dichos hechiceros, omos e condevicis, se pueblen junto a las normas de los curas para que con más aparejo los dotrinen e corrijan de sus errores e no dañen a los demás que son buenos cristianos.

33.- Iten, porque hay muchos indios infieles escondidos en partes donde los sacerdotes no los ven ni los indios oyen la dotrina cristiana porque los caciques los tienen escondidos para su servidumbre e otros viven entre los indios en su infidelidad, Vuestra Alteza sea servido mandar que todos los indios se re- 


\section{Doctrinas y Parroquias del Obispado de Quito /335}

cojan e pueblen juntos, con parecer de su cura, para que en su Dotrina haya lugar de bien enseñarlos en las cosas de nuestra santa fe católica por la orden que por nuestras constituciones para esto hemos dado.

\section{TRIBUTAR}

34.- Las cosas que se han fecho en los tributos ha sido el remedio en partes para dar alivio en la desorden que se tenía, llevando a estos indios los Encomenderos sus haciendas en servicios personales en diferentes modos, llevándoles el tributo sin tasa, otros muchos más de la tasa, e otros con excesivas medidas de la ropa, de lo cual ha habido e hay muchas quejas en Vuestra Real Audiencia y es de sus Repartimientos e otros que se ausentan, no descuentan la parte que les cabe a los dichos muertos e ausentes, antes, lo cobran todo por entero de los indios vivos y otros, que estando en las tasas que den a sus Encomenderos en oro coral de quinto, que es de diez e nueve quilates e tres granos, se lo hacen pagar en oro de veinte e dos quilates e medio. Vuestra Alteza mande restituir todos estos excesos a los indios, poner remedio en lo de adelante.

35.- Iten, de cualquier manera que los indios salen destas tierras, siendo su ausencia distante de sus casas, se les siguen muchos daños muriéndose en los caminos, unos sin bautismo y otros sin confesión; y en sus ausencias se pierden sus chácaras y sementeras, por lo cual e otros infinitos inconvenientes, Vuestra Alteza debe mandar que los tributos paguen los dichos indios a sus Encomenderos, se los paguen en sus tierras e que, al tiempo de la paga, el sacerdote-cura de los indios haga cuenta por parte dellos indios para que no reciban agravio.

36.- Iten, el tributo que dan los indios a sus Encomenderos sea uno e común de todos los indios de toda la tierra, e así lo tiene mandado Vuestra Alteza en la Nueva España, atendiendo a que por agora todo el tributo es personal porque el real, que son otros pechos y alcabalas, lo ha por agora suspendido y este tributo lo ha moderado. En la Nueva España cada indio paga en cada un año de tributo un peso de ocho reales y media fanega de maiz, e los indios de aquel reino, a su modo, son más ricos y tienen granjerías e aprovechamiento que los destos reinos, en los cuales bastaría que cada indio pagase el tributo de un año un peso y medio de plata; conviene que lo valga lo que hobiere de tributos y no más, porque lo demás es exceso.

37.- Iten, las tasas que de nuevo se hicieren para los tributos destos naturales y Encomenderos, se tenga consideración a que los indios tributen de lo que tienen en sus tierras e comarcas porque es lo que conviene al bien e susten- 


\section{6 / Augusto E. Albuja}

to de los indios e a la conservación de la tierra. (En nota: Que esto está proveído; acuda al padre que lo haga ejecutar).

38.- Iten, que los tributos de los indios no los puedan comutar los Encomenderos ni justicias, de los indios a españoles, porque todos son unos e dello resulta agravio para los indios.

39.- Iten, que las tasas se hagan como en la Nueva España, dando las dos partes de lo que se sacare al Encomendero y que la tercia e cuarta parte para que se saque la dotrina e se dé a cacique e principales porque tenga que ver el Encomendero.

40.- Iten, que los viudos, solteros por casar, de veinte años arriba, no paguen más que la mitad del tributo, e los viejos de grande edad e los mozos de hasta veinte años, no tributen.

41.- Iten, que los indios que murieren o se ausentaren del pueblo, por Vuestra Real Cédula dé libertad no se cuenten en el número de los tributarios sino los que quedan paguen lo que les caben, descontando los que faltan, rata por cantidad, e no se apremie a los caciques paguen por los dichos muertos o ausentes.

42.- Iten, que en el tributar los señores naturales principales e sus hijos sean libres, pues son hijosdalgo a su modo y, de juri gentium, son exentos los tales entre todas las naciones.

43.- Iten, se dé la tasa a los doctrineros para que manifiesten a los indios lo que a cada uno tocare en la paga del tributo e les declare no estar obligados a más, aunque se les pida más por el cacique e Encomendero no se lo debe dar por evitar los robos que los caciques en esto hacen a los pobres. (En nota: Que acuda al Presidente y Audiencia).

44.- Iten, que se guarden Vuestras Cédulas Reales en que se manda que ningún Encomendero entre ni esté en sus pueblos, ni su mujer, ni hijos, ni criados, por los grandes daños e perjuicios e ningún provecho que dello se le sigue a los indios, como consta por isperiencia. (En nota: Que está proveído y acudan al Presidente que lo haga guardar).

45.- Iten, que ningún español ni mestizo ande entre los indios en sus pueblos resgatando oro, plata o algodón, ni otro género de resgate ni granjería, porque los engañan con vino, con fruta, plumas, cuentas de vidrio, trampas, agujas o con otras cosas que valen poco a comparación de lo que les tomaba; e si se permitiese contratar, sea en los mercados e tiangues que se hacen en los pueblos de españoles. 


\section{Doctrinas y Parroquias del Obispado de Quito /337}

\section{BORRACHERAS E SUPERSTICIONES}

46.- Iten, que no se permita a los indios hacer borracheras ni mandalarse (sic), ni traer gargantillas los hombres, ni orejeras, ni atarse los cabellos sobre la cabeza, ni ofrecer chicha, ropa, ni otras cosas en las taquies, ni envijarse, ni tener armas, ni caballos de silla, ni servicio de hermanas casaderas, ni mujeres de sus padres difuntos, ni cuñadas, ni parientes de que se presuma, pues tienen por pecados porque hemos sido informados en este santo Sínodo y tenemos por ispiriencia que dello suceden grandes males e pecados e incestos que se deben remediar y estorbar que las tales patriense no se casen.

47.- Iten, los negros, mulatos, mestizos, e indios ladinos e yanaconas que andan entre los indios, son muy perjudiciales; Vuestra Alteza mande que vivan en los pueblos despañoles e no se permita anden entre los indios porque dan avilantez a los indios y les amuestran malas costumbres.

48.- Iten, a los indios se les hacen vejaciones en convenillos ante las justicias de las ciudades en cualquier delito y ansí, para que esto se evite como para que estos indios empiecen a tener policía, Vuestra Alteza debe proveer que entre los indios haya Alcaldes ordinarios, Regidores, Escribanos e Alguacil mayor, e que las causas que entre ellos contecieren ceviles y en las de las criminales, las determinen e tengan su jurisdición e juzgado como vuestros vasallos. (En nota: Que se proveerá lo que convenga).

49.- Iten, en esta tierra los Encomenderos e algunas justicias han despojado a los señores naturales de sus cacicazgos e señoríos e puesto en ellos yanaconas e criados por sus fines, Vuestra Alteza debe proveer que los señores naturales se les restituyan sus estados y señoríos, pues de los Reyes es deshacer las fuerzas y agravio. (En nota: Que está proveído lo que conviene).

50.- Iten, conviene mucho que perpetuamente ande visitando un Oidor, como Vuestra Alteza lo tiene mandado, y que, siendo posible, de cuatro en cuatro años se haga visita general para deshacer los agravios, renovar las tasas si hobiere necesidad, e proveer en los daños que a los indios se les hacen, porque, en saliendo vuesto Oidor de la visita, aunque lo deje bien concertados los Encomenderos, lo tornan de nuevo a hacer los agravios antiguos e más daño, a entender que ellos son los señores que han de permanecer y que no han de haber cosa, e así los traen vejados a los indios e hacen muchos malos tratamientos e grandes castigos a los que ellos se quejaron en la visita.

51.- Iten, por cuanto los Cabildos de vuestras ciudades reparten baldíos para estancias, labranzas y edificios, Vuestra Alteza mande con gran rigor se den 


\section{8 / Augusto E. Albuja}

a los pobres, conquistadores, pobladores que han servido en estos reinos y no reparta todo entre los Cabildos e amigos suyos.

52.- Iten, por Vuestras Cédulas Reales e premáticas está mandado que las justicias mayores e los Corregidores de pueblos de españoles, por cuanto se ponen para desagraviar a los indios e mirar por ellos e por los demás, no sean vecinos ni naturales de las tales ciudades; Vuestra Alteza sea servido mandar se guarde en su reino porque los inconvenientes notables vemos se siguen a los extranjeros e indios, e las tales justicias no pueden poner Alguacil mayor e vecino e natural del tal pueblo.

53.- Iten, que ningún Contador se provea en partes do tenga indios, ni chácaras, ni heredades, ni minas, ni se le permita contratación entre los indios de su distrito.

54.- Iten, por cuanto por vuestra real persona está mandado los registros de los indios se hagan sumariamente atento a su pobreza e miseria por no tener para pagar procuradores e letrados e los demás derechos, e porque no anden inquietos, especial en las causas eclesiásticas e las que son de mixto fuero, son muchas e si se hiciesen procesos, nuestros ministros se ocuparían en más tiempo en los pleitos e otras cosas de los indios e sería en daño de la ordenación de los santos sacramentos e doctrina; por lo cual, nos tenemos mandado a nuestros ministros que en causas ceviles no hagan procesos sino que, sumariamente, averiguada la causa, reprehendan, avisen, enmienden e corrijan como padres. Vuestra Alteza mande proveer como en semejantes casos, de no haber proceso ni ejemplar castigo, no sea necesario vuestro real auxilio. (En nota: Que lo acuerde al Presidente).

55.- Iten, por cuanto por nuestras constituciones tenemos mandado a los curas de los indios que en sus Parroquias celebren los oficios divinos todas las fiestas, en especial las pascuas e tiempos de procesiones e otras fiestas señaladas, para que den a entender los dichos nuestros curas a los indios los ministros (sic) que celebra en las tales festividades la santa madre Iglesia, y en los tales días sus Encomenderos les hacen venir a las ciudades a traerles amarezos (sic) e otros servicios personales que es nuevo tributo a las justicias, por ser ellos Encomenderos, e todos a sus deudos les fuerzan a ello a los caciques, los cuales traen consigo la más de la gente castigados e padecen e aún perecen muchos e los pueblos quedan solos, de manera que no se puede hacer decentemene lo que toca al culto divino e dotrina, Vuestra Alteza lo mande remediar con todo rigor. (En nota: Hasta el presente que no consienta que esto se haga). 


\section{Doctrinas y Parroquias del Obispado de Quito /339}

De los cuales dichos capítulos hago yo presentación para que, atento la necesidad que hay, Vuestra Alteza mande proveer en ello y en cada uno dellos dé remedio con justicia, pues es en servicio de Dios e de Vuestra Alteza e bien de la república e naturales e para ello etc.

Epíscopus Quitensis.

E de los dichos capítulos se mandó dar traslado al Cabildo desta ciudad de Quito, según todo lo susodicho consta y parece más largamente por el original de todo lo susodicho a que me refiero, y para que conste de todo ello, di el presente, que es fecho en Quito, en dos de mayo de mil y quinientos y setenta y uno. Y en fe de lo que dicho es y por mandado del Muy Ilustre Reverendísimo Señor Don Fray Pedro de la Peña, Obispo deste Obispado y del Consejo de Su Majestad que aquí firmó, lo fice escribir y aquí mi signo en testimonio de verdad.

Melchor de Alarcón, clérigo,

Notario apostólico /rubricado/.

\section{APÉNDICE \# 11}

Memorial que el Ilmo. Señor Pedro de la Peña, Obispo de Quito, envió al Excmo. Señor Don Francisco de Toledo, Virrey del Perú, pidiéndole que remedie ciertos abusos cometidos en algunas Doctrinas de la Diócesis.
AGI, Lima, Leg. 300
Quito, 4 de mayo de 1571

Primeramente, su Majestad y su Excelencia han mandado que se publicase la Bula que Su Santidad concedió a los religiosos de las Ordenes del Perú, por la cual les concedía facultad para que pudiesen administrar los sacramentos a los naturales y doctrinallos en las Doctrinas que les habían sido señaladas y se les asignasen, de que han sido gran confusión y aún escándalo en todo este Obispado porque, sin tener ningún monasterio Doctrina asignada en los lugares que tienen monasterios, por su propia autoridad, sin haber consentimiento del Prelado e sin asignarles las Doctrinas, administran los sacramentos; e demás desto, so color de la dicha Bula, piden y toman otras de nuevo donde están puestos clérigos curas en nombre de Su Majestad; y en esta ciudad, por la dicha razón, han 
deshecho dos Parroquias, que la una de San Blas y la otra de San Sebastián, habiéndose instituido con acuerdo y parecer del Presidente y Oidores desta Real Audiencia e con renunciación que los frailes hicieron de cualquier derechos que podían tener a los feligreses e indios de las dichas Parroquias y éstas deshicieron por razón de un colegio que pretenden, del cual certifico no se seguir ningún provecho a los indios, de lo cual tengo avisado a Vuestra Excelencia y enviados los recaudos dello.

2.- Iten, del capítulo antecedente resultan otros inconvenientes en deservicio del dicho y de Su Majestad porque los frailes menores de San Francisco, por razón de las dichas Doctrinas, contra su regla y orden, tienen propios y es que está situado para el cura lo reciben y apropian para sí como los clérigos, demás de la comida y sustento que los indios les dan; y, demás desto, gozan y les dan los oficiales reales el aceite e vino que Su Majestad les manda dar por razón de su pobreza que profesaron y la ocasión por donde los Encomenderos les metieron y sustentaron en su Repartimiento y en las Doctrinas fue entendido que no les habían de dar salario y agora lo llevan como los clérigos y más el sustento que les dan los indios.

3.- Iten, los dichos frailes franciscos de las Doctrinas que tienen y ocuparan por su abtoridad usan de jurisdicción, prenden y castigan y no admiten al Vicario del Obispo ni quieren que se cumplan sus mandatos, e de los agravios que hacen a los indios no tienen Superior.

4.- Iten, que los frailes del monasterio de San Francisco desta ciudad, no teniendo sobre los yanaconas, que en ella sirven a españoles, jurisdicción ni facultad para administrarles los sacramentos, se entrementen a se los administrar, casar y velar, contra lo que está ordenado por Derecho.

5.- Ansi mesmo hay otro inconveniente, porque la dicha Bula se concede por causa de que había falta de sacerdotes que doctrinasen los naturales, y en este Obispado hay muchos clérigos, hijos de conquistadoresy pobladores, muy buenas lenguas y de mucho recogimiento y hábiles; y demás de cesar la causa por qué se concedió la dicha Bula, éstos han de ser preferidos por los méritos e servicios de sus personas, pues muchos dellos son pobres y es justo que los dichos frailes no adquieran posesión para apropiar así las dichas Doctrinas, ni administren sacramentos, habiendo clérigos. Y suplica a Vuestra Excelencia la mande remediar para que la dicha Bula se guarde en esta limitación y habrá en qué aprovechar a los hijos de los conquistadores y pobladores, los cuales se aplicarán a virtud y se asegurará más la tierra. Y como los hijos de los tales conquistadores y po- 


\section{Doctrinas y Parroquias del Obispado de Quito /341}

bladores se crían entre los naturales e saben la lengua dellos y en ella les pueden predicar y enseñar, como agora los que hay lo hacen a los dichos naturales, tomarán mejor la Doctrina y los religiosos estarán en sus monasterios e no andarán tan destraidos como lo andan.

6.- Iten, parece grande inconveniente contra el real servicio y Patronazgo que los dichos religiosos tengan beneficios y Doctrinas, porque, una vez aprehendida la posesión, la adquiere el monasterio y por la dicha Bula pueden administrar los sacramentos y ansí los monasterios se hacen señores de los beneficios de las dichas Doctrinas y extingue y consume el derecho del Patronazgo, y pues el monasterio nunca ven acaso en que Su Majestad pueda presentar la persona que fuere servido al dicho beneficio y Doctrina; y parece cosa muy conveniente y necesaria que Vuestra Excelencia provea y dé orden cómo los dichos religiosos no adquieran el dicho derecho y que se les dé las provisiones en nombre de $\mathrm{Su}$ Majestad en cuanto su voluntad fuere. No he proveído a ninguno hasta ver lo que Vuestra Excelencia en esto ordena; y viniendo a tiempo en que los clérigos tengan las Doctrinas, podrían los religiosos salir de sus monasterios a enseñar, predicar y confesar, como se hace en los reinos de Castilla, y con esto darán muy buen ejemplo y se haría mucho fruto y no se perdería el derecho del Patronazgo de Su Majestad.

7.- Iten, Presidente e Oidores desta Real Audiencia han mandada a los Alcaldes ordinarios que no den auxilio a la justicia eclesiástica y como ellos están ocupados se dejan por falta de lo susodicho de castigar muchos pecados públicos. Vuestra Excelencia mande proveer sobrello que los Alcaldes ordinarios den los auxilios que les pidieren conforme a derecho.

8.- Ansi mesmo, como tengo escripto a Vuestra Excelencia, se tomó asiento con los religiosos para que de las Doctrinas que tuviesen pagasen como los clérigos para el servicio y pues las dichas Doctrinas han de ser beneficios, suplican a Vuestra Excelencia mande proveer que el dicho concierto y el que se tomó sobre las Parroquias se guarde y cumpla por ser cosa conviniente.

9.- Los días pasados envié a Vuestra Excelencia ciertos casos que presencié para que se ivitasen los pecados públicos y después prediqué en un sermón, que hice esta Cuaresma, que podía reservar los dichos casos y los publiqué e di a entender e dije que, conforme al santo Concilio Tridentino, el que dijese que no podía reservar los dichos casos era con temor y en perjuicio desto se juntaran todos los religiosos de las Ordenes y para me poner mal con el pueblo, como lo hicieron, acordaron que predicase un fray Andrés de Obando de la Orden de Santo Domingo, el cual predicó lo contrario diciendo que él y cualquier religioso po- 


\section{2 / Augusto E. Albuja}

drían absolver de los dichos casos, y que era Obispo y otras cosas bien descomedidas contra el Prelado, prometiendo absolución, con lo cual causó grande escándalo y demás desto allegar así el pueblo y los absolvieron indistintamente, de manera que yo quedé odioso y los Encomenderos y personas a quien tocaba con sus cargos.

10.- Iten, los Oidores de la Audiencia e sus mujeres se asientan en la capilla mayor e por la indecencia de sentarse allí las mujeres e dalles paz, hélo prohibido y por esto me han cobrado mucho odio y temor; agora la venida del Presidente, Vuestra Excelencia provea lo que convenga.

11.- Ansi mesmo, el Capitán Rodrigo de Salazar, vecino desta ciudad, hizo una capilla en el monasterio de San francisco de esta ciudad, la cual cae en la capilla mayor sobre el altar donde está el Santisimo Sacramento y allí se recogió la semana santa y tenía allí su servicio, dormiendo e comiendo allí, y el servicio del cuerpo sacaban por la capilla mayor delante del Santísimo Sacramento; causó escándalo en todo el pueblo y más en los naturales; y abrieron una puerta de la dicha capilla para la plaza pública y la llave tiene el dicho Salazar, y viendo la indecencia y desacato del Santísimo Sacramento y el riesgo en que estaba y está el Santo Sacramento porque por la dicha puerta que se abría quienquiera que quisiese entrar y a cualquiera hora lo puede hacer, envié al Provincial y Guardián que advirtiesen la tan indecencia y que viesen que en ninguna parte del mundo tal permitiera ninguna orden para persona pública, cuanto más particular, y que lo remediasen mirando la nota del pueblo y escándalo de los naturales, reprehendieron como suelen, lo cual, visto, procuré remediarlo por censuras y viendo lo que con tanto rigor me encarga el Concilio Tridentino, en el capítulo primero de reformatione, en la sesión veinte e dos, mandando con tanto rigor provea y ordene lo que la decendia del Santo Sacramento conviene, los religiosos y les avisar se juntarían para no obedecer y cosa ninguna y fue causa de nuevo odio y de recusación y desacatos a que se opuso el dicho Capitán Salazar. Envío los autos que sobre ello se hicieron, aunque no envío la recusación porque se llevó el proceso a la Audiencia, por parte del dicho Capitán. A Vuestra Excelencia suplico mande a los Prelados de las Ordenes que en semejantes casos no les mueva codicia ni ambición y que tengan respeto al Prelado.

12.- Asi mesmo, como los religiosos con estas Bulas traen desasosegado al pueblo, dándolas a entender de otra manera que ellas suenan, los vecinos no quieren pagar los derechos de curas e funerales y apelan de lo que se les manda; suplico a Vuestra Excelencia provea que se guarde en el llevar y paga de los dichos derechos la costumbre que se ha tenido. 


\title{
Doctrinas y Parroquias del Obispado de Quito /343
}

Y porque en todo espero de Vuestra Excelencia que proveerá de manera que Dios y Su Majestad sean servidos e yo no padezca tanto trabajo, no me obligo más; y siempre que se ofrezca de qué dar aviso y ocurrir a Vuestra Excelencia, lo haré nuestro Señor, etc. de Quito y de mayo cuatro 1571.

Fr. P. Epíscopus Quitensis/rubricado/.

\section{APÉNDICE \# 12}

\section{Carta dirigida por el Ilmo Sr. Pedro de la Peña al Rey Felipe II.}

\author{
AGI, Quito, leg. $76 \quad$ Quito, 15 de mayo de 1572
}

\section{C.R.M.}

Porque en la ejecución de lo que Vuestra Majestad me mandó por su Real Cédula informase, envío larga relación de todo el estado eclesiástico, sacerdotes y Doctrinas y sitio dellas, y lo que rentan cada una; y demás doy relación de cómo se administran los santos sacramentos a los naturales y de los abusos dellos y de los excesos y agravios que les hacen y de otras cosas muy importantes al descargo de vuestra real conciencia y gobierno y administración de justicia. No tengo más que remitirme a ella y suplicar a Vuestra Majestad mande se vea y provea en ello de remedio cual convenga en cosa tan importante a su real servicio, porque lo que por ella digo e informo a Vuestra Majestad es cierto y verdadero, sin demasía ninguna, antes en algunas cosas quedo falto por lo que debo al acatamiento de Vuestra Majestad y a la dignidad episopal que tengo. Y prometo a Vuestra Majestad, por la fe que a Dios y a Vuestra Majestad debo, que es así como se contiene en mi relación; y pues tanto conviene al remedio, Vuestra Majestad sea servido venga con brevedad. Cuya católica real persona guarde Nuestro Señor en su gracia con acrecentamiento de mayores reinos y señoríos. De Quito y de mayo quince de 1572 años.

De V.C.R.M.

humilde siervo y menor capellán

El Obispo de Quito/rubricado/. 


\section{APÉNDICE \# 13}

Expendientes enviados por el presbítero Gaspar de Ulloa al Rey Felipe II para que, en calidad de Patrón de las Indias, le presentara para la provisión canónica del beneficio curado de Tiquizambe-Sibambe-Pomallacta, al cual lo servía por nombramiento provisional extendido por el Ilmo. Señor Pedro de la Peña, Obispo de Quito.

AGI, Quito, leg. 82

Quito, 9 de septiembre de $1582 \quad$ Cuenca, 21 de octubre de 1572

Ilustrísimo Señor:

Gaspar de Ulloa, clérigo presbítero, residente en el Obispado de Quito, en el Pirú, digo que el Obispo de aquel Obispado por el orden de una Real Cédula de Su Majestad a él dirigida, fue proveído e denominado para el beneficio de la Doctrina de Tiquizambe, Sibambe e Pomallastla y dello le fue dado su título con la dicha Real Cédula, de lo cual, juntamente con la información de sus servicios, vida e costumbres, suficiencia e de como es hijo de conquistador, hace presentación dentro del tiempo de los dos años que le están asignados para ello.

Pide y suplica a Vuestra Señoría sea servido mandar ver los recaudos; y constando por ellos, cabe en su persona se le haga merced del dicho beneficio, en lo cual etc.

Nos, el Maestro Don Fray Pedro de la Peña, Obispo de Quito y del Consejo de Su Majestad etc., por cuanto Su Majestad Real, del Rey Don Felipe, nuestro Señor, es Patrón de todas las Dignidades y beneficios eclesiásticos destos reinos y es servido que sin presentación suya, no se haga la colocación de los beneficios, y tiene dada la orden que en el entretanto que los presenta, se provean, como se contiene en una Cédula firmada de su real nombre y refrendada de Marín de Gastelu, su secretario, y demás de la dicha Cédula, el Muy Excelente Señor Don Francisco de Toledo, Visorrey destos reinos, ha librado con título de Su Majestad otra provisión real, firmada de su nombre y sellada con el sello real, para que los dichos beneficios se presenten y se provean en nombre de $\mathrm{Su}$ Majestad, como se contiene en la dicha Cédula y provisión, que su tenor es el siguiente: El Rey, por cuanto somos informados que en las nuestras Indias, Islas e Tierra Firme del mar océano, algunas personas que tienen indios encomendados e también nuestros oficiales reales y justicias de ellas han tentado de pretender 


\section{Doctrinas y Parroquias del Obispado de Quito /345}

presentar los beneficios de sus Encomiendas y los dichos oficiales y justicias en los pueblos que están en nuestra Real Corona, y por otra parte, en estos mismos pueblos y en otros de españoles y en otras partes han tentado algunos Prelados hacer institución y colocación de los beneficios eclesiásticos sin presentación nuestra, y porque esto es contra nuestro derecho y preheminencia real, a quien pertenece la presentación, en las dichas nuestras Indias, de todas las iglesias, Dignidades y otros beneficios eclesiásticos, de cualquier calidad que sean, para que de aquí adelante se sepa lo que en esto se ha de hacer y se excusen los dichos excesos y pretensiones, por la presente encargamos a todos e cualesquier Prelados de las dichas nuestras Indias, a cada uno en su Diócesis, que sin presentación nuestra no hagan colocación ni provisión de ninguna Dignidad ni beneficio, de cualquier calidad que sea, y en los lugares donde conviniere haber curas, puedan los dichos Prelados dar el título de cura al clérigo o beneficiado por nos presentado e darle poder de administrar los santos sacramentos y hacer las otras cosas al oficio de cura pertenecientes. Y tenemos por bien, que habiendo en algún pueblo necesidad de clérigo beneficiado, porque no haya dilación en la doctrina cristiana y en la administración de los sacramentos, confesiones y otras cosas necesarias para la instrucción de nuestra santa fe católica y provecho de las ánimas, que habiendo la dicha necesidad, los dichos Prelados puedan dar licencia a los dichos clérigos para administrar los dichos beneficios sin hacerles dellos canónica institución, poniéndoles término de dos años, dentro de los cuales presenten las dichas licencias, con aprobación de sus Prelados, ante nos, en el nuestro Consejo de las Indias, para que a ellos o a quien más fuere servido presentemos a los dichos beneficios; y por virtud de la dicha presentación, les hagan los dichos Prelados la colación y canónica institución de los tales beneficios; y no trayendo la dicha presentación dentro del dicho término, los dichos Prelados remuevan los tales clérigos y den la dicha licencia a otros clérigos con la misma obligación de llevar la dicha presentación dentro de los dichos dos años. Y porque por nuestras Cédulas está hecha merced a los Prelados de las Iglesias de las dichas nuestras Indias, que habiendo falta de ministros en las dichas iglesias, puedan ellos poner los que faltaren hasta número de cuatro, y porque los proveídos por los dichos Obispos han tenido descuido de inviar por nuestras presentaciones, declaramos y mandamos que, dentro de los dichos dos años, sean obligados los así proveídos de llevar presentación nuestra ante los dichos Prelados, de la prebenda que así fueren proveídos por el tal Prelado; el cual término pasado no habiendo llevado la dicha presentación, los dichos Prelados remuevan y pongan otros en su 
lugar, obligándoles a llevar la dicha presentación dentro del dicho término. Los cuales dichos Prelados den sus cartas para nos en que den relación de la calidad de sus personas, vida y letras, para que nos, siendo servido, les hagamos la dicha presentación o presentemos a las personas que entendemos convenir más para el servicio de Dios, nuestro Señor y nuestro, lo cual mandamos que cumplan, asi los proveídos hasta agora como los que proveyeren de aquí adelante, hasta el dicho número de cuatro, conforme a las dichas nuestras Cédulas. E, asimesmo, mandamos que si algunos estuvieren por los tales Prelados proveídos hasta agora sin la dicha nuestra presentación, que los haga llevarla dentro de los dichos dos años, y no la llevando, pongan otros en su lugar con la mesma obligación de llevarla, como dicho es. Y mandamos que esta nuestra Cédula y lo en ella contenida sea guardado y cumplido en todo y por todo, como en ella se contiene, en las dichas nuestras Indias, Islas e Tierra Firme del mar océano, e que los Prelados que en ellas hobiere tengan cuidado de la guarda e cumplimiento della. Fecha en El Escorial, a tres de noviembre de mil e quinientos e sesenta y siete. YO, EL REY. Por mandato de Su Majestad, Martín de Gastelu.

Provisión.- Don Felipe, por la gracia de Dios, Rey de Castilla, de León, de Aragón, de las dos Sicilias, de Jerusalén, de Navarra, de Granada, de Toledo, de Valencia, de Galicia, de Mallorca, de Sevilla, de Cerdeña, de Córdoba, de Córcega, de Murcia, de Jaén, del Algarves, de Algecira, de Gibraltar, de las Islas de Canaria, de las Indias, Islas e Tierra Firme del mar océano, Conde de Barcelona, Señor de Vizcaya e de Molina, Duque de Atenas e de Neo-patria, Conde de Ruisellón y de Cerdania, Marqués de Oristan y de Gociano, Conde de Flandes y de Tirol, etc., por cuanto, por derecho y Bulas y concesiones apostólicas a nos y a los Reyes de Castilla y León concedidas por los Sumos Pontífices, somos Patrones de todas las iglesias, Doctrinas y otros cualesquier beneficios eclesiásticos de todas las Indias, Islas e Tierra Firme del mar océano, y conforme a esto nos pertenece y es a nuestro cargo el presentar los clérigos y sacerdotes que fueren necesarios para las Doctrinas y curazgos de nuestros reinos y provincias del Pirú, por las instrucciones, poderes y omisiones que tenemos dado a don Francisco de Toledo, nuestro Visorrey, Gobernador y Capitán General de los dichos nuestros reinos y provincias del Pirú e Presidente de la nuestra Audiencia y Cancillería Real que reside en la dicha ciudad de los Reyes, mandamos que se hagan las dichas presentaciones en nuestro real nombre; y con su acuerdo y con su parecer, habemos nombrado sacerdotes para algunas Doctrinas, asi del Arzobispado de los Reyes como en otras partes, e conviene que todas las demás se provean 


\section{Doctrinas y Parroquias del Obispado de Quito /347}

por presentación hecha en el dicho nuestro real nombre, en continuación y conservación del dicho nuestro Patronazgo, y porque por algunas causas cumplideras al servicio de Dios, Nuestro Señor, y nuestro, y bien destos reinos, conservación y conversión de los naturales dellas, el dicho nuestro Visorrey ha mandado que se haga la visita general y sale por su persona a hacer la parte que della pudiere, y por la distancia que hay desde donde va a la ciudad de Quito, es necesario y conviene dar poder y comisión al Reverendo in Christo Padre, Don Fray Pedro de la Peña, Obispo de Quito, para que en el entretanto que por nos, con acuerdo del dicho nuestro Visorrey, se hacen las presentaciones en las Doctrinas y curazgo del dicho Obispado, asi en las personas que están puestas por el dicho Obispo del dicho Obispado en las dichas Doctrinas e curazgos, como en las demás que vacaren de aquí adelante se hobieren de proveer, las haga y provea en nuestro real nombre el dicho Obispo porque, si se hobiese de ocurrir adonde estuviese el dicho nuestro Visorrey, habría mucha dilación en la provisión dellas, por lo que dicho es, y sería causa que los indios estuviesen sin doctrina y administración de sacramentos e sería de grande inconveniente para su conversión y podrían morir algunos de ellos sin baptismo ni confesión; y para ello fue acordado por el dicho nuestro Visorrey que debíamos mandar dar esta nuestra carta y provisión real en la dicha razón, e nos tuvímoslo por bien, por la cual damos poder e comisión al dicho Obispo de Quito para que pueda hacer y haga en nuestro real nombre la nominación y presentación de las dichas personas a las dichas Doctrinas, así en los sacerdotes que están nombrados por él en las Doctrinas y curazgos y lo que adelante vacaren como en las demás que adelante se hobiere de hacer proveer, hallándolos, por su diligente examinación, hábiles y suficientes, según e de la manera que nos lo podemos hacer en continuación y conservación del dicho nuestro Patronazgo Real, en el entretanto, con acuerdo del dicho nuestro Visorrey, hacemos las dichas presentaciones a cualesquier dellas para que, en virtud de la dicha presentación que el dicho Obispo hiciere en nuestro nombre, juntamente con la licencia que les diere para la administración de sacramentos y en todo a ello anejo y concerniente, como si por nos fuesen nombrados, aceptando e recibiendo las tales personas su provisión y licencia en virtud de la dicha presentación, la cual dicha comisión, poder y facultad damos al dicho Obispo con todas sus incidencias e dependencias, anecidades y conexidades, tal cual, en tal caso de derecho, se requiere, con que vaya incerta en las presentaciones, nombramientos que en virtud della el dicho Obispo ha de hacer a las dichas personas esta dicha comisión y con que se haga ante uno de los nuestros escribano de cáma- 


\section{8 / Augusto E. Albuja}

ra de la dicha Real Audiencia de Quito, cual al dicho Obispo pareciere y no de otra manera, atento que, como dicho es, se ha de hacer todas en nuestro real nombre; y le rogamos y encargamos que tenga mucha consideración a no hacer agravio a los religiosos en quitarles de las Doctrinas en que ya estuvieren puestos y aprobados. Fecho en el pueblo de la concesión, que es en la provincia de Jauja, a diez y ocho días del mes de noviembre de mil e quinientos e setenta años. Don Francisco de Toledo y Alvaro Ruiz de Navamuel, escribano de Cámara de su católica Real Majestad, la fice escrebir por su mandado, con su acuerdo de su Visorrey. Registrada. Diego de Mollinedo. Canciller, Gaspar de Solís.

Y porque conforme a la dicha Cédula y provisión real, nos habemos hecho y ordenado, en este nuestro Obispado, beneficio y proveído en ellos a personas hábiles y suficientes, en nombre de Su Majestad y al presente, atendiendo la calidad y suficiencia de vos, el Reverendo Padre Gaspar de Ulloa, constándonos que sois hijos de padres conquistadores y pobladores deste reino y natural desta ciudad de San Francisco de Quito y benemérito en este Obispado y sabéis la lengua de los naturales y en ella les confesáis y predicáis, os nombramos, en nombre de Su Majestad, al beneficio de Alausí, Tiquizambe, Pomallata y Sibambe, términos y jurisdición de la ciudad de Cuenca, que por la presente vos damos poder y facultad para que como tal cura beneficiado de Alaua (sic), podáis administrar y administréis los santos sacramentos y divinos oficios a los españoles, caciques e indios que estuvieren y residieren en el dicho beneficio y pueblos dél, e les oir e oyáis de confesión y los absolver, conforme a derecho, guardando, cuanto a los españoles los casos que tenemos reservados, y a los naturales, demás de lo susodicho, le podáis absolver y absolváis de los casos por Su Santidad cometidos a los Prelados destas partes, Y vos encargamos la conciencia, que con toda deligencia y cuidado entendáis en la instrución y conversión de los naturales, e que con todo amor procuréis de los atraer a la congregación de los fieles, porque con vos descargamos la conciencia de Su Majestad y la nuestra. Y por la ocupación y trabajo que en la dicha Doctrina habéis de tener, para ayuda a vuestra sustentación, mandamos sea dado y pagado trescientos y cincuenta pesos de oro, con que de ellos gastéis el vino y cera necesaria para el culto divino.

Y para lo que dicho es y lo a ello dependiente y anejo, os damos poder y facultad y cometemos nuestras veces y casos ordinarios y vos mandamos que dentro de dos años os presentéis con esta licencia o su traslado en manera que haga fe ante Su Majestad en su Real Consejo de las Indias, conforme a la dicha Real Cédula, so pena que os removeremos conforme a ella. 


\section{Doctrinas y Parroquias del Obispado de Quito /349}

E mandamos a todas e cualesquier personas que por tal beneficiado-cura del dicho beneficio y Doctrina y pueblos della os hayan e tengan por tal e usen con vos los dichos oficios y vos acudan y hagan acudir con los derechos, proventos y emolumentos a los dichos oficios anejos, debidos e pertenecientes; y vos guarden y hagan guardar todas las honras y preheminencias que, por razón de los dichos oficios, debéis haber y gozar; y no vos impidan en el uso y ejercicio dellos, so pena de excomunión mayor. Fecho en Cuenca, en veinte e uno de octubre de mil e quinientos y setenta y dos años.

Fr. P. Epíscopus Quitensis /rubricado/

Por mandato de su Señoría Reverendísima,

Luis de Ortega,

apostólico notario /rúbrica/.

\section{APÉNDICE \# 14}

Examen de algunos sacerdotes de la Diócesis de Quito para recibir licencia de confesores.

AGI, Quito, leg. $76 \quad$ Quito, 11, 14 y 16 de febrero de 1574

El licenciado Michael de la Torre, cura desta Santa Iglesia.-

En la ciudad de Quito, a once días del mes de febrero de mil e quinientos y setenta y cuatro años, ante el Muy Ilustrísimo e Reverendísimo Señor el Maestro Don Fray Pedro de la Peña, Obispo deste dicho Obispado del Consejo de Su Majestad, y en presencia de mí, Hernando Despinar, clérigo subdiácono, notario, pareció el Licenciado Michael de la Torre, cura desta santa Iglesia y en cumplimiento del auto proveído por su Señoría Rma. acerca del examen que se ha de hacer de los confesores, se presentó ante su Señoría Rma. para ser examinado conforme al Motu Proprio de Su Santidad.

Su Señoría Rma. le examinó e, haciendo el dicho examen, le hizo las preguntas siguientes:

- Fuele preguntado: ¿qué cosas se requieren para que un confesor fuese idoneo para confesar?. E dijo que tres: poder, saber y santidad de vida. 
- Fuele preguntado: este poder ¿¿de quién lo recibía el tal sacerdote? Dijo que el sacerdote tiene necesidad de dos potencias o dos poderes, el uno que llaman potestas ordinis, el cual tienen todos los sacerdotes desde la hora que se ordenaron, otro poder llaman jurisdicionis, y este poder les debe venir del Papa para todo el mundo o del Obispo para su Obispado, y conforme al poder que les dieren pueden absolver.

\section{El padre Juan Yánez, clérigo presbitero.-}

Este dicho día, mes y año, ante su Señoría Reverendísima, pareció el Padre Juan Yáñez, clérigo presbítero, y en cumplimiento del auto por su Señoría Reverendísima proveído acerca del examen que se ha de hacer de los confesores, se presentó ante su Señoría reverendísima, y en presencia de mí, Hernando Despinar, clérigo subdiácono, notario para el dicho examen, le hizo las preguntas siguientes:

- Fuele preguntado: ¿qué partes ha de tener el confesor para confesar y que sea idoneo confesor?. Dijo que dos: que ha de tener ciencia e buena conciencia, de manera que ha de saber lo que hace y entender bien lo que toca a las conciencias de los penitentes, $y$ ha de tener bondad de manera que sin pecado mortal confiese.

- Fuele preguntado: si el tal confesor, confesaba estando en pecado mortal, ¿si verdaderamente absolvía?. Dijo que sí, aunque pecaba el tal confesor mortalmente, e que no solamente este sacramento es válido recebido del que está en pecado mortal, pero aún todos los otros sacramentos lo son.

- Fuele preguntado del modo que tiene y se debe tener en confesar, acerca de las peguntas que se ha de hacer al penitente al principio de la confesión e cómo se ha de haber acerca del aparejo e dispusición. E respondió a todo razonablemente, aunque no tan en consecuencia por no deber estar ejercitado de próximo en leer libros, según él dijo; por lo cual, su Señoría Reverendísima, de presente, le manda por obra que, pues es buen latino e de tan buenas canas y edad e prudencia, para que en el servicio de Dios haga más fruto, tenga e compre luego, dentro de ocho días, la Suma Silvestrina o la de Navarro o la de Pedraza o otra que sea Suma de casos de conciencia que sea de persona docta e aprobada.

\section{El padre Miguel Delgado.-}

En la ciudad de Quito, a 14 días del mes de febrero de mil e quinientos y setenta e cuatro años, ante el Muy Ilustre e Reverendísimo Señor el Maestro 


\section{Doctrinas y Parroquias del Obispado de Quito /351}

Don Fr. Pedro de la Peña, Obispo deste dicho Obispado y del Consejo de Su Majestad etc., y en presencia de mí, Hernando Despinar, clérigo subdiácono, pareció el Padre Miguel Delgado, cura de Puratico, y en cumplimiento del auto proveído por su Señoría Reverendísima acerca del examen que se ha de hacer de los confesores, se presentó ante su Señoría Reverendísima para ser examinado conforme al Motu Propio.

- Fuele preguntado: ¿cuántas cosas se requieren para que un confesor sea idoneo para poder confesar?. Dijo que se requiere que tenga ciencia y prudencia y que sea aprobado y, presupónese lo principal, que sea sacerdote.

- Preguntado, ¿qué ciencia ha de saber?. Dijo: que sepa bien lo que toca a la penitencia y todo lo anejo a ella.

- Preguntado, si ¿bastará para saberse esto ser latino y tener libros?. Dice que mejor sería saber Teulugía y cánones; pero, que si no, que esto basta.

- Preguntado, si un sacerdote que no sabe latín, si ¿podría ser expuesto? Dice: que si lee las Sumas que hay casos de conciencia,que hay muchas y muy buenas en romance, y es hombre de buena prudencia y expiriencia y temeroso de Dios, que bien puede.

- Preguntado, que si se viniese a confesar con él un hombre, que ¡cómo le confesaría?. Dice: que le preguntaría cuánto había que ha se confesaba y que si venía apercibido para confesarse; y después, le preguntaría los pecados y las demás cosas anejas a él, conforme al estado que tuviere y hubiese tenido.

- Fuéronle preguntadas otras cosas de casos de conciencia y respondió como quien de todo tiene poca espiriencia; y por ser buen latino, se le manda compre y tenga al presente una Suma de casos de conciencia de autor auténtico, lo cual se le manda so pena de excomunión ipso facto incurrenda, que no vaya sin ella. Y, al presente, se le da facultad para que confiese a negros y gente menuda de mestizos y mulatos y a los indios ladinos y a los españoles estancieros que están en su distrito.

- Que lo que toca a los indios y la lengua general del inga, fue examinado por el Padre Diego Lobato y afirmó, debajo del juramento que tiene hecho, que puede confesar a todos los indios de su Dotrina y que su Señoría le mande estudie más en la lengua porque, aunque la sabe razonablemente, con la buena habilidad que tiene, puede saber muchas curiosidades de la dicha lengua y aprovechar mucho en ella. 
El padre Antonio Borjes.-

En la ciudad de Quito, a 14 del mes de febrero de mil e quinientos e setenta e cuatro años, ante el Muy Ilustre e Reverendísimo Señor el Maestro Don Fray Pedro de la Peña, Obispo deste dicho Obispado del Consejo de Su Majestad etc., y en presencia de mí, Hernando Despinar, clérigo subdiácono, notario, pareció el Padre Antonio Borjes, cura de Chapi, y en cumplimiento del auto proveído por su Señoría Reverendísima acerca del examen que se ha de hacer de los confesores, fue preguntado: ¿cuántas cosas son necesarias para que un confesor sea idoneo confesor?. Dijo: que tres: poder y ciencia y prudencia y bondad y que tenga secreto.

- $\quad$ Preguntado que ¿qué poder ha de tener y de quién?. Dijo: que sea presbítero y poder de jurisdición, que es que tenga poder del Papa o del Obispo o del Ordinario, porque sin el tal poder no puede absolver sino en extrema necesidad, que es en artículo mortis, y, entonces, no habiendo otro, puede absolver de todas censuras reservadas al Papa y al Obispo.

- $\quad$ Preguntado que ¿de quién tiene, entonces, el tal poder?. Dijo: que de Dios porque es sacerdote y no hay otro que absuelva y no perezca aquel alma, y del Papa y del Obispo le tiene implícito, y explícito en el derecho.

- Preguntado que si aquel tal penitente tiene deudas de restitución de hacienda y fama, ¿qué hará el confesor? y ¿qué, conforme a la hacienda que dejare, hacer con los albaceas?. Que las restituyan y presupuesto que el tal penitente deje declaradas las deudas.

- Preguntáronsele otras cosas de casos de conciencia, mándasele tenga los libros de casos de conciencia que tiene y que sea en ellos, so pena de descomunión, y que, debajo de la misma pena, no tenga instrumento de música en su poder y se le encarga mire muy bien por los estancieros y ganaderos que están en su distrito y los confiese.

- En lo que toca a los indios y la lengua general del inga, fue examinado por el Padre Diego Lobato y afirmó, debajo del juramento que tiene hecho, que puede confesar los indios de su Dotrina y los caciques della, y que su Señoría Reverendísima le mande que, pues es buena lengua, se ejercite en ella y podrá hacer mucho fruto en las almas de los naturales, y lo firmó de su nombre

\section{El padre Melchior de Alarcón.-}

En la ciudad de Quito, a diez y seis de febrero de mil e quinientos y setenta e cuatro. 


\section{Doctrinas y Parroquias del Obispado de Quito /353}

- Fuele preguntado ¿qué cosas son necesarias para que un sacerdote sea idóneo confesor?. Dijo: que tenga jurisdición ordinaria y ciencia y prudencia.

- Preguntado ciertas cosas destas materias, parece muestra hasta ahora no estar experto en materia de confesiones. Mándasele tenga las Sumas de conciencia, en especial la Suma que dicen de Navarro para que, experto, adelante, con la buena habilidad y prudencia, que pueda ayudar; y en tanto se le da licencia para que pueda confesar la gente menuda despañoles y mestizos y todos los negros y negras. Fr. Epíscopus Quitensis /rubricado/.

En lo que toca a los indios y a la lengua general del inga, fue examinado por el Padre Diego Lobato y afirmó, debajo del juramento que tiene hecho, que puede confesar a todos los caciques deste Obispado, alcaldes, oficiales y toda suerte de indios, sin exceptuar ninguno, y lo firmó de su nombre.

Diego Lobato/rubricado/.

\section{APÉNDICE \# 15}

Provisión canónica del beneficio de la ciudad de Jaén hecha por el Obispo de Quito, Ilmo. Sr. Pedro de la Peña, en favor del presbítero Juan de Herrera Sarmiento.

AGI, Quito, leg. $46 \quad$ Loja, 10 de mayo de 1574

Nos. el Maestro don Fr. Pedro de la Peña, Obispo deste Obispado y del Consejo de Su Majestad etc., por cuanto la Majestad Real del Rey Don Felipe Nuestro Señor es Patrón de las Dignidades y Beneficios eclesiásticos destos reinos y es servido que, sin presentación suya, no se haga colación de los dichos beneficios y tiene dada la orden como, en el entretanto que los presenta se provean, como se contiene en una su Real Cédula firmada de su real mano y refrendada del Secretario Martín de Gastelu; y en la provisión que en su real nombre despachó e libró el Muy Excelente Señor Don Francisco de Toledo, Visorrey destos reinos, para proveer los beneficios y curatos y Doctrinas deste Obispado entretanto que Su Majestad los presenta, que por su notoriedad no van aquí insertas. Por ende, en cumplimiento de lo contenido en la dicha Real Cédula y proveído por Su Majestad, porque en la ciudad de Jaén hay necesidad de clérigo beneficiado, acatando la habilidad y suficiencia de vos, el Reverendo Padre Juan Herrera Sar- 


\section{4 / Augusto E. Albuja}

mientos, que nos consta que sois benemérito en este Obispado, os damos licencia en nombre de Su Majestad, conforme a la dicha Real Cédula, para que seáis beneficiado en la iglesia de la ciudad de Jaén, la cual dicha licencia vos damos con que dentro de dos años primeros siguientes presentéis esta dicha licencia ante $\mathrm{Su}$ Majestad Real, en el su Consejo Real de las Indias, para que a vos o a quien $\mathrm{Su}$ Majestad fuere servido presente el dicho beneficio, e no trayendo la dicha presentación dentro del dicho término, os habemos por removido del dicho beneficio e daremos licencia a quien viéremos que conviene para que sirva el dicho beneficio.

Mandamos que os acudan con la parte que por la ereción deste Obispado pertenece a semejantes beneficiados. Otro sí, en cuanto nuestra voluntad fuere, os proveemos por cura en la dicha ciudad e vos damos licencia para que como tal podáis administrar y administréis los santos sacramentos a los vecinos y moradores estantes e habitantes en la dicha ciudad e a todas las personas de cualquier calidad y condición que en ellas tuvieren y residieren, y los absolver de todos e cualesquier pecados, crímenes e delitos que hobieren cometido y en que hobieren incurrido, que para ello vos damos poder y cometemos nuestras veces y casos ordinarios. Otro sí, vos mandamos por nuestro vicario en la dicha ciudad y sus términos para que como tal congnozcáis de todas las causas civiles y criminales tocantes a nuestro fuero y jurisdición eclesiástica, excepto en los casos de matrimonio, cuanto a la separación, que en los dichos casos, hechos los procesos, nos los remitiréis para que nos lo determinemos y sentenciemos; y en los casos tocantes a la fe, los remitiréis a quien pertenece; y en los demás casos, haréis justicia conforme a derecho y al Sínodo deste nuestro Obispado. E para el uso y ejercicio de la jurisdicción eclesiástica, nombraréis los oficiales necesarios en las partes que por nos no estuvieren o fueren nombrados.

E mandamos a todas e cualesquier personas, de cualquier calidad y condición que sean, que por tal beneficiado vos hayan y tengan e por tal nuestro cura y vicario usen con vos los dichos oficios e vos acudan e hagan acudir con todos los derechos, probentos (sic) y emolumentos, a los dichos oficios anexos e pertenecientes, e vos guarden y hagan guardar todas las honras e preminencias a los dichos oficios anexos y debidos e pertenecientes, so pena de excomunión mayor los mandamos; que tengáis el Sínodo por nos fecho, signado y firmado del nuestro Notario infrascripto, para que sepáis lo que conforme dél debéis hacer. Otro sí, mandamos e damos por ningunas otras cualesquier provisiones que hayamos dado antes desta para el dicho beneficio y queremos que sola ésta vala 


\section{Doctrinas y Parroquias del Obispado de Quito /355}

(sic); y mandamos al dicho Juan de Herrera Sarmiento, so pena de excomunión mayor late sentencie ipso facto incurrenda lo contrario haciendo, y de ducientos pesos de buen oro, que no deje el dicho beneficio y curato hasta que dé residencia de su persona y cuenta de todo lo que ha sido a su cargo a nos o en la persona que por nos fuere señalada y nombrada.

En testimonio de lo cual mandamos dar e dimos presente, firmada de nuestro nombre y sellada con nuestro sello, refrendada del nuestro Notario, que es fecha en la ciudad de Loja, a diez días del mes de mayo de mil e quinientos y setenta e cuatro.

Fr. P. Epíscopus Quitensis/rúbrica/

Por mandato de Su Señoría Reverendísima

Hernando Despinar,

Notario /rúbrica/.

\section{APÉNDICE \# 16}

Carta dirigida por el Ilmo. Sr. Pedro de la Peña para manifestar a Su Majestad, el Rey Felipe II, el poco prestigio de que goza en la Diócesis de Quito.

AGI, Quito, leg. 76

Quito, 25 de febrero de 1575

\section{C.R.M.}

Si no tuviera consolación y favor de Vuestra Majestad según los trabajos que paso, me diera pena y turbara mi ánimo y esfuerzo a no pasar lo que paso en el gobierno deste Obispado, porque ningún socorro ni ayuda tengo de vuestro Presidente e Oidores, antes ellos me hacen abatir, si Dios no fuese servido esforzarme con los favores que de Vuestra Majestad recibo, porque sobre lo que proveí de los asientos de las mujeres de Presidente e Oidores cerca de los estrados de la Iglesia y haber quitado que Diácono no diese paz sino un clérigo, e que no se asentasen sus mujeres en la capilla mayor junto con ellos, les soy odioso, que ni tengo jurisdicción en lo eclesiástico, ni aún los clérigos de mi Obispado me tienen la reverencia e obediencia que me tenían y debían, y mucho me- 


\section{6 / Augusto E. Albuja}

nos los seglares que por dalles contento totalmente me han quitado la obediencia de Pastor, y lo que peor es que tienen contra mí insolencias y atrevimientos como a enemigo porque procuro su bien y conciencias, que es cosa que me duele mucho. Han venido a tan mal término estos negocios, que los religiosos de las Ordenes de San Francisco y Santo Domingo, confederados con vuestro Presidente e Oidores, contra mí nombraron jueces conservadores en perjuicio de vuestro Patronazgo Real e hicieron lo que Vuestra Majestad mandará ver por los testimonios e informaciones que envío, y desto estará Vuestra Real Majestad cierto durante el tiempo del oficio de este vuestro Presidente e Oidores, cuan regida y gobernada estará esta provincia y en qué estado estarán las cosas eclesiásticas y, andando desta manera, el suceso que Dios dará en ellas no lo remediando Vuestra Real Majestad como conviene.

Y por la que Vuestra Real Majestad me hizo merced, entendí que la nominación y presentación de los beneficios venía cometido a vuestro Presidente; y si esto se hubiese de ejecutar mayormente en este tiempo o en otro cualquiera, sería de muy gran inconviniente al estado eclesiástico, porque habiendo de recibir los clérigos y sacerdotes los beneficios por nominación y presentación de vuestro Presidente, totalmente quitarían la obediencia al Prelado; y en estas tierras tan remotas y estancias extrañas, con favor de los que los proveyesen, andaría todo el estado eclesiástico abatido y desordenado y ternían Presidente e Oidores mano para extirpar el autoridad del estado eclesiástico por pequeños enojos que tuviesen, y así los Prelados no habría para qué los hobiese y todo andaría confuso y en gran daño de la edificación de los naturales; y pues con los Prelados hacer la nominación y presentación en vuestro real nombre, se cumple con vuestro real intento e que ningun otro beneficiado sea admitido si no se hiciese la nominación y presentación en vuestro real nombre ante escribano de Cabildo, y con esto se quitan todos los inconvenientes arriba dichos. Y Vuestra Real Majestad lo mande proveer como convenga a su real servicio y descargo de vuestra real conciencia y cesen estos inconvenientes.

Diego de Arce, clérigo presbítero, va a esos reinos para volver; lo principal a dar cuenta a vuestra real persona de todo lo de acá, espiritual y temporal, aún del asiento y dispusición de la tierra y particularidades della; y si no entendiera importar mucho vuestro real servicio, no le dejara ir. Tiene expiriencia de la tierra, de veinte e dos años que ha que pasó a ella con licencia de Vuestra Majestad, y tiene buen entendimiento, es curioso y muy celoso de vuestro real servicio; al cual conviene sea oído de vuestra real persona y se le puede dar todo crédito. 


\section{Doctrinas y Parroquias del Obispado de Quito /357}

Y nuestro Señor la católica real persona de Vuestra Majestad guarde por muy largos años con acrecentamiento de mayores reinos. De la ciudad de San Francisco del Quito, a 25 de febrero de MDLXXV años.

De V.C.R.M. leal vasallo y menor capellán que sus reales manos besa,

El Obispo de Quito/rubricado/.

\section{APÉNDICE \# 17}

Nombramiento de Vicario General en toda la Gobernación de Juan de Salinas Loyola, extendido por el Obispo de Quito, Ilmo. Señor Pedro de la Peña, en favor del presbítero Juan de Olmos Volaños.

\section{AGI, Charcas, leg. $142 \quad$ Loja, 12 de octubre de 1575}

Nos, el Maestro Don Fray Pedro de la Peña, Obispo del Quito, del Consejo de Su Majestad etc., por cuanto en la Gobernación de Juan de Salinas hay muchos pueblos despañoles e de indios, cuyos curatos y beneficios y vicarías proveemos y habemos proveído, y de presente por haber muchos días que la dicha Gobernación no se visita, como por ser tierra áspera y nuevamente descubierta, conviene en ella tengamos Juez que mantenga en paz y justicia nuestra jurisdición.

Confiando de vos, el Reverendo Padre Juan de Volaños, nuestro cura y vicario de la ciudad de Loyola, en la dicha Gobernación, que sois persona cual conviene para lo de yuso escripto, por la presente vos nombramos por nuestro Vicario General en toda la dicha Gobernación de Juan de Salinas: ciudades, villas y lugares e de los pueblos de indios della y de todos los clérigos y vecinos y estantes y habitantes e indios de la dicha Gobernación, y asi vicarios como doctrineros, en tal manera que sobre ellos tengáis jurisdición civil y criminal, conociendo de sus culpas y otros negocios que ante vos vengan contra los dichos clérigos de pedimiento de parte y contra los legos de oficio e de pedimiento de parte oir e determinar las personas como convenga, ejecutando vuestro juzgado y otorgando las apelaciones que de vos se interpusieren para ante nos o ante nuestro Provisor deste Obispado o como de derecho hobiere lugar, haciendo en todo cumplimiento de justicia en cualquier parte de la dicha Gobernación. Y vos da- 


\section{8 / Augusto E. Albuja}

mos facultad para que, faltando en alguna parte de la dicha Gobernación alguno de los curas y vicarios de ciudades, villas y lugares de españoles o de pueblos y Doctrinas de indios, podáis, en nuestro nombre, ponerlo y señalarlo el que vos pareciere conviene, examinándole primero si trae recaudos bastantes de su Prelado, dónde viene; y porque hay muchos religiosos de todas Ordenes que suele entrar en la dicha Gobernación y andar en ella apóstatas e sin licencia de su Prelado, la doy ausentes de su clausura a estos tales, vos mandamos que, demás de no encargarles curatos ni Doctrinas, no les déis ni podáis dar licencia para administrar los santos sacramentos, ni para predicar, hasta que de sus Prelados traigan bastante licencia y absolución de su via (sic)e trato, porque así se nos ha pedido por los dichos sus Prelados de la dicha ciudad de Quito.

Y porque en la Doctrina de los naturales de Loyola ha destar (sic) Juan Ruiz Flores, clérigo presbítero, a quien tenemos nombrado por cura de la dicha Doctrina, vos encargamos que tengáis sobre él jurisdición plena en tal manera que, demás de la jurisdición sobre dicha, si supiéredes o entendiéredes que no usa su oficio como por nos le es encargado, y con la decencia que conviene, de oficio e de pedimiento de parte conozcáis de sus causas, y si vos pareciere que conviene, le desterréis de la dicha Doctrina y pongáis en ella otro sacerdote haciendo en ello el deber; demás de lo cual, porque nos tenemos proveído para la Doctrina de Aconipa, en Jaén, al Padre Diego Flores y somos informados se quiere ir la dicha Gobernación, sin ir vía reta, como por nos está mandado, vos mandamos que con toda diligencia y cuidado vos informéis si así pasare; y siendo así, por vos e por persona que para ello podáis nombrar, prenderéis al dicho Diego Flores, y, castigado, lo enviaréis, a su costa, con guarda, a la dicha Doctrina, porniéndole en nuestro nombre censura.

Y para el cumplimiento de lo susodicho y sobre todo lo susodicho hacer y hagáis lo que nos haríamos presente seyendo porque cuan cumplido poder tenemos para ello, vos lo damos con libre y general administración y revelación en forma de derecho, para lo cual dicho es y para lo que en vuestro juzgado nombréis Notario, Fiscal y los demás oficiales que para la ejecución de lo susodicho necesario fuere.

E mandamos a todos los nuestros curas, vicarios y a los demás personas estantes y habitantes en la dicha Gobernación, de cualquier ciudad que sean, obedezcan y acaten al dicho Juan de Volaños por tal nuestro Vicario General de toda la dicha Gobernación, y acudan a vuestros llamamientos, hagan ante nos cualquier juramento e declaración que por él nos fueren mandado, so las penas 


\section{Doctrinas y Parroquias del Obispado de Quito /359}

que de nuestra parte vos pusiere, en las cuales les damos por incurridos al que lo contrario hiciere. Fecho en Loja, a doce de octubre de mil y quinientos setenta y cinco años.

Fr. P. Epíscopus Quitensis

Por mandato de su Señoría Ilustrísima, Alonso Núñez de Sampedro, notario apostólico /rúbrica/.

\section{APÉNDICE \# 18}

Informe que Alonso de Herrera presentó al Rey porque algunos religiosos no querían someterse al examen previo para recibir del Obispo la licencia para confesar en la Diócesis de Quito.

AGI, Quito, leg. $76 \quad$ Madrid, 29 de agosto de 1576

Muy poderoso Señor:

Alonso de Herrera, en nombre del Obispo de la santa Iglesia de Quito, digo que habiendo predicado el dicho Obispo un sermón diciendo que, conforme a un Propio Motu de Su Santidad, ningún confesor podrá confesar sin ser por el dicho Obispo examinado y que mirasen todos los que se confesaban con los que no estaban por él aprobados, no los daba por confesados, ni que cumplían con el precepto de la santa madre Iglesia, y es así que un fray Antonio de Erbias en un sermón dijo palabras muy escandalosas, derechamente contra lo que el dicho Obispo había predicado, diciendo que aquéllos eran papeles y no Propio Motu de Su Santidad y que ellos podían asolver y asolvían a todos los que se fuesen a confesar con ellos y ansí lo hicieron, sin que quisiesen examinar ni examinaron, de que redundó grande escándalo entre los frailes cristianos de aquel Obispado; y aunque se dio noticia a la Real Audiencia, no lo remedió.

A Vuestra Alteza suplico se dé Cédula para que se guarde el Propio Motu porque los dominicos y franciscanos, yendo contra él, no se quieren examinar, y reprehensión para el Audiencia por no lo haber querido remediar, y que el Prelado castigue el exceso del dicho fray Antonio de Erbias con rigor, porque en tie- 
rras nuevas semejantes escándalos son muy odiosos y causan graves daños, según todo consta por la información que dello presento.

\author{
Alonso de Herrera /rúbrica/ \\ Cédula para que en cuanto a esto se guarde lo \\ dispuesto en el Concilio Tridentino, en la \\ sesión 23, c.15, en 6 de septiembre de 1576 años. \\ El Licenciado Zorrilla/rubricado/.
}

\title{
APÉNDICE \# 19
}

Relación que el Arcediano de la Catedral de Quito envió al Rey Felipe II acerca de los clérigos mestizos de dicha Diócesis.

\author{
AGI, Quito, leg. 81 \\ Quito, 3 de noviembre de 1576
}

Muy poderoso Señor:

Don Francisco Galavís, Arcediano de la santa Iglesia de Quito, en nombre de los clérigos del dicho Obispado, digo que para que a Vuestra Alteza conste e sea notorio de la orden, modo e aprovechamiento de las Doctrinas que a su cargo tienen clérigos, e de los mestizos ordenados en dicho Obispado qué personas, habilidades e costumbres tienen, e cómo sirven en la Iglesia Catedral, beneficios e Doctrinas e fruto que en ellos hacen; e de los clérigos que están en dicho Obispado qué personas, habilidades, suficiencias e costumbres e provechos que han hecho e hacen en sus Doctrinas; e cómo los indios que están a cargo de los clérigos son bien doctrinados, sobrellevados e favorecidos; e los que están en Doctrina de religiosos son oprimidos, trabajados e molestados; e cómo muchos clérigos beneméritos, hijos de conquistadores e pobladores de aquellos reinos, están sin beneficios e Doctrinas, e a otros muchos el Presidente de vuestra Real Audiencia de Quito, sin tener atención a lo dispuesto por vuestras Reales Cédulas e pedido por el Cabildo de la dicha ciudad, se las ha quitado e dado a frailes, como todo constará por este testimonio e información que en vuestro Real Consejo presento. E, pues hay tanta copia de clérigos tan beneméritos e buenas lenguas, pido e suplico a Vuestra Alteza, por servicio de Dios e bien de los naturales, mande dar su Real Cédula para que los dichos clérigos sean preferidos o se 


\section{Doctrinas y Parroquias del Obispado de Quito /361}

prefieran a los religiosos en los beneficios e Doctrinas; e las que se han quitado, se le vuelvan, e que ansí lo guarden e cumplan, so graves penas, el Presidente e Oidores de vuestra Real Audiencia de Quito y para ello etc. El Arcediano de Quito /rubricado/.

\section{Informacion de los clérigos deste obispado}

En la ciudad del Quito, a tres días del mes de noviembre de mil e quinientos y setenta y seis años, su Señoría Reverendísima dijo que convenía informar a Su Real Majestad de la orden y modo y aprovechamiento de las Doctrinas y excesos que en ellas se hacen, y de los mestizos ordenados en este Obispado qué personas, habilidades y costumbres tienen, y cómo sirven en la Iglesia y beneficios y Doctrinas y fruto que en ellas hacen; y de los clérigos que tiene en este Obispado qué personas, habilidades, suficiencias y costumbres y provechos que han hecho las Doctrinas, y cómo los indios naturales que están a cargo de los clérigos están sobrellevados y favorecidos, y que los naturales que están en Doctrinas de religiosos son oprimidos y trabajados y molestados con prisiones y otros agravios; y que los naturales que están en las Doctrinas de los clérigos sacerdotes están edificados en sus conciencias y con gran cuidado ocurren a la doctrina y a los mandamientos de la Iglesia y los tienen en gran veneración y los sacramentos, y ansí dan mucha señal de cristiandad, especialmente en los Pastos a donde los naturales estaban mejor doctrinados en poder de clérigos sacerdotes que están agora, porque los clérigos sacerdotes sabían la lengua y les predicaban y confesaban y estaban muy aprovechados en la doctrina cristiana y sobrellevados de trabajos temporales y ninguno de los clérigos de Pasto jamás tuvieron contratación ni ganados en sus Doctrinas y fuera dellas; y para que Su Majestad sea informado dello susodicho, hizo la información siguiente:

Juan Mosquera, testigo.- Después de lo susodicho, en la ciudad de Quito, a cinco de noviembre del dicho año, para información de lo susodicho, fue recebido juramento por Dios nuestro Señor y sobre la señal de la cruz, en forma de derecho, del Capitán Juan Mosquera, vecino y Visitador desta provincia de Quito, y él lo hizo bien y prometió de decir verdad. Y siendo preguntado por el tenor de la dicha cabeza de proceso, dijo que este testigo conoce muchos o los más sacerdotes de este Obispado, y los ha visto ejercer los santos sacramentos entre los naturales en muchos pueblos dél, andando visitando de diez y seis años acá por madado de los Gobernadores que han sido en estas provincias y de la Real Audiencia, después que en ella reside, y ha visto que los dichos sacerdotes 


\section{2 / Augusto E. Albuja}

han vivido y viven modesta y ordenadamente y dando de sí buen ejemplo, y son amigables a los naturales, y hacen buena y santa doctrina entre ellos con la predicación del sagrado evangelio y baptismo y confisiones y administraciones de los demás sacramentos; y ha visto este testigo que los naturales, en general, en las partes necesarias, son buenas lenguas y como tales usan en las dichas Doctrinas lo que dicho tiene, de que los naturales reciben consuelo y notable provecho, especialmente con el sacramento de la confisión y penitencia, que como es más necesario, el señor Obispo tiene gran cuenta y cuidado sean lenguas y de buena vida para el dicho efecto; $y$ ha visto que este testigo que los indios doctrinados por sacerdotes clérigos son mucho más sobrellevados en servicios personales y obras que los demás religiosos por razón del castigo y visitas a menudo que el señor Obispo hace y con esto están los indios tan sobrellevados y en virtud, que en cualquiera cosa que les suceda con los clérigos,aunque sea muy liviano, se vienen a quejar al dicho señor Obispo o a su Provisor, y los ha visto castigar por ello y amedrentallos para que con todo regalo y amor consigan lo que Su Majestad manda sobre la doctrina de los naturales.

Y este testigo ha visto que el Padre Diego Lobato, que es mestizo e hijo de conquistador desta ciudad y deste reino, es clérigo de misa de más de diez años a esta parte y es muy buena lengua y muy virtuoso; y ha visto este testigo hacer sermones a los naturales y en ellos convertir número dellos que se baptizasen y a los baptizados, en movellos (sic) a contrición que se vengan a confesar con él y esto ha visto en este testigo en la plaza pública desta ciudad y en la Parroquia de San Blas y en los indios de su Encomienda y de otros; y sabe este testigo que el dicho Diego Lobato es de muy buena vida y costumbres, porque ha tratado con él mucho tiempo y estado juntos, y es clérigo de muy buena habilidad en la Latinidad y en el canto y tecla y en todas las cosas tocantes al culto divino, que muy aventajados clérigos que vienen de Castilla no le exceden. Y que este testigo conoce a otro que se dice Juan de Campo, el cual vino a este Obispado ordenado de evangelio y el señor Obispo le ordenó de misa por ser hábil y suficiente en el canto y en las demás cosas tocantes al culto divino y ser buena lengua y asimismo ser hijo de conquistador, que es muy notorio, y ser hombre de buena vida y costumbres y que de siete años, poco más o menos, que ha que este testigo le ha visto estar en Doctrinas entre indios; no ha habido de su persona nota de cosa mal hecha y si alguna hobiere, este testigo no podía dejar de la saber por lo que dicho tiene. Y este testigo conoce a Martín de Gaviria y Gonzalo de Saavedra desde que nacieron, y sabe este testigo que son hijos de hombres nobles e hidalgos 


\section{Doctrinas y Parroquias del Obispado de Quito /363}

y conquistadores y que han trabajado mucho en la tierra en servicio de Su Majestad; y sabe este testigo que dende su niñez han sido virtuosos y recogidos y hombres de bien, y les ha visto aplicarse al estudio y servicio de la santa Iglesia desta ciudad hasta que han venido por ello al Sacerdocio que tienen; y ha visto este testigo que son buenas lenguas y les ha visto hacer sermones a los naturales $\mathrm{y}$, como personas que los entienden y conocen, hacer mucho fruto en sus predicaciones y persuasiones más que otros; y entiende este testigo que son muy buenos sacerdotes y hábiles para el ejercicio de los santos sacramentos, y que son de buena vida y costumbres, recogidos y honestos, y hasta agora este testigo no ha oído ni entendido cosa alguna al contrario de lo que dicho tiene. Y que asimismo conoce que están ordenados de Diácono y Subdiácono Francisco de Rodríguez y Jerónimo Cepeda, los cuales este testigo asimismo conoce desde su niñez y los tiene por muy virtuosos, hijos de hombres honrados y principales y que han servido a Su Majestad en la conquista y pacificación destos reinos y batallas en su real servicio; y ha visto este testigo que dellos no ha habido ni hay ninguna nota, y que son hábiles para el oficio de sacerdotes, porque se dan a ello con estudio y buena vida, como es notorio en esta ciudad, sirviendo la Iglesia y siguiendo el coro y haciendo otras obras de virtud convinientes a sacerdotes, y son buenas lenguas, y no ha visto ni ha entendido cosa en contrario; y que en todo este Obispado no hay más clérigos mestizos.

Y que este testigo, en el tiempo que ha visitado muchos pueblos de naturales en este partido, ha visto grandes quejas de religiosos de todas Ordenes, de molestias que hacían a los naturales, así con cargas de comidas y reparos para los monasterios como en demasiados edificios muy trabajosos, y aunque en algunos pueblos se han muerto indios haciéndoles hacer paredes, cayéndoles encima y matando algunos dellos y otros muriendo de trabajo, y este testigo tiene informado dello a Su Majestad y a su Visorrey, don Francisco de Toledo, por cumplir con el mandato de la Cédula general que Su Majestad manda le informen sus vasallos donde, siendo Su Majestad servido, habrá visto los defectos y necesarios de remedio que hay en los dichos religiosos de Doctrinas, y que este testigo ha visto venirse a quejar los indios de religiosos de San Francisco y de Santo Domingo y de Nuestra Señora de la Merced, de malos tratamientos y cosas exhorbitas que hacen entre ellos y volverse sin castigo los religiosos y tomar los indios y decilles (sic) que son unos perros y que les hicieron por ello y que se le han de pagar doblado, y así los castigan y amedrentan de modo que los dichos indios pasan con sus trabajos e prisiones y malos tratamientos, lo cual no hacen los cléri- 


\section{4 / Augusto E. Albuja}

gos ni osan de temor del castigo que dicho tiene este testigo que les hacen; y este testigo ha visto muchos frailes en Doctrinas que no saben la lengua, y ha visto muchos descuidos en el ejercicio de los santos sacramentos en los indios de parte de los dichos religiosos, y por apañar demasiada gente de la que pueden doctrinar; y que en las visitas que ha hecho donde hay religiosos, ha hecho baptizar este testigo, sacándolos del monte e otras partes, más de cinco mil ánimas, al cual baptismo el Reverendísimo señor Obispo recién venido de Castilla, como supo el fruto que se hacía y el descuido que había habido, salió el dicho señor Obispo en persona a este fruto y remedio, por cuya causa los frailes estuvieron mal con él y así lo están el día de hoy por esto y otras cosas semejantes que han sucedido después acá. Y esto que este testigo dice lo ha enviado a Su Majestad auturizado, y lo tiene en su poder auturizado de dos escribanos y firmado de los mismos religiosos frailes que estaban en las dichas Doctrinas; y que este testigo ha visto que si algunos clérigos han querido tratar o contratar en cosas ilícitas, el dicho señor Obispo los ha castigado y corregido, y por no vivir en tanta libertad como ellos querían, se han ido deste Obispado algunos clérigos que en esto ex-

cedían. Y que esto es la verdad, so cargo de su juramento, y en ello se afirmó y ratificó y lo firmó de su nombre, y que es de edad de cincuenta años, poco más o menos, y que no le tocan ninguna de las generales de la ley.

Fr. P. Epíscopus Quitensis.- Juan Mosquera. Ante mí, Francisco Rodríguez, notario.

Testigo Juan de Zárate Chacón, Corregidor en Otavalo.- Luego fue recibido juramento por Dios nuestro Señor y sobre la señal de la cruz, en forma de derecho, del Capitán Juan de Zárate Chacón, Corregidor por Su Majestad de la provincia de Otavalo y su partido, y vecino desta ciudad. Y siendo preguntado por el tenor de lo susodicho, dijo que sabe este testigo que las Doctrinas que tienen los clérigos en este Obispado son muy bien doctrinados, porque ha visto, por vista de ojos,la mayor parte dellas y de las demás lo ha oído decir por público y notorio, y sabe que ha hecho y hacen gran fruto en la administración de los santos sacramentos: del baptismo, confesión y predicación y las demás cosas tocantes al culto divino y a nuestra santa fe católica, declarando a los indios naturales el santo evangelio en la lengua y demás oraciones, por ser casi que todos buenas lenguas y la mayor parte; y jamás exceden ni hacen cosas que no deban, porque si la cometen a hacer, su Señoría Reverendísima los envía a visitar y el dicho señor Obispo la va a hacer en persona; y por este temor que tienen, los dichos doc- 


\section{Doctrinas y Parroquias del Obispado de Quito /365}

trineros no exceden de lo que son obligados, ni tienen ni les dan lugar para ello, y que dondequiera que están los dichos doctrineros clérigos no reciben vejación los indios en edificios ni en otros servicios, y que este testigo conoce a seis mestizos ordenados en este Obispado, casi desde que nacieron, que los cuatro son sacerdotes y los dos, el uno Diácono y el otro Subdiácono; y sabe que todos estos son muy hábiles latinos, músicos y otras habilidades para el oficio que tienen, y hombres nobles, de buena vida, fama y ejemplo, e hijos de personas honradas, nobles conquistadores y pobladores destos reinos del Perú; y son personas que merecen que se les haga toda cortesía y merced; y nunca ha visto, oído ni entendido cosa en contrario desto, porque si lo fuera,este testigo lo supiera y no pudiera ser menos por lo que dicho tiene, y que los dichos clérigos sacerdotes declaran el santo evangelio a los indios, de que ha resultado gran pro y utilidad a los naturales; y que de las predicaciones ha resultado gran enmienda entre los naturales y cristiandad, y les tienen amor y voluntad; y que nunca ha visto, oído ni entendido que los dichos clérigos hayan tenido trato ni granjería ni ganados ni otra desorden, porque si alguna cosa destas hacen, son castigados por el dicho señor Obispo; y que asimismo sabe este testigo que en recibiendo el menor agravio, los indios naturales de los dichos doctrineros se vienen a quejar al dicho señor Obispo, como ven que con tanta vigilancia provee de remedio en todo; y que nunca este testigo ha visto, oído ni entendido que se hayan quejado de los clérigos mestizos que tienen Docrinas de los naturales, porque sabe que les hace todo el buen tratamiento que un buen sacerdote les puede hacer, los cuales sabe que son muy buenas lenguas, con las cuales, como dicho tiene, hacen gran fruto, y esto es la verdad y firmólo, y que es de edad de cuarenta años, y que no le toca ninguna de las generales de la ley. Fr. P. Epíscopus Quitensis. Juan de Zárate Chacón. Ante mí, Francisco Rodríguez, notario.

Testigo Miguel Cabello, clérigo presbitero.- En la ciudad de Quito, cinco de noviembre del dicho año, fue recibido juramento, por Dios nuestro Señor y sobre la señal de la cruz, en forma de derecho, según orden sacerdotal, de Miguel Cabello Balboa, clérigo presbítero. Y siendo preguntado por el tenor de lo susodicho, dijo que sabe este testigo que en todas las Doctrinas deste Obispado los doctrineros clérigos sacerdotes, que en ellas han estado y están, han hecho y hacen gran fruto y provecho entre los naturales, porque administran los santos sacramentos muy a contento de los indios, así en lo tocante a las confesiones y demás sacramentos, por saber y entender la lengua de los naturales; y los que no la 


\section{6 / Augusto E. Albuja}

saben, también se dan con curiosidad y vigilancia a saberla, y así salen con ellos y hacen gran fruto por declararles los santos evangelios y las oraciones en la lengua general del inga, de que reciben los naturales gran contento espiritual y temporal, y les tienen mucho amor, así por esto como por los buenos tratamientos, que todos, en general, les hacen, porque por la más mínima cosa, vienen a se quejar ante su Señoría Reverendísima, y viendo los dichos indios que el señor Obispo ordinariamente provee de remedio en este caso, se vienen a quejar, y así ha visto que el dicho señor Obispo en persona ha visitado muchas veces las dichas Doctrinas y visita y envía Visitadores y se les hace todo cumplimiento de justicia, y por esta causa ningún clérigo se osa a hacer cosa que no deba, ni en descubrimientos de indios, antes los procura en conservar y regalar con todo amor y caridad, lo que no hacen los religiosos frailes de todas Ordenes, en especial porque ha visto excesivas vejaciones, trabajos y crueles castigos de manos de frailes, como hombres que no son castigados ni reprehendidos de sus Prelados, antes, si acaso los indios se quejan a los Prelados, sabe este testigo que le dan el castigo doblado y con mayor crueldad, y a los dichos frailes sus Prelados no les hacen cosa alguna, de donde toman los dichos religiosos ocasión y brío para mayor libertad, y que en la provincia de los Pastos, donde este testigo ha residido algún tiempo, vido sacar una acequia de agua para Pupiales, de más de una legua, por interese de hacer los frailes un molino, pudiéndose sustentar sin él, en la cual obra y en los supérfluos edificios que hacen y han hecho para un monasterio de dos frailes, han recebido los naturales notables vejaciones, así en hacer ladrillos, cal y teja, como en los demás trabajos personales. Demás que en la dicha provincia, en un pueblo que se llama Fuñes, un religioso de San Francisco vido este testigo que hacía bajar por agua a los indios una cuesta de una legua mortal. y para testimonio de aquella agua era del río, les hacía traer una piedra del dicho río, habiendo como había dentro del dicho pueblo una fuente de donde bebían y bebieran los clérigos siempre que doctrinaban aquella Doctrina; y sabe que quitaban las dichas Doctrinas a los clérigos y las dieron a frailes; y vido que viniendo a llamar a un sacerdote para que fuese a confesaar uno que se estaba muriendo, los frailes, a cuyo cargo estaba la Doctrina les dijeron al alguacil que vino a llamar el confesor, que se fuese con Dios, que no había allí quien supiese la lengua; y en fin, fue un clérigo que a la sazón se halló allí, que sabía la lengua; y que conoce y ha conocido muchos frailes en Doctrinas y la mayor parte dellos que no saben ni entienden la lengua, ni se les da nada por aprenderla, confiados en que si no les dieren Doctrinas, tienen la mesa y el vestido seguro, lo que no tienen los 


\section{Doctrinas y Parroquias del Obispado de Quito /367}

clérigos, y por esta causa y razón sabe que las Doctrinas de los clérigos son mejor doctrinados y menos trabajados que no la de los frailes; y así, los clérigos sabe que han hecho y hacen mucho fruto porque, como dicho es, les declara el santo evangelio en la lengua, por saberla e así todos e la mayor parte, e así todos los indios son aprovechados en gran manera; y que sabe que todo el Obispado no hay más de seis clérigos ordenados por su Señoría Reverendísima, que son mestizos, los cuatro son sacerdotes y los dos, Diácono y Subdiácono, los cuales sabe que son todos muy hábiles, virtuosos, de buenas costumbres y ejemplos y criados en la Iglesia y muy expertos en las cosas de ella, buenos latinos, músicos, cantores, buenos escribanos, de buen entendimiento, hijo de conquistadores y pobladores y servidores de Su Majestad, personas nobles, honradas; y así éstos a quien ha ordenado Su Señoría merecen que Su Majestad les haga toda merced por lo que dicho tiene, y buenas lenguas, en especial Diego Lobato, clérigo, el cual sabe este testigo que demás de ser latino, es lógico, tiene gran curiosidad en la conversión de los naturales, porque le ha visto predicar en la plaza pública desta ciudad e Indias dellas e Parroquias, y ha visto que los naturales han recebido gran ejemplo y consolación, y muchos indios e indias se han apartado de pecados públicos y de hechicerías y supersticiones por los sermones y persuaciones del dicho Diego Lobato, por tener en el persuadir grandes términos y muy vivos, buenos y santos, y así los dichos naturales tienen gran amor y les veneran y acatan. Y que sabe este testigo que los dichos frailes usan en sus Doctrinas cárceles públicas donde aprisionan y maltratan a los naturales por muy pocas ocasiones; y así cuando un fraile va a un pueblo de indios, con temor que les tienen, salen todos con comidas y mochas, lo cual no hacen a los clérigos porque los tienen por afables y menos rigurosos, y si así no salen, aunque no sea su Doctrina del dicho fraile, los azotan y maltratan; y sabe este testigo esto, porque así lo ha visto, por vista de ojos, y que sabe más que por su Señoría Reverendísima son castigados los clérigos, con mucho rigor, los que tratan y contratan, y así ninguno tiene atrevimiento de hacerlo por temor de las visitas ordinarias del dicho señor Obispo, y así lo tiene puesto por estatuto y por mando, so ciertas penas que les tienen puestas, y que todos tengan medicinas y regalos para los enfermos, lo cual los dichos clérigos cumplen con cuidado, y que así son mejor doctrinados los naturales por los clérigos que por los frailes, por lo que dicho tiene; y sabe que las mejores Doctrinas tienen los frailes y se ocupan en ellas y hay muchos clérigos pobres que no tienen qué comer, ni su Señoría Reverendísima en qué los proveer; y así hay en todo el Obispado más de setenta y cinco clérigos, y esto es la verdad, 
y firmólo de su nombre, y que es de edad de treinta y tres años, poco más o menos, y que no le tocan las generales de la ley.

Fr.P.Epíscopus Quitensis

Miguel Cabello Balboa.

Ante mí, Francisco Rodríguez, notario.

\section{APÉNDICE \# 20}

Solicitud dirigida al Rey a fin de que presente al presbítero Juan de Herrera Sarmiento y así el Obispo pueda conferirle la provisión canónica del beneficio de Jaén.
AGI, Quito, leg. 46
Quito, 1576

Muy Poderoso Señor: Juan de Herrera Sarmiento, clérigo presbítero, estante en Pirú, dice que el Obispo de Quito le proveyó en el beneficio de la iglesia de la ciudad de Jaén, como constará a Vuestra Alteza en este Real Consejo para que se le diese aprobación del dicho beneficio, y le puso término de dos años, dentro de los cuales él no ha podido enviar por ser la dicha ciudad en la sierra y la tierra adentro, apartada de los puertos de mar, y pues él ha servido a Vuestra Alteza en otros beneficios doctrinando los naturales de aquel reino y es hábil y suficiente y gran lengua, como a Vuestra Alteza consta por la provisión del dicho Obispo de que hace presentación.

A Vuestra Alteza pide y suplica, sin embargo de haberse pasado el término de los dos años, lo haya por presentado y se le haga merced en mandar se le dé título de Vuestra Alteza del dicho beneficio, sin embargo de que por el dicho Obispo, atento que él no ha llevado la probación de Vuestra Alteza, lo hubiere presentado en otro y pide justicia y merced y para ello etc.

Juan Maldonado de Huelmos/rubricado/. 


\section{Doctrinas y Parroquias del Obispado de Quito /369}

\section{APÉNDICE \# 21}

\section{Carta del Ilmo. Sr. Pedro de la Peña, Obispo de Quito, dirigida al Rey Felipe II.}
AGI, Quito, leg. 76
Quito 20 de enero de 1577

\section{C.R.M.}

Por las Cédulas Reales que vuestra Real Majestad fue servido de inviarme a mandar sobre lo de los mestizos y sobre que no imponga penas pecuniarias a seglares y otra sobre guardar la erección de esta santa Iglesia. En lo de los mestizos, me parece bien lo que Vuestra Majestad por ella tiene proveído, y la razón me dictaba que así se había de mandar, y con esto he tenido siempre la mano abreviada, como Vuestra Real Majestad mandará ver por la descripción deste Obispado que envío, y así por todo el discurso del tiempo que Vuestra Real Majestad me hizo merced de presentarme a este Obispado, que anda en doce años, sólo dellos hay cuatro sacerdotes en todo este Obispado, que ningún español de buena vida les hace ventaja.

En la otra, de que no se condemne a ningún seglar en pena pecuniaria, guardarse ha lo que Vuestra Real Majestad manda. Empero, parece que hay un inconviniente: que ocurren delitos de diversos géneros, que son necesarias diversas penitencias; y como la gente de Indias sea grandemente presumptuosa, mayormente la que en España tuvo presumpción, y a éstos condemnarlos en penitencias parece que lo toman por infamia y engendra escándalo y alteración. Vuestra Real Majestad provea lo que fuere servido; y entretanto, guardaré lo que Vuestra Real Majestad tiene mandado.

En lo tocante a la Cédula de erección, se informó a Vuestra Real Majestad siniestramente, porque ninguna hay en esta santa Iglesia; y si la hubiera, se guardará como vuestra Real Majestad lo manda. Y así, yo y todo el Cabildo desta santa Iglesia enviamos a suplicar a Vuestra Real Majestad, como Patrón desta santa Iglesia, provea lo que más convenga al servicio de Dios y Vuestra Real Majestad porque acá ha parecido que conviene a vuestro real servicio se guarde lo contenido en la descripción de que arriba hago mención.

Vuestra Real Majestad mandó por otra su Real Cédula que no llevase derechos ni intereses de los curas y vicarios de las ciudades y villas de españoles. 
El que hizo esta relación, hizo grave yerro contra su conciencia e informó muy siniestramente, porque, por los sacerdotes deste Obispado y favorecerlos con justicia, he padecido grandes trabajos porque ellos no reciban mal tratamiento, y así los he aprovechado en todo lo que según fuere y conciencia se han podido aprovechar, y jamás de ninguno dellos he recibido cosa de lo que la dicha Cédula Real contiene, como Vuestra Real Majestad mandará ver por las informaciones que cerca desto van.

Sé que el Bachiller Bartolomé Hernández de Soto, Deán presentado a esta santa Iglesia, por ser inquieto y habérsele contradicho la posesión, ha procurado informarme a mí y a los prebendados desta santa Iglesia como parece por una carta que escribió a don Juan de Obando, Presidente que fue de vuestro Real Consejo de Indias, que ansimismo envío a Vuestra Real Majestad un traslado autorizado en pública forma. A cosas tan ajenas de la profesión del sacerdocio, no tengo qué responder; sólo por lo que toca a la autoridad de la obediencia que se debe a Vuestra Real Majestad, cierto, es siniestro y contra lo que debe a oficio de sacerdote, porque ningún Prelado hay en Indias ni en otra parte que con tanto amor y temor ame y quiera y obedezca los mandatos de su Rey y Señor natural como yo, que aún Presidente y Oidores desta vuestra Real Audiencia se admiran de mi obediencia, como ansimesmo Vuestra Real Majestad mandará ver por los testimonios que envío de la cristiandad deste. Parece por la misma carta, pues no trae otro fruto sino haberme infamado y a sus compañeros; y que todos los demás siguen a su Prelado, y éste sólo le persigue. Solamente encarezco, con todo el encarecimiento que puedo, que éste alaba por su carta a uno que fue Maestre-escuela en esta santa Iglesia, el cual por haber tocado en veneración de imágenes y otras cosas semejantes (como el dicho presentado Deán Soto tocó, como Vuestra Real Majestad mandará ver por los autos que acerca dello envío) ha estado preso, y creo que agora está actualmente en el Santo Oficio por no haber sido castigado competentemente y por otras causas secretas que no se saben. Vuestra Real Majestad, como tan católico Príncipe, proveerá lo que convenga a honor de Dios y vuestro real servicio.

Por la pobreza de las iglesias deste Obispado no hay facultad para sustentar más de un cura y vicario en cada pueblo de españoles, y este cura solo no puede administrar los sacramentos a todos los españoles, y ansí conviene que haya un coadjutor. Este se podría sustentar con Doctrinas las más cercanas al pueblo, porque hay Doctrinas que están cercanas a los dichos pueblos de españoles a media legua, legua y dos leguas, y sería descanso para los sacerdotes y gran apro- 


\section{Doctrinas y Parroquias del Obispado de Quito /371}

vechamiento para los vecinos y sin perjuicio de los indios. Ocurrí a la Real Audiencia para que se pusiese remedio en esto, y no se ha dado traza en ello; y pues el remedio deste me pertenece, pues estas ovejas están debajo de mi aprisco, Vuestra Real Majestad me lo mande remitir para que yo pueda señalar Doctrinas para este efecto y que Presidente y Oidores den el favor y ayuda que fuere necesario para esto.

(En nota: Fecha Cédula con esta relación para que el Presidente y Obispo se junten y vean esto, y lo provean y envíen relación de lo que hicieren).

Vuestra Real Majestad me envió otra su Real Cédula para el castigo de los excesos de los religiosos que estuvieren en Doctrina. Esto importa mucho al descargo de vuestra real conciencia por los atrevidos y continuos excesos que hacen por no tener juez que los castigue. Vuestro Presidente y Oidores desta Real Audiencia entienden vuestra Real Cédula que el castigo han de hacer sus Prelados; y ansí sería de ningún fruto y efecto la Cédula de Vuestra Real Majestad, y el castigo principal para ello y remedio de los naturales es castigarlos en lo que ofendieron, quitándoles las Doctrinas. (En nota: Tráigase esta Cédula para que se provea).

Ya he dado a Vuestra Majestad relación y está informado de lo mucho que he servido, así en la Nueva España como en este reino del Perú, y lo que he padecido por defender siempre las cosas de vuestro real servicio. He estado siempre tan perseguido en este Obispado, que nunca he tenido día de contento; y ansí, si vuestra Real Majestad fuese servido, lo que me resta de la vida querría emplear en vuestro real servicio en parte donde tuviese un poco de contento, porque en este Obispado es imposible porque las cosas entre vuestro Presidente y Oidores se van continuando, porque unos Oidores se subrogan a otros de manera que queda siempre la primera causa que fue de los asientos de las mujeres en la iglesia y el de la paz y otras ceremonias que querían se les guardase en la iglesia, que hacerse es inconveniente, aunque en los asientos se guarda lo que está proveído por vuestra Cédula Real; y sería acertado que no lo tuviesen con estrado, que sin él, justo es que sean aventajadas, como se hace en la iglesia mayor de la ciudad de los Reyes, por ser indecencia los estrados de madera porque impiden el uso y ejercicio de los divinos oficios, especialmente en procesiones, y debíanse contentar que se hiciese con ellos lo que se hace con los de vuestro Consejo en España y con lo que se hace en la dicha ciudad de Lima, cabeza de este reino; y ansí, suplico a Vuestra Real Majestad sea servico de emplearme en otra parte para que mejor pueda continuar lo que tanto deseo, que es vuestro real ser- 
vicio y remediar lo arriba dicho porque no quede causa para el que sucediere en mi lugar.

Por ser todos los negocios tan importantes, ha convenido inviar persona de la Iglesia a que, como persona que le duele, dé noticia de todos ellos a Vuestra Real Majestad y procurar el bien de su Iglesia. Y así se escogió al Arcediano que vuestra Real Majestad ahora presentó a esta Dignidad. Vuestra Real Majestad le dará crédito porque va muy instructo de todos los negocios, demás de tener persona y ser para que se le dé.

El Presidente desta Real Audiencia ha hecho un repartimiento entre los vecinos de todo este Obispado, de que se ha hecho un monasterio de monjas, del cual se recogieron doce mil pesos de oro y más, porque hizo juntar los vecinos, y teniendo respecto a la persona del Presidente, hicieron mandas muy crecidas; y demás desto, dio licencia y facultad para que los indios de las minas sacasen oro, algunos domingos y fiestas de guardar para ellos, para que contribuyesen para este monasterio, que esto derechamente pertenece a lo eclesiástico, y los indios no han de contribuir en semejantes derramas. Vuestra Real Majestad mandará proveer lo que fuera servido para que se guarde a la jurisdicción eclesiástica lo que es suyo; y en lo que toca a lo temporal, Vuestra Real Majestad mandará lo que debe guardar vuestro Presidente e Audiencia Real porque no se exceda en lo que toca a vuestro real servicio y vuestros vasallos no reciban daño por esta vía y respectos.

En todo lo demás, me remito a las informaciones, memoriales que lleva el dicho Arcediano. Y por amor de Dios, con toda brevedad se provea todo de mano de Vuestra Majestad, cuya católica Real Majestad Nuestro Señor guarde por muchos años en su gracia, con aumento de reinos y estados.

De Quito y de enero a 20 de 1577 años. Besa las manos de Vuestra Real Majestad su muy humilde siervo y capellán,

El Obispo de Quito /rubricado/. 
Doctrinas y Parroquias del Obispado de Quito /373

\section{APÉNDICE \# 22}

\section{Informe dirigido al Rey acerca del estado de las Indias, en lo relacio- nado con la Audiencia de Quito.}

AGI, Quito, leg. $17 \quad$ Quito, 23 de enero de 1577

\section{C.R.M.}

Por orden del Presidente e Oidores de la Audiencia Real, que por mandato de Vuestra Real Majestad reside en esta ciudad, se notificaron a este Cabildo los capítulos de las ordenanzas de Vuestra Majestad que tratan acerca de lo que es servido se le informe de las cosas del estado de las Indias, y por lo que a nosotros toca, de lo que tenemos de que hacer relación e informar a Vuestra Majestad del distrito desta Real Audiencia es lo siguiente:

Primeramente, reside en esta ciudad la Real Audiencia con un Presidente, tres Oidores, un fiscal, dos secretarios, un relator, seis procuradores, un alguacil mayor, otro menor, dos porteros, un alcalde y un capellán.

Hay en el distrito de la Real Audiencia cuatro gobernaciones sujetas a ella, llamadas, la una de Yagualsongo y Pacamoros que tiene a cargo Juan de Salinas Loyola; la otra de los Quijos que tiene a cargo Melchior Vázquez de Avila; y la otra de Popayán que llaman la de Benalcázar; y la otra de las Esmeraldas que tiene Andrés Cantero. Tiene por términos esta ciudad, desde un pueblo de indios llamado Tiquizambe hasta otro llamado Tulcán, que están en el camino real desta ciudad, hasta el dicho pueblo de Tiquizambe hay treinta y cinco leguas y en todo este camino hay tambos o ventas, de cuatro a cuatro leguas, con personas que las tienen a cargo, bastecidas de comida y mantenimientos necesarios para los pasajeros; está en el mismo camino, veinte y cinco leguas de aquí, un pueblo despañoles, sujeto a esta ciudad, poblado por orden deste Cabildo con confirmación desta Real Audiencia, y por la otra parte, a la parte de Tulcán, hay treinta leguas que asimismo hay ventas por la orden que está dicho, y por la parte de levante-puniente, están dos gobernaciones que participan de las montañas que esta ciudad tiene, que la una es la de los Quijos, que tiene a cargo el gobernador Melchior Vázquez de Avila, y la otra, la de las Esmeraldas, que tiene Andrés Contero; y por no estar señalados ni definidos los términos de las dichas go- 
bernaciones, no se ponen aquí. Particularmente participa esta ciudad de sus montañas que están a seis y a diez leguas della.

En los términos y jurisdición desta ciudad, los vecinos de ella tienen y poseen por Encomienda los Repartimientos de indios siguientes:

Primeramente Don Rodrigo Núñez de Bonilla tiene y posee el Repartimiento de Pomallata con los pueblos de Macas y de Zuña y Latacunga y los Cañares y Langasí y el Repartimiento de Pachamana, en la gobernación de los Quijos, por muerte y sucesión del gobernador Rodrigo Núnez de Bonilla, su padre.

Diego Montañero posee la mitad del Repartimiento de Tiquizambe con los pueblos de Tomavela y Cotocollao, por muerte y sucesión del fator Pedro Martín Montañero, su padre. La otra mitad del dicho Repartimiento está puesto en la Corona Real; goza de los frutos de él Alonso Galindo por situación de Vuestra Majestad.

Alonso Flores de Avila posee otro Repartimiento en los términos de Tiquizambe por Encomienda.

Lorenzo de Vargas tiene el Repartimiento de Pallatanga y Guamarica y Puratico, por muerte y sucesión de Francisco de Vargas, su padre.

El Capitán Miguel Fernández de Sandoval posee el Repartimiento de Chimbo y los Cañarejos y Sangay, con doña Ana de Sandoval, su mujer, la cual los heredó por muerte de Juan de Larrea, su primero marido, en quien estaban encomendados.

Lucas Poncel tiene en Encomienda el Repartimiento de Angamarca por dos vidas. Juan de la Puente tiene en Encomienda el Repartimiento de Hatunsucho por muerte y sucesión de su padre.

Garciponce tiene en Encomienda el Repartimiento de Sucho y los pueblos de Puzoqui y Guallabamba, por muerte y sucesión de su padre.

Catalina Díaz tiene un Repartimiento en la provincia de los Puruáes, por muerte y sucesión de su marido.

Gaspar Ruíz tiene en la dicha provincia otro Repartimiento.

Don Francisco de Arellano posee el Repartimiento de Guano y Chambo por dos vidas.

Cristóbal Calvache tiene en las provincias de Macas y Puruáes un Repartimiento por dos vidas.

Rodrigo de Paz Maldonado posee con doña Isabel de Aguilar, su mujer, el Repartimiento de Chambo con los pueblos de Perucho y Porugachi, en los cuales sucedió por muerte de Diego de Torres, primero marido de la dicha doña 


\section{Doctrinas y Parroquias del Obispado de Quito /375}

Isabel, en quien estaban encomendados, y él tiene nueva Encomienda dellos de el Licenciado Castro, gobernador que fue de estos reinos por sus servicios.

Ruidíaz de Fuenmayor posee el Repartimiento de Luisa por Encomienda.

Juan de Galarza, alguacil mayor de la Real Audiencia, posee el Repartimiento de Azacos, por muerte y sucesión de su padre.

Hernando de Paredes posee un Repartimiento en Tungurahua, por Encomienda.

Juan Arias Altamirano posee el Repartimiento de Ambato con el pueblo de Zámbiza y otro en las montañas de Yumbo, por dos vidas.

Cristóbal Moreno Maroto posee, por muerte y sucesión de su padre, los pueblos de Ambato y Cotocollao y Pisingalí.

Alonso de Aguilar y doña María de Salazar, su mujer, posee en el Repartimiento de Píllaro y Patate, Cochesquí y Tulcán, por muerte de Anton Díaz, primero marido de la dicha doña María.

Don Juan de Londoño posee el Repartimiento de los Mitimas y Alaquez, por sucesión de su padre, y Vuestra Majestad le hizo merced de nueva Encomienda del dicho Repartimiento. dos vidas.

El Capitán Diego de Sandoval posee el Repartimiento de Mulaló, por

Garciduque de Estrada posee el Repartimiento de Cotocollao, por dos vidas.

Don Francisco de la Carrera posee el Repartimiento de Pansaleo con un pueblo en la montaña de Yumbo, por muerte y sucesión de su padre.

El Capitán Francisco Ruiz posee en el valle de Chillo cuatro pueblos y otros en Yumbicho y dos en las montañas de Yumbo y otro que se llama Pingolquí y otro que se llama Pifo, por dos vidas.

Lorenzo de Cepeda posee el Repartimiento de Pinta con otro pueblo en la montaña de Yumbo, por dos vidas.

Don Francisco de Atahualpa, inga, posee otro Repartimiento en los términos desta ciudad, por dos vidas.

Francisco Hernández posee el pueblo de Guangopolo por dos vidas.

Carlos de Salazar, el Repartimiento de yumbos y otro pueblo en Chillogallo, por dos vidas.

Diego Arcos posee el Repartimiento de Litaquilca e Caguasquí con otro pueblo en Alangasí, por dos vidas. 
Don Alonso de Bastidas posee los pueblos de Tumbaco, Apianda, Tungurahua, Zuña y Guambaló, por muerte y sucesión de su padre.

El Capitán Juan Mosquera posee el Repartimiento de Laracachi con un pueblo en Cotocollao, por sucesión de su padre.

Francisco de Olmos posee el Repartimiento de Mindo-Yambe en los yumbos con el pueblo de Guanca, por sucesión de su padre.

Martín de Aizaga e Leonor Méndez, su mujer, posee en el Repartimiento de Cayambe, Guallabamba y Añequito y Hoyacachi, por muerte de Gonzalo Marín, primero marido de la dicha Leonor de Méndez.

Cristóbal Pérez Concha y Juana Muñoz, su mujer, poseen un pueblo en Pomasque, por muerte y sucesión del primero marido de la dicha.

Mateo de Galárraga posee el pueblo de Calicalí, por muerte y sucesión de su padre.

El Capitán Rodrigo de Salazar posee el pueblo de Otavalo con otros seis pueblos que están en su provincia y otros dos en los yumbos y Cumbayá, por dos vidas.

La mitad del Repartimiento de Carangue, Chapiguaza y Tulcán está puesto en la Corona Real y de sus tributos se pagan algunas situaciones a personas a quien Vuestra Majestad ha hecho merced.

Diego Gutiérrez de Logroño posee el Repartimiento de Mira, por sucesión de su padre.

Por fin e muerte de Hernando de Villanueva está vaco el Repartimiento de Tulcán y Pomasque que poseía el susodicho y el Virrey destos reinos lo ha dado al monasterio de monjas desta ciudad.

El Capitán Martín Ruiz de Marchena posee el Repartimiento de Tuza, por dos vidas.

Diego Méndez de los Ríos posee la mitad del Repartimiento de Carangue, Chapi y Chuqui, por muerte y sucesión de su padre.

Todos los cuales dichos pueblos y Repartimientos de indios están encomendados y los poseen las personas de suso declaradas de la manera que está dicha, conforme a lo que Vuestra Majestad tiene proveído; los cuales viven en esta ciudad y en ella hacen vecindad personalmente, guardando la orden que Vuestra Majestad tiene dada a los feudarios deste reino. Todos los cuales dichos Repartimientos están visitados por mandato de don Francisco de Toledo, Visorrey de estos reinos. En la última y general visita que de ellos mandó hacer y por ella parece que hay en los dichos Repartimientos cincuenta mil indios tributarios, poco 


\section{Doctrinas y Parroquias del Obispado de Quito /377}

más o menos, de edad de diez y ocho años y hasta cincuenta, sacando los viejos, tullidos y enfermos, los cuales son reservados, conforme a lo que Vuestra Majestad tiene proveído, de tributo y otros trabajos de comunidad. Habrá ducientas mil ánimas, hombres y mujeres, chicos y grandes. Están tasados los dichos cincuenta mil indios tributarios por esta Real Audiencia: algunos de ellos a peso y medio y otros a peso y ducado y otros en dos de plata corriente marcada sin ley porque no está ensayada, cada un indio, y alguna manta de algodón, trigo, maiz, sal, ají y otras cosas que tienen en sus tierras, conforme a la calidad, cosecha y dispusición dellas, que todo lo que da cada indio no vendrá a valer dos pesos y ducado y, cuando mucho, tres pesos de la dicha plata corriente marcada arriba, que resumido a buena moneda, será más de la tercia parte, menos de los dichos tres pesos, la cual dicha tasa la hizo esta Real Audiencia y el Presidente e Oidores que en ella residen, habiéndose informado primero, particularmente de los visitadores, de la calidad de los indios y de sus tierras y temple y de lo que cada uno posee en ellas, y, ansimismo, de los religiosos y sacerdotes que los dotrinan y otras personas que tienen práctica y espiriencia dellas y habiéndolo primero consultado, comunicado entre sí, teniendo consideración al bien y conservación de todos que, según lo que está dicho, valdrán cada año los tributos de los dichos Repartimientos más de cien mil pesos de la dicha plata corriente marcada sin ley, que en buena moneda será la tercera parte, menos como está dicho, y lo demás lo pagan en mantas de algodón, trigo, maiz y las otras cosas que están referidas, e todas ellas las gastan los dichos vecinos Encomenderos en sus casas, en vestir y dar de comer a la gente de su servicio, todo lo cual pagan los dichos indios, cada uno a su Encomendero, de seis en seis meses, conforme a la tasa que tienen para ello de la Real Audiencia, y lo demás que se les da en dinero, como está dicho, lo gastan los dichos Encomenderos en mercaderías de Castilla necesarias forzosamente para su sustentación e trato y vestidos de su persona y casa y apenas se puede sustentar el que más tiene por tratarse bien y como persona principal y valer las dichas mercaderías a precios excesivos y más que en las ciudades de los Reyes, Cuzco y las demás deste reino y no haber minas de oro ni plata en esta dicha ciudad y sus términos con qué se poder ayudar, de cuya causa y otras que adelante se dirán, viven los dichos vecinos y los demás moradores y habitantes en ella con mucha pobreza y siempre empeñados y necesitados, de tal manera que muchos se visten del paño que se hace en esta tierra por no tener con qué comprar el que viene de Castilla. 
En todos los Repartimientos y pueblos declarados de suso hay iglesias y monasterios en que se administran los santos sacramentos y se reza y enseña la doctrina cristiana a los naturales, y en muchos dellos hay escuelas fundadas en que se enseñan los naturales y huérfanos leer y escribir, cantar y tañer. Ansimismo hay en las dichas iglesias pilas de bautismo. Hay alcaldes y alguaciles de dotrina que ayudan al religioso o sacerdote dotrinero y castigan con autoridad de la real justicia las culpas que, conforme a su ley antigua, cometen los indios; y en las partes donde residen de urdinario, los tales religiosos tienen sus huertas y recreaciones de frutas y verdura en mucha abundancia, por la destreza y curiosidad que tienen los indios en plantar y cultivar la tierra.

Ansí, en este pueblo y toda su comarca y jurisdición, hay muchos indios oficiales, como son: plateros, sastres, zapateros, zurradores, herreros, carpinteros y albañiles, tejedores, perailes, labradores y cargadores, sombrereros, tundidores, arrieros, vaqueros, gañanes y ovejeros, los cuales, por la mucha flema que todos generalmente tienen, usan con destreza cualquiera cosa a que se ponen, especialmente los que apuntan libros de canto y usan otros oficios sutiles de manera que, demás de ser muy provechosos en la república, viven en pulicía y ellos son muy aprovechados, de manera que favorecen y ayudan a sus deudos y amigos pobres ansí para su sustentación como para pagar sus tributos, a todo lo cual ayudan y persuaden mucho los sacerdotes y religiosos que los tienen a cargo con su buena dotrina y ejemplo, de que en esta ciudad hay suficiente número, porque, demás de la Iglesia Catedral que está muy servida, hay cuatro monasterios de las Ordenes de Señor San Francisco, Santo Domingo, y San Agustín y Nuestra Señora de las Mercedes, en las cuales muy de ordinario residen muchos frailes, demás de que entre todas las dichas Ordenes están repartidas todas las Dotrinas de los Repartimientos que están declarados. Había en el distrito desta Real Audiencia ducientos clérigos y frailes, poco más o menos.

Esta ciudad es cabeza de Obispado y reside en ella de ordinario Don Fray Pedro de la Peña, Obispo dél. Es persona muy dota, de buena vida e loables costumbres, gran teólogo y predicador y en todo da de sí buen ejemplo. Residen, ansimismo de ordinario en el servicio desta santa Iglesia, el Deán, Arcediano, Chantre y Tesorero y Maestreescuela y cuatro canónigos de ella y un cura y sacristán, de manera que la dicha santa Iglesia está muy bien servida con las personas que están dichas y otros sacerdotes y personas principales que de urdinario asisten en ella. 


\section{Doctrinas y Parroquias del Obispado de Quito /379}

Tiene su Obispado debajo de su Diócesis y sujetos a sí las ciudades y pueblos siguientes: el pueblo de Puerto Viejo, la ciudad de Santiago de Guayaquil, la ciudad de Piura, las ciudades de Jaén, Loja y Zamora, Cuenca y toda la gobernación de Juan de Salinas y en ella cuatro pueblos despañoless, la gobernación de los quijos y en ella tres pueblos de españoles; todas las cuales dichas ciudades y pueblos están en el distrito de la Real Audiencia y sujetos a ella y todas las iglesias y Dotrinas de los dichos pueblos se proveen por orden y mano del dicho Obispo con mucho concierto, justicia y buen gobierno, de manera que todos viven quietos y pacíficos y los frailes de todas las dichas Ordenes de la misma manera con el buen gobierno de sus Prelados que son personas de buena vida y ejemplo, y porque cuando ocurre alguna necesidad, la Real Audiencia, como Patrón Real, los mantiene en justicia, por manera que todo está en servicio de Dios y de Vuestra Majestad.

Cuanto a lo que toca al número de las iglesias y monasterios que hay en los términos desta ciudad y distrito de la Real Audiencia y el servicio de ellas, se entenderá por lo que el Deán y Cabildo, particularmente, escriben a Vuestra Merced, como les es mandado.

Ansi mismo hay un colegio donde se enseña a los niños pobres y huérfanos y a los naturales, de que todos reciben gran beneficio.

Todo lo cual se declara como está dicho, por ser ansí verdad que Vuestra Majestad sea informado dello como lo manda por los capítulos de sus reales ordenanzas, las cuales, como está dicho en la cabeza desta relación y memoria, se notificaron por orden de Vuestro Presidente e Oidores en este Cabildo, en cuyo cumplimiento dimos esta relación firmada de nuestros nombres, estando juntos en nuestro Cabildo y Ayuntamiento, a veinte y tres días del mes de enero de mil e quinientos y setenta y siete.

Vasallos de Vuestra Majestad que sus reales pies y manos besan: Don Francisco de la Carrera, Miguel de Sandoval, Pedro de Valverde, Juan Rodríguez, Alonso de Paz, Antonio de Ribera Melgarejo, Fermín de Aizaga, Francisco de Orozco, Don Juan de Londoño, Francisco Ruiz, Francisco García de Vargas, Bernardino de Cisneros, escribano del Cabildo. /rúbricas/. 
380 / Augusto E. Albuja

\section{APÉNDICE \# 23}

Carta dirigida al Rey por el Presbítero Pedro Hernández de Narváez, en representación del Deán y Cabildo de la catedral, a raiz de la ordenación sacerdotal de unos pocos mestizos.

AGI, Quito, leg. 80

Quito 20 de marzo de 1577

Colegio eclesiástico de la Iglesia de Quito.

Muy poderoso Señor:

Pedro Hernández de Narváez, en nombre del Deán y Cabildo de la santa y Catedral Iglesia de Quito, en los reinos del Perú, digo que no embargante que Vuestra Real Cédula ha sido intimada al Obispo Don Fray Pedro de la Peña sobre que no ordene mestizos, ansí porque conforme a derecho son inhábiles, como porque por experiencia se ve son escandalosos y de mal vivir, el dicho Obispo ha ordenado, después acá, nueve de los dichos mestizos, los cuales y otros muchos tiene ocupados en los mejores beneficios de aquel Obispado, de que, ansí los españoles como los propios indios naturales, se sienten por agraviados; $y$ habiendo acudido a vuestro Presidente y Oidores de aquella Audiencia ha sido encomendado y encargado a los Obispos guarde y cumpla la dicha vuestra Cédula Real y se abstenga de ordenar los dichos mestizos y los ya ordenados y ocupados en los dichos beneficios los recoja y ocupe en otros ministerios y no lo ha querido hacer, como consta por estos autos que hago presentación.

A Vuestra Alteza pido y suplico sea servido de mandar se vean los dichos autos y que se recojan los dichos mestizos y se ocupen en capellanía o sacristías o otros ministerios y se provean en sus lugares otras personas beneméritas y capaces y que se espere dellos se servirá Dios Nuestro Señor y Vuestra Alteza, y en esto recibirá el dicho Cabildo bien y merced y Vuestra Alteza será muy servido y para ello etc.

Pedro Hernández de Narváez/rubricado/. 


\section{Doctrinas y Parroquias del Obispado de Quito /381}

\section{APÉNDICE \# 24}

Carta que el Arcediano de la Iglesia Catedral de Quito, Francisco Galavís, dirigió al Rey cuando le presentaba la Instrucción del Obispo Peña acerca del estado de su Diócesis.

AGI, Quito, leg. 76

Muy poderoso Señor:

Don Francisco Galavís, Arcediano de la santa Iglesia de Quito, en nombre del Maestro Don Fray Pedro de la Peña, Obispo de la Iglesia, digo que de entender los indios que lo espiritual pertenece al estado eclesiástico de quien han de recebir doctrina para sus almas, e lo temporal que pertenece a sus cuerpos e hacienda, al estado seglar depende la mayor parte de su conversión e pulicía; e si todo anda mezclado, le es a confusión e no pueden entender lo que conviene al remedio de sus almas, ni bien e pulicía de sus cuerpos e haciendas.

Tiene Vuestra Alteza proveído por sus Reales Cédulas que el señalar e repartir Doctrinas e Parroquias sea a cargo del Prelado; demás de ser ansí de derecho e contra ello, el Presidente e Oidores de vuestra Real Audiencia de Quito se han entremetido e entremeten dividiendo e señalando por su autoridad e sin el Prelado las Doctrinas, en lo cual ha habido grandes excesos a causa de no haber sido repartidas e señaladas como convenía. E así, no teniendo los dichos indios doctrina necesaria para su conversión e salvación, han ocurrido muchos al Prelado para que lo remedie, e como no puede porque vuestro Presidente e Oidores se lo impiden, no ha proveído de remedio, como todo constará por estas informaciones que presento, de que los indios padecen gran daño. Porque pido e suplico a Vuestra Alteza mande por su Real Cédula que el dicho vuestro Presidente e Oidores, so graves penas, no se entremetan a lo susodicho, e lo que han hecho por su propia autoridad, se declare por ninguno e que el Prelado haga en ello como cosa que le pertenece e está a su cargo y para ello etc.

El Arcediano de Quito /rubricado/. 
382 / Augusto E. Albuja

\section{APÉNDICE \# 25}

La Instrucción del Obispo de Quito, Ilmo. Sr. Fr. Pedro de la Peña, para que don Francisco Galavís, Arcediano de dicha Iglesia, presente en Madrid a Su Majestad el Rey Felipe II.

AGI, Quito, leg. 80

Quito, 1577

Cabildo eclesiástico de Quito.

Memoria de las cosas que se han de suplicar y pedir a Su Majestad provea demás de lo contenido en la discripción del Obispado, es lo siguiente, e de cada un capítulo se ha de dar petición y enviar Cédula Real sobre ello:

1.- Lo primero, que en esta Real Audiencia se presentó la Cédula Real en que su Real Majestad manda que el Obispo de la ciudad de Quito pudiese castigar a todos los clérigos sacerdotes y religiosos de cualquier Orden que excediesen en la administración de las Doctrinas e buen regimiento dellas; y aunque Presidente y Oidores la obedecieron y particulares han dado peticiones para que el Obispo castigue los excesos de los religiosos, han respondido que no ha lugar y que ocurran a los Prelados de las Ordenes, y así no quieren que se cumpla la dicha Cédula Real. Conviene darse petición sobre ello para que con pena se mande guardar y cumplir, porque los excesos de los religiosos son grandes porque obran sin temor de pena porque el Prelado, por su interese y aprovechamiento de la Orden, no se las impone, y así los indios de las Doctrinas de los religiosos son los naturales gravemente molestados y vejados, y que sobre esto no se les admita juez conservador.

2.- Para el descargo de la real conciencia, por lo contenido en el capítulo antes deste, conviene que su Real Majestad envíe el Propio Motu de Pío Quinto que conforme el Concilio tridentino en lo que toca a los religiosos de todas las Ordenes, sin embargo del mare mano y todos los privilegios de las Ordenes, y el Proprio Motu de Gregorio Décimo Tercio, en que manda se guarde el Concilio tridentino y todas las Ordenes se reduzcan a él, sin embargo de cualesquier privilegios que tengan. Ha se de suplicar a su Real Majestad envíe los dichos Propios Motus con Cédula Real para que se guarden y cumplan como en ellos y en cada uno dellos se contiene, y que para esto su Presidente e Oidores den todo el favor y ayuda necesario, con pena de suspensión de los oficios lo contrario haciendo. 


\section{Doctrinas y Parroquias del Obispado de Quito /383}

3.- Los religiosos de todas las Ordenes hacen grandísimos excesos en todos los pueblos de este reino donde nuevamente vienen a hacer monasterios porque, a principio, los pobladores, con caridad movidos les dan cosas y sitios en que hagan monasterios y grandes limosnas para este efecto; y después de haber recogido grandes limosnas y estando ricos, dejan los edificios que tienen hechos con las limosnas que les han dado, y en lo mejor de las ciudades vuelven a fundar nuevos monasterios y pedir nuevas limosnas, y Presidente e Oidores y otras justicias, unos por favor porque los tienen obligados porque les captan las voluntades publicando bien de ellos, así en sermones como por otras vías, y otros por importunidades, le hacen coger grandes limosnas y así edifican nuevas casas y monasterios muy suptuosos de que nacen grandes inconvenientes, porque venden la primera casa y la convierten en usos profanos, y a donde Dios ha sido servido y consagrado, vienen a hacer muchas veces caballerizas y aposentos de hombres casados e a las veces amancebados, e se destruyen los edificios de las ciudades y casas y poblaciones dellas, porque lo que así ocupan no se vuelve a edificar porque cada uno se pasa como puede por estar la tierra estrecha, y así se profanan las cosas de Dios y se destruyen las públicas y las repúblicas vienen a menos. Conviene al servicio de Dios Nuestro Señor y de su Real Majestad que con gran pena se prohiba esto y para ello se envíe Cédula Real para que las justicias lo defiendan que no se hagan.

4.- Otro sí, se ha de dar petición que en todos estos reinos del Perú, especialmente en la Gobernación de Salinas, se recogen muchos religiosos apóstatas con hábito y sin él, y el dicho Gobernador y sus tinientes y justicias los favorecen y admiten a los beneficios sin ser presentados en su real nombre, ni haber precedido edicto, ni nominacción del Prelado, y aunque los Prelados de los tales religiosos envían por ellos, no son oídos, y aunque el Obispo lo quiere remediar, no puede porque lo resiste el dicho Gobernador; conviene, para el descargo de la real conciencia, se envíe Real Cédula con graves penas para que el dicho Gobernador dé favor y ayuda para que se prendan a los dichos religiosos apóstatas y se echen de la dicha Gobernación y no les consientan celebrar los divinos oficios, y con graves penas den todo el favor y ayuda que pidiere el dicho Obispo y para todas las justicias.

5.- Ansimesmo, se ha de dar petición que muchos religiosos se favorecen con Presidente e Oidores y se encargan de solicitar sus negocios en España y sobre esto les ganan tanto las voluntades que se sujetan a los dichos religiosos y en esto se hacen muchos excesos en lo que toca a la justicia; y para más persua- 
dir a los religiosos por vías y modos ilícitas, hacen con los vecinos que les ayuden con dinero a los tales religiosos, imponiendo a los vecinos que negociaran por ellos en lo que toca a los indios, y a los Cabildos de las ciudades, villas y lugares, que le den salario para que hagan los negocios de la república; y los tales vecinos y Cabildos, por tener propicios a los dichos Presidente y Oidores, hacen su voluntad e dan dinero a los dichos religiosos, e destos inconvenientes nacen otros muchos como se verán en los negocios que lleva fray Hernando Téllez, religioso dominico, que por estas vías y otras lleva cantidad de dinero. Al servicio de su Real Majestad e descargo de su real conciencia conviene remediar esto con graves penas, mandando a los Prelados de todas las Ordenes que ninguno de sus religiosos trate de lo dicho, ni ningún Presidente ni Oidores entienda con los dichos religiosos en semejantes negocios, pues es fuera de Religión tratar semejantes causas.

6.- Item, se ha de dar petición en que se pida en que Presidente e Oidores estando en estrados públicamente en los negocios del Prelado y clérigos que no hacen a su voluntad, sin causa, públicamente dicen injurias y oprobios contra el Prelado y Dignidades e de todos los clérigos, diciendo que son robadores y que los delitos salen dellos, y amancebados, y otras injurias, que ninguna cabe en ellos ni en ninguno dellos; y abaten tanto el orden sacerdotal, que por su causa y malos tratamientos son todos tenidos en poco, que es en gran peligro y perjuicio a los naturales. Y esto importa mucho que su Real Majestad lo remedie para descargo de su real conciencia y edificación y bien de los naturales. (En nota: Los papeles e despachos tocantes a este capítulo están vistos e respondido a ello; están en poder del secretario Ledesma y por despachar).

7.- Item, Presidente y Oidores se entremeten en tasar los salarios de las Doctrinas, perteneciendo al Prelado, y por odio y enemistad que le tienen, estando tasada cada Doctrina en trescientos y cincuenta pesos de oro de a cuatrocientos y cincuenta marevedís, que son las más pobres de todos estos reinos del Perú, las tasan a trescientos pesos de plata corriente, y como no se pueden sustentar con lo susodicho, se van muchos del Obispado, y así quedan las Doctrinas en poder de religiosos, y saliendo a las dichas Doctrinas, como están solos e fuera de convento, hacen muchos excesos y ofensas a Dios Nuestro Señor. Conviene que se remedie y se envíe Cédula Real para que los salarios sean de los trescientos y cincuenta pesos y que, habiendo clérigos sacerdotes, se prefieran en las Doctrinas a los religiosos, porque desta manera se evitarán muchos pecados e ofensas de Dios Nuestro Señor. 


\section{Doctrinas y Parroquias del Obispado de Quito /385}

8.- Otro sí, se ha de suplicar a Su Majestad se remedie un agravio muy grande y excesivo que se hace a los beneficiados doctrineros y a los naturales, porque Presidente y Oidores mandan que los beneficiados vengan a cobrar a esta ciudad sus estipendios de que resultan muchos daños, porque muchas veces estando uno, dos e tres meses cobrando su estipendio, y, entretanto, los naturales están sin doctrina y quien les administre los sacramentos; y en este tiempo acaeció morir niños sin baptismo y adultos sin confesión, y el beneficiado cuando viene a cobrar el estipendio, lo tiene ya gastado; y aunque se ha pedido a Presidente y Oidores lo remedien, no lo han querido hacer por estar mal con el Prelado y sus clérigos. Como parecerá por los testimonios que se envían a su Real Majestad, conviene que con grandes penas se provea lo de este capítulo y que todos los beneficiados cobren en sus Doctrinas el estipendio de los naturales antes que el Encomendero cobre el tributo. (En nota: Los despachos tocantes a este capítulo están en poder del Licenciado Baños).

9.- Ansimesmo, compellen a los naturales vengan a pagar el tributo desde sus pueblos a los pueblos do viven sus Encomenderos, que a las veces están veinte, treinta, cuarenta y cincuenta leguas; y los principales que vienen a pagar el dicho tributo, sacan muchos indios comunes que traen consigo, parte con cargas y parte para su servicio, y están en ir y volver dos e tres e cuatro meses, y en el entretanto que vuelven están sin doctrina y en borracheras, y con la mudanza de la tierra, algunos enferman y mueren, y otros se quedan en esta ciudad e no vuelven a sus tierras, en especial muchachos e indias que quedan vendidas, destruidas y perdidas, y como no son conocidas, andan destraidas; y todos estos inconvenientes se quitarán con mandar que los Encomenderos cobren los tributos en los pueblos de sus Repartimientos y no en otra parte, so graves penas, porque aunque el Prelado ha pedido al Presidente y Oidores que lo remedien por evitar los dichos daños, no lo quieren hacer y por complacer a los Encomenderos e por mala voluntad que tienen al Prelado.

10.- Item, con grande instancia se ha de suplicar y enviar Cédula Real sobre que Presidente ni Oidores no se puedan entremeter a dar Doctrina alguna aunque sea con fundación de monasterio, porque como están mal con el Prelado y juntos con las Ordenes contra el Obispo, aunque tiene proveído dé Doctrina en algún pueblo conforme a la Cédula Real y puestos los edictos y hecha la nominación y la presentación por el Presidente, para quitar el beneficiado, fundan un monasterio en que ponen solo un religioso, o dos a lo más, y lo hacen de un bahareque; y estando hecho el dicho monasterio de bahareque, despiden al 


\section{6 / Augusto E. Albuja}

beneficiado y proveen sobre el auto. El Presidente y Oidores dan real provisión en que se guarde el autor del Presidente y a otros derechamente les quitan las Doctrinas sin haber deméritos ni consultarlo con el Prelado; y así los clérigos del Obispado andan descontentos y no pueden hacer buena doctrina por la alteración que traen y movimientos que hacen dellos, como todo parecerá por los testimonios que se envían. Esto es una de las cosas que más pesan para el buen gobierno del estado eclesiástico, que por ninguna vía el Presidente pueda remover el proveído conforme a lo que su Real Majestad tiene mandado. (En nota: Los despachos tocantes a este capítulo están en poder del Licenciado Baños).

11.- Es en gran perjuicio de los naturales que ningún convento tenga ganado ni granjerías de sementeras ni otra alguna en los términos donde algún religioso haga doctrina, ni ocho leguas a la redonda, cercanos a la dicha Doctrina, porque vejan y molestan a los indios e naturales con la guarda de sus ganados, y por ocupallos (sic) en esto, no los doctrinan, y lo mesmo hacen los clérigos, aunque en esto de los clérigos hay mejor orden porque el Ordinario tiene cuidado que no haya exceso. Ha se de procurar que venga Cédula Real para que se haga lo contenido en este capítulo.

12.- Conviene dar noticia a su Real Majestad del gran inconveniente que hay en el buen gobierno eclesiástico de que presente a los beneficios el Presidente en su real nombre, porque procura de favorecer a sus familiares y allegados y a religiosos. Con importunidades, irrespetos y obligaciones presentan inhábiles y personas que no saben ni entienden la lengua, y quitan los que tienen las Doctrinas legítimamente por dárselas a semejantes personas, como están dichas, como parecerá por el testimonio que se envía; por donde se quitó la Doctrina al Licenciado Atienza para dársela a un familiar suyo nombrado Antón de la Calle; y pues el Prelado conoce mejor y a él incumbe según derecho descargar la conciencia en el nombrar y poner curas y beneficiados, lo hiciese en nombre de $\mathrm{Su}$ Majestad y se acudiese al Presidente para que hiciese asentar en el libro de los beneficiados los beneficiados y curas que se proveen, y desta manera andaría la Iglesia y cosas della bien regida y gobernada, y conservado el derecho del Real Patronazgo, y no se darían los beneficios por afición, ni se ganarían por ruegos y por medios ilícitos, que es en ofensa de Dios y de la real conciencia. Sobre esto se ha de trabajar que se dé alguna buena orden y se dé Cédula Real para que cesen estos inconvenientes. (En nota: Este testimonio e otros tocantes a esto no están presentados). 


\section{Doctrinas y Parroquias del Obispado de Quito /387}

13.- En los Pastos estaban puestos nuestros clérigos buenas lenguas de las Doctrinas que tenían, porque allí no usan la lengua general sino particular que ninguno la sabe sino los dichos sacerdotes; y el Licenciado Valverde, siendo Oidor, visitando los Pastos, por quitar los clérigos de las dichas Doctrinas, hizo fundar monasterios donde con los soberbios edificios los naturales han recebido graves molestias y vejaciones, y no han tenido doctrina porque ninguno de los religiosos que están en los dichos monasterios saben la lengua de los naturales, ni la entienden; y así conviene suplicar a Su Majestad que se vuelvan las Doctrinas a los clérigos que las tenían y venga Cédula Real y expresa para ello, con graves penas, porque de otra manera no aprovechará. Para información desto va la descripción del Obispado y relación de la visita que se hace e de los estorbos que se pone para que no se cumpla y los capítulos que se han hecho para oviar (sic) los excesos de los beneficiados y doctrineros,y ansimesmo, otra información tocante a lo mismo. (En nota: Esta descripción se dio al secretario Ledesma y se envió al Licenciado Zorilla. Esta información está en poder del Licenciado Baños).

14.- Al descargo de la real conciencia conviene haber Bula para que el Ordinario, sin embargo de los privilegios que tienen los religiosos y mare manum (sic), el Ordinario pueda hacer información contra los religiosos que tiene beneficios y Doctrinas y castigarles de los excesos que hicieren, e, asimesmo, contra predicadores sueltos de lengua, porque como no temen castigo y está muy lejos el remedio, tienen grandes atrevimientos y desenvolturas en infamia de Prelado e orden sacerdotal,o que Su Majestad ponga el mejor remedio que convenga porque semejantes predicadores escandalizan y aún despedazan la Iglesia de Dios. Y así conviene que con instancia se suplique a Su Majestad ponga remedio con brevedad en esto. (En nota: Hay ciertos despachos tocantes a esto contra Fray Hernando Téllez, fraile dominico; no están presentados).

16.- Suplicar a su Real Majestad que la Bula que concedió Pío Quinto, por la cual dio facultad a los Prelados de estas partes que pudiesen dispensar en cualesquiera irregularidades, excepto simonía y homicidio voluntario extra bellum, se restrinja, en que se entienda cada Obispo con los de su Obispado, e que en ninguna manera puedan dispensar con los de ajeno Obispado, y también por constitución de nuevo domicilio no se puedan ordenar porque en esto, en lo uno y en lo otro, hay gran desorden e inconvenientes graves, porque hacen las relaciones como les parecen y el Prelado, no sabiendo más de lo que dicen, dispensa con ellos o toma el domicilio, y así sin quedar dispensados los irregulares por siniestra relación, celebran, e los otros, no sabiendo sus costumbres y modo de 


\section{8 / Augusto E. Albuja}

vivir, con dos testigos que hallan a su voluntad de moribus et vita, se ordenan; y esto es una cosa que requiere remedio que Su Majestad lo procure con Su Santidad, y que los mestizos que estuvieren ordenados los obligue a que ningún otro Obispado puedan administrar los santos sacramentos sino donde fueren ordenados.

17.- Otro sí, se ha de pedir Cédula Real, con graves penas, para que Presidente ni Oidores no reciban petición alguna contra clérigos en la Real Audiencia a donde los vecinos Encomenderos y otras personas inducen a los indios de sus Encomiendas a que, no haciendo los clérigos lo que quieren los Encomenderos, con falsedad, porque quiten los clérigos de sus beneficios, les imponen grandes infamias, amancebamientos, tratos y granjerías y se le leen públicamente en las Audiencias; y después parece todo falsedad y quedan los clérigos injuriados mayormente, que en muchos casos Presidente y Oidores proveen que el Prelado, con brevedad, lo remedie, donde no que ellos lo proveerán; y pues no tienen jurisdición sobre los clérigos, que por ninguna vía admitan semejantes peticiones ni se consientan leer, porque demás de quedar los clérigos injuriados e afrentados sin causa, se les quita el respeto que se les debe y la devoción en la celebración de los divinos oficios y hace gran daño para recebir los indios los santos sacramentos y la doctrina del sacerdote que ha infamado. Esto importa mucho y conviene que su Real Majestad lo remedie con reprehensión y castigo.

18.- Otro sí, se ha de suplicar a su Real Majestad que las Doctrinas que Presidente e Oidores quitaron a Diego Pérez, clérigo presbítero de Daule, pues le tenía con justo título, y sin él la dieron a un religioso, se le vuelvan; $y$, asimesmo, la Doctrina que quitaron a Martín de Gavira, presbítero de Atunquijo, estando proveída por edicto y nominación e presentación del Presidente, sin demérito ni causa alguna se le quitaron y dieron a un religioso de Santo Domingo; e, asimesmo, las tres Doctrinas de Sicho que se quitaron a don Alonso de Aguilar y Diego de Cantos e Francisco de la Carrera, clérigos presbíteros, y las dieron a los religiosos de San Agustín, y la Doctrina de Cayambe que quitaron a Hernán Suárez, como se verán por los autos que sobre esto se envían, se quiten a los dichos religiosos y se vuelvan a los dichos clérigos sacerdotes con otras que han quitado, por ser hijos de conquistadores, beneméritos y muy buenas lenguas e hábiles para las Doctrinas, y los dichos religiosos de Sicho inhábiles, porque ninguno dellos sabe la lengua y solo uno es sacerdote y los otros frailes legos y no pueden administrar sacramentos, y por lo menos están distantes las Doctrinas y lo más 


\section{Doctrinas y Parroquias del Obispado de Quito /389}

cerca una Doctrina a otra de cuatro leguas, de manera que no pueden tener misa ni confesiones, y los demás sacramentos recibirán con trabajo.

19.- Item, conviene al descargo de la real conciencia y bien común, que Su Real Majestad mande que ningún religioso pueda tener ni tenga Doctrina donde hubiere españoles, como es en ingenios de azúcar, e donde hubiere estancias de ganados, ni tampoco puedan tener Doctrina donde ellos tuvieren ganados en las Doctrinas comarcanas a ella, porque a estas partes comunmente se allegan y ocurren hombres de mal vivir y mestizos traviesos y los religiosos lo consienten y no escrudiñan ni procuran saber sus vidas, y así el nefando luterano de Riobamba estuvo en la Doctrina de Guamote mucho tiempo, que es Doctrina de religiosos franciscos de la Doctrina de Chambo; y en las Doctrinas de sacerdotes clérigos no hay este inconveniente por el cuidado que se tiene de la enmienda de la vida de los susodichos.

20.- Otro sí, conviene, y es muy necesario al descargo de la real conciencia, que se declare el Motu Propio (sic) de Su Santidad para que los religiosos de todas las Ordenes no puedan administrar más sacramentos del de la penitencia y baptismo, porque hay grandes abusos y aún escándalos en que frailes hacen y administran los demás sacramentos, excepto los dichos, especialmente a anaconas y personas que no son de sus Doctrinas, porque para administrar a éstos los santos sacramentos, instituyen cofradías o que son sus familiares, porque están en algunas casas o estancias suyas o heredades, y así los indios reciben daño porque se quedan en sus ritos y ceremonias e injustamente favorecidos de los dichos religiosos; y aunque el Prelado lo quiere remediar, no es parte con el favor que prestan Presidente y Oidores a los dichos religiosos debajo de título que los religiosos han venido a costa de Su Majestad e a las demás causas contenidas en los capítulos precedentes, y que no tengan pilas de baptismo.

21.- Asi mesmo, por el Propio Motu de Su Santidad está mandado que los religiosos en las Doctrinas asignadas y que se asignaren puedan administrar sacramentos sabiendo la lengua, e no está declarado por quién se ha de asignar los dichos lugares, ni quién ha de examinar si los dichos religiosos saben la lengua; e aunque en la Real Audiencia se ha pedido se declare lo susodicho, no se ha proveído, y es una de las cosas que importan al descargo de la real conciencia porque ninguno puede administrar santos sacramentos sino en los lugares asignados por el Prelado, y pues el saber la lengua para los administrar es necesaria y como dependientes, pertenece al dicho Prelado a cuyo cargo están las ánimas de las dichas Doctrinas, y así la dicha asignación se ha de hacer por el Prelado; y por- 


\section{0 / Augusto E. Albuja}

que muchos tienen Doctrinas sin tener lugares asignados por el Prelado, ni tampoco saben la lengua porque no hay quien los examine ni se lo consienten hacer al Prelado, y así mueren muchos indios sin confesión; y otros administran sacramentos no pudiendo, por no tener lugar asignado. Y de cuánto perjuicio sea esto, a la real conciencia es manifiesto.

22.- Item, que su Real Majestad tiene proveído por su Real Cédula la orden que se ha de tener en el proveer de los beneficios y Doctrinas, poniéndose edicto y que de los que se opusieren el Prelado apruebe dos dellos y destos dos el Presidente, en nombre de Su Majestad, presente al que le pareciere; y porque muchas veces acaece el dicho Presidente no querer presentar ninguno de los aprobados por el Prelado, porque se venga a nombrar a quien el quiere gratificar, no admite los aprobados, y así se vienen a presentar a inhábiles y personas que no tienen respeto al Prelado, recibiendo beneficio del Presidente; y cuando el Prelado no quiere hacer la colación al que ansí el Presidente quiere presentar, sin aprobación del Prelado lo presenta el Presidente y manda que el presentado por él administre los sacramentos y le acudan con el estipendio y camarico, especialmente con religiosos por razón del Propio Motu. Y por esto importa mucho que se declare quién ha de hacer la asignación y examen de lengua, se ha de procurar remedio con gran diligencia y cuidado a entender los inconvenientes que resultarían de no proveerse lo susodicho.

23.- Item, porque muchos, atrevidamente, sin guardar lo dispuesto por derechos ni por el sacro Concilio tridentino, se atreven con temeraria osadía a administrar los santos sacramentos en ajenas Parroquias, de que suelen nacer y nacen escándalos y pasiones, especialmente entre clérigos y frailes, que Su Santidad mande, so graves penas de censura, que ninguno en ajena Parroquia administre sacramentos sin licencia del Prelado o párroco.

24.- Otro sí, porque sin embargo de la Cédula Real que Su Majestad tiene dada para que las justicias ordinarias presten auxilio al juez eclesiástico, Presidente y Oidores no lo quieren guardar; mas, antes, se entremeten en la jurisdición eclesiástica tasando y moderando el dicho auxilio que no es de jurisdición, como se hizo en una causa de Martín de Gaviria, clérigo presbítero, que habiendo pedido que se le mandase pagar el salario que se le dio como juez delegado, se le pidió auxilio y proveyeron que se le diese el auxilio por la mitad del salario y otras cosas semejantes, proveyendo autos que si hiciere tal y tal cosa, no hace fuerza, y no lo haciendo así, que hace fuerza, y esto generalmente en todos los negocios, de manera que donde no hay fuerza declaran fuerza y así el Prelado 


\section{Doctrinas y Parroquias del Obispado de Quito /391}

ninguna jurisdición tiene más de la que el Presidente y Oidores quieren que tenga.

25.- Item, se padece gran trabajo con la justicia eclesiástica que resulta en gran daño y conversión de los naturales para apartarlos de sus ritos y ceremonias que hacen muchas, y si para esto y cosas tocantes a la doctrina y conversión y apartallos de sus ritos y ceremonias se hubiese de hacer implorando el auxilio de la justicia real, resulta muy grandes daños a la conversión de los indios y hacelles costas; y porque todo esto se hace sumariamente y en provecho de su conversión y sin estrépitu ni figura de juicio, suplicar a Su Majestad dé su Real Cédula para que en este caso los jueces eclesiásticos, sin auxilio, castiguen los dichos excesos e que las justicias seglares y Audiencias lo favorezcan.

26.- Item, su Real Majestad por sus Reales Cédulas tiene proveído que el señalar y repartir de Doctrinas y Parroquias sea a cargo del Prelado; demás de ser de derecho y contra todo esto, Presidente y Oidores se entremeten a dividir y señalar Doctrinas y Parroquias en lo cual ha habido grandes yerros y excesos. Que su Real Majestad, con graves penas, mande que Presidente ni Oidores no se entremetan en lo susodicho e lo que han hecho por su propia autoridad, se declare por ninguno, e que el Prelado haga como cosa a él tocante y perteneciente. En este capítulo se ha de estriar mucho porque importa mucho a la conversión de los naturales, porque no estando repartidas las Doctrinas como deben, no pueden los indios tener doctrina que les aproveche a su conversión, demás que conviene que entiendan que lo espiritual pertenece al estado eclesiástico de quien han de recebir doctrina para sus almas, y lo seglar para el cuerpo y haciendas; porque de entender qué cosa es las cosas espirituales y temporales depende su conversión y pulicía; y si todo anda mezclado, es confusión y no pueden entender lo que conviene al remedio de sus almas, ni bien ni pulicía de sus cuerpos e haciendas. (En nota: Los despachos tocantes a este capítulo están en poder del Licenciado Baños).

27.- Item, se ha de suplicar a su Real Majestad que mande dar su Real Cédula para que con gran rigor mande que se guarde y cumpla lo dispuesto por derecho y por el sacro Concilio tridentino que ningún clérigo salga de su Diócesis sin demisoria de su Prelado, porque como la tierra es larga, unos se pasan de un Obispado a otros excomulgados, apóstatas y irregulares, suspensos con casos que en su Obispado no los consentían celebrar ni administrar sacramentos, y sin temor de conciencia lo hacen; y porque demás de lo dispuesto por derecho, con- 
viene para esto el auxilio real porque cesen estos inconvenientes que Su Majestad dé su Real Cédula para ello, pues tanto importa.

28.- Hase de dar noticia a su Real Majestad y a los señores de su Real Consejo, que porque el modo del doctrinar que se había tenido hasta agora parecía suficiente e la experiencia ha mostrado que convenía otro más suficiente para la conversión y aprovechamiento de los naturales y que entendiesen mejor lo que convenía al provecho de sus conciencias, hice que en el doctrinar se tuviese la orden y modo que se contiene en el Catecismo que envío; y para mejor aprovechamiento y buen régimen de la dicha doctrina, hice los estatutos que ansimesmo envío con el dicho Catecismo. Lo uno y lo otro se ha de presentar en el Real Consejo y traer Cédula Real para que Presidente y Oidores y Prelados de las Ordenes, todos guarden y hagan guardar, con gran pena, los dichos Catecismos y estatutos, y que la jurisdicción y castigo dello lo haga el Obispo, e, con grandes penas, a Presidente y Oidores que lo guarden. (En nota: No está presentado. No están presentados).

29.- En lo del sermón del día de San Pedro y el sermón del día de Santiago de que se escandalizaron Presidente y Oidores y de la farza de Cabello, lleva el Arcediano; destos usará para mostrar si fuere necesario y en el Real Consejo hubiere queja del Obispo o de Presidente y Oidores que se hayan inviado a quejar. E conforme a la relación que tiene de todo con lo susodicho dará el descargo para que conste que el Obispo en los dichos sermones ninguna culpa tuvo, ni el dicho Cabello lleva la descripción del volcán y de los efectos que hace; y una obra hecha por Cabello sobre ello, en verso, informará a los señores del Real Consejo dello, mostrándoles la dicha descripción y obra del dicho Cabello para que se entienda más formalmente y el asiento de esta ciudad y el riesgo que tiene de el dicho volcán. (En nota: Lo contenido en este capítulo no se ha presentado).

30.- Item, por la Real Audiencia se proveyó que los vicarios no entendiesen en las causas ni tuviesen jurisdicción para hacer pagar a los beneficiados y doctrineros los estipendios de sus beneficios y Doctrinas, y que las justicias seglares entiendan en lo susodicho; y para hacer cobrar los estipendios, nombran un depositario en cada pueblo de españoles, y estos depositarios del estipendio toman a los beneficiados y doctrineros a tanto por ciento y les dilatan las pagas a efecto que lo tomen en mercaderías y se las cargan a excesivos precios, mucho más de lo que valen, y así, por la mayor parte, los beneficiados y doctrineros se quedan sin paga; y ya que se le dan, es de la manera dicha. Sobre esto se pide, 


\section{Doctrinas y Parroquias del Obispado de Quito /393}

con gran instancia por el daño que reciben los clérigos, Cédula de Su Majestad, sin embargo de lo que está proveído por esta Real Audiencia para que los vicarios puedan compeler y apremiar a los Encomenderos a que paguen los estipendios a los doctrineros y que no haya depositarios de los dichos estipendios.

31.- Ansimesmo, en esta santa Iglesia se instituyó la cofradía del Santísimo Sacramento; y en España y en estas partes siempre estas cofradías han estado y están en las iglesias Catedrales, y donde no las hay en las parroquias, porque como dellas sale el Santísimo Sacramento y son los más entierros, y para esto se instituyó esta cofradía. Los religiosos de San Francisco desta ciudad han procurado que esté en su monasterio, y esto es indecencia y no se guarda el honor que se debe al Santísimo Sacramento; y demás desto, importa al honor de la Iglesia Catedral y devoción della que la dicha cofradía se vuelva a la dicha Iglesia Catedral, como la institución della estaba, y para ello el nuncio de su Bula en forma, con provisión de su Real Majestad, para que se mande guardar y cumplir. Y lo mesmo mande su Real Majestad proveer que se haga en todas las iglesias parroquiales que se le vuelvan todas las cofradías que se han pasado a monasterios de religiosos; y asimesmo, que todas las cofradías que se han instituido sin consentimiento ni autoridad de Prelado, se declaren por ningunas.

Suplicar a su Real Majestad mande proveer sobre todo esto porque, aunque es de derecho, yo no soy parte para hacer guardar y cumplir cosa ninguna dello; y es claro, si Presidente y Oidores me dejaran usar mi oficio pastoral, no importunara a su Real Majestad lo mandara proveer.

32.- Pedir en lo de los indios de Calicalí para que se puedan estar donde antes estaban y que se gocen de sus tierras.

\section{El Arcediano de Quito /rubricado/.}

(En nota: Que la Audiencia vea estos capítulos y informe de lo que en ellos pasa con su parecer). En Madrid, a 7 de septiembre de 1579. El Licenciado Lopidaña /rubricado/. 
394 / Augusto E. Albuja

\title{
APÉNDICE \# 26
}

\section{Carta del Obispo de Quito al Rey Felipe II.}

\author{
AGI, Quito, leg. $76 \quad$ Lima, 12 de marzo de 1578
}

\section{S.C.R.M.}

Por otra doy cuenta a Vuestra Majestad en vuestro Real Consejo de las Indias de la causa de mi venida a esta ciudad a negocios del Santo Oficio deste reino y por llamamiento de vuestro Visorrey, don Francisco de Toledo, e Inquisidores; y llegado aquí, se ha diferido el efecto por algunos respectos. $\mathrm{Y}$ agora se me encarga por vuestro Visorrey que me detenga y convoque, como Obispo más antiguo, a los demás Obispos sufragáneos desta Metrópolis para el Concilio provincial, cosa importantísima para el bien universal destas iglesias, para que cuando llegue el Arzobispo, que se espera en los primeros navíos, se celebre; y así lo he fecho y se comenzará en todo este año, y aunque otras tres veces me puse en camino para el mesmo efecto, en vida del Arzobispo pasado, y se difirió por la ausencia de vuestro Visorrey en las provincias de arriba y después por muerte del Arzobispo. Estando yo más de doscientas y cincuenta leguas de mi Arzobispado (sic), habré de esperar porque no cese tan santa obra y de que Dios Nuestro Señor y Vuestra Majestad han de ser muy servidos.

Del estado destos reinos dará cuenta a vuestra Majestad don Francisco de Toledo, vuestro Visorrey, el cual los tiene tan bien gobernados que demuestran bien ser labor del cristianísimo y prudentísimo gobierno de Vuestra Majestad, y sobre todo cuidadoso del acrecentamiento de vuestro real patrimonio con la tranquilidad y riqueza que nunca jamás tuvo esta tierra.

De otras particularidades de negocios informo en vuestro Real Consejo, y suplico a Vuestra Majestad sea servido mandar se tenga memoria de mí en las ocasiones que se ofrecieren, atento que ha más de treinta años que en mi Religión, en lo principal del asiento y policía cristiana que en Nueva España ha quedado, y para ello sacado del Colegio de San Pablo de Valladolid, y en esta Dignidad he servido a Vuestra Majestad, para promoverme donde, con alguna quietud, pueda pasar el resto de los trabajados años sirviendo a Dios y a Vuestra Ma- 
jestad, cuya sagrada católica real persona Nuestro Señor guarde con acrecentamiento del orbe universo.

De los Reyes y de marzo 12 de 78. Humilde siervo y capellán de Vuestra Majestad, El Obispo de Quito /rubricado/.

\section{APÉNDICE \# 27}

Carta del Obispo de Quito, Ilmo. Señor Pedro de la Peña, en la que comunica al Rey Felipe II las decisiones tomadas por el Tribunal del Santo Oficio contra tres religiosos dominicos sospechosos de herejía.
AGI, Quito, leg 76
Lima, 25 de abril de 1578

\section{S.C.R.M.}

Por otra di cuenta a Vuestra Majestad en esta armada de cómo, residiendo en mi Obispado de Quito destos reinos del Perú. fue llamado del Virrey, don Francisco de Toledo, y del Santo Oficio para cosas convinientes al servicio de Dios nuestro Señor y de Vuestra Majestad. Y venido a esta ciudad de los Reyes, vuestro Virrey me encargó y requirió que, como Obispo más antiguo de los sufragáneos a esta Metrópoli, los convocase para el Concilio provincial que tan encarecido el sacro Concilio de Trento y Vuestra Majestad nos tiene ordenado y mandado, demás de las justísimas causas que había para la breve celebración del por muchas cosas convinientes a la reformación espiritual y temporal destos reinos y buen gobierno de ambas repúblicas de ellos, sobre que algunos días conferimos. Y resueltos en que así convenía, los convoqué y cité para el mes de septiembre próximo venidero, que es el tiempo que nos pareció que podría tardar el Arzobispo que se espera en estas provincias.

Y por el Santo Oficio, demás de haberme significado la necesidad que de mí se tenía en él, por las que me escribieron, se me presentó el estado de los negocios que tenían pendientes y acabados graves y de mucha sustancia, que requerían mi Dignidad para la expedición y ejecución de ellos, los principales de los cuales que tocaban a tres religiosos de la Orden de Santo Domingo: fray Francisco de la Cruz, de los más venerados de este reino y a quien el Arzobispo que 
murió tenía suplicado a Su Santidad y a Vuestra Majestad se le diese por coadjutor; y fray Pedro de Toro, Provincial y administrador que muchos años fue del Obispado del Cuzco; y fray Alonso Gasco, (sic), muy docto Prelado y Lector de Teología. Fue yo, mediante la luz que Dios nuestro Señor fue servido darme, el descubridor de sus invenciones y tramas infernales que dejado lo principal de sus proposiciones, especial del fray Francisco de la Cruz, en que había casi de todas las especies de sectas: magomética y luterana y otras y ley judaica e otras nuevas e inauditas, a título de revelaciones angélicas y divinas. Por modos extraños tenían ordenado repartirse en todo el reino y dogmatizar sus invenciones diabólicas, y tiranizarlo, y quedarse con espiritual y temporal, sin recognocer a Su Santidad y a Vuestra Majestad, con libertades viciosísimas con que tenían ordenado de atraer este vulgazo y aún con algunos hombres tratados y convencidos del evidente error en que estaban.

Al fray Alonso Ogasco, (sic) y hecha averiguación e información en Quito, donde había ido a persuadirme a su opinión si pudiera, le remití, y la causa a este Santo Oficio, donde se averiguaron estos errores. Y ayer se hizo auto general de la fe en que fueron condenados: el fray Francisco de la Cruz por hereje heresiarca y a degradar y relajar al brazo seglar, y estuvo pertinaz hasta la mitad del auto, que se convirtió y fue degradado y relajado y quemado; y el fray Pedro de Toro, que murió en la prisión, fue reconciliado y salió su estatua con San Benito; y el fray Alonso Gasco, por haber sido el primero que se convirtió y pidió misericordia y el que menos errores tuvo, se condenó a salir en el auto con una vela en las manos y ciertas suspensiones y reclusiones. Y se condenaron otras personas por diversas herejías y errores, y sin duda, que después de Dios, se me debe por señalado servicio que a Dios y a Vuestra Majestad, y en particular, se ha hecho la extirpación y castigo de tan terribles errores, porque se ponía en condición todo el reino, que una de las causas que pone freno a los ánimos bulliciosos, es no atreverse a descubrir para junta de gente que comunicados con religiosos semejantes y por tales modos fuera irreparable el daño. Gracias a Dios Nuestro Señor, a quien todo bueno se debe referir. Y prediqué en el auto y advertí a todo el pueblo, en que había muy grande concurso, lo mucho que todos debíamos a Vuestra Majestad por el gran bien y merced que a esta tiera había hecho en proveerle este santo Tribunal, y el celo con que a todos nos mantenía en cristiandad, paz y justicia. Asistió al auto vuestro Visorrey, dando mucha autoridad a este santo oficio; en lo demás, ni estar ocioso momento, he trabajado en predicaciones y administración de mi oficio pastoral, ordenando y confirmando, y 


\section{Doctrinas y Parroquias del Obispado de Quito /397}

previniendo para adelante cosas que han parecido convenientes. Y por estar falto y con necesidad, por el gasto que he hecho en el camino y en este pueblo, y en el interim que venían los Obispos convocados, nos pareció, a vuestro Visorrey y a mí, volver a dar asiento en las cosas de mi Obispado por ser necesaria mi asistencia a este santo Concilio, mucho tiempo que se entiende tardará lo que en él habrá que decir.

En cualquier acto y ministerio siempre tengo particular cuenta con suplicar a Dios Nuestro Señor por la salud y larga vida de Vuestra Majestad, en que hoy, después de la fundamental piedra apostólica, depende su católica Iglesia, y la terné (sic) de informar del estado destos reinos a Vuestra Majestad.

Yo ha treinta años que sirvo a Dios y a Vuestra Majestad en la Nueva España. para donde me sacó y llevó por su confesor del Colegio de Valladolid don Luis de Velasco, vuestro Visrrey que fue allí. Residí lo más deste tiempo en las prelacías más principales y hice grandísimo fruto con mi predicación y doctrina, así a los españoles como a los naturales, y fue el primero catedrático de Teología y fundador de aquella universidad; y cierto que fue mucha parte de la policía humana y cristiana que hoy tienen en aquel reino, como consta por recaudos que del se enviaron en aquel tiempo a ese Real Consejo, a donde fue a negocios de la Orden y convinientes al espiritual del y despachos. Se me mandó viniese a servir este Obispado y lo he administrado con el cuidado y celo que he podido, visitando personalmente mis ovejuelas y después lo en pueblo, sin temer aspereza de caminos y diversidad de temples y excesivos gastos que me tiene en más necesidad de la que he entendido se ha significado en vuestro Real Consejo.

He informado a vuestra Majestad de las pesadumbres que he tenido con la Audiencia de aquella tierra por querer entremeterse a cosas que no pueden y contra mi Dignidad y lo que deben al respeto que Vuestra Majestad quiere que vuestros ministros tengan a los Prelados, y más en la nueva Iglesia por el ejemplo de los naturales para el crédito de la doctrina que les enseñamos. He suplicado a Vuestra Majestad quite de aquella Iglesia Catedral al Deán y Tesorero por las muchas causas justas que he informado, que conviene a la quietud de aquella Iglesia; y lo mesmo, un canónigo Villaquirán, facineroso, que últimamente vino proveído que, entre la Audiencia y mí, causó cizañas, levantando cosas no imaginadas, de que me envió por descargo de su conciencia. Se retrató, como entenderá Vuestra Majestad; por este papel traslado fice de el propio, que de su letra y firma me envió por descargo de su conciencia. 
Suplico a Vuestra Majestad sea servido acordarse de mi persona en las ocasiones e iglesias vacantes que se ofrecen, como acá se ha dicho y dice desta Iglesia de Lima e de las Charcas, donde con más quietud pueda continuar el servicio de Vuestra Majestad, cuya sacra católica persona real Nuestro Señor guarde con acrecentamiento del orbe universo.

De los Reyes y de abril 25 de 1578 años.

Menor siervo y capellán de Vuestra Majestad,

El Obispo de Quito/rubricado/.

\section{APÉNDICE \# 28}

\section{Informe del Obispo de Quito, Ilmo. Pedro de la Peña, respecto al Presbítero Pedro Arias.}
AGI, Quito, leg. 82
Quito, 13 de octubre de 1579

En la ciudad de Quito, a trece días del mes de octubre de mil e quinientos y setenta y nueve, el Muy Ilustre Reverendísimo Señor Maestro Don Fray Pedro de la Peña, Obispo deste Obispado de Quito, del Consejo de Su Majestad, etc. habiendo visto la información dada por el Padre Pedro Arias Dávila, clérigo presbítero, dijo que le consta ser así lo que el dicho Pedro Arias tiene probado, que ha tenido a su cargo el beneficio y Doctrina de Pacaybamba por provisión y colación en él hecha, conforme al derecho del Patronazgo Real, y dello y de las demás Doctrinas a que ha sido proveído en este Obispado ha dado buena cuenta y es sacerdote honrado, de buena fama y vida y costumbres, y ha vivido en ésta recogidamente y con buen ejemplo; y en la dicha Doctrina de Pacaybamba ha hecho mucho fruto a los naturales y ellos por ser así, le tienen mucho amor. El cual tiene habilidad y suficiencia para servir cualquier beneficio curado de españoles y de Doctrinas de indios, por lo cual, y saber como sabe la lengua general del inga, que es lo que principalmente se requiere para la doctrina de los indios y haber servido en esta santa Iglesia, cabe en el dicho Pedro Arias Dávila la merced que Su Majestad fuere servido de le hacer y será bien empleado. Y esto dio por su parecer y aprobación y firmólo. Fr. P. Episcopus Quitensis. E yo, Cristóbal 


\section{Doctrinas y Parroquias del Obispado de Quito /399}

Pérez Concha, Notario Apostólico, por la autoridad apostólica y público del Audiencia episcopal desta ciudad de Quito, presente fui con su Señoría Reverendísima al parecer de suso; y por ende lo firmé y signé en testimonio de verdad. Cristóbal Pérez Concha, Notario.

E yo, Francisco de Corviera, Notario apostólico y público en esta Audiencia episcopal de la ciudad de Quito, de pedimento del Padre Pedro Arias, fice sacar este traslado y lo corregí y concerté con el original que va escrito en catorce hojas con ésta. En Quito, a veinte y seis de febrero de mil y quinientos y ochenta e tres años. Y en fe dello lo firmé de mi nombre y signé con mi signo que es a tal en testimonio de verdad. Francisco de Corviera, Notario apostólico /rubricado/.

Nos, los Escribanos de Su Majestad e públicos desta ciudad de San Francisco de Quito, certificamos y damos fe cómo Francisco de Corviera, de quien va firmada e signada este probanza, es tal Notario en el juzgado eclesiástico desta ciudad, y a los autos que antel (sic) han pasado y pasan se ha dado y da entera fe e crédito en juicio y fuera del; y, porque dello conste, dimos la presente en Quito, a veinte e seis de febrero de mil e quinientos y ochenta e tres. Diego Lucio de Mendaño, Escribano Real e de Provincia; Juan Baptista Arias, Escribano de Su Majestad; Sebastián Hidalgo, Escribano público. /rúbricas/.

\section{APÉNDICE \# 29}

Solicitud dirigida al Rey por Pedro Hernández de Narváez, en representación del presbítero Gómez de Moscoso, para que a éste se le conceda un mejor beneficio, teniendo en cuenta sus méritos y servicios.

AGI, Quito, leg. 82

$$
\text { Quito, } 15 \text { de diciembre de } 1579
$$

\section{C.R.M.}

Pedro Hernández de Narváez, en nombe de Gómez de Moscoso, clérigo presbítero, vecino de la ciudad de San Francisco de Quito, de las provincias del Perú, digo que el dicho, mi parte, de más de cuarenta y tres años que ha que pasó aquellas partes, siempre se ha ocupado en servir a Dios, nuestro Señor, y a Vuestra Majestad en oficios y cargos que se le han encomendado, de lo cual ha 
resultado mucho beneficio a los indios que ha tenido a su cargo por ser una de las mejores lenguas que hay en aquella tierra y hasta agora no se le ha hecho merced alguna, en recompensa de los dichos servicios que constan por esta información y papeles que presento juntamente con la que de oficio envía aquella Real Audiencia.

A Vuestra Majestad suplico que, atento lo mucho y bien que ha servido, se le haga merced de le proveer en uno de los beneficios curados de la Catedral de la dicha ciudad de Lima o en el beneficio curado de Guanujo o beneficio curado de Jaén o el de Guayaquil, que en ello recibirá merced. Pedro Hernández de Narváez. /rúbrica/ Ante mí, Juan de Ledesma. /signo/. (En nota: Estoy pagado deste expediente).

\section{Provisión del beneficio de Loja en favor del presbitero Gómez de Moscoso}

Nos, el Maestro Don Fray Pedro de la Peña, Obispo de Quito, del Consejo de Su Majestad etc., por cuanto al servicio de Dios nuestro Señor y bien de los españoles, vecinos y moradores de la ciudad de Loja deste nuestro Obispado y naturales della conviene que vos, el Reverendo Padre Gómez de Moscoso, clérigo presbítero, estéis y residáis en la dicha ciudad de Loja por cura y vicario della hasta que otra cosa proveamos.

Por tanto, os proveemos y señalamos por tal cura y vicario de la dicha ciudad de Loja; y por ésta os damos todo el poder y facultad necesaria para usar y ejercer el dicho oficio de tal cura y vicario con todas las preeminencias que los demás curas y vicarios tienen y suelen tener en este nuestro Obispado.

Y mandamos a todas y cualesquier personas, de cualquier estado y condición que sean, vos hayan y tengan por tal cura y vicario de la dicha ciudad de Loja, y no vos impidan ni perturben el uso y ejercicio del tal oficio; y, ansimismo, mandamos a los sobredichos vos acudan con los salarios y molumentos que hasta agora, en esta dicha ciudad, han dado a los otros curas y vicarios que en ella han sido. Todo lo cual mandamos so pena de excomunión mayor late sentencia, ipso facto incurrenda, lo contrario haciendo.

Fecha en Quito, a tres días del mes de diciembre de mil y quinientos y setenta y tres años. Fr. Epíscopus Quitensis/rubricado/ Por mandado de su Señoría Reverendísima del Obispo, mi Señor, De Villazón, notario /rúbrical. 


\section{Doctrinas y Parroquias del Obispado de Quito /401}

Provisión del beneficio de Zamora en favor del presbitero Gómez de Moscoso.

Nos, Don Fray Pedro de la Peña, Maestro en santa Teología, Obispo del Quito y del Consejo de Su Majestad etc., por cuanto Su Majestad del Rey Don Felipe, nuestro Señor, es Patrón de todas las Dignidades e beneficios eclesiásticos destos reinos y es servido que sin presentación suya no se haga colación de los dichos beneficios y tiene dado el orden, como en el entretanto que los presenta, se proveen, como se contiene en una su Real Cédula dada en El Escurial, a tres de noviembre de mil y quinientos y sesenta y siete años, firmado de su real mano y refrendada de Martin de Gastelu, su secretario, que por su notoriedad no va aquí inserta, a la cual nos referimos.

Por ende, en cumplimiento de la dicha real Cédula e porque en la santa iglesia de la ciudad de Zamora de nuestra Diócesis hay necesidad de clérigo beneficiado que administre los santos sacramentos a los vecinos de la dicha ciudad e naturales della, y acatando la habilidad y suficiencia que vos, el Reverendo Padre Gómez de Moscoso, clérigo presbítero, e que sois hijo deste Obispado y benemérito en él, y que habéis dado buena cuenta de lo que por nos ha sido encargado y mandado, por la presente, en nombre de Su Majestad conforme a la dicha Real Cédula, vos damos licencia para que seáis beneficiado en la dicha iglesia e ciudad de Zamora con tal que, dentro de dos años primeros siguientes, presentéis esta dicha licencia ante Su Majestad en su Consejo Real de las Indias para que a vos, o a quien Su Majestad fuere servido, presente al dicho beneficio; e no trayendo la dicha presentación, dentro del dicho término, vos habremos por removido del dicho beneficio y daremos licencia a quien viéremos que conviene para servir al dicho beneficio.

Otro sí, en tanto que vuestra voluntad fuere, vos proveemos y nombramos por cura y vicario de la dicha iglesia y ciudad de Zamora e sus términos y jurisdición para que, como tal nuestro cura e vicario, podáis administrar e administréis los santos sacramentos e divinos oficios a los españoles e indios que la dicha ciudad y sus términos están señalados o se señalaren para el cura e vicario; e los oir e oigáis de confesión, conforme a derecho, guardando los casos que tenemos reservados, y a los naturales los podáis absolver de los casos por Su Santidad cometidos a los Prelados destas partes y podáis conocer y conozcáis de cualesquier causas ceviles e criminales, pendientes lo que pendieren, tocantes a nuestro fuero y jurisdición eclesiástica, e los seguir y fenecer conforme a derecho y al Sínodo diocesano por nos celebrado, otorgando las apelaciones que de vos se interpusieren para nos o para nuestro Provisor. 
E por el trabajo e ocupación que en ello habéis de tener, mandamos que vos sea dado y pagado y hayáis e llevéis para ayuda a vuestra sustentación el salario e pesos de oro, comida y camarico y todo lo demás que está tasadoy señalado para el dicho vicario e cura, y de la manera y en la moneda y pagas que está señalado.

E para lo susodicho vos damos poder cumplido y bastante comisión, tal cual de derecho en tal caso se requiere, y vos encargamos la conciencia que con toda diligencia e cuidado entendáis en la instrución e conversión de los dichos naturales que así están señalados al dicho nuestro cura y vicario o se señalaren, porque con vos descargamos la conciencia de Su Majestad e la nuestra; y mandamos a todas e cualesquier personas, de cualquier estado y condición que sean, que vos hayan e tengan por tal beneficiado e nuestro cura y vicario, y usen con vos los dichos oficios y os acudan con los salarios y derechos a ellos anejos y pertenecientes, y os guarden todas las preheminencias, inmunidades e libertades que por razón de los dichos oficios debéis e podéis haber e gozar, so pena de excomunión mayor latie sentencie ipso facto incurrenda lo contrario haciendo. Y os mandamos, so pena de excomunión mayor en la cual incurráis ipso facto lo contrario haciendo, que no dejéis el dicho beneficio, curazgo y vicarías, ni os salgáis del sin expresa licencia nuestra, y que tengáis en vuestro poder un traslado del Sínodo desta Diócesi, por nos celebrado, para que por él os risgáis y sepáis lo que debéis de hacer. Dada en Loja, en veinte y siete días del mes de diciembre de mil y quinientos y setenta y dos años, entrante el año de setenta y tres. Fr. P. Epíscopus Quitensis. Por mandado de su Señoría Reverendísima, Luis de Ortega, apostólico notario. /rúbrica/.

\section{APÉNDICE \# 30}

Testimonio que los miembros del Cabildo de la Catedral de Quito dieron acerca de las virtudes y méritos del presbítero Jácome Freile de Andrade, a fin de que el Rey le concediera alguna prebenda o un mejor beneficio.

$$
\text { AGI, Quito, leg. } 84 \quad \text { Quito, } 5 \text { de marzo de } 1585
$$

En la ciudad de San Francisco de Quito del Pirú, cinco días del mes de marzo de mil y quinientos y ochenta y cinco años, ante el Muy Ilustre señor Deán y Cabildo desta santa Iglesia, sede vacante, estando juntos en su Cabildo e 


\section{Doctrinas y Parroquias del Obispado de Quito /403}

ayuntamiento, como lo han de uso y costumbre de se juntar, pareció Jácome Freile de Andrade, Comisario del Santo Oficio, cura rector desta santa Iglesia, y presentó la petición siguiente: Muy Ilustrísimos Señores: Jácome Freile de Andrade, Comisario del Santo Oficio de la Inquisición en esta ciudad y Obispado, cura rector desta santa Iglesia Catedral de Quito, digo que yo he servido a $\mathrm{Su}$ Majestad en todo lo sea ofrecido desde viente años que ha que estoy en este reino, y asimesmo he servido en este Obispado y santa Iglesia desde nueve años a esta parte que soy sacerdote en doctrinar a los naturales y su conversión y servicio desta santa Iglesia, y al presente estoy ocupado en lo susodicho. Y para que se me haga merced de la presentación de alguna prebenda o beneficio, a Vuesa Alteza pido y suplico se mande dar y dé certificación de lo dicho y de mi habilidad y suficiencia y ser benemérito y de buena vida y costumbres y lo más que se requiere para que Su Majestad me haga las dichas mercedes, sobre que pido justicia. Jácome Freile.

Los dichos Señores dijeron que les consta y es así que el dicho Jácome Freile de Andrade es cura rector en esta santa Iglesia Catedral y en ella ha servido de muchos años a esta parte, y administra los santos sacramentos a españoles y naturales, cuya lengua sabe, y fue Provisor en este Obispado, y asimesmo es Comisario del Santo Oficio de la Inquisición en esta ciudad y Obispado, hábil, virtuoso, de buenas costumbres y fama, natural gallego, de noble y limpia generación, de edad de cuarenta y cinco años, y tal persona, que siendo Su Majestad servido de le presentar a alguna Dignidad, prebenda o beneficio en esta santa Iglesia o en otra deste reino, será bien empleado, y cabe en él la merced que $\mathrm{Su}$ Majestad le hiciere.

Y para que conste de lo dicho, mandaron se saque por duplicado y se envíe cerrado y sellado con el sello deste Cabildo a Su Majestad y a su Real Consejo de las Indias, y lo firmaron el Deán Soto, el Arcediano Galavís, el Chantre de Quito, el Maestreescuela, el Tesorero Valderrama, Juan Francisco Talavera. Ante mí, Francisco García Durán, notario y secretario. El Deán Soto, El Arcediano Galavís, el Chantre de Quito, El Maestre, El Tesorero Valderrama /rúbricas/. Ante el dicho Francisco García Durán, notario apostólico y secretario de los dichos Señores, a lo que dicho es, presente fui,e por ende fice mi signo que es tal signo /signo/.

En testimonio de verdad,

Francisco García Durán,

Notario apostólico y secretario/rúbrica/. 
404 / Augusto E. Albuja

\title{
APÉNDICE \# 31
}

Carta que el Dr. Barros, Presidente de la Audiencia de Quito, dirigió al Rey Felipe II manifestándole los inconvenientes de que las Diócesis estuviesen por muchos años vacantes.

\author{
AGI, Quito, leg. 8 \\ Quito, 4 de abril de 1590
}

Señor:

Don fray Agustín de la Coruña, religioso de la Orden de San Agustín, Obispo de la ciudad de Popayán, que es distrito de esta Audiencia de Quito, murió por el mes de noviembre del año pasado de ochenta y nueve. Todo lo de aquel Obispado, ansí en lo que toca a la nación española como la república de los indios, queda muy desamparado porque los prebendados que allí asisten son hombres de poco talento y capacidad y cada uno ha de acudir a su interese particular, como lo acostumbran en las demás iglesias faltando el Obispo.

En otras mis cartas, celando el servicio de Vuestra Majestad, descargo de su real conciencia es...(roto) dos cosas, y ambas las tengo por de mucha importancia y ansí las torno a repetir en ...(roto)... La una es que Vuestra Majestad alcanzase de Su Santidad en que durante la sede vacante... o audiencia del distrito en que vacase algún Obispado, pudiese señalar un..(roto) A....(Administrador) en el interin que viniese el Obispo a residir en su Iglesia, pues, de ordinario, vemos la dilación de tiempo que hay desde la muerte del tal Obispo hasta que llega sucesor, lo cual se puede bien entender por el suceso que ha tenido este Obispado de Quito, pues, habiendo proveído el Consejo de Vuestra Majestad, con tanta presteza y celeridad, al Obispo de la Imperial de Chile, (elección muy acertada), para que viniese desta Iglesia, ha tardado seis o siete años, y no sabemos cuándo vendrá, con ser el viaje desde su Obispado hasta aquí, a lo muy largo, dos meses. Y con este nombramiento de tal Administrador, cesarían mil estragos, simonías, disensiones que cada día vemos en estos prebendados; y el tal Administrador, o con esperanza de que Vuestra Majestad le presentaría en aquella Iglesia o en otra, procuraría de esmerarse en la administración de el tal Obispado. La otra cosa que suplicaba a Vuestra Majestad era inclinase su ánimo para presentar en las Iglesias de estas partes clérigos virtuosos en profesión, canonistas, porque con los frailes o clérigos teólogos se pasa cada día grandísimo trabajo sobre el alzar de las censuras y otras ocasiones que se ofrecen; y como no tienen qué per- 


\section{Doctrinas y Parroquias del Obispado de Quito /405}

der, son demasiadamente atrevidos y libres. Presento por testigo, de lo que ahora voy tratando, lo que sucedió en esta Audiencia con el Obispo Fray Agustín que ahora murió. Negocio más grave y de mayor escándalo que debe haber sucedido en esos reinos ni en éste; aunque presumo yo que en Ginebra no pudiera acaecer, y fue que por no querer alzar ciertas censuras que había discernido el dicho Obispo, lo enviaron a prender con una infinidad de gente y lo sacaron de cabe el Santísimo Sacramento, estando él vestido de pontifical, y le ultrajaron, descubriéndole sus vergüenzas y haciéndole otras ignominias que, refiriéndolas, quebrantan el corazón. Espectáculo lastimoso para los naturales desta tierra y para los españoles. $\mathrm{Y}$ en resolución le trajeron metido en unas andas, ochenta leguas del camino, sin consentir que entrase en ninguna iglesia. Llegó a esta ciudad de Quito, a do se detuvo por tiempo de seis años, hasta que con una Cédula que despachó el Consejo de Vuestra Majestad y con mis ruegos y cartas, le hice volver a su Obispado, donde ahora acabó la vida. Verdad es que el Obispo, en la residencia que hacía, favorecía la verdad y lo justo, que era querer cumplir una presentación de Vuestra Majestad, firmada de su real mano, y la Audiencia le ordenaba, por provisiones, que no la cumpliese. Al principio le tomaron tres mil pesos de oro, y después, porque los absolviese, se los restituyeron; y por otra parte, el Licenciado Pedro Venegas del Cañaveral, estando sólo en esta Audiencia, envió persona particular para que de su hacienda del dicho Obispo le tornase a tomar otros tres mil, y ansí se hizo; y parece que jugaban con el pobre Obispo. Plega su Divina Majestad que el dicho Cañaveral y los demás lo vayan ahora pagando parte de los oprobios y ignominias que en él ejecutaron. Todo esto, por ventura, cesara si allí estuviera un hombre que entendiera las derechos y se dejara llevar de los mandatos de el Audiencia, aunque ellos eran injustos. Y no se le ponga por delante a Vuestra Majestad lo que toca a la predicación evangélica, pareciéndole que esto lo harán mejor los Obispos teólogos que no los juristas, porque en todo el año no predica un Obispo dos o tres veces, y hay por acá tantos predicadores que pueden suplir muy bien la falta que en esto haría el canonista.

He significado lo que siento cerca de estas provisiones tocantes a los Obispos. Vuestra Majestad y su Consejo acordarán lo que más convenga para el bien de esta tierra, descargo de su real conciencia. Y guarde Nuestro Señor a Vuestra Majestad por luengos y dichosos años como puede etc. En Quito y abril 4, 1590.

\section{El Doctor}

Barros/rubricado/. 
406 / Augusto E. Albuja

\title{
APÉNDICE \# 32
}

\section{Carta del Dr. Barros, Presidente de la Audiencia de Quito, en que ma- nifestaba al Rey Felipe II las vacantes de ciertos cargos.}

\author{
AGI, Quito, leg. 8
}

Quito, 28 de febrero de 1591

Señor:

Con cartas particulares se ha dado razón a Vuestra Majestad de las vacantes que ha habido, así en lo temporal como en lo espiritual, en todo el distrito desta Audiencia. Y ahora le torno aquí a repetir por si las cartas no hubieren llegado al Consejo de Vuestra Majestad.

Fray Agustín de la Coruña, Obispo que fue de Popayán, murió en el año pasado de 1 U 590, y la Iglesia quedó en poder de dos o tres hombres de poco saber; y así convendría que con brevedad Vuestra Majestad presentase para ello persona cual conviniese al bien de la nación española y naturales de aquella Gobernación.

Don Fray Antonio de San Miguel, Obispo que era de la Imperial de Chile, que venía a asistir en esta Iglesia de San Francisco del Quito, después de le haber esperado como siete años, fue Nuestro Señor servido, que habiendo llegado a la Villa de Riobamba, 25 leguas desta ciudad, lo llevó para sí, cuya muerte fue muy sentida, porque se creía era un Prelado de las partes y condición que esta tierra había menester. Aquí quedaron mucho número de prebendados ocupados en sus codicias y otras cosas. Siempre se ha advertido a Vuestra Majestad que convendría presentar en estas Iglesias personas que fuesen canonistas y no teólogos, porque la experiencia nos enseña en que por este camino habría más paz y conformidad, entre las Audiencias y los Prelados, que la que hay cuando son teólogos o frailes; y lo que toca a la predicación evangélica, para que podría ser necesario ser el Obispo ante teólogo que canonista, dejado aparte que son pocas las veces que en el discurso del año predican los tales Obispos, hay tanto número de predicadores, clérigos y frailes, que se supliría bien la falta que el tal Obispo jurista pudiese hacer. En todo proveerá Vuestra Majestad lo que más a su servicio convenga.

4.- Y lo que será de mucho efecto, según que acá muy de ordinario lo platicamos y dello se ha dado noticia a Vuestra Majestad, es que se debería pedir a Su Santidad diese facultad para que en las sede-vacantes, que cada día suceden 


\section{Doctrinas y Parroquias del Obispado de Quito /407}

y en que con tanta dificultad se provee de remedio y tan a la larga, Su Santidad tuviese por bien que el Virrey destos reinos o las Audiencias en su distrito nombrasen un Administrador para que gobernase el tal Obispado, con que cesarían las disesiones (sic) de los prebendados y otras cosas ruines que en estos tiempos se hacen.

5.- En la ciudad de Cali, Gobernación de Popayán, asisten dos oficiales reales de Vuestra Majestad; y el uno dellos se llamaba don Pedro de Figueroa, que hacía el oficio de contador, el cual murió y el Gobernador proveyó un tiniente en su lugar. Convendría proveer con brevedad, porque en aquella caja se recoge, cada año, suma de dinero y el salario que allí se da es competente, que debe llegar a mil pesos ensayados.

6.- En esta ciudad del Quito murió Juan Rodríguez de Ocampo, que era tesorero de la real hacienda de Vuestra Majestad, a el cual y a los demás oficiales que ha habido, de cuarenta años a esta parte, se hizo alcance de setenta y seis mil pesos. Voy procurando enterar la caja real, y Vuestra Majestad convendría proveyese una persona hábil que asistiese en el dicho oficio, acrecentando el salario de trescientos pesos de oro que tienen en cada un año, a seiscientos, porque de otra manera no se pueden sustentar, y tienen color, con tan corto salario, meter la mano en algunas otras granjerías y aprovechamientos de la hacienda de Vuestra Majestad.

7.- Diego Diez de Fuenmayor era canciller de esta Audiencia por merced que Vuestra Majestad le había hecho. Habrá dos años que murió. Vale este oficio, en cada año, como cuatrocientos ducados; y vendiéndole aquí, se hallaran por él como 2 U 500 o 3 U ducados. Vuestra Majestad ordenará lo que más convenga a su servicio.

8.- El Bachiller Bartolomé de Gálvez era relator de esta Audiencia, y en días pasados se dió noticia a Vuestra Majestad, en carta della, cómo era inhábil y descuidado, y que realmente no se descargaba la conciencia de Vuestra Majestad ni la nuestra. El salió de esta ciudad, con su casa y familia, para el nuevo reino de Granada. Demás de lo cual, yo, en la visita que le tomé, le suspendí. Parece convendría que Vuestra Majestad enviase otro relator. Y tiene este oficio de aprovechamiento, con sus derechos y salario que Vuestra Majestad le da en penas de cámara, más que tres mil pesos en cada un año.

9.- En la ciudad de Loja hay una caja real con dos oficiales: el uno es propietario, proveído por Vuestra Majestad en la tesorería, que se llama Pedro Dalbia; y el otro nombra el Virrey en el entretanto que Vuestra Majestad le pro- 


\section{8 / Augusto E. Albuja}

vee de esos reinos. Tiene salario competente y aún demasiado. Y respecto del aprovechamiento que Vuestra Majestad lleva en cada un año, tira cada uno seiscientos pesos ensayados, y el trabajo es muy poco. Y habiendo tomado posesión, el dicho Pedro Dalbia, de su oficio, el Virrey le proveyó por Corregidor del partido de Latacunga, aquí junto, para que fuese más aprovechado, con facultad de dejar allí un tiniente en su lugar. A mí no me parece bien que nadie sirva su oficio por sustituto, mayormente en negocio de la hacienda de Vuestra Majestad; y como tengo profesado el no me atravesar con los Virreyes, paso por algunas cosas que no son precisas de la obligación de mi oficio. Vuestra Majestad en esto provea lo que más a su real servicio convenga.

10.- Con las enfermedades que han sobrevenido en estas provincias y reinos del Pirú, los naturales della han venido en alguna diminución, y en particular en la Gobernación de Yaguarsongo y Pacamoro, a do asiste por Gobernador Juan Alderete. Y en la primera ciudad, que se llama Valladolid, reside él y la caja de Vuestra Majestad con dos oficiales reales, los que les tienen de salario, en cada un año, cada uno, quinientos pesos ensayados. Y conforme a la pobreza con que ha quedado aquella tierra y el poco oro y aprovechamiento que dello resulta a Vuestra Majestad, parece que convendría, que pues los mismos vecinos de aquella ciudad, a quien el Gobernador nombra para el ejercicio destos oficios con el dicho salario y no hay propietarios porveídos por Vuestra Majestad, se les moderase, llevando a cien pesos o ciento y cincuenta, que les basta por estarse en su casa y ser el trabajo que tienen de muy poco momento, y no ganan otro tanto o poco más los oficiales de esta caja de Vuestra Majestad que está en la ciudad de Santiago de la misma Gobernación.

11.- En otra carta doy cuenta a Vuestra Majestad de lo que entiendo se recogerá en el servicio gratuito que el estado eclesiástico y seglar hacen a Vuestra Majestad para el socorro de los gastos de la guerra, que llegará como a cien mil pesos. Puédese estimar en algo, porque esta tierra no es rica como la de Potosí y otras partes. Irá en esta flota lo más que ser pueda; y lo que restare, en la primera ocasión.

12.- El Obispo don fray Antonio de San Miguel sirvió a Vuestra Majestad con seis mil pesos ensayados. Guarde Nuestro Señor a Vuestra Majestad por luengos y dichosos años como puede etc.

En Quito y febrero postrero 1591.

Doctor Barros /rubricado/. 
Doctrinas y Parroquias del Obispado de Quito /409

\section{APÉNDICE \# 33}

Carta dirigida por el Rey Felipe II al Deán y Cabildo de la Catedral de Quito para comunicarles que el Padre Fr. Luis López de Solís ha sido elegido Obispo de Quito y, hasta que se despachen las Bulas, les recomienda el buen gobierno de la Diócesis.

AGI, Quito, leg. 209

Madrid, 17 de abril de 1592

\section{El Rey}

Venerable Deán y Cabildo (sede vacante) de la Iglesia Catedral de la provincia de Quito, habiendo elegido y nombrado para Obispo de las provincias de el Río de la Plata al Maestro Fray Luis López, de la Orden de San Agustín, Catedrático de Teulogía en la Universidad de la ciudad de los Reyes, por la buena relación que he tenido de su persona, vida y letras, y entender que así cumple al servicio de Nuestro Señor y buena administración de ese Obispado, he tendio por bien de le volver a elegir y nombrar a ese Obispado que, como sabéis, está vaco por muerte de don Fray Antonio de San Miguel, último Obispo y Prelado que fue della, y sus Bulas se despacharán y enviarán con toda brevedad; y porque en el entretanto conviene al servicio de Dios y mío que haya persona que tenga cargo de gobernar este Obispado, y el dicho Maestro Fray Luis López lo podría hacer con la comodidad y cuidado que se requiere, os encargo que, queriendo el dicho Obispo encargarse de ello, le recibáis y dejéis gobernar y administrar las cosas de ese Obispado, como dicho es, y le déis poder para que pueda ejercer todas las que vos podríades hacer, en Sede vacante, en el entretanto que se despachan y envían las dichas Bulas, que de ello tendré contentamiento.

De Madrid a XVII de abril de MDLXXXXII.

Yo El Rey

Refrendada de Juan de Ibarra y señalada de el Consejo. 
410 / Augusto E. Albuja

\section{APÉNDICE \# 34}

Carta dirigida por el Rey Felipe II al Padre Fr. Luis López de Solís, Obispo electo del Río de la Plata, para comunicarle su nueva elección como Obispo de la Diócesis de Quito.

AGI, Quito, leg $209 \quad$ Madrid, 17 de abril de 1592

El Rey

Venerable y devoto Padre Maestro Fray Luis López, de la Orden de San Agustín, catedrático de Teulogía en la Universidad de la ciudad de los Reyes, de las provincias del Perú, y a quien tenía elegido para Obispo de las provincias de el Río de la Plata, porque estando al presente vaca la Iglesia y Obispado de la provincia de Quito, por muerte de Fray Antonio de San Miguel, y entender que, demás de ser en ello servido Nuestro Señor, vuestra persona es más a propósito para el dicho Obispado de Quito, he tenido por bien de volveros a elegir y nombrar para él. Yo os encargo que, si conformándoos con la voluntad de Nuestro Señor le aceptáredes, os váis luego a gobernarle en las cosas que no fueren de orden, para cuyo efecto escribo al Deán y Cabildo de aquella Iglesia encargándole os den poder, y en este caso podréis publicar vuestra elección y en la primera ocasión enviaréis las informaciones y demás recaudos que se requieren para que juntamente con la carta que yo escribiese a Su Santidad suplicándole os haga gracia y merced de la dicha Iglesia y Obispado a mi presentación, se envíe a mi Embajador en Roma y se expidan luego las Bulas; y si, habiéndolo encomendado muy de veras a Nuestro Señor, os determináredes a no aceptar, guardaréis secreto, volveréis a enviar este despacho, con toda brevedad, para que se provea aquella Iglesia de Prelado. De Madrid, a diez y siete de abril de mil y quinientos y noventa y dos años.

Yo el Rey

Refrendada de Juan de Ibarra y señalada de el Consejo. 


\title{
Doctrinas y Parroquias del Obispado de Quito /411
}

\section{APÉNDICE \# 35}

Carta que el Ilmo. Señor Luis López de Solís, a los cuatro meses de haber llegado a Quito, dirigió al Rey, manifestándole sus primeras impresiones del estado en que encontró su Diócesis y la fundación del Colegio-Seminario.

\author{
AGI, Quito, leg $76 \quad$ Quito, 12 de Octubre de 1594
}

Señor:

De las ciudades de Trujillo y Guayaquil di cuenta a Vuestra Majestad de mi viaje para ésta de Quito y de mi consagración y las causas tan forzosas de vuestro real servicio que no me habían dado lugar antes a venir a este Obispado. Aura cuatro meses que llegué a él; y por el camino confirmé diez mil ánimas y restan otras cincuenta mil, a que acudiré con mucha brevedad. Y por haber hallado esta tierra tan libre, respecto de haber estado doce años sin Prelado y por las ocasiones pasadas, ha sido necesario reparar al remedio y asiento de muchas cosas de consideración que me obligan a salir de esta ciudad en muchos días; y por ser este distrito largo y con muchas provincias, he proveído cuatro Visitadores para que reformen y castiguen los excesos que en esta larga vacante han sucedido.

Las revoluciones pasadas de esta ciudad han tenido freno con la buena diligencia del Marqués de Cañete, vuestro Visorrey, que lo remedió y previno con muy buena industria y maña, de que se deben las gracias a Dios nuestro Señor por haberse atajado una de las mayores traiciones que en este reino ha habido; y como estas cosas no se acaban tan presto, por tantas dependencias como tienen, sin embargo de que han sido perdonados, han quedado con tanta libertad y desvergüenza muchas personas, que es lástima ver cuan fuera van del camino que es razón; y en quien más demostración he visto de este mal intento, ha sido en religiosos que desde el principio se señalaron, y como se hallan tan exentos de jurisdición que los corrija, han pasado muy adelante, y no es en general porque hay muchos religiosos que merecen ser premiados; y el estado seglar como ve muchos religiosos graves los favorecen, atrévense más en estas ocasiones.

Con mucha diligencia y cuidado he inquirido de las principales personas y he dado aviso a esta Audiencia con testimonio e informaciones que he presentado contra los religiosos culpados y vuestro real acuerdo entré y me ofrecí a ayudar y servir en cuanto se me ordenase. Lo mismo he hecho al Virrey y se le ha advertido que saque de aquí algunas personas para quietar más la tierra. Los 


\section{2 / Augusto E. Albuja}

clérigos que en ella han andado sospechosos, no aguardaré aquella Audiencia ni el Virrey lo remedie, ni quedará ninguno en el Obispado, ni sin castigo.

Como este Obispado estaba tan olvidado de leyes y preceptos por la vacante y en todo él no se guardaba ninguno, lo primero que hice fue Concilio diocesano donde asistieron dos personas de el Audiencia y las más graves del Obispado. Ordenáronse ciento y veinte constituciones y quedó recebido el Concilio provincial de Lima del año de 83, que está probado por el Consejo y confirmado por Su Santidad y de hoy más se guardará y cumplirá lo uno y otro y se remediarán muchas costumbres en que ha estado el clero, porque había veinte años que no se había hecho Sínodo ni lo guardaban.

Hallé Cédula de Vuestra Majestad, en que me manda funde Colegio-Seminario y que se cobre la renta para sustento en la conformidad que el Concilio de Trento y el provincial de Lima de 83 disponen, lo cual puse en ejecución y he tendio la mayor contradicción del mundo con las Ordenes, diciendo no habían de pagar la renta. Y como es cosa tan cierta deberla los religiosos que tienen beneficios y Doctrinas, por razón del salario y estipendio que se les paga, de lo cual ha declarado Vuestra Majestad y los Cardenales que se debe a tres por ciento, tratóse pleito y como estaba tan cierto de la justificación del caso, sin aguardar a la determinación, fundé el Colegio en una muy buena casa, donde metí cuarenta colegiales, con hábito pardo y beca de grana, hijos de conquistadores y de la gente más principal de esta tierra, y tan buenos estudiantes que pueden competir con los buenos seminarios de España. Los pobres entran como tales, y los ricos pagan un tanto al seminario para ayuda a su costa.

Determinóse la causa en esta Real Audiencia y declaróse que los religiosos que tuviesen Doctrinas y beneficios debían pagar el seminario a tres por ciento, en conformidad que el Concilio ordena.

Este Colegio he encargado a los religiosos de la Compañía de Jesús por ser, como es, su Instituto inclinado a estas cosas de virtud y del servicio de Dios nuestro Señor; los cuales han puesto Rector en el dicho Colegio y religiosos, y tienen maestros que los enseñan, y van tan adelante en letras y virtud que de hoy más se proveerán del seminario los clérigos que fueren menester en el Obispado, porque los voy ordenando y preparando con este intento.

Suplica a Vuestra Majestad sea servido hacer merced a este Colegio-Seminario de cuatro mil pesos de renta en los primeros indios que vacaren en esta ciudad para que prosiga en el aumento de toda esta tierra, acrecentándose en él otros muchos que no se reciben por la pobreza y poca renta que tienen, lo cual 


\section{Doctrinas y Parroquias del Obispado de Quito /413}

será una de las limosnas más aceptas y bien empleadas de todo este reino, por ser el primer Colegio-seminario del y comunicarse esta buena obra a tantos conquistadores y pobres que aquí meten sus hijos, y ellos mismos darán la recompensa con el fruto que han de hacer, con el favor divino, siendo Vuestra Majestad servido que el cumplimiento y ejecución venga a esta Real Audiencia, prefiriendo otra cualquiera Cédula.

Veo tantos clérigos y frailes en las Indias que no hay en qué ocuparlos, que ahora se ha de echar más deber respecto del seminario y se podría excusar la costa y gasto que hacen a Vuestra Majestad, en cada un año, para pasar acá, mandando cerrar la puerta porque no son menester, y cuando por acá llegan es la mitad menos, por muertes y otras causas, y los que llegan están tan olvidados de la clausura de su Religión con la libertad que acá tienen en Doctrinas y beneficios que, olvidados de sus votos y profesión, dan en mercaderes que tratan y contratan y otras cosas con deseo de volver a España, de que se sigue notable perjuicio a los naturales porque los dejan vivir en sus malas costumbres, con consideración de que son huéspedes y se han de ir mañana. Y en este Obispado, de tres partes de Doctrinas tienen las dos religiosos, y como no los puedo visitar de vida y costumbres, viven en las que quieren y no guardan lo que deben, y es una cosa muy considerable y que pide remedio en dos maneras: o que sean visitados como personas que tienen beneficios y están extra clausa, o que dejen los tales beneficios, pues no han de dar residencia y cuenta de ellos. Mande Vuestra Majestad proveer en este capítulo lo que más convenga, porque es un negocio de los más graves de este reino y en que se encarga la conciencia y yo no la puedo descargar como quisiera.

Ahora comienzo la visita del Cabildo de mi Iglesia, que no es lo menos que hay que remediar porque son pocos y mal avenidos. Faltan tres Dignidades que son: Deán, Chantre y Tesorero, que no la hacen pequeña; cada día los aguardo.

Esta ciudad de Quito es de muy buen temple y sano y muy abundante de mantenimientos, por lo cual ha muchos años que se ha suplicado a Vuestra Majestad mande dar licencia para que en ellla se funde universidad por cuanto en el Pirú no hay lugar más cómodo por las razones referidas. Vuestra Majestad ha mandado que se dé aviso, por parte de esta Audiencia y por el Obispo, de lo que conviene; y en esta conformidad y respecto de lo que he dicho, en ninguna parte de todo el reino estará mejor una universidad que en esta ciudad de Quito, y acudirá a estudiar a ella todo el reino por la sanidad de la tierra y poca cos-

ta. Suplico a Vuestra Majestad favorezca esta causa como lo hace y ha hecho a las que son de letras, pues dello resultan tan buenos efectos como es: tener sabios 


\section{4 / Augusto E. Albuja}

en la tierra que ayuden a la justicia de Dios y de Vuestra Majestad, por cuya falta ha sucedido en ella lo que se ha visto por expiriencia, y que se funde con mucha brevedad, enviando licencia para ello.

Por mandado de Vuestra Majestad se ha leído la cátedra de la lengua general de esta tierra en el convento de Santo Domingo, por tiempo limitado, y se paga el salario de vuestra real caja. Suplico a Vuestra Majestad dé licencia para que de aquí adelante se lea la cátedra en el colegio-seminario, pues demás de que allí está la práctica de la lengua más afinada, los mismos colegiales han de ser de hoy más proveídos en Doctrinas y beneficios y la han de administrar y se leerá con mucho cuidado; y por este trabajo, sea Vuestra Majestad servido, se le acuda al Colegio con el salario que es de costumbre y que no se pueda leer en otra parte.

Esta Audiencia queda muy falta de ministros por haber suspendido un Oidor en visita y otro dejado la plaza por casarse. Tiene mucha necesidad de remedio, así de Presidente como de Oidores.

El Corregimiento de esta ciudad es muy bueno; al presente le sirve por orden del Virrey don Francisco de Mendoza Manrique. Tiene necesidad esta tierra, por la libertad que en ella veo, de un hombre de mucho brío y a quien nadie se atreva; y si lo hicieren, ejecute un castigo ejemplar.

En general se han seguido y siguen en este reino notables inconvenientes de irse los Provinciales y Prelados de las Ordenes, de este reino a ése, a pretenciones particulares, porque, demás de que por ello recogen cuanta plata hay en los conventos, quedan las provincias con mil disensiones como sucede agora en ésta con la ida del Provincial de Santo Domingo, fray Jerónimo de Mendoza, que va a pretender a esa Corte; y aunque he dado aviso a esta ciudad de los inconvenientes que se ofrecen, no lo remedian, y así es necesario que se provea en vuestro Real Consejo que acaben sus oficios y no los desamparen por causas particulares, dejando la general de toda su Religión.

Guarde Nuestro Señor la católica y real persona de Vuestra Majestad con acrecentamiento de mayores reinos y señoríos.

En Quito 12 de octubre 1594.

Epíscopus quitensis.

/al dorso dice/ Quito a Su Majestad 1594

Obispo de Quito 12 de octubre. Vista en 13 de octubre de 1595 proveída en los capítulos que se vieron a instancia del mismo Obispo

$\mathrm{Al}$ rey nuestro Señor en su Real Consejo de las Indias. 


\title{
Doctrinas y Parroquias del Obispado de Quito /415
}

\section{APÉNDICE \# 36}

Carta del Obispo de Quito al Rey Felipe II, dándole a conocer los trabajos realizados durante los pocos meses que lleva en la Diócesis.

\author{
AGI, Quito, leg. 76 \\ Quito, 20 de febrero de 1595
}

Señor:

En las ocasiones que se han ofrecido, he dado cuenta al Consejo de las Indias de lo que es a mi cargo y obligación. Y en ésta escribo largo de lo que conviene al servicio de Dios Nuestro Señor y de Vuestra Majestad en esta provincia de Quito y de lo que en ella he hecho después que llegué a este Obispado, y de la disposición de la dotrina, gente y otras circunstancias que, por excusar cansancio a Vuestra Majestad, no las refiero. Sólo diré que los naturales son muchos, gente doméstica y aficionada a las cosas de Dios, con cuyo auxilio he comenzado a confirmar, que por la larga vacante de Obispo había mucha necesidad; y en el poco tiempo, he confirmado veinte mil ánimas y hecho Sínodo diocesano y visitado mi Iglesia y fundado el Colegio-seminario, que es el primero del Pirú, y una casa de corregimiento para evitar los divorcios, que había muchos, con la cual se han atajado.

Agora salgo a hacer lo mismo en el Obispado, que es distrito de trescientas leguas de latitud y donde hay doscientas mil ánimas que confirmar. Ruego a Nuestro Señor se haga fruto de su servicio.

El Licenciado Francisco de Sotomayor ha nueve años que es abogado en esta Real Audiencia, y ha tenido cargos y oficios de importancia como han sido: de alcalde de Corte, relator, alcalde ordinario, y ahora es teniente general de Corregidor en esta ciudad, de los cuales ha dado y da muy buena cuenta, y hecho obras de muy buen republicano, y servido en las revoluciones pasadas muy aventajadamente, por lo cual, y por sus letras y experiencia, merece que Vuestra Majestad se sirva de ocuparle en una de estas Audiencias, porque dará muy buena cuenta de lo que fuere a su cargo. Tiene papeles de muy buenos servicios en el Real Consejo de las Indias; suplico a Vuestra Majestad mande hacerle merced. Y guarde Nuestro Señor la católica y real persona de Vuestra Majestad como principal columna de la cristiandad y defensor de nuestra santa fe.

En Quito y de febrero 20 de 1595.

Fray Ludovicus, Epíscopus quitensis /rubricado/

/Al dorso. Al Rey nuestro señor en sus Reales manos,

Obispo de Quito en las Indias. 
416 / Augusto E. Albuja

\title{
APÉNDICE \# 37
}

\begin{abstract}
Carta que Miguel de Horozco, Fiscal de la Real Audiencia de Quito, envió al Rey Felipe II para poner en su conocimiento ciertas alteraciones civiles y la labor desempeñada por el nuevo Obispo de la Diócesis.
\end{abstract}

\author{
AGI, Quito, leg. 76 \\ Quito, 22 de marzo de 1595
}

\section{Señor:}

En muchos pliegos que han ido para Vuestra Majestad, de esta Real Audiencia y míos, he dado aviso de todo lo sucedido en las alteraciones pasadas y de otros particulares tocantes al servicio de Vuestra Majestad; y porque en aquéllos escrebí largo, en ésta diré sucintamente lo que de nuevo se ofrece.

Vuestro Fiscal siguió pleito contra Juan de la Vega y los Regidores de esta ciudad en razón de las sediciones que hubo en ella. Y estando el uno condenado, sin embargo, a muerte y en confiscación de bienes, y los otros en la misma pena, por primera sentencia, envió al Virrey vuestra carta y sobrecarta, por donde aduzco así las causas por vía de gobierno y guerra, diéronsele los autos y delincuentes.

También siguió vuestro real fisco, sobre lo propio, a don Rodrigo de Bonilla, uno de los más principales y ricos Encomenderos de esta provincia, sustanciado ya en el negocio para sentencia, en vista se le remitió con él, preso por lo mismo.

Aquí se ha dicho que el Arzobispo de México, a quien Vuestra Majestad cometió la averiguación de lo sucedido en esta ciudad, tiene tanto que hacer en la de Lima, que no podrá venir a ella; y ya que venga, no se despachará en mucho tiempo.

A los 15 de junio del año pasado de 94 entró en esta ciudad el Maestro don fray Luis López de Solís, Obispo della. Es un Prelado sagaz, de grandes letras y gobierno; trae tan ajustado y corregido el estado eclesiástico y Religiones, que con su venida y autoridad han cobrado asiento; tiene tanta experiencia de las Indias, que si hobiera sido antes no pasaran tan adelante las cosas de este reino, porque el valor que ha mostrado en algunas y la prudencia de que usa en otras, fuera de mucho efecto para imponerlas. Ha hecho información contra el clero; presúmese que ha averiguado en ella muchos excesos de las alteraciones pasadas. Hasta ahora no se sabe nada por el grande recato con que ha procedido. Es muy 


\title{
Doctrinas y Parroquias del Obispado de Quito /417
}

caritativo, aunque la renta de este obispado tan poca, que apenas puede sustentarse con ella.

El Virrey envió por su Teniente General y Corregidor de esta ciudad a don Francisco de Mendoza Manrique. Es un caballero muy honrado y prudente. Usa su oficio con mucha rectitud y vigilancia, a satisfacción de esta Audiencia.

De todo lo demás que se fuere ofreciendo, iré dando aviso a Vuestra Majestad, cuya católica real persona Nuestro Señor guarde. Quito 22 de marzo de 95 .

El Licenciado

Miguel de Horozco /rubricado/.

\section{APÉNDICE \# 38}

Carta colectiva de los representantes de las cuatro Ordenes religiosas: franciscanos, dominicos, agustinos y mercedarios, para quejarse ante el Rey por los malos tratos que le da el Obispo, Ilmo. Luis López de Solís.

\author{
AGI, Quito, leg. 83 \\ Quito, 10 de junio de 1595
}

Señor:

Son tantas las vejaciones que de parte del Obispo desta ciudad recebimos todas las Religiones y hallamos tan poca defensa en el Presidente y Oidores desta Vuestra Real Audiencia, que no podemos dejarnos de quejar como a Rey y Señor Nuestro, para que con justicia nos haga merced y así, de acuerdo de todas las Religiones desta provincia del Quito, dimos nuestro parecer a el Padre Provincial de San Agustín, Fray Pedro de...(roto), el cual informará a Vuestra Majestad de todos los agravios que recibimos y la vejación que de presente padecemos es que después que nos libramos de la primera que el Obispo intentó que fue querer visitar los religosos que en las Doctrinas tenemos de moribus e vita y habiéndole sacado Su Santidad deste trabajo por su Propio Motu, agora ha intentado, con consejo de los Padres de la Compañía, pedirnos el subsidio seminario, de quien, por el santo Concilio de Trento y otros muchos motus del santo Papa Pío Quinto, hechos en favor de las Ordenes y confirmados po el santo Papa Gre- 
gorio 13, estamos libres y exentos, fundándose solamente el Obispo desta ciudad, para demandarnos el dicho seminario, en el Concilio particular de Lima que manda que todos los que tuvieren Doctrinas paguen esta contribución y seminario, siendo como es contra el Concilio General Tridentino. Procura el Obispo visitar los frailes de las Doctrinas a fin de, con sus visitas, se desacrediten, aunque sean tales que se puedan canonizar; y así Vuestra Majestad nos los quite y poderlas dar a sus clérigos, de los cuales ha ordenado tanta chusma en espacio de un año que ha que está en esta tierra que parece haber querido hacer escarnio del Orden Sagrado Sacerdotal, porque ha ordenado gente tan ordinaria que puestos en viles oficios como son: herreros, zapateros, mestizos, mulatos y otros muchos que por no ofender las orejas pías de Vuestra Majestad no los especificamos, los cuales por no haber podido salir con sus oficios por granjería se hacen sacerdotes, y los que fueron inhábiles para ellos y no podían ganar ni aún la comida, a esos mesmos ha hallado el Obispo suficientes para sacerdotes; y esto a fin de poderse quejar a Vuestra Majestad que tiene muchos sacerdotes con quien cumplir y que no los puede sustentar sino es quitando a nosotros el sustento.

Para que los sacerdotes sean tantos y más que los seculares ha fundado un Seminario con que todos morimos de hambre, pues los quiere sustentar y sustenta a costa de nuestra pobreza que, aunque los monasterios tuvieran más propios de que echar mano para su sustentación, aún faltará mucho para lo necesario; y pues a costa de nuestro sudor los indios han alcanzado la pulicía que tienen, ansí en cristiandad como en lo demás, con tanto trabajo nuestro y el Obispo se quiere entrar en lo que tenemos nosotros beneficiado y a él no ha costado nada.

Vea Vuestra Majestad cuan poca contienen sus intentos pídenos también las cuartas que no debemos de los entierros y si alguno intenta enterrarse en nuestras iglesias son tan excesivos los derechos que le llevan que, de miedo de no pagarlos, nadien osa enterrarse en ellas. Tenemos muchos motus, carta y sobrecarta de Vuestra Majestad que nos libran destas contribuciones y no nos lo quieren obedecer; y como, por otra parte, Vuesta Real Audiencia, cuando tenemos justicia, no declara tenerla para criar juez conservados, de todo punto parece nuestra justicia y no hallamos quien nos favorezca en ella, porque con las ocasiones pasadas de las alteraciones que en esta ciudad ha habido deben tomarla vuestro Presidente y Oidores para no declarar nuestra justicia, porque entre nosotros y el Obispo no haya discordias que tengan ellos que componer. 


\section{Doctrinas y Parroquias del Obispado de Quito /419}

Suplicamos a Vuestra Majestad, pues fue servido de servirse de nosotros enviándonos a estas partes para que ayudásemos a descargar vuestra real conciencia, ocupándonos en la conversión de los naturales, sea servido de ampararnos y librarnos del rigor del Obispo y mandar a vuestro Presidente y Oidores contra él nos amparen y favorezcan con justicia, haciéndonos merced en defendernos en ella, como Vuestra Majestad siempre lo ha hecho y hace, a quien Nuestro Señor, por muchos siglos, conserve en su servicio y guarde para bien de su Iglesia y aumento de vuestros reinos. Fecha en Quito, a 10 de junio de 1591 (sic)- 1595-años.

$$
\text { S.C.R.M. }
$$

Fray Juan de Santiago = Fray Cristóbal Gutiérrez de Vaillo Fray Francisco de Cuevas = Fray Rodrigo de Lassa /rúbricas/.

\section{APÉNDICE \# 39}

Carta del Obispo de Quito dirigida al Rey Felipe II con el fin de solicitar dos mil pesos de renta para el sostenimiento del reformatorio de mujeres que había fundado.

AGI, Quito, leg. $76 \quad$ Quito, año 1595 ?

Muy poderoso Señor:

El Maestro don fray Luis López de Solís, Obispo de la provincia de Quito y vuestro Consejo, dice que en la ciudad de Quito hizo y fundó una casa de recogimiento, de la vocación de Santa Marta, para que en ella se recogiesen muchas mujeres que eran perjudiciales en la república; y habiéndose dado buen asiento en sus vidas y costumbres, trató de reformar los muchos divorcios que estaban pendientes, de pedimento de muchas mujeres, que sólo pretendían aparte de sus maridos para vivir con más libertad, y se metieron dentro las que estaban de esta manera y de allí se consiguió paz y concordia con sus maridos y cesó la descompostura que tenían.

Y porque en esta casa, de donde han resultado tan buenos efectos, se surtan otros mayores, ha tratado de recoger en ella niñas huérfanas, sin padres, hijas de españoles conquistadores y mestizos, porque se excusen los pecados e inconvenientes en que pueden caer en breves años, porque algunas andan en hábi- 
to de indias, y que en el dicho recogimiento sean enseñadas e industriadas y de allí se procure su remedio, el efecto que se pretende, suplica a Vuestra Alteza sea servido de mandar señalar dos mil pesos de renta, en indios vacos o que vacaren, para la dicha casa y recogimiento de Santa Marta, pues la obra es tan meritoria y se extiende por tantas personas, hijos y nietos de conquistadores, y entre ellos muchos a quien Vuestra Alteza debe remunerar y hacer merced. Para lo cual etc.

Epíscopus quitensis.

\section{APÉNDICE \# 40}

Carta que Francisco Gil Aponte escribió al Rey Felipe II para manifestarle que los religiosos doctrineros no querían pagar la contribución del tres por ciento para el sostenimiento del Seminario de Quito.

$$
\text { AGI, Quito, leg. } 76 \quad \text { Quito, sin fecha (1596?) }
$$

Muy poderoso Señor:

Francisco Gil Aponte, en nombre del Obispo de Quito, dice que otras muchas veces tiene suplicado a Vuestra Alteza mande proveer de remedio acerca del no pagar las Ordenes los tres por ciento, como les está mandado, para la sustentación del Seminario. Y aunque tiene representado de cuan gran beneficio es su conservación, y la falta que haría si no se prosiguiese en su perdición (sic), hasta agora Vuestra Alteza no ha sido servido de proveer del dicho remedio. Y últimamente se mandó traerse la respuesta que dio el Obispo cuando se le notificó no quitase las Doctrinas a los frailes dominicos; y en el oficio de Pedro de Ledesma, en donde había de estar la dicha respuesta, no se ha hallado ni razón de que la haya habido. Y si se diese más larga a este negocio, podría ser que cuando se proveyese del dicho remedio, ya el Seminario estuviese deshecho.

Atento a lo cual, suplico a Vuestra Alteza mande proveer, según pedido y suplicado tiene antes de agora, con que el dicho Obispo recibirá merced. A Vuestra Alteza, por lo cual etc.

Francisco Gil Aponte/rubricado/. 


\section{Doctrinas y Parroquias del Obispado de Quito /421}

\section{APÉNDICE \# 41}

Auto del pleito sostenido entre las Ordenes religiosas y el Obispo de Quito, Ilmo. Señor Luis López de Solís, acerca de ciertos puntos relacionados con la provisión de las Doctrinas.

\section{AGI, Quito leg. $8 \quad$ Quito, 11 de febrero de 1597}

Muy poderoso Señor: El Licenciado Miguel de Horozco, vuestro Fiscal en el pleito con las Ordenes de Santo Domingo, San Francisco y las demás de esta ciudad sobre la guarda del Patronazgo Real y cumplimiento de las Reales Cédulas que para ello se libraron, digo que el auto proveído por vuestro Presidente e Oidores en esta causa, en que se mandan guardar inviolablemente las dichas Cédulas y Patronazgos en cuanto a la forma y orden que se ha de tener en las presentaciones de sacerdotes y religiosos para los beneficios y Doctrinas y colación que dello ha de hacer el Prelado diocesano, es bueno, justo y a derecho conforme, y por tal se debe confirmar y ejecutar, sin embargo de lo dicho y alegado por las dichas Ordenes, por lo siguiente:

Lo uno, por lo general.

Lo otro, porque la forma y orden que se debe guardar y guarda por el dicho Patronazgo Real en las presentaciones y colaciones de los clérigos presbísteros para los beneficios y Doctrinas, ésa misma sea y debe guardar con todos los religiosos que se presentaren a ellas por sus Prelados, sin mudar ni alterar cosa alguna en cuanto a las dichas presentaciones y colaciones del Prelado diocesano, como se contiene en el dicho auto y se ordena y manda por el dicho Patronazgo y Cédulas Reales. Y por no lo haber hecho así, las dichas Ordenes han contravenido y contravienen a lo ordenado y mandado en las dichas Cédulas y Patronazgo Real y a lo dispuesto en el santo Concilio de Trento, a que no se debe dar lugar.

Lo otro, porque no obsta decir las partes contrarias que no están obligados a pedir al dicho Diocesano las tales colaciones y canónicas instituciones y que sin ellas los religiosos que fueren presentados por sus Prelados y nombrados por el Patrón podrán y pueden servir las dichas Doctrinas y administrar los santos sacramentos, por ser exentos del fuero y jurisdicción del dicho Diocesano, porque, allende que lo tal sería contra lo contenido en el dicho auto, Cédulas y Patronazgo Real, conforme a derecho y lo dispuesto por el santo Concilio de 


\section{2 / Augusto E. Albuja}

Trento, no pueden los dichos religiosos, sin las tales colaciones y canónicas instituciones del dicho Diocesano, servir las dichas Doctrinas, ni ser puestos en ellas, etiam ad nutum amovibiles, sin su consentimiento y examen, a cuya jurisdición, visitación y corrección han de estar y están inmediatamente sujetos en todo lo que toca a las dichas Doctrinas, cura de ánimas y administración de sacramentos, como se dispone por el dicho santo Concilio.

Lo otro, porque la Bula y Propio Motu de Su Santidad del Papa Pío Quinto, de que se pretenden aprovechar las dichas Religiones para eximirse de la jurisdición del Ordinario, en lo que está dicho no les es de provecho ni se pueden ayudar della, porque, allende que no quita ni puede quitar la forma y orden del dicho santo Concilio en lo que está referido, en cuanto a ello está revocada por otra Bula de Su Santidad del Papa Gregorio Décimo Tercio, sucesor suyo, que está y anda incorporada en las constituciones y propios motus del mismo Pío Quinto; y esto parece más claro ser así por las declaraciones que hicieron los Cardenales de Roma, intérpretess de los decretos del dicho santo Concilio, en las dudas que el Arzobispo de la ciudad de los Reyes les remitió sobre ello y otras cosas, donde declararon estar derogada y revocada la dicha Bula y Proprio Motu y obligados los religiosos regulares que hobieren de servir Doctrinas a ser examinados primero por el Diocesano y a cumplir en todo la forma y orden que pone el dicho santo Concilio, como todo consta y parece por las letras apostólicas de que hago presentación, sacadas en pública forma del original que dellas se envió de Roma al dicho Arzobispo.

Lo otro, porque estando como está revocada la dicha Bula y Proprio Motu de Pío Quinto, clara cosa es que también lo están las Cédulas que se hobieron dado por virtud della en favor de las dichas Religiones.

Lo otro, porque menos hace al caso decir las partes contrarias que después de haberse librado las Cédulas arriba dichas en favor del dicho Patronazgo Real, se libró otra contraria en favor de las dichas Religiones, eximiéndolas por ella de la jurisdición del dicho Ordinario, en lo que toca a servir las dichas Doctrinas, porque las últimas Cédulas que se despacharon fueron y son las que a pedimiento del Obispo desta ciudad se dieron y presentaron ahora en esta Real Audiencia, las cuales contienen cierta y verdadera relación, como todo es notorio; y su decisión es justa y conforme a lo contenido en el dicho Patronazgo Real y dispuesto en el dicho santo Concilio que se ha de guardar so las penas en él contenidas, dándose por ninguno todo loque en contrario se hobiere hecho o hiciere en virtud del dicho propio motu y Bula revocada. 


\section{Doctrinas y Parroquias del Obispado de Quito /423}

Lo otro, porque no es de consideración decir las partes contarias que, proveyéndose las Doctrinas en sus religiosos por colación y canónica institución del Prelado diocesano, se daría causa para que los proveídos a ellas perdiesen la obediencia a sus Prelados y no los obedeciesen en lo que los mandasen por estar sujetos al tal Diocesano, porque a esto se satisface con que la tal colación y canónica institución del Ordinario no es ni puede ser causa de que los religiosos que sirven las Doctrinas pierdan la tal obediencia, ni a sus Prelados se les quita por ello que no les puedan castigar, si delinquieren, ni dejalles de mandar lo que pareciere convenir al cumplimiento de su Orden. Y, pues, el santo Concilio lo proveyó así, cierto es que considero que por ello no se perjudicaba la tal obediencia, ni se seguían otros algunos inconvenientes a las Religiones, ni los daños que alegan en sus peticiones.

Por todo lo cual, y lo que más puede hacer y hace en favor del dicho vuestro Patronazgo y Cédulas Reales que para su conservación se dieron y están presentadas en esta dicha causa, a Vuestra Alteza pido y suplico mande confirmar y confirme el dicho auto en todo y por todo, como en él se contiene, y que se guarde y cumpla inviolablemente, sin embargo de lo dicho y alegado por las partes contrarias, no dando lugar a sus dilaciones, porque así conviene a vuestro real servicio y entero cumplimiento del dicho Patronazgo y para ello etc. y pido justicia.

Otro sí, digo que se ha de denegar a las partes contrarias la prueba que piden por ser de malicia y para dilatar la determinación desta causa, la cual consiste en punto de derecho y en lo dispuesto por el dicho santo Concilio. A Vuestra Alteza pido y suplico se la mande denegar y para ello etc. El Licenciado Miguel de Horozco.

En Quito, a once días de febrero de mil y quinientos e noventa y siete años, en audiencia pública, ante los Señores Presidente e Oidores desta Real Audiencia la presentó el contenido en ella. Los dichos Señores mandaron dar traslado a las otras partes y que respondan para la primera audiencia y se notificó a Diego de Valverde. Superior, Suárez. 
424 / Augusto E. Albuja

\section{APÉNDICE \# 42}

Relación que hace el Obispo López de Solís acerca de los sacerdotes del clero secular que tenían Prebendas, Parroquias y Doctrinas en la Diócesis de Quito por presentación del Patrono y colación del Ordinario. Además se expone los nombres de las Doctrinas a cargo del clero regular.

$$
\text { AGI, Quito, leg. } 76 \quad \text { Quito, } 8 \text { de mayo de } 1597
$$

En la Santa Iglesia Catedral de Quito:

El Bachiller don Francisco Galavís

El Maestro don Juan de Obando

Don Jorge Ramírez

Juan Francisco Talaverano Mancera

Andrés López de Alvarrán

Gaspar de Zamora

Diego de Agüero Maldonado

Don Alonso de Aguilar Maldonado

García de Valencia

El Maestro Benito Hernández de Ortega

Diego Lobato de Sosa
Deán

Arcediano

Chantre

Canónigo

Canónigo

Canónigo

Canónigo

Canónigo

Canónigo

Es Provisor y Vicario General

Maestro de capilla jubilado

\section{En la ciudad de Quito:}

El beneficio curato desta ciudad sirven dos curas

La sacristía de la Catedral

Maestro de capilla

La Doctrina de San Sebastián

La Doctrina de San Blas

La Doctrina de Santa Bárbara

La Doctrina de Santa Prisca

La Doctrina de San Marcos

La Doctrina de Machángara
Jácome Freile Andrade

Miguel Sánchez Solmerón

El Padre Santiago

Hernando de la Parra Cisneros

El Padre Durán, músico

Francisco Suárez Salgado, sabe la lengua

Antonio Borja, sabe la lengua

El Padre Mansilla, sabe la lengua

Martín de Gaviria-lengua

Francisco del Castillo Figueroa-lengua 
La Doctrina de Machangarilla

La Doctrina de Chillo

La Doctrina de Conocoto

La Doctrina de Chillogallo

La Doctrina de Pelileo

La de Tisaleo

La de Patate

La de Quero

La Doctrina de Angamarca

La de Calpi

La de Lican

La de Yaruquiz
El Padre Saavedra-lengua

Cosme de Robles-lengua

Gabriel de Peralta -lentgua

Gabriel de Jaramillo-lengua

Andrés de Urbina-lengua

Gregorio Vázquez-lengua

Gaspar de Chávez-lengua

Cristóbal Núñez-lengua

Andrés Cansino-lengua

Jun Alvarez-lengua

Francisco de Basurto-lengua

Alvaro Guerrero-lengua y predicador

- Villa de Riobamba de Españoles-

El beneficio desta Villa

Beneficio de yanaconas de la Villa.

La de Chimbo

La de Santiago y San Lorenzo

La de San Miguel

La de Guanuzo

La de Azancoto y Chapacoto

La de Pallatanga
Bernardino de Cantos Guerrero

Francisco Canseco-lengua

Diego Gutiérrez

Diego Alonso Bastidas-lengua

Lorenzo Yánez-lengua

Diego de Castillo-lengua

Lorenzo Díaz Docampo-lengua

Melchor Pérez Quivira-lengua

-La ciudad de Guayaquil de españoles-

El beneficio y curato della

La Doctrina de Pimocha

La de Yaguache
Don Diego Ugarte de Velasco

Juan Luis Pérez-lengua

El Licenciado Copete-lengua

\section{- La ciudad de Puerto Viejo-}

El beneficio y curato della

La Doctrina de Jipijapa

La de Manta

La de Cumbayá
Gabriel de Zúñiga

Diego Pérez-lengua

Hernando de Alarcón-lengua

Juan Antonio de Rueda, lengua y

predicador 
426 / Augusto E. Albuja

La de Tumbaco

La de Pifo y Puembo

La de Yaruquí

La de Oyacachi

La de Guallabamba

La de Cayambe

La de Pimampiro

La de Mira

La de Zámbeza
Gregorio de Vera

Fancisco de Londoño-lengua

Luis Suárez Ponce-lengua

Cristóbal Marmolejo-lengua

Francisco Sancho de la Carrera-lengua

Juan Cortés-lengua

Pedro Ordóñez-lengua

Francisco Martínez Yáñez-lengua

Gerardo Suárez Vinueza-lengua

\section{- La ciudad de San Juan de Pasto-}

El beneficio desta ciudad

La Doctrina del valle de Pasto

La de Joanambu

La doctrina de Quiña

La Doctrina de Los Abades

La Doctrina de Yascual

La Doctrina y Parroquia de

San Sebastián

La Doctrina de los indios de Madrigal

La vicaría y capellanía de las monjas Salvador Lucero
El Licenciado Diego de Bracamonte por provisión de Su Majestad

Antonio de Benavides-lengua

Francisco Vélez de Zúñiga-lengua

Blas Rosero-lengua

Andrés Moreno de Zúñiga-lengua

Francisco González Calderón-lengua

Diego Bermúdez-lengua

Juan de la Roca-lengua

- La ciudad de Mocoa-

El beneficio desta ciudad

El Bachiller Alvarez López

La Doctrina de Cuyoy

Francisco de Mendoza-lengua

- La ciudad de Ecija-

El beneficio desta ciudad

Don Francisco de Torres 


\section{-La ciudad de Cuenca-}

El beneficio desta ciudad

La Doctrina de Alausí

La Doctrina de Guataisi

La de Cibamba

La del Azogue

La de yanaconas de Cuenca

La de San Sebastián de Cuenca

La de Pacaibamba y Jirón

La de Cañaribamba

La de Oña y Nabón
El Bachiller Antonio Morán-teólogo

Diego de Mendieta-lengua

Fernando de Villalobos-lengua

Melchor de Rojas-lengua

Gaspar de Vega-lengua y predicador

Juan Sánchez Mejía-lengua y predicador

Rodrigo Márquez-lengua

Pedro Arias de Avila-lengua

Pedro de Cárdenas-lengua y predicador

Juan de Campos- lengua

- La Villa de San Antonio de Zaruma-

El beneficio desta Villa

El beneficio de yanaconas

La Doctrina de Yauna
Pedro de Coronado

Diego de Chávez-lengua

Juan Gómez-lengua

- La ciudad de Loja-

El beneficio desta ciudad

El beneficio de yanaconas

El beneficio de San Juan del Valle

La Doctrina de Amboca

La Doctrina de Ayavaca

La capellanía de las monjas de Loja Diego Pérez
Hernando Martín de Cáceres

Juan de Losada Castro-lengua

Luis de Jerez-lengua

Cristóbal de Ortegón-lengua

Diegode Ribera-lengua

\section{- La ciudad de Zamora-}

El beneficio desta ciudad

La Doctrina de Zurinanga

La Doctrina de Nambija
El Bachiller Francisco Castellanos

-canonista

Serván de la Roca-lengua

Juan de Flandes Grimaldo-lengua 
428 / Augusto E. Albuja

\section{- La ciudad de Jaén-}

El beneficio desta ciudad

La Doctrina de Lomas y Copalcen

La Doctrina de los guambos

La de Chirinos

La de Acoñipa

Otra en los guambos
El Bachiller Cristóbal Arias-teólogo

Rafael de Alarcón-lengua y predicador

El Padre Barreto-lengua

Pedro Quintero-lengua y predicador

El Bachiller Milena-canonista y lengua

Alonso Núñez de Saavedra-lengua

\section{- La ciudad de San Miguel de Piura-}

El beneficio desta ciudad

La vicaría y yanaconas

La de Paita y Colán

La de Sechura

La de Catacoas

La de Olmos

La de Motupe

La de Jayanca

La de Pacora

La de Guancabamba

La de Salas y Penachi

La de Moscalaque

En las estancias del valle de Piura
Francisco de Alvear

Gabriel Pérez

Juan de Llerena y Luis Baras traen pleito Melchor de Morado-coadjutor post ordo Francisco de Mendoza, por provisión de Su Majestad

Andrés de Sepúlveda-lengua

Gaspar de Cáceres-lengua

Alonso Núñez de San Pedro-lengua, predicador

Juan Rodríguez Ramos-lengua

Miguel Fernández de Córdova-lengua

Alonso de Carvajal-lengua

Alonso Ruis Calderón-lengua

Diego López

\section{-EN LA GOBERNACIÓN DE LOS QUIJOS- \\ - La ciudad de Baeza-}

El beneficio desta ciudad

La Doctrina de la coca
Pedro de Rojas

Alvaro Alonso-lengua

- La ciudad de Avila-

El beneficio desta ciudad

La de los calientes de carito
Gonzalo Hernández

Juan Gómez-lengua 
Doctrinas y Parroquias del Obispado de Quito /429

- La ciudad de Archidona-

Sirve este beneficio Benito Velázquez

\section{- EN LA GOBERNACIÓN DE YAGUARSONGO- \\ - La ciudad de Valladolid-}

El beneficio desta ciudad Esteban Riveros

La Doctrina del Valle Juan de León-lengua

- La ciudad de Cumbinamá-

El benenficio desta ciudad Pedro Pacheco de Centenares

La Doctrina de las Caballerizas Diego Espínola Malatesta

- La ciudad de Santigo de las Montañas-

El beneficio desta ciudad

La Doctrina de Cangacas

Bernabé de Ferraguto

La Doctrina de Yranacas

Juan de Cáceres Patiño

La Doctrina del río de Jaén Bartolomé Martínez Hidalgo-lengua

\section{- La ciudad de Santa María de Nieva-}

El beneficio desta ciudad

Marcos Rodríguez Lozano

La Doctrina aneja a esta ciudad Diego de Mora-lengua

\section{- La ciudad de Sevilla de Oro-}

El beneficio desta ciudad

La Doctrina de Paira y Suña

Otra Doctrina comarcana
Gabriel de Minaya-lengua y predicador El Padre Zurita-lengua Manuel Rodríguez de Castro-lengua 
430 / Augusto E. Albuja

- LAS DOCTRINAS QUE LOS RELIGIOSOS DE LAS CUATRO ORDENES MENDICANTES TIENEN EN EL OBISPADO DE QUITO A 8 DE MAYO DE 97.

EL ORDEN DE SANTO DOMINGO TIENE LAS SIGUIENTES:

La Doctrina de Alangasí

La de Pinta

La de Oyambicho

La de Pansaleo

La de Aloa y Canzacoto

La de Ambato

La de Píllaro

La de Tomavela

La de Pupiales

La de Ipiales

La de Cibundoy

La de la Laguna

La de los Ingenios
La del Valle

La de Pacha

La de Garruchamba

La de Pozol

La de Calva

La de Cariamanga

Otra en aquel distrito

La de Daule

La de Chongón

La de Cozanga

La de Atunquijo

La de Pachamana

La de Maspa

\section{EL ORDEN DE SEÑOR SAN FRANCISCO TIENE LAS SIGUIENTES:}

La Doctrina de Cotocollao

La de Pomasque

La de Calicali

La de San Antonio

La de Perucho

La de Malchinguí

La de Otavalo

La de la Laguna

La de Cotacache

La de Tontaqui

La de Urcuquí

La de Carangue

La de San Antonio de Carangue

La de Salinas
La de Pusillí

La de Saquisillí

La de San Andrés

La de Guano

La de Punín

La de Chambo

La de Calahote

La de Tunguragua

La de Quinña

La de Penipe

La de Tangua

La de Chapagua

La del valle de Angonsí

La de Yaconque 


\section{Doctrinas y Parroquias del Obispado de Quito /431}

La de Mulahaló

La de Latacunga

La de los Alaquez

La de San Miguel
La de Paute

La de Gualaseo

La de Molleturo

La de Hilapo

La de Pungalá

\section{EL ORDEN DE SAN AGUSTÍN:}

La Doctrina de Atunsicho

La de los Cañares

La del Ingenio

La de los Calientes de Sichos
La de Túqueres

La de Capuis

La de los malacatos

\section{EL ORDEN DE NUESTRA SEÑORA DE LAS MERCEDES:}

$\begin{array}{ll}\text { La Doctrina de Caguasquí } & \text { La de Males } \\ \text { La de Túcar } & \text { La de Mallana } \\ \text { La de Puntal } & \text { La de Carlosama } \\ \text { La de Guacan } & \text { La del Valle } \\ \text { La del Tulcán } & \text { La de Túmbez } \\ \text { La de Gualea } & \text { La de Frías } \\ \text { La de Comaqui } & \text { La de Capuna } \\ & \text { La de Picoaza }\end{array}$


Clérigos.- Por manera de los beneficios de los españoles, de indios, que están a cargo de clérigos en este Obispado, en las partes y lugares que está declarado, son ciento y catorce beneficios

114 beneficios

Dominicos.- Los que están a cargo del Orden de Santo Domingo son veinte y seis beneficios y Doctrinas de indios

26 beneficios

Franciscos.- Están a cargo de los franciscos treinta y siete beneficios y Doctrinas de indios

037 beneficios

San Agustinn.- Están a cargo del Orden de San Agustín siete beneficios y Doctrinas de indios

007 beneficios

Mercenarios.- Están a cargo de los mercenarios quince beneficios y Doctrinas de indios

200 beneficios

Por manera que todas las Doctrinas del Obispado de Quito, que están a cargo de clérigos y frailes, son doscientas, y en las de religiosos se pueden acrecentar veinte más, porque están muy cargadas con mucho número de indios.

Fr. Ludovicus

Epíscopus Quitensis/rúbrica/. 


\title{
Doctrinas y Parroquias del Obispado de Quito /433
}

\section{APÉNDICE \# 43}

Carta que los miembros del Cabildo de Quito dirigieron al Rey Felipe II para darle a conocer la administración de los bienes eclesiásticos.

\author{
AGI, Quito, leg. $8 \quad$ Quito, 20 de mayo de 1597
}

Señor:

Recebimos la Real Cédula de Vuestra Majestad tocante a la santa cruzada, y su recebimiento cumplióse como Vuestra Majestad nos manda. Hallóse al recebimiento solemne que le hicimos: el Prelado, la Real Audiencia, toda la clerecía y Prelados y religiosos de las Ordenes de esta ciudad y Cabildo de ella; trujose con procesión solemne a esta santa Iglesia Catedral; hubo sermón. En lo demás de su buena expedición es cargo del Prelado; acudió a ello con cuidado, como tiene dado aviso a Vuestra Majestad.

También recebimos las Reales Cédulas de la merced que Vuestra Majestad hace a la fábrica de esta santa Iglesia, de la mitad de las vacantes de don fray Pedro de la Peña y don fray Antonio de San Miguel, Obispos deste Obispado, y la Real Cédula de la merced de los dos novenos pertenecientes a Vuestra Majestad, por seis años. Besamos a Vuestra Majestad las manos por tan crecida y señalada merced como a esta santa Iglesia Catedral Vuestra Majestad ha hecho esta limosna, con las demás que habemos recebido. Hallará Vuestra Majestad colocada en el cielo ante la Divina Majestad para aumento de gloria.

Esta Iglesia es la mejor y más pobre del Perú y la más bien servida. Lo que vamos cobrando de los oficiales reales y nos van dando por cuenta de las dichas vacantes, se va gastando con acuerdo y parecer del Prelado y Presidente de esta Audiencia, en el claustro y cosas necesarias y provechosas para el bien de esta santa Iglesia y aumento de su fábrica. Y por serlo tanto, compramos unas cosas que están pegadas con el claustro de la dicha fábrica, con que se ha aumentado en más cantidad de un mil y ducientos pesos de plata de renta en cada un año. Pagamos luego parte dellas con la merced que Vuestra Majestad nos ha hecho; lo demás tomamos prestado y fiado a cierto tiempo, en que se puede pagar con descanso e sin daño de la renta de la dicha fábrica.

Teniendo celebrada esta venta y hecha paga real y en posesión la fábrica de las dichas casas, los Padres de la Compañía, que se pusieron contra nuestra voluntad y derecho, pagados con el claustro, pretenden quitarlas a la dicha fábri- 
ca y que la dicha venta se dé por nula, porque los corrales de sus casas comunican con los corrales de las dichas casas, y que las quieren para alargar sus casas y renta. Sobre ello tratan pleito con la fábrica en la Real Audiencia. Sobre este artículo

tenemos declinado jurisdición. Vamos haciendo las diligencias necesarias en favor y defensa de la dicha fábrica, y las haremos hasta poner esta causa ante Vuestra Majestad para que, como Patrón y Rey y Señor nuestro, la ampare y nos defienda, y sea informado de semejantes agravios y otros muchos que se causan y siguen en estar puestos los Padres de la Compañía pared en medio con nuestra Iglesia. Con sus campanas nos perturban en los divinos oficios y sermones, y no puede ser menos, en que hay y dan mucha nota.

El Doctor Barros, Presidente que fue desta Audiencia, por odio que nos tenía, aunque lo contradijimos, por fuerza y contra derecho, estando bien acomodados y en lo mejor de la ciudad, por sus fines particulares no los puso aquí, y después acá no somos parte para remediarlo. Por servicio de Dios, Vuestra Majestad lo remedie cometiéndolo por Cédula particular al nuevo Presidente lo vea, oiga y desagravie, y los mande pasar a otra parte cómoda, y nosotros podamos cumplir con la obligación que tenemos y debemos al servicio de nuestra Iglesia.

Los años pasados enviamos a Vuestra Majestad la erección de esta santa Iglesia con relación de las rentas decimales de este obispado y su pobreza, que por ser tan grande y los gastos de esta tierra muchos, por ser las cosas de Castilla caras, aunque la erección llama más prebendados, solos ha habido proveídos para el servicio desta Iglesia cinco dignidades y cinco canónigos, y a muchos dellos los Obispos pasados, viendo la pobreza de esta Iglesia y que no se podían sustentar, los acomodaban en beneficios y Doctrinas fuera della para que los demás, cómodamente, se sustentasen en ella. Al presente estamos proveídos por Vuestra Majestad en esta santa Iglesia cuatro Dignidades -estábamos cinco, faltó el Maestrescuela, murió a primero de marzo pasado-, y seis canónigos y otro que falta, que no viene por la poca renta, y dos curas rectores, cuatro acólitos, un maestro de capilla y cantores e música muy buena, de vigüelas de arco, y ministros servidores de la Iglesia que llama la dicha erección.

Las rentas decimales de este obispado son pobres y se cobran mal por la longitud que tiene. Valdrán este año como diez y ocho mil pesos de plata. Destos lleva el Prelado cuatro mil y quinientos pesos; los nueve mil pesos restantes, conforme a la dicha erección, se hacen nueve partes: dellas lleva Vuestra Majestad dos novenos, la fábrica noveno y medio, el hospital otro noveno y medio; las 


\section{Doctrinas y Parroquias del Obispado de Quito /435}

cuatro partes restantes se dividen y llevan los beneficios y sacristanes de las ciudades, y de la misma manera las dichas fábricas y hospitales de ella.

La dicha cuarta, perteneciente al Déan y Cabildo y ministros, se reparte con ventajas, conforme a la dicha erección, de que en la folta primera daremos más larga relación a Vuestra Majestad, y enviaremos los testimonios del remate de las dichas rentas y más en forma cómo se reparten. En el interim, suplicamos a Vuestra Majestad, pues esta Iglesia está bien servida, tenga por bien suspender proveer más prebendados, porque los que estamos no nos podemos sustentar cómodamente por lo referido, que en ello recibiremos bien y merced de la cristianísima mano de Vuestra Majestad, a quien Dios Nuestro Señor dé muchos años de vida con aumento de reinos y señoríos etc. De Quito 20 de mayo de 1597 años.

Señor:

Capellanes de Vuestra Majestad etc.

Deán de Quito = Arcediano de Quito =

El Comisario Talavera Mancera

El de Albarrán = Gaspar de Zamora

El Canónigo Diego de Agüero Maldonado=

Don Alonso de Aguilar = Canónigo García de Valencia /rúbricas/.

\section{APÉNDICE \# 44}

Carta que el Licenciado Miguel de Horozco, Fiscal de la Audiencia de Quito, envió al Rey Felipe II dándole a conocer los trabajos realizados en la diócesis por el Ilmo. Sr. Luis López de Solís.
AGI, Quito, leg. 8
Quito, 20 de mayo de 1597

Señor:

En otras doy cuenta a Vuestra Majestad de algunas cosas fuera de las que contiene la carta del Audiencia a que me hallé presente. En ésta la daré de las que tocan a lo eclesiástico porque Vuestra Majestad esté informado de lo que hay en un estado y otro. 
436 / Augusto E. Albuja

Conformidad de Audiencia y Obispo.- Los jueces y ministros desta Audiencia tienen mucha conformidad con el Obispo, el cual guarda la misma con ellos y acude con todo cuidado en lo que se ofrece del servicio de Vuestra Majestad.

Reformación de clérigos por el Obispo y enemistad que le tienen por ello.Como este Obispado ha estado tanto tiempo sin Pastor, han vivido con mucha libertad los más clérigos del; y como el Obispo los ha limitado y reformado y hace vivir con la justificación que conviene, que no es tanta como la que él guarda en su vida, lleva lo mal y procuran por todas vías darle disgusto y, por la misma razón, los más Dignidades de esta santa Iglesia. Es tan prudente que sufre mucho y pasa por todo.

Florecen virtud y letras en el Seminario de esta ciudad. El Obispo gasta sus rentas en ésta y otras buenas obras.- En el Seminario que ha fundado en esta ciudad florecen mucho virtud y letras, y como es gran letrado y asiste a las conclusiones que de ordinario sustentan los colegiares (sic), procuran todos ir adelante por imitalles. Gasta en ésta y otras buenas obras sus rentas, y mucho más; y así anda muy empeñado, porque es grande el gasto de este Colegio y poco lo que se cobra para él de lo que manda el santo Concilio de Trento.

Pleito del Obispo con los religiosos sobre la cobranza del seminario desde el año de 83, remitido al Consejo.- Ha tratado pleito en esta Audiencia con los clérigos y religiosos que tienen beneficios, capellanías y Doctrinas, sobre la cobranza de lo corrido para el Seminario desde el año de 83 acá. Estando concluso para sentencia, se remitió su determinación a ese Real Consejo, donde Vuestra Majestad mandará hacer justicia y proveer de manera que esta santa obra vaya adelante, por ser notable el bien que della ha de resultar para doctrina y conservación de estos reinos.

Pleito sobre que los religiosos no sirvan las Doctrinas sin la colación del Diocesano.- También se trata pleito sobre que los religiosos de las Ordenes guarden en todo vuestro Patronazgo Real, y en su cumplimiento hayan de acudir al Diocesano por la colación y canónica institución de las Doctrinas a que fueren presentados, y que de manera no las pueden servir. El Audiencia proveyó auto, en que mandó que así se guarde y cumpla. Habiendo suplicado del las Religiones y dádoseme traslado de sus suplicaciones, alegué en defensa de vuestro Patronazgo Real y del auto proveído lo que contiene la petición que van con ésta. Recibióse la causa a prueba, sin embargo de mi contradición; y con término de seis meses para Lima, tengo entendido que ha de haber en la determinación de esto 


\section{Doctrinas y Parroquias del Obispado de Quito /437}

mucha dilación, y podría ser que después della se remitiese esta causa, sin sentenciar, a ese Real Consejo, como lo demás. Vuestra Majestad lo mande ver y proveer lo que convenga a la guarda y cumplimiento del Patronazgo Real, que lo que yo puedo certificar es que, según viven con libertad los más religiosos en las Doctrinas, será provisión justísima que estén sujetos al Diocesano en todo lo que toca a ellas. /En nota: Que se lo agradezca la diligencia que hace y que procure que se guarde el Patronazgo y que venga el dicho pleito/.

Pretende el Obispo fundar Seminario para los hijos de caciques e indios principales, y el bien que dello resultará.- Allende del Seminario que ha hecho el Obispo para los hijos de españoles, pretende fundar, junto a él, otro, donde se doctrinen y enseñen los hijos de caciques e indios principales de estas provincias, que no será de menor fruto para el bien de la tierra, pulicía y conversión de los naturales; y aunque para esta obra han mandado los indios de dos o tres Repartimientos hasta tres mil pesos de plata corriente, de la que tienen en sus cajas de comunidades, no han faltado personas que los inducen a que no los den y que pidan se revoque lo que han prometido. Vuestra Majestad, sea servido de mandar favorecer y ayudar a tan santa obra, que, sin duda, resultará della el bien que está dicho.

El provecho y bien que nace de la casa de Recogimiento para mujeres perdidas que el Obispo ha hecho en esta ciudad.- Tiene también el Obispo fundada casa de Recogimiento para mujeres e indias perdidas, en que de presente están muchas recogidas y otras se enmiendan porque no las metan dentro. Es freno esta clausura para que no vivan con la disolución que hasta aquí. Y aunque para esta obra se ha pedido limosna, hay tanta pobreza en el pueblo que no es de consideración lo que sea llegado; y todo lo más que es menester para el gasto y sustento de esta casa, lo provee, de la suya, el Obispo.

Fundación del Obispo de un monasterio de monjas en la ciudad de Loja.Pocos días ha que fundó él mismo un monasterio de monjas en la ciudad de Loja, 80 leguas desta. Dotóle en muchos pesos de oro Juan de Alderete, Corregidor de las provincias de Yaguarsongo. Entiéndese ha de ser uno de los más principales de estas partes. Dícese que se van haciendo sus edificios con mucho cuidado, fuera de los que ya están hechos, en que viven las monjas. / En nota: Está bien/.

Elección de Provincial para el Orden de San Francisco de estas provincias y lo que hubo en ellas.- Un fraile francisco, que vino el año pasado por Visitador General de su Orden, asistió en esta ciudad a la elección de Provincial de este distrito. Salió electo para ello un fraile mozo, de nación portugués, recién venido de 
esas partes, habiendo muchos religiosos antiguos castellanos, muy recolectos y de mucha cristiandad, que han tenido el mismo oficio y gobernado este Orden con toda aprobación. Unos sospechan que el Visitador hizo esta elección por sus fines; otros, que algunos frailes por huir de los viejos. Lo que más se afirma es que hubo de todo. Dios se sirva que acierte a hacer el deber. / En nota: Que se dé noticia desto al Comisario para que se provea del remedio necesario. Diósele/.

Que no convendría enviar por ahora más frailes acá si no fuese viejos para gobernar, porque mozos sobran.- Hay tantos religiosos en los conventos de estas provincias, que por ahora parece convendría no viniesen más de esos reinos si no fuesen algunos viejos aprobados para el gobierno de sus Ordenes, porque mozos, acá, sobran muchos. Vuestra Majestad lo mande considerar y proveer lo que más fuere servido. / En nota: Que se tenga cuenta con esto/.

Nuestro Señor guarde la católica real persona de Vuestra Majestad. Quito 20 de mayo de 97.

Licenciado Miguel de Orozco/rubricado/.

\section{APÉNDICE \# 45}

\section{Quito. \\ Lista de beneméritos sacerdotes y oficiales reales en la Diócesis de}
AGI, Quito, leg. 76
Quito, 12 de marzo de 1598

En cumplimiento de mi obligación y de lo que Vuestra Majestad me tiene mandado que envíe relación de las personas beneméritas deste Obispado para cargos y oficios, los hago en esta manera:

\section{Para Obispados}

P. Maestro Saona $=$ El Padre Fray Gabriel de Saona, del Orden de San Agustín, Maestro en santa Teología, Catedrático de Escriptura en la universidad de Lima, tiene muchas y graves partes; es muy antiguo en este reino y aura diez años vino por Vicario General a estos reinos del Pirú; no hay quien le haga ventaja. 


\section{Doctrinas y Parroquias del Obispado de Quito /439}

Maestro Fr. Roque = El Padre Fray Roque de San Vicente, del Orden de San Agustín, Maestro en santa Teología, es muy gran sujeto y merece ser premiado.

\section{Clérigos del Obispado de Quito para Prebendas}

Maestro Ortega $=$ Benito Hernández de Ortega, presbítero, es Maestro en Artes y Licenciado en Teología; ha sido cura y Vicario de la ciudad de Cuenca y Provisor y Vicario General deste Obispado y ahora es Visitador General, hombre de buena vida y ejemplo, merece una Dignidad en las Catedrales del Perú.

Baltazar Soto = El Bachiller Baltazar Tello de Soto, canónigo de Medina del Campo, canonista ha tenido beneficios en este Obispado y por sus buenas partes, vida y ejemplo está sirviendo el oficio de Provisor y Vicario General de este Obispado con mucha aprobación; merece ser promovido a una Dignidad desta Iglesia de Quito o de las del Pirú.

Licenciado Bracamonte $=$ El Licenciado Diego de Bracamonte, beneficiado y vicario de la ciudad de Pasto, ha muchos años que sirve aquel beneficio, de que ha dado muy buena cuenta; merece ser promovido a una Prebenda.

Bachiller Antonio Morán = El Bachiller Antonio Morán, teólogo, predicador, es beneficiado y vicario de Cuenca, hombre de buena vida y costumbres; merece servir una Prebenda.

Bachiller Arias = El Bachiller Cristóbal Arias, teólogo, beneficiado y vicario de la ciudad de Jaén, hombre de buena vida y costumbres y Visitador deste Obispado; merece una Prebenda.

Doctor Alonso de Cirues = El Doctor Alonso de Cirues, graduado en Teología, predicador, es cura y Vicario de Manta; merece una Dignidad.

Bachiller Pedro de Paredes = El Bachiller Pedro de Paredes, capellán de la Audiencia de Quito, vino proveído a una ración de Lima si el que la tenía aceptara el Arcedianato de Popayán. No aceptó y quedó sin suerte. Merece una Prebenda.

Diego Lobato de Sosa = Diego Lobato de Sosa, presbítero,lengua general y predicador de los naturales, es muy antiguo en este oficio y ha hecho notable fruto y servicio a Dios Nuestro Señor y a Vuestra Majestad; hijo de conquistador, merece una canonjía en la Iglesia de Quito, que es su patria. 
440 / Augusto E. Albuja

Miguel Sánchez = Miguel Sánchez Solmirón, cura-rector de la Iglesia Catedral de Quito que de ser cura en el Sagrario de Toledo; muy diestro en la música y maestro de capilla. Merece una Chantría o Canonjía.

Sepúlveda $=$ Andrés de Sepúlveda, presbítero, es antiguo en este Obispado en beneficios de españoles y indios y ahora es Visitador General; merece una Canonjía.

Hernando Martín de Cáceres = Hernando Martín de Cáceres, presbítero beneficiado y vicario de la ciudad de Loja, es muy buen eclesiástico, es Visitador General deste Obispado; merece una Prebenda.

Juan Antonio de Rueda = Juan Antonio de Rueda, beneficiado y vicario de Cumbayá, ha muchos años que sirve beneficios con mucha aprobación; es hijo desta tierra, buen lengua y predicador; merece más premio.

Luis Suárez Ponce = Luis Suárez Ponce de León, beneficiado y vicario de Yaroquí, ha muchos años que sirve en ese Obispado con mucha aprobación; merece ser premiado.

Francisco de Mendoza = Francisco de Mendoza, beneficiado de Caracas por merced de Vuestra Majestad, ha muchos años que sirve beneficios en este Obispado; merece más premio.

Francisco Vélez = Francisco Vélez de Zúniga, beneficiado y vicario de Mocoa, hombre de buena vida y costumbres; merece más premio.

Ortunio $=$ Diego de Ortunio de Larrea, presbítero, es hijo de conquistador; merece premio.

Licenciado Copete $=$ El Licenciado Juan Copete de Herrera, beneficiado $\mathrm{y}$ vicario, lengua, $\mathrm{y}$ aquí merece premio.

Reyes $=$ Pedro Núnez de los Reyes es beneficiado y vicario de Pasto, es antiguo y muy buen eclesiástico; merece premio.

\section{LAS PERSONAS QUE PUEDEN SERVIR OFICIOS REALES}

Licenciado Diego de Zorrilla = El Licenciado Diego de Zorrilla, graduado en leyes por Salamanca, es hijo del Licenciado Pedro de Zorrilla, Oidor de esta Audiencia, es de muy buena vida y costumbres, ha dado muy buena cuenta de los oficios de Provisor y Vicario General y Visitador deste Obispado; tiene partes y suficiencia para servir una plaza de Oidor, oficial, fuera de Quito porque está aquí su padre.

Licenciado Pedro de Zorrilla = El Licenciado Pedro de Zorrilla, Oidor desta Audiencia, es buen letrado, recto y buen cristiano; merece más premio. 


\section{Doctrinas y Parroquias del Obispado de Quito /441}

Doctor Mera = El Doctor Moreno de Mera, Oidor que fue desta Audiencia de Quito, está sin plaza por haberse casado, servirá bien otra fuera de Quito.

Licenciado Orozco = El Licenciado Miguel de Orozco, oficial desta Real Audiencia, ha muchos años que sirve este oficio en la Audiencia del reino y está con mucha rectitud y cristiandad; merece que Vuestra Majestad lo promueva y honre.

Licenciado Zambrano = El Licenciado Alvaro Zambrano, abogado de la Real Audiencia de Quito, es buena vida y costumbres; ha tenido cargos en esta república como han sido: Asesor deste Obispado, Teniente General del Corregidor, y dellos ha dado buena plaza de Oidor o Fiscal.

Licenciado Machado = El Licenciado Hernán Machado, Relator desta Real Audiencia de Quito, es buen letrado, y en su oficio y otros que se le han encargado de juez de Comisión y Residencia, ha dado buena cuenta. Merece que Vuestra Majestad le ocupe una plaza de juez.

D. Diego Portugal $=$ Don Diego de Portugal, Corregidor de Quito proveído por el Virrey, usa el oficio muy bien, con demostración de buen republicano y celoso del servicio de Dios Nuestro Señor; ha remediado muchos pecados públicos; es sobrino del Virrey y Conde del Billar. Merece mayor merced.

D. Francisco de Mendoza = El General Francisco de Mendoza Manrique ha sido Corregidor en esta ciudad, ha dado muy buena residencia y cuenta de su oficio y por lo que ha servido en este reino a Vuestra Majestad en la mayor y en la tierra y en entablar las Alcabalas en la ciudad del Cuzco, por mandato del Virrey Marqués de Cañete, merece que Vuestra Majestad le honre y premie en un oficio preheminente de Corregidor de Quito, Cuzco o Potosí. Está en esta ciudad con su casa aguardando merced de Vuestra Majestad.

Gaspar Alfonso = Gaspar Alfonso de Zúñiga vino por Tesorero a esta Caja de Quito donde es tan poco lo que tiene que no se puede sustentar. Tiene obligaciones de familia honrada y merece, por sus canas y antigüedad, Vuestra Majestad le promueva y haga merced.

El Licenciado Marañón, que preside en esta Audiencia, es buen juez recto, pero es muy viejo y con necesidad de descansar, aunque muy pobre y con obligaciones de mujer y hijos, y en esta conformidad escribo otras a que me remito, y si alguna de su pedimiento fuere con diferente relación, ésta es la cierta y lo otro, cumplimiento que no se pudo excusar.

En Quito 12 de marzo de 98.

Fr. Luis, Obispo de San Francisco de Quito. 
442 / Augusto E. Albuja

\title{
APÉNDICE \# 46
}

\section{Testimonio de las rentas decimales del Obispado de Quito correspon- dientes al año 1598.}

\author{
AGI, Quito, leg. $76 \quad$ Quito, 24 de marzo de 1598
}

Yo, García de Valencia, canónigo de la santa Iglesia Catedral desta ciudad de San Francisco del Quito de los reinos del Pirú, juez colector de las rentas decimales desta ciudad y Obispado por el Excelentísimo Señor Maestro Don Fray Luis López de Solís, Obispo deste Obispado, y por el Deán y Cabildo desta santa Iglesia, certifico que las rentas decimales desde Obispado se arrendaron el año pasado de noventa y siete y éste de noventa y ocho en la cantidad de pesos siguientes:

Esta ciudad de Quito, Riobamba, Chimbo, Latacunga y Otavalo en nueve mil pesos de plata corriente marcada, pagaderos ..............9 U 000 ps.

Iten, los diezmos de la ciudad de Pasto, en mil y cuatrocientos pesos de oro de veinte quilates, como corre en la dicha ciudad, que valen de plata dos mil y cien pesos corrientes ..........................2 U 100 ps.

Iten, los diezmos de la ciudad de Cuenca, en dos mil pesos de plata corriente $.2 \mathrm{U} 000$ ps.

Los diezmos de la ciudad de Loja, en seiscientos pesos de plata corriente marcada U 600 ps.

Iten, los diezmos de la ciudad de San Miguel de Piura, en mil y novecientos y diez pesos de plata corriente 1 U 910 ps.

Los diezmos de la ciudad de Jaén, en novecientos pesos de plata corriente marcada U 910 ps.

Iten, los diezmos de la ciudad de Puerto-Viejo, en quinientos pesos de plata corriente marcada U 500 ps. 


\section{Doctrinas y Parroquias del Obispado de Quito /443}

Iten, los diezmos de Guayaquil, en cuatrocientos y ochenta pesos de plata corriente

U 480 ps.

Iten, los diezmos de Baeza en los quijos, en sesenta pesos de plata

Iten, los diezmos de Archidona en los quijos, en setenta pesos de plata U 070 ps.

Iten, los diezmos de Avila en los quijos, en setenta y ocho pesos de plata corriente U 078 ps.

Iten, los diezmos de Santiago de las Montañas, en la gobernación de Joan de Salinas, en doscientos y veinte pesos de oro, que valen en plata doscientos y noventa pesos corrientes

U 290 ps.

Iten, Valladolid, en la dicha gobernación, sesenta pesos de plata.........U 060 ps.

Iten, Combinamá, en la dicha gobernación de Salinas, en sesenta pesos de plata .............................................................................. 060 ps.

Iten, en la ciudad de Zamora, en ciento y seis pesos de oro, que vale en plata ciento y treinta pesos corrientes

Sevilla del Oro, en la gobernación de los quijos, en ciento y sesenta pesos de plata U 160 ps.

La ciudad de Agreda vale treinta y cinco pesos de oro, vale en plata cincuenta pesos corrientes $\underline{\mathrm{U} 050 \mathrm{ps} .}$ $18 \mathrm{U} 538$

Según que todo lo susodicho consta y parece por los testimonios y recaudos de los remates que están en mi poder a que me refiero y de mandamiento del dicho Señor Obispo, di el presente en Quito, a veinte y cuatro días del mes de marzo de mil y quinientos y noventa y ocho años. 
444 / Augusto E. Albuja

Item, los diezmos del asiento de las minas de Zaruma que se ha hecho ahora, desmería de por sí; está arrendado en trescientos pesos de plata corriente marcada, fecho ut supra

\title{
El Canónigo Valencia/rubricado/.
}

Yo, Cristóbal Pérez Concha, Notario apostólico y público del Audiencia episcopal de esta ciudad de Quito, presente fui con el dicho canónigo García de Valencia, juez recolector de las rentas decimales deste Obispado, y lo firmé y signé en testimonio de verdad.

\author{
Cristóbal Pérez Concha \\ Notario público /rubricado/.
}

\begin{abstract}
APÉNDICE \# 47
Nómina de los prebendados que servían en la Catedral de Quito.
\end{abstract}

AGI, Quito, leg. $76 \quad$ Quito, 30 de marzo de 1598

Yo, Cristóbal Pérez Concha, notario apostólico y público del audiencia episcopal desta ciudad de Quito, doy fe e verdadero testimonio a los señores que la presente vieren, en cómo en esta santa Iglesia Catedral de Quito están al presente en el servicio della: el Deán, don Francisco Galavís, y el Arcediano, don Juan de Obando, y el Chantre, don Jorge Ramírez de Arellano, y el canónigo Juan Francisco Talaberano Mansera, el cual está al presente ausente desta Iglesia, con licencia de su Señoría Ilustrísima del señor Obispo deste Obispado, que fue a la Isla Española a ciertos negocios que dijo tener; y el canónigo Andrés López Albarrán, y el canónigo Diego Agüero Maldonado, y el canónigo Gaspar de Zamora, y el canónigo don Alonso de Aguilar Maldonado, y el canónigo García de Valencia.

En fe de lo cual, lo firmé y signé en Quito, a treinta de marzo de mil e quinientos noventa y ocho años.

En testimonio de verdad

Cristóbal Pérez Concha

Notario público/rubricado/. 


\section{Doctrinas y Parroquias del Obispado de Quito /445}

\section{APÉNDICE \# 48}

\section{Relación de Prebendas, Parroquias y Doctrinas del Obispado de Qui-} to, enviada por el Ilmo. Sr. Luis López de Solís al Consejo de Indias.

$$
\text { AGI, Quito, leg. } 76 \quad \text { Quito, año } 1598
$$

En conformidad de lo que se me mandó por la Real Cédula acerca de que dé aviso de las prebendas que hay en esta Catedral de Quito y beneficios de españoles e indios y quién los sirve y qué renta tienen, y fecha la averiguación siguiente: el Obispado de Quito tiene de longitud 226 leguas y de latitud 70, la mayor parte dello por poblar. Hay en el Obispado 18 ciudades y una Villa, en las cuales y Doctrinas de indios que provee el Obispo hay noventa y siete. Ansimismo, tienen en el Obispado 30 Doctrinas los frailes de San Francisco, 27 los de Santo Domingo, 5 los de San Agustín, 15 los de Nuestra Señora de las Mercedes. Todos estos beneficios, ansí los clérigos como los de frailes, se proveen conforme al Real Patronazgo. Lo que valen y quien lo sirven, se pondrá por extenso adelante.

En la ciudad de Quito reside la Catedral de este Obispado donde, conforme a la erección, hay Obispo, Dignidades y canónigos, porque aunque por la erección había de haber Racioneros y medios Racioneros, no los ha habido, ni todo el número de canónigos que la erección nombra, por ser tenues las rentas decimales y no lo podrían sustentar.

Este año presente se arrendaron los diezmos en 18 mil pesos de plata corriente, y los años pasados en lo mismo, poco más o menos; lleva el Obispo de esto la cuarta parte, y el Cabildo otra cuarta parte, y las otras dos restantes se hacen nueve novenos, de los cuales lleva dos Su Majestad, y lo demás la fábrica y hospital, curas-rectores y otros ministros de la Iglesia. Tiene el Obispo demás de esto la cuarta funeral de todo su Obispado, que valdrá, unos años con otros 2 mil pesos de plata corriente, poco más o menos. Ansimismo, tiene el Cabildo 1.002 pesos de capellanías que, juntos con la cuarta que queda dicha, parten entre sí el Deán y Cabildo.

\section{CATEDRAL DE QUITO}

Es el Obispo el Maestro Don Fray Luis López; válele el Obispado 6 mil pesos de plata corriente, poco más o menos, de ambas cuartas. Deán, el Licen- 


\section{6 / Augusto E. Albuja}

ciado Don Francisco Galavís; válele su prebenda, de cuarta y capellanía, 850 pesos corrientes, poco más o menos. Arcediano, el Maestro Don Juan de Ovando; valdrále su prebenda 730 pesos corrientes. El Chantre, Jorge Ramírez de Arellano; valdrále su prebenda 730 pesos, poco más o menos. Maestreescuela y Tesorero están vacas, si acaso Su Majestad no las ha proveído. Al presente hay seis canónigos: Juan Francisco Talaverano, a quien Su Majestad presentó a la Chantría de Santo Domingo, no la ha aceptado; está ausente con licencia del Obispo, por dos años, para ir a cobrar cierta hacienda que dice le deben en La Habana; Andrés López de Albarrán, Gaspar de Zamora, Diego de Agüero Maldonado, Don Alonso de Aguilar, García de Valencia. Valdráles a cada uno el canonicato 550 pesos, poco más o menos, y proveídas las Dignidades que faltan será mucho menos, pues se ha de repartir la renta referida que tiene el Cabildo, que es de cuarta y capellanías 5 mil 700 pesos, entre todos los prebendados que hubiere, con las ventajas que tienen conforme a la erección.

Hay, ansimismo, en la Catedral dos curas rectores, el uno Jácome Freile de Andrade, comisario del Santo Oficio, y el otro Miguel Sánchez Salmerón, a los cuales se les dan 180 pesos a cada uno de las rentas decimales y las primicias de los vecinos de esta ciudad que caen en la colación de la Catedral y el pie de altar; que le valdrá todo, a cada uno, 400 pesos de plata corriente, poco más o menos. Hay un sacristán mayor, a quien se le da de los diezmos otros 180 pesos, que con los aprovechamientos le vale 350 pesos de plata corriente. Hay otros ministros, como es: sacristán menor y cantores, monacillos e indios que sirven en la iglesia, a los cuales se les dan salarios de poca consideración de los novenos que quedan referidos, que se quita para esto y fábrica.

\section{HAY EN LA CIUDAD LOS BENEFICIOS CURADOS, LOS SIGUIENTES:}

El de San Sebastián que valdrá, con el salario y aprovechamientos de algunos españoles que tiene por parroquianos, 500 pesos; sírvelo Durán, clérigo cantor.

El de San Blas, que valdrá 600 pesos, sírvelo Francisco Suárez, clérigo. El de Santa Bárbara, que valdrá 250 pesos, sírvelo Antonio Borja, clérigo.

El de San Marcos valdrá 200 pesos; sírvelo Martín de Gaviria, clérigo. El de Santa Prisca valdrá 300 pesos; sírvelo Andrés de Mansilla, clérigo. El de San Juan de Machángara valdrá 250 pesos; sírvelo Alonso Mosquera, clérigo. 
Doctrinas y Parroquias del Obispado de Quito /447

BENEFICIOS QUE HAY EN EL DISTRITO DE QUITO DE FRAILES $Y$ CLERIGOS:

El de Cotocollao tiene 800 indios, poco más o menos; tiene de estipendio y camarico, que ansí lo llaman a la comida que los indios dan al sacerdote que los doctrina, 400 pesos; sírvelo fray Juan Ramos de la Orden de San Francisco.

En Pomasque hay un convento donde está un Guardián y su compañero; es Guardián fray Juan de Paz; tiene cuatrocientos indios tributarios y de estipendio 200 pesos, y el camarico valdrá otros cien pesos.

San Antonio de Pomasque tiénela el Padre fray Gabriel Martín. Hay 200 indios. Pagan 80 pesos de estipendio y camarico, que serán 100 pesos.

Calacalí tiene 200 indios. Pagan cien pesos y un camarico; sírvela el Padre fray Jerónimo Picón.

Perucho: son cuatro pueblos en que hay 300 indios, poco más. Dan de estipendio 150 pesos y un camarico; sírvela el Padre Palomo.

Guayllabamba y El Quinche, Doctrina de clérigo, sírvela el Padre Francisco de la Carrera; valdrále 350 pesos.

Cayambe, Doctrina de clérigo, sírvela Juan Cortés; valdrále 450 pesos.

Zámbiza y Nayón, sírvela Hernando Suárez, clérigo; válele 300 pesos.

Yaruquí, sírvela Luis Suárez, clérigo; valdrále 450 pesos.

Puembo y Pifo, sírvela Hernán García, clérigo; valdrále 350 pesos.

Tumbaco, sírvela Gregorio de Vera; válele 350 pesos.

Cumbayá, sírvela Juan Antonio de Rueda; vale 350 pesos.

Pinta, Doctrina de frailes dominicos, sírvela fray Jerónimo de Londoño. Son 400 indios; vale 350 pesos y un camarico.

Alangasí, serán 200 indios, dan de estipendio 250 pesos; sírvela fray Tomás de Porras.

Amaguaña tiene 400 indios y de estipendio 350 pesos y el camarico; sírvela fray Gaspar de Lara.

Hayumbicho es Priorato. Tiene 400 indios y de estipendio 300 pesos, sírvela fray Domingo de Santa María, Prior.

Pansaleo de arriba tendrá cuatrocientos indios; tiene de estipendio 350 pesos y camarico.

Aloasi, Doctrina ansimismo de frailes dominicos, tiene 500 indios y de estipendio 350 pesos y un camarico que son 100 pesos; sírvela fray Diego de Mediavilla. 
448 / Augusto E. Albuja

Aloa tiene 160 indios. Pagan de estipendio 130 pesos y camarico; sírvela el Padre fray Felipe de Ortega.

Conocoto valdrá 300 pesos; sírvela un clérigo.

Sangolqui valdrá 450 pesos; sírvela Cosme de Robles, clérigo.

Chillogallo vale 450 pesos; sírvela Diego Alonso, clérigo.

Machangarilla vale 200 pesos; sírvela Gonzalo de Sayavedra.

Gualea vale 300 pesos y el camarico, que son 400 pesos; sírvela el Padre fray Diego de Carvajal.

Nanigal vale 360 pesos; sírvela fray Rodrigo Lozano.

Mindo vale 450 pesos; sírvela Francisco de Londoño, clérigo.

\section{PROVINCIA DE OTAVALO}

En Otavalo hay convento de San Francisco. Es Guardián fray Cristóbal Martínez; tiene dos compañeros sacerdotes que le ayudan. Hay 1 mil 200 indios; dan 400 pesos y dos camaricos que valen 200 pesos. Asisten en este pueblo algunos españoles, a los cuales administran también los sacramentos.

San Pablo de la Laguna tiene más de 700 indios tributarios. Dan de estipendio al religioso 200 pesos y un camarico; sírvela fray Juan Jímenez.

Cotacache tiene 330 indios. Dan de estipendio 200 pesos y un camarico, que vale 100 pesos; sírvela fray Antonio Martínez.

Tontaqui tiene 500 indios tributarios. Tiene de estipendio 200 pesos y un camarico; sírvela el Padre fray Miguel Romero.

Urcuquí tiene más de 300 indios tributarios. Dan 200 pesos y más el camarico, que son otros 100 pesos; sirve esta Doctrina fray Alonso Rodríguez.

Caranque tiene 300 indios tributarios. Es Guardianía; está en ella fray Alonso Díaz por Guardián, tiene un compañero; dánle 150 pesos de estipendio y un camarico.

San Antonio tiene 200 indios tributarios; dan de estipendio 150 pesos y camarico.

Pimampiro vale 450 pesos. Estaba proveída por el Rey, nuestro Señor, en Juan Antonio de Rueda, clérigo; no la sirve, que está en otra. Sírvela Ordóñez, clérigo.

Mira vale 450 pesos; sírvela Francisco Rodríguez, clérigo.

Tuza, de frailes de la Merced, tiene de salario 350 pesos y un camarico; es doctrinero fray Alonso López. 


\section{Doctrinas y Parroquias del Obispado de Quito /449}

Puntal tiene de salario 300 pesos y un camarico; es doctrinero el Padre fray Juan de Molina.

Guacan tiene de salario 300 pesos y un camarico, sírvela fray Hernando del Espada.

Tulcán tiene de salario 300 pesos y un camarico; sírvela fray Jerónimo de Aguilar.

Taycaguasquí tiene de salario 300 pesos y un camarico; sírvela fray Juan de Meneses.

Quilca tiene de salario 250 pesos y un camarico; sírvela fray Hernando Saldaña.

PASTO Y LAS DOCTRINAS DE SU JURISDICCIÓN DE FRALLES $Y$ CLERIGOS

El beneficio de la ciudad de Pasto vale un mil pesos de plata corriente. Está proveído por el Rey, nuestro Señor, en el Licenciado Bracamonte, que es ido a Castilla; sírvelo, en el inter, Pedro de los Reyes, clérigo.

Santiago, Parroquia de indios, vale 200 pesos.

El Valle de Pasto vale 300 pesos; sírvela Diego Bermúdez, clérigo.

En el mismo Valle otra Doctrina que vale 300 pesos; sírvela Antonio de Benavides, clérigo.

Joanambú vale 400 pesos; sírvela Pedro Quirós, clérigo.

Quina vale 400 pesos; sírvela Peñafiel, clérigo.

Cipundoy tiene 400 indios. Vale 400 pesos de oro de 20 quilates de estipendio y camarico; sírvela fray Domingo de Cevallos. fray Jacinto.

Los Ingenios tienen de salario 250 pesos de oro de 20 quilates; sírvela

Ipiales, es Priorato, tendrá 800 indios. Asiste el Prior y otro religioso. Es Prior fray Juan de Mesa; tiene de estipendio, con las dos Doctrinas que se siguen, 750 pesos de oro de 20 quilates. Pupiales, Doctrina del Priorato arriba dicho, sírvela fray Diego de Aguirao. Iles, sírvela fray Francisco García con el estipendio arriba dicho.

La Laguna tiene de estipendio 90 pesos de oro; sírvela fray Pedro de Moncayo.

El mismo convento de Pasto administra allí Doctrina a otros indios, sin estipendio. 
La Doctrina de Males tiene de salario 280 pesos de oro de a 20 quilates; está por doctrinero el Padre fray Gaspar Velásquez.

El Arlusama tiene de salario 300 pesos de oro de a 20 quilates; sírvela fray Pedro de Quiroga.

Mallana tiene de salario 300 pesos de oro de a 20 quilates; sírvela fray Juan del Castillo.

Tangua tiene 300 indios tributarios. Da de estipendio 200 pesos y un camarico; sírvela fray Juan Guerrero.

Túqueres, Priorato, Capuil, llevan ambas de salario 500 pesos de a 20 quilates.

Yascual vale 400 pesos; sírvela Francisco González, clérigo.

Los Abadis, sírvela Andrés Moreno, clérigo; vale 450 pesos.

La ciudad de Ecija en los Sucumbíos, nuevamente poblada, válele al sacerdote lo que le diere el pueblo.

La ciudad de Mocoa, valdrá el beneficio 600 pesos; sírvela Francisco Vélez, clérigo.

Una Doctrina del Valle valdrá quinientos pesos; sírvela Alonso de Mendoza, clérigo.

\section{GOBERNACIÓN DE LOS QUIJOS TIENE 3 CIUDADES}

La ciudad de Baeza valdrá 450 pesos; el beneficio sírvelo Pedro de Rojas, clérigo.

La Doctrina del Valle de Baeza, Hatunquijo, Cosanga, todas estas Doctrinas que son 3, valen 1 mil 283 pesos con el Priorato. Tienen 1 mil 140 indios; sírvenla fray Francisco de Arcos, fray Francisco de Hinojosa y fray Joseph García.

La Coca vale 400 pesos; sírvela un clérigo.

Hoyacachi vale doscientos pesos; sírvela Cupita, clérigo.

La ciudad de Avila: vale el beneficio tan poco que da Su Majestad 50 mil maravedís por no llegar los diezmos a ellos.

Factocarito, Doctrina, vale 400 pesos; sírvela Muela, clérigo.

La ciudad de Archidona: da Su Majestad los 50 mil maravedís al clérigo, por no valer los diezmos.

La ciudad de Sevilla del Oro, que llaman Macas, vale el beneficio 500 pesos; sírvela Alvaro de Minaya, clérigo. 


\section{Doctrinas y Parroquias del Obispado de Quito /451}

Zuna vale 450 pesos, sírvela Zurita, clérigo.

\section{PROVINCIA DE LATACUNGA}

Hay allí convento de San Francisco; es Guardián fray Antonio Maldonado y está con él otro religioso. Dan de estipendio 400 pesos y dos camaricos. Hay más de 800 indios.

Mulahaló tiene 700 indios y dan de estipendio 200 pesos y un camarico; sírvela fray Juan de la Concepción.

Los Alaquez tienen 400 indios. Sírvela fray Martín de Nava; dan de estipendio 150 pesos y un camarico.

Saquijilí tiene 800 indios. Dan de estipendio 800 pesos y un camarico; sírvela fray Alonso de Sayavedra.

Pujilí tiene 400 indios. Dan de estipendio 100 pesos y medio camarico; sírvela fray Pablo de Hinojosa.

San Miguel tiene 200 indios. Dan de estipendio 100 pesos y medio camarico; sírvela fray Juan Farfán.

Los Sichos es Priorato de San Agustín. Hatunsicho, Isinliví y Los Calientes, tienen estas 3 Doctrinas 1.050 pesos de salario.

Tomavela tiene 700 indios. Dan de estipendio 350 pesos y un camarico; sírvela fray Manuel Rodríguez.

Angamarca vale 500 pesos; sírvela Juan Campino, clérigo.

Ambato tiene 500 indios. Dan de estipendio 350 pesos y un camarico; sírvela fray Miguel de Santa María.

Píllaro vale 350 pesos y un camarico; sírvela fray Pedro de Torres.

Guanuzo vale 200 pesos; sírvela Castillo, clérigo.

Pelileo vale 450 pesos; sírvela Urbina, clérigo.

Quero vale 450 pesos; sírvela Cristóbal Núnez.

La Villa de Riobamba: vale el beneficio 600 pesos; sírvela Bernardino de Cantos, clérigo.

San Sebastián, Parroquia, vale 400 pesos; sírvela Canseco.

PROVINCIA DE LOS PURUAYES

Guano es Guardianía y Guardián fray Juan Gallegos; tiene consigo otro religioso. Hay 800 indios; dan de estipendio 400 pesos y dos camaricos. 
Ilapo tiene 700 indios. Dan de estipendio 100 pesos y medio camarico; sírvela fray Pedro de Machado.

Penipe tiene 300 indios. Dan de estipendio 150 pesos y un camarico; sírvela fray Juan de Estrada.

Quimna tiene 300 indios. Dan de estipendio 100 pesos y un camarico; sírvela fray Francisco Rabelo.

Achambo es Guardianía y Guardián fray Juan Muñoz; tiene consigo otro religioso. Hay 600 indios; dan de estipendio 250 pesos y dos camaricos.

San Andrés tiene 800 indios; sírvela dos religiosos que son: fray Francisco de Torres y fray Juan de Castro; llevan de estipendio 400 pesos y dos camaricos.

Lito tiene 400 indios. Dan de estipendio 200 pesos y un camarico; sirvela fray Antonio de Villasancte.

Pongalá tiene 200 indios. No lleva estipendio ni camarico; susténtalo el Guardián de Achambo.

Puni tiene 400 indios. Dan de estipendio 200 pesos; sírvela fray Lucas Hernández.

Lican vale 450 pesos; sírvela Lorenzo Yánez, clérigo.

Calpi, sírvela Juan Alvarez, clérigo; vale 450 pesos.

Yaloquiz vale 450 pesos; sírvela Alvaro Guerrero, clérigo.

PROVINCIA DE CHIMBO

Chimbo, a donde residen algunos españoles, vale 500 pesos; sírvela Juan Luis, clérigo.

San Miguel de Chimbo vale 450 pesos; sírvelo Basurto, clérigo.

San Lorenzo de Guamarica 450 pesos vale; sírvela Jaramillo, clérigo.

Azancoto vale 450 pesos; sírvela Lorenzo Díaz Cavallón, clérigo.

Ingenios de Pallatanga valen 350 pesos.

\section{CUENCA}

Vale el beneficio curado 750 pesos. Proveyólo el Rey, nuestro Señor, en García Jiménez Franco; ha doce años que está ausente, sírvelo Antonio Morán, clérigo.

La Doctrina de los yanaconas vale 350 pesos; sírvela Valladolid, clérigo. 


\section{Doctrinas y Parroquias del Obispado de Quito /453}

Alausívale 450 pesos; sírvela Gabriel de Peralta, clérigo.

Chunche vale 450 pesos; sírvela Diego de Rojas, clérigo.

Paute tiene 300 indios. Dan de estipendio 200 pesos y camarico; sírvela fray Juan García.

Gualaseo tiene 300 indios. Dan de estipendio 200 pesos y un camarico; sírvela Juan Márquez.

Pacaybamba vale 450 pesos; sírvela Pedro Arias, proveído por el Rey, nuestro Señor.

El Azogue vale 450 pesos; sírvela Gaspar Gallegos por nombramiento del Rey, nuesro Señor.

Paccha tiene de estipendio 280 pesos y un camarico; sírvela fray Juan de Arce.

Cañaribamba: sírvela Juan de Cárdenas, clérigo; vale 450 pesos.

\section{CERRO DE ZARUMA}

Hay españoles e indios. Vale el beneficio 800 pesos; sírvelo Pedro Coronado.

Canuchamba vale cuatrocientos pesos; sírvela Juan Gómez.

LOJA

El beneficio de aquella ciudad vale 800 pesos. Tiénelo Juan de Campos por nombramiento del Rey, nuestro Señor; anda en pleito y sírvelo, por su ausencia, Pedro Martín, clérigo.

El Valle vale 450 pesos; sírvelo Luis García, clérigo.

Amboca vale 450 pesos, sírvela Cristóbal de Ortega, clérigo.

Calba tiene de estipendio 400 pesos; sírvela fray Alonso Pérez.

vedra.

Cariamanga vale de estipendio 400 pesos; sírvela fray Alonso de Saya-

Otuana vale 400 pesos; sírvela fray Diego de Guzmán.

Garruchamba: sírvela Manuel Quero; tiene de estipendio cuatrocientos pesos.

Guarnahama: sirve esta Doctrina fray Francisco Correa; tiene de estipendio 400 pesos.

Pozol: sirve esta Doctrina fray Gabriel Felipe, vale 400 pesos. 
454 / Augusto E. Albuja

ZAMORA

El beneficio de aquella ciudad vale 400 pesos; sírvelo Juan Gómez, clérigo.

Nambiza vale 450 pesos; sírvelo Juan de León, clérigo.

Purinanga vale 600 pesos; sírvelo Zebrian de la Roca.

GOBERNACIÓN DE YAGUARSONGO

La ciudad de Loyola: vale el beneficio 500 pesos; sírvelo Riberos.

Las Caballerizas, Doctrina, vale 450 pesos.

La ciudad de Santiago de las Montañas: vale el beneficio 600 pesos; sírvelo Ferraguto.

Cangassa vale 450 pesos; sírvela Cáceres, clérigo.

Vuinaca vale 450 pesos; sírvelo Diego de Morales, clérigo.

La ciudad de Valladolid: vale el beneficio 400 pesos; sírvela Pacheco.

Yaguarsongo vale 400 pesos; sírvelo Malatesta, clérigo.

La ciudad de Nieva: vale el beneficio curado 400 pesos; sírvelo Marcos Rodríguez, clérigo.

La Doctrina de indios de aquel pueblo vale 400 pesos; sírvela Juan Perdomo, clérigo.

$J A E ́ N$

El beneficio de aquella ciudad valdrá 750 pesos; sírvelo Cristóbal Arias. Cherinos, Doctrina, vale 450 pesos; sírvela Juan Quintero, clérigo.

Cherinos, otra Doctrina del río de Jaén, vale 450 pesos; sírvela Alarcón. Mullupa vale 450 pesos; sírvela Tenorio, clérigo.

La Doctrina del Valle de este pueblo vale 450 pesos; sírvela un fraile mercenario.

GUAYAQUIL

Vale el beneficio curado de aquella ciudad setecientos pesos. Tiénelo proveído por el Rey, nuestro Señor, Juan de Sepúlveda, clérigo; está ausente, sírvelo Juan de Copete. 


\section{Doctrinas y Parroquias del Obispado de Quito /455}

Amay, Doctrina, vale 450 pesos; sírvela un clérigo.

Yaguache vale 450 pesos; sírvela Luis de la Peña, clérigo.

Daule tiene de estipendio 400 pesos; sírvela Vicente de Mendoza.

Chongón tiene de estipendio 400 pesos; sírvela fray Juan de Zamora.

La Isla de Puná vale 250 pesos; sírvela fray Juan de Camudio.

PUERTO VIEJO

Vale el beneficio 250 pesos.

Jipijapa vale 450 pesos.

Manta vale 300 pesos.

La Doctrina de Picoasa sírvela fray Pedro de Malagata; tiene de estipendio 700 pesos.

PIURA Y LOS LLANOS

La ciudad de Piura: vale el beneficio 450 pesos.

Catacaos proveyólo el Rey, nuestro Señor, a Francisco de Mendoza, clérigo, que es ido a Castilla con licencia; sírvelo otro en su ausencia. Vale 800 pesos.

Paita no tiene indios; valdrá cuatrocientos pesos.

Colán valdrá 500 pesos; tiénela proveída por el Rey, nuestro Señor, Juan de Echerena.

Sechura valdrá 400 pesos; sírvela Morales, clérigo.

Motupe valdrá 600 pesos; sírvela Andrés Gómez, clérigo.

Zayanca vale 700 pesos; sírvela Alonso Núnez, clérigo.

Pacora vale 400 pesos; sírvela Peinado, clérigo.

Ayavaca vale 500 pesos, sírvela Diego de Ribera, clérigo.

Guancabamba vale 700 pesos; sírvela Hernando de Alarcón, clérigo.

Halao y Penachi valen cuatrocientos pesos; sírvela Diego López Morales, clérigo.

Lomao y Capollan valen 500 pesos; sírvelos un clérigo.

La Doctrina de Túmbez vale ducientos y cincuenta pesos; sírvela fray Diego de Avila.

Háse de advertir que lo que se dice del valor de los beneficios de indios, es sin lo que ofrecen los indios, que es muy poco, porque conforme al Patronaz- 
go, no se les puede llevar nada por el administración de los sacramentos, ni entierros, ni velaciones; que, por eso, se les da el estipendio y camarico, lo cual paga el Encomendero de los indios, conforme a la tasa.

También se ha de advertir que donde va declarado, que los pesos son de plata de a nueve reales el peso.

\section{APÉNDICE \# 49}

\section{Quejas del Obispo de Quito, Ilmo. Señor Luis López de Solís, presen- tadas al Rey}

AGI, Quito, leg. 76

Quito, año 1598

El Maestro Don Fray Luis López de Solís de Quito, de Vuestro Consejo, digo que por muchas Cédulas de vuestra real persona está mandado a vuestros Presidente y Oidores y demás justicias inferiores guarden al Obispo su jurisdicción y le amparen y favorezcan, y no sólo no se le ha guardado ni guarda, pero antes, me siento por agraviado en las cosas siguientes:

1. INMUNIDAD. Lo primero, en que a la Iglesia no se le guarda su inmunidad porque, con mucha nota y escándalo, se sacan con gran libertad los retraídos, sin mostrar ni hacer justificación con el Ordinario para los poder sacar, pareciéndoles a los jueces que con volver el preso después de sacado, vuelven y con no se les dando nada de las censuras en que incurren por quebrantar la inmunidad de la Iglesia de primera instancia, lo cual en una tierra tan nueva como ésta es de mucho inconviniente, particularmente cuando se sacan los retraídos con desacato y irreverencia de las imágenes, como aconteció en un monasterio de frailes dominicos en un pueblo que se dice Ambato, que sacando un retículo que estaba abrazado con una imagen de Nuestra Señora, pegada con el Santísimo Sacramento, por saciar el retraído, sacó la imagen arastrando por el suelo y le rompió las tocas y el manto y le quebró la corona que tenía puesta, de que los indios quedaron muy escandalizados, como lo están en toda esta provincia, porque no hay iglesia ni pueblo donde no se haya quebrantado esta inmunidad muchas veces; y conviene poner remedio antes que la justicia del cielo lo ponga, castigando las injurias que a la esposa de Jesucristo, Nuestro Señor, se hacen. 


\section{Doctrinas y Parroquias del Obispado de Quito /457}

2. NO SE SUJETAN A LA ABSOLUCIÓN. Lo segundo, que en los tales excesos los transgresores y violadores de la tal inmunidad, no se queriendo sujetar a la absolución y obediencia de la Iglesia, apelando por vía de fuerza, son defendidos, mandando que sin costa ni condición alguna se absuelvan, lo cual se ha hecho por evitar escándalos y competencias de que Vuestra Majestad no se sirve, pero es justo que se remedie, porque quedando sin castigo y con atrevimiento para ofender a la Iglesia, cada día se atreven.

3. BULA DE LA CENA. Lo tercero, se ha hecho y hace grande agravio a la jurisdicción eclesiástica, en mandar que la Bula de la Cena no se lea ni publique en el tiempo que se suele publicar en la Iglesia de Dios, como a mí se me ha notificado por esta Real Audiencia, de que estoy muy escandalizado por sonar $\tan$ mal en materia de fe.

4. CONSTITUCIONES SINODALES. Lo cuarto, está la jurisdicción eclesiástica muy agraviada en habérseme notificado por esta Real Audiencia que no use de constituciones sinodales, sin que primero vengan aprobadas por el Consejo Real, que ha sido quitar totalmente la reformación del clero porque si primero que se ejecuten los Sínodos han de ir y venir de España, ya cuando vuelven es cumplido el término del tiempo que los Concilios manda se hagan los tales Sínodos, por lo cual yo he cesado de cumplir con esta obligación porque no habiendo de tener efecto, es hacer costa y tomar trabajo en vano con menosprecio de la jurisdicción eclesiástica, apelando cada paso por vía de fuerza del Sínodo, que aunque es verdad que no por eso la Bula de la Cena y las sinodales que se hacen por el orden que los santos Concilios mandan, dejan de obligar en conciencia y ligar las censuras; con todo eso, la gente inorante y sin letras paréceles que están fuera de obligación y no forman escrúpulo en la transgresión, de que se siguen los inconvinientes que se pueden imaginar.

5. CONCILIO DE LIMA.-

SEMINARIO. Lo quinto, que estando por Vuestra Majestad mandado se guarde el Concilio limense de 83, confirmado por Su Santidad, en muchas veces vuestro Presidente y Oidores no lo han querido guardar como parece que habiéndose ordenado en el dicho Concilio, acción Z.C. 44, que todos los que tuviesen Doctrinas de indios, aunque fuesen religiosos, pagasen a tres por ciento de sus estipendios, dende el año 83 que se celebró el dicho Concilio en adelante, y habiéndose así cobrado en el Arzobispado de los Reyes, como constó por testimonios y notoriedad, siempre me fue denegada la cobranza de más de diez años para el seminario que fundé en esta ciudad, teniendo obligación de pagarlo mu- 
chos años antes del Concilio limense de 83 por haberlo ansí instituido el Reverendisimo Don Fray Pedro de la Peña con parecer de todo su Cabildo y de todos los Prelados de las Ordenes que consintieron en la cota y lo dejaron firmado de sus nombres por ante el notario del Cabildo, como parecerá por el libro del dicho Cabildo de esta Iglesia. Habiendo pedido justicia se me denegó y remitió a España, siendo cosa clara que se debía así por el Concilio limense como por el santo Concilio de Trento, en la sesión 23, c.18.

\section{FRAILE PARA LAS ESMERALDAS SIN LICENCIA DEL PRELADO}

Iten, estando ordenado por el dicho Concilio limense, acta $\mathrm{n}^{\circ} .4$, capítulo 16, que ninguno administre oficio de cura, aunque sea religioso, si no fuere con colación y aprobación y consentimiento del Obispo, lo cual es conforme a lo que manda el santo Concilio de Trento, vuestro Presidente y Oidores, contra la voluntad del Obispo, proveyeron un fraile mercenario a los mulatos e indios de las Esmeraldas donde antes había estado clérigo, y a otro pueblo de Lita, en los indios comarcanos y recién traídos a la fe, proveyeron otro fraile mercenario contra mi voluntad porque señalase clérigos que pudiesen ir de más suficiencia que los dichos frailes, lo cual, fuera de ser contra los Concilios, es contra Cédulas de Vuestra Majestad que tiene mandado: donde hubiere clérigo, no se ponga fraile.

FALTA DE DOCTRINA. Iten, estando ordenado en el mismo Concilio limense, acción 3, capítulo décimo cuarto, y por particulares Cédulas de Vuestra Majestad mandado que las faltas de Doctrinas que llaman resíduos, se conviertan en pro y utilidad de las iglesias de los dichos indios a quien se les hizo la falta de Doctrina, o se reparta entre los pobres indios, al arbitrio del Obispo, no se ha guardado; antes, de la caja de la ciudad de Jaén un visitador o comisario desta Real Audiencia, llamado Luis Suárez, con provisión particular de la dicha Real Audiencia, sacó más de quinientos pesos de residuos y faltas de Doctrina y lo trajo a esta ciudad y con haberlos pedido muchas veces para proveer las necesidades de las iglesias que son muchas, como en mi visita general lo vi, por vista de ojos, nunca me los han querido dar y están en la caja real de esta ciudad y en las demás partes los Corregidores granjean con ello y con lo que pertenece a los hospitales, sin ser parte el Obispo para remediarlo.

EL NÚMERO QUE HA DE DOCTRINAR UN CURA DE INDIOS. Iten, en la acción 3, capítulo 11 del dicho Concilio limense de 83, conformándose con el Concilio de Trento, sesión 21, capítulo 4, se ordena que a doscientos 


\section{Doctrinas y Parroquias del Obispado de Quito /459}

indios, y cuando mucho a trescientos, se ponga un sacerdote y se tenga por Doctrina entera, lo cual vuestro Presidente e Oidores, aunque muchas veces lo he pedido y puesto escrúpulo, no lo han querido guardar, sino que a cuatrocientos indios tributarios se ponga clérigo, lo cual el dicho Concilio limense reprueba en el lugar alegado, pareciéndole mucho número para un cura, y declara que si en algún tiempo se permitió, fue por la falta que hubo de ministros pero que, ya que no hay la dicha falta sino que antes sobran, se debe dar por suficiente Doctrina 200 indios, particularmente que cuando están divisos, como lo están en las montañas; es más doctrinar doscientos, que fuera de las montañas quinientos. Y de no se haber guardado lo que el dicho Concilio manda, ha resultado gran falta en la doctrina de los naturales y grande agravio a los sacerdotes que los doctrinan porque a los que no tienen cuatrocientos indios, no se les ha querido dar su estipendio y sustento, como el santo evangelio lo manda, sino tan disminuido y tan poco y eso tan pleiteado en procurar su salario, que gastan más tiempo en esto que en la doctrina de todo el año, de que se han seguido muchas faltas a los naturales con sus ausencias, como yo lo he visto, por mis ojos, estar un sacerdote cura seis y más meses pleiteando y pidiendo se le señale su estipendio y volverse a su Doctrina sin remedio; y aunque muchas veces he pedido a esta Real Audiencia que dé asiento en los estipendios y salarios de los sacerdotes como está dado en todo el reino del Pirú, que en los Charcas tienen señalado un cura, setecientos y cincuenta pesos ensayados, en el Cuzco quinientos y cincuenta, Guamanga quinientos, Lima cuatrocientos y cincuenta, todo ensayado, nunca se ha dado el tal asiento para este Obispado; de donde resulta andar los sacerdotes tan desguetados que si no es con excomuniones, no los puedo sustentar en Doctrinas y hacen muchas faltas en ellas y toman ocasión de granjear por vías ilícitas prohibidas para sustentarse, contra lo que por los Concilios les está prohibido. Y con estar ordenado por el Concilio limense de 67, ses. 3, c.6, que los Obispos señalen los estipendios a los sacerdotes, porque son los que mejor saben la dispusión de la tierra y posibilidad de los indios y es conforme a lo que pone el Concilio de Trento, ses. 21, c.4, vuestro Presidente y Oidores no me lo han consentido.

Ornamentos y necesidades de las iglesias. Iten,estando tan bien ordenado en la Ses. 3, cap. 87 del dicho Concilio limense de 83 que los Obispos tengan mucho cuidado en hacer proveer las iglesias de los indios a costa de los Encomenderos y como mejor pudieren, como también lo manda el santo Concilio de Trento en la Ses. 21, cap. 7, y Vuestra Majestad me lo tiene mandado por parti- 
culares Cédulas, haciendo relación de la grande necesidad que las iglesias tienen, por relación verdadera que de ello se ha dado a Vuestra Majestad, vuestro Presidente y Oidores me lo han estorbado diciendo que no me entremeta en lo dicho, porque es entremeterme en la jurisdicción real; y cuando los sacerdotes curas, viendo que yo no lo puedo remediar, acuden a esta Real Audiencia a pedir remedio, se les responde con dar traslado al Encomendero, haciéndolo pleito ordinario, lo cual es causa que los sacerdotes, por no pleitear y evitar trabajo, lo dejan y así se quedan las iglesias con la misma indecencia y necesidad que Vuestra Majestad le ha informado que es menos de lo que yo,por vista de ojos, he visto y debía bastar para remediar esto que, pues, el Obispo lo ve por sus ojos y por sus visitadores se les diese crédito y se les dejase remediar, pues se ve que los Encomenderos lo han de contradecir.

Cuando se erige algún beneficio y doctrina. Iten, cuando el Obispo quiere poner Doctrina en alguna parte que conviene por constarle, por vista de ojos y por vista de informaciones, ser necesaria, cuando lo viene a consultar con vuestro Presidente, por guardar vuestro Patronazgo Real, lo que se provee es dar traslado al Encomendero que es cierto lo ha de contradecir por su interés y hacer pleito ordinario, debiendo bastar que el Prelado lo diga, pues, cuando viene a poner la dicha Doctrina se funda en los Concilios y en las diligencias e informaciones que para ello hace del conviene.

Reducción de indios. Iten, estando ordenado en las ses.3, capítulo 8 del Concilio limense de 67 y por particulares Cédulas de Vuestra Majestad, se reduzcan los indios, no sólo no se han reducido, pero los reducidos por la visita general han desamparado las reducciones que costaron mucho trabajos e intereses por las provisiones que se le han dado a los indios en particular, de que han resultado grandes inconvinientes en la doctrina cristiana y conversión de las almas y están, el día de hoy peores que nunca: huidos y escondidos en guaicos, muriendo sin sacramentos y sin sepultura; y habiendo yo mandado a todos los sacerdotes curas que están en Doctrinas de indios tuviesen cuidado de reducir los indios y sacarlos de los guaicos y quebradas donde se habían huido, se me ha prohibido, diciendo que no me entremeta en eso que es entremeterse en la jurisdición real, siendo el medio de los sacerdotes más suave y más cómodo para reducirlos que no inviar reducidores que los roban y los dejan como se estaban, contentándose con quemalles una choza.

6.- Censuras a los corregidores que contratan e impidan la conversión. Lo sexto en que se me ha hecho agravio es en que, habiendo yo puesto censura de 


\section{Doctrinas y Parroquias del Obispado de Quito /461}

excomunión mayor contra los Corregidores que contratan entre sus indios, por los grandes inconvinientes que de ello se siguen a la doctrina cristiana, imitando en esto al Metropolitano de los Reyes que así la tiene puesta por ver que las penas que están puestas por los Visorreyes no bastan y se ve andar los indios por las tales contrataciones tan descontentos y apurados que muchos derreniegan de la fe y del baptismo que recibieron, y siendo en tanto favor del evangelio y para mayor ejecución de lo que Vuestra Majestad tiene mandado, y siendo la censura tan justificada por ser en favor del evangelio y doctrina y conversión de los naturales, vuestro Presidente y Oidores han declarado no valer la censura porque es meterme en la jurisdición real, y habiendo yo avisado y pedido a vuestro Presidente y Oidores una y muchas veces que, pues se me prohibe a mí el remediar una cosa tan importante para las almas y consuelo de estos naturales, lo remediasen por otra vía, señalando particulares Corregidores, que en esto excedían mucho, no sólo no se dio remedio, pero, al contrario, teniéndolos yo excomulgados, los han mandado con violencia absolver sin haber habido castigo ni hecho diligencia para el remedio, avisándoles de la coyuntura en que podían ejecutar las penas en los Corregidores, de suerte que siempre han quedado defendidos y amparados en sus malas y prohibidas contrataciones, como se ha visto en cuatro Corregidores de Chimbo, que con razón se puede creer ser verdad lo que los dichos Corregidores dicen públicamente que les dan los oficios para que se aprovechen y que así se lo dicen cuando se los dan.

7.- Fuerzas. Lo séptimo en que se me ha hecho agravio es en que, mandando el santo Concilio de Trento, ses. 6, capítulo 4 de reform 55, décima, 3ra., capítulo 1 de refor y ses. 24, capítulo 20 de refor y ses. 25, capítulo 6, que de autos interlocutorios que no tienen fuerza de definitiva y reparable, no se admita apelación ni los jueces superiores impidan la prosecución de la causa hasta la definitiva, porque sería totalmente impedir la reformación de costumbres y la jurisdición eclesiástica, vuestro Presidente e Oidores han concedido por vía de fuerza de los tales autos, de tal suerte que han atajado la prosecución de las causas para no poder castigar ni remediar lo que conviene y se quedan los reos riendo y como exemptos de la jurisdición; y lo mismo pasa en los amancebados, que por eximirse de la pena, el remedio que tienen es apelar y si les descomulgan, les mandan luego absolver por ciento treinta días que no sirve sino de dejarlos en su mal estado y cansar los jueces.

8.- Que no se despachan las causas eclesiásticas. Lo octavo en que me siento agraviado es que teniendo Vuestra Majestad mandado que las causas eclesiás- 
ticas que fueren por vía de fuerza se despachen las primeras y con mucha brevedad, anteponiendo las otras, se dilata tanto que se quedan olvidadas.

9.- Sobre los religiosos que no tienen colacion del Obispo ni guardan Patronazgo. Lo nono, que habiendo Vuestra Majestad enviádome Cédula para que ningun religioso estuviese en Doctrina sin colación mía porque, por este camino, pudiese yo entender la suficiencia de cada uno y si saben la lengua o no y para hacer guardar vuestro Real Patronazgo, que fue el último remedio que en esta materia se pudo dar para atajar los inconvinientes que de lo contrario se siguen, vuestro Presidente y Oidores me prohibieron usar de la dicha Cédula, remitiéndola otra vez a vuestra real persona, por lo cual entre religiosos en Doctrinas no se ha guardado ni guarda vuestro Patronazgo Real, ni se descarga vuestra real conciencia, porque, por maravilla, hay fraile que quiera aprender la lengua, ni predicar en ella, si no es cual o cual, y de esto se me quejan mucho los indios.

10.- Caso de un descomulgado. Lo décimo, que habiendo yo remitido la absolución de un excomulgado para mí porque convino reservarla, vuestro Presidente y Oidores llamaron al vicario que lo excomulgó, al acuerdo, haciéndole venir de más de treinta leguas de camino y le forzaron, con autos y reprehensiones ásperas, a que absolviese al excomulgado, sin que le aprovechase decir que no podía absolver por no tener jurisdición, mostrando la prohibición y reservación que para ello tenía, lo cual causó mucho escándalo particularmente, que fue defendido los delitos de un Corregidor que había vivido muy disolutamente en un Repartimiento de indios y hecho información contra clérigos, con mucha injuria y agravio, que se llamaba Pedro de Saavedra Roe.

11.- Los agravios del doctor Pineda con los indios en el ingenio. Lo undécimo, que habiéndose presentado, por mi parte y en mi nombre, una petición en pública audiencia, pidiendo se le mediasen los agravios que el Doctor Pineda de Zurita hacía a sus indios, particularmente no queriendo recibir la doctrina y sacerdotes que yo he puesto en sus ingenios con orden del Patronazgo, despidiéndome todos cuantos he enviado para doctrinar aquella gente y negando al sacerdote los ornamentos con que había de decir misa, mandándoles esconder y no queriendo darlos con censuras de excomunión, respondió el dicho Doctor Pineda a voces, públicamente, que yo informaba falsamente y que quien me mentía a mí en aquello, de lo cual causó mucha nota y escándalo en los circunstantes, y no sólo no fue reprehendido por ello, pero, ni aún se proveyó a la dicha petición, como se debía proveer, ni se remedió lo que se pedía, aunque se pidió muchas veces, y quedé afrentado por un particular por cumplir con mi oficio y con lo que Vuestra Majestad me ha mandado que avise a sus Audiencias y Virreyes. 


\section{Doctrinas y Parroquias del Obispado de Quito /463}

12.- Que no castigaron a un Corregidor que dijo mal del Obispo. Iten, que habiendo el Corregidor de Chimbo tratado mal de mi persona, como pareció por unas informaciones que el dicho Corregidor hizo, y asimismo, de algunos clérigos de su distrito, viniendo la causa en relación a la Audiencia, no sólo no fue castigado ni reprehendido, pero, el proceso se quedó hundido, que bastaba ser de Vuestro Consejo para que se castigara un caso escandaloso; y aquel oficio de Obispo es tenido en tan poco.

13.- Diezmos. Iten, se ha hecho agravio a la Audiencia en haber desfavorecido los diezmos, no queriendo reponer una provisión dada en contra más ha de veinte años y constando, y como consta por ser cosa notoria en todo el Obispado, que los indios han dezmado y diezman y por este respecto se ha causado mucho daño a la Iglesia y a los novenos y hospitales, teniendo tanta obligación por derecho divino y humano a favorecer esta causa y la loable costumbre que han tenido y tienen los naturales y ahora se eximen con esta provisión.

14.- Albaceadgo. Asimismo se me ha hecho agravio en que habiéndome dejado por albacea dos clérigos, que fueron Bernardo de Ribera y Jerónimo de Villegas, difuntos, e lo otorgó Joan del Barrio de Sepúlveda, vuestro Oidor, juez de difuntos, no me consintió ni aún encomendar las misas de testamento y metió en la caja de difuntos las haciendas y no sé si han descargado las almas.

15.- Que se juntó el Audiencia en un dia feriado. Iten, teniendo presos tres prebendados por desacatos contra mi persona, vuestro Presidente y Oidores, en un día feriado de fiesta, se juntaron con gran presteza al acuerdo para los mandar soltar, como en efecto me fue forzoso por evitar escándalos a hacerlo ansí.

16.- Suspensión de decir misa a un clérigo. Iten, que habiendo mandado suspender de decir misa a un clérigo llamado Andrés García por su inhabilidad y no querer estudiar, lo defendió el Audiencia por vía de fuerza y no me consintió proseguir en la corrección.

17.- Otro clérigo que desamparó la Doctrina. Iten, queriendo castigar otro clérigo, llamado Alonso Suárez, por haber desamparado su Doctrina donde está una imagen de mucha devoción y dejado muchos españoles sin misa, muy desconsolados, fue defendido por vía de fuerza y se quedó sin castigo.

18.- Prisión de Agüero. Iten, que teniendo preso al canónigo Agüero por desacatos y otros delitos en tiempo de punto que no se hacía Audiencia dentro de una hora, convocó el Licenciado Marañón los Oidores en su casa para que lo remediasen como si fuera negocio de momento o la tierra estuviera alborotada, pues en tiempo de punto se convoca a los Oidores para causas tan leves, y como no se acertaron a juntar todos, se reservó para otro día; y por quitar este escán- 
dalo y juntas de Oidores, le solté de la prisión, que aún para esto no tiene poder el Obispo.

19.- Jurisdición real. El Doctor del Barrio ha publicado que yo me entremeto en la jurisdición real y que así lo ha escrito a Vuestra Majestad y, siendo ansí, me ha hecho mucho agravio porque quien no tiene jurisdición, cómo se ha de entremeter en la que no puede ni debe entremeterse en ella? Y si lo supiese de cierto, me querellare del dicho Oidor, el cual le es tan grande la enemiga que me tiene porque, en tiempo de entredicho y cesación a divinis, no di licencia para que enterrase una hija suya, que en los acuerdos y fuera de ellos es enemigo conocido y de las cosas eclesiásticas; y más he hecho en no recusarle que en sufrírselas. Y por no causar escándalo, pierde mi derecho y él está el más malquisto de esta tierra y con obligación de dar residencia de la plaza de Panamá y de la de Quito. Suplico a Vuestra Alteza la mande proveer el remedio que conviene a todo lo sobredicho, que en ello recibiré merced, y que se despachen en razón de ello las Cédulas y provisiones necesarias y para ello etc.

20.- Tesorería. La tesorería de esta santa Iglesia ha más de ocho años que está vaca por muerte del tesorero Balderrama. Mande Vuestra Majestad que se provea; y es digno y merecedor della el Maestro Benito Hernández de Ortega, Provisor y Vicario General de este Obispado, y el más virtuoso clérigo dél.

21.- Las cuatro canonjias. Al presente hay cinco canónigos en esta santa Iglesia y conforme a la erección ha de haber diez; mande Vuestra Majestad que se conceda a esta Iglesia la merced que se ha concedido a las de Lima, Cuzco y Charcas, que cuatro canónigos se provean, conforme al santo Concilio de Trento: en la Magistral, Doctoral, casos de conciencia y Penitenciaría, o, a lo menos, las dos: Magistral y Doctoral, inviando provisión para ello.

Capellán.- La erección manda que haya seis caspellanes para el servicio de la Iglesia con salario en la renta decimal, y por ser poco, se acordó ahora veinte años, entre el Obispo y el Cabildo, que estos seis se resumiesen en uno y se proveyó por el Obispo y Cabildo con orden del Real Patronazgo, lo cual quitó la sede vacante por ahorrar el salario. Ahora resucité esto como otras cosas para que hubiese el dicho capellán como de antes y con el salario que se le señaló, que fueron ciento y veinte pesos de oro de Quito, y con estar tan justificado y no ser cosa nueva sino ejecución de lo que estaba instituido, se remitió a Vuestro Consejo. Suplico a Vuestra Majestad mande proveer en ello.

Fray Luis, Obispo de San Francisco de Quito/rubricado/. 
Doctrinas y Parroquias del Obispado de Quito /465

\title{
APÉNDICE \# 50
}

Carta que el Obispo de Quito envió al Rey Felipe III con ocasión de la muerte de su padre Felipe II y su exaltación al trono.

\author{
AGI, Quito, leg. $76 \quad$ Quito, 6 de marzo de 1600
}

Señor:

Por Cédula de Vuestra Majestad de 26 de septiembre del año de 598, que recebí por marzo de 99, entendí cómo Dios Nuestro Señor fue servido de llevarse para sí al Rey nuestro Señor, habiendo recebido los santos sacramentos como tan gran cristiano y vivo ejemplo de la cristiandad; y tan gran pérdida me causó la pena y dolor y sentimiento que tan justa y debida era, porque demás del particular, se juntó el general de haber perdido la cristiandad el mayor protector y defensor que tenía en la secular la Iglesia católica, la columna más fuerte de su edificio; los reinos de España, el más sabio, prudente, cristianísimo y poderoso Rey que ha habido después de Salomón; los Prelados y estado eclesiástico, el que los honraba y amparaba; lo secular, quien con tanta paz y justicia los sustentaba con tanto cuidado, en tantos años de su gobierno de tantas y tan grandes inquietudes, calamidades, guerras y herejes y otros infortunios que han sobrevenido por mis pecados, y aunque la vida, obra y muerte de Su Majestad, que tanto resplandece en el acatamiento de la Divina, me tienen confiadísimo en su misericordia que lo está gozando y de sus reinos con mayores coronas del premio debido que es la gloria.

Luego se hicieron en este Obispado del Quito las exequias reales, hallándome en dos ciudades que fueron Loja y Cuenca, con las demostraciones de pena y sentimiento, que por no refrescar el que Vuestra Majestad con tanta razón recibió, no alcago (sic) la significación del mío.

De allí algunos días se hizo la demostración de alegría, levantando pendones en nombre de Vuestra Majestad, dando gracias a Nuestro Señor, por la sucesión que le ha dado en estos reinos como a Rey y Señor natural de ellos. Que sea muy enhorabuena y los goce Vuestra Majestad, y de otros muchos a servicio del mismo Dios, y meditando a tan gran Monarca, como al Rey nuestro Señor que está en el cielo, a quien todos debemos dar gracias por lo uno y otro, suspendiendo las lágrimas de tristeza por lo que falta y continuando las de alegría por tanto bien que tenemos, mayormente con el casamiento con la serenísima Rei- 
na, nuestra Señora, a quien goce Vuestra Majestad, dándole la Suprema muchos Príncipes e Infantes para que las generaciones crezcan como lo desean sus reinos y vasallos y este menor capellán de Vuestra Majestad, a quien la Divina guarde como deseo y es menester. En Quito 6 de marzo de 1600 años.

Fray Luis, Obispo

de San Francisco de Quito /rubricado/.

\section{APÉNDICE \# 51}

Relación de los beneficios y prebendas que estan a cargo de sacerdotes clérigos por orden del Real Patronazgo y colación del Obispo en la diócesis de Quito, y la renta y gastos de la iglesia Catedral.

$$
\text { AGI, Quito, leg. } 76 \quad \text { Quito, } 10 \text { de marzo de } 1600
$$

- El Bachiller don Francisco Galavís

- El Maestro don Juan de Obando

- Don George Ramírez de Arellano

Deán.

Arcediano.

Chantre.

- El Doctor don Miguel León de Almonte

Maestreescuela.

- Ha diez años que no hay Tesorero

- Juan Francisco Talaverano Mancera hizo ausencia para Santo Domingo donde fue proveído por Chantre; ha escrito que quiere más la canonjía de Quito.

- Andrés López Albarrán

- Gaspar de Zamora

- Diego de Agüero

- Don Alonso de Aguilar

Canónigo.

Canónigo.

- García de Valencia

Canónigo.

Canónigo.

- El Maestro Benito Hernández de Ortega

Canónigo.

- El Licenciado Diego de Bracamonte

Provisor y Vicario General.

- Francisco Suárez Salgado

Visitador General.

Visitador General. 
-BENEFICIOS DENTRO DE LA CIUDAD DE QUITO-

- El beneficio curado de la Catedral tiene tres personas

- Jácome Freire de Andrade.

- Miguel de Salmerón.

- Antonio Borja.

- La sacristía de la Catedral tienen dos personas

- Maestro de capilla

- La Parroquia de San Sebastián

- La Parroquia de San Blas

- La Parroquia de Santa Bárbara

- La Parroquia de San Roque

- La Parroquia de San Marcos

- La Parroquia de Santa Prisca

- La vicaría y capellanía de las monjas de la Concepción

- La Doctrina de Machángara

- La Doctrina de Machangarilla

- La Doctrina del valle de Chillo

- La de Conocoto

- La de Chillogallo

- La de Pelileo

- La de Tisaleo

- La de Patate

- La de Quero

- La de Angamarca

- La de Calpi

- La de Litan

- La de Yaruquis

- Francisco de Santiago, presbítero.

- Juan de Olmedo, presbítero.

- Hernando de la Parra Cisneros.

- Francisco Durán, músico.

- Juan Antonio de Rueda.

- Diego Ortuño de Larrea.

- Melchor de la Puente.

- Pedro de Rojas.

- Hernando de Zamora.

- Juan Cortés.

- Luis Suárez Ponce.

- Gonzalo de Saavedra.

- Bachiller Jerónimo de la Plaza.

- Juan de Paredes.

- Diego Alonso de Bastidas.

- Antonio de Urbina.

- Gil Guerrero de Luna.

- Gaspar de Chávez.

- Rodrigo de Araujo.

- Andrés Cansino.

- Juan Alvarez.

- Lorenciañez.

- Francisco Peñafiel.

\section{RIOBAMBA}

- El beneficio de la Villa de Riobamba

- El beneficio de Yanaconas
- Bernardino de Cantos Guerrero.

- Miguel Muñiz. 
468 / Augusto E. Albuja

- La Doctrina de Chimbo

- La de Santiago y San Lorenzo

- La de San Miguel

- La de Guanujo

- La de Azancoto y Chapacoto

- La de Pallatanga
- Juan Luis Pérez de Ayala.

- Gabriel Jaramillo.

- Alonso López Mejorada.

- Francisco de Buendía.

- Alvaro Guerrero Zalamea.

- Melchor Pérez de Quevira.

-GUAYAQUIL-

- El beneficio de la ciudad de Guayaquil - Licenciado Juan Pérez de Herrera.

- La Doctrina de Baba y Pimocha

- Pedro de Cárdenas.

- La de Yaguache

- Luis de la Peña.

-PUERTO VIEJO-

- El beneficio de la ciudad de Puerto Viejo - Licenciado Roque Maldonado.

- La Doctrina de Jipijapa

- La de Manta y Charapotó

- Rodrigo Maldonado.

- La Doctrina de Vimbayá

- Francisco Basurto.

- La de Tumbaco

- Martín de Gaviria.

- La de Pifo e Puembo

- Francisco del Castillo Figueroa.

- La de Yaruquí

- La de Oyacachi

- La de Guayabamba

- Bachiller Hernán García.

- Francisco Suárez Salgado.

- Alonso Suárez.

- La de Tabacundo

- Francisco Sancho de la Carrera.

- La de Cayamba

- La de Pimampiru

- Francisco de Mendoza.

- Gregorio de Beza.

- La de Mira

- Pedro Ordóñez.

- La de Zámbiza

- Francisco Sánchez Yáñez.

- La de Guápulo

- Lorenzo Díaz de Ocampo.

- El Padre Cerrano.

-PASTO-

- El beneficio de la ciudad de Pasto

- La Doctrina de Santiago
- El Licenciado Bracamonte, por merced de Su Majestad.

- Antonio de Benavides. 


\section{Doctrinas y Parroquias del Obispado de Quito /469}

- La de Joanambu

- La de Quina

- La de Los Abades

- La de Mangalapun

- La de San Sebastián

- La de vicaría y capellanías de monjas

- La de Ancuya
- Francisco Vélez de Zúñiga.

- Jerónimo de Cepeda.

- Andrés Moreno de Zúñiga.

- Blas Rosero.

- Melchor de los Reyes.

- Salvador Lucero.

- Padre Bermúdez.

\section{$-M O C O A-$}

- El beneficio de la ciudad de Mocoa

- La Doctrina de Cuyo y Yoaqueta

- La Doctrina de Mandiaco
- Bachiller Rodrigo Alvarez.

- Gaspar Ribero Pacheco.

- Juan de Moreta.

$-E C I J A-$

- El beneficio de la ciudad de Ecija $\quad$ - Juan de Corcuera.

\section{$-C U E N C A-$}

- El beneficio de la ciudad de Cuenca

- La Doctrina de Alausí

- La de Guatagsi

- La de Guasuntos

- La de Abambe

- La del Azogue

- Yanaconas de Cuenca

- San Blas de Cuenca

- La de Pacaybamba

- La de Cañaribamba

- La de Caragaro
- Bachiller Antonio Morán.

- Gabriel Peralta.

- Hernando de Villalobos.

- Juan Enrísquez.

- Melchor de Rojas.

- Gaspar de Gallegos.

- Rodrigo Mejía.

- Rodrígo Márquez.

- Andrés de Villaslada.

- Juan Sánchez Mejía.

\section{-ZARUMA-}

- El beneficio de la Villa de Zaruma

- La Doctrina de los mitayos

- La de Yazña
- Pedro Coronado.

- Diego de Chávez.

- Juan Gómez. 
470 / Augusto E. Albuja

$-L O J A-$

- El beneficio de la ciudad de Loja

- El de los yanaconas

- El de San Juan del Valle

- El de Amboca

- El de Ayabaca

- Las capellanías de las monjas de Loja
- El Bachiller Zurita.

- Juan Losada de Castro.

- Luis de Jerez.

- Rafael Alarcón.

- Diego de Ribera.

- Gaspar de Vega.

\section{-ZAMORA-}

- El beneficio de la ciudad de Zamora

- La Doctrina de Curenanga

- La de Ambixa
- Juan Gómez de Talavera.

- Alonso de Peralta.

- Juan de Flandes.

\section{$-J A E N-$}

- El beneficio de la ciudad de Jaén

- La Doctrina de Lomas y Capaleón

- La de Calleque y Guartoca

- La de Cherinos

- La de Acompa

- Otra en los guambos

- La de Jolluca
- Bachiller Cristóbal Arias.

- Andrés González.

- Bartolomé Rodríguez Hidalgo.

- Pedro Quintero.

- Diego de Mora.

- Alonso Núñez de Saavedra.

-PIURA-

- El benefico de la ciudad de Piura

- La vicaría y capellanía, yanaconas

- La Doctrina de Paita y Colán, por merced de su Majestad

- La de Sechura
- Francisco Alvear.

- Antonio Gómez.

- Juan de Llerena.

- Juan de Llerena, Melchor de Morales con coadjutor.

- Francisco de Mendoza, y por él Juan González Castro. 


\section{Doctrinas y Parroquias del Obispado de Quito /471}

- La de Olmos

- La de Motupe

- La de Jayanca

- La de Pacora

- La de Guancabamba

- La de Salas y Penache

- La de Moscalaque
- Andrés de Sepúlveda.

- Gaspar de Cáceres Galadi.

- Alonso Núñez de Sampedro.

- Alonso Rodríguez Ramos.

- Fernando de Alarcón.

- Alonso de Carvajal.

- Alonso Ruiz.

\section{$-B A E Z A-$}

- El beneficio de la ciudad de Baeza, de la gobernación de los quijos.

- La Doctrina de la coca, Cenacato

- Gonzalo Fernández.

- Alvar Núñez.

\section{-AVILA-}

- El beneficio de la ciudad de Avila

- La Doctrina de Los Calientes
- Bachiller Lucas Cerrato de Godoy. - Julián de Muela.

-ARCHIDONA-

- El beneficio de la ciudad de Archidona - Cristóbal Marmolejo.

$$
\text { -VALLADOLID- }
$$

- El beneficio de la ciudad de Valladolid, en la gobernación de Yagualsongo

- Esteban de Riberos.

- La Doctrina del Valle

\section{-CUMBINAMA-}

- El beneficio de la ciudad de Cumbinamá - Pedro Pacheco de Centenares.

- La Doctrina de las Caballerizas

- Pedro de Orellana.

- El beneficio de Santiago de las Montañas - Bachiller Ayala, con coadjutor.

- La Doctrina de Cangaza
- Juan de Cáceres Patiño. 
- La de Iranaca

- La del río Jaén
- El Bachiller Juan Baptista Zuleta.

- Antonio Rodríguez Hidalgo.

-SANTA MARIA DE LAS NIEVES-

- El beneficio de Santa María de las Nieves - Marcos Rodríguez Lozano.

- La Doctrina aneja a esta ciudad

\section{-SEVILLA DEL ORO-}

- El beneficio de la ciudad de Sevilla del Oro - Gabriel de Minaya.

- La Doctrina de Paira y Zuña

- Otra Doctrina comarcana
- El Padre Zurita.

- Manuel Rodríguez de Castro.

LAS RELIGIONES.- Las Religiones y las Doctrinas de los dichos religiosos de las cuatro Ordenes mendicantes que tienen en el Obispado de Quito, a 10 de marzo de 1600, son las siguientes:

\section{-LAS DE SANTO DOMINGO-}

- La Doctrina de Langasí

- La de Pinta

- La de Oyumbicho

- La de Amaguaña

- La de Pansaleo

- Otra en Pansaleo

- La de Alóa

- La de Cansacoto

- La de Hambato

- La de Píllaro
- La de Tomavela

- La de Pupiales

- La de Ipiales

- La de Abundoy

- La de La Laguna

- La de los Ingenios

- La del Valle

- La de Paccha

- La de Garruchamba

- La de Pozol
- La de Calva

- La de Cariamanga

- Otra en aquel distrito

- La de Daule

- La de Chongón

- La de Cozanga

- La de Atunquijo

- La de Pachamama

- La de Maspa

-LA ORDEN DE SAN FRANCISCO-

- La Doctrina de Cotocollao

- La de Pomasque
- La de S.Antonio de Carangue

- La de las Salinas
- La de Tungurahua

- La de Quina 
Doctrinas y Parroquias del Obispado de Quito /473

- La de Calacalí

- La de San Antonio

- La de Perucho

- La de Malchinguí

- La de Otavalo

- La de La Laguna

- La de Cotacache

- La de Tontaqui

- La de Tontaqui(sic)

- La de Urcuquí

- La de Carangue
- La de Mulahaló

- La de Latacunga

- La de los Alaquez

- La de San Miguel

- La de Pusillí

- La de Saquisillí

- La de San Andrés

- La de Guano

- La de Punín

- La de Chambo

- La de Calahote
- La de Penipe

- La de Tangua

- La de Chapascual

- La del Valle de Angonsí

- La de Yacoanquez

- La de Paute

- La de Gualaseo

- La de Molleturo

- La de Hilapo

- La de Pungalá

\section{-LA ORDEN DE SAN AGUSTÍN-}

- La Doctrina de Atunsicho

- La de los cañares

- La del Ingenio

- La de los Calentes de Sichos
- La de Túqueres

- La de Capuis

- La de los malacatos

-LA ORDEN DE LA MERCED-

- La Doctrina de Caguasquí

- La de Tuza

- La de Puntal

- La de Guaca

- La de Tulcán

- La le Gualea

- La de Males

- La de Mallama
- La de Carlosama

- La de Mangal

- La del Valle

- La de Túmbez

- La de Frías

- La de Puná

- La de Picoaza 
474 / Augusto E. Albuja

\section{RESUMEN DE TODO}

CLÉRIGOS.- Por manera que los beneficios de españoles y naturales que están a cargo de los clérigos en este Obispado, en las partes referidas, son ciento y veinte.

120 beneficios

DOMINICOS.- Las Doctrinas de indios que tienen los dominicos son veinte y nueve.

FRANCISCOS.- Las Doctrinas de indios que están a cargo de los franciscos son treinta y siete.

AUGUSTINOS.- Las Doctrinas que están a cargo de los augustinos son siete.

007

MERCENARIOS(sic).- Las Doctrinas que están a cargo de los mercenarios son quince.

208 beneficios

Suman todas las Doctrinas.- Que todas las Doctrinas referidas que están a cargo de los clérigos y religiosos en este Obispado son doscientos y ocho Doctrinas y Beneficios.

ESTIPENDIOS.- El salario y estipendio de los beneficios de indios es de a trescientos y cincuenta pesos de plata en cada un año, en general, y en algunas partes más y menos, excepto en alguna de las ciudades de españoles, que en seis o siete partes son buenos beneficios; pero, el mejor, nunca ahorra el clérigo quinientos pesos por año.

La Iglesia Catedral de la ciudad de San Francisco del Quito, en los reinos del Pirú, tiene de renta, en cada un año, tres mil y doscientos pesos de plata corriente marcada, de a nueve reales a cada peso; cincuenta pesos, más o menos, regulando la dicha renta por este año de mil y seiscientos, en las partidas siguientes: 


\section{Doctrinas y Parroquias del Obispado de Quito /475}

-Del noveno y medio de las rentas decimales, tiene la dicha Iglesia,de renta este año de 1.600 , setecientos y cincuenta pesos de plata corriente marcada, de a nueve reales cada peso. Porque los diezmos de esta ciudad de Quito y su Partido se arrendaron este dicho año de 1.600 en nueve mil pesos corrientes y le viene al dicho noveno y medio los dichos setecientos y cincuenta pesos.

$\mathrm{U} 750$ ps.

-Tiene la dicha Iglesia, asimismo de renta de censos situados sobre posesiones de casas y estancias, quinientos pesos de plata corriente marcada, de a nueve reales cada peso, treinta pesos más o menos aunque estos censos se pagan muy mal.

U 500 ps.

-De casas y tiendas propias, tiene la dicha Iglesia, asimismo de renta, mil y trescientos pesos de plata corriente marcada, de a nueve reales cada peso, aunque algunos años no se arriendan las dichas casas y tiendas.

1 U 300 ps.

-Demás de lo susodicho, tiene la dicha Iglesia, de renta, los escusados de las ciudades y villas de este Obispado de Quito, que conforme a la erección los ha de haber la dicha Iglesia, y valdrán en este año de 1600, treinta pesos más o menos, seiscientos y cincuenta pesos de plata corriente marcada, de a nueve reales.

U 650 ps.

$\underline{\underline{3 \mathrm{U} 200 \mathrm{ps} .}}$

El gasto ordinario que la Iglesia Catedral desta ciudad de San Francisco del Quito, en los reinos del Pirú, tiene cada año es lo siguiente: 
-Ha menester, cada año, de cera más de mil pesos de plata corriente marcada, de a nueve reales cada peso, por valer ordinariamente cada libra de cera a más de a dos pesos.

$1 \mathrm{U} 000$ ps.

-Gasta cada año más de 250 pesos de vino para decir las misas, por haber menester de 74 botijas cada año y valer cada una a conce y a doce pesos y ser vino de la tierra.

U 250 ps.

-Para comprar el aceite para las lámparas, que arden tres de ordinario, son menester más de 200 pesos, y es aceite de nabo, que es muy bueno para este menester, porque si se gastara aceite de Castilla, era menester más de 500 pesos.

U 200 ps.

-Tiene de gasto ordinario, asimismo, la dicha Iglesia y su fábrica, de ministros que la sirven, más de 300 pesos: de mayordomo, de lavar la ropa blanca, letrado y procurador y sobrestante.

U 300 ps.

$\underline{1 \mathrm{U} 750 \mathrm{ps} .}$

Por manera que, sacados estos 1 U 750 pesos de los dichos 3 U 200 pesos, quedan líquidos $1 \mathrm{U} 450$ pesos, los cuales son muy pocos para comprar lo mucho que la Iglesia ha menester de plata labrada, ornamentos, casullas, frontales, ropa blanca y otras muchas cosas que cada día son menester comprar y se ofrecen haber menester, valiendo tan caro todas las cosas de Castilla; demás de lo cual, ha menester muchos edificios la dicha Iglesia, que se han de hacer de nuevo y otros que están comenzados, que por ser la dicha Iglesia tan pobre, no se han hecho ni pueden hacer.

Fecha en Quito, a 10 de marzo, año de 1600.

Fr. Luis, Obispo de

San Francisco del Quito/rubricado/. 


\title{
Doctrinas y Parroquias del Obispado de Quito /477
}

\section{APÉNDICE \# 52}

\section{Lista de beneméritos sacerdotes en la Diócesis de Quito.}

\author{
AGI, Quito, leg. $76 \quad$ Quito, 10 de marzo de 1600
}

Señor:

En conformidad de lo que Vuestra Majestad me ha mandado que envíe memoria de las personas eclesiásticas beneméritas de este obispado, haré relación de las que al presente se me ofrecen:

CHANTRE.- Don Jorge Ramírez de Arellano, chantre de la santa Iglesia, es un prebendado muy honrado, ha cinco años poco menos que sirve esta prebenda con mucha autoridad. Es muy virtuoso, de buena vida y ejemplo, de más de cincuenta años. Merece, así por esto como porque han muchos años que sirve el oficio de Comisario de el Santo Oficio, que Vuestra Majestad le honre y acreciente.

MAESTRO ORTEGA.- El Maestro Benito Hernández de Ortega ha muchos años que escribe el oficio de Provisor y Vicario General y Visitador de este Obispado. Es uno de los más virtuosos, sobrino del Deán Soto que tanto sirvió en las ocasiones pasadas. Es sujeto para servir una Dignidad de Deán. Arcediano o Maestreescuela en cualquiera de las Catedrales del Pirú.

MAESTRESCUELA.- El Doctor Don Miguel León y Almonte, Maestrescuela de la santa Iglesia, ha poco tiempo que vino a ella. Es hombre docto y virtuoso, buen eclesiástico.

JÁCOME FREIRE.- Jácome Freire de Andrade, cura-rector de esta Catedral, ha muchos años que sirve este oficio y el de Comisario del Santo Oficio en esta ciudad de Quito. Es muy antiguo; merece que se le dé una canonjía en esta Iglesia Catedral.

LICENCIADO BRACAMONTE.- El Licenciado Diego de Bracamonte, beneficiado y vicario de la ciudad de Pasto por merced de Vuestra Majestad, es hombre de buena vida y costumbres. Al presente es Visitador General en este Obispado; desea mucho no tener carga de almas; es digno y merecedor de una prebenda.

BACHILLER MORÁN.- El Bachiller Antonio Morán, cura y vicario de la ciudad de Cuenca, es hombre de buena vida y costumbres, buen predicador; merece ser proveído a una prebenda. 
BACHILLER CRISTÓBAL ARIAS.- El Bachiller Cristóbal Arias, cura y vicario de la ciudad de Jaén, es predicador, hombre virtuoso y ha sido Visitador en este Obispado; es digno y merecedor de una prebenda.

MIGUEL SÁNCHEZ.- Miguel Sánchez Solmirón, cura-rector de la Catedral de Quito, es uno de los mayores eclesiásticos deste reino, gran voz y muy diestro en el canto de órgano, es Sochantre de esta santa Iglesia y de los eclesiásticos de más virtud y ejemplo que hay en ella. Merece que Vuestra Majestad le haga merced en la Tesorería que ha mucho tiempo que está vaca o en otra prebenda.

PADRE LOBATO.- Diego Lobato de Sosa, presbítero, es el más antiguo clérigo de este Obispado y que ha treinta años que se ocupa en la predicación a los naturales con notable fruto, porque es el que más ha trabajado en este ministerio y el que ha enseñado a otros a predicarles, con lo cual se ha descargado la real conciencia. Merece premio en una Canonjía en esta santa Iglesia.

SEPÚLVEDA.- Andrés de Sepúlveda, cura y vicario de Olmos en los llanos, Visitador que ha sido en este Obispado, es muy antiguo y de buena vida y costumbres; desea no tener cargo de almas;merece una prebenda.

JUAN ANTONIO DE RUEDA.- Juan Antonio de Rueda, beneficiado de la Parroquia de San Blas de Quito, es hombre virtuoso, buen eclesiástico y predicador de naturales; merece más premio.

ANTONIO BORJA.- Antonio Borja, coadjutor de cura-rector de la Catedral, es antiguo, de buena vida y costumbre; merece más premio.

PADRE PEGO.- Pedro Ruiz Cabeza Pego, presbítero, ha sido capellán y vicario de las monjas de la Concepción, va a España a sus pretensiones; lleva probanzas y parecer, a que me remito.

FRANCISCO VÉLEZ DE ZÚNIIGA.- Francisco Vélez de Zúñiga, beneficiado de Joanambu, ha sido Visitador, es hombre virtuoso; merece más de lo que tiene.

PERALTA.- Gabriel de Peralta y de la Cueva, beneficiado de Alausí, es hombre virtuoso, de buena vida y costumbres, buen eclesiástico; merece más de lo que tiene.

En Quito, a diez de marzo del año de mil y seiscientos.

Fray Luis, Obispo de

San Francisco de Quito /rubricado/. 


\title{
Doctrinas y Parroquias del Obispado de Quito /479
}

\section{APÉNDICE \# 53}

\section{Carta del Obispo de Quito al Rey Felipe III, pidiendo la remoción del Deán de la Catedral.}

\author{
AGI, Quito, leg. $76 \quad$ Quito, 23 de junio de 1600
}

\section{Señor:}

En esta flota tengo escrito muy largo a Vuestra Majestad y a su Real Consejo de las Indias sobre lo que se ofreció; y en la dicha carta, entre otros avisos, le doy a Vuestra Majestad de los tractos y contractos del Deán de esta Iglesia, el Bachiller Galavís, y cómo envía a España, a sus pretenciones, a un hombre con mucha suma de plata, y en el discurso de la visita que hago contra el Deán y Cabildo tengo averiguado que Pedro Bello, que esta dicha persona lleva de cuenta y hacienda del dicho Deán seis mil y doscientos pesos de buen oro, que valen cuasi doce mil pesos de plata, los cuales le entregó por tercera persona, y el tercero ha declarado ser y pertenecer al dicho Deán para que los vuelva empleados. Con ésta se va la escriptura y declaración del tercero, en confianza, para que conste a vuestro Consejo y provea lo que conviniere. Y sería de importancia para esta Iglesia y su quietud y buen gobierno del coro, que el dicho Deán fuese mudado a otra parte, porque es de la opinión mala en las revoluciones pasadas y por ello fue castigado, y no tiene gobierno para hacer el oficio de Deán y Presidente.

Aunque mis enfermedades y mucha pobreza me tenían reservado de ir al Concilio provincial limense, por hallarme con más salud quedo resuelto y determinado de salir de aquí dentro de dos meses al dicho Concilio, por servir a nuestro Señor y a Vuestra Majestad y por el bien de estos naturales, que el haberlos tratado y residido en este reino más de cuarenta años, me hará, con la experiencia y buen deseo, acertar; ordenándolo nuestro Señor que guarde a Vuestra Majestad, como es menester, para el acrecentamiento de su Iglesia. De Quito y junio 23, 1600 años.

Fr. Luis Obispo de

San Francisco del Quito/rubricado/

/Al dorso/ Que se envíe esta escriptura y copia del capítulo de carta al Fiscal de la casa para que, con el secreto y consideración necesaria, haga su diligencia pa- 
ra que se entienda si este dinero y la persona que lo trae están en Sevilla, y lo que me conviniera.- $\mathrm{Y}$ al Obispo se le agadezca el advertimiento que ha hecho, y haga justicia en el caso. /signo/.

\section{APÉNDICE \# 54}

Carta que el presbítero Jácome Freile de Andrade envió al Rey para que, teniendo en cuenta los servicios prestados en la Diócesis de Quito, le concediese la merced de un mejor beneficio.
AGI, Quito, leg. 84
Quito, 22 de marzo de 1601

Señor:

Tengo dado relación a Vuestra Majestad de que ha cuarenta años que estoy en esta provincia de Quito y he servido en la población y reducción destos indios y en la visita general dellos y de sus tasas, y después en su conversión y doctrina cristiana y buenas costumbres, y en el gobierno deste Obispado siendo en él Provisor y Vicario General por los Obispos don fr. Pedro de la Peña y fr. Antonio de San Miguel; y ansimismo, de veinte y cuatro años hasta agora soy Comisario de la Inquisición. En todo lo cual y otras cosas he servido a Vuestra Majestad y en la ocasión desto de Quito sin haber deservido en cosa ninguna, suplicando a Vuestra Majestad me haga mercedes como Rey y Señor natural, a quien nuestro Señor guarde. Y estas mercedes espero serán cumplidas como Vuestra Majestad las hace a los que lealmente le sirven como dicho e hecho.

El Obispo deste Obispado, don fray Luis López de Solís, ahora nueve meses fue a la ciudad de Lima para el Concilio provincial, por tener celo cristiano y remediar algunas cosas que convenían. Es muy diligente en su oficio y de ejemplar vida y costumbres; empero como nunca faltan malévolos, después que él hizo ausencia, se ha entendido que algunos, a quien ha castigado, han escrito a vuestro Real Consejo contra él cosas que son ajenas de su cristiandad, y ansí debe y merece ser honrado por sus letras y antigüedad y descargar la conciencia de Vuestra Majestad.

El Licenciado don Rodrigo de Aguiar Yacuña, Oidor desta Real Audiencia, se ocupa con mucho cuidado y diligencia en su oficio y servicio de Vuestra Majestad, con buen ejemplo. Es juez recto y limpio, y por ser ansí bien quisto, 


\section{Doctrinas y Parroquias del Obispado de Quito /481}

que se tiene en mucho por la desgracia que en esto han tenido otros jueces pasados, será Dios servido prosiga en su buen proceder para que Vuestra Majestad sea servido hacerle mercedes, que tiene sujeto para ello.

Dios nuestro Señor guarde a Vuestra Majestad con acrecentamiento de vida y de más y mayores reinos y señoríos.

Vuestro siervo en Quito del Pirú, 22 de marzo de 1601 años.

Señor

de Vuestra Majestad siervo y capellán

Jácome Freile de Andrade /rubricado/.

\section{APÉNDICE \# 55}

Carta del Obispo de Quito dirigida al Rey Felipe III para comunicarle ciertas necesidades de la Diócesis, al mismo tiempo que señala de un modo particular los nombres de algunos oficiales reales dignos de tomarse en cuenta por sus servicios prestados en la Audiencia de dicha ciudad.
AGI, Quito, leg. 76 Quito,
12 de octubre de 1601

Señor:

De la ciudad de Lima di cuenta a Vuestra Majestad de lo que se ofreció y de la conclusión del Concilio. Llegué a esta ciudad de Quito pocos días ha, con trabajo y cansancio de tan largo y mal camino, y con salud, gracias a Dios.

ARZOBISPO DE LA CIUDAD DE LA PLATA.- Recibí Cédula de Vuestra Majestad, hecha en Valladolid a 12 de abril deste año, sobre lo que escribió el Audiencia de la Plata de cuanto conviene que en aquella ciudad haya Arzobispo y Metrópoli, la cual he considerado muy particularmente. Y respondiendo a lo que Vuestra Majestad manda, digo que por descargo de mi conciencia y como persona que ha cuarenta y cinco años que conozco esta tierra y las razones que hay, conviene muy mucho que se erija Arzobispo en la ciudad de la Plata y sea Metrópoli de los Obispados de Tucumán, el Río de la Plata, Santiago de Chile y la Imperial de Chile; y no hallo que tenga inconveniente, con lo cual será mejor gobernada aquella provincia y sus Obispados, los Concilios más cómodos sin los gastos, trabajos y largas ausencias que han hecho estos Obispos en venir a los Concilios pasados con riesgo de sus vidas y ausencias larguísimas y fal- 


\section{2 / Augusto E. Albuja}

ta que hacen en sus Iglesias, y daños que resultan dellas por estar tan lejos del Arzobispado de Lima, y las causas que van en grado de apelación al Metropolitano han sido infinitas en haberse y concluirse, porque el Río de la Plata dista de Lima mil leguas, Tucumán seiscientas, el reino de Chile quinientas por la mar, y estos cuatro Obispados están más cerca de la ciudad de la Plata treinta leguas que hay de allí a Lima; y haciéndose esta división, quedará el Arzobispado de Lima con sufragáneos: éste de Quito, Cuzco y Panamá, que es bastante para Concilios. JURISDICCIÓN ECLESIÁSTICA.- Como en otras ocasiones he dado cuenta a Vuestra Majestad, se me han hecho antes de agora agravios por esta Audiencia, de que ha resultado discordia,aunque por mi parte no ha habido nota por aguardar el remedio de Vuestra Majestad y que se sirva de favorecer las causas eclesiásticas. Todo se funda porque el Audiencia se ha querido meter en todo, quitándome lo que el derecho y Concilios me conceden y por Cédulas de Vuestra Majestad; y esto se remedia con que Vuestra Majestad mande enviarme Cédula para que los Concilios provinciales que están aprobados y mandados guardar, se guarden y se favorezca esta jurisdición, que generalmente claman todos los Prelados y aguardan el remedio de Vuestra Majestad, y yo también. (En nota: Tráigase todo lo que hay en este punto y son escriptos por los Prelados y Audiencias).

NOVENOS POR EL GUAYCO.- Esta santa Iglesia tiene por vecino un guayco o quebrada grande y peligrosa para ella, y es necesario remediar el daño que puede hacer y edificar para el servicio de la Iglesia, curas y sacristanes, junto a la dicha quebrada; y las rentas son tan pocas que no alcanzan a hacer ornamentos, de que hay mucha falta. Suplico a Vuestra Majestad haga merced a esta Iglesia de los novenos, por cinco o seis años, para este edificio que es muy necesario para el servicio de la Iglesia y su conservación. (En nota: Informe el Presidente y Audiencia).

DIEZMOS.- Los indios deste Obispado están en costumbre de dezmar de tiempo inmemorial y con hacerlo así, como esta tierra es pobre, valen poco las rentas decimales; la mía vale cada año cinco mil pesos de plata y por aquí se entenderá lo demás. Algunas justicias, inconsideradamente, dicen a los indios que no deben los diezmos, y demás de ir contra este derecho y loable costumbre, vienen a dagnificar las rentas en que son tantos interesados: Vuestra Majestad, Iglesia, fábrica, hospitales, Obispo, Deán y Cabildo, ministros de la Iglesia. Mande Vuestra Majestad despachar Cédula para que se guarde la dicha costumbre y la justicia lo favorezca y no lo repugne como lo ha hecho con alguna ocasión, de 


\section{Doctrinas y Parroquias del Obispado de Quito /483}

que algún cobrador ha hecho agravios a los indios; que a los tales es muy justo castigarlos y por esto no se ha de perder lo que tanto importa, que a no tener estos contrastes, hubieran crecido las rentas la mitad más, y en esta tierra no hay otras minas sino pan y ganados. (En nota: Lo proveído en la carta del Cabildo desta Iglesia).

CLERIGOS Y FRAILES.- En esta tierra hay más clérigos y frailes en su tanto que en España; y los que de allá vienen para Doctrinas, demás del gasto que hacen, no pueden cumplir con este ministerio por la inorancia que tienen de las lenguas tan importantes para la esnseñanza de los naturales, y con los que por acá estudian y se ordenan, se suple esta falta. Y los que más fruto han hecho y hacen son los religiosos de la Compañía de Jesús. Y en materia de Doctrinas y cuanto conviene que Doctrinas no las tengan religiosos, tengo escripto muy largo, y cuan poco obedecen al Ordinario que es el dueño; por lo cual, y poca mano que hay en esto, tengo ante Vuestra Majestad hecha exoneración deste gremio. (En nota: Tráigase lo que otras veces ha escripto el Obispo erecto y está proveído dello).

DOCTRINAS.- He sabido que algunos religiosos piden a Vuestra Majestad Doctrinas de clérigos que están a cargo del Ordinario, y esto es en mucho perjuicio de los Obispos y del clero. Estoy cierto que Vuestra Majestad no hace mercedes con tanto daño de terceros y que esto no se puede conceder. (En nota: Que queda el Consejo advertido).

SÍNODOS.- Seis años ha que no celebro Sínodo diocesano respecto de haberme notificado el Audiencia una Cédula de Vuestra Majestad para que no use dellos sin estar aprobados por el Consejo; y aunque yo quisiera excusarme del trabajo y cuidado, como me obliga el Concilio de Trento es fuerza tratar desto; y aunque agora siete años envié el que hice al Consejo, no se me respondió y la dilación es grande; y no sólo se cumple lo que en esto ordena el Concilio de Trento, pero váse contra él, pues no se reforma lo que conviene y manda. Suplico a Vuestra Majestad lo mande remediar. (En nota: Tráigase esta Cédula y también el Sínodo que envíe cuando dice y lo que en ello está proveído).

PRESIDENTE.- El licenciado Miguel de Ibarra, Presidente desta Audiencia, procede con mucha prudencia y cristiandad desde el tiempo que está en este oficio, acompañado de virtud y mucho recogimiento y limpieza de su cargo. (En nota: Júntese con lo que le tocare).

DON RODRIGO.- El licenciado don Rodrigo de Aguiar y Acuña, Oidor desta Real Audiencia, que a ella vino agora tres años casado, ha procedido y 
procede con mucha cristiandad, virtud y letras, y es merecedor de que Vuestra Majestad le honre y acreciente en oficio de más consideración. (En nota: idem).

LICENCIADOS ZORRILLA Y HOROZCO.- Aquí ha venido nueva que Vuestra Majestad, visto el servicio que hicieron los licenciados Zorrilla y Horozco y que en su recompensa los ha de proveer a las plazas de los charcas, honrado sus personas y mandando volver los salarios que han dejado de ganar en el tiempo de su reclusión, con lo cual Vuestra Majestad descargará su conciencia y premiará a los que verdaderamente le sirvieron y otros se animarán a sus obligaciones, y esto conviene que sea con brevedad. (En nota: Idem).

DON FRANCISCO.- El General don Francisco de Mendoza Manrique es un caballero que ha servido muy bien en este reino y tiene muy buenos papeles en el Consejo. El año de 84 fue por General en esta mar del sur al reino de Tierra Firme en que gastó muy gran hacienda. El Marqués de Cañete le eligió con cuidado para asentar las alcabalas en el Cuzco, en tiempo en que todo el reino estaba inquieto con las revoluciones de Quito; y aunque pasó mucho riesgo, con su prudencia y buenos medios lo hizo con mucha satisfacción y gusto del Virrey y Audiencia. En medio de las turbaciones de Quito, le envió el Virrey a la pacificación, y con buenos medios lo hizo y acabó. Quedando a servir el oficio de lugarteniente, de Capitán General y Corregidor, dio muy buena residencia deste oficio sin tener demanda pública ni secreta. Está pobre, con obligaciones de mujer e hijos; merece que Vuestra Majestad honre su persona con un hábito y le dé acrecentamiento de renta (En nota: Júntese con sus papeles).

EL LICENCIADO SOTOMAYOR.- El licenciado Sotomayor, abogado desta Real Audiencia, ha servido cargos y oficios muy honrados, de que ha dado buena cuenta. Tiene sus papeles en el Consejo; merece plaza de asiento y que Vuestra Majestad le haga merced (En nota: Idem).

EL LICENCIADO MACHADO.- El licenciado Hernando Machado, relator desta Audiencia, es muy buen letrado, cuerdo y de prudencia y virtuoso, digno de oficio de asiento en una Audiencia. Merece que Vuestra Majestad le honre y haga merced. Tiene mujer y hijos y obligaciones. (En nota: Idem).

ECLESIÁSTICOS CULPADOS.- A algunos eclesiásticos culpados en las revoluciones pasadas no doy beneficios en pena de sus culpas, los cuales hacen juntas y monipodios secretos para escribir contra mí lo que suelen los semejantes, tomando por cabeza a Alonso Mejía Mosquera, clérigo, el mayor delincuente que hay en las Indias, a quien tengo castigado por sus excesos y dellos constará por su sentencia y dos peticiones que envió al Consejo, donde está acos- 


\title{
Doctrinas y Parroquias del Obispado de Quito /485
}

tumbrado a escrebir testimonios contra sus Prelados. Suplico a Vuestra Majestad mande se advierta con este capítulo que de aquí nacen los que quisieren autorizar con sus lenguas y plumas. (En nota: Queda el Consejo advertido desto y júntese con lo que Mosquera y otros escribieren o hubieren escripto).

Con el Audiencia y Cabildo de mi Iglesia profeso mucha paz y buena correspondencia, porque sé que con esto se sirve a Nuestro Señor, y el remedio de los agravios aguardo de Vuestra Majestad, a quien la Divina guarde como deseo y es menester. Quito y Octubre 12 de 1601 años.

Fray Luis Obispo de San Francisco de Quito/rubricado/

/Al dorso/= está respondida dentro en 9 de diciembre de 1602.

\section{APÉNDICE \# 56}

Los Representantes de las cuatro Ordenes religiosas presentan sus quejas en contra del Obispo, Ilmo. Señor Luis López de Solís, ante Su Majestad, el Rey.

\author{
AGI, Quito, leg. 84 \\ Quito, 12 de abril de 1602
}

Lo primero pretende -el Obispo de Quito- quitar las Doctrinas a todas las Religiones para darlas a sus clérigos, por augmentar sus rentas y aprovechamiento de sus oficiales, y esto so color de que tiene muchos clérigos, habiendo ordenado clérigos insuficientes e inhábiles y muchos dellos mestizos, siendo este su intento contra las Reales Cédulas de Vuestra Majestad libradas después de muy largas consultas que sobre ello se hicieron en que a los religiosos que están en Doctrinas los hace curas y declara ser conforme a las Bulas dadas por los Pontífices Romanos y que no hace este oficio ex voto charitatis sino de obligación precisa.

Ha puesto pleito a las Religiones el dicho Obispo, pidiendo que le paguen seminario y lo cobra de hecho de los estipendios que a los religiosos se les dan, y para esto ha librado censuras contra los Corregidores de los partidos para que ante todas cosas se le paguen, teniendo las Religiones seminarios en sus conventos adonde crían frailes que prediquen y confiesen y enseñen Artes y Apología a hijos de conquistadores; y no sólo de los estipendios cobra el seminario, más 
aún, también de las cofradías que están en los conventos, haciendo prenda de los mantos de nuestras para ser pagado dellos, como se hizo en Cuenca, ciudad de su Obispado, en el convento de Santo Domingo.

Pretende visitar y visita de hecho a los religiosos que están en Doctrinas, teniendo Bulas y proprios motus de Su Santidad para que sean visitados como religiosos que están debajo de la obediencia de sus Superiores y Provinciales que los visitan muy a menudo, corrigiendo las faltas que hubiere en ellos, lo cual ha causado y causa grandes escándalos e inquietudes en esta tierra; y no sólo los quiere visitar en cuanto a curas, más aún, también de moribus et vita, haciendo informaciones de secreto, recibiendo ríos de gente apasionada e interesada contra los tales religiosos.

Pretende asimismo que los frailes que están en Doctrinas, cuando hubieren de ir a ella sea por su mano, poniéndoles el examinado y aprobado y dado licencia para administrar sacramentos, siendo como es esto directamente contra las Bulas de Su Santidad de Pío Quinto, dado a instancia de Su Majestad del Rey Don Felipe 2 Nuestro Señor, que santa gloria tenga, confirmada por Gregorio 14, los cuales cometen esto a los Provinciales de las Religiones, cada uno en la suya, lo cual se guarda por ellos con mucho rigor, no señalando para esto sino los hábiles y suficientes; y si esto se dejase al examen y aprobación del dicho Obispo, no habría religioso suficiente y sería eximir los súbditos de la obediencia de sus Prelados.

Está mandado por Cédula de Su Majestad que los Obispos den facultad a los religiosos de administrar sacramentos a los españoles que viven entre indios y el dicho Obispo de Quito, aunque le ha sido notificada la Cédula, no ha querido acudir al cumplimiento della y ha le sido mandado por la Real Audiencia desta ciudad, con carta y sobre carta, que conceda la dicha facultad y nunca ha querido.

Fray Jerónimo de Mendoza, dominico

Fray Bartolomé Rubio, ministro principal de San Francisco
Fr. Agustín, agustino

Fr. Antonio de Prado mercedario 
Doctrinas y Parroquias del Obispado de Quito /487

\title{
APÉNDICE \# 57
}

Carta que los Representantes de las cuatro Ordenes religiosas dirigieron al Rey a fin de manifestarle quejas contra el Ilmo. Sr. Luis López de Solís, Obispo de Quito.

\author{
AGI, Quito, leg. $84 \quad$ Quito, 16 de abril de 1602
}

Señor:

Las ocasiones que continuamente se ofrecen en esta tierra como nueva que es y no estar en ella las cosas tan asentadas como era razón, hacen que continuamente acudamos a Vuestra Majestad para que en ellas favorezca el partido de las Religiones que tan arrastrado y por el suelo lo traen algunos Obispos destas Indias, particular el de Quito, intentando con ellas pleitos que sólo sirven de inquietarlas, estando sus demandas ya determinadas por el Rey Don Phelipensis, Señor que santa gloria tenga, padre de Vuestra Majestad, y puesto perpetuo silencio en ellas y estando libradas Cédulas Reales de muy atrás en favor de las Religiones y del ministerio en que cotidianamente se ocupan de la conversión de los naturales con tan notorio aprovechamiento de las almas. El no solamente no ayuda, pero aún desfavorece esta causa con tantas veces que casi en un punto quiere desaparecer lo que las Religiones en tanto hecho y con tan inmenso trabajo han edificado, con cudicia de acrecentar sus rentas, enriquecer sus oficiales y favorecer sus clérigos; y si esta Real Audiencia no hubiera tan de veras acudido a remediar y atajar los intentos del Obispo, favoreciendo con cristiandad y justicia lo que tan de nuestra parte está, ya estuviéramos todos de todo punto desacreditados y nuestro ministerio y oficio por el suelo.

Suplicamos a Vuestra Majestad,humildemente, atienda a que el trabajo que acerca de lo dicho hemos pasado y cada día se pasa, en esta ocasión no sólo no se desayude, mas antes de Vuestra Majestad, como tan católico y cristianísimo, sea favorecido para todos los que procuran molestarnos; y para que de todo esto esté Vuestra Majestad más enterado, va un memorial que en suma contiene los insultos y pleitos y demandas que el Obispo desta ciudad de Quito nos ha puesto y pone para que, vista la injusticia de su parte y la justicia que tenemos de la nuestra, Vuestra Majestad nos haga merced, favorezca y ampare el partido de quien tan de veras se ha ocupado y ocupa en el descargo de la real conciencia 
488 / Augusto E. Albuja

de Vuestra Majestad, a quien nuestro Señor, con próspero y felice acrecentamiento, largos años guarde. Desta ciudad de Quito y de abril 16 de 1602 años.

Fray Jerónimo de Mendoza, Provincial de Santo Domingo; Fray Bartolomé Rubio, de San Francisco; Fr. Agustín, Provincial de S. Agustín; Fr. Antonio de Prado, Comendador de Nuestra Señora de la Merced. /rúbricas/.

\title{
APÉNDICE \# 58
}

Lista de oficiales reales y de beneméritos sacerdotes en la Diócesis de

\section{Quito.}

\author{
AGI, Quito, leg. $76 \quad$ Quito, 10 de abril de 1603
}

Señor:

En cumplimiento de lo que Vuestra Majestad me tiene ordenado y mandado invíe aviso y relación, en cada flota, de personas beneméritas de partes, virtud y ciencia y habilidad, lo haré en la manera que sigue:

Licenciado don Rodrigo.- El Liceniado don Rodrigo de Aguiar y Acuña, Oidor más antiguo desta Real Audiencia de Quito, ha servido y sirve en ella con muy buen nombre y reputación de ciencia y conciencia, virtud y prudencia, tiene partes y talento para servir muy gran oficio y es digno y merecedor del que Vuestra Majestad se sirva de le ocupar en una de las presidencias que están vacas en el Nuevo Reino o las Charcas o en una plaza del Consejo de Indias o de otro Consejo cerca de la persona de Vuestra Majestad.

Doctor Meza.- El Doctor Moreno de Meza fue Oidor desta Audiencia y ahora diez años se casó y dejó la plaza. Tiene ispiriencia por muchos oficios que ha tenido en España y en esta tierra. Es hombre recto y merece ser ocupado en plaza de Oidor de las Audiencias deste reino.

Don Lope- El General don Lope de Mendoza es Corregidor desta ciudad por título del Virrey. Es un caballero principal, de muy buenas partes y gobierno y que lo ha mostrado en este oficio y en otros, rico y descansado; merece que Vuestra Majestad le ocupe en cosas de más importancia. 


\section{Doctrinas y Parroquias del Obispado de Quito /489}

Don Francisco de Mendoza.- El General don Francisco de Mendoza Manrique fue Corregidor desta ciudad de Quito. Ha servido a Vuestra Majestad como parecerá por sus papeles; es merecedor de uno de los Corregimientos del Cuzco, Potosí u otro principal deste reino.

Capitán Jerez.- El Capitán Juan Sánchez de Jerez Bohorquez, vecino Encomendero desta ciudad, hizo a Vuestra Majestad el mejor servicio deste reino porque fue el que descubrió y delactó de la traición tan notable que estaba ordenada, como en otras ocasiones tengo avisado. Merece un gran premio para que se le pague y remunere este servicio y otros se animen. Suplico a Vuestra Majestad mande ver sus papeles, por donde constará más de lo que digo, y se le haga merced en persona y hacienda.

Melchor de Castro y Macedo.- El sargento Melchior de Castro Macedo que va a vivir a la Corte, es hombre de mucha habilidad y pluma, secreto y confianza y espiriencia en este reino del Pirú y de quien se puede fiar cualquier negocio muy grave. Suplico a Vuestra Majestad le haga merced, que esto constará mejor por el parecer secreto del Audiencia de Quito.

Licenciado Zorrilla.- El Licenciado Diego de Zorrilla que está en España, sirvió a Vuestra Majestad muy bien en las revoluciones pasadas. Tiene virtud y ciencia; es hijo del Oidor Pedro de Zorrilla; merece que Vuestra Majestad le mande ocupar en una plaza de Inquisidor, Oidor, en este reino del Pirú.

Licenciado Machado.- El Licenciado Hernando Machado, relator de esta Real Audiencia, es persona de mucha ciencia y muy buen sujeto para cualquier plaza de asiento en las Audiencias deste reino, y con quien se descargará muy bien la conciencia, y es digno de mayores cosas.

Sotomayor.- El Licenciado Francisco Sotomayor, abogado desta Real Audiencia de Quito, es muy antiguo en oficios y cargos de justicia, buen republicano y de buena ispiriencia y letras; merece oficio de asiento en una de las Audiencias deste reino.

Licenciado Caravajal.- El Licenciado Juan Alonso de Caravajal, abogado desta Audiencia, tiene muy buenos papeles y títulos de auditor de la guerra y pacificación de Quito y de las armadas, Corregidor de Otavalo y juez de cajas reales. Merece una plaza de Audiencia deste reino porque, junto con sus letras, tiene ispiriencia.

Juan Piñán Castillo.- Juan Piñán Castillo es un hidalgo a quien Vuestra Majestad dio Cédula para que el Virrey del Pirú le ocupase. Dióle una administración, que por ser tan pobre la dejó. Merece un Corregimiento de indios. 
490 / Augusto E. Albuja

Juan de Gauna.- Juan Sánchez de Gauna, alguacil mayor de esta ciudad, es hijodalgo. Va a representar los servicios de su mujer y de sus antepasados, que fueron muchos,y a pedir se le haga merced; por sus papeles constará.

Capitán Zapata.- El Capitán Francisco Zapata ha servido a Vuestra Majestad en Flandes y otras partes; y en éstas ha servido los Corregimientos de Riobamba y Otavalo por merced del Virrey, de que ha dado buena cuenta. Es casado en esta ciudad y va a pretender; remítome a sus papeles.

\section{LOS ECLESIÁSTICOS BENEMÉRITOS EN ESTE OBISPADO SON LOS SIGUIENTES:}

Maestro Ortega.- El Maestro Benito Hernández de Ortega, cura rector de la Catedral de Lima, es muy digno y merecedor de una Dignidad en esta Iglesia y en las demás Catedrales.

Luis Tasi.- El Bachiller Luis Tasi, Visitador General de este Obispado, merece una Dignidad en esta Catedral o en las demás del Pirú.

Juan Muñoz.- El Bachiller Juan Muñoz, vicario de Cuenca y Visitador General deste Obispado, merece una prebenda.

Pedro Núnez.- Pedro Núñez de los Reyes Montesdoca, Visitador General deste Obispado, merece una prebenda en esta Iglesia o en las demás.

Bracamonte.- El Licenciado Diego de Bracamonte, beneficiado y Vicario General de Pasto, merece una prebenda en esta Catedral o en las demás del Pirú.

Morán.- El Bachiller Antonio Morán, beneficiado y Vicario General de la ciudad de Piura, merece una prebenda.

Copete.- El Licenciado Juan Copete de Herrera, beneficiado y Vicario General de la ciudad de Guayaquil, merece una prebenda.

Cristóbal Arias.- El Bachiller Cristóbal Arias, beneficiaddo y vicario de Jaén y Visitador general deste Obispado, merece una prebenda.

Juan de Quirós.- Juan de Quirós, beneficiado y Vicario General de la Villa de Riobamba, merece una prebenda.

Francisco del Castillo.- Francisco del Castillo Figueroa, beneficiado y vicario de Tumbaco, merece una prebenda en esta santa Iglesia.

Antonio Borja.- Antonio Borja, cura rector de la Iglesia Catedral, merece una prebenda. 


\section{Doctrinas y Parroquias del Obispado de Quito /491}

Diego Lobato-- Diego Lobato de Sosa, maestro de capilla, predicador general de los naturales, es muy digno y merece una prebenda.

Zúñiga.- Francisco Vélez de Zúñiga, Visitador General del Obispado de Popayán, merece una prebenda.

Peralta.- Gabriel de Peralta, beneficiado y vicario de Catacaos, merece una prebenda.

Bachiller Plaza.- El Bachiller Jerónimo de la Plaza, beneficiado y vicario de Chillo, es predicador; merece una prebenda.

Sepúlveda.- Andrés de Sepúlveda, beneficiado y vicario de Olmos, merece una prebenda.

Juan Antonio.- Juan Antonio de Rueda, beneficiado de Pimampiro, merece una prebenda.

Pedro Nieto de Solís.-Pedro Nieto de Solís, beneficiado y vicario de Mira, merece una prebenda.

Francisco Rodríguez Yánez.- Francisco Rodríguez Yáñez, beneficiado de San Blas, merece una prebenda.

Pedro de Vera.- Pedro de Vera, tesorero de Vuestra Real Hacienda, ha poco tiempo que vino a servir este oficio proveído por vuestra real persona. Es hombre virtuoso y procede muy bien; pero el oficio es muy pobre porque apenas podrá sustentarse, mayormente procediendo tan cristianamente. Merece otra cosa de más momento.

Y esto es lo que se me ofrece en cumplimiento de mi obligación y en descargo de mi conciencia. Guarde Nuestro Señor la católica y real persona de Vuestra Majestad, con acrecimiento de mayores reinos y señoríos.

En Quito, a 10 de abril de 1603 años.

Fray Luis, Obispo de

San Francisco de Quito/rubricado/. 
492 / Augusto E. Albuja

\title{
APÉNDICE \# 59
}

\section{Carta que Fr. Juan Gallegos dirigió al Rey para quejarse del Obispo de Quito.}

\author{
AGI, Quito, leg. $84 \quad$ Riobamba, 15 de abril de 1603
}

\begin{abstract}
S.C.R.M.
Después de haber escripto a Vuestra Majestad otra que va con ésta, ha querido el Maestro Don Fr. Luis López, Obispo de este Obispado, proseguir su mal intento y agora, en particular, se ha echado de ver, en que habiendo fundado dos conventos, uno en la ciudad de Guayaquil y otro en el asiento de Chimbo, con su licencia, y que van con mucho augmento para provecho de españoles y naturales, ha puesto censuras y descomuniones que no acudan a oir la misa a los dichos conventos y evita las limosnas acostumbradas, y como tengo referido en la otra que escribo a Vuestra Majestad, nos pide seminarios, evita que no tengamos pilas de Baptismo, publica tener Cédulas de Vuestra Majestad para visitarnos de moribus et vita y otras estorciones y agravios que con su pecho dañado nos hace; y, pues incumbe a Vuestra Real Majestad el favorecernos y ampararnos, suplicamos a Vuestra Majestad nos haga justicia librando su real provisión para que cesen estas vejaciones, que todas son por fines e intereses de las Doctrinas de los naturales que tenemos a cargo, con las cuales descargamos la real consciencia de Vuestra Majestad, a quien Dios prospere y guarde. De esta Villa de Riobamba, 15 de abril de 1603 años.
\end{abstract}

Vasallo y humilde

Capellán de Vuestra Majestad

Fray Juan Gallegos /rubricado/. 


\title{
Doctrinas y Parroquias del Obispado de Quito /493
}

\section{APÉNDICE \# 60}

Carta del Obispo de Quito al Rey Felipe III, manifestándole la necesidad de que el Colegio-seminario de la Diócesis concediese grados académicos al igual que la universidad de Lima; y también comunica que ha fundado otro Colegio - seminario para los hijos de los caciques.

\author{
AGI, Quito, leg. 76 \\ Quito, año 1604
}

Muy poderoso Señor:

El Maestro don fray Luis López, Obispo de Quito, digo que yo he fundado un Colegio-seminario de clérigos en la dicha ciudad, conforme a lo dispuesto en el santo Concilio tridentino y por las Cédulas de Vuestra Alteza; y en espacio de diez años que ha que se erigió el dicho Colegio, han salido muchos clérigos virtuosos y de buena suficiencia que agora son curas con grande aprovechamiento de los indios y descargo de la conciencia de Vuestra Alteza, aunque por no se poder graduar, a causa de estar la universidad de Lima distancia de trescientas leguas, se desaniman mucho los estudiantes y se entibian en el fervor de sus estudios viendo que no pueden alcanzar el premio proporcionado a ellos. Suplico a Vuestra Alteza se sirva mandar dar licencia para que se puedan graduar los dichos colegiales en Artes y Teología, por los privilegios de la Compañía, cuyos maestros les leen, que ellos y yo recibiremos muy grande merced.

Y otro sí, digo que yo fundé otro Colegio-seminario de hijos de caciques en la misma ciudad, por haber servido los indios de la provincia, en todas las ocasiones pasadas, a Vuestra Alteza con entera fidelidad y ser gente de buena capacidad; pero como la renta de mi Obispado es tan poca (aunque mucha más de la que yo merezco), no puedo sustentar y llevar adelante el dicho Colegio. Y espero, que así como el primer Seminario de clérigos deste Obispado ha sido el primero deste reino y movido y ayudado algo a que se vayan haciéndole de más, y se ha tomado experiencia en él, que lo mismo sucederá en el Colegio de los hijos de los caciques, dignándose Vuestra Alteza de que se funde, pues ha tantos años que en este reino se desean y Vuestra Alteza lo tiene ordenado en las instrucciones de los Virreyes. Suplico a Vuestra Alteza se sirva de mandar se den hasta dos mil ducados de renta al dicho Colegio, de pensiones sobre las primeras Encomiendas que vacaren o de los novenos deste Obispado o comunidades de los indios; que demás de que a ellos y a todo este Obispado se le hará gran bien y merced, yo la recibiré por grandísima y por premio temporal de mis servicios, cuando hubieran sido más etc. 



\section{BIBLIOGRAFÍA}

\section{FUENTES}

A) MANUSCRITAS:

ARCHIVO GENERAL DE INDIAS (AGI)

Secciones:

Audiencia de Quito: legajos 1, 8, 17, 23, 46, 76,

$$
77,80,81,82,83,84,209
$$

Audiencia de Charcas: legajo 142

Audiencia de Lima: legajo 300

Contaduría: legajo 1538

Indiferente General: legajos 532, 427, libro 30,

2589, libro 2.

Patronato: legajos: 29, Ro (Ramo) 31; 185, Ro 39;

legajo 189, Ramos 34, 40, 41; y legajo 240. Ro 6

B) IMPRESAS:

Canones et Decreta Sacrosancti Oecumenici Concilii Tridentini, Romae 1882

Codex Iuris Canonici, Romae 1918

GARCES G. Jorge A.

1935 Colección de Cédulas Reales dirigidas a la Audiencia de Quito (15381600). Quito.

HERNAEZ, Francisco Javier

1879 Colección de Bulas, Breves y otros documentos relativos a la Iglesia de América y Filipinas, I-II, Bruselas. 
496 / Augusto E. Albuja

PEÑA MONTENEGRO, Alonso de la

Itinerario para párrocos de indios, Madrid M.DC. LXVIII.

1943 Recopilación de leyes de Indias, Madrid.

VARGAS UGARTE, Rubén

1954 Concilios Limenses, I, (1551-1772), Lima 1951; III, (Historia) Lima.

\section{AUTORES Y OBRAS CITADOS}

ACOSTA, José de

1589 De promulgando Evangelio apud barbaros seu de procuranda indorum salute. Salamanca.

ALVAREZ DE ABREU, Antonio José

1769 Vacantes de Indias, Madrid.

1950-1 Anuario de estudios americanos, VII-VIII, Sevilla.

ARCILA FARÍAS, Eduardo

1947 El Régimen de la Encomienda en Venezuela. Sevilla.

ARMAS MEDINA, Fernando de

1952 Evolución Histórica de las Doctrinas de Indias, Sevilla.

BANDIN HERMO, Manuel

1951 El Obispo de Quito, D.Alonso de la Peña (1597-1687), Madrid.

CUEVAS, Mariano

1928 Historia de la Iglesia en México, 5 vol. El Paso-Texas. 
Cartas de Indias

1877 Publícalas por primera vez el Ministerio de Fomento, Madrid.

Código de Derecho Canónico

1957 6a Edición, Madrid.

Código de Derecho Canónico

1983 Pamplona.

España Misionera

1948 V, Madrid.

GAMS, Pius Bonifacius

1957 Series Episcoporum Ecclesiae Catholicae, Akademische Druck-UVerlagsanstalt, Graz.

GARCÍA GUTIÉRREZ, Jesús

1941 Apuntes para la Historia del origen y desenvolvimiento del Regio Patronato Indiano hasta 1857, México.

GÓMEZ HOYOS, Rafael

1945 Leyes de Indias y el Derecho Eclesiástico en América Española e Islas Filipinas, Medellín.

GONZÁLEZ SUÁREZ, Federico

1890-1893 Historia General de la República del Ecuador, I-VII, Quito.

HANKE, Lewis

1949 La lucha por la Justicia en la Conquista de América. Traducción de Ramón Iglesias, Buenos Aires.

1949 Bartolomé de las Casas, La Habana.

JARAMILLO ALVARADO, Pío

1954 El Indio Ecuatoriano, Quito. 
498 / Augusto E. Albuja

LEVILLIER, Roberto

1919-1920 Organización de la Iglesia y Ordenes religiosas en el Virreinato del Perú en el siglo XVI, I-II, Madrid.

LISSON CHAVES, Emilio

1943 La Iglesia de España en el Perú, I, Sevilla.

LÓPEZ DE VELASCO, Juan

1894 Geografia y Descripción Universal de las Indias, Madrid.

OTS CAPDEQUI, José María

1941 El Estado Español en las Indias, México

PATTEE, Richard

1823 El Catolicismo contemporáneo en Hispanoamérica, Buenos Aires.

REGATILLO, Eduardus F.

1956 Institutiones Iuris Canonici, I-II, Santander.

RODRÍGUEZ VALENCIA, Vicente

1956 Santo Toribio de Mogrovejo, Organizador y Apóstol de Sur-América, I-II, Madrid.

SCHÄFER, Ernesto

1947 El Consejo Real y Supremo de las Indias, I-II, Sevilla.

SERRANO Y SANZ, Manuel

1868 Origenes de la dominación española en América, Madrid.

SOLÓRZANO PEREIRA, Juan de

1930 Politica Indiana, I-V, Madrid.

VARGAS, José María

1948 La Conquista Espiritual del Imperio de los Incas, Quito. 


\section{Doctrinas y Parroquias del Obispado de Quito /499}

VARGAS UGARTE, Rubén

1959 Historia de la Iglesia en el Perú, I (1511-1568), Lima 1953; II (1570-1640), Burgos.

VÁZQUEZ DE ESPINOSA, Antonio

1948 Compendio y Descripción de las Indias Occidentales, Washington.

ZABALA, Silvio A.

1935 La Encomienda indiana, Madrid. 